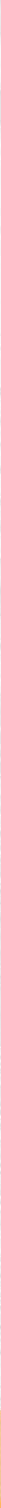

\title{
Lucien BAROU
}

Mémoires de la Grande Guerre 187 Poilus du Forez et de sa périphérie témoignent...

Tome 2 : 1915 


\section{Chapitre 8}

\section{5 \\ Installation dans la guerre de tranchées}




\section{Chap. 8 - 1915 - Installation dans la guerre de tranchées}

"La tranchée protégeait bougrement" - Jean-François Ollier, commandant, né en 1894 mais engagé en 1913, Saint-Etienne

"Oh! la tranchée, c'était utile! Ah, mais on pouvait pas faire autrement! A découvert, comme ça, là, y a pas besoin de canons: avec les mitrailleuses!" - Antoine Souchon, classe 1913, Lentigny - Roanne.

"Demain, on monte aux tranchées". Prévu ou surgissant soudain, cet ordre est toujours accueilli avec un petit serrement de cœur. Il va falloir quitter la demi-sécurité du cantonnement, la bonne paille, voire même le lit de fortune ${ }^{l}$, la bonne table qui réunit tous les camarades et faire trêve aux bonnes nuits. Et qui sait? L'éternelle question! Que trouvera-t-on là-haut ${ }^{2}$, là-bas! La mort, peut-être! A moins que ce ne soit la blessure! le sang, les membres pantelants, le corps entr'ouvert! »- Récit d'Antonin Granet, classe 1903, Chamboeuf

"On creusait tout le temps des tranchées! Il fallait toujours les changer. Et puis alors, y avait ces fameux coups de main qui changeaient légèrement le front. Alors vous étiez obligé... pour quelques mètres de terrain, on faisait tuer je sais pas combien d'hommes! Et ces tranchées-là, il fallait les refaire, les reconstruire". - Jean-Louis Monier, classe 1913, Marols.

Avertissement au lecteur: jusqu'à maintenant, un ordre chronologique a pu être maintenu tant bien que mal pour l'année 1914. Nous essaierons de nous y tenir pour les événements clairement datés par les témoins, et représentatifs de l'évolution du conflit. Mais la nature même de la collecte qui est à la base de cet ouvrage nous obligera de plus en plus à faire des parties thématiques rassemblant des faits de même nature (par exemple l'attaque, la blessure, l'hospitalisation, la captivité, etc.) que chaque combattant a pu vivre à des périodes différentes de la guerre, même si l'évolution technique de cette guerre a pu introduire des variantes que nous nous efforcerons de préciser, dans la mesure du possible.

On a vu dans le chap. V (Automne 14-Aspects de l'évolution de la guerre) que dès le tout début de la guerre parfois dès fin août- certains combattants ont connu les tranchées, en ont creusé, ou s'y sont abrité. Mais tant que dure la guerre de mouvement, qu'on appelle assez couramment la "course à la mer", datée le plus souvent du 14 septembre au 17 novembre, la tranchée n'est qu'un élément défensif occasionnel. Elle devient systématique avec la fixation du front qui s'opère dès la mi-novembre 1914: "Car les fronts sont équipés, installés, fixés pour longtemps dans leurs lignes sinueuses, dès le 15 novembre 1914." écrit l'historien Pierre Miquel. ${ }^{3}$ L'année 1915 est celle de l'installation générale dans la guerre de tranchées, guerre de position qu'on pourrait appeler de siège, si l'on ne l'entrecoupait pas d'attaques assez fréquentes, et souvent très meurtrières, visant à prendre les tranchées ennemies pour gagner du terrain.

Dans ce chapitre, nous nous contenterons d'envisager l'aspect défensif de la vie en tranchée, les variantes qu'impose la nature du terrain, la proximité entre les lignes, et ce moment crucial qu'est la montée en tranchée, la relève, quand le réseau est déjà organisé.

\section{Utilité protectrice de la tranchée}

Antoine Souchon (cl 13) né à Lentigny, boulanger à Roanne après la guerre, incorporé au $16^{\mathrm{e}}$ R.I. de Montbrison en décembre 1913 a connu les tranchées dès l'automne 14, dans la Somme, où le besoin de se protéger se faisait cruellement sentir et où le trou individuel était le premier moyen de protection, en l'absence de tranchées.. Il évalue le progrès qu'a constitué la tranchée:

$\mathrm{E}-$ «Donc en tranchée, on était quand même mieux protégé?

T- Ah ben, y a pas de comparaison! Oh là! Quand les tranchées sont venues (c'est qu'on faisait des tranchées comme la fenêtre, là). Vous comprenez, ils avaient beau... Une machine (un obus ou une torpille) qui tombait sur le parapet, y avait personne de touché, vous comprenez! Fallait réellement qu'elle tombe au milieu du boyau! Oh oui oui! Oh! la tranchée, c'était utile! Ah, mais on pouvait pas faire autrement! A découvert, comme ça, là, y a pas besoin de canons: avec les mitrailleuses!

\footnotetext{
${ }^{1}$ Sauf exception, la paille dans des granges de maisons plus ou moins détruites, ou pas encore touchées par les bombardement, en arrière du front, était le lot des soldats, alors que les gradés (dont Antonin fait partie, étant sergent) et surtout les officiers bénéficiaient souvent, dans les cantonnements, de chambres réquisitionnées

2 "La-haut": la relève est presque toujours évoquée comme une ascension vers le danger (l'expression consacrée étant "monter aux tranchées" ) même s'il n'y a aucune progression en altitude entre l'arrière et la première ligne.

${ }^{3}$ Pierre Miquel, La Grande Guerre, op. cit. p. 214
} 
François Potin (cl. 14), ouvrier agricole dans l'Allier vers Saint-Pourçain-sur-Sioule avant guerre, puis métayer en divers lieux de l'Allier après guerre, venu à Saint-Just-en-Chevalet (Loire) pour soigner ses poumons gazés, incorporé au $85^{\mathrm{e}}$ R.I. de Cosnes-sur-Loire, montre aussi tout l'intérêt protecteur de la tranchée contre la gerbe d'éclats meurtriers que projettent les obus, non sans faire preuve d'humour noir, ou de réalisme: "L'obus, ça dépend comme il éclate. S'il éclate par terre, ça fauche tout ce que ça peut attraper, dans cent mètres de rayon. Tandis que dans une tranchée, vous craignez rien. S'il vous tombe dessus, vous êtes mis en bouillie, mais ça m'est égal, on n'y sent toujours pas..."

Selon les secteurs, et selon la stabilité ou la mobilité du front, parfois infime, parfois plus conséquente, la nécessité de creuser immédiatement s'impose ou non. Jean Auroy (cl. 14), agriculteur à Arfeuilles (Allier), incorporé au $142^{\mathrm{e}}$ R.I. de Mende, se souvient d'être arrivé dans son premier secteur de l'Aisne au début de l'année 1915, de nuit, et évalue le travail à faire aussitôt, selon que l'on tombe en secteur aménagé ou pas: "Ah! De nuit toujours! De jour on pouvait pas voyager parce que les lignes étaient pas loin les unes des autres, hein! Oh la la, bon Dieu, j'en ai fait des tours la nuit! Incroyable!

E- Vous êtes arrivés de nuit, ce qui fait que vous ne voyiez pas l'endroit où vous étiez

T- Ben bien sûr que non qu'on y voyait pas! Et encore: y avait des secteurs où ça allait bien, que c'était bien fait. Et puis d'autres secteurs, y avait plus rien! Eh bien on était obligé de prendre les pioches et les pelles et puis faire des trous! Parce que tant que c'était nuit, ça allait, ils nous voyaient pas. Mais aussitôt qu'il faisait clair, ça petait, hein! Ça petait, oui! On était bien obligé de faire des trous pour se cacher!"

Notons que l'obscurité protectrice de la nuit sans lune a vite été dissipée par les fusées éclairantes qui, munies d'un parachute, reconstituaient une luminosité suffisante pour permettre le tir ennemi.

Par ailleurs, ce témoin revendique la supériorité manuelle des paysans sur les citadins dans le creusement des tranchées: "Ça dépend lesquels qu'avaient fait le travail! Si c'était des gens qui comprenaient, que le travail soit bien fait, c'était impeccable! Tandis que s'ils mettaient à faire ça des types de la ville qu'ont jamais manié le manche, eh ben là, y avait du propre travail! On pouvait repasser par derrière, nous les paysans!"

Même après un an de guerre, tous les secteurs ne sont pas creusés, pour peu que le front se soit déplacé un peu. Ainsi pour la préparation de la grande offensive de Champagne de fin septembre 1915, Claudius Recorbet (cl. 15) né à Fos-sur-Mer, garde-chasse puis ouvrier à Sury-le-Comtal, incorporé au $16^{\mathrm{e}}$ R.I. de Montbrison, se souvient d'avoir dû creuser son trou individuel: "Il fallait les faire soi-même; on a vu ça pour les attaques de Champagne. C'était complètement nu, comme le jardin, là. Alors "Débrouillez-vous!". Alors on a commencé avec ces petits outils qu'on avait. Je me rappelle: j'avais une petite pioche, j'avais encore pas mal avancé. Alors, quand nous prenions pas la garde, nous venions vite creuser notre trou; à ce moment, j'étais plus souple que maintenant: je m'y mettais, le menton sur les genoux. C'est qu'il pleuvait! Et puis après, en deux jours, j'ai agrandi mon trou et j'ai pu m'y allonger. Chaque soldat faisait son trou; y avait que les officiers, c'est le Génie qui leur faisait les leurs. Ils étaient encore pas mal abrités, mais nous!"

\section{$\underline{\text { L'influence de la nature du terrain }}$}

Selon qu'il est meuble ou rocheux, fait de terre franche ou friable, d'argile, de craie ou de sable, sec ou humide, en altitude ou proche de la mer ou d'un canal, le terrain se prête plus ou moins bien au creusement, et parfois très mal, ce qui ralentit d'autant l'excavation, donc la protection relative. Ce que les agriculteurs, les jardiniers ou les mineurs savent par profession, les autres devront l'apprendre. Mais il est des terrains tout à fait étrangers par leur nature à la connaissance des agriculteurs d'une autre région.

Antonin Cote (cl. 15), agriculteur à Saint-Priest-la-Prugne, incorporé en décembre 1914 au $121^{\mathrm{e}}$ R.I. de Montluçon, montre au front au printemps 1915 dans la Somme, à Guerbigny, vers Roye et y demeure toute l'année 15. Il évalue, en paysan, la nature du terrain de la Somme, pour le creusement des tranchées:

E- « Je crois que dans la Somme, les tranchées tenaient mal, non?

T- Elles tenaient mal: c'était un terrain gras! Quand on voulait faire une tranchée, la terre se collait après la pelle, et puis les souliers, tout! C'était mouillé, quoi! Mais on trouvait pas de pierres! Dans la Somme, on trouvait pas de pierres: une pierre grosse comme un œuf, c'était rien..."

On aura compris qu'Antonin pèse ici l'avantage (l'absence de gros cailloux) et l'inconvénient (une terre grasse, collante, compacte, difficile à creuser à la pelle).

Très vite, le front s'est étendu jusqu'à la mer du Nord, en Flandres française et belge, ce qui a occasionné des difficultés insoupçonnées, mais prévisibles, pour le creusement des tranchées. et leur stabilité.

Joseph Richard (cl. 16), agriculteur à Bourg-Argental, incorporé en avril 1915 au $2^{\mathrm{e}}$ Régiment de Zouaves de Lyon, monte aux tranchées à Zuydcoote, à l'est de Dunkerque à l'automne 1915, et découvre l'inconvénient des tranchées faites en bord de mer, en terrain sablonneux: "A Zuydcoote, il en restait peu de la Belgique, vous savez $^{4}$. Y avait des tranchées, c'était tout dans les dunes. Et un jour de grand vent, ça les bouchait! Ben, on les refaisait!"

\footnotetext{
${ }^{4}$ Zuydcotte est pourtant en France, à 6 km environ de la frontière belge
} 
Antonin Morin (cl. 16) né à Pralong, mais venu jeune au Chambon-Feugerolles où il travaille comme mineur, puis après guerre conducteur de locomotive aux Houillères de la Loire à la gare du Clapier, à Saint-Etienne, et retraité à Champdieu, se trouve, du fait de sa profession de mineur, engagé au $4{ }^{e}$ Régiment du Génie de Grenoble. Il explique que le terrain sablonneux nécessite un dispositif pour retenir le sable lors du creusement de tranchées: "On les boisait. C'étaient pas des planches, c'étaient des claies. On plantait des piquets, puis on y entrelaçait des branches. On faisait des claies de deux mètres de large, et puis avec les piquets, on les plantait en bord de la tranchée, ça retenait la terre". Quand l'environnement ne pouvait pas fournir le bois ou les branches pour constituer les claies, ils étaient apportés en camions.

Jean-Marie Penet (cl. 13) né à Cusset dans l'Allier, venu à Roanne, graveur-lithographe, puis ayant épousé une pharmacienne, gérant de pharmacie à Chazay-d'Azergue (Rhône) puis à Feurs, sergent au $37^{\mathfrak{e}}$ R.I. de Troyes en décembre 1914 en Belgique vers Ypres, découvre aussi comment l'absence de relief et l'eau affleurante se prêtent mal au creusement de tranchée et obligent à utiliser d'autres techniques: "La première corvée, c'est moi qui l'ai eue; c'était la nuit, pour aller chercher des fascines. J'avais une scie et sept ou huit Poilus et on allait chercher des fascines pour les ramener en première ligne parce que, je vous le répète, en Belgique, il n'y avait pas de relief. Alors c'étaient des gabions: des paniers remplis de terre, qu'on mettait là, et des fascines: des branches d'arbres qui étaient tressées...

E- Qui servaient de camouflage

T- Oui, alors on les mettait là contre les gabions, et on remplissait de terre. Alors on pouvait circuler la journée, en se baissant un peu, à l'abri

E- Ça vous faisait des protections de quelle hauteur?

T- 1, 50 mètre.. Mais on ne creusait pas de trop, puisque l'eau venait tout de suite...Y avait le canal de l'Yser qui serpentait dans la nature. Le village qui était devant nous s'appelait Saint-Julien, dans la périphérie d'Ypres"

Il va sans dire que la profondeur de la tranchée accroît sa capacité à protéger les individus, surtout dans les deux premiers tiers de l'année 1915 où le casque n'a pas encore équipé l'armée française et où les blessures à la tête sont innombrables. Dans une tranchée trop peu profonde, l'on est mal protégé, surtout les grands. C'est ce que fait remarquer Charles Fraty (cl. 18), horloger à Roanne, qui n'a pas connu les tranchées avant le début de 1917; il signale l'inconvénient pour les grands, dont il ne fait pas partie, de ces tranchées trop peu profondes, sans parapet de terre pour les rehausser, ce qui revient à souligner l'avantage d'être petit: "Fallait faire attention de pas trop relever la tête en dehors des tranchées! Fallait rester dans les tranchées. Comme j'étais pas grand, moi, ça m'allait tout seul. Mais celui qui faisait un mètre quatre-vingt! Y en a qui se faisaient tuer sans le vouloir!"

E- C'est-à-dire que celui d'1,80 mètre dépassait les tranchées?

T- Ah ben, oui, s'il se cachait pas, s'il se baissait pas bien sûr! Y avait 1,50 m, 1, $60 \mathrm{~m}$ à peine. Les tranchées étaient pas très très profondes!"

Mais on sait qu'au début du XXe siècle, la taille d'1,80 mètre était rare, surtout dans certaines régions. Toutefois, la profondeur de deux mètres, avec l'effet rehausseur du parapet de terre rejetée en avant et souvent des sacs de sable, est généralement attestée. Mais celui qui jugerait la tranchée française à la reconstitution qu'en donne Stanley Kubrick dans son célèbre film Les Sentiers de la Gloire (Paths of Glory) en aurait une vision idéalisée et fausse...

François Baizet (cl. 97), agriculteur à Chassigny-sous-Dun (Saône-et-Loire), sergent de l'armée territoriale (il a 37 ans à la mobilisation de 1914), versé rapidement, en octobre 1914, dans l'armée active, au $153^{\mathrm{e}}$ R.I. de Béziers, où il est promu adjudant, puis après une blessure au genou, au $322^{\mathrm{e}}$ R.I. de Rodez, en décembre 1915, passe l'hiver 15-16 en Champagne, et le $1^{\text {er }}$ mars 1916, à Moussy, au sud d'Epernay (où il va être nouveau blessé le 19 mars), alors que la bataille de Verdun vient de commencer, note une invention qu'il présente comme ingénieuse pour le mieux être du Poilu dans les tranchées: "Une heureuse innovation pour les tranchées et boyaux sont les cailleboutis ${ }^{*}$, petites échelles de $1,50 \mathrm{~m}$ à $2 \mathrm{~m}$ de long ayant des traverses très rapprochées; une rigole est faite au milieu de la tranchée pour l'écoulement de l'eau et les cailleboutis* posés dessus les uns au bout des autres, ce qui fait un parquet assez sain. Il est vrai que la terre des parois de la tranchée tombant sous l'influence de la gelée ou de la pluie finit vite par boucher la rigole d'écoulement de l'eau, mais avec un entretien journalier, cet inconvénient est éviter* dans une grande mesure. Ma section est assez bien placée. J'ai une centaine de mètres de terrain à défendre et la surveillance se fait par petit poste.". François Baizet, qui est à la guerre depuis le premier jour, parle d'innovation, ce qui permet de situer l'introduction du caillebotis au début de l'année $1916^{6}$. Mais il ne faut surtout pas en conclure que toutes les tranchées en seront équipées: la plupart conserveront leur fond boueux, où l'on s'enfonce parfois jusqu'au genoux quand il pleut sans discontinuer, jusqu'en 1918.

Quant au "petit poste" qu'évoque ce témoin, il s'agit d'un appendice de la tranchée vers l'avant, en direction de l'ennemi, trou pour deux sentinelles relié à la tranchée par un boyau.

\footnotetext{
${ }^{5}$ Cette écriture "cailleboutis" pour "caillebottis" reflète ce qui doit être la prononciation générale; mes témoins parlent aussi de "caliboutis"

${ }^{6}$ Cette date de 1916 est corroborée par le Dictionnaire Historique de la Langue Français - Le Robert (Alain Rey). Alors que le terme de caillebotis (remplaçant «caillebottis » en 1678) existe depuis le XVII ${ }^{\mathrm{e}}$ siècle dans la marine, c'est en 1916 qu'il devient "un panneau de lattes servant de passage sur un sol boueux"
} 
Jean-Louis Monier (cl. 13), agriculteur à Marols, décrit la proximité des tranchées dans l'Argonne, les petits postes, ainsi que la densification progressive du réseau de tranchées.

"Les tranchées étaient à peu près à 20 mètres de distance. Et tenez-vous bien: les petits postes, qu'on a supprimés plus tard, ils étaient à 7-8 mètres des tranchées! C'est-à-dire quand vous étiez dans ce petit poste, vous entendiez l'autre (l'ennemi) quand il se mouchait ou quand il toussait, vous l'entendiez qui se relevait, vous entendiez tout... Mais elles étaient à peu près à $20 \mathrm{~m}$, là.. Et puis alors après, quand j'étais dans l'Oise, c'était la plaine, dans la région de Reims, les tranchées étaient peut-être à 30 mètres"

Il évoque le creusement de la tranchée: "Alors on rejetait la terre par dessus, qui vous faisait une hauteur de 2 mètres à peu près. Et puis alors dans cette tranchée, il y avait une banquette. Alors la journée, vous étiez dans le fond de la tranchée pour monter la garde...Non! La journée vous étiez au fond de la tranchée, et puis alors la nuit, vous montiez sur cette banquette, qui avait $30-40 \mathrm{~cm}$ de hauteur, et vous aviez la tête dehors pour surveiller ce qui se passait"

E- Mais alors la nuit, est-ce que ça circulait dans la tranchée? Est-ce qu'en se couchant dans la tranchée, on ne bouchait pas le passage?

T- Ah! mais nous avions des abris! Des abris! Des trous qui étaient pratiqués dans la terre, en arrière! Parce qu'il y avait des tranchées de première ligne, des tranchées de deuxième ligne, des tranchées de soutien, y avait tout un bazar, tout un second réseau de tranchées qui se correspondaient l'une à l'autre par des boyaux, qu'on appelait...

E- Alors, finalement, c'est parti des trous, mais ça a continué de se creuser pendant combien de temps?

T- Oh! Jusqu'à la fin! Jusqu'en 18! On creusait tout le temps des tranchées! Il fallait toujours les changer. Et puis alors, y avait ces fameux coups de main qui changeaient légèrement le front. Alors vous étiez obligé... pour quelques mètres de terrain, on faisait tuer je sais pas combien d'hommes! Et ces tranchées-là, il fallait les refaire, les reconstruire. Et puis alors, entre les tranchées allemandes et les nôtres, c'était plein de fils de fer barbelés qu'on avait placés, des fils de fer qu'on jetait par-dessus comme on pouvait de façon de que ce soit à peu près impassable. C'était à peu près impossible de passer.

E- Oui, mais alors, pour les coups de main, il fallait bien essayer de passer!

$\mathrm{T}$ - Mais c'était qu'il y avait l'artillerie avant qui passait! Alors, l'artillerie, à force de tomber des obus et des obus, coupait les fils de fer, arrivait à faire des petits passages".

Le normalien agrégé de Lettres Jacques Meyer, combattant de la Grande Guerre, a donné dans son ouvrage remarquable Les soldats de la Grande Guerre, une description synthétique des tranchées qui en montre à la fois l'aspect général et les variantes locales, dépendantes du type de sol où l'on creusait, et du relief: "Il va de soi que les tranchées étaient plus ou moins profondes, leurs parois plus ou moins rectilignes et stables suivant la nature du terrain où on les creusait, roche, argile, marne, glaise; que le climat jouait son rôle pour transformer, avec l'abondance des pluies, la terre en boue, et que la multiplicité comme la densité des bombardements bouleversaient plus ou moins les divers secteurs. Ce qui les distinguait aussi les uns des autres, c'était l'activité ou la paresse de leurs occupants. [...] Quand on ne pouvait approfondir la tranchée de première ligne sans trop craindre l'éboulement, on édifiait du côté de l'ennemi $i^{7}$ une banquette de tir, où montaient les guetteurs. On évitait de creuser des tranchées trop rectilignes car on s'y serait exposé aux feux d'enfilade des mitrailleuses ennemies. Au demeurant, les différences d'altitude, les bois, les sinuosités du terrain, les rentrants et saillants compliquaient souvent assez la perspective pour qu'on s'imaginât ne pas être vu de l'ennemi dans des endroits particulièrement exposés aux vues d'un observateur latéral. Le tracé de la tranchée était du reste coupé d'obstacles de terre, dont le nom disait bien l'utilité: les pare-éclats. On ménageait souvent aussi dans les tranchées des passages rétrécis, des chicanes, pour arrêter plus facilement d'éventuelles infiltrations ennemies. Dans les terrains humides, on renforçait les parois par des claies, des fascines, voire des gabions ${ }^{8}$, ceux-là même du temps de Vauban. Parfois même, là où on ne pouvait absolument pas creuser, la tranchée n'était qu'un chemin, balisé par des caillebottis ${ }^{9}$, entre deux rangées de gabions. La partie supérieure du parapet était généralement consolidée par des sacs à terre, où devaient se perdre les balles. Dans cette ordure, on introduisait des boîtes creuses en bois en forme de triangle, à la pointe ouverte vers l'adversaire: les créneaux, destinés au tir et surtout à l'observation. Ils se réduisaient souvent à une embrasure ménagée entre les sacs à terre. C'est là que veillaient les guetteurs." 10

La réfection des tranchées dans un secteur où des combats se sont déroulés (ce qui est presque partout au bout d'un an de stabilisation du front) réserve bien des surprises. Ainsi le Père Jean Renesson_(cl 15) né à Chevrières, prêtre après la guerre à Fleury en Beaujolais (1926-1933) puis à Dancé de 1933 à 1975, incorporé en décembre 1914 au $98^{\mathrm{e}}$ R.I. de Roanne, versé au 96 ${ }^{\mathrm{e}}$ R.I. de Béziers en septembre 15 vers Tahure, en Champagne, fait remarquer: "En septembre, on nous a mis au $96^{e}$, nous sommes allés à Tahure... Alors là, fallait creuser des tranchées, y a des moments qu'on sortait une jambe, une tête! On le mettait sur le parapet (rire)"

\footnotetext{
${ }^{7}$ Note de Jacques Meyer: "Cette face de la tranchée constituait le parapet, la face opposée, le parados."

${ }^{8}$ Ces deux derniers termes ont été expliqués dans le témoignage de Jean-Marie Penet; les claies, ou clôtures à claire-voie, s'apparentent aux fascines par l'entrelacement de planchettes ou de branches sur des piquets verticaux afin de retenir le sable ou la terre très meuble formant la paroi de la tranchée.

${ }^{9}$ Note de Jacques Meyer: "Sorte de planchers à claire-voie en lattes de bois"

${ }^{10}$ Jacques Meyer, Les soldats de la Grande Guerre, éd. Hachette, Paris, 1966, pp. 58-59
} 
Si l'on creuse en permanence au front, même quand on arrive dans un secteur déjà aménagé en tranchées, c'est que celles-ci soit s'effondrent partiellement du fait de la pluie qui détrempe le sol, soit du fait des bombardements qui, bien ajustés, détruisent toute une portion des tranchées existantes. Il faut alors les reconstruire pour reconstituer l'abri qu'offraient les précédentes. Benoît Desseigné (cl. 16) artisan menuisier à Villers, incorporé au $5^{\mathrm{e}}$ R.I.Coloniale de Lyon, reçoit son baptême du feu dans la Somme le 19 septembre 16 à Barleux, au sud-est de Péronne, et découvre ce qu'est le front ainsi que le travail de terrassier des Poilus, et les autres travaux annexes de la première ligne: "Au jour, je voulus me rendre compte de ce que ressemblait le terrain se trouvant entre les lignes. J'en fus vite rassasié en hasardant quelques minutes de lever la tête au-dessus du parapet de la tranchée. J'aperçus quantité de cadavres qui séchaient au soleil sur le sol et dans les trous d'obus et qui dégageaient une odeur intenable. J'aperçus aussi à $150 \mathrm{~m}$ la tranchée boche, et, les camarades m'indiquant le danger qu'il y avait à regarder par-dessus, je cessai de regarder. Pendant douze jours ma compagnie resta en $1^{\text {ere }}$ ligne ainsi, sans abri et attendait d'un moment à l'autre une attaque boche. Je me fis assez vite à cette vie, pendant les 12 jours je ne pus dormir, étant continuellement de garde ou à travailler à la réfection des tranchées démolies chaque jour. Je n'avais pas le souci du danger, car je ne connaissais pas assez les effets du bombardement. Chaque nuit, et à tour de rôle, nous allions au ravitaillement, à $3 \mathrm{~km}$, et le matin au jour on distribuait le café, l'eau-de-vie, et les vivres pour toute la journée. A mon $3^{e}$ jour de tranchées, je suis désigné pour poser des fils de fer barbelés entre les leres lignes."

Le creusement de tranchées en avant d'autres tranchées s'effectue aussi pour rendre une attaque moins périlleuse, comme le note Edmond Deloule (cl. 13) de Saint-Martin d'Ardèche, maçon avant guerre devenu après sa grave blessure à la tête employé à l'octroi à Paris, caporal au $23^{\mathrm{e}}$ B.C.A. de Grasse, qui, après des combats vers Ypres puis Dixmude, en Belgique, en décembre 14, revient en France pour cantonner à Magnicourt-en-Comté et creuser des tranchées à Carency, à l'ouest de Lens, à proximité de ce qui est maintenant le cimetière national de Notre-Dame-de-Lorette. Il explique dans une grande lettre à ses parents, datée du 7 janvier 1915, comment la nécessité de rendre une attaque plus efficace peut amener à doubler des tranchées par une autre plus proche de l'ennemi et raconte les péripéties personnelles liées à la protection des camarades creusant la tranchée: "Le lendemain on partit prendre les avant-postes près du village de Clarency (Carency). On devait attaquer, mais comme le temps était brumeux, l'artillerie ne put pas tirer et l'attaque n'eut pas lieu. Le surlendemain on retourna pour l'attaque; de nouveau le temps se fit brumeux, et ma foi de nouveau l'artillerie ne put tirer. Alors l'on combina un plan: nos tranchées était* peut-être à $300 \mathrm{~m}$ de celles des boches* et l'on décida que dans la nuit on irait (c'est ma section qui fut désignée) creuser une tranchée $150 \mathrm{~m}$ en avant pour n'avoir pas tant de parcours à faire à découvert pour attaquer les boches*. Le soir vers les huit heures on sorti* des tranchées, et moi je fus désigner* avec quatre hommes pour aller me placer beaucoup plus en avant en halte gardée pour surveiller pendant que les autres travaillaient, c'est-à-dire peut-être $80 \mathrm{~m}$ des boches*. Comme j'allais arriver à l'endroit qu'on m'avait fixé, les boches* lancent une fusée éclairante et là vous savez on y voit presque comme en plein jour. Je me trouvai nez à nez à peut-être une quinzaine de mètres d'un poste d'écoute qui était placé là la nuit; ils étaient au moins une douzaine, ils commencèrent par nous tirer dessus et alors viro brido l'asél ${ }^{11}$, je n'eus pas besoin de commander demi-tour à mes hommes, ils étaient déjà loin. Ils lancent une autre fusée et alors j'étais une cible vivante; le poste allemand s'était replié dans leurs tranchées et les mitrailleuses commencèrent à battre le terrain en tous sens. Heureusement pour moi j'alla* tomber directement à un gros trou d'obus, je m'y glisse dedans, il était temps, j'entendais les balles qui passait* au-dessus de ma tête, mais je m'en foutais j'étais en sûreté. Au bout d'une heure quand les boches* ne tiraient plus je sortis de mon trou qui m'avait sauvé la vie et j'arrivait* à la tranchée content de m'en être tiré à si bon compte. On ne comptait plus me revoir."

\section{Les abris : gourbis, cagnas, sapes...}

Au dispositif de la tranchée se greffe aussi un système d'abris, parfois pour les soldats de base (plus fréquemment pour les artilleurs que pour les fantassins), le plus souvent pour les officiers, abris qualifiés des deux termes issus du vocabulaire de l'armée de colonisation, empruntés aux peuples colonisés. Selon le Dictionnaire Historique de la Langue Française (le Robert) dirigé par Alain Rey, "cagna" est un terme militaire de l'armée française en Indochine (de l'annamite "cainha") répandu lors de la Première Guerre mondiale dans l'argot des poilus, et désignant alors un abri de tranchée généralement souterrain. Il a quelquefois pris par extension le sens de "cabane, abri"; tandis que "gourbi" est un emprunt à l'arabe d'Algérie "gurbi", maison de terre, chaumière" qui a désigné par analogie (dès 1855) un abri de tranchée et, par extension, une habitation misérable et sale. Leur creusement ou leur édification dépend du terrain, du matériel de construction dont on dispose, ainsi que de la plus ou moins grande proximité de l'ennemi, sachant que beaucoup n'offrent qu'une protection limitée contre les bombardements adverses.

Mathieu Grand (cl. 14), agriculteur à La Tuilière jusqu'au début des années 30, puis facteur, principalement à Panissières, de 1937 à sa retraite, mort à 105 ans, est incorporé le 3 septembre 1914 au $22^{\mathrm{e}}$ B.C.A. d'Albertville et

\footnotetext{
${ }^{11}$ En patois ardéchois du sud: "viro brido l'asé" = "tourne bride l'âne", indiquant une volte-face rapide.
} 
rejoint le front des Vosges le 17 novembre 14. Il découvre des gourbis pour Chasseurs Alpins d'un type très spécial, lié à l'absence de bombardement ennemi dans le secteur: "Où j'étais, on se mettait à l'abri (on était dans les Vosges) avec des branches de sapins. On faisait un gourbi, qu'on appelait ça, on s'enfilait à quatre pattes comme les castors (rire) et puis on sortait à reculons. Et puis la nuit on veillait. Ça protégeait un peu du froid, de la neige... Oh! ça protégeait pas du tout d'une balle! Ni encore moins d'un obus!

E- Et là, vous étiez à quelle distance de la première ligne allemande?

T- Oh! Le premier hiver, je me suis vu à 20 mètres! On s'entendait tousser, avec les Allemands! C'était pas loin, hein! Des endroits, c'était un peu plus loin, 30-40 mètres peut-être. Mais là, le premier endroit, 20 mètres!

E- Je suppose qu'il y avait des fils de fer entre les deux premières lignes?

T- Ah non! Oh non! Rien! Y en avait encore point, le premier hiver, la première année. Après! Mais on pouvait pas en mettre: qu'est-ce que vous voulez, ils auraient vu! Tout comme les Allemands, ils pouvaient pas en mettre! On les aurait vus! On leur aurait tiré dessus". Il est clair que Mathieu Grand décrit ici une situation d'entente tacite entre ennemis pour passer l'hiver au mieux, sans s'agresser. D'après les divers témoignages de soldats ayant appartenu à ce type de régiment (appelé "bataillon" pour eux) les Chasseurs Alpins passaient d'ailleurs assez régulièrement une partie de l'hiver dans un secteur relativement tranquille des Vosges

Amand Beyron (cl. 11) de Chazelles-sur-Lyon, fils d'un fabricant de chapeaux, devenu après guerre directeur de diverses usines textiles, dont celle de Régny, retraité à Roanne, est musicien-brancardier au $99^{\mathrm{e}}$ R.I. de Vienne. En août 1915, le régiment est transféré de la Somme à la Champagne, en prévision de la grande offensive prévue fin septembre. Les musiciens, relativement embusqués tant qu'ils ne sont pas brancardiers, après les combats, doivent faire eux-mêmes leur "gourbi", comme il le note dans son journal: "Samedi 21 Août - Nous avons commencé de faire les fondations d'un "gourbi" neuf avec des pelles et pioches barbotées au train de combat, et le chef nous fait faire une répétition dans la matinée. Repos l'après-midi. Nous finissons notre "gourbi", recouvert de nos toiles de tentes, assez bien arrangées pour la pluie, si elle vient à tomber... En douce, sans être vus, nous rendons pelles et pioches où nous les avions trouvées la nuit précédente... Pas vu...pas pris!"

Si gourbis et cagnas protègent des intempéries, mais très peu des bombardements, il n'en est pas de même des sapes, abris souterrains, surtout s'ils sont suffisamment profonds, et renforcés. Ainsi Francis Ferret (cl 16), agriculteur à Saint-Christo-en-Jarez, monte au front en décembre 1915, dans la Meuse. Il découvre la protection que ces sapes offrent contre les obus, lorsqu'elles sont bien faites: "Ces sapes, y avait une montée d'escaliers, une cave, profonde. On avait mis des gros rondins de bois dessus, comme des chênes, c'était costaud. Et on descendait dans les sapes quand ça bombardait. Ou bien ceux qui étaient dans les sapes... Ils (les Allemands) tiraient des torpilles $^{12}$, ou tout; alors, au lieu de rester dans les tranchées, ils (les Poilus) allaient en bas. Les sentinelles restaient dans le boyau et donnaient l'alerte. Ils appelaient vite, si jamais il y avait quelque chose."

La cagna devient pour l'officier, voire le sous-officier, un abri individuel qu'il aménage ou fait aménager presque confortablement quand il séjourne dans un secteur suffisamment longtemps.

Jean Giraudon (cl. 11), né à Saint-Etienne, qui aura après guerre deux carrières successives, une militaire au $38^{\mathrm{e}}$ R.I. de Saint-Etienne jusqu'en 1928 terminée comme adjudant-chef (lieutenant de réserve en 1935), une civile dans les Postes, terminée comme inspecteur, retraité à Bourg-Argental, est déjà sergent au $16^{\mathrm{e}}$ R.I. en novembre 14 , au Bois des Loges, dans l'Aisne. Il décrit une cagna d'officier singulièrement améliorée par les "prélèvements" faits dans les maisons démolies: "On avait fait des tranchées, des cagnas. Moi j'étais dans une cagna (rire) On avait été chercher des draps, on l'avait tapissée avec des draps. C'était le lieutenant qui avait fait faire ça, je le remplaçais.. [...] C'était évacué, quoi, complètement. Alors, on allait dans les maisons, on se servait de ce qu'on avait besoin! On avait une table, on avait des chaises, on avait ce qu'il fallait pour la cagna... Et puis alors au-dessus, nous avions ça épais d'arbres qui étaient coupés, comme abri. Alors si un obus tombait dessus, on risquait moins, quoi!"

François Baizet (cl. 97), agriculteur à Chassigny-sous-Dun (Saône-et-Loire) que nous avons présenté précédemment, deux fois blessé, quatre fois changé de régiment, promu adjudant, se retrouve fin 1917, à 40 ans, commandant une section du $64^{\mathrm{e}}$ R.I. territoriale chargée de travaux de bûcheronnage à Vaubécourt, au nord de Bar-le-Duc. Il termine un de ses carnets, le 17 décembre 1917, par un morceau de bravoure littéraire, un superbe adieu lyrique de presque cinq pages (malheureusement amputé de deux) à la cagna qu'il occupe pourtant depuis peu, s'étant déplacé à Vigneville (Cote 232):

"Encore une fois, il me faudra faire mes adieux à ma cagna.

Ma Cagna, comme le juif errant, je vais partir et te dire au revoir. Au revoir, est-ce bien sûr? Par la force des choses ne te serai-je pas infidèle et te reverrai-je jamais? Il est bien probable que c'est adieu qu'il faut que je te dise. Que veux-tu, c'est la guerre. Toi qui m'a* abrité pendant 4 jours, toi dont malgré ce temps si court où* je suis resté dans ton enceinte, je connaissais les moindres recoins. Tu n'en avais guère du reste de recoins étant toute ronde, montée comme une cave ${ }^{13}$ par de grosses et grandes tôles ondulées et renforcées. Et sur ton plancher comme mobilier une table boiteuse fabriquée par un poilu qui savait peut-être manier la scie et le marteau, les seuls outils

\footnotetext{
${ }^{12}$ Les torpilles, quand elle ne désignent pas une arme sous-marine, qualifient en 1914-1918, soit une bombe aérienne, soit plus couramment une bombe de tranchée à ailettes.

${ }^{13}$ François Baizet semble vouloir dire "montée comme une case", en raison de la forme ronde qu'il vient de décrire.
} 
qu'il devait posséder, tes deux bancs rugueux, un pour moi, l'autre pour le camarade qui pouvait venir me voir, tes deux lits bien bas, bien étroit*; la place est chère et il ne faut pas la gaspiller, n'est-ce pas? Et ton poële taillée* dans un fut* de carbure en fer blanc par un fumiste de génie ${ }^{14}$, rendait ton habitation presque gaie et confortable en raison de la douce chaleur qui s'en dégageait. Et ton intérieur bardé de fer ne laissait pas rentrer les rats, ces vilaines bêtes, compagnon* du poilu toujours. Tu les retenais derrière tes tôles et malgré leur ruse et leur activité, tu semblais leur dire: "Vous ne passerez pas" ${ }^{15}$. Va, je les ai entendus bien des fois s'acharner, grattant, couinant et trottant sur tes tôles. Ils ne passaient pas. En cela, tu es semblable au soldat de Verdun. Tu sais, le boche* à Verdun, là tout près de nous, au mois de février 1916, il voulait passer. Il voulait s'introduire [deux pages manquantes] reposer chez toi: sois leur avenante, protège-les contre les bolides qui font pet dans l'air ${ }^{16}$ et si par hasard, c'est sur toi qu'il vient (corrigé en "viennent") s'abattre, que la terre dont tu es recouverte et les tôles qui sont tes murailles ne permettent pas à l'intrus de déranger celui qui repose dans ton sein.

Ma cagna, telle que tu es, je te préfère $a^{*}$ un château, telle que tu es, je t'aime. Adieu, ma cagna"

François Baizet devient souvent lyrique, et il meuble son temps de solitude par l'écriture, qu'il manie bien, conçue comme un réconfort, son carnet devenant son confident. Sur le plan documentaire, cette cagna d'officier n'est qu'un modèle parmi d'autres, étant donné que toutes étaient faites de bric et de broc, avec les matériaux que fournissaient l'environnement naturel (les troncs d'arbres) ou ce qu'il en restait, les maisons détruites ou les accessoires disponibles qu'on pouvait chaparder au Génie, ou marchander. Les officiers et sous-officiers disposaient ainsi d'un confort inconnu du soldat du rang, ce qui n'était pas sans susciter des jalousies (voir la remarque de Claudius Recorbet dans ce chapitre, à propos des officiers: "Ils étaient encore pas mal abrités, mais nous!")..

\section{$\underline{\text { Supériorité allemande en matière de tranchées et d'abris }}$}

Mais en matière d'abris comme d'armement, les Allemands auraient été supérieurs aux Français, s'il faut en croire plusieurs témoignages, dont celui de Jean Pouzerat (cl. 13) agriculteur à Arfeuilles et au Breuil (Allier) qui, monté au front en décembre 1914 vers Saint-Quentin, dans l'Aisne, ira en 1915 dans la Somme et le Pas-deCalais:"Mais les Boches, ils étaient pas si bêtes que nous! Les Boches, tout l'hiver 14, ils avaient fait des abris, tandis que chez nous on n'avait rien fait du tout! Les Boches, tous les matins, on voyait du feu...pas du feu, de la fumée! Alors ils avaient des abris, ils se mettaient dedans, et ils sortaient que quand y avait un coup dur, hein! Ils étaient pas si bêtes que nous! Y avait pas de comparaison! Quand on a pris les premières lignes, on disait: "Mon vieux!" ... Ils avaient des abris y avait dix marches d'escalier pour descendre! Fallait voir le boulot qu'ils avaient fait!".

Confirmant cette opinion de Jean Pouzerat, la revue L'Illustration, dans son numéro du 21 août 1915, présente un très long article, très documenté, et illustré de dessins, sur "L'organisation défensive allemande au nord $d^{\prime}$ Arras $^{\prime \prime 17}$, à partir des observations faites sur le terrain conquis à l'ennemi dans ce secteur; après avoir énuméré les divers modes de défense (chausse-trapes à quatre piques, dont l'une toujours verticale, réseaux "inextricables" de barbelés et de chevaux de frise, organisation méthodique de la tranchée) l'auteur en vient à un bilan qui s'achève par l'évocation des abris: "Toutes ces défenses, établies de manière continue et sur des profondeurs de 10 à 15 mètres, interdisent complètement la surprise des tranchées. Grâce à cette sécurité, il suffit de laisser des guetteurs dans la tranchée, la plupart des hommes se reposant dans des abris à l'épreuve du bombardement. L'accès de ces abris allemands se fait soit par un rameau en escalier, soit par un puits. Ils sont très confortables, mesurant 10 mètres de longueur sur 2 mètres de largeur et 1,80 m de hauteur. Ils sont coffrés jointifs de madriers de $8 \mathrm{~cm}$ d'épaisseur et recouverts de 5 à 6 mètres de terre au-dessus du ciel. Cette protection suffit généralement contre les obus de gros calibre qui pénètrent dans le sol à plusieurs mètres de profondeur en produisant un entonnoir semblable à celui d'un fourneau de mine."

Mathieu Grand (cl. 14), de la Tuilière, déjà présenté, soldat au $22^{\mathrm{e}} \mathrm{BCA}$ d'Alberville, est blessé à la jambe par un éclat d'obus à la bataille du Linge, dans les Vosges, le 20 juillet 1915, bataille meurtrière s'il en fut pour son bataillon: "Au Lingekopf... Alors, là on a reçu une raclée, hein! Sur 1200 qu'on était le matin (j'ai été blessé là) ils se sont retrouvés 250 le soir! Alors, ça faisait du déchet, hein! Et ils avaient pas le moral, les gars qui sont revenus!" . Ils avaient d'autant moins le moral qu'ils avaient pu prendre la mesure de la supériorité allemande, en armement et en installation:

E- Qu'est-ce qu'il fallait prendre ce jour-là?

\footnotetext{
${ }_{15}^{14}$ Qu'on ne se méprenne pas: un fumiste, c'est, au sens propre, un fabriquant de poêles, et non un individu paresseux!

${ }^{15}$ On a compris qu'il y a là une allusion humoristique à un mort d'ordre patriotique très répandu en 14-18, surtout au moment de la grande bataille de Verdun, à l'adresse des Allemands: "Ils ne passeront pas!", comme la suite commence à l'expliciter.

${ }^{16}$ Il s'agit évidemment des obus

${ }^{17}$ Revue L'Illustration du 21 août 1915, n³ 3781,pp. 197-198
} 
T- La tranchée des Allemands! Oui, mais organisés comme ils étaient! Ils avaient des tranchées en ciment armé, déjà, eux! Et puis ils avaient prévu l'attaque! Alors, ils avaient tout ce qu'il fallait, quoi!"18

Ces tranchées bétonnées, même si elles ne sont le cas général, impressionneront toujours les soldats français. Ainsi un soldat beaucoup plus jeune, car de la classe 18, Etienne Carton, engagé volontaire à 18 ans en 1916, par patriotisme, mais aussi pour choisir son arme, l'artillerie (est au $113^{\mathrm{e}} \mathrm{R}$. A. Lourde d'Issoire), réputée à juste titre moins dangereuse, expliquera par ce fait les échecs successifs des chasseurs alpins au Moulin d'Herpy (Herpy l'Arlésienne), à une douzaine de km à l'ouest de Rethel, dans les Ardennes, en 1918: "Ils avaient attaqué six fois, les chasseurs alpins, six fois ils avaient pas pu prendre le moulin d'Herpy! Ils risquaient pas de le prendre! Nos obus pouvaient pas crever leurs tranchées! Ils avaient des tranchées, faites chez nous, de deux mètres d'épaisseur, avec du béton armé! Et les cagnas de mitrailleuses, 2,50 mètres d'épaisseur! Les obus pouvaient pas les percer, vous comprenez!"

Ainsi, par leur confort relatif et par la résistance offerte aux bombardements, certaines tranchées allemandes, de 1915 à 1918, feront l'admiration et l'envie des Poilus, qui auront tôt fait de généraliser pour mieux dénoncer l'incompétence de l'armée française et le mépris de certains de ses chefs pour les conditions de vie et de survie du soldat de base.

\section{La distance entre les tranchées}

La question concernant la distance entre les tranchées de première ligne française et allemande a très souvent été posée, et a entraîné des réponses variables. Il va sans dire que selon les endroits où se sont trouvés les soldats dans les divers secteurs qu'ils ont occupés, les distances ont pu être très variables, notamment en raison de la nature du terrain, ou de la phase de la guerre (des tranchées éloignées ont été rapprochées par le creusement d'autres tranchées) et que le souvenir du danger encouru du fait de la proximité de ces tranchées a pu entraîner à minimiser la distance, ou à ne retenir que le plus minime écartement. Si l'on essaie de synthétiser la multiplicité des réponses, on peut dire que les tranchées très proches sont estimées de 20 à 50 mètres, et les tranchées relativement éloignées de 100 à 300 mètres Une preuve souvent donnée de la grande proximité est que les Poilus entendaient les bruits des Allemands, comme dans le témoignage de Mathieu Grand précédemment cité à propos du premier hiver de guerre 1914-15 dans les Vosges: "On s'entendait tousser, avec les Allemands". Un autre détail lui revient: "Y en avait un, le matin, un Allemand, qui chantait le coq! Il chantait bien, Bon Dieu, le coq! (rire). Ils étaient comme nous, les pauvres!"

A la question qui reprend sa formulation: "Le plus près que vous ayez été des Boches, c'est à combien?" Marius Dubuis (cl. 16), agriculteur à Coutouvre, et caporal, répond: "Ah! le plus près, c'est une vingtaine de mètres! On les écoutait bien causer!"

Plusieurs témoignages évoquent des distances extrêmement réduites, si réduites qu'on serait amené à relativiser, si des témoignages écrits tout à fait fiables ne les corroboraient pas. Référons-nous à celui que cite le général André Bach chef du Service Historique de l'Armée de Terre dans son ouvrage Fusillés pour l'exemple 1914-1915 paru en 2003: "Dorénévant, les troupes se terrent dans les tranchées, souvent à un jet de grenade de l'adversaire. On note dans le Journal de marche du $147^{e}$ R.I., en novembre, quelques propos significatifs: "7 novembre: la séparation avec l'ennemi se fait parfois par quelques portions de terrain éboulée, parfois par une simple traverse. On se demande avec appréhension comment une telle situation pourra être maintenue"19

La revue illustrée Le Miroir du 31 janvier 1915 présente en double page (pp. 8-9) sous le titre "Français et Allemands face à face, à 6 mètres les uns des autres, dans la même tranchée" une photo de cette tranchée vue du côté français, dont voici une partie de la légende: "C'est une ancienne tranchée de première ligne des Allemands. Nous l'avons occupée par l'est et par l'ouest, jusqu'au point extrême ou "saillant" qui reste aux mains des Allemands. Nous sommes donc dans la même tranchée qu'eux et nous tentons, comme eux-mêmes, de gagner du terrain en poussant les sacs du mur mobile qui sépare les uns des autres. Le sapeur, sans armes, que l'on voit au dernier plan, se livre à ce travail extrêmement périlleux."

Francisque Viallon (cl. 15), agriculteur puis entrepreneur de transport à Chalmazel, témoigne de cette distance très réduite rencontrée une fois: "Il y avait toutes les distances. Moi, le plus près, j'ai vu 12 mètres, 12 mètres, oui! C'était pas rigolo, ça! On avait mis des fils de fer! Mais 12 mètres, c'était exceptionnel, c'était une pointe avancée, mais $50 \mathrm{~m}$, c'était courant, 50-100 mètres"

François Potin (cl. 14) ouvrier agricole dans l'Allier jusqu'à son incorporation, a vécu la fin de l'année 14 et une partie de l'année 1915 en forêt d'Apremont dans la Meuse: "En forêt d'Apremont, on était à 4 mètres des Boches! C'est le secteur qu'on a été le plus près avec les Boches!

E- Les deux premières lignes étaient à 4 mètres, Mais qu'est-ce qu'il y avait entre les deux? Des barbelés?

\footnotetext{
${ }^{18}$ Cependant les sommets du Lingekopf et de son voisin le Barrenkopf, dominant la vallée de Munster, sont donnés comme enlevés par les Français le 21 juillet 1915, dans la revue L'Illustration du 14 août 1915, pp. 168-169, soit le lendemain de la "raclée" infligée au bataillon de Matthieu Grand

${ }^{19}$ Général André Bach, op.cit, p. 395
} 
T- Oui, des barbelés; des fils de fer qu'ils avaient jetés comme ils pouvaient, et puis des tués, au milieu, qui pourrissaient! ... On était à 4 mètres les uns des autres. Fallait pas qu'ils bougent! On les aurait vus, on les descendaient. Et ils faisaient pareil, eux!"

Marius Gondy (cl. 11) de Chauffailles, valet de chambre avant guerre, puis après guerre hôtelier à Annecy, puis à Chauffailles à partir de 1935, écrivait à son frère pendant sa guerre, et une de ses lettres est à la fois lue et commentée par sa petite nièce pendant mon enquête : "Le 14 juin (1915), vous écrivez: "Je suis du côté de Beauséjour et de Perthes, c'est-à-dire en Champagne. Ce n'est pas si mauvais que du côté d'Arras, mais ce n'est pas bon quand même car il y a des mines et des bombes qui sont terribles. Nous sommes trop près des Boches, à 10 ou 15 mètres en certains endroits. Alors on peut pas bouger ou alors tu es tué"

Deux témoignages concordent concernant la grande proximité des tranchées au Vieil Armand ou Hartmanwillerkopf, dans les Vosges du Haut-Rhin. Antoine Guillot (cl. 14), cordonnier à Perreux, s'y trouve en février 1915 avec le $371^{\mathrm{e}}$ R.I. de Belfort: "Au Vieil Armand, on a eu 28 tués dans la compagnie sans combattre! Sans combattre! On a pas attaqué, on a rien fait du tout, mais alors on recevait quelque chose! (comme obus)

$\mathrm{E}-\mathrm{Au}$ Vieil Armand, vous étiez à quelle distance des lignes allemandes?

T- Ah ben moi, j'étais à 5 mètres! Quand on a remplacé le 152, on a monté à la crête, j'étais à 5-6 mètres d'eux!

E- Et eux étaient de l'autre côté de la crête?

$\mathrm{T}-$ Eh oui! Et puis alors nous, on voyait Mulhouse..."

En décembre de cette même année 1915, Claude Chaume (cl. 12), agriculteur à Bully, qui sera amputé d'une jambe en 1918, se retrouve dans ce même secteur avec son $5^{\mathrm{e}}$ Bataillon de Chasseurs à Pieds de Remiremont, et décrit le dispositif défensif imaginé: "A l'Hartmanwillerkopf, quand on était en faction, on entendait le Boche de l'autre côté qui tapait du pied parce qu'il avait froid! On n'était pas loin, hein! On avait mis des grillages au-dessus des tranchées parce qu'ils nous envoyaient des grenades, pour empêcher les grenades de nous atterrir sur la tête!"

Cependant, on imagine mal que des grillages puissent annihiler l'aspect meurtrier de grenades, sauf si, très hauts et tendus de biais, ils les renvoient chez l'ennemi qui les lance, le dissuadant alors de le faire!

Une proximité aussi grande, Claudius Mestrallet (cl. 16), mineur à Roche-la Molière mais résidant à SaintGenest-Lerpt, l'a retrouvée dans la Somme, à proximité d'Amiens en 1916: "Amiens, dans la Somme. Alors, il me dit: "Votre sous-of, il est pas content de vous!" Moi, je savais pas quoi dire, je lève les yeux. Il me dit: "On va vous envoyer aux crapouillots!" Alors, les Boches, y avait juste la route qui nous séparait! Nous autres, on était de là, les Boches étaient de l'autre!"

E- C'est-à-dire qu'ils étaient à combien de vous, à peu près!

T- Là? A 5-6 mètres! La largeur d'une route!"

Cette proximité si grande qu'elle en devient invivable entraîne quelquefois, voire assez souvent, le phénomène de l'entente tacite consistant à laisser l'ennemi tranquille tant qu'il ne vous agresse pas, ou tant que l'ordre d'attaquer n'est pas donné.

Jean-François Ollier (né en 1914, mais cl. 13, car ayant devancé l'appel), fabricants de soieries à SaintEtienne, alors jeune sous-lieutenant au $14^{\mathrm{e}}$ B.C.A. de Grenoble, évoque la très grande proximité des lignes au Linge en janvier 1916 et l'entente tacite qui en résultait, rompue parfois par un ordre jugé "imbécile" par le témoin: "En hiver, là-bas, on se battait pas beaucoup. Sur trois bataillons, il y a une compagnie en ligne et les autres en réserve. Je suis arrivé, moi, dans une compagnie en ligne, et les tranchées étaient très bien faites, parce que le Génie avait aidé à les faire comme c'était l'hiver et qu'on ne se battait plus beaucoup depuis des semaines, et même des mois. Et cette tranchée très bien faite était, tenez-vous bien, à moins de 10 mètres de la tranchée allemande! Mais beaucoup moins de 10 mètres! Par endroit 2 mètres! Y avait des fils de fer...

$\mathrm{E}-$ On devait être tenté de se jeter des grenades?

T- Eh bien, vous comprenez qu'il y avait un petit machin réciproque. Si l'un avait fait... Ils étaient comme nous, les Allemands, c'étaient que des hommes! Alors, pour un peu de repos qu'on avait, on gigaudait ${ }^{20}$ pas trop avec ça. Il y avait des endroits où ça repartait. Dans des secteurs comme ça, on se servait un peu de ce qu'on appelait les crapouillots $^{21}$. Alors de temps en temps, on s'emmiellait ${ }^{22}$ un peu avec ces cochonneries-là; ça faisait des dégâts, il fallait les réparer. On refaisait les fils de fer, c'était vrai pour eux comme pour nous.

E- Donc on s'efforçait de pas trop se nuire?

T- Il y avait parfois un chef imbécile! Ça n'avançait pas à grand'chose, ça tuait pas beaucoup de monde, mais ça embêtait tout le monde, n'est-ce pas? Enfin, c'était la guerre!"

\section{Chevaux de frise et fils de fer barbelés}

Peu à peu, avec la proximité croissante des tranchées lorsque les armées ennemies se faisaient face dans une immobilité relative de leurs positions, le dispositif passif de défense contre l'intrusion surprise des Allemands s'est

\footnotetext{
20 "on gigaudait": la prononciation claire de ce mot ne se confond pas avec "gigotait"; c'est sans doute un terme de français local, non répertorié. On devine que le sens est "on ne plaisantait pas"

${ }^{21}$ Le terme "crapouillot" désigne un petit mortier de tranchée permettant d'effectuer des tirs très rapprochés

22 "S'emmieller" est un euphémisme poli pour "s'emmerder", euphémisme pratiquement sorti de l'usage
} 
renforcé de fils de fer barbelés et de chevaux de frise, dispositifs à croisillons posés sur le sol, servant le plus souvent de supports à des rouleaux de fils de fer barbelés ${ }^{23}$, dont le nom apparaît en 1572, avec comme origine la Frise néerlandaise, région où ce dispositif aurait été inventé.

Claudius Recorbet (cl. 15), garde-chasse puis ouvrier à Sury-le-Comtal, incorporé au $16^{\mathrm{e}}$ R.I. de Montbrison, se souvient d'une installation de ces chevaux de frise dans l'Aisne en 1915 (il témoigne en patois, mais deux fois l'expression "joli travail" surgit en français, tout comme la suggestion faite au sergent): "Je me rappelle une fois, c'était toujours dans l'Aisne, ça, y avait une grande étendue de plaine, mais c'était encore assez loin (comprendre: de l'ennemi), y en avait qu'un qui nous embêtait, c'était le fort de Condé24 qui était sur la gauche. Le fort, de temps en temps, t'envoyait quelques gros pruneaux, comme ça là, mais le secteur était encore assez calme. Et là il fallait transporter les chevaux de frise qu'ils faisaient (sans doute le Génie). C'était des machins de ferraille, des grands croisillons. Alors on était deux, non, on était plus que ça! Alors on portait les machins pour les ficeler après ${ }^{25}$. Après, quand on a eu fini la corvée, on s'est aperçu que les Boches venaient les chercher et les emportaient! Ah! Et ben on a dit: "Un joli travail! " Alors, on a changé de tactique: "Y a qu'à mettre des piquets!" Un joli travail, tiens! Et pour enfoncer ces piquets, tous les coups qu'on faisait peter (la masse sur la tête du piquet) : "Pan! Ziou!" (imite le sifflement d'une balle". Oh! j'ai dit au sergent: "Mais y aurait pas un autre système, pour pas faire de bruit?" "- Et comment faire?" - "Mais cherchez une pince!". Alors, avec une pince, tu te mettais à plat cul (assis par terre), tu faisais ton trou assez profond et tu y enfilais ton piquet, et tu enfilais ton fil de fer (dans l'orifice ménagé au sommet du piquet) et tu faisais pas de bruit"

Antonin Cote (cl. 16) agriculteur avant guerre à Laprugne (Allier), avant de l'être après son mariage, à SaintPriest-la-Prugne (Loire) est en 1915 dans la Somme, vers Roye; il évoque aussi cette pose des fils de fer, toujours trop bruyante: "Et d'autres fois, on était à pas même 50 mètres! Mais c'était la nuit qu'on posait les barbelés entre les lignes. Et il fallait pas, bien sûr, faire trop de bruit quand vous plantiez les piquets, les pieux qu'on appelait. Eh ben, ça fait du bruit! On empaquetait la masse avec des chiffons, alors ça faisait un peu plus sourd. Mais on y restait pas longtemps!"

E- On m'a dit qu'on avait trouvé un système pour planter les piquets, avec une sorte de tire-bouchon ${ }^{26}$ : vous l'avez $v u, c ̧ a$ ?

T- Après ça! Bien sûr! Un tire-bouchon! On faisait faire un tour, on entendait pas de bruit! Mais à ce moment, j'y étais plus!"

Selon Antonin Morin (cl. 16) de Pralong, fils d'agriculteurs, mais devenu mineur au Chambon-Feugerolles, incorporé au $4^{\mathrm{e}}$ régiment du Génie de Grenoble, les pieux en tire-bouchon sont une invention allemande copiée par les Français: "Les Allemands, eux, ils étaient plus intelligents! Ils avaient du matériel qu'on avait pas! C'était tout des piquets en fer, eux, à tire-bouchon! Ça fait que nous, quand on plantait des piquets, il fallait taper. Mais eusses* ils les enfonçaient sans faire du bruit!"

Un de ces piquets en fer à bout en tire-bouchon est dessiné dans l'article de L'Illustration déjà cité, du 31 août 1915, intitulé "L'organisation défensive allemande au nord d'Arras" (page 197). L'extrémité supérieure est une pique pointue qui accroît l'aspect défensif, mais interdit l'usage d'une masse; sous la pique, un orifice résultant d'une torsion complète imposée au métal permet le passage d'une tige de fer, sans doute tenue aux deux extrémités par les deux mains du soldat, dans un mouvement rotatif, pour enfoncer le tire-bouchon dans la terre et l'y ancrer solidement. Le fil de fer barbelé s'ancre au piquet par un œillet métallique.

Venu beaucoup plus tard à la guerre, car de la classe 18, Victor Fréry du Lac, hameau de Saint-JeanSoleymieux, qui sera plus tard cantonnier, surtout à Boën-sur-Lignon, nouvellement versé au $147^{\mathrm{e}}$ R.I. de Sedan, a passé l'hiver 17-18 à installer des réseaux de fils de fer barbelés: "L'hiver 17-18, on était dans les environs de Reims pour poser des barbelés. Il fallait mettre des piquets, ou choisir ce qui existait déjà sur le sol, tout obstacle. Il fallait détortiller ces machins..."

E- C'étaient les gros barbelés avec beaucoup de piquants?

$\mathrm{T}$ - Eh oui! Et je vous assure: on avait des gants de laine, ils étaient déchirés tout de suite, et on avait les mains tout en sang parce qu'on se piquait! Vous aviez beau prendre des dispositions... On entortillait ça dans un arbre, dans un... dans plusieurs sens, n'importe comment, quoi! On accrochait ça de façon que ça fasse un obstacle."

\footnotetext{
${ }^{23}$ Pour avoir vu dans mon enfance, vers 1955, au hameau de Chatelville (commune de Chazelles-sur-Lavieu, dans la Loire) ce fil de fer récupéré de la guerre de 14-18, et m'y être frotté lors d'une chute à vélo, je puis garantir qu'il n'avait pas le moindre rapport avec le moderne fil de fer barbelé pour enclore un pré: c'était un fil de fer très rigide, très épais, avec de forts piquots tous les $4 \mathrm{~cm}$ environ, dont l'installation sans gants de protection devait être très douloureuse...

${ }^{24} \mathrm{Ce}$ fort de Condé, tenu par les Allemands, doit renvoyer à la localité de Condé -sur- Aisne, à une dizaine de km à l'est de Soissons

${ }^{25}$ La phrase est ambiguë, à cause de l'imprécision de "machins": on ne sait si les soldats portent les chevaux de frise à l'emplacement indiqué, ou des fils de fer barbelés pour les ficeler sur les chevaux de frise précédemment posés.

${ }^{26} \mathrm{Au}$ lieu d'avoir un piquet dont l'extrémité plantée dans le sol était droite (ce qui impliquait qu'on frappe sur ce piquet avec une masse), le génie la torsadait en tire-bouchon, de sorte qu'une rotation (opérée avec une barre placée dans l'ouverture de l'extrémité haute du piquet destinée à recevoir le fil de fer) du piquet l'enfonçait graduellement dans la terre, sans bruit.
} 
On mesure donc que malgré l'amélioration des techniques au fil de la guerre, la pose de barbelés a été manuellement douloureuse, dangereuse du fait de l'exposition aux tirs ennemis, et n'a pas été rationalisée partout avec chevaux de frise et rouleaux barbelés. Dans le glossaire technique qu'il donne au livre illustré de Gaston Lavy Ma Grande Guerre ${ }^{27}$, Stéphane Audouin-Rouzeau note: "Chicane, fils barbelés. Les lignes de tranchées sont protégées par des réseaux de fil de fer barbelé qui constituent une défense très efficace contre les assauts adverses pendant toute la guerre de position. Les barbelés rencontrés par Lavy sont surtout des "réseaux Brun" constitués de fils de fer fixés horizontalement sur des piquets fichés dans le sol. Sont aussi disposés des chevalets et des rouleaux de fils barbelés, déroulés à la manière de ressorts. La "chicane" désigne un espace volontairement pratiqué dans son propre réseau de fils de fer afin de pouvoir accéder au no man's land." (page II des notes)

\section{Deux belles évocations de la vie en tranchée}

Bien que datée du 28 novembre 1914, cette lettre est incluse dans cette étude de l'installation en tranchées de l'année 15, car elle fournit un document de première main sur la vie en tranchée, par un soldat ayant le sens de l'observation et du détail. Il s'agit d'une lettre ${ }^{28}$ envoyée par Antoine Limousin, domestique, de Saint-Maurice-enGourgois, incorporé au 23 $3^{\mathrm{e}}$ R.I., régiment de Bourg-en-Bresse ("Armée des Vosges" comme il l'indique), à son patron Eugène Reymondon (cl. 98) agriculteur à Saint-Maurice-en-Gourgois, sergent au 23 ${ }^{\mathrm{e}}$ B.C.A. de Grasse, lui aussi au front, en Belgique à ce moment-là. Nous la citerons en entier, tant elle décrit d'homme à homme, avec une retenue émouvante, les dures conditions de vie du Poilu en tranchée:

\section{Cher Patron,}

\section{"Le 28 novembre 14}

Je vous envois* ces quelques mots de lettres* pour vous donner de mes nouvelles et en savoir des votres*. Pour moi je suis toujours en bonne santé et je souhaite de tout cour que ma lettre vous en trouve tous ${ }^{29}$ de même chez vous. Vous mescuserez* si j'ai tarder* un peu a* vous écrire car vous savez que je ne peu* pas faire comme je veux. Enfin je me fais toujours pas du mauvais sang car sa* m'avance a* rien. $A^{*}$ tout ce finira bien le temps et la patience mais ça sera long. ${ }^{* 30}$ maintenant ce n'est pas bien agréable pour coucher dehors surtout avec le temps qu'il fait: il y a eu 8 jours nous avons eu un froid terrible. Je croyais que tout par un beau matin ont* serais* tous gelée* ensemble dans la tranchée! Des gelées affreuse*, de la neige et maintenant nous avons de nouveau la pluie, un brouillard épais mais d'une épaisseur comme je n'est* jamais vu*.

Je veux vous dire que nous creusons des tranchées dans les rochers et nous naviguons ${ }^{31}$ toujours dans les boyaux qui se comuniquent* dans toutes les tranchées de première ligne que nous avons creuser* nous même*. Nous sommes à 300 mètres de ces maudits boches* et ont* se regardent* comme des renards. Et le premier qui sor* la tête de la tranchée il es* saluer* par une pluie de prunaud ${ }^{* 32}$, pendant le jour par la clarter* du soleil, par la lune lorsqu ele temps et* clair; lorsqu'il es* sombre par les progecteurs* ou bien par les fusées? ${ }^{33}$

Pour nous abriter, nous construisons des barraques en rondins de sapins dans terre à une profondeur de 3 mètres à $4 \mathrm{~m}$, dans terre, vous parlez d'une vie! Tout de même comme matelat* du lit nous avons des branches de sapins don* je vais vous en envoyer un morceau dans ma lettre, vous le garderez en souvenir de moi, mais j'espère bien aller vous revoir bientôt ${ }^{*}$.

Vous donnerez bien le bonjour a* toutes les connaissance* et et à bientot* le grand plaisir de vous revoir tous. Votre Domestiques* qui pense toujours a* vous. Une forte poignée de main. Vivement la fin!

Je termine à $7 \mathrm{~h}$ du soir et je vais prendre la fraction $*^{34}$

Limousin Antoine

Sur la première page, à l'envers, au-dessus de l'en-tête, il indique son adresse: "Voilà mon adresse Limousin Antoine au 23 d'inf. $9^{e}$ Cmgnie $3^{e}$ bataillon Armée des Vosges ${ }^{35}$

\footnotetext{
${ }^{27}$ Gaston Lavy, "Ma Grande Guerre", 318 pages + notes et postface de Stéphane Audouin-Rouzeau, édition Larousse BDIC, 2005

${ }^{28}$ Cette lettre n'étant pratiquement pas ponctuée (une seule virgule, un seul point, un point d'interrogation mal employé), nous restituons une ponctuation minimale pour faciliter la compréhension

${ }^{29}$ Au-delà de son patron, Antoine s'adresse aussi aux deux membres de la famille qui sont à Saint-Maurice, au hameau de Sabonnaire: la jeune épouse d'Eugène, Antonia, et le père d'Antonia.

30 "A": on aura compris que ces deux phrases commencent par l'interjection "Ah!"

31 "Nous naviguons": le verbe "naviguer" est couramment employé en français local forézien avec le sens de "circuler", "aller et venir"

${ }^{32}$ La lecture "prunaud / prunard" est incertaine pour ce qui est la fin du mot; l'emploi familier de "pruneau" au sens de "balle" est attesté depuis 1830, selon le Dictionnaire historique de la Langue français Le Robert (direction Alain Rey)

${ }^{33}$ Ce point d'interrogation surprenant figure dans la lettre. Dans cette phrase, Antoine nous apprend que les moyens artificiels d'éclairage nocturne (projecteurs, fusées éclairantes) étaient en usage dès le tout début de la guerre.

34 "Prendre la fraction" : Antoine veut dire "prendre la faction", c'est-à-dire son tour de rôle comme sentinelle.

${ }^{35}$ Cette adresse nous montre que le système centralisé d'adresse, par secteur postal, ne comportant plus l'adresse précise du régiment, pour déjouer d'éventuelles saisies de courrier par l'ennemi, n'est pas encore mis en place.
} 
On ne peut s'empêcher d'être touché par la façon dont cette lettre, informative dans sa plus grande longueur devient pudiquement sentimentale à la fin, avec l'envoie de la branchette de sapin comme souvenir de lui (avec implicitement l'idée de mort possible, rejetée par "mais j'espère bien aller vous revoir bientôt"), l'affirmation qu'il pense à eux, et le cri du cœur final: "Vivement la fin!". Apparemment Antoine Limousin ne mourra pas à la guerre de 14, puisque son nom ne figure pas dans la liste de "Nos glorieux Morts de la grande Guerre" figurant dans l' Almanach Paroissial de St Maurice-en-Gourgois (Loire) publié en 1920, mais deux Limousin (ses frères? ses cousins?) y figurent, tous deux du hameau de Château-le-Bois, ce qui laisse penser qu'ils sont apparentés: Claudius Limousin, tué le 27 septembre 1914 à Confrécourt (Aisne) et Benoît Limousin, tué le 11 juillet 1915 au Bois-lePrêtre (Meuse).

Antonin Granet (cl. 13) né à Savigneux, instituteur après guerre essentiellement à Chamboeuf (1912-1914 puis 1919-1940, retraité à Montrond-les-Bains, a rédigé en captivité, à partir de mars 1916, le récit de sa guerre. Avec le recul que lui donne son état de prisonnier, cet intellectuel, sergent au $38^{\mathrm{e}}$ R.I. de Saint-Etienne, analyse la mutation de la vie du soldat à partir de la fin de l'année 1914, à partir des notes qu'il a prises régulièrement: "Ainsi commence la vie de tranchées. Le fantassin s'est mué en soldat du génie: la hache, la serpe, la cisaille, la pelle, la pioche complètent l'armement. Vie déprimante où l'homme à demi-enterré creuse encore, bâtit, démolit, rebâtit pour sa sécurité. Activement, fébrilement et non sans ronchonner, on se met au travail. Aux fatigues de la garde, des longues heures de faction, s'ajoutent les lassitudes d'un travail pénible et pourtant nécessaire.

Nos petits postes occupent de petits tronçons de tranchées où il faut s'accroupir pour prendre place; l'hiver approche et les branches ne sont plus un toit suffisant contre les intempéries, encore moins contre les projectiles. Ce n'est pas une petite besogne que de relier par des boyaux les différentes sections, que de creuser des abris souterrains où le gîte sera meilleur, c'est pourtant indispensable. Et pour se garder des surprises nocturnes ne faut-il pas organiser des défenses accessoires, tendre des fils de fer protecteurs? Sans autre donnée que sa jugeotte*, on organise sans méthode, l'expérience vient ensuite faire abandonner ou démolir pour reconstruire mieux et ailleurs. Nos hommes ne boudent pas à la tâche et chaque jour tout se transforme et c'est à qui donnera le conseil le plus sage ou le coup de main le plus adroit"

Il y a peut-être quelque idéalisation de la bonne volonté du Poilu du rang par le sergent prisonnier, nostalgique de la France, de sa famille et de la camaraderie de ses frères d'armes.

Deux semaines après, Antonin revient à la cote 124 et ne reconnaît presque plus l'endroit, tant les travaux d'aménagement l'ont modifié: "Le 29 nous sommes à nouveau à la cote 124. Depuis 15 jours elle s'est transformée; le dédale à demi-souterrain s'est augmenté, les toiles d'araignée en fils de fer épineux se font de plus en plus serrées, les abris améliorés deviennent de plus en plus confortables. Sans relâche nous continuons un ouvrage incessant et jamais à fin. Travaux nocturnes d'approche pour pousser les postes d'écoute plus avant, patrouilles périlleuses avec missions insensées, sommeil agité dans la paille humide avec les membres brisés par des douleurs rhumatismales; encore plus de boue où l'on patauge, que de misères, que de souffrances!"

\section{$\underline{\text { La relève ou la montée en tranchées }}$}

Parmi les erreurs grossières les plus répandues de nos jours, presque un siècle après la Grande Guerre, réside la croyance que les fantassins (quand on les différencie des artilleurs et soldats des autres armes!) stationnaient toujours en tranchées, attendant l'attaque ou la blessure par bombardement. On le verra, la vie du fantassin est heureusement ponctuée de replis plus ou moins loin de la première ligne et de repos en villages de cantonnement, et en général, on ne passe guère plus de huit jours en première ligne. Mais la montée en tranchées, appelée la relève par ceux que l'on remplace, est nocturne, et toujours impressionnante et dangereuse, d'autant plus frappante pour l'esprit si l'on n'est pas familiarisé avec le secteur, ou si l'on va pour la première fois au feu, car l'ennemi profite des bruits de la troupe en marche pour essayer de l'anéantir par des tirs et des bombardements.

Le sergent Edmond Deloule (cl. 13) de Saint-Martin d'Ardèche, dont nous avons cité un extrait de la lettre à ses parents du 7 janvier 1915, évoquait auparavant, dans la même longue lettre compte-rendu, la façon dont il a pris la relève avec son régiment en avant d'Ypres, en Belgique, après un long trajet en train de deux jours à partir de Toul, après un passage à proximité de Paris: "On roula toute la nuit et le lendemain vers 9 heures on débarquait en Belgique. On avait eu froid tout le long du trajet, et pour comble en descendant du train, une pluie battante glaciale qui vous cinglait la figure. Enfin bref, on arrive à un pays du nom de Blamerting où l'on cantonna dans une ferme avec les Anglais et le lendemain on allait prendre les avants-postes, c'est-à-dire aux tranchées en avant de la ville d'Ipres* dont vous devez avoir vu souvent le nom sur les journaux. Là quelque chose de bon nous attendait, une bonne salade ${ }^{36}$. Pendant plus de douze kilomètres, marche sous une pluie d'obus et de marmites (nom que l'on donne aux projectiles des grosses pièces allemandes) et jamais on arrivait à ces sacrées tranchées. A $2 \mathrm{~km}$ des tranchées, on commença à recevoir des balles car la fusillade était continue. C'est la relève qui n'est pas commode dans des cas pareils. Plusieurs hommes tombèrent blessés avant d'arriver aux tranchées. Enfin on arriva au boyau (sorte de conduit de 1 m50 de profondeur où l'on passe pour arriver jusqu'aux tranchées de première

\footnotetext{
${ }^{36}$ La phrase est évidemment ironique et cette "salade" annonce le bombardement qu'il va décrire.
} 
ligne). Oh! là là qu'elle* mélasse, de l'eau boueuse jusqu'au* genou, pas moyen de s'en sortir. Enfin on arrive, la biffe ${ }^{37}$ passe ses consignes et se fout le camp .La nuit se passa sans incident. Je travaille presque toute la nuit à me creuser un trou dans la terre et ma foi je l'ai fait un peu large et nous nous y casâmes avec mon lieutenant qui est agé* de dix-neuf ans ${ }^{38}$, on se serra, on mit le couvre-pied, la toile de tente, et ma foi on était pas mal si ces sales boches nous avaient laissé* tranquilles. Voilà que les obus se mettent à pleuvoir et tombaient en plein sur les tranchées qui cependant étaient larges que de 80 cent.. Deux hommes de mon escouade tombent blessés par une grenade lancée de la tranchée boche, distante à cet endroit que de trente à quarante mètres. Le soir, la $C^{i e}$ (compagnie) avait 52 hommes hors de combat, il n'était plus possible de tenir dans la tranchée."

Pour les classes suivant celles qui ont vécu le creusement des premières tranchées, la tragique renommée qu'a acquise ce nom de tranchée, par les récits lus ou entendus, ne peut qu'impressionner davantage. Jean Rivet (cl. 16) de Pouilly-sur-Charlieu, devenu coquetier en gros après la guerre, incorporé en avril 1915 au $121^{\mathrm{e}}$ R.I. de Montluçon, passé après son instruction, fin décembre, au $105^{\mathrm{e}}$ R.I. de Riom, arrive en juillet 1916 dans la Somme à Rosières-en-Santerre, et découvre vers Lihons la montée nocturne en tranchées, ce qu'il décrit dans un petit document (dont le coin inférieur est malheureusement mangé, ce qui fait perdre quelques mots) qui doit restituer assez fidèlement les impressions du novice des tranchées, quelle que soit l'année de la guerre: "Enfin vers 8 heures nous arrivons à Rosière, la moitié des maisons démolies nous servent encore d'abri partiel, nous touchons un repas froid, et puis en route de nouveau, cette fois enfin c'est les tranchées. Nous n'entendons pas encore le canon mais nous voyons par contre des multitudes de clarté* sillonné* l'espace, sa clarté. Nous nous formons en petit groupe et arrivons tout près de Lihons, la* nous faisons la pose* derrière des arbres, puis un ordre qui se répercute dans la nuit, pas gymnastique, l'endroit est dangereux, en effet pas une maison debout, les obus maintenant sifflent par raffale*, nous rencontrons à l'entrée de notre b (boyau?) (plu) sieurs soldats du $121^{e}$ qui ont été fauch (és par la ) raffale* quelques minutes avant notre arrivée, les autres plus heureux se sauvent à toutes jambes vers l'arrière. Nous nous engageons cette fois dans le boyau, là commence notre (...) martyr*, la terre détrempée par la pluie, trouée par les obus, s'écroule et transforme les boyaux en ornière, des fils de fer à chaque pas s'enroule* autour des pieds. Avec cela s'ajoute* les obus qui maintenant tombent presque aussi serrés que la pluie. Après avoir traversé quelques centaines de mètres de ce boyau, nous passons à travers champs. Là en plus des fils de fer nous avons les trous d'obus où nous nous cassons le nez à chaque pas. Enfin nous arrivons après toutes ces difficultés à la lisière d'un bois et quelle* bois? Quelques trons* d'arbres boulversés* par les obus, des petits trous individuelles* creusés dans une tranchée et voilà nos abris, notre habitation des longs jours de souffrance avec comme compagnons les poux, les rats. Le boche* devient de plus en plus rageur, les marmites ${ }^{39}$ tombent devant, derrière la tranchée, ce qui fait veiller et prévoir un coup de main ${ }^{40}$ de leur par*. Malgré tout ce vacarme, la fatigue, je m'endors d'un sommeille* de plomb. La relève ce* fait tout* les dix jours pour huit jours de repos et ainsi jusqu'au 30 novembre où nous sommes relever* cette fois pour le grand repos ${ }^{41}$

Cette expérience de la relève, déjà difficile par les conditions de marche, la boue, les obstacles, l'obscurité si elle est nocturne, ce qui semble le cas le plus fréquent, est, on l'a vu, rendue très dangereuse par l'ennemi qui profite du mouvement de la troupe pour l'assaillir, au fusil, à la mitrailleuse ou au canon. Dans son orthographe déficiente mais si émouvante, Jean-Baptiste Jourjon (cl. 15) de Villars n'hésite pas à le confier à sa fiancée Claudine, quitte à l'inquiéter: "Je suis toujours dans le secteur ou* j'ai fait lataque* est* tu peus* croire quise* pase* des moments terribles, sa*fait bien vilin* est* le plus pénible sait* pour faire la relève: les bôches* te tire* toujours desus $*$ est* tu peux croire quile* faut faire vitte* $a^{*}$ des endroits* quils* y a nous les mitrailleurs"

Ce rituel de la relève, qui fait passer soit du relatif inconfort mais de la relative sécurité de la troisième ligne, soit du relatif confort, surtout pour les gradés, et de la sécurité quasi assurée du cantonnement ou du secteur de repos à l'inconfort et au péril extrêmes de la vie en tranchée de première ligne, l'instituteur Antonin Granet, (cl. 03), sergent au $38^{\mathrm{e}}$ R.I. de Saint-Etienne, le décrit précisément sans le dramatiser (sauf au début), sans l'héroïser, puisqu'il ne se place pas dans le cas du bombardement ennemi sur la troupe qui monte, avouant aussi sans honte le confort ou les plaisirs divers (éventuellement la fréquentation d'une femme) que peut procurer le cantonnement, et profitant du temps et du recul que lui donne sa captivité en Allemagne à partir de mars 1916 pour écrire ses souvenirs récents:

"Demain, on monte aux tranchées". Prévu ou surgissant soudain, cet ordre est toujours accueilli avec un petit serrement de cœur. Il va falloir quitter la demi-sécurité du cantonnement, la bonne paille, voire même le lit de

\footnotetext{
37 "La biffe" est un terme d'argot militaire désignant l'infanterie, un fantassin étant un "biffin"; ici il semble que cela désigne la compagnie qui est relevée.

${ }^{38}$ Un lieutenant si jeune ne peut qu'être un élève d'une grande école militaire (Saint-Cyr, Polytechnique...)

${ }^{39}$ Les marmites désignent, en argot militaire, les obus de gros calibre, d'où le dérivé "marmitage" pour bombardement.

${ }^{40}$ Un coup de main est une attaque sur un point de la tranchée, d'assez faible ampleur

${ }^{41}$ Le grand repos est une période d'un mois environ où le régiment n'est plus soumis à l'alternance séjour en tranchée - petit repos un peu à l'arrière; Il est pris dans la zone des armées, dans un secteur tranquille, un peu éloigné du front.
} 
fortune ${ }^{42}$, la bonne table qui réunit tous les camarades et faire trêve aux bonnes nuits. Et qui sait? L'éternelle question! Que trouvera-t-on là-haut ${ }^{43}$, là-bas! La mort, peut-être! A moins que ce ne soit la blessure! le sang, les membres pantelants, le corps entr'ouvert!

"Tant mieux" s'écrie le poilu frondeur 44 "au moins nous aurons la paix et si les heures de garde sont fatigantes, plus d'exercices, de revues, de chinoiseries!" ${ }^{45}$

Au soir, les préparatifs sont faits. En guise d'adieu, une tournée aux bistros* enfumés, un sourire, un serrement de mains, un baiser même à la belle qui a su vous plaire ${ }^{46}$, un bidon encore, la beuverie, les chants, la nuit encore écourtée.

"Allons, debout!" C'est le réveil! Dans une heure, il faut que tout soit prêt. Il fait encore nuit. Dans les granges ou les caves, les bougies éclairent les hommes affairés. Boucler le sac n'est pas une chose si simple avec un attirail qui va sans cesse en augmentant. Il faut aussi nettoyer les abris. Cris, vociférations, appels, contre appels, rassemblements. Puis le départ. Dans la demi-obscurité du jour naissant, les sections se mettent en marche, séparées entre elles par de grands intervalles. Le fusil pèse, le sac est lourd ${ }^{47}$, les musettes rebondies de victuailles sont gênantes. Les yeux sont encore gros de sommeil et le cerveau embrumé, abruti par les excès de la veille! Le silence est de rigueur! On entend le cliquetis des armes choquées, des gamelles tintent, des gémissements de fatigues*. Pas une parole, que la voix des chefs guidant la troupe. Clopin-clopant, on geint, on sue, on souffle. A travers les bois, par des sentiers défoncés, on gagne la grand'garde pour s'acheminer ensuite vers les emplacements désignés. Cette fois, ce sont les longs boyaux à suivre. Entre les parois resserrées des étroits couloirs, les hommes serpentent en file indienne. Le sac butte à chaque pas, les musettes s'accrochent et il faut se mettre en biais pour pouvoir franchir certains passages et il faut s'aplatir contre la terre pour croiser les camarades. Clac! clac! Un petit frisson court sous la peau. Clac! le bruit sec et bien connu des balles.

Enfin voici le poste à occuper! Les camarades plus veinards sont prêts à céder la place. Ecrasés contre le parapet, ils se rangent pour nous laisser passer. On les questionne minutieusement, on exige des consignes précises, les points particuliers à surveiller sont signalés, les sentinelles sont placées, les hommes s'installent dans les sombres abris, se débarassent* de leur fardeau. Puis c'est la tournée de chacun ${ }^{48}$ pour se rendre compte des lieux. On risque furtivement l'œil, la tête par dessus le talus de la tranchée, on cherche à voir à travers les réseaux ce qui se passe au-delà...

Les premières heures, la première nuit sont toujours les plus émotionnantes, puis peu à peu on s'habitue, on se sent plus hardi.

En nous est placée maintenant la confiance de surveiller, de défendre ce morceau infime du vaste front; sur nous pèse la lourde responsabilité d'empêcher à tout prix l'ennemi d'approcher, de s'emparer de ce petit morceau de terre de France!"

Ce lyrisme patriotique final est d'autant plus frappant que l'instituteur Antonin Granet, déjà pacifique de nature, est devenu pacifiste au contact des Allemands chez qui il a été placé...

Ainsi tout fantassin qui a peu ou prou, selon son âge, sa durée de séjour au front, vécu l'expérience de la simple survie en tranchées, en dehors des moments paroxystiques que sont les attaques et les bombardements, et l'expérience répétée, mais jamais anodine de la relève, en garde l'empreinte indélébile dans sa mémoire, quand ce n'est pas dans son corps. Nous étudierons plus loin la vie quotidienne en tranchées. En 1915 s'est mis en place, pour les fantassins surtout, et à un moindre degré, pour les artilleurs, un mode de vie et un mode de guerre qui perdurera jusqu'au printemps de 1918 , avec la reprise de la guerre de mouvement.

\section{$* * *$}

\footnotetext{
${ }^{42}$ Sauf exception, la paille dans des granges de maisons plus ou moins détruites, ou pas encore touchées par les bombardement, en arrière du front, était le lot des soldats, alors que les gradés (dont Antonin fait partie, étant sergent) et surtout les officiers bénéficiaient souvent, dans les cantonnements, de chambres réquisitionnées

43 "La-haut": la relève est presque toujours évoquée comme une ascension vers le danger (l'expression consacrée étant "monter aux tranchées" ) même s'il n'y a aucune progression en altitude entre l'arrière et la première ligne.

${ }^{44}$ Avant de devenir le terme générique pour tout combattant de la Grande Guerre, simples soldats et officiers, le mot "poilu", vaguement péjoratif pendant les deux premières années au moins du conflit, a désigné seulement le soldat du rang.

${ }^{45}$ Beaucoup de soldats pestaient contre le fait que leur temps de repos ou semi-repos soit gâché par des exercices militaires qui, dans l'optique des officiers, avaient pour but d'éviter le relâchement, de maintenir une certaine discipline.

${ }^{46}$ On a compris qu'Antonin Granet évoque ici un secteur de repos, très en arrière du front, dans une bourgade où les civils résident, où les cafetiers bénéficient de la présence de la troupe, et où des idylles peuvent se nouer avec des villageoises

${ }^{47}$ Ce poids du sac, surnommé "Azor", Jacques Meyer (op. cit. p. 83), l'estime au moins à $20 \mathrm{~kg}$, s'il ne contient que les effets et outils réglementaires (paquetage comportant une couverture, une toile de tente, une pelle-bêche, des vivres de réserve et la provision de cartouches, les grenades étant dans un ou des musettes) il peut aussi comporter des vêtements personnels, des vivres envoyées par la famille, des objets de toilette, éventuellement des trophées pris sur le champ de bataille, du courrier ou des livres; le plus gradé de mes témoins, Jean-François Ollier, l'évalue pour sa part à $30 \mathrm{~kg}$, pouvant aller parfois jusqu'à 50 !

${ }^{48}$ Il faut comprendre: de chacun des gradés et officiers, devant avoir une connaissance précise du terrain. On imagine mal que chaque soldat, dans l'espace étroit et encombrée de la tranchée, se mette à l'arpenter!
} 


\title{
Chapitre 9
}

\author{
1915 \\ La guerre des mines : \\ Apparition et apogée
}


«On en entendait sauter tous les jours, des mines! » - Jean-Pierre Voldoire, classe 1915, Valcivières (Puyde-Dôme)

"Cette mine a fait un entonnoir de 20 mètres de profond et de 100 mètres de diamètre. Nous avons environ 150 morts enterrés, ou prisonniers ». Lettre du 14 juillet 1915 de Marius Gondy (classe 1911) à son frère, de Chassigny-sous-Dun puis Chauffailles (Saône-et-Loire)

"Moi je l'ai vu après que les batailles se soient terminées. Je peux vous dire que le terrain était bouleversé comme... comme si la terre avait explosé! Comme au temps des volcans! Voilà, c'est à peu près ça! Vauquois, vous savez, il faut l'avoir vu pour y croire! »-Armand Primpier, classe 1912, Roanne.

"Là, c'était une grosse mine, et y a pas un type, un Français, qui a demeuré: tous engloutis! Ça te faisait peter des monticules de terre comme un tombereaul qui montaient en l'air! Je sais pas combien! Je sais pas ce qui m'a roulé sur la jambe, moi! J'ai été blessé pas par cette mine, mais par une autre, le même jour! Nous on a fait peter une mine et on s'est précipité pour aller occuper le machin (le bord du cratère). Les Boches, tu comprends, en ont fait peter une autre! Et là, ils nous ont pris: on était quinze et y en a treize qui ont été amochés et deux qui ont été préservés; c'est bizarre: rien! »- Claudius Recorbet, classe 1915, Sury-le-Comtal.

Avec la mise en place progressive de la guerre de position et rapprochement des tranchées de première ligne, l'année 1915 a vu s'installer et culminer ce qu'on a appelé "la guerre des mines" que tous les fantassins n'ont pas vécue, mais qui a laissé à ses témoins et à ses victimes un souvenir ineffaçable. Bien qu'on la rencontre, on le verra, plus loin dans la guerre (voir les témoignages de 1917 sur les environs de Vauquois, en bordure d'Argonne, à une petite trentaine de $\mathrm{km}$ à l'ouest de Verdun), il semble bien que c'est en 1915 qu'elle a atteint son apogée, des dispositifs d'écoute des bruits souterrains et des contre-mines appelées "camouflets" ayant plus tard contrecarré quelque peu cette forme de guerre redoutée, car invisible tant que la mine souterraine (qui n'a aucun rapport avec la mine moderne: elle mettait en œuvre plusieurs centaines de kilos, voire plusieurs tonnes d'explosifs -un de nos témoignages écrits de l'époque, fiable, indique un cas de 6 tonnes! - en une seule explosion) n'explosait pas, alors que l'on avait la certitude que la galerie se sape ennemie progressait vers votre tranchée, parfois à la verticale de celle-ci...

François Cochet écrit dans son ouvrage "Survivre au front - 1914-1918 - Les Poilus entre contrainte et consentement $^{2}{ }^{2}$ "La guerre des mines constitue un moment tout à fait à part de la vie du "système-tranchées". On la rencontre surtout en 1915. Henri B.Robert décrit ses impressions de soldat pris dans l'angoisse de celui qui sait que le sol peut s'ouvrir sous ses pieds à tout instant, sous l'effet d'une formidable explosion. Car les mines accumulent des centaines de kilos, mis en place par des professionnels de l'exploitation des veines de charbon. Le résultat de ces explosions est effrayant et laisse encore des traces dans le paysage rural d'aujourd'hui. Regarder une photographie aérienne actuelle des crêtes d'Argonne est suffisamment éloquent. Les restes d'énormes cratères de plusieurs dizaines de mètres de largeur laissent encore une impression d'horreur devant le caractère apocalyptique des explosions qui ont eu lieu."

Cette vision, non aérienne, mais à ras du sol, un de nos témoins l'a eue après la guerre des mines, mais presqu'une année avant l'armistice.

Armand Primpier (cl. 12) de Roanne, horloger avant guerre, représentant en textiles après, musicienbrancardier au $121^{\mathrm{e}}$ R.I. de Montluçon, a vu à la fin de 1917 ou au début de 1918 à Vauquois $(25 \mathrm{~km}$ à l'ouest de Verdun), plus de deux ans après l'apogée de la guerre des mines, les immenses cratères laissés par ces explosions: "On a fait quatre fois Verdun : on a fait l'étang de Vaux, on a vu le Morthomme, le bois des Caures... On a vu Vauquois! Ah ben, Vauquois avec les mines! Seulement les mines, c'était fini. J'ai vu des trous à engloutir (sur $5 \mathrm{~km}$ de large, sur $3 \mathrm{~km}$ de profondeur), des trous à engloutir des maisons de deux ou trois étages! Les mines, ça a été terrible à Vauquois! Mais quand nous y sommes allés, presque en repos: le secteur était délaissé, on avait quelques obus dans une journée, c'était rien! [...] Moi je l'ai vu après que les batailles se soient terminées. Je peux vous dire que le terrain était bouleversé comme...comme si la terre avait explosé! Comme au temps des volcans! Voilà, c'est à peu près ça! Vauquois, vous savez, il faut l'avoir vu pour y croire!"

\footnotetext{
${ }^{1}$ L'image du tombereau est parlante, mais bien sous-estimée, car sa contenance n'est guère que de 2 ou $3 \mathrm{~m}^{3}$, alors que ce sont des dizaines de $\mathrm{m}^{3}$ qui peuvent être soulevés par l'explosion d'une grosse mine, et les excavations auraient pu contenir une maison, voire plusieurs (cf témoignage de Marius Gondy)

${ }^{2}$ François Cochet, "Survivre au front 1914-1918", édité par Soteca - 14-18 Editions, 2005, p. 85
} 
Le général André Bach, ancien chef du Service Historique des Armées de Terre de Vincennes, cite dans son étude très fouillée sur les Fusillés pour l'exemple - 1914-1915 ${ }^{3}$ une note du 12 mars 1915 du général Pétain où ce dernier s'attribue une vision prophétique, le rapprochement extrême des fronts qu'il redoutait lui ayant paru, selon lui, comme potentiellement générateur de la guerre des mines, alors que celle-ci sévit depuis les derniers jours de décembre 1914 (le témoignage de J.B. Grousson l'attestera pour Vingré) : "Le 12 mars 1915, le général Pétain adresse à son supérieur le général de Maudhuy, une lettre dont à la réflexion il n'envoyait pas le dernier paragraphe (cité ici) qui illustrait bien sa pensée. Il rappelait que, si le $33^{e}$ C.A. (Corps d'Armée) était sur une grande partie de son front en contact immédiat avec l'ennemi,

"Ce fait n'est pas le résultat de la volonté de son chef. J'avais au contraire dès ma prise de commandement interdit aux troupes placées sous mes ordres de se rapprocher de l'ennemi, afin d'éviter la guerre des mines et l'accumulation des troupes de garde dans les tranchées. Ce sont les ordres d'offensive reçus au cours des mois de décembre et de janvier qui m'ont obligé à envisager le problème sous un autre jour; et c'est pour m'y conformer que j'ai rapproché ma ligne sur le front d'attaque choisi"

\section{L'expression usuelle de "guerre des mines"}

Jean Roche (cl. 14), de Saint-Symphorien-de-Laye, ouvrier tisseur avant guerre à Lay, qui finira sa carrière comme employé à l'arsenal de Roanne, caporal au $92^{\mathrm{e}}$ R.I. de Clermond-Ferrant, est dans l'Oise, au nord de Conchy-les-Pots à partir d'avril 1915 et y découvre la guerre des mines. Le bref témoignage qu'il donne montre qu'elle n'était pas systématique dans tous les secteurs du front: " A notre droite, un peu plus loin, au Bois des Loges, il y avait un régiment de Roanne, le 98. Et je me souviens, quand on était au repos, on s'est trouvé à l'arrière, à Conchy-les-Pots, un petit patelin: "Mais qu'est-ce que c'est donc qui fait tant de bruit, chez vous, là-bas, que ça pète tant?" J'ai dit: "Eh ben, venez voir, c'est la guerre des mines!"

E- Donc on devait vivre sans arrêt dans la peur de sauter?

T- Oh! Continuellement! Continuellement!"

Jean-Pierre Voldoire (cl. 15), agriculteur à Valcivières (Puy-de-Dôme), incorporé au 80 ${ }^{\mathrm{e}}$ R.I. de Narbonne en décembre 1914, a connu la guerre des mines en Champagne pendant tout le mois qu'il a passé au front, en mai 1915, avant qu'il ne soit grièvement blessé par de nombreux éclats de grenade le 25 mai à Perthes-les-Hurlus, ce qui lui vaudra deux ans d'hospitalisation suivis d'une réforme définitive. Il témoigne en patois auvergnat (enquête de thèse, où je réponds en patois forézien) dont voici la version française: "Il y avait des fils de fer barbelés et des mines même! On en entendait sauter tous les jours, des mines! C'était que de la craie, et ils (les Allemands) creusaient comme ils voulaient! Ça changeait des Français les Boches! Ils creusaient comme ils voulaient!

E- Mais ils creusaient avec quoi? Avec des pioches?

T- Oui, oui! Ils sortaient la terre, ils la mettaient sur le côté. Pour la sortir, ils la mettaient dans des petits sacs. Le Génie envoyait des petits sacs, ils la mettaient dedans, et chacun en prenait un sous le bras et l'emportait"

Premières attestations écrites parmi nos témoins: fin décembre 1914 -janvier-mars 1915

Jean-Baptiste Grousson (cl. 95) de Saint-Etienne, mobilisé à 39 ans au $102^{\mathrm{e}}$ R.Territorial de Saint-Etienne, versé au $298^{\mathrm{e}}$ R.I. de Roanne qu'il rejoint le 15 novembre à Vingré, où il sera témoin le 4 décembre de l'exécution inique des six martyrs de Vingré (voir chap. VI), note pour la première fois, le 31 décembre 1914, dans son carnet de guerre très succinct, mais très factuel, l'explosion d'une mine: "31 X bre - poste des grottes, vu M. Déléage. La mine allemande saute à la tranchée, ensevelissant 5 des nôtres et créant un immense entonnoir. Reçu lettres et colis de ma femme et de mes enfants (au milieu de nos malheurs ces envois me rappellent le pays, ma gorge se serre et je vais me cacher pour...pleurer à mon aise). Faiblesse vite passée, je me dispute moi-même. A 5 heures, je rentre à la grotte où avec Jules, Malbron, Heyraud et Damour, nous mangeons le jambon et boîte saumon d'Antoinette. Nous n'avions pas terminé qu'un ordre arrive "Sac au dos! au * armes!" Les allemands* occupent "l'entonnoir", on fait monter plusieurs sections de renfort, nous sommes tous prêts, lieut ${ }^{t}$ Diot, à l'entrée des grottes, fusil canon en bas sous sa pélerine." Finalement, il n'y a pas d'attaque.

Cette première mention de la guerre des mines, le dernier jour de l'année 1914, montre que le vocabulaire de cette guerre n'est pas encore familier à ce caporal fourrier (il écrit encore "entonnoir" avec des guillemets), mais que la technique de la prise des bordures du cratère creusé par l'explosion (qui deviendront plus tard "les lèvres de l'entonnoir") par celui qui a fait exploser la mine est déjà bien au point.

Amand Beyron (cl. 11) de Chazelles-sur-Lyon, qui sera après guerre directeur de plusieurs usines textiles (dont celle de Régny, dans la Loire), musicien-brancardier au $99^{\mathrm{e}}$ R.I. de Roanne, donne dans ses carnets une belle description d'un épisode (le premier qu'il cite) de la guerre des mines en janvier-février 1915 vers Chuignes, dans la Somme; il écrit à la date du vendredi 22 janvier: "Les tranchées de Dompierre s'éboulent toutes, et les pauvres soldats ${ }^{4}$ sont obligés de passer le temps comme ils le peuvent, au-dessus, à la pluie, autour des tranchées. Les

\footnotetext{
${ }^{3}$ Général André Bach, op.cit, 2003, p. 519

${ }^{4}$ Son affectation de musicien-brancardier l'exempte du séjour en première ligne; il plaint le sort de ses camarades.
} 
boyaux d'accès, eux aussi sont impraticables et remplis d'eau et de boue. A certains endroits, on est obligé de les quitter et marcher sur les à-côtés, au risque de se faire tuer, si on est vu à travers le brouillard. Dans la nuit du

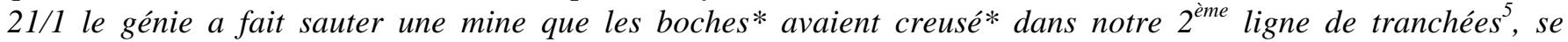
réservant le plaisir de nous jouer un sale tour. C'est par une contre-mine que nous pûment* les entendre travailler. On les laisse faire, et au matin, pour que les boches* puissent bien voir, au moment de leur reprise de sape, on les envoya au "Paradis" des "Teutons". Ce fut une forte explosion, et les boches* en furent les victimes. Malheureusement pour nous, de ce fait, 5 sapeurs du génie furent ensevelis dans une galerie de mine, minée par les eaux de déversement des tranchées. Après de grosses difficultés, on pût* en sauver 4. Le $5^{e}$ allait l'être aussi, mais un autre éboulement se produisit, l'enterrant complètement. Triste fut sa mort. De tous côtés les tranchées s'éboulent, c'est lamentable."

François Baizet (cl. 97) agriculteur à Chassigny-sous-Dun jusqu'à sa mort en 1928, sergent dans la Territoriale à la déclaration de guerre, versé dans l'armée active (au $153^{\mathrm{e}}$ R.I. de Béziers) deux mois plus tard, se trouve en Belgique, en Flandre Occidentale, pendant l'hiver 14-15, jusqu'à sa blessure au genou le 8 avril 1915. Le 13 mars, il décrit dans son carnet le champ de bataille ravagé par les explosions de mines et les obus: "Samedi 13 mars. Tranchées de Zonnebeck. La journée on s'oriente un peu et on distingue les diverses tranchées. On peut voyager un peu. De grands et profonds boyaux le permettent. Un peu en arrière de notre tranchée, il y a eu plusieurs maisons. Des unes, il ne reste plus rien, d'autres sont bien endommagées et branlent de tous côtés. Le poste du Lt Hamond, Ct la $C^{i e} 6$ est dans la cave de la meilleure. Il y a eu lutte terrible dans ces parages; 2 gros cerisiers sont criblés de balles et de mitraille. Il ne reste d'eux que les grosses, très grosses branches, tout le reste a disparu. A l'extrémité de notre tranchée, il y avait une maison, la mine allemande l'a fait sauter et l'on y voit un peu de tout, ferraille, poutres cassées et enchevêtrées, pommes de terre roulent* au milieu de briques, fusils tordus et cassés. En avant, trou énorme de $25 \mathrm{~m}$ de diamètre et de $10 \mathrm{~m}$ de profondeur. Tranchées allemandes sur un côté de cet entonnoir, nous de l'autre. A l'est de ce trou, poste d'écoute allemand, à $100 \mathrm{~m}$ de notre tranchée. Un peu en arrière, caissons ${ }^{7}$ et voitures d'artilleries les roues en l'air. Que de bois cassé! 15 chevaux sont crevés, les harnais sur le dos. Cela schlingue (pue). Un peu en arrière dans la plaine on distingue 7 chevaux crevés dans les champs de navets. En avant de notre tranchée, à 2 mètres à peine, un soldat français sac au dos la face contre terre est mort. Triste partout."

\section{Premières mentions de la guerre des mines dans les revues Le Miroir et L'Illustration}

Possédant la collection complète de L'Illustration pour la guerre de 1914-1918 et la collection quasi complète du Miroir, nous pouvons apprécier l'apparition du thème de la guerre des mines dans ces deux revues hebdomadaires, au demeurant fort dissemblables, la première coûteuse (1 F le numéro pour 1915), à la fois très riche en textes de qualité et en illustrations (photos, dessins, peintures en couleur), la seconde beaucoup moins chère (25 centimes en 1915), avec une seule page de texte racontant l'évolution de la guerre et 15 pages de photographies assez sommairement légendées, sauf exception.

Dans Le Miroir, la première mention est faite dans le numéro du 17 janvier 1915, à la page 11, avec un dessin en pleine page titré "A la conquête d'une tranchée: la sape" et légendé d'une façon qui montre clairement la nouveauté du procédé; sous la mention en gras au bas du dessin "Au fond de leur étroit tunnel, les sapeurs préparent une charge de dynamite", figure le commentaire suivant: "L'assaut d'une tranchée étant rendu extrêmement difficile, c'est sous terre que l'on s'attaque maintenant. Nous avons figuré ici par une coupe la galerie creusée par les sapeurs, et qui, partant d'une tranchée de première ligne, permet d'arriver sous l'ennemi. Des charges de dynamite, reliées par un cordon Bickford ${ }^{8}$, font sauter, au moment voulu, la ligne de défense qu'il s'agit d'occuper immédiatement après. Ce travail de sape s'opérant des deux côtés à la fois, la victoire est aux premiers arrivants". La seconde mention se trouve moins d'un mois après, dans le numéro du 7 février, avec trois photos sur une page réunies sous un titre commun: "Nos sapeurs font sauter une tranchée"; la première représente un sapeur dans une galerie de sape étayée de bois; la seconde l'explosion d'une mine près d'Arras et la troisième est une vue aérienne intitulée "Tranchée ennemie bouleversée par les explosions, vue prise d'un aérostat" (un ballon); 7 cratères apparaissent nettement. La troisième mention est plus tardive, elle date du 29 août 1915 et regroupe sur deux pages 7 photos d'explosions, assez nettes malgré la relative lenteur des obturateurs à l'époque, sous le titre synthétique: "Explosions d'obus, de marmites et de mines telles qu'on les voit de nos tranchées". Les soldats équipés d'un appareil de photo sont d'autant plus mis à contribution que le $1^{\text {er }}$ avril 1915 Le Miroir, composé essentiellement de photographies, a ouvert deux concours de photographies de guerre: un mensuel doté de trois prix $(1000 \mathrm{~F}, 500 \mathrm{~F}$ et $250 \mathrm{~F}$, ce qui fait tout de même, pour le premier le prix de 4000 numéros du Miroir, qui est un

\footnotetext{
${ }^{5}$ La galerie de sape passait donc au-dessous de la première ligne de tranchées pour atteindre la seconde ligne.

${ }^{6}$ Il faut évidemment comprendre: "du Lieutenant Hamand, commandant la compagnie"

${ }^{7}$ Les caissons d'artillerie sont des véhicules servant à transporter les obus.

${ }^{8}$ L'ingénier anglais William Bickford (1774-1834) a inventé en 1831 la mèche de sûreté pour les mineurs, servant, à l'aide d'un long cordon, à transmettre à distance de la charge de poudre l'étincelle du détonateur
} 
hebdomadaire!) et un annuel récompensant le premier de $30000 \mathrm{~F}$, ce qui est considérable, ce prix annuel ne devant "se clôturer qu'à la fin des hostilités"!

L'apparition du thème de la guerre des mines est plus tardive, mais beaucoup mieux documentée dans L'Illustration. La première mention apparaît dans le numéro du 20 mars 1915, avec quatre photos réparties sur deux pages, la dernière concernant les "marmites", obus à ailettes tirés des tranchées par les mortiers de tranchées appelés familièrement "crapouillots". Les trois autres concernent la guerre souterraine, dont deux la guerre des mines (mais l'expression n'est pas écrite), représentant "Un sapeur mineur au travail dans une galerie", "Un poste téléphonique souterrain dans la Meuse" (sans rapport direct avec la guerre des mines) et la troisième l'explosion d'une mine plutôt que d'une bombe, comme l'indique la légende. Il faut attendre le numéro du 10 juillet 1915 pour avoir une photo double page censée représenter les effets de l'explosion d'une mine, comme l'indique la légende en majuscules: "Après l'explosion d'une mine, quelque part en Flandre, sous une position allemande". C'est une vue d'un terrain ravagé, prise de près, comme sur le rebord de l'entonnoir d'une mine, avec un mélange curieux d'uniformes parmi les quelque trente soldats y figurant, certains regardant l'objectif, d'autres paraissant dormir, un groupe debout, armé, s'apprêtant à quitter la position; le commentaire éclaire le mélange d'uniformes, tout en exagérant beaucoup les effets de la mine, car aucun soldat n'est couvert de terre, ou partiellement enterré: "Pêlemêle, dans le cratère, les "Tommies" britanniques qui s'y sont jetés, baïonnette au canon, leurs prisonniers, les survivants de l'explosion, accroupis ou étendus, et les morts, gisant parmi les blessés.".

La troisième mention est un grand article de deux pages illustré de dessins dans le numéro du 15 mai 1915 (pages 502-503) intitulé "L'offensive souterraine" et signé T. L'auteur montre clairement, dans son préambule, que c'est le rapprochement progressif des tranchées à la fin de l'année 1914 et au tout début de 1915 qui a créé la guerre des mines: "La guerre de tranchées a conduit insensiblement et par la force des événements à la guerre de mines." [...] Tant que le contact ne s'est pas établi d'une manière complète entre deux adversaires et qu'ils restent séparés par des distances de 500 à 600 mètres, cette ligne avancée n'est pas continue; elle est occupée simplement par des sentinelles et des postes. Quand, par des bonds à découvert et ensuite par la sape, les lignes avancées se sont suffisamment rapprochées pour qu'il soit impossible de faire aucune progression sans de fortes pertes par les bombes et les grenades, la guerre de mines commence. Dans cette nouvelle période, la distances des tranchées françaises et allemandes varie de 25 mètres à 50 mètres".

La quatrième mention est aussi un article, non signé, intitulé "Nos sapeurs dans l'Argonne" dans le numéro du 15 novembre 1915. L'Argonne semble en effet le secteur par excellence où s'est systématisée et complexifiée la guerre des mines. L'article débute ainsi: "A cause du caractère accidenté du terrain, et surtout du voisinage des tranchées adverses, la guerre de sapes et de mines a pris en Argonne un développement sans cesse grandissant. A mesure que la guerre de tranchées se rapprochait de plus en plus de la guerre de siège, nos sapeurs amélioraient leurs procédés et perfectionnaient leurs techniques." L'expression est bien trouvée: c'est en effet la "guerre de siège" médiévale ou de l'époque de Louis XIV qui reprend, à ceci près que ce n'est pas un château, ou une citadelle qu'on assiège en creusant des galeries souterraines sous les douves et les murailles, mais une position ennemie. L'auteur explique que cette guerre a d'abord commencé en Argonne par des "sapes découvertes" allemandes, en surface, vite repérées. Elle s'est poursuivie par la destruction d'une crête tenue par les Allemands, d'où ils mitraillaient les Français en contrebas, à l'aide d'une dizaine de galeries de mines souterraines creusées sous ladite crête, non nommée. Puis l'auteur anonyme décrit avec talent et précision le travail harassant et mentalement stressant des sapeurs, extracteurs et évacuateurs de terre, voire de cailloux ou de petits rochers: "Il s'agit de creuser des puits de 15 à 20 mètres. De ces puits partent des galeries dans lesquelles le mineur, avec une aération presque toujours insuffisante, travaille dans des conditions difficiles, à demi courbé, toujours recroquevillé sur lui-même. L'essentiel est d'aller vite et surtout de ne point donner l'éveil à l'ennemi. La terre une fois extraite, c'est une rude besogne que d'en débarrasser les galeries et les puits. On en bourre des sacs qu'on se fait passer de main en main jusqu'à une certaine distance en arrière des tranchées.

Le travail se poursuit de nuit et de jour, sans arrêt, sans répit, Quand on approche des tranchées allemandes, c'est le moment de redoubler de précautions. Le sapeur se tient là, l'oreille tendue, aux écoutes du moindre bruit suspect. Voici, à faible distance, des coups de pic qui retentissent sous le sol. Ce sont les mineurs ennemis qui poussent leurs travaux dans la direction des nôtres. Lequel des deux éventera l'autre et déjouera ses projets? On prépare les camouflets. ${ }^{9}$ Mais c'est tout un art que de savoir faire à propos jouer le camouflet. Si on s'y prenait trop tôt, l'effet attendu ne se produirait pas. L'explosion, loin d'endommager les galeries de l'adversaire, ne servirait qu'à détruire, tout au moins à endommager nos propres travaux.". L'auteur envisage ensuite une éventualité qu'il présente comme fréquente, car nous sommes avant l'invention des appareils d'écoute appelés "géophones": "Il arrive souvent que, dans leurs galeries souterraines, nos sapeurs se trouvent subitement nez à nez

\footnotetext{
${ }^{9}$ Le "camouflet" est un fourneau de mine destiné, dans la guerre des mines, à écraser une galerie souterraine ennemie, et éventuellement à tuer les sapeurs ennemis dans la galerie de sape qu'ils sont en train de creuser. L'article de L'Illustration du 15 mai le définit ainsi: "Un camouflet est un fourneau de mine secondaire, plus profond, foré à la barre à mine dans la direction supposée des travaux de l'ennemi, pour en provoquer l'écroulement". L'indication de l'outil, la barre à mine, montre qu'il s'agit plus d'un trou étroit qui sert à l'écoulement de la poudre et à l'insertion du cordon détonateur que d'une galerie. Un dessin confirme cette explication.
} 
avec les Allemands. Un dernier coup de pioche jette à bas la cloison, un corps à corps s'engage à coups de revolver, de pioche ou de pelle." Bien que le revolver soit l'arme des officiers, elle devient ici celle des sapeurs, qui ne pourraient pas s'encombrer d'un long fusil Lebel, ou même d'un mousqueton (fusil court) dans l'étroitesse des galeries. Après la narration d'une anecdote de ce type, l'auteur revient ensuite sur l'aspect psychologique de cette guerre: "L'essentiel est de ne pas se laisser impressionner par l'avance de l'adversaire, de ne pas s'énerver. Le mineur qui s'énerve est fatalement amené à allumer son fourneau trop tôt et, dans ce cas, l'effet est tout le contraire de celui qu'on escomptait. A force de courir ensemble les mêmes dangers, qui sont des dangers de tous les instants, nos sapeurs sont attachés entre eux par les liens de la plus étroite et de la plus touchante camaraderie. Les hommes de la même escouade travaillent toujours ensemble dans le même trou, et cette escouade devient pour eux une véritable famille. Le puits qu'ils creusent, c'est leur maison.". Parfois une galerie s'effondre, mal étayée, ou secouée par un camouflet ennemi: ceux qui survivent tentent alors de secourir ceux qui sont ensevelis; l'auteur cite le cas récent d'un sapeur resté 36 heures enseveli, dans une galerie partiellement détruite, mais dont l'accès s'était effondré, et qui a été sauvé et qui aurait manifesté ensuite (vérité ou propagande?) le désir d'y retourner: "ayant appris qu'on préparait une belle explosion, il dit à son infirmier: "Je m'en retourne, je ne puis pas (la formulation est trop soutenue pour sonner vrai) laisser les autres faire tout le travail sans moi.".

Redonnons la parole à nos témoins, décrivant par écrit ou oralement leur expérience, parfois brève, de la guerre des mines, les deux seuls sapeurs, mineurs avant leur incorporation, n'ayant pas su décrire leur travail autrement que par des bribes de phrases arrachées par l'enquêteur, ce qui nous empêche d'utiliser leur témoignage.

\section{$\underline{\text { L' effet meurtrier de l'explosion de la mine évité de justesse par le témoin }}$}

Le Père Jean Renesson (cl. 15) né à Chevrières, avant guerre séminariste à Francheville (Rhône), qui sera pendant 42 ans le curé de Dancé, et qui, on l'a vu, souhaitait au départ des soldats, en août 1914, que la guerre dure suffisamment longtemps pour que sa classe 1915 puisse y aller, sera amplement exaucé! Incorporé en décembre 1914, arrivé au front en avril 1915, il manque être enseveli par l'explosion d'un poste de sentinelle qu'il venait de recreuser:

T- A la Fille Morte (ça me plaît bien: la Fille Morte!) ${ }^{10}$... c'est à côté de Vauquois; là c'était la guerre des mines!

E- La fameuse guerre des mines!

T- Oui. Alors un soir, le sergent me dit, avec un autre: "Allons remonter le petit poste que les Boches ont fait sauter!" On part le soir, on porte des outils, des sacs à terre pour remplir, on remonte bien le petit poste comme il faut. Et puis, à 5 heures du matin, on avait terminé, le sergent dit: "Allons boire le jus!" On était pas arrivé, le sergent me dit: "Va donc chercher les outils qu'on a laissés là-bas au petit poste!" Je vais chercher les outils, je les rapporte, je sors mon quart de ma musette... Pssss! Le poste saute! 5 mn! Je faisais un vol plané!

E- Vous y avez échappé de très peu, là!

T- Oui! Et puis il y en eu quatre d'enterrés, qui étaient assommés, dans une tranchée!

E- C'était un obus qui avait écrasé le poste?

T- Non, non! La mine! Quand j'ai présenté mon quart pour boire le jus, ça s'est mis à sauter! On était à l'entrée de la sape, on s'est tous enfilés dedans pour pas être enterrés, vous comprenez!"

Cette dernière réaction peut paraître paradoxale, car entrer dans la sape (l'abri souterrain), c'est justement prendre le risque d'y être enterré vivant. Mais la mine a explosé sous le petit poste de sentinelle, donc pas à proximité immédiate de la tranchée où s'ouvre cet abri. qui pouvait les protéger d'éventuelles retombées de terre ou de pierres.

Marius Gondy (cl. 11) de Chassigny-sous-Dun (Saöne-et-Loire), valet de chambre dans le Cher puis à Paris avant guerre, puis hôtelier après guerre à Annecy, puis à Chauffailles, affecté au $81^{\mathrm{e}}$ R.I. de Narbonne, se trouve au front, en Champagne, vers la ferme de Beauséjour, pendant tout l'été 1915, et sera blessé et fait prisonnier lors de la grande offensive de Champagne de fin septembre; mais le 14 juillet, il a failli être victime de l'explosion de plusieurs mines. A côté du témoignage oral recueilli le 27 février 1988, qui évoque aussi la stratégie pour s'emparer des bords de l'entonnoir creusé par la mine, sa nièce, présente à l'entretien, donne des informations complémentaires lues dans des lettres envoyées à son frère:

N- "Le 14 juin, vous écrivez: "Je suis du côté de Beauséjour et de Perthes" c'est-à-dire en Champagne. "Ce n'est pas aussi mauvais que du côté d'Arras, mais ce n'est pas bon quand même, car il y a des mines et des bombes qui sont terribles. Nous sommes trop près des Boches, à 10 ou à 15 mètres, à certains endroits. Alors on peut pas bouger ou alors tu es tué.."

E- C'était le moment de la guerre des mines?

T-Voilà! Là où elle parle, justement le 14 juillet 1915, j'ai été à la soupe. C'était une corvée. On allait à Suippes, un nom comme ça, Somme-Suippes ou Suippes. Il y avait $4 \mathrm{~km} 500$ de boyaux pour aller chercher les gamelles de soupe et c'était une vraie corvée, et puis alors dangereuse! Parce que les boyaux étaient tout en zigzags de

\footnotetext{
${ }^{10}$ Le ravin de la "Fille Morte" se trouve en Argonne; selon Le Miroir du 10 octobre 1915, elle aurait été un des hauts-lieux de l'offensive de Champagne, s'il faut en croire les titres et les photos de la page 14: "En Argonne aussi les Allemands ont souffert" - "Le ravin de la Fille Morte où 8 bataillons ennemis ont été défaits le 27 septembre"
} 
façon...Les Boches étaient perchés là-haut...Où c'était droit, y avait 10 mètres de long! C'est que les mitrailleuses...

E- Vous faisiez des coudes pour éviter d'être pris en long!

T- Absolument! Il fallait faire vite quand il y avait une ligne droite qu'ils visaient! Les Boches, là-haut, avec les mitrailleuses, ils nous attendaient! ...Le 14 juillet 1915, les Boches ont fait sauter trois mines Je sais pas (on l'a probablement su) combien il y a eu d'enterrés vivants...Trois mines à chaque trou! Je sais pas si le Bon Dieu était avec moi ou pas...J'en sais rien. En tout cas, j'étais parti à la soupe: il a fallu faire demi-tour [...] Ils ont fait sauter trois mines: il a fallu reprendre les lèvres ${ }^{11}$. C'est-à-dire trois mines, ça fait un trou! Vous vous rendez compte: la gare (de Chauffailles, en face de l'hôtel) ou la maison ici auraient été cachées dans le trou! On l'aurait mis dans le trou, on voyait pas le faîtage! Il a fallu faire demi-tour et monter sur la terre (on enfonçait jusqu'aux genoux) pour arriver le premier sur la lèvre, qu'on appelait, la lèvre des trous: la bordure. Parce que les Allemands en faisaient autant! Et si on les avait laissés venir à la bordure de notre côté, eh bien, ils nous mitraillaient!

E- Un trou de mine, c'était une bonne position stratégique?

T- Ah voilà! Seulement, ça en enterrait vivant! Y avait ceux qui dormaient dans les cagnas, comme on dit, qui n'étaient pas de garde, et puis tous ceux qui étaient alignés dans les endroits où il y avait un machin pour voir la tranchée des Boches.

E- Madame, vous avez un chiffre?

N- Oui. (elle lit) "Cette mine a fait un entonnoir de 20 mètres de profond et de 100 mètres de diamètre. Nous avons environ 150 morts enterrés, ou prisonniers"

L'immensité du trou n'est pas exagérée, et peut même être dépassée, à voir les photos figurant dans les revues Le Miroir et L'Illustration de la fin de 1915.

\section{Une blessure grave infligée par une mine}

Claudius Recorbet (cl. 15), né à Fos-sur-Mer, mais ouvrier à Sury-le-Comtal, versé au $16^{\mathrm{e}}$ R.I. de Montbrison en 1915, a connu la guerre des mines dans l'Aisne au printemps 1915, vers Grand-Rozoy, et en Champagne lors de la grande offensive de fin septembre-début octobre 1915; mais c'est au $96^{\mathrm{e}}$ R.I. de Béziers, en 1916, après avoir participié à la bataille de Verdun en juillet, qu'il est grièvement blessé par une mine le 16 octobre, ce qui lui vaudra un an d'hospitalisation et une réforme partielle; il témoigne en patois (enquête de thèse): "C'est dans ce secteur que j'ai été blessé. C'étaient que des mines! Y avait des moments qu'on était à six mètres! (des Allemands). Y avait rien, que des trous! Ces petites mines qu'ils faisaient, qu'ils bourraient facilement ${ }^{12}$ de deux cents kilos de poudre, et puis qu'ils faisaient sauter.. C'est ici que j'ai été pris, moi!"

E- On pouvait rester à six mètres l'un de l'autre?

T- Oh oui! Mais personne bougeait! Seulement voilà le machin: on faisait peter à peu près à la même heure, et ce qui est arrivé... Le génie français, c'est lui qui creusait pour aller poser ses caisses (de dynamite). Ils tombent sur une mine allemande, une mine boche! Chargée, toute prête, et les fils accrochés! Alors le chef du génie a commandé: "Oh ben, amorcez la vôtre aussi,de votre côté; s'ils la font pas partir demain matin, nous on la fera partir!". Ça fait que les deux mines ont peté comme ça, ensemble, tu comprends? Ça a surpris les Boches! Seulement y en avait d'autres qui étaient chargées! Alors il fallait vite, aussitôt la mine petée, c'était au premier qui pouvait aller sur le bord du machin (du cratère fait par l'explosion), c'était que comme ça qu'on pouvait progresser! ça faisait des "boutasses"13 de quinze mètres de profondeur là où la mine petait!

E- On progressait en faisant une galerie de sape?

T- En dessous! Elle était souterraine!

E- On y mettait la mine, on faisait péter: ça faisait un trou, et on se précipitait dans le remblai du trou?

T- Dans le remblai du trou! De son côté bien sûr! Je me rappelle, y avait un régiment, c'est le $10^{e}$ d'infanterie $^{14}$, je crois, il a eu toute une compagnie (environ 250 hommes) qui a été prise avec une seule mine! Toute!

E- Ils en faisaient péter plusieurs à la fois, non?

T- Oh! ça dépend! ça dépend leurs idées! Là, c'était une grosse mine, et y a pas un type, un Français, qui a demeuré: tous engloutis! Ça te faisait peter des monticules de terre comme un tombereau ${ }^{I S}$ qui montaient en l'air! Je sais pas combien! Je sais pas ce qui m'a roulé sur la jambe, moi! J'ai été blessé pas par cette mine, mais par une autre, le même jour! Nous on a fait peter une mine et on s'est précipité pour aller occuper le machin (le bord du

\footnotetext{
${ }^{11}$ Les lèvres désignent le bord de l'entonnoir creusé par l'explosion des mines

12 "Facilement" en français local forézien des personnes âgées signifie "sans doute", peut-être", "environ"

13 "Une boutasse" est en patois et en français local forézien une très grand trou d'eau, aux murs bâtis, pouvant avoir de 6 à $10 \mathrm{~m}$ de diamètre, aménagé dans un pré, ou à proximité de la ferme, pour constituer une réserve d'eau

${ }^{14}$ Le $10^{\mathrm{e}}$ R.I. était un régime caserné à Auxonne, en Côte d'Or

${ }^{15}$ L'image du tombereau est parlante, mais bien sous-estimée, car sa contenance n'est guère que de 2 ou $3 \mathrm{~m}^{3}$, alors que ce sont des dizaines de $\mathrm{m}^{3}$ qui peuvent être soulevés par l'explosion d'une grosse mine, et les excavations auraient pu contenir une maison, voire plusieurs (cf témoignage de Marius Gondy)
} 
cratère). Les Boches, tu comprends, en ont fait peter une autre! Et là, ils nous ont pris: on était quinze et y en a treize qui ont été amochés et deux qui ont été préservés; c'est bizarre: rien! Dans les militaires, y en a toujours qui sont courageux. Moi, je devais même pas y aller, mais seulement j'avais froid, alors je me suis dit: "Il te faut prendre une marre ${ }^{16}$, une pelle, n'importe quoi, pour te réchauffer!". Et là, les autres ont fait peter: ils m'ont pris. Je crois que c'est l'adjudant qui m'a secoué, j'étais dans le cirage: "Tu es blessé?" Je l'ai regardé: il avait reçu quelques pavés sur le casque, ça lui avait rentré le casque dans la tête!" "Oh, je lui ai dit, mais qu'est-ce qui t'arrive?" Je vais pour me lever, mais tiens! La jambe est passée de l'autre côté!" (rire)"

\section{La poursuite de la guerre des mines au-delà de 1915}

En 1916: une guerre modifiée par le perfectionnement des écoutes et la systématisation de l'usage du camouflet

Jean-Louis Monier (cl. 13), agriculteur à Marols, incorporé au $13^{\mathrm{e}}$ escadron du train des équipages, rattaché au $13^{\mathrm{e}}$ corps, passe l'année 1915 dans la Somme, vers Fontaine-sous-Montdidier, puis touché par la loi Dalbiez et Mourier, va se retrouver dans l'infanterie, au 363 ${ }^{\mathrm{e}}$ R.I. de Nice, qui tient les tranchées en Argonne, en 1916. Il explique avec beaucoup de précision la guerre des mines qui avait ravagé le secteur l'année précédente, en laissant de profondes excavations dans le sol, alors qu'une forme atténuée de cette guerre se déroulait en 1916: "Et puis là nous avons pris ces fameuses tranchées de l'Argonne. Alors là, c'était le pays montagneux, boisé et montagneux, le pays des sangliers (d'abord on dit "le sanglier de l'Argonne"17 ), et y en avait, vous savez! Y en avait! Et dans ces pays montagneux, les tranchées étaient très rapprochées. Et on y faisait la guerre des mines. Je ne sais pas si vous vous êtes représenté ce qu'était la guerre des mines? Attendez: je vais prendre un crayon pour vous faire voir! [...] Voilà ce que consistait la mine. On faisait un trou là, dans la tranchée française, comme un puits, de deux mètres de profondeur. Et puis de là on creusait une galerie, en dessous, là. Cette galerie on la creusait, on la creusait jusqu'à ce qu'elle venait en arrière des lignes allemandes, par dessous! Y avait rien en dessus qui la produisait!

E- Mais y avait pas d'éboulements, parfois?

T-Ah, moi, je savais pas ce qu'ils faisaient là-dedans! Parce que ça, c'était encore une spécialité: c'étaient les mineurs! C'étaient des fantassins, mais qui faisaient cette affaire! ... La galerie, elle avait 20-25 mètres. Elle passait en-dessous de la tranchée ennemie, à environ deux mètres. Et cette galerie, quand elle avait passé endessous de la tranchée allemande, on la garnissait d'explosifs, de poudre... Et puis on la faisait sauter! Alors quante* la mine avait sauté, ça faisait un entonnoir. Alors ça consistait que les troupes françaises avancent pour prendre cet entonnoir! Pour rien du tout! C'était une affaire de quelques mètres! Et j'avais pris la garde en face d'un de ces entonnoirs, là...Alors l'entonnoir, les Allemands étaient d'un côté et les Français de l'autre!

E- Ils se voyaient?

T- Oh! C'était pas le moment de se faire voir! J'avais regardé moi, un matin, pour me rendre compte de ce qu'était cet entonnoir.... Alors j'avais calculé que cet entonnoir, l'embouchure en haut devait avoir à peu près 20 mètres, et à peu près deux ou trois mètres de profondeur...Et un jour, un matin (la journée, il fallait pas essayer, parce que c'était tout à fait risqué) je m'étais sorti un peu de la tranchée pour regarder la profondeur et la grandeur de ce trou. Seulement, quante* j'y étais, moi, le vrai machin de mines que je viens de vous décrire n'existait déjà plus. Alors voilà ce qui se passait: vous aviez la tranchée allemande, vous aviez la tranchée française, vous aviez les sapeurs français qui faisaient leur machin, les Boches de leur côté faisaient pareil. Alors il y avait ce que nous appelions des écouteurs: des gars qui avaient un casque et qui posaient des affaires - c'était à peu près comme un bol- ils posaient ça à même le sol et puis ils écoutaient ${ }^{18}$. Alors ils entendaient quante* les autres venaient! Pour empêcher qu'ils aillent plus loin, on faisait ce qu'on appelle le camouflet ${ }^{19}$ (il dessine)

$\mathrm{E}$ - Ils faisaient un coude à leur sape

T- Un coude, là. Ce coude, ils le garnisssaient. Et quante* lesAllemands étaient bien tranquilles, on faisait peter cette affaire pour tuer les sapeurs! Ce qui fait que quand j'y étais, y avait que des camouflets qui partaient à peu

\footnotetext{
16 "Une marre" en patois et français local forézien est une sorte d'outil double, à son extrémité, avec un pic d'un côté et un tranchant de l'autre, l'un servant à briser les rochers, l'autre à excaver la terre, comme une pioche.

${ }^{17} \mathrm{Il}$ semble que J.L. Monier confonde avec l'expression plus célèbre évoquant "le sanglier des Ardennes"...

${ }^{18}$ Jean-Louis Monier présente cet appareil d'écoute (que François Baizet va nommer "géophone": cf infra) comme une innovation de 1916. Or l'article du 15 mai 1915 de L'Illustration montre un dessin d'un "Ecoutant au microphone dans un rameau de combat", l'appareil étant une grosse boite avec des écouteurs, et explique le fonctionnement des écoutes à amplification acoustique qui n'a dû se généraliser qu'à la fin de 1915 ou en 1916: "L'organisation des écoutes permet d'éviter d'être surpris par les explosions des camouflets de l'adversaire. L'écoute est une opération des plus délicates, elle consiste à déterminer la direction, la hauteur et la distance des bruits entendus, dont l'intensité varie suivant la nature de l'objet qui les provoque et des terrains rencontrés. Ordinairement l'écoute est faite par des sapeurs dressés spécialement dès le temps de paix et sans le secours d'aucun appareil (souligné par nous). Pour obtenir plus de netteté, on utilise des tambours et aussi des microphones spéciaux" (p. 503)

${ }^{19}$ Idem: le témoin présente comme propre à 1916 une technique qu'on a déjà vu apparaître en 1915, selon les deux articles de L'Illustration du 15 mai 1915 et du 13 novembre 1915 déjà cités, ce dernier concernant aussi le secteur de l'Argonne.
} 
près tous les matins, vers les 5 h du matin. Mais des mines, y en avait plus! Elles pouvaient plus exister! ${ }^{20}$ Que ce soit Français ou que ce soit Allemands, ils ne pouvaient pas aller à la tranchée (ennemie): ils étaient arrêtés avant par ce camouflet! [...]

E- Donc c'est l'invention des écouteurs qui a arrêté les galeries de sape par dessous?

T- Oui, et puis alors là, ces camouflets...

E- Mais les autres faisaient pareil, je suppose?

T- Ah mais bien sûr! Mais attendez! Un matin, nous, quante* nous étions en réserve, que nous avions abandonné les premières lignes, nous y allions! Parce qu'il fallait la sortir cette terre! On faisait pas une galerie sans sortir la terre! Alors avec des corbeilles, avec deux anses, deux poignées, nous prenions cette terre et nous l'emportions un petit peu plus loin, en marchant à quatre pattes! Parce que dans une de ces corvées que nous faisions, là, ceux qui avaient passé avant moi, y en avait un, un seul coup de fusil lui avait percé le casque, et la tête dedans, quoi, bien sûr! $!^{21}$ Alors il fallait bien faire attention! Alors un jour que nous allions dans cette corvée, là, le sous-officier qui nous commandait, qui distribuait le travail, nous dit: "Ceux qui vont à la mine..." (il y avait un numéro et un chiffre, c'était $S 5$ donc) "ceux qui vont à la mine $S 5$, vous iriez à une autre mine, pas celle-là, n'y allez plus!". Quand nous sommes passés devant cette mine $S 5$, qu'est-ce que nous avons vu? Cinq corps qui étaient là, étendus! Les Boches avaient fait sauter le camouflet, les autres (les mineurs) étaient en train de travailler: ils ont été tués non pas par l'éboulement, mais par les gaz, paraît-il, que l'explosion a dégagés! Alors, ils étaient noirs comme cette affaire-là (le micro), ils étaient complètement noirs, tout noirs, mais je sais pas si c'était une explosion de poudre...

E- Mais le corps pas abîmé?

T- Le corps pas abîmé du tout! Ils avaient pas de trace de blessure, n'importe ${ }^{22}$. Ils étaient allongés, tous les cinq! Vous savez, on en voyait tellement! Eh oui, ils y étaient restés! Alors, pour en finir, je vous dis bien, la guerre des mines, là, ne pouvait plus avoir lieu parce que c'étaient les camouflets"

\section{7 : le cas de Vauquois en bordure d'Argonne - Les surprises que réserve la guerre des mines}

Deux ans après son premier témoignage écrit cité pour mars 1915, au début de l'année 1917, ayant été blessé encore une fois, versé successivement dans deux autres régiments, François Baizet, à 40 ans, devenu adjudant, dirige des travaux du Génie près de Vauquois, en bordure est de forêt d'Argonne, où la guerre des mines fait encore rage, mais avec la technique systématique du camouflet expliquée par Jean-Louis Monier, et, chose nouvelle dans nos témoignages, avec une entente tacite avec l'ennemi pour éviter les pertes humaines. Il écrit dans son carnet, avec des considérations stratégiques et morales intéressantes, comme d'habitude chez lui:

"14 février 1917 - Mamelon Blanc. Ce matin le génie a fait sauter un camouflet. $1000 \mathrm{~kg}$ de cheddite 23 à P9. Par un accord tacite, les boches* et nous faisons sauter à la même heure, le matin, de 6 h30 à 7 heures. A 6 heures, les fantassins et le génie des 2 côtés évacuent les lères lignes et rentrent après 7 heures. Drôle de guerre. Quand un parti évacue ses lignes (il n'y a pas de tranchées, c'est trop bouleversé tous les jours) si le parti adverse venait pendant ce temps-là et les occupait, ce ne serait peut-être pas mal joué. Qu'est-ce qui dit que ça n'arrivera pas un jour? D'un autre côté on a raison. En évacuant, ce sont des vies humaines sauvées. La guerre se fait donc sous terre, et c'est sous terre que l'on avance à 40 ou 50 mètres de profondeur ${ }^{24}$. Dès que l'on entend au géophone ${ }^{25}$ ou à l'oreille les boches qui avancent leur galerie souterraine, vite on fait un camouflet et on la démolie* les empêchant par là d'avancer. Eux font de même. Que de temps perdu, d'argent dépensé pour ces bois de coffrage, de poudre brûlée on peut dire presque bêtement. Ici il y a eu des fourneaux ${ }^{26}$ de $80000 \mathrm{~kg}$ de poudre paraît-il. C'est insensé. Vive l'infanterie encore! Une attaque en règle, en 10 minutes, la montagne serait prise. Mais non c'est la guerre de position dans toutes ses règles, avec ses sapes et ses galeries. On dit du reste que cette montagne serait impossible à garder, soit par nous soit par les boches".

Les jours suivants, quelques notations reviennent sur cette guerre des mines. Ainsi le 31 mars, toujours au Mamelon blanc, on lit: "Ce soir activité un peu fiévreuse au Génie. La principale galerie de la 8/64 (à Y) est

\footnotetext{
20 Jean-Louis Monier se trompe sur ce point, comme le montreront les témoignages concernant 1917

${ }^{21}$ On comprend donc que la marche à quatre pattes pour évacuer la terre est à la fois souterraine (imposée par la faible hauteur de la galerie de sape) et extérieure, pour échapper à la vue de l'ennemi à la sortie de la galerie

${ }^{22}$ Ce mot "n'importe", en patois et en français local, signifie "ou de n'importe quelle autre chose"

${ }^{23}$ La cheddite est, selon le Grand Larousse de la Langue française, un explosif à base de chlorate de potassium. Cette invention, apparue en 1908, tire son nom de Chedde, localité de Haute-Savoie où cet explosif était fabriqué.

${ }^{24}$ Cette profondeur paraît tout à fait considérable, et exagérée en regard des autres témoignages qui parlent de quelques mètres. Mais François Baizet est pourtant un observateur précis; serait-ce une tentative d'échapper par la profondeur au repérage par les écouteurs utilisant le"géophone", qualifié par le même dictionnaire, d'instrument d'écoute servant à déceler les bruits provenant du sol?

${ }^{25}$ Géophone est le nom technique de l'appareil d'écoute que Jean-Louis Monier a décrit comme une sorte de bol, le terme "écouteurs" désignant plutôt les soldats préposés à l'écoute grâce à cet appareil.

${ }^{26}$ Toujours selon le GLLF, le fourneau de mine est "une cavité dans laquelle est introduite la charge d'explosif destinée à la destruction d'un ouvrage déterminé."
} 
menacé* de sauter sans doute pour demain. D'après les écoutes, les boches* sont arrivés entre les deux antennes de cette attaque et très près. Depuis hier, ils, les boches*, ne travaillent plus au pic et on les entend remuer des caisses de cheddite. Ils chargent et ils mettent sans doute une charge kolossale ${ }^{27}$, 2 nuits et 2 jours, ce n'est pas l'habitude. Aussi on a résolu de camouflet* leur fourneau de mine cette nuit. On va donc faire un petit fourneau de cheddite et demain à $7 \mathrm{hl} 3 \mathrm{il}$ sautera, à moins que les boches ne fassent sauter avant. Ce serait un sale coup pour nous. L'autre jour, ils ont fait un entonnoir de $80 \mathrm{~m}$ de diamètre presque de notre côté. S'ils en font autant cette fois-ci, il faudra prendre les entonnoirs ou sans cela ils auront des vues dans le ravin qui sépare Vauquois du Mamelon. Attendons demain"

On mesure difficilement quelle angoisse doit étreindre les hommes se sachant installés au-dessus d'une énorme charge de poudre qui peut exploser à tout moment, les ensevelir dans des tonnes de terre, ou les déchiqueter...

Le lendemain, François Baizet note assez flegmatiquement: "A 6 h 30 le fourrier Birou et le cap fourrier avec lesquels je partage l'abri se lèvent pour aller voir la montagne de Vauquois sauter. J'ai un moment l'intention d'aller voir le...spectacle. Et puis non. A $7 \mathrm{~h}$ 16, une secousse, c'est notre camouflet qui a joué, quelques secondes après 2eme secousse moins forte: c'est un camouflet boche et c'est tout. Les boches* n'ont pas fait entonnoir. C'est l'essentiel, notre camouflet les retardera."

Parfois l'inévitable se produit: les sapeurs ennemis qui creusent en direction les uns des autres se rencontrent du fait de la jonction accidentelle de leurs galeries de sape. Ainsi le $1^{\text {er }}$ juillet, dans le même secteur, François Baizet, rentrant de permission, reçoit l'information: "J'arrive à Dervin vers midi et demi et les camarades m'apprennent qu'il y a eu du grabuge à Vauquois dans les mines. A $T^{28}$ français* et allemands* se sont rencontrés dans la galerie. Les sapeurs français firent aussitôt un barrage de sacs à terre et les allemands*, pour faire leur barrage, firent exploser une ou deux caisses de dynamite vers 7 heures du matin le 24 (juin). Le cap al Avignon qui était derrière le barrage français fut tué net et le lieutenant Bonnier fortement secoué. Dans l'après-midi nos sapeurs continuèrent leur barrage et les boches* firent encore un camouflet. Le cap ${ }^{\text {al }}$ Lemmaret, gentil garçon, un subsistant, fut tué net encore et un sapeur Jacobs enterré en partie. On voulut le dégager. Les gaz produits par l'explosion asphixièrent* à moitié l'équipe de secours et quand une 2eme équipe arriva pour continuer à dégager ce pauvre Jacobs, celui-ci était mort asphixié* par le gaz."

Un autre accident dramatique lié à la proximité des galeries de sape ennemies survient le 27 juillet, dans le même secteur du Mamelon blanc, près de Vauquois. François Baizet note: "Fort camouflet ce matin à Vauquois qui nous balance dans nos plumard ${ }^{29}$ Violet qui vient dans notre abri 2 heures après ce camouflet nous dit que l'adjudant Castor de service à la M.S.T ${ }^{30}$. a été blessé grièvement a* ce camouflet. Aux renseignements ${ }^{31} j^{\prime}$ apprends que Castor préparait l'allumage de son camouflet et tenait en main les détonateurs pour l'amorçage. Les boches* firent jouer leur camouflet 2 minutes avant l'heure habituelle, qui fit jouer le nôtre, les charges étaient très près l'une de l'autre, quelques mètres seulement les séparaient. L'explosion de la charge alluma le cordeau détonant et les détonateurs explosèrent dans les mains de Castor qui eut les 2 mains coupées et un oil arraché. 15 hommes furent blessés. Le capitaine est consterné."

On voit à travers ces accidents mortels que si les galeries sont creusées par des sapeurs de base du génie, le soin de déclencher les explosions est confié à des gradés, voire à des officiers.

Un troisième accident dramatique, imprévu bien que prévisible, se produit quinze jours après, dans le même secteur toujours: "D 6 Une attaque souterraine de la M.S.T. a été prise par les boches*. Ces messieurs ont percé dans la tête de notre galerie au moment où les hommes prenaient leur repas, et lorsque nos mineurs retournèrent au travail ils furent accueillis à coup de revolver. Surpris les mineurs descendants* en tête d'attaque, sans armes, firent demi-tour en vitesse, et se sauvèrent! L'un d'eux, le premier qui avançait, ne revint pas. Est-il tué ou fait prisonnier? On l'ignore. Les boches* avancèrent et firent un camouflet près de l'entrée de la mine. Ils ont pris de la sorte 40 mètres de rameau ${ }^{32}$, ce qui leur fait une avance considérable et leur donnera le temps de préparer un fort fourneau pour faire un entonnoir sous nos lignes. Mauvaise affaire pour nous. Cela provient sans doute de la

\footnotetext{
27 "Kolossale": le K allemand au lieu du "C" français est une constante orthographique dans de nombreux journaux de la période 1914-1918, pour ridiculiser la "Kultur" allemande, et par contamination, dans les lettres et carnets d'intellectuels ou de soldats cultivés, bien que de profession modeste (cas de François Baizet). L'Illustration du 16 janvier 1915 présente une photo de deux canons français dont les fûts portent, à la peinture, les inscriptions "Kolossal" et "Kultur", avec la légende suivante: "Nos artilleurs ont donné ironiquement les noms de "Kolossal" et de "Kultur" à deux canons de 155mm qui, des hauteurs dominant Steinbach bombardent les tranchées allemandes dans la plaine de Cernay" (rubrique "Les opérations en Alsace")

28 " $A T^{\prime \prime}$ : on a vu précédemment ("à $Y$ ") que les secteurs précis de galeries de sape étaient identifiés par des lettres.

${ }^{29}$ On a vu qu'étant adjudant, François Baizet bénéficie d'un abri qu'il partage avec deux autres gradés; le lit dont ils bénéficient tranche singulièrement avec les conditions de vie des soldats de base.

${ }^{30} \mathrm{Je}$ n'ai pu trouver aucune explication de ce sigle, dont le "M" renvoie peut-être à "Mines" et le "T" à "Terre "

${ }^{31}$ Ces renseignements désignent la réunion matinale de tous les gradés et sous-officiers avec le capitaine, qui donne ses instructions.

${ }^{32}$ Ce terme de "rameau" renvoie à un plan des galeries de sape dessinées en arborescence, avec un tronc, des branches et des rameaux, comme le confirme le récit de Benoît Desseigné (la hauteur de la galerie diminuant progressivement).
} 
négligence des officiers qui croient que les écouteurs signalent toujours trop près. Là, comme à T le 24 juin, les écouteurs avaient raison et si on avait fait attention à leurs rapports, cela ne serait pas arrivé."

Ce récit permet de comprendre que la saisie par l'ennemi d'un tronçon de notre galerie avance considérablement sa tâche et met davantage en péril les soldats français qui se trouvent en surface, qui risquent d'être engloutis par l'énorme charge du "fort fourneau". Par ailleurs, on apprend qu'existe une méfiance des officiers envers les soldats écouteurs, qu'ils soupçonnent de minimiser la distance de la tête de la galerie de sape ennemie afin que soit donné plus tôt l'ordre de faire exploser le camouflet français, ce qui les préserverait d'une explosion inopinée déclenchée par les Allemands. On mesure ici la tension nerveuse que devait requérir cette spécialisation d'"écouteurs"...

Cette énorme explosion que redoute François Baizet ne se produira pas: une attaque d'envergure dans tout ce secteur de l'ouest de Verdun aboutira, selon lui, à la prise de plus de quatre mille Allemands, le 21 août.

Ainsi, dans ces divers extraits de ses carnets, François Baizet nous montre que la guerre des mines ne s'est pas achevée en 1915, qu'elle se poursuit en 1917 et que les techniques systématisées, l'une acoustique du géophone et l'autre explosive du camouflet préventif, l'ont simplement compliquée, et l'ont sans doute circonscrite en certains endroits du front où creuser des galeries était plus facile ou plus vital pour la stratégie militaire.

\section{Mars 1917 - Une mission d'écoute de quatre jours}

Benoît Desseigné (cl. 16), artisan menuisier à Villers, dans le Roannais, a laissé un journal-carnet de route précis (récit d'un trait rédigé d'après des carnets antérieurs); il se trouve avec le $5^{\mathrm{e}}$ R.I. Coloniale de Lyon en mars 17, dans l'Aisne, à la Cote 177, en prévision de l'attaque du Chemin des Dames prévue à la mi-avril. On lui confie, ainsi qu'à ses camarades une mission souterraine assez extraordinaire qu'il narre avec sobriété: "Le 5 (mars) au soir, je vais prendre mon poste avec les camarades; on nous emmène dans les lignes creusées sous les lignes boches à une profondeur d'environ 10 mètres. Nous descendons d'abord dans le puits et nous suivons des galeries et petits rameaux pour arriver sous les boches*. Là, on ne s'y fiait pas beaucoup, ne connaissant pas beaucoup ce filon. Enfin, nous étions deux hommes par poste, on s'y installe, nous avons chacun un microphone pour faire des écoutes dans différentes parties du secteur qui nous était confié. Toutes les deux heures nous suivions toutes les galeries pour s'assurer que les boches* ne travaillaient pas à percer nos mines pour les faire sauter ou en creuser chez eux. Nous passons deux heures de garde sans sortir, nous avons des grenades pour nous défendre et un pistolet automatique chacun; comme éclairage nous avons des bougies et sommes obligés de circuler à genoux ou en rampant dans les rameaux. Le temps passe assez vite, mais on n'est pas trop tranquille dans ces pièges à loups. Enfin quatre jours se passent comme ça et le génie vient nous remplacer."

Fin février- début avril 1918: entente tacite en Argonne pour se signaler l'explosion imminente de la mine

Le témoignage écrit de François Baizet a déjà signalé brièvement des cas réguliers, en 1917 en Argonne, d'accord tacite entre ennemis pour minimiser, voire neutraliser les pertes en vies humaines: " Par un accord tacite, les boches* et nous faisons sauter à la même heure, le matin, de 6 h30 à 7 heures. A 6 heures, les fantassins et le génie des 2 côtés évacuent les lères lignes et rentrent après 7 heures. Drôle de guerre." Ce cas a été observé sur une période assez longue par un autre combattant, témoignant oralement, mais ne datant pas son témoignage. Par chance, l'historique de son régiment, le $16^{\mathrm{e}}$ R.I. de Montbrison (j'ai photocopié son exemplaire qui porte sur la couverture, sous le nom du régiment la fière mention manuscrite: "où j'ai fait toute la guerre"), permet de situer le séjour en Argonne du 23 février 1918 au 5 avril (secteurs de Vraincourt, puis La Fille Morte et la Haute Chevauchée, les trois bataillons du régiment pouvant être dans des secteurs voisins)

Jean Giraudon (cl. 11) de Saint-Etienne - il prendra sa retraite à Bourg-Argental- alors sergent au $16^{\mathrm{e}}$ R.I. de Montbrison (il sera lieutenant de réserve en 1935), a été témoin lors de la guerre des mines d'une forme de complicité, voire de fraternisation entre ennemis, relativement longue, consistant à se prévenir mutuellement de l'imminence de l'explosion, toujours en Argonne: "A la Haute Chevauchée ${ }^{33}$, je me rappelle, on était dans les forêts, dans une forêt... Et alors on se faisait sauter! On faisait des machins en dessous et puis on faisait sauter! Et alors, une ou deux fois, ça a pris, et puis ça prenait plus après, parce que quand ça allait sauter, on faisait signe aux Allemands de (geste: partir)... que ça allait sauter, et ils s'en allaient! Et ils nous rendaient la pareille! Alors les charges sautaient et y avait personne! [...] On creusait pour faire des sapes, on creusait en-dessous pour aller chez les Allemands. On était à 20 mètres les uns des autres, 30 mètres, pas loin. Alors on faisait des sapes, et puis ils mettaient de la dynamite, et puis on faisait sauter!

E- Mais alors, en faisant ça, vous perturbiez le travail de ceux qui faisaient le...

T- (rire) On le faisait quand même! (rire) Alors le commandant était content: ça sautait! (rire)

E- Ah bon? Il suffisait que ça saute?

\footnotetext{
${ }^{33}$ La Haute Chevauchée est le nom donné à une crête de la forêt d'Argonne, à proximité du bois de la Gruerie
} 
T- Oui: suffisait que ça saute! Alors on se faisait signe, alors ça faisait rien à l'ennemi, et nous, ça nous faisait rien, nous!"

E- C'était une sorte d'entente?

T- Une sorte d'entente! C'était une entente: c'était fictif, quoi. Y a pas eu d'entente: ça s'est fait tout d'un coup, comme ça!

E - Donc là, sans vous concerter, y a eu cet épisode. Vous étiez restés un certain temps quand même, parce qu'il faut connaître les gens qui sont en face?

T- Eh ben oui! (rire). On se faisait signe comme ça, et puis ça y était, on faisait sauter après! C'était pas nous qui faisions le machin (la galerie de sape), c'étaient des sapeurs. Ils faisaient le trou, tout, puis ils nous disaient quand ça allait sauter, alors nous on faisait signe!

E- Les sapeurs ne devaient pas être ravis que vous leur gâchiez leur travail!

T- Ils s'en foutaient! Ils s'en foutaient, les sapeurs! Ils faisaient leur travail et puis ils s'en allaient. Ils nous disaient: "Ça va sauter demain ${ }^{34}$, attention!" Alors, attention! (rire)

E- C'est intéressant, cet épisode!

T- C'était intéressant! Oh! ça a duré ...peut-être deux mois, un mois et demi, deux mois. Et puis on s'est repliés, nous..."

Ce témoignage illustre la hantise de l'état-major: des troupes ennemies qui séjournent assez longtemps l'une face à l'autre finissent, même sans concertation explicite, surtout après plusieurs années de guerre, par trouver des formes d'entente visant à préserver les vies humaines. Mais il suffit d'un officier zélé ou d'une relève pour que recommence l'enfer meurtrier de la guerre des mines...

\section{$* * *$}

${ }^{34}$ Cette précision suppose soit un mécanisme de retardement, soit, plus sûrement, le retour d'un sapeur chargé le lendemain de la mise à feu du dispositif, du détonateur. 


\title{
Chapitre 10
}

\author{
1915
}

La guerre d'Orient : L'expédition des Dardanelles et le début de la guerre en Serbie 


\section{Chap. 10 - 1915 - La guerre d'Orient: l'expédition des Dardanelles et le début de la guerre en Serbie}

"Alors les Dardanelles, ce qui est un peu ridicule, n'est-ce pas, c'est que les Français avaient la moitié du front et les Anglais la moitié de l'autre, ce qui fait qu'il y avait pas toujours bonne entente quand y avait des attaques. Enfin, bon...ça, c'est une question militaire."- Florent Badiou, classe 1915, Saint-Etienne

"C'était une tranchée conquise, comme je l'ai dit plus haut, quelques jours auparavant et non encore organisée. Cet ouvrage avait subit* les terribles effets du 75. Des Turcs, enterrés au fond de la tranchée par l'éclatement des projectiles, prouvaient l'efficacité et la précision de notre tir et de chaque côté, le long des parapets, les nombreux cadavres de soldats ottomans répandaient une odeur épouvantable."- Récit de Claudius Viricel, classe 1910, Grammond (Loire)

"Cette malheureuse nation (la Serbie) a souffert un martyre qu'on ne peut se figurer, et comme ils sont loin et qu'on les considère comme des moitié sauvages et que nos écrivains ont peu pénétré dans leur malheureux pays pour nous peindre leur détresse, on les ignore"

"Tout combattant a connu dans ces moments terribles cet anéantissement de la sensibilité qui n'est ni du désespoir, ni de l'esprit de sacrifice, mais comme une absence de pensée qui fait un corps un automate qui n'est plus guidé par une volonté endormie et qui suit le mouvement. C'est justement dans ces moments que les chefs sont l'âme de leurs hommes: qu'ils soient à la hauteur de leur tache*, tout va bien, que ce soient des "gourdes", rien ne va plus"- Journal de guerre de Camille Richier, classe 1910, Saint-Julien-Chapteuil (Haute-Loire)

Forcer le passage du détroit des Dardanelles: l'expédition navale puis terrestre selon l'éclairage de trois historiens

Ce qu'on appelle "l'expédition des Dardanelles" ou "l'opération des Dardanelles" (expression préférée par Jean-Jacques Becker dans son ouvrage à classement alphabétique très dense et documenté intitulé "La première guerre mondiale ${ }^{\prime \prime}$ ) résulte de la volonté, plus britannique que française, de soulager le front de France en créant un front d'Orient, qui pourrait de surcroît soulager aussi l'allié russe dans le Caucase et faciliter la liaison avec lui, par la Mer Noire. Elle commence par une opération navale en février-mars 1915, qui échoue, et se poursuit par une opération terrestre débutée le 25 avril, qui échouera aussi.

Cette opération fait partie de ce que Jean-Baptiste Duroselle, dans La Grande Guerre des Français 19141918, appelle "stratégie de la diversion", qu'il expose succinctement ainsi, pour ce qui est des Dardanelles, avec une vision géo-stratégique à l'échelle de ce conflit mondial: "La France a été mêlée en 1915 à trois tentatives de diversion. La première, conçue par Churchill à la fin de 1914, consistait à envoyer une expédition navale aux Dardanelles. Le but était de s'emparer de ce détroit ottoman, puis du Bosphore, et ainsi de rétablir avec la Russie des communications qui, vu la suprématie allemande dans la Baltique, ne pouvaient plus guère se faire que par Arkhangelsk, sur l'Océan Glacial arctique, et par Vladivostok, en Sibérie orientale. Le gouvernement anglais donna son accord le 13 janvier 1915 [...] Le 9 février 1915, Augagneur, ministre de la Marine, après un voyage en Angleterre, approuva le projet et promit l'envoi d'une escadre commandée par le contre-amiral Guépratte. Au surplus, une force terrestre d'appui fut constituée (dont l'une avait été primitivement destinée au front ouest, et d'une, puis deux divisions françaises. Joffre s'opposa absolument à ce que ces divisions fussent distraites du front. On les constitua donc avec des éléments prélevés sur les dépôts, et elles furent placées sous le commandement du général d'Amade." ${ }^{2}$. On verra, au moins avec un de nos quatre témoignages, celui de Camille Richier (cl. 10), qui depuis fin août 1914 combattait en Lorraine, puis en Alsace et enfin dans les Vosges avec son $19^{\mathrm{e}}$ Régiment d'Artillerie de montagne de Grenoble, que malgré l'opposition de Joffre, des troupes furent tout de même retirées du front ouest, ce qui explique sans doute le secret maintenu par les officiers envers leurs hommes sur ce retrait partiel de quelques batteries du régiment pour les expédier en Orient, comme l'explique, sans le comprendre, le témoin.

A propos de la première offensive, la navale, Jean Jacques Becker écrit: "L'opération ne put débuter, après une série de tergiversations sur la meilleure méthode à employer, que le 19 février 1915, elle se révéla beaucoup moins simple que certains ne l'avaient cru. Il fallait d'abord forcer le détroit des Dardanelles, long goulet d'une soixantaine de kilomètres de longueur, de $4 \mathrm{~km}$ de largeur en moyenne avec un minimum de 1270 mètres à proximité de son débouché sur la Méditerranée. Or les Turcs avaient eu le temps d'en fortifier les deux rives et d'immerger des mines, ce qui rendait le passage très hasardeux. Effectivement, l'opération navale échoua complètement: après différentes attaques partielles, l'attaque en force fut lancée le 18 mars et à la fin de la journée trois cuirassés dont un français avaient été coulés, et quatre autres dont deux français mis hors de combat"

\footnotetext{
${ }^{1}$ Jean-Jacques Becker, op.cit; M.A. Editions, 1985, collection "Le monde de...", pp. 40-42

${ }^{2}$ Jean-Baptiste Duroselle, op.cit. pp. 104-105
} 
Le cuirassé français coulé est "Le Bouvet", sombrant le 18 mars, à 13 h 58, selon les observateurs, touché par une mine dérivante. Le numéro de L'Illustration du 17 avril 1915 consacre deux pages de photos et dessins à "La fin du "Bouvet" aux Dardanelles", photos prises et dessins effectués par un observateur anglais qui se trouvait sur le cuirassé anglais "Triumph". Les deux cuirassés anglais "Ocean" et "Irresistible" coulèrent aussi, mais sans chavirer, ce qui permit de sauver presque tout l'équipage, à la différence du "Bouvet" qui sombra en quelques minutes. L"Illustration du 27 mars décrit le naufrage: "Au moment où l'escadre française franchissait le goulet après avoir canonné les forts de la façon la plus brillante, le cuirassé "Bouvet" heurta une mine dérivante qui, explosant près d'une soute à poudre, déterminant l'inflammation de toutes les munitions et causa la perte du navire qui coula, en trois minutes, par plus de soixante mètres de fond, au Nord d'Aren-Keui. De tout son équipage, composé de 600 hommes, 64 seulement ont été sauvés."

L'historien Pierre Miquel, dans Les Poilus d'Orient, donne une vison encore plus spectaculaire de ce drame du "Bouvet", par le nombre de victimes (645 au lieu de 536, dans le récit de L'Illustration) et la rapidité du naufrage: "13h 40 approximativement: le Bouvet est éventré par une mine dérivante et coule en cinquante secondes. 645 hommes périssent. Quarante-sept sont recueillis en mer par les vedettes des torpilleurs anglais. ${ }^{13}$

Jean-Jacques Becker ne peut s'empêcher de refaire l'histoire en conjecturant une victoire possible, qui n'a pas eu lieu par manque de lucidité du commandement franco-anglais, échaudé par ce premier revers inattendu, plus que par déséquilibre des forces en notre défaveur. Ainsi il pronostique: ." En fait, si l'attaque avait été reprise le lendemain -les Turcs n'avaient pratiquement plus de munitions et de mines -, elle aurait probablement réussi, mais à peine franchis les Dardanelles et traversée la mer de Marmara, le flotte se serait trouvée face à 15 divisions turques regroupées autour de Contantinople".

Faute de victoire navale pour forcer le passage du détroit des Dardanelles, le recours à une expédition terrestre apparaît comme la solution dans le camp des Alliés. Laissons Jean-Jacques Becker poursuivre son récit: "Le 25 avril, des forces alliées (Anglais, Australiens, Néo-Zélandais et Français) tentaient de débarquer dans la presqu'île de Gallipoli, à l'extrémité de la rive européenne des Dardanelles. Après avoir subi de terribles pertes, les troupes mises à terre étaient bloquées à l'extrémité de la presqu'île par les troupes turques commandées par le général allemand Liman Von Sanders (sous les ordres de qui devait se distinguer le jeune colonel, bientôt général, Mustapha Kemal). Tandis que des renforts de plus en plus nombreux étaient envoyés, les combats continuaient en vain. Au mois d'août, les Anglais tentèrent un nouveau débarquement un peu plus au nord de la presqu'île de Gallipoli qui fut également bloqué par Mustapha Kemal. Il était évident que l'opération des Dardanelles était définitivement bloquée"

A la suite de cet échec, l'opération terrestre du corps expéditionnaire, tout à fait remanié dans sa répartition entre Français et Anglais, ces derniers devenant très minoritaires, est transférée sur le territoire grec, à partir de la base que va constituer le grand port de Salonique, à proximité duquel va être construit le grand camp de Zeitenlik, qui servira de base arrière et de base de repli à la guerre en Serbie contre les forces armées bulgares. J.J. Becker explique rapidement cette nouvelle phase: "Quand, à l'automne 1915, les Allemands aidés par les Bulgares se préparent à passer à l'offensive dans les Balkans, une partie des troupes des Dardanelles est envoyée à Salonique et on liquide l'opération. Dans la nuit du 8 au 9 janvier 1916, les dernières troupes alliées quittent les Dardanelles." 4

\section{L'expédition des Dardanelles vécue par nos témoins}

Deux de mes témoins ont participé à la première phase terrestre de l'opération des Dardanelles, celle du printemps 1915 (Jean-Baptiste Meunier et Claudius Viricel) et trois à la seconde phase, celle de l'automne qui se prolonge en guerre en Serbie (Jean-Baptiste Meunier encore, Florient Badiou et Camille Richier) . Comme trois témoignages sur quatre sont des écrits de qualité et fiables (le quatrième étant un entretien), je privilégierai pour une fois la succession des témoignages, pour ne pas casser l'unité du récit et la familiarité croissante du lecteur avec le narrateur, plutôt que leur entrecroisement.

\section{Le témoignage de Jean-Baptiste Meunier}

Jean-Baptiste Meunier (cl. 10) né à Bard-en-Forez, fils d'agriculteur (qui sera agent de l'E.D.F. à Montbrison), d'abord incorporé au $97^{\mathrm{e}}$ R.I. de Chambéry, est versé en février 1915 au $175^{\mathrm{e}}$ R.I. de Grenoble, désigné le 2 mars pour faire partie du corps expéditionnaire pour les Dardanelles. Il a rédigé de sa guerre, sans doute en 1919 d'après des notes antérieures, une relation précise, datée au jour le jour, bien que brève (61 pages d'un carnet de petit format) qui comporte, entre autres, deux volets de sa campagne d'Orient: l'expédition des Dardanelles (de début mars 1915 à son rapatriement fin juillet) et, à partir de novembre 1915, Salonique puis la Serbie, pour l'année 1915. Il restera en Orient jusqu'en août 1917.

La traversée jusqu'aux Dardanelles en passant par l'Egypte

La narration est très rapide, très sèche, pour beaucoup de points, sans fioritures, ni détails pittoresques ou simplement documentaires. Parti de Grenoble le 2 mars 1915, il embarque à Marseille le 4 sur "La Provence" qui

\footnotetext{
${ }^{3}$ Pierre Miquel,op.cit., p. 39

${ }^{4}$ J.J. Becker, op.cit pp. 43-44
} 
lui paraît "une véritable merveille" mais qu'il ne décrit pas. Le 6 mars, le navire mouille à Bizerte et en repart le 10 pour entrer dans la mer Egée le 15, sans aucun incident de traversée, ni alerte aux sous-marins; le 16, débarquement dans l'île de Lemnos: "Nous avons traversé un bourg appelé "Moudros" à l'aspect pauvre." Le seul incident est découvert à Lemnos: "Nous avons vu débarquer les chevaux dans des petits bâteaux* pour les mener sur terre afin qu'ils puissent manger à leur aise et se régaler car sur le bâteau* ils devenaient malades et plusieurs étaient morts". Après une dizaine de jours passés à soigner les chevaux et à nettoyer le navire, les soldats repartent le 27 mars sur un autre navire, "Le Savoie", en direction d'Alexandrie en Egypte; la traversée d'Alexandrie ne lui inspire aucun commentaire; les troupes sont logées "dans un camp nommé "Victoria College". Un office religieux est brièvement évoqué: "Le 4 avril, jour de Pâques, nous assistons à la messe dite par un prêtre d'Alexandrie. On a élevé un autel en plein air un peu en dehors du camp. Beaucoup d'hommes font la communion". On verra, dans un chapitre, que la pratique religieuse masculine a été singulièrement renforcée pendant la guerre, par la perspective de la mort et l'espoir de la protection divine...

La monotonie de la vie au camp est bien rendue par "Les 6,7,8,9,10,11,12, 13 et 14 exercices dans le sable." Aucune sortie dans la ville d'Alexandrie apparemment. Le 15 avril, départ du camp, embarquement sur "La Provence" en direction de Lemnos.

En route est faite lecture d'une proclamation quelque peu grandiloquente du chef du corps expéditionnaire, le général anglais Ian Hamilton, et du général français d'Amade, que Jean-Baptiste, si sec d'habitude, note en entier, ce qui indique qu'il doit disposer d'une version écrite distribuée aux troupes, en français: "Ordre général - Soldats de France et soldats du roi ${ }^{*}$ nous avons à accomplir une entreprise sans précédent dans la guerre moderne. De concert avec nos camarades de la flotte, nous allons opérer un débarquement de vive force sur une plage ouverte en face de nos positions que l'orgueil de nos ennemis présente comme inexpugnable. Le débarquement sera mené à bien avec l'aide de Dieu et de la marine. Les positions seront emportées d'assaut et la guerre saura franchir une étape de plus vers un glorieux achèvement. "Souvenez-vous" a dit Lord Kitchner ${ }^{* 6}$ dans ses adieux à votre général, "Souvenez-vous que quand vous aurez débarqué sur la presqu'île de Gallipoli, vous devrez combattre jusqu'au triomphe définitif. Le monde entier aura les yeux fixés sur notre marche en avant. Prouvons-leur que nous sommes dignes de la grande œuvre confiée à nos armes" P.C.C. Signé Hamilton-d'Amade" .

Cette proclamation a-t-elle galvanisé ou effrayé les soldats? Jean-Baptiste n'en dit rien, mais quand on sait ce que sera l'opération des Dardanelles, on mesure l'écart entre les intentions affichées dans la proclamation et la réalité... Le 27 avril, après une escale à Lemnos, le corps expéditionnaire débarque à Seddul Bahr, à la pointe de la presqu'île de Gallipoli, sur le territoire turc d'Europe.

La brève bataille des Dardanelles pour J.B. Meunier

C'est seulement là que Jean-Baptiste se fait plus descriptif, moins laconique, alors que commence vraiment sa "première campagne" comme il l'a indiqué en lettres gothiques soigneusement calligraphiées en tête de son carnet: "Le 27 nous débarquons à 6 heures du matin à Seddul Bahr. Nous creusons des tranchées et nous y restons jusqu'à 2 heures. On nous distribue encore des cartouches, nous en avons 320. A 2 heures, le chef de ma section reçoit l'ordre d'aller en reconnaissance. Il prend avec lui une dizaine d'hommes dont je fais partie. Nous découvrons l'ennemi dans une vallée. Nous essuyons quelques coups de feu puis nos mitrailleuses donnent et forcent les leurs à abandonner leurs tranchées. Ensuite nous rejoignons notre $C^{\text {nie }}$ et le soir, nous avançons de trois ou quatre kilomètres sans tirer un coup de feu en tenant toute la largeur de la presqu'île de Gallipoli , les Anglais à gauche, le $175^{e}$ au centre, les zouaves et les sénégalais* à droite. A la nuit nous faisons des tranchées puis nous nous préparons à dormir. A 8 heures je suis de garde avec mon caporal et quatre hommes au devant des tranchées. Nous y restons environ deux heures, puis on nous relève. Aussitôt arrivés à notre section, au moment où nous nous préparions à manger un peu, les balles commencent à siffler. C'étaient des Turcs qui nous attaquaient. Notre première ligne a donné un feu nourri et les Turcs sont partis pour revenir trois ou quatre heures après. Ils ont recommencé le feu et ont été obligés de se replier de nouveau sous nos fusillades. Ils sont revenus encore trois heures après mais ils n'ont pas mieux réussis* que les premières fois. Le 28 avril au matin, on fait le café bien tranquille* avec le sergent Soubie et cinq de mes camarades Pétrier, Canet, Epinet, Beurrier, Gauthier. Nous n'avions pas fait deux cents mètres que l'ennemi commence à nous canarder. Me trouvant derrière un talus, je me cache un instant, ne pensant pas me replier et pensant que ma $C^{\text {nie }}$ avancerait. A ce moment arrive un éclat d'obus qui me touche au front. Je saigne mais je ne sens pas grand mal. Les balles pleuvaient toujours, les mitrailleuses donnaient beaucoup. Voyant ça je me cache derrière mon sac et me mets à creuser un trou avec ma pelle-bêche. Je m'y abrite et reste là, au moins deux heures au milieu des balles et des obus. A un moment donné je vois les Turcs sortant de leur tranchée et venant dans ma direction. Je me replie en suivant le talus et j'arrive jusqu'à ma section,

\footnotetext{
${ }^{5}$ On remarquera la dissymétrie de l'appellation, les soldats anglais n'étant pas nommés ainsi, mais rattachés à leur roi, Georges $\mathrm{V}$, petit-fils de la reine Victoria, régnant depuis 1911, et qui devra renoncer à son nom allemand de Saxe-Cobourg en 1917 pour prendre le patronyme plus anglais de Windsor, devenant ainsi le premier roi de la maison de Windsor, toujours régnante.

${ }^{6}$ Lord Horatio Kitchener, général déjà illustre, né en 1850, a été nommé ministre de la Guerre le 3 août 1914 . Selon JeanJacques Becker, dans La Première Guerre mondiale, M.A. Editions, 1985, "Kitchener avait été très réticent envers l'opération des Dardanelles imposée par le premier Lord de l'Amirauté, Winston Churchill" (p. 111)

${ }^{7}$ Cette largeur n'est pas considérable, et ne doit pas excéder $25 \mathrm{~km}$ dans son point le plus large
} 
je trouve le sergent Favre qui la commandait, caché derrière un autre talus. Il prend mon fusil pour remplacer le sien qui était cassé. Moi, étant abrité, j'y reste assez longtemps. Je trouve un camarade qui me fait un pansement. Les balles sifflaient toujours de plus en plus. Je vois une section qui se replie, je pense que les Turcs avancent. Je me replie aussi malgré les balles qui pleuvent. Heureusement, il n'y en a pas qui m'ont touché et j'ai pu me débiner et me cacher dans un trou ou* se trouvaient plusieurs camarades qui m'ont fait signe. Là, j'y reste encore, peut-être deux heures, jusqu'à ce que le feu se soit un peu calmé. C'était environ 2 heures du soir (= de l'après-midi). Je pars de nouveau , j'ai (?) lourds. Les balles sifflaient beaucoup moins et j'arrive au poste de secours sur les trois heures. La* un infirmier me refait mon pansement puis le Major ${ }^{8}$ 'évacue.

\section{L'hospitalisation en Egypte}

Le récit continue sans interruption, nous apprenant que les blessés atteints gravement n'étaient pas soignés sur place, par manque d'infrastructure hospitalière sans doute, même provisoire, vu l'impréparation de l'expédition, mais après une traversée de la Méditerranée dans sa largeur orientale qui pouvait leur coûter la vie, bien que le navire qui transporte les blessés soit équipé pour les soins: "Comme je peux marcher, je vais au débarcadère à pied, lequel se trouvait à $2 \mathrm{~km}$ environ. Là j'ai été embarqué avec tous les autres blessés sur un bateau-hôpital "Le Dugay-Trouin". Il était déjà plein de blessés. Etant complet, il est parti aussitôt pour Alexandrie."

Jean-Baptiste Meunier suspend un instant la narration de son histoire personnelle pour faire un bilan des pertes: "Cette journée sera remarquable; ça a été un vrai carnage. Je crois que le $175^{e}$ a été bien esquinté. Je ne sais pas s'il y a eu beaucoup de morts, mais de nombreux blessés. Dans son ouvrage sur Les Poilus d'Orient, Pierre Miquel nous renseigne sur les pertes considérables de cette journée, et précisément celles du $175^{\mathrm{e}}$ R.I.: "Les Français ont été attaqués très vivement dès leur débarquement. Dans la nuit du 27 avril, le $175^{e}$ d'infanterie a gagné ses positions dans le "ruisseau des Morts" et le "ruisseau des Ecrevisses", où coule le filet d'eau rouge sang du Kérévès Déré. Guidés par le général d'Amade, que l'on reconnaît à son burnous et à son calot bleu, ils ont gagné la ligne des tranchées. Les officiers d'état-major, autour de François Charles-Roux, ont entraîné le général à l'abri du vieux fort de Seddul Bahr. On entend les hurlements des Turcs qui chargent à la baïonnette. Les trois quarts des officiers du $175^{e}$ sont tués. Un homme sur quatre meurt dans cette affaire." ${ }^{\prime 9}$

Quand on dispose d'une relation historique d'une bataille, même très résumée comme ici, on est toujours frappé de l'écart entre l'histoire individuelle de chaque blessé, presque toujours moins spectaculaire, et l'histoire collective, qui semble, dans ce récit de P. Miquel, incarnée par le seul destin de son chef, le général d'Amade, pourtant moins exposé que ses hommes, puisque ceux-ci n'ont trouvé personne pour les soustraire au danger de "la ligne des tranchées" et les mettre "à l'abri du vieux fort". Quant à la proportion de trois-quarts des officiers tués pour un quart des soldats, elle a de quoi surprendre... Cependant, il est avéré que dans l'infanterie, surtout jusqu'au grade de capitaine (officiers de troupe, en tranchées), le pourcentage de tués parmi les officiers a excédé, mais pas dans ces proportions, le pourcentage de tués parmi les soldats de base; ainsi, dans le numéro spécial de L'Histoire de nov.déc. 2003, consacré à la Grande Guerre, l'historien Stéphane Audouin-Rouzeau fait le bilan suivant, pour toute la guerre: "Parmi les troupes combattantes, $22 \%$ des officiers et $18 \%$ des soldats sont morts, ainsi que dans l'infanterie, un officier sur trois et un homme de troupe sur quatre". ${ }^{10}$

Jean-Baptiste Meunier poursuit après son récit, sans autre évocation de cette traversée que ces notes laconiques: "Le 28 nous marchons sur Alexandrie. Le 30 toujours sur l'eau. Nous arrivons à Alexandrie le $1^{\text {er }}$ Mai à 7 heures du matin. On commence à nous débarquer à midi, les plus grands blessés les premiers. A six heures du soir, c'est mon tour ainsi que celui de mes camarades qui pouvaient marcher. On nous fait monter dans des autos ambulances qui nous transportent dans un hôpital en dehors d'Alexandrie. Un hôpital allemand appelé "Diaconissen Hospital". Là nous sommes soignés par des infirmières allemandes et des médecins anglais. ${ }^{11}$ Nous y sommes très bien. J'y reste jusqu'au 11 Mai, jour ou* je suis conduit dans une maison de Frères transformée en hôpital, ou plutôt dépôt de convalescence. Le 25 mai, je quitte l'hôpital pour aller au dépôt au régiment qui se trouve au camp des chasseurs d'Afrique "Camp Victoria College".

Se sentant mieux, le 27 mai 1915, Jean-Baptiste se porte volontaire pour aller effectuer le service des malades dans les hôpitaux d'Alexandrie, et se trouve affecté, avec 21 de ses camarades, à l'hôpital Larrey, dont il n'indique pas qu'il est français, mais on peut le deviner car il tire son nom du célèbre chirurgien en chef de la Grande Armée, Dominique Larrey, fait baron par Napoléon; né en 1766 il mourra en 1842. Jean-Baptiste ne peut exercer son service que quelques jours car le voilà atteint de coliques dès le $1^{\text {er }}$ juin, assorties d'une forte fièvre ("je me fais porter malade et je suis reconnu"). Il est à nouveau hospitalisé sans doute à l'hôpital Larrey, mis à la diète, et se

\footnotetext{
${ }^{8}$ Le Major est le nom couramment donné au médecin major, ayant grade de capitaine

${ }^{9}$ Pierre Miquel, op.cit., p. 93

${ }^{10}$ Article "L'épreuve du feu" de Stéphane Audouin-Rouzeau, dans la revue spéciale "Collections de l'Histoire" intitulée "19141918 La Grande Guerre", n 21, nov-déc 2003, p. 39

${ }^{11}$ Cette collaboration entre médecins anglais et infirmières allemandes dans un hôpital allemand d'Alexandrie où l'on héberge et soigne des blessés français est surprenante; on s'attendrait à ce que ce soit un hôpital anglais (la présence britannique étant forte en Egypte colonisée) à défaut de lieux de soins français qui existent pourtant, comme l'indique la suite du témoignage... La vocation religieuse proclamée par son nom "Hôpital des Diaconnesses", terme qualifiant des infirmières allemandes protestantes, peut expliquer cet œcuménisme médical transcendant les antagonismes.
} 
retrouve presque guéri, mais très affaibli, le 14 juillet, seul jour notable pour lui depuis un mois et demi: "Le 14, jour de la fête nationale, on nous a donné la permission de descendre dans la cour. Nos infirmières avaient monté une petite tombola. Chaque soldat a eu son petit prix. Nous avons passé encore une belle journée."

Jean-Baptiste Meunier va finalement embarquer sur le "Sydney" le 26 juillet, arrivant sans incident de traversée à Marseille le 30, pour passer une permission de convalescence de deux mois en France, dans sa famille, à Bard. L'arrivée en France, pas plus que dans Montbrison et dans son Bard natal, ne le rend pas lyrique, comme on s'y attendrait: "Je suis parti le lendemain matin (2 août 1915) à 6 heures et demie pour Montbrison où je suis arrivé à huit heures. Me voilà donc de nouveau au pays. Ma première campagne est terminée."

\section{Florent Badiou, un technicien aux Dardanelles d'août 1915 à janvier 1916}

Florent Badiou (cl. 15) né à Saint-Jean-Bonnefonds, électricien-mécanicien à Saint-Etienne avant son incorporation en décembre 1914 au $8^{\mathrm{e}}$ régiment de Génie du Mont Valérien replié à Angoulême (après guerre monteur-bobineur à ce qui deviendra l'E.D.F.), part comme volontaire ${ }^{12}$ pour l'armée d'Orient en août 1915: "J'avais embarqué à Marseille sur un cargo "Ville de Rouen"(qui a été coulé ensuite par les Allemands peut-être deux ans après) qui était un cargo, un transport de marchandises; j'en ai gardé un très mauvais souvenir: nous couchions en dessous du pont. Au-dessus de nous, on avait embarqué des vaches, des vaches... Et alors, nous avons été pris dans une tempête! Notre voyage a duré huit jours pour aller jusqu'aux Dardanelles. C'était au mois d'août 15. On a fait escale à... Alors oui, les vaches étaient au-dessus de nous; alors en pleine mer, y avait des rafales de vent qui nous envoyaient le fumier sur le...Ah! J'ai été malade, malade! Un de mes camarades a été très gentil: il est venu me chercher et on a monté sur le pont où j'ai couché, directement sur le pont. Sur le pont, on était au grand air! Et nous avons fait escale à Bizerte pour prendre un bataillon de zouaves, qui allait en Orient avec nous. Et nous avons mis huit jours de traversée jusqu'à Moudros ${ }^{13}$.

E- A Moudros, vous y êtes restés?

T- J'y suis resté un mois environ, et puis je suis parti aux Dardanelles, où les troupes françaises et anglaises avaient débarqué quelques mois avant.

E- Et qui avaient été bombardés par les Turcs!

T- Et bombardés par les Turcs! Et le front des Dardanelles avait $7 \mathrm{~km}$ de long

E- Ça se présentait comment, les Dardanelles? C'était un défilé? Un canal menacé de chaque côté?

T- Oui. C'est-à-dire qui y avait le détroit de Gallipoli qui nous séparait de l'Asie. Et l'Asie était à certains moments, aux Dardanelles, à $5 \mathrm{~km}$ ! Notre occupation aux Dardanelles représentait un triangle de $7 \mathrm{~km}$ de côté: nous étions pas loin des... (Turcs) On était bombardé depuis les lignes turques, et c'est là que le général Gouraud, qui commandait l'armée, a perdu un bras, en visitant l'hôpital de Seddul Bahr ${ }^{14}$. Y a un obus qui est tombé sur l'hôpital et qui lui a arraché le bras...

E- Et votre travail consistait...

T- J'ai été d'abord affecté à l'état-major du général Simonin. Mon travail consistait à réparer les lignes et à aller sur le front, entre l'état-major et les lignes (du front), à aller réparer les lignes (électriques) qui étaient coupées très souvent par les gros obus. Ils avaient des gros obus de 210! Et des 75, malheureusement!

E- Des $77 !^{15}$

T- Des 75 !

E- Ils avaient récupéré nos 75 ?

T- C'est nous qui leur les* avions vendus! On avait vendu des armes avant la guerre aux Turcs, aux Bulgares et aux Roumains, je crois [...] Moi j'étais pas en première ligne, mais enfin j'étais pas loin du front, et mon rôle

\footnotetext{
${ }^{12}$ Sans vouloir médire de ce témoin et de la sincérité de son engagement, l'engagement pour l'armée d'Orient, à travers les divers soldats que j'ai interrogés, est presque toujours apparu, plus en 1917 qu'en 1915 cependant, comme un moyen de fuir l'horreur du front français, en même temps que de satisfaire le désir de "voir du pays"

${ }_{13}^{13}$ Moudros est le port principal de l'île grecque de Lemnos, qui se trouve environ à $80 \mathrm{~km}$ de l'entrée du détroit des Dardanelles

${ }^{14}$ Seddul Bahr est la ville qui se trouve à l'entrée du détroit des Dardanelles, du côté européen (ouest). Le général Henri Gouraud, récemment arrivé en Grèce, avait été effectivement blessé par un obus le 30 juin 1915, en visitant l'ambulance (hôpital temporaire) de Seddul Bahr et amputé du bras droit à bord du navire-hôpital Tchad; il a été remplacé par le général Bailloud. Le numéro de L'Illustration du 17 juillet 1915 (p. 54) raconte, alors qu'il vient d'arriver à Paris, les circonstances de sa grave blessure: "Le 30 juin, comme il venait de se mettre à table pour dîner, il fut prévenu, par un colonel, de l'arrivée d'un convoi de blessés à l'hôpital installé non loin de son quartier général. Il s'y rendit immédiatment, remettant à plus tard son repas. Il allait pénétrer dans l'ambulance quand un obus éclata à ses pieds. La commotion fut si violente que le général fut projeté à 6 mètres de là, de l'autre côté d'un petit mur. Au premier moment, ne le voyant plus près de lui, le colonel qui l'avait amené, et qui fut lui-même touché, le crut pulvérisé, disparu. Le général avait les deux jambes et le bras droit fracturés. Il a fallu, nous l'avons dit, sacrifier le bras."

Sa silhouette de général amputé contribuera à frapper les esprits des soldats. Le commandant de l'expédition anglaise chapeautant l'ensemble des deux armées, le général Ian Hamilton, aurait déclaré, selon Pierre Miquel dans son ouvrage Les Poilus d'Orient (édition Fayard, 1998): "J'aimerais mieux perdre une brigade que le général Gouraud" (p. 11)

${ }^{15}$ Les 77 sont des canons utilisés dans l'armée allemande, alliée des Turcs
} 
consistait à aller réparer quand les lignes étaient coupées. Et ce qui était un peu extraordinaire, c'est que les Turcs, ils avaient pas beaucoup de munitions! Ils tiraient donc avec des obus de 210 ; les obus, ils se suivaient à quelques minutes près. Ils tiraient toujours deux coups, deux obus, et les obus tombaient environ à cinquante mètres l'un de l'autre. Alors quand nous avions une ligne coupée, que nous allions réparer, si le premier obus tombait à plus de cent mètres de nous, on disait: "On risque rien!" [...]

Le regret de Florent Badiou que nous ayons imprudemment vendu nos fameux canons de 75 à la Turquie n'est pas seulement inspiré par le patriotisme, mais par une considération personnelle qu'il va finalement exposer:

E- Donc vous êtes arrivé aux Dardanelles vers la fin de l'été, le début de l'automne 15...

T- Au mois de septembre probablement, et j'y suis resté jusqu'au 15 janvier 16 où on a évacué les Dardanelles. Alors les Dardanelles, ce qui est un peu ridicule, n'est-ce pas, c'est que les Français avaient la moitié du front et les Anglais la moitié de l'autre, ce qui fait qu'il y avait pas toujours bonne entente quand y avait des attaques. Enfin, bon...ça, c'est une question militaire. Alors les Français ont évacué les Dardanelles le $1^{\text {er }}$ janvier 1916. Nous sommes restés quinze télégraphistes, je crois, quinze télégraphistes du $8^{e}$ Génie en liaison avec les Anglais et avec une batterie d'artillerie. On avait laissé une batterie d'artillerie française. Alors y avait quelques artilleurs qui sont restés, et les télégraphistes: et nous! Nous avons évacué le 15 janvier. Quand nous avons évacué - c'est pour revenir au 75 - quelques jours avant, moi, j'étais affecté aux Dunes (nous avions un central téléphonique aux Dunes). Alors avec un de mes camarades, la veille de notre départ, on nous a dit: "Vous allez descendre votre barda à Seddul Bahr". Nous sommes partis à Seddul Bahr tous les deux, et le long de la route (y avait un chemin), tout d'un coup... Les Turcs voyaient plus personne, probablement; ils voient ces deux pèlerins: ils nous tirent dessus avec... J'ai été ramassé l'ogive ${ }^{16}$ : elle est tombée à deux cents mètres de moi! J'ai été ramasser l'ogive et j'ai vu "Schneider"! C'était un 75! Je l'ai mis dans ma musette et malheureusement on me l'a barboté ${ }^{17}$ quand j'étais à l'hôpital.

E- Ça devait vous faire mal au cœur de voir que des armes françaises vous tiraient dessus?

T- Eh oui! Oui, oui, oui, oui! Alors y avait "Schneider!". Bien sûr, c'était le 75 et on nous tirait dessus! Et ils étaient pourtant avares de munitions! Mais enfin je ne sais pas pourquoi...

E- Et là, il n'y avait que des Turcs? Il n'y avait pas d'Allemands?

T- Ah non! non, non! Y'avait que des Turcs!"

La réaction de Florian Badiou de ramasser et de vouloir conserver l'ogive de l'obus qui aurait pu le tuer est très représentative: la plupart de mes témoins blessés m'ont montré les balles, les éclats d'obus ou les shrapnels qu'on leur a retirés du corps quand on les a opérés, et qu'ils ont conservés toute leur vie comme un trophée...

Quant à l'évacuation des Dardanelles par les troupes françaises le $1^{\text {er }}$ janvier 1916, elle s'explique par des considérations stratégiques qu'expose Pierre Miquel dans son ouvrage Les Poilus d'Orient " : "Joffre est partisan de l'évacuation totale et le déclare au Conseil des ministres du $1^{e r}$ décembre (1915). Gallieni affirme qu'il veut "aller plus loin que Kirchener" et exige qu'on s'en aille. Mais pour passer à l'exécution, il faut l'accord de l'Angleterre. Une négociation d'ensemble doit être engagée, car si les Anglais ne sont pas pressés d'évacuer les Dardanelles, et veulent concentrer leurs troupes sur l'Egypte, les Français prétendent les contraindre à respecter les promesses qu'ils ont faites d'envoyer 90000 hommes à Salonique, seul moyen, pense-t-on à Paris, "de maintenir la neutralité de la Grèce et d'entraîner la Roumanie" ${ }^{\prime 18}$. Il s'agit aussi, pour les Français, de venir efficacement au secours de la Serbie, pays allié, en mauvaise posture face à l'offensive bulgare (Monastir vient d'être prise début décembre), mais le consensus sur cette aide est loin d'être réalisé: "Les Serbes n'ont plus d'illusions: les Britanniques les ont traités avec la plus grande indifférence, les Français leur ont ménagé leur aide et les Italiens se sont montrés si hostiles. Le 28 décembre, les Anglais et les Italiens ont d'ailleurs refusé à Vesnié de garantir l'indépendance et l'intégrité territoriale de la Serbie, pour laisser la voie ouverte à une négociation future avec la Bulgarie." 19

Le 15 janvier 1916, Florian Badiou et ses quatorze autres camarades télégraphistes sont évacués sur Salonique, en Grèce, et cantonnés au camp de Zeitenlik.

\section{La guerre aux Dardanelles de Claudius Viricel}

Claudius Viricel (cl. 10), de Grammond (hameau de Combelagier) est un fils d'agriculteurs, fort intelligent il avait été premier du canton de Saint-Galmier au certificat d'études ${ }^{20}$ - qui rêvait de devenir instituteur, mais qui,

\footnotetext{
${ }_{16}^{16}$ L'ogive est la pointe en forme ogivale de l'obus, qui se retrouve au point d'impact, à moins qu'elle ne s'enterre

17 "Barboter", au sens de "voler", verbe familier très courant au début du XX $\mathrm{X}^{\mathrm{e}}$ siècle semble avoir presque disparu de l'usage

${ }^{18}$ Pierre Miquel, Les Poilus d'Orient, éditions Fayard, 1998, p. 143

${ }^{19}$ Pierre Miquel, op.cit, p. 149

${ }^{20}$ Cette place peut apparaître modeste, voire dérisoire aujourd'hui; elle ne l'était pas au tout début du XX ${ }^{\mathrm{e}}$ siècle (étant né en 1890, Claudius a dû passer son "certificat" en 1902) où très peu d'élèves poursuivait leurs études dans le secondaire (en cours supérieur), et où des élèves brillants mais pauvres des campagnes -alors très peuplées- et des villes achevaient leurs études à douze ans. Les instituteurs des cantons rivalisaient avec leurs meilleurs "poulains". Pour avoir obtenu la même récompense, beaucoup plus tard (en 1960, dans le canton de Saint-Jean Soleymieux), je puis attester la vénération que portait ma mère,
} 
unique garçon de la famille, avait dû reprendre la ferme familiale, comme me l'a confié son épouse Marie, de Grammond elle aussi, que j'ai vue en mars 1988 en maison de retraite, au Foyer des Roses à la Tour-en-Jarez. Elle m'a confié, pour le photocopier, le récit de guerre - écrit en novembre-décembre 1915 pour la partie relative à l'Orient- par son mari, mort en 1961, à qui elle vouait un véritable culte ("La guerre, il m'en parlait quasi tous les soirs. Ouh la la! C'était une valeur humaine! Et je suis fière de l'avoir épousé!"), me signalant qu'on lui avait plusieurs fois demandé d'être maire de Grammond, offre qu'il avait déclinée par modestie. Ce récit, dont la précision des dates et des lieux révèle qu'il s'appuie sur des carnets de route tenus régulièrement, révèle une qualité d'écriture peu commune, et une culture importante. Malheureusement, les bords du cahier de 48 pages sont abîmés, ce qui altère quelques mots, d'autres étant rendus pratiquement illisibles par la mauvaise qualité de la photocopie de photocopie.

A la mobilisation, Claudius est depuis 1912 au service militaire au $2^{\mathrm{e}}$ Régiment de Zouaves d'Oran. Ses "Souvenirs" (titre du récit) commencent le 14 mai 1915 à Oran, lors du départ de la $66^{\mathrm{e}}$ compagnie de zouaves pour l'Orient. C'est dire que, pour lui, ce qui a précédé compte peu. Mais l'imprégnation qu'il en a retiré de la culture arabe, et sans doute une lecture assidue des romans de Pierre Loti (on pense à Aziyadé) ont marqué son imagination et vont colorer son récit d'orientalisme. Rappelons que la bataille des Dardanelles a commencé le 25 avril; son régiment est donc envoyé en renfort.

\section{L'annonce du départ pour les Dardanelles}

Claudius Viricel va insister, dès la première page de son récit, sur les raisons qui l'ont poussé à se porter volontaire pour l'Orient, car tous ne partent pas.

"14 mai 1915 - 11 heures sonnaient; la $66^{e} C^{\text {nie }}$ rentrait dans son cantonnement. Partie de bon matin, elle venait d'effectuer une marche d'entraînement et les zouaves, bien qu'un peu fatigués, se dirigeaient gaîment chacun de leur côté déposer leur équipement et se préparaient aussitôt à prendre le repas que leur appétit, aiguisé par cette marche matinale, réclamait impérieusement. Très curieuse, cette $66^{e}$, composée de vieux approchant la quarantaine, formés à 20 ans et reconnus bons pour combattre le Bôche*, des adolescents de la classe 15 que leur faiblesse avait fait écarter jusqu'à cette date à chaque envoi au front ${ }^{21}$, formaient la minorité. Et comme pour servir de traits* d'union entre jeunes zouaves et les premiers cités, déjà vieux, des hommes de 25 à 30 ans, naguère auxiliaires et versés depuis peu au service armé. Néanmoins une grande camaraderie régnait entre ces personnes d'âge si différent et c'est en "chahutant" que prit fin le repas de ce matin-là. Tout à coup une rumeur circula parmi des groupes vite formés: on parlait de départ pour la Turquie. Le capitaine avait déjà, paraît-il, (choisi?) d'office quelques camarades les plus instruits pour faire partie de ce convoi qui devait comprendre primitivement 25 hommes, mais qui fut augmenté de 20 le soir-même. A cette nouvelle, des* rapides conciliabules se tinrent, et des résolutions furent prises. Plusieurs parmi les plus jeunes et les plus décidés se dirigèrent vers le bureau de Compie et demandèrent instamment à être inscrits comme volontaires sur la liste de départ. Ces derniers, métropolitains pour la plupart, Français de notre belle France et dans les veines desquels coulait, vif et généreux, le pur sang gaulois, ces derniers, dis-je, étaient mes amis les meilleurs, et pensant à ce qu'ils venaient de faire, je me mis à songer. Ainsi donc, ces vieux camarades, que j'avais connus au $6^{e} G$. d'Artre et sur lesquels je savais pouvoir compter, ils allaient partir. Et moi! Je resterait* donc seul avec les vieux et les malingres, parmi ces juifs (+ mot illisible + page écornée) ne pouvais voir? Non, ma décision fut vite prise, je suivrais* mes amis. J'allai donc au bureau $a^{*}$ mon tour et je demandai à partir, mais une déception m'attendait: la liste était complète, j'étais de trop! Que faire? Une chose simple, insister, insister jusqu'à ce que, fatigué de m'entendre, on m'accepte. Le "truc"réussit et le sergent-major, un brave homme au fond, ému de mon insistance, fit droit à ma demande. On raya un père de famille qui fut ravi de l'aubaine ${ }^{22}$, et j'allai me préparer après."

C'est donc en premier lieu la camaraderie qui pousse Claudius à se porter volontaire pour l'Orient, le désir de ne pas se couper de ses amis les plus anciens, mais aussi le patriotisme car il se sent "Français de notre belle France", et le désir de figurer au nombre des aptes et des courageux, donc, négativement, une certaine forme de mépris pour les "vieux et les malingres" et pour ces "juifs", terme qui pour lui doit englober tous les non-métropolitains.

Il raconte ensuite brièvement comment cette section de 45 hommes embarque en train pour le camp d'Eckmülh où elle reçoit la nouvelle tenue bleu horizon, ce qui confirme son arrivée au printemps 1915 ("Le lendemain nous fûmes habillés avec la nouvelle tenue de guerre et équipés de neuf"), puis Oran, d'où ce qui est devenu un bataillon va s'embarquer le lundi 17 mai. Le récit devient alors lyrique et patriotique, retrouvant l'esprit de conquête des Croisades, mais laisse place à la fin à la désillusion que permet le récit rétrospectif: "Ce lundi 17 donc, nous fûmes rassemblés vers midi, le bataillon, sous le Commandement* $d u$ Ct Droit, défila et prit la direction du port. Ah!

agricultrice pauvre des Monts du Forez et veuve de surcrôt, à son propre certificat ("j'étais la seule des six sœurs à l'avoir $\left.e u !^{\prime \prime}\right)$ et au mien, dont le tableau, fort illustré, était suspendu au mur de sa chambre...

${ }^{21}$ Les soldats de la classe 15 étant dans l'année de leurs vingt ans en 1915, il ne viendrait pas à l'idée maintenant de les qualifier d'"adolescents"! Ce terme employé par Claudius Viricel s'explique de deux façons: par rapport à lui, qui a 25 ans, ils paraissent très jeunes, et par rapport à leur "faiblesse": ce sont les moins aptes physiquement de la classe 15, les plus chétifs, les plus légers, qui ne sont pas partis avec leur classe mi-décembre 1914, mais six mois après.

${ }^{22}$ Cette remarque nous indique que tous n'étaient pas volontaires; sans doute ce "père de famille" faisait-il partie des présélectionnés d'office par le capitaine, parmi "les plus instruits" 


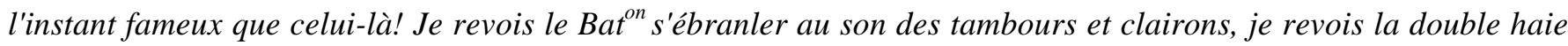
de curieux, de parents, d'amis, venus nous dire "au revoir" et nous saluer de leurs acclamations. Et nous! entousiasmés* , fiers de partir pour offrir nos services et notre sang à la mère Patrie, nous marchions crânement avec dans les yeux l'orgueil d'être Français. Il nous semblait (rajout au-dessus: "à ce moment-là") que nos ennemis les Turcs, que nous allions combattre, ne pouvaient rien contre nous, que nous allions les pourfendre, les exterminer!... Quelle déception......... si nous avions su ce qu'est la guerre!!...."

\section{La traversée vers l'Orient}

Cette expérience de la traversée va être longuement évoquée, bien qu'elle ne soit pas nouvelle pour Claudius, "Français de France" incorporé au Maroc; mais cette fois-ci la distance est beaucoup plus grande, la traversée périlleuse, et c'est vers la guerre que les soldats se dirigent, guerre qui fait rage depuis neuf mois et qu'ils n'ont pas encore connue: "Nous voilà donc arrivés au port, l'embarquement commence aussitôt sur le Paul Lecat", beau paquebot de la $C^{i e}$ des Messageries Maritimes sur lequel avaient déjà pris place 400 légionnaires. Nous nous installâmes pour le mieux et aux acclamations redoublées de la foule, après un dernier salut à la ville d'Oran, le vaisseau se mit en mouvement, sortit du port et prit le large!...... Ainsi donc je quittais Oran où j'avais vécu 31 mois de ma vie ${ }^{24}$ Je contemplais la vielle* caserne du Château-Neuf (rajout au-dessus de la ligne: "qui m'abrita lorsque j'étais jeune bleu") et mon regard s'attardait surtout sur le vieux donjon bâti par un seigneur espagnol vers 1750, qui avait abrité-sous les mûrs* duquel j'avais passé 1 an et demi étant planton ${ }^{25}$ au Parc d'Artillerie où j'avais si souvent pensé à mon petit pays de Grammond et à celles, toute ma vie, que j'y avaient laissées...26....Du haut de ce donjon, mon ami Tardy me faisait des signes d'adieu, je lui répondis, mais lentement le bateau s'éloignait: Oran, s'estompant dans la brume du soir, disparut à mes yeux. Le reverrai-je? Je lui dis adieu.

Le lendemain, le Paul Lecat arrive à "Alger-la-Blanche", que Claudius peut seulement admirer du pont car le régiment est consigné à bord; le bateau repart le soir pour arriver à Bizerte le surlendemain matin, où des renforts montent à bord: "De même qu'à Alger, un détachement du $4^{e}$ zouaves vint compléter le chargement du navire qui cette fois partit, s'éloigna de la côte mettant le cap sur l'Orient".

Ce dernier mot va déclencher sous la plume de Claudius Viricel un couplet lyrique qu'on aurait tort de trouver grandiloquent, et qui nous révèle sa source littéraire principale, à lui le paysan de Grammond qui a déjà beaucoup lu et qui continuera à la faire toute sa vie: "L'Orient! nom fabuleux, évocateur de visions délicieusement char (mantes) et enchanteresses. Pays tant chanté par Pierre Loti, nous allions pouvoir l'admirer à l'aise, contempler son soleil se couchant dans un flamboiement de pourpre et d'or. Et le soleil en ce jour du 22 mai éclairait des visions sanglantes de batailles, des Français versaient leur sang là-bas et mourraient* en jetant parmi les splendeurs de la nature de grands cris de détresse!..."

Si le couplet lyrique s'achève de façon à la fois dramatique et épique, c'est que le récit rétrospectif, fait en décembre 1915, bénéficie des connaissances ultérieures acquises sur la réalité militaire de l'offensive en cours aux Dardanelles et de la prise de conscience du "bourrage de crâne" opéré par les journaux. Le récit se poursuit ainsi: "Mal renseignés par la presse, nous croyions que le Corps Expéditionnaire franco-anglais avait déjà conquis beaucoup de terrain et nous étions persuadés qu'avec l'appoint nouveau que nous formions, nous allions pouvoir aller de l'avant, prendre Gallipolli et suivre la route de Constantinople". La désillusion qui les guette, à l'issue d'une traversée sans encombre, n'est pas que militaire, elle est aussi, oserions-nous dire, si le terme n'était pas incongru et frivole dans ce contexte de guerre, "touristique", mettant à mal la vision mythique de l'Orient issue des romans de Pierre Loti et de ses épigones moins connus: "Aussi quelle* ne fut pas notre stupéfaction quand le 24 au soir nous arrivâmes dans la baie de Moudros où nous fûmes débarqués le lendemain 25 mai. Que nous étions loin des contrées riches, merveilleuses, que nous comptions voir. L'île de Lemnos en effet est un pays pauvres*, peuplés* de pauvres gens naguère courbés sous le joug Turc* et maintenant rendus à la Grèce. Là il nous fallut installer un camp et créer un dépôt intermédiaire des régiments de zouaves."

A Moudros, le régiment ne demeure que dix jours, puis va installer un camp dans un village voisin, à une dizaine de kilomètres, Varos, toujours dans l'île de Lemnos. Là, Claudius reçoit ce qu'il appelle son "baptême du

\footnotetext{
${ }^{23}$ C'est aussi sur le Paul Lecat que traversera un autre de mes témoins, Antoine Pélissier, de Firminy (voir sa carte postale)

${ }^{24}$ Claudius Viricel, né en 1890, fait partie de la classe 1910 incorporée normalement en 1911, à 21 ans, la loi de trois ans n'ayant été votée qu'en 1913, s'appliquant à la classe 1913, incorporée en décembre 1913, deux mois après la classe 1912; il ne devrait donc n'effectuer que deux ans de service militaire, donc être rentré en France à la fin de 1913. Il faut supposer que, pour une raison que nous ignorons, il est parti au service militaire avec la classe 1911, incorporée en 1912, ce que confirme la durée de 31 mois en Algérie qu'il mentionne; comme nous sommes en mai 1915, cela indique un début de séjour en Algérie en novembre 1912.

${ }^{25}$ Un "planton" est un agent de liaison à la disposition d'un officier pour assurer la liaison avec ses collègues, ses inférieurs ou ses supérieurs, ainsi qu'avec les divers services du régiment. Il est généralement choisi parmi les soldats plus instruits, plus cultivés que les autres. Ce poste constitue un "filon" bien connu et recherché.

26 "Celles" qu'il a laissées à Grammond, ce sont sa mère et sa sœur (le père étant mort), et peut-être Marie Thizy, s'il la "fréquentait" à l'époque, comme on dit en Forez, qui deviendra sa femme en 1921
} 
feu", bien qu'il ne combatte pas, pas plus que ses camarades: "un Taube ${ }^{27}$ étant venu survoler notre camp jeta deux bombes qui causèrent une petite panique mais aucun mal. Je fus content de moi ce jour-là car j'avais gardé mon sang-froid". La mention de ce menu épisode de guerre, qui certes aurait pu être meurtrier, fait mesure à quel point Claudius est resté jusque là à l'abri de l'horreur de la guerre et des bombardements qui sévissent sur le front français.

\section{Sa campagne des Dardanelles dans l'été 1915}

Elle va commencer fin juin, soit deux mois après le début de l'offensive terrestre sur les Dardanelles. Son récit reprend : "Au lendemain de l'attaque fameuse du 21 juin, le Ct Droit reçut l'ordre d'envoyer un renfort aux Dardanelles. Je fis partie de ce renfort ainsi que tous mes amis et le 24 nous embarquions à Moudros à bord du petit vapeur L'Infatigable; six heures après nous étions à Seddul Bahr. Le détachement prit la route du camp de repos $d u 2^{e}$ de marche, nous y arrivions un quart d'heure après, vers minuit, par un beau clair de lune. A Varos nous avions peu à peu appris la vérité et nous savions qu'en débarquant à Seddul Bahr nous étions près des tranchées ennemies. Aussi en regardant avec curiosité les nombreuses fusées éclairantes lancées là-haut en face de la fameuse crête 216, nous ne pouvions nous défendre d'une forte émotion. L'adjudant Rocher, après nous avoir montré quelques tranchées nous invita $a^{*} y$ chercher un refuge pour le reste de la nuit, ce que nous fîmes avec empressement. Chacun s'installa le plus commodément possible et, la fatigue aidant, tout le monde s'endormit. Ce ne fut pas pour longtemps car les Turcs se mirent à nous bombarder tout à coup. Les obus tombaient un peu à notre gauche vers le camp anglais (nous pûmes nous en rendre compte le lendemain), mais sur le moment quel épouvantement nous causèrent ces détonations successives, auxquelles nous n'étions pas habitués. Heureusement une batterie de 75 cachée juste derrière nous se mit de la partie et son tir fit bientôt taire les 77 ennemis ${ }^{28}$. Le jour nous trouva remis de notre émotion, mais pas très bien rassurés encore. Pendant cette journée, nous fûmes versés à la $4^{e}$ Compagnie du $2^{e}$ de marche et répartis par sections et escouades ${ }^{29}$, après quoi on nous laisse en repos. Mais les Turcs décidément en voulaient à notre tranquillité, le bombardement recommença, notre artillerie riposta vigoureusement, mais n'empêcha pas les schrappnels ${ }^{30}$ bôches* d'éclater juste au-dessus de nos têtes nous causant de nouveau une belle peur, bien compréhensible en somme. Une de mes impressions, qu'il convient de fixer ici, est que je fus émerveillé de l'assurance des anciens de ma section, sous ce bombardement. Ils circulaient dans la campagne, le sourire sur les lèvres, sans souci des projectiles qui aurait pu les atteindre et il me semblait à ce moment que jamais je ne serais pareil à eux; je les enviai* beaucoup. Trois semaines après cette assurance m'était venue, comme quoi le proverbe est vrai qui dit que tout n'est qu'affaire d'habitude"

On voit que pour la deuxième fois dans son récit, Claudius, sans honte, bien loin de la forfanterie de matamore de certains, mentionne sa peur de "bleu" de la guerre - bien qu'étant enrégimenté depuis 31 mois - sous les bombardements; et modestement, il n'attribue pas son assurance acquise au bout de trois semaines à son courage, mais à la force de l'habitude...

Après cette période de repos tout relatif, Claudius monte vraiment au front, un front qui a reproduit en première ligne les tranchées du front français. Son récit se poursuit, l'amenant à voir pour la première fois la mort et à risquer sa vie, récit émaillé de drames, mais aussi d'incidents dont un, objectivement minime pourtant, lui demeure en mémoire comme une blessure mentale, et lui laisse un fort ressentiment à l'égard de son commandant : "Cinq ou six jours se passèrent ainsi, fertiles en émotions, mais sans évènements importants, quand le soir du sixième jour, des bruits circulèrent: nous devions paraît il aller faire la relève pendant la nuit; mon peloton devait occuper un élément de tranchée nouvellement conquis. Ce point était très avancé et assez dangereux, disaient des zouaves paraissant bien informés. Quelques instants après en effet, nous reçûmes l'ordre de nous préparer et d'aller dormir un instant. Le réveil eut lieu à minuit; un quart d'heure après la compagnie se mit en marche. En file indienne à travers des sentiers nous gagnâmes la grande route des pylônes et remontant la pente du côté de la ferme Zimmermann nous fûmes bientôt à l'entrée du boyau montant, surnommé depuis "Avenue de Constantinople"! ... Quelle dérision! --

La petite troupe s'engagea donc dans ce boyau où, après avoir fait quelques pas, je vis le premier cadavre de soldat français de ma campagne. Un petit incident, qui m'émeut fortement, mérite d'être raconté. Continuant notre route, nous atteignîmes le poste du Commandant Rivat, chef de mon bataillon; en tête de la $12^{e}$ escouade, dont je faisait partie, marchait le caporal, un alsacien* âgé de 38 ans, engagé au début de la guerre. Malencontreusement, il accrocha avec son fusil un des nombreux fils téléphoniques aboutissant au poste cité plus haut; ce que voyant le Commandant qui se trouvait là, avec son petit bâton qui ne le quittait jamais, asséna deux coups de bâton à mon

\footnotetext{
${ }^{27}$ Un Taube ("pigeon" en allemand) est le nom donné à un avion très léger d'observation, pouvant aussi bombarder d'une façon "artisanale"

${ }^{28}$ Il faut évidemment comprendre: "fit taire les canons de $77 \mathrm{~mm}$ des ennemis"

${ }^{29}$ Rappelons que l'escouade est l'unité de base de l'infanterie, de douze hommes environ, commandés par un caporal, et qu'il faut quatre escouades pour former une section, commandée au début de la guerre par un sous-lieutenant ou un lieutenant (l'unité intermédiaire, la demi-section, composée de deux escouades étant commandée par un sergent, parfois par un adjudant).

${ }^{30}$ Les shrapnels ou shrapnells (du nom de leur inventeur le général anglais Shrapnell, mort en 1842) sont des obus à dispersion contenant des centaines de billes de plomb ou d'éclats métalliques aux arêtes vives projetés en large gerbe au moment de l'explosion en l'air des obus fusants , afin d'accroître leur capacité meurtrière, et infliger de plus graves blessures...
} 
caporal. Ce dernier, se redressant sous l'outrage, voulut protester, mais un troisième coup vint lui fermer la bouche!... Et la troupe reprit sa marche. - Je fus défavorablement impressionné par ce spectacle honteux, et mon enthousiasme du début fut singulièrement refroidi. Cette mauvaise impression dura longtemps; à l'heure actuelle elle n'est pas encore complètement dissipée! Quelques instants après cet incident fâcheux, nous arrivâmes au but qui nous était assigné. C'était une tranchée conquise, comme je l'ai dit plus haut, quelques jours auparavant et non encore organisée. Cet ouvrage avait subit* les terribles effets $d u$ 75. Des Turcs, enterrés au fond de la tranchée par l'éclatement des projectiles, prouvaient l'efficacité et la précision de notre tir et de chaque côté, le long des parapets, les nombreux cadavres de soldats ottomans répandaient une odeur épouvantable.

Notre adjudant chef de section nous donna des instructions pour mettre l'ouvrage en état de défense; nous ne possédions qu'une partie de cette tranchée, l'autre étant encore au pouvoir de l'ennemi. Pour séparer les antagonistes, un barrage de sacs avait été établi, et pour relier notre position a* celles de droite et de gauche, il fallut creuser des boyaux. Je fus désigné pour cela avec un de mes camarades; le travail commencé dans de bonnes conditions alla très bien jusqu'à l'arrivée du Com dant qui, trouvant que nous n'avancions pas assez, a* son gré, nous donna l'ordre de jalonner la ligne du boyau avec des sacs de terre qu'il fallait rouler en rampant pour les placer et en faire un petit mur d'environ 25 centimètres de hauteur qui seul, au fur et a* mesure de la construction, nous abritait contre les balles des Turcs, postés a* environ 30 mètres de là, et qui ne cessaient de tirer sur nous. Un de mes camarades, paraissant très jeune, fut transporté devant moi: gravement blessé il appelait sa mère, et c'était bien triste.

Le reste de la journée se passa sans autre événement, mais le soir à la nuit tombante, l'ennemi tenta de nous attaquer, une fusillade nourrie le reçut et l'obligea à rentrer dans ses trous. A part quelques uns, les nouveaux arrivés avaient supporté vaillamment les multiples émotions de cette première journée; aussi le Colonel, après nous avoir fait relever de ce poste périlleux où nous avions passé 24 heures, nous félicita vivement. - Ce premier séjour, dans les tranchées de première et de deuxième ligne, dura quatre jours, puis nous revînmes passer 5 jours au camp de repos. Au commencement de Juillet, nouveau séjour de 5 jours aux tranchées, mais sans événements saillants; le troisième du 9 au 15 du même mois, fut très mouvementé. Une attaque générale du Corps Expéditionnaire ayant été décidée, ce fut, dans le secteur attribué à mon régiment, le $2^{e}$ Bataillon ${ }^{31}$ qui le premier donna l'assaut. Des charges successives, bien conduites, nous rendirent maîtres de nouvelles tranchées, le $3^{e}$ Bat ${ }^{o n}$ donna à son tour et le 14 juillet, ce fut le $1^{\text {er }}$ Bat ${ }^{o n}$, le mien, qui fut appelé au terrible honneur de conquérir quelques mètres de terrain à la France. Ma compagnie fut appelée la dernière, et en allant prendre position pour la charge, je pus constater que les ordres suivis aussitôt de contre-ordres finissaient par créer un grand désorde*! un affolement général s'ensuivit et, marchant sous une grêle de balles, au milieu des blessés et des morts dont les boyaux étaient encombrés, nous eûmes grand peine a* trouver notre emplacement. - En ce moment, un assaut se livrait par une Cie du $176^{e}$ de ligne, parallèlement à celui que nous devions faire. Il échoua complètement et ce fut la cause que nous reçûmes l'ordre de ne pas charger ce jour-là. Heureusement, car si l'assaut avait été donné contre la tranchée ennemie défendue par de nombreuses mitrailleuses, très peu d'entre nous en auraient réchappé."

Claudius note un autre incident qui confirme que sur le front d'Orient aussi, la distribution d'alcool avant l'attaque est pratiquée (sans être la règle: nous verrons plus tard les témoignages divergents sur ce point, à propos $\mathrm{du}$ front français) et peut être détournée de son objectif: "Plusieurs fois par la suite nous fûmes de même prêts à partir à la baïonnette, chaque fois un événement vint, au denier moment, nous en empêcher. Je me souviens particulièrement d'un jour où, en prévision d'une attaque probable, l'adjudant, chef de ma section, et ses deux sergents s'ennivrèrent*, pour se donner du courage, avec l'eau-de-vie qu'ils devaient nous distribuer!... Tout commentaire serait, je crois, superflu."

Un changement de secteur va amener Claudius à voir les Anglais du Corps Expéditionnaire en action et à les juger, alors qu'il n'en a jusque là jamais fait mention dans son récit. Le jugement est mitigé, mais plus admiratif que critique, et l'amène à stigmatiser la stratégie du "grignotage" du terrain, coûteuse en vies humaines. "Le 7 août, mon régiment changea de secteur; il alla remplacer des Anglais partis de la* pour aller opérer un débarquement dans la baie de Suvla. ${ }^{32}$. Notre nouvelle position, formant saillant dans les lignes turques, était par cela même assez précaire. Pour la consolider, les Anglais qui se trouvaient à notre gauche, préparèrent une offensive; pendant une douzaine d'heures, l'artillerie anglaise, renforcée de la majeure partie des canons français et ayant en plus l'appui de deux croiseurs, fit subir, aux ouvrages défensifs ennemis, un feu terrible. La cannonade* était tellement intense qu'elle semblait un roulement de tonnerre sans fin. A un moment donné le bombardement s'arrêta,

\footnotetext{
${ }^{31}$ Un bataillon constitue un tiers d'un régiment d'infanterie, comprenant environ un bon millier d'hommes, avec à sa tête un commandant (ici le commandant Rivat); chaque bataillon comporte, en principe, quatre compagnies, placées chacune sous les ordres d'un capitaine.

${ }^{32}$ Le cap Suvla, avec sa baie, se trouve de l'autre côté de la presqu'île de Gallipoli, qui se déploie entre le détroit des Dardanelles et le Golfe de Saros, appartenant à la mer Egée. Cette tentative anglaise constitue donc un moyen de forcer le passage du corps expéditionnaire par la voie terrestre, loin des forts turcs défendant, avec leurs canons, la voie maritime des Dardanelles (cf cartes figurant dans L'Illustration du 31 juillet 1915, pp. 120-121). L'opération de début août tentée par les Anglais correspond à celle qu'a indiquée Jean-Jacques Becker: "Au mois d'août, les Anglais tentèrent un nouveau débarquement un peu plus au nord de la presqu'île de Gallipoli qui fut également bloqué par Mustapha Kemal"
} 
les Anglais, s'élançant de leurs tranchées, en une charge magnifique, prirent d'un seul bond trois tranchées. Le soldat anglais ne sait pas toujours profiter de ses victoires et se fortifier dans le terrain conquis; c'est ainsi que les Turcs les ayant contre-attaqués avec de grandes forces, ils évacuèrent deux tranchées. Le gain réalisé ce jour ne valait certainement pas les sacrifices consentis. Il en est souvent ainsi à la guerre, chez eux et...aussi chez nous"

Claudius dresse ensuite un bilan de sa campagne de l'été 1915 sur la presqu'île de Gallipoli, délimitant du côté ouest le détroit des Dardanelles, en nous donnant un renseignement précieux sur l'alternance entre le séjour en tranchées et les périodes de repos, puis en critiquant, comme tous les Poilus, les exercices militaires fastidieux, jugés inutiles par le soldat de base qu'il est, qui dénaturent complètement ce temps dit "de repos", surtout quand ils sont effectués sur des terrains exposés aux obus de l'ennemi: "Mes trois mois de séjour aux Dardanelles se sont passés ainsi; 4, 6, puis quelques fois 8 jours aux tranchées, suivis d'un temps égal à passer au camp de repos. Les premiers temps, une fois les ("nombreuses" rajouté au-dessus de la ligne) corvées faites, nous pouvions jouir vraiment d'un peu de repos, mais petit à petit, le répit qui nous était laissé devint tout à fait illusoire. En effet, sur les ordres du Commandant, on nous mena faire de l'exercice dans un grand camp plat complètement dénudé, situé juste en face de la principale position ennemie; lesTurcs se chargèrent souvent de nous faire rentrer vivement dans nos trous avec les obus dont ils nous gratifiaient pendant ces séances, mais cela n'empêcha jamais nos chefs de nous faire recommencer le lendemain, et si nous n'avons pas eu à déplorer des pertes pendant ces inutiles exercices, ce n'est pas la faute de ceux qui nous commandaient.

Quand nous n'étions pas à l'exercice, de nombreux travaux nous attendaient: routes à construire, abris à creuser pour les officiers, etc. etc.. Ajoutez à cela des obus quotidiennement envoyés par la Côte d'Asie ${ }^{33}$, et vous comprendrez que ce camp n'était pas précisément un lieu de repos."

Finalement, le mode de vie du front français a été transposé à l'autre bout de la Méditerranée, ou presque. On est aux antipodes du rêve d'Orient mythique, dérivé de Pierre Loti, qui a inspiré à Claudius, au début de ses souvenirs, son beau couplet lyrique sur l'Orient grandiose et ses merveilles ! Mais ce rêve, il le revivra devant Salonique vue de la mer!

Le 19 septembre, le bataillon de Claudius est embarqué sur un navire au nom rassurant, mais témoignant d'humour noir involontaire dans ces parages, le "Bon Voyage", et débarqué sur l'île de Ténédos, à quelque trente kilomètres de la pointe de la presqu'île de Gallipoli, où il va camper à proximité d'un camp d'aviation francoanglais. Repos, travaux divers et exercices militaires exécrés se succèdent jusqu'à fin septembre. Des rumeurs enflent et des supputations surgissent à l'annonce que le bataillon va partir: "Les uns, bien renseignés, nous annoncèrent que nous devions partir à Salonique, d'autres non moins affirmatifs tenaient pour la France, tous préférant cette dernière éventualité, se réjouissant de pouvoir enfin revoir notre beau pays". On voit que le moral des troupes a eu sa ration d'exotisme, et que la nostalgie de la patrie l'emporte (surtout pour ceux qui, comme Claudius, ont déjà derrière eux un long séjour en Algérie sans retour en France) même si ce retour en France, personne n'est dupe, signifie l'envoi sur le front français après une permission relativement longue chez soi. Hélas! C'est la rumeur du départ à Salonique qui reçoit la confirmation des faits: "Le soir du $1^{\text {er }}$ Octobre, le régiment s'embarqua de nouveau sur le "Britannia" ${ }^{34}$, le lendemain matin nous étions à Moudros, où vinrent nous rejoindre le $1^{e r}$ régiment de marche, le $175^{e}$ (où se trouvait Jean-Baptiste Meunier jusqu'à sa blessure du 27 avril) et le $176^{e}$ Régt d'infanterie. Après y avoir passé deux jours, un nouvel embarquement eut lieu sur le "Britannia" qui, traversant la baie de Lemnos, passa au milieu des superbes cuirassés et croiseurs de la flotte française et gagna la haute mer. 16 heures après nous étions au terme du voyage maritime, en vue de Salonique."

\section{Visions de Salonique: grandeur et misères d'une ville orientale}

Et là le mirage de l'Orient étrange et fastueux, exprimé au départ de l'Algérie, mais plus qu'estompé par l'été meurtrier passé aux Dardanelles, se revivifie sous la plume alerte de Claudius, paysan cultivé au sens esthétique aiguisé, qui, par l'emploi du "nous", fait partager son admiration à tous ses camarades, point de vue subjectif généralisant dont rien n'atteste la réalité, ni la fausseté d'ailleurs: "Nos yeux avides de beauté s'extasiaient au spectacle de la ville, s'éveillant sous les rayons du soleil d'Orient; un léger nuage recouvrant la ville se dissipait lentement, tel un rideau, cachant une merveille aux regards curieux de la foule, (qui) serait soulevé pour quelques privilégiés. Nous admirions la Ville "aux cents Minarets" et le panorama de cette ville orientale nous étonnait tout en nous ravissant". La métaphore théâtrale du lever de rideau et la métaphore religieuse du dévoilement, de l'apparition progressive aux rares Elus se conjuguent ici, dans l'évocation de cette Ville, mythique pour Claudius, qui emprunte à Rome sa majuscule!

Claudius va vivre la même désillusion que Camille Richier, à quelques jours de distance, en ce début octobre 1915. Salonique, de près, parcourue à pied, révèle un envers du décor qui détruit partiellement ou totalement la

\footnotetext{
${ }^{33}$ Ces obus envoyés "de la Cote d'Asie" sont donc des obus de canons à longue portée, tirés depuis le territoire turc d'Asie (où se trouvent de nombreux forts) et passant au-dessus du couloir maritime que constitue le détroit des Dardanelles

${ }^{34}$ Comme son nom l'indique, le "Britannia" est évidemment un navire anglais: on voit que le corps expéditionnaire utilise parfois des navires de l'allié pour le transport des troupes.
} 
vison magnifique et magnifiée qu'elle offre de loin, aux passagers des navires: "Je pus aussi visiter une partie de la ville de Salonique et cette visite me causa une déception. Le beau panorama de la ville vue de loin, était menteur. Vue de près, ce n'étaient que rues tortueuses, mal pavées et sales! ...De misérables boutiques les bordaient, et les habitants, pour la plupart minables, mal vêtus, n'étaient guère sympathiques. Quelques rares quartiers, seuls, avaient un ar plus modernes*. La principale beauté de la ville est dans ses minarets, frêles et blancs, et dans ses nombreux arbres donne une note gaie." On voit que Claudius, de naturel optimiste, n'approfondit pas longuement le mensonge de la ville, et l'aspect déguenillé de ses habitants, et préfère revenir à sa vision positive.

\section{Voir Salonique et partir pour ne pas mourir}

Les régiments débarqués s'installent dans un camp sommaire, à proximité de Salonique, que Claudius ne nomme pas, mais qui doit être celui de Zeitenlik. Mais notre témoin n'y restera pas longtemps, touché par l'épuisement et la maladie: "Au camp, l'exercice reprit, plus pénible que jamais, si bien qu'affaibli, malade, par la mauvaise nourriture, le climat et les fatigues imposées, après dix jours passés au camp, je fus envoyé à l'hôpital.

Des 45 zouaves de la $6^{e}$ Cie, deux seulement restaient au Bataillon. Quelques-uns avaient été tués, hélas! d'autres blessés et le reste avait été évacué, malade". Ce bilan des "pertes", selon la terminologie militaire, qui englobe tués, blessés évacués, disparus et prisonniers (et éventuellement exécutés et déserteurs) atteint donc, pour la section de 45 zouaves, $43 / 45^{\mathrm{e}}$ soit $95,5 \%$ ! Mais la proportion des tués parmi les "pertes" est très inférieure, puisque Claudius ne parle que de "quelques-uns", ce qui peut être interprété sans doute entre cinq et huit, peut-être dix (mais il dirait "le quart" dans ce cas): une approximation raisonnable, autour de sept, ferait une fraction de $7 / 45^{\mathrm{e}}$, soit $15,5 \%$.

On devine Claudius pressé d'achever le récit de sa "Campagne d'Orient" qui se réduit pour lui à l'opération des Dardanelles, de fin juin à début octobre 1915, puisqu'il ne participera pas à celle de Serbie, qu'il mentionne cependant pour inscrire son destin dans l'histoire générale, celle aussi de ses camarades restés en Orient: "La Campagne des Dardanelles était terminée, celle de Serbie, pleine d'aléas, allait commencer."

De l'hôpital des Lazaristes, je fus évacué sur le navire "Ceylan" qui me ramena en France à Toulon. Ah! le beau jour que celui-là! Revoir son pays après 28 mois d'absence ${ }^{35}$ est un bonheur que tout le monde ne peut apprécier et comprendre, mais l'arrivée au hameau natal ${ }^{36}$, dans la vieille maison où vivent, courageuses et dignes, la chère maman et la sæur affectionnée, c'est une chose qui fait pleurer de joie."

Claudius, le paysan littéraire, est, on le voit, un grand sentimental. Ces dernières lignes nous apprennent que son père est mort, et que sa mère et sa sœur ont dû assumer le travail de la ferme depuis le départ du fils en Algérie, à la fin de 1912. Elles ne sont pas au bout de leurs peines, car Claudius, après presque deux mois de permission de convalescence, (la fameuse "convalo" à laquelle aspirent les Poilus) repartira pour le front français et ne sera démobilisé que le 23 mars 1919.

Il repartira au front à la mi-décembre 1915, comme l'indique la mention qu'il fait figurer au bas de ce premier récit de sa guerre: "Fin - Combelagier, le 11 décembre 1915" avec sa signature "C.Viricel", et le dernier paragraphe, admirable, de ce récit, exprime son mélange de pacifisme et de patriotisme, contradiction devenue courante chez les soldats à ce stade de la guerre: "Et maintenant, sur le point de repartir, je maudis davantage la guerre, mais le peuple français, bien que ne l'ayant pas voulue, doit la supporter courageusement. Il ne faut pas laisser le Bôche* barbare violer la France, salir le pays. Pour cela les soldats Français* feront le nécessaire, et s'il me faut marcher vers un sombre horizon, j'entrevois néanmoins de bien radieux espoirs."

Ce "sombre horizon" ne sera pas, pour Claudius, celui de la mort, mais, toujours dans les rangs des zouaves, la Somme en 1916, le Chemin des Dames en 1917, la Picardie au printemps 1918 pour s'opposer à la grande offensive allemande, et l'Aisne, vers Berry-au-Bac, dans les deux derniers mois de guerre. Passant entre les balles et les éclats, d'obus, échappant aux carnages que subit son régiment, il n'aura, comme motif d'hospitalisation, en juillet 1918, qu'un abcès au cou...

Il se mariera le 4 septembre 1921 avec sa voisine, du hameau du Chambon, Marie Thizy. Ils n'auront qu'une petite fille, morte à l'accouchement.

\section{Les Dardanelles: un bilan désastreux}

Faisant le bilan de l'opération des Dardanelles pour toute l'année 1915, l'historien Jean-Jacques Becker constate amèrement: "La chaleur, le manque d'eau, la prolifération incroyable des mouches et des rats, la dysenterie avaient rendu horriblement dure la vie des soldats entassés à l'extrémité de la presqu'île de Gallipoli. 180000 soldats, dont 30000 Français y étaient morts... pratiquement pour rien. De leur côté, les Turcs avaient eu

\footnotetext{
${ }^{35}$ Cette indication nous permet de savoir que Claudius a eu une permission pour rentrer en France (ce qu'il n'avait pas mentionné dans son récit) quand il était zouave en Algérie: ayant déjà passé trente et un mois en Algérie au moment du départ pour l'Orient, et ayant séjourné quatre mois et demi en Orient (de fin mai à mi-octobre, en comptant le temps de l'hospitalisation), il a eu cette permission vers juin 1913, en profitant sans doute pour commencer la fenaison dans la ferme familiale.

${ }^{36}$ Ce ha meau est celui de Combelagier, appartenant à la commune de Grammond, non loin de Saint-Héand, dans les Monts du Lyonnais, mais du côté forézien (département de la Loire)
} 
66000 tués $^{\prime \prime 37}$. C'est un chiffre à peu près comparable que fournit Jean-Baptiste Duroselle pour les Français, mais nettement inférieur pour l'ensemble des morts franco-anglais (sachant qu'au sein des troupes anglaises, il y avait aussi des Australiens et des Néo-Zélandais): "En fait c'est l'échec de Gallipoli qui va hâter la décision. En août 1915, il est patent. Les Britanniques ont perdu 117000 hommes, les Français 27000 sur 79000 ", ce qui fait un total de 144000 morts au lieu de 180000 chez Becker; mais il est vrai que Duroselle arrête le décompte en août, après l'arrêt de l'offensive principale.

Pour une fois, par rapport à Becker, le bilan du côté allié est minoré chez un troisième historien Pierre Miquel, qui écrit: "L'expédition des Dardanelles, à elle seule, devait conduire à la mort ou a l'élimination par blessure 145000 Anglais et Français dans le "chaudron du diable",38. Mais il fournit un bilan autrement plus élevé, plus avant dans son ouvrage, où il paraît considérer l'ensemble des pertes pour toute l'année 1915, et non pour la seule offensive du printemps 1915: "L'affaire des Dardanelles s'était révélée pour les Anglais un véritable désastre. Cependant les Français avaient eu également leur part de malheur: sur un total de 125000 hommes morts par le feu et de 100000 par la maladie, ils avaient 40000 tués et autant de blessés ou de malades. ${ }^{139} \mathrm{La}$ phrase est pour le moins ambiguë comme le décompte des tués: 125000 "morts par le feu"ou 40000 "tués"? Où est la différence entre le genre de mort? Et le bilan total des morts, en incluant la maladie est-il de 225000 ou de 180 000 chez Becker, ou de 27000 chez Duroselle, alors qu'en août l'opération principale des Dardanelles, qui a échoué, est finie? Miquel inclurait-il, sans le dire, sous la dénomination "affaire des Dardanelles" les chiffres des pertes françaises dans l'opération de Serbie (pourtant très différente des Dardanelles, bien qu'y étant liée stratégiquement) de novembre-décembre 1915, que nous allons évoquer? Sûrement pas, car il fournit le chiffre relativement peu élevé (un peu plus de 6400) de ces pertes encore plus loin dans son ouvrage: "Le corps expéditionnaire réussit pourtant sa retraite en file indienne sur les sentiers escarpés aux prix d'efforts démesurés qui exigent des hommes des marches épuisantes: elle ne laisse sur le terrain que 1800 hommes pour 50000 combattants" auquel il faut rajouter les "4822 des leurs" perdus "en près de deux mois de guerre acharnée" "du 20 octobre au 12 décembre" ${ }^{\prime 40}$, ce qui aboutit à 6422 morts. Et en dehors de cette précision surprenante, au mort près, les chiffres ronds qui précèdent, arrondis à la dizaine de milliers, ne laissent pas d'inquiéter! Devant cette imprécision, et la discordance énorme entre les bilans fournis par trois historiens de renom, force est de constater que la mort des soldats d'Orient semble ne pas avoir mérité une comptabilité fiable... On songe à Voltaire ironisant cruellement, pour mieux combattre la guerre, dans le chapitre III de Candide, sur la comptabilité approximative des chefs militaires, en reprenant le vocabulaire leibnizien du précepteur de Candide, l'optimiste à tout crin Pangloss: "ensuite la mousqueterie ôta du meilleur des mondes neuf à dix mille coquins qui en infectaient la surface [...] Le tout pouvait bien se monter à une trentaine de mille âmes"

\section{La campagne d'Orient après l'échec des Dardanelles: Salonique et le début de la guerre en Serbie La seconde campagne d'Orient de Jean-Baptiste Meunier débutant en novembre 15: Salonique et la Serbie}

Comme on l'a vu, après avoir participé au début de l'expédition terrestre des Dardanelles et avoir été blessé le premier jour, Jean-Baptiste Meunier est revenu pour convalescence dans son Forez natal à partir de début août 1915. Il repart de Bard le 30 septembre (pas le moindre commentaire sur son séjour de deux mois chez lui!), arrive à Marseille, est renvoyé au dépôt du $175^{\mathrm{e}}$ R.I. à Grenoble où il est "reconnu apte" à la visite médicale, y reste tout le mois d'octobre, revient à Marseille pour embarquer le 3 novembre sur le navire "Algérie" en partance pour Salonique où il débarque le 9 , après une traversée sans incident, ce qui nous indique que les sous-marins allemands n'étaient pas omniprésents, aucune de ses trois traversées n'ayant été perturbée, tout comme celles de Florent Badiou et de Claudius Viricel, à la différence de celle du départ en Orient de Camille Richier. Il n'a pas le temps de visiter la ville, et va tout de suite dans un camp qu'il ne nomme pas (mais qui doit être celui de Zeitenlik): "Nous allons dans un camp qui se trouve à 8 kilomètres de la ville". Il en part, avec deux cents de ses camarades du $175^{\mathrm{e}}$ R.I. le 21 novembre, n'ayant accompli que des corvées au camp: "Nous embarquons à la gare des Orientaux le 21 à une heure du matin, pour aller en Serbie où nous arrivons le 22 à 9 heures du matin, dans un village appelé "Stroumitza" $a^{\prime \prime 1}$. Village qui avait été bombardé quelques jours avant par les Bulgares. Nous montons nos tentes et passons la nuit là". La mission assignée à sa compagnie, la $8^{\mathrm{e}}$, est de garder la voie de chemin de fer. L'ennemi paraît d'abord être plus le climat que les Bulgares: "Là on n'est pas trop mal quoiqu'on souffre du froid qui est très froid ces jours-là. Nous couchons dans des cabanes faites en branches et recouvertes de terre. Nous y restons jusqu'au 9 décembre, jour où nous sommes relevés pour aller maintenir la retraite de Serbie qui était commencée depuis deux jours. On nous mène à 5 ou 6 kilomètres d'ou* nous étions".

\footnotetext{
${ }^{37}$ J.J. Becker, op.cit, p. 42

${ }^{38}$ Pierre Miquel, op.cit., p. 10

${ }^{39}$ Pierre Miquel, op.cit., pp. 151-152

${ }^{40}$ Pierre Miquel, op.cit., p. 181

41 "Stroumitza" est maintenant "Strumica" à $20 \mathrm{~km}$ au nord de la frontière grecque et à l'est du lac Doiran, en Macédoine serbe
} 
La première rencontre avec l'ennemi survient le surlendemain 11 décembre: "On ne s'est pas encore retranché que les Bulgares nous poursuivent. Nous restons toute la journée sous leur mitraille, puis nous nous replions à 5 heures du soir pour marcher toute la nuit. Nous allons jusqu'à "Gevguelli" où nous avons traversé le Vardar. A 10 heures du matin, 12 décembre, nous faisons une pose*, puis nous partons dans la direction de Salonique". Après une nouvelle escarmouche avec les Bulgares, les voici sur le territoire grec le lendemain 13 décembre. Ils arrivent le 17 à Salonique "où les fusilliers-marins ont commencé à creuser des tranchées pour fortifier Salonique. Nous sommes donc dans le camp retranché de Salonique". Jean-Baptiste devint ordonnance de son lieutenant le 20 décembre, ce qui est un poste de faveur que les soldats de base considèrent comme un bon "filon", selon le mot consacré des Poilus, affectation de faveur qu'il note en toute simplicité, sans forfanterie: "Quelques jours après la retraite, je passe ordonnance du lieutenant cdant (commandant) la C nie (Lieutenant Bonin)"; il le reste jusqu'au 20 janvier 1916, où le lieutenant est évacué pour dysenterie, une des plaies de la guerre d'Orient, avec le paludisme.

\section{L'itinéraire en Grèce et Serbie de Camille Richier à l'automne 1915}

Du nouveau corps expéditionnaire français envoyé en Orient à la fin de l'année 1915, Camille Richier (cl. 10) de Saint-Julien-Chapteuil (Haute-Loire) fera partie. Agriculteur dans la ferme familiale du hameau de La Chapuze, où il restera toute sa vie, jusqu'à sa mort en 1954, il a d'abord combattu sur le front français, dans les Vosges et en Alsace, au $19^{\mathrm{e}}$ R.d'Artillerie de montagne de Grenoble, jusqu'en septembre 1915 où une partie du régiment découvre qu'elle part pour l'Orient! Il évoque cette expérience dans un récit fort bien écrit rédigé en 1919 d'après les lettres numérotées envoyées à ses parents, et des carnets de route non retrouvés, ce qui assure un curieux, mais plaisant mélange entre des impressions au jour le jour et un recul rétrospectif. A la différence de beaucoup d'autres, il n'est pas volontaire, et se trouve, comme ses camarades de batterie, désemparé devant cette nouvelle, tenue secrète par les officiers: "Dans la matinée on est à Epinal. Jusque là on a encore douté, les officiers ont conservé le mutisme le plus profond, puis le train se met en marche: direction de Lyon! Alors, il n'y a plus de doute, nous allons en Orient! Un morne découragement nous écrase, c'est l'inconnu, mais on sent bien que nous pouvons avoir des désagréables surprises, et s'expatrier pour des pays $a^{*}$ moitié sauvages n'a jamais beaucoup d'intérêt; puis il faut traverser la mer, et les sous-marins boches font des dégats*; et aussi, ce qui nous tourmente le plus, c'est que la permission sur laquelle on comptait bientôt sera probablement flambée!!! »

Cette permission est d'autant plus attendue (et la chose paraît incroyable aujourd'hui, même pour ceux qui ont vécu le service militaire) que c'est la première depuis le début de la guerre pour les soldats, soit plus d'un an pour le régiment de Camille Richier, le principe des permissions n'ayant été voté que le 6 juillet 1915, permission de six jours pleins plus les délais de voyage, bénéficiant d'abord à ceux qui n'ont pas été évacués depuis le début de la guerre, devant s'étaler jusqu'à Noël 1915, la proportion de permissionnaires ne pouvant jamais excéder 5\% des unités en ligne et $10 \%$ des unités en repos! Ces considérations ne figurent pas dans le texte de Camille Richier, qui les ignore peut-être, mais dans le journal de Joseph Sorgues (cl. 15), professeur à Neuville-sur-Saône, et lecteur assidu de la presse.

Camille Richier, après avoir décrit son voyage en train jusqu'à Saint-Maurice de Beynost, près de Lyon, où les soldats "touchent" la nouvelle tenue ("Nous sommes habillés tout à neuf, de bleu horizon, la nouvelle tenue que nous voyons presque pour la première fois, c'est bien beau") ce qui indique qu'arrivée au printemps 15 , elle a mis plusieurs mois pour se généraliser, puis en train à nouveau jusqu'à Marseille, évoque leur embarquement, expérience nouvelle pour la plus grande partie de ses camarades, qui n'ont pour la plupart jamais vu la mer, mais pas pour lui qui a fait son régiment dans l'infanterie coloniale, au Maroc, de 1911 à 1913. Il s'émeut cependant de ce départ loin de la patrie et des siens: "Quand on arrive à Marseille, on débarque de suite, on se rend au port, et en moins de trois heures, matériel, animaux et hommes sont engouffrés dans le "Dumbéa" qui lève l'ancre vers minuit, le 7 octobre 1915. Au jour nous sommes au large de Toulon dont on voit les montagnes environnantes. Adieu, terre de France, nos cceurs sont bien gros en te quittant entassés sur le pont; nos yeux s'attachent à ces montagnes qui bientôt vont disparaître; notre esprit est vers ceux qui au foyer pleurent sur leur absent; nous avons beaucoup d'amertume au cœur, des imprécations sortent de notre bouche; Ah! puissions-nous te revoir bientôt!"

\section{Une traversée mouvementée}

Ensuite c'est la description de la traversée, faite avec beaucoup de précision et de talent, avec l'évocation des aléas qu'elle comporte: "Puis l'on vogue dans l'immensité de la mer, nous marchons a* assez bonne allure, nous sommes assez empilés dans le navire; comme d'habitude, on n'est pas bien nourris, ce qu'est que le commencement de notre calvaire. On sait qu'on va débarquer à Salonique, et on voit que la mer est infectée de sous-marins boches qui chaque jour torpillent un bon nombre de navires. On nous a distribué les ceintures de sauvetage avec ordre de ne plus les quitter, ni nuit ni jour; le navire est cerné de deux canons de marine de 47, les deux batteries de 65 ${ }^{42}$ sont mises en batterie de chaque côté du navire, et en permanence une cinquantaine d'hommes veillent et

\footnotetext{
${ }^{42}$ Le calibre 47 est un petit calibre pour une pièce de marine; le calibre de 67 est celui qui équipe l'artillerie de montagne (les deux batteries du régiment de Camille Richier), ainsi que le plus petit canon de 37,5, démontable en trois éléments, et portable grâce à des mulets (cf chapitre sur l'artillerie). Rappelons qu'une batterie comporte quatre canons.
} 
signalent aux vigies ce que l'on aperçoit; l'officier de quart du navire ne quitte pas son poste une seconde, les portes de sortie des entreponts sont soigneusement ouvertes ${ }^{43}$ et les compartiments étanches soigneusement fermés. A la nuit il est expressément défendu de faire aucune lumière; on fait deux fois l'exercice de sauvetage. Peut-on peindre tout ce qu'a d'angoissant notre situation, la gaîté est partie; je me rappelle que lorsque nous partions au Maroc, au début on avait un bon cafard, puis au bout d'un jour on ses* remit* à rire; ici on sent trop la terrible menace qui pèse sur nos têtes, et l'aspect de la mer où l'on se dit que nous plongerions peut-être d'un moment à l'autre n'a rien de rassurant.. Un après-midi le bruit court qu'il y a de nouveaux ordres, on ne parle rien moins que nous allons peut-être faire demi tour, ce qui nous ferait tant plaisir, puis on se dirige sur Malte. Le navire mouille en rade et nous restons immobiles toute la nuit. Ici commencent tous les pays orientaux à l'air brulée*par le soleil avec ces maisons blanches en terrasses, le sol gris, sans végétation, sans un arbre. Le port est vaste et a l'air très bien arrangé, mais on en* distingue pas les détails étant assez éloignés. Puis un matin nous voilà en marche et a* notre grande douleur on pique vers l'Orient. Nous voguons en pleine mer sans rien apercevoir, marchant hors de la route ordinaire afin de dépister les sous-marins. un soir circule un tuyau peu rassurant: trois sous-marins seraient signalés dans les parages, les machines ne donnent que très faiblement ${ }^{44}$, les vigies sont doublées, les artilleurs sont à côté de leurs pièces ${ }^{45}$, tout le monde couche sur le pont à proximité des canots. Le commandant et les officiers du navire se tiennent en permanence sur leur passerelle. La nuit était aussi noire que sinistre, la mer un brin agitée balançait un peu le navire; sur le pont où l'on ne pouvait circuler que très difficilement en raison de l'encombrement produit par les dormeurs à la belle étoile régnait le plus pesant silence. Et on dormit bien peu, de temps en temps la sans fil ${ }^{46}$ marchait, les machines furent complètement arrêtées un bon moment; on devait trouver un torpilleur ${ }^{47}$ qui ne vint pas; au matin on repartit $a^{*}$ petite allure, le torpilleur nous rejoint, on entre dans $l^{\prime}$ Archipel ${ }^{48}$, on suit des passes étroites, on dépasse un convoi de cargos grecs qui sont combles* de troupes. Enfin on signale Salonique au fond d'un golfe profond et quel soupir de soulagement s'exale de nos poitrines lorsqu'on a franchi le barrage de mines ${ }^{49}$ derrière lequel nous sommes en sécurité."

Cette hantise des sous-marins, un des deux marins parmi mes témoins me l'a décrite sobrement. Louis Soulier (cl. 14), né à Tarentaize, mécanicien auto à Saint-Etienne, puis garagiste après guerre jusqu'en 1969, s'est embarqué sur le navire-amiral "Le Provence" en octobre 1914, en direction de l'Orient, navire où il était tourneur à l'atelier de mécanique du bord. Toute traversée en Méditerranée était périlleuse, bien qu'il minimise le danger pour le navireamiral, très bien armé: "On tirait de loin: on tirait à 35 km, nous! On irait à 35 km droit, hein! Moi, je les ai vus partir les obus, comme ça, hein! Quand ils nous mettaient derrière, quand on tirait, on voyait bien partir les obus!"

E- Sur le trajet, est-ce que vous avez rencontré une escadre allemande? Vous n'avez pas été attaqués?

T- On a eu des avertissements de sous-marins. Mais alors, on était sur le qui-vive! Parce que si on nous avait touchés...pour nous couler, c'était assez difficile, mais pour nous faire du mal, ils nous auraient fait du mal! Parce que le bâtiment faisait $180 \mathrm{~m}$ de long et $28 \mathrm{~m}$ de large! Alors sur les côtés, il y avait des caissons, il y avait des coffres qui étaient faits pour recevoir la torpille: elle l'aurait fait éclater (le caisson), et puis nous on aurait fermé les à-cotés, on aurait pu continuer, mais...Oh! c'était bien organisé, vous savez!"

La description de Salonique en octobre 1915, vue de la mer puis de la terre

Camille Richier poursuit son récit par l'évocation du port grec de Salonique, but de la traversée: "Salonique nous apparaît toute blanche, et émergeant de nombreux minarets comme dans toute ville orientale; une partie qui paraît être plus moderne est bâtie le long du rivage; la vieille ville s'étage en ruelles qu'on devine tortueuses et étroites en amphithéâtre et une sorte de massive citadelle la couronne. Des remparts gris l'encerclent. Nous arrivons en rade dans l'après-midi; l'ancre est jetée; le port trop étroit pour la circonstance fourmille d'une vie intense; de nombreux bateaux anglais et français attendent leur tour de débarquer, des navires grecs apportent des cargaisons de troupes, car ils sont en pleine mobilisation et cependant ils ne veulent pas faire la guerre."

La description est interrompue alors par une brève analyse historique montrant que Camille Richier a dû se renseigner sur l'évolution des événements politiques et militaires. En avait-il conscience au moment où il débarquait, ou cette connaissance est-elle livresque, acquise plus tard par la lecture de journaux ou d'ouvrages historiques? Il est difficile de le dire, mais la plupart des combattants d'Orient, parmi mes témoins (surtout ceux

\footnotetext{
${ }^{43}$ Pour permettre une évacuation rapide du navire s'il était torpillé par un sous-marin ennemi...

${ }^{44}$ Pour réduire le bruit des moteurs, facilement repérables par les appareils d'écoute des sous-marins

${ }^{45}$ En terminologie militaire de l'époque, un canon n'est jamais appelé "canon" par un artilleur, mais toujours "pièce". Voir le titre du très beau témoignage de l'artilleur Paul Lintier, mort à 23 ans en mars 1916, Ma pièce, que Jean-Norton Cru, dans son analyse synthétique de 251 témoignages de guerre édités "Témoins" parue en 1929, n'hésite pas à placer très haut: "Paul Lintier est l'un des trois ou quatre meilleurs auteurs de livres de guerre et parmi ceux-là il est peut-être le premier par ses dons naturels d'écrivain" (p. 180)

46 "La sans fil" est la radio, pour les jeunes lecteurs; les autres auront reconnu la T.S.F. ("Téléphonie sans Fil")

${ }^{47}$ Un torpilleur français pour protéger le navire, et éventuellement tenter de couler le sous-marin allemand

${ }^{48}$ L'archipel que forment les nombreuses îles de la mer Egée, entre lesquelles il faut naviguer pour rejoindre Salonique

${ }^{49}$ Il s'agit évidemment de mines marines, protégeant l'accès du port de Salonique
} 
qui iront plus tard, notamment en 1917), ne possèdent pas ce degré de culture historique, qui est l'actualité de l'époque. Nous conservons cette parenthèse explicative pour en montrer la pertinence et les limites: "Lorsque la Bulgarie a déclaré la guerre $a^{*}$ la Serbie, alliée de la Grèce, Vénizélos, l'âme damnée $e^{50}$ des alliés, qui était alors ministre voulant tenir ses engagements, décrète la mobilisation de l'armée grecque, mais il est renversé du pouvoir; le nouveau gouvernement ne veut même pas nous laisser débarquer à Salonique qui est en territoire grec, mais où la Serbie a des droits. C'est $a^{*}$ ce moment que nous étions $a^{*}$ Malte indécis. Mais les alliés ${ }^{51}$ envoient des navires de guerre $a^{*}$ Salonique, un ultimatum est adressé $a^{*}$ la Grèce et comme toujours force est au petit de laisser faire le fort."

Camille Richier n'explique pas que la Grèce est soumise à un tiraillement entre le premier ministre Vénizélos, favorable aux Alliés, et le roi Constantin, d'origine allemande, beau-frère de Guillaume II et germanophile convaincu tout comme l'est l'Etat-major de l'armée grecque. L'un voudrait respecter le traité d'alliance qui lie depuis 1913 la Grèce à la Serbie, alliée des Alliés, dans l'hypothèse d'une attaque de la Bulgarie qui s'est produite en octobre, la capitale Belgrade ayant été prise le 9 octobre par les Austro-Allemands, l'autre voudrait dépecer la Serbie en cédant au besoin la Macédoine serbe aux Bulgares, mais en cherchant à la récupérer de préférence. Le corps expéditionnaire franco-anglais est donc souhaité par le premier, redouté par le second qui a pris l'initiative, le 21 septembre, de décréter la mobilisation générale sans l'accord du Parlement. Le jour de l'entrée officielle de la Bulgarie en guerre, le 5 octobre 1915, comme l'écrit Pierre Miquel dans Les Poilus d'Orient "Vénizélos est démissionné par son roi, qui affiche une politique de neutralité bienveillante à l'égard de l'Allemagne" ${ }^{\prime 52}$, qui est pour lui une neutralité de façade, tout comme avait été de façade la protestation officielle de Vénizélos, le 2 octobre, contre le débarquement à Salonique des troupes franco-anglaises engagées aux Dardanelles. Par ailleurs la Russie, participant à la Triple Alliance, est intervenue auprès de son protégé traditionnel, la Bulgarie: "Le ministre russe à Sofia, au nom des Alliés, exige du roi Ferdinand une rupture "ouverte" avec Berlin et Vienne, ainsi que le renvoi des officiers allemands ${ }^{\prime \prime 53}$

Camille Richier reprend ensuite sa description de Salonique, moins glorieuse de près que de loin, comme l'a constaté aussi Claudius Viricel: "Le 15 octobre nous débarquons, les rues avoisinant le port sont à peu près passables; on y voit quelques batiments* assez bien, mais voisinant avec de misérables boutiques indigènes. La chaussée quoique passablement défoncée est pavée; un tram circule sans trop se presser. Des lampes électriques sont posées de distance en distance. Mais à part les deux ou trois meilleures rues, le reste est un vaste cloaque de boue: les chaussées ne sont plus empierrées, il n'y a pas de fossés, et avec le mouvement de voitures, de cavaliers et piétons de ces jours, une boue infecte, épaisse par endroits d'au moins 25 centimètres, partout de dix, colle aux pieds et en nous éclaboussant sous le pas des animaux nous crotte jusque par dessus la tête. Les maisons pour la plupart sont un mélange d'européen et d'oriental qui ne serait peut-être pas sans goût; mais la saleté repoussante de la rue nous dégoûte de ses abords."

Toutefois, Camille Richier a la modestie de confesser: "Je connais fort peu Salonique ne l'ayant entrevue que ce jour-ci à notre débarquement et comme les grecs* sont en pleine mobilisation, tous les immeubles regorgent de monde, les magasins sont vides" et va même jusqu'à relativiser davantage son jugement d'Européen de pays développé, prompt à dauber sur la crasse orientale, ce que bien peu feront: "Comme il a plu depuis peu et avec le piétinement intensif de tout ce monde, forcément il y a surabondance de boue; aussi ai-je gardé un assez mauvais souvenir de cette ville et comme je ne l'ai plus revue, n'ai-je pu corriger les erreurs de ma première impression".

Il est moins mesuré et plus ethnocentrique dans sa vision de la population cosmopolite de la ville: "La population composée comme dans tous les pays orientaux d'un mélange bizarre d'individus de toutes nationnalités*: des grecs*, des serbes*, des bulgares* vêtus un peu à l'européenne, mais conservant quelque particularité distinctive, des européens* de tous pays, commerçants, industriels ou espions; des juifs* vêtus moitié civils* moitié de leur habit traditionnel. Des turcs* à la tête peu sympathique avec un accoutrement tenant de l'arabe. Tout ce monde nous regarde passer, presque indifférent tout en vaquant à ses travaux; mais on croit remarquer que notre présence ne les réjouit guère. Les journaux français qui sur ces intervalles annonçaient que nous étions couverts de fleurs étaient loin de la vérité." On voit dans cette dernière phrase l'effet du recul qu'a pris Camille par rapport à l'expérience vécue, en rédigeant en 1919, ou peut-être avant, car à partir du 14 décembre 1916, atteint d'un ictère, il sera rapatrié et ne repartira plus en Orient.

\section{Le camp de Zeitenlik en octobre 1915}

S'il n'a pas davantage eu le temps de voir Salonique, c'est qu'un camp à construire les attend: celui de Zeitenlik, qui regroupera les soldats du corps expéditionnaire franco-britannique après l'échec des Dardanelles, ainsi, plus

\footnotetext{
50 "L'âme damnée" : une expression aussi péjorative est surprenante de la part de Camille Richier, qualifiant un allié de la France!

51 "Les alliés" : on aura remarqué, pour la deuxième fois, que Camille Richier n'emploie pas la majuscule pour désigner les Alliés, ce que font tous les journaux; la minuscule ne paraît pas prendre ici la valeur péjorative qu'on retrouve dans "les boches", où la majuscule n'est pratiquement jamais employée par les Poilus dans leurs écrits de l'époque

${ }^{52}$ Pierre Miquel, op.cit. p. 160

${ }^{53}$ Pierre Miquel, op.cit., p. 160
} 
tard, que les vestiges de l'armée serbe défaite en novembre, sous le commandement du général Sarrail: "Après avoir traversé une partie de la ville, nous nous trouvons dans une campagne nue et aride où sont déjà montées de nombreuses tentes; on nous assigne un emplacement, c'est le futur camp de Zéteinlik* qui éclot; nous avons un moment à l'arrivée, un petit moment, quelques-uns demandent où l'on va cantonner; je ne suis pas surpris ni embarassé* lorsqu'on nous dit qu'il faut monter les tentes; nous avons les toiles, pas de piquets, mais on se débrouille et comme nous sommes un bon nombre de "marocains" ${ }^{154}$, le campement est vite debout. La terre paraît bien un peu dure, la tente basse, le soleil chaud, mais nos officiers qui n'ont pas d'autre logement n'ayant pas prévu l'affaire doivent y trouver plus mauvais que nous ». On sent dans ces derniers propos une secrète satisfaction de voir enfin des officiers partager le lot quotidien du soldat, car au front français, ils bénéficiaient, et même parfois des gradés de rang moindre, comme on l'a vu, d'abris, de cagnas, les soustrayant partiellement ou totalement aux rigueurs des intempéries...

Camille Richier évoque ensuite une incertitude générale qui reflète bien l'impréparation de cette poursuite de l'opération des Dardanelles par une campagne d'Orient qui vise à se porter au secours de la Serbie occupée, avec une armée d'Orient qui devait comporter 150000 soldats franco-anglais, dont 90000 Anglais, et qui ne comporte plus que 15000 Anglais, dont des divisions pas encore arrivées car faisant étape en Egypte: "Nous sommes là sans trop savoir ce que nous allons faire, sans même savoir pourquoi nous sommes venus ici, tant dans l'armée, on a l'habitude de manier l'homme comme une bête de somme qui doit aller où on la pousse. A chaque moment il arrive de nouvelles troupes qui campent à côté de nous; les anglais* arrivent aussi en masses et établissent leur campement $a^{*}$ quelque distance."

\section{Le départ pour la Serbie le 18 octobre 1915}

Camille ne décrit pas plus longuement l'édification du camp. Et pour cause: "Au bout de trois jours, on nous annonce que nous allons embarquer pour la Serbie, et un matin on va faire le tour à Salonique pour faire de l'effet moral. On patauge dans la boue qui est a* moitié sèche, collée a* ne pouvoir s'en arracher, et l'on embarque dans une gare dite la gare serbe, dans la banlieue de la ville. Puis on roule, la nuit vient, et au jour nous sommes dans une assez belle vallée parcourue par un fleuve assez large. Devant nous se trouvent plusieurs trains dont le premier débarque des troupes dans une petite gare assez semblable aux gares de chez nous, mais dont l'ensemble est cloturé* de hautes murailles et les voies pouvant se fermer aucune maison, a* quelque distance on voit un petit village, et sur la rive gauches* du fleuve: le Vardar, on voit un village assez gros, Pépélitch, composé de maisons basses et grises couvertes de grosses pierres plates; de chaumes ou de tuiles."

A l'opposé du jugement négatif porté sur la population cosmopolite et plutôt pouilleuse de Salonique, Camille Richier dresse un portrait pathétique et sympathique du peuple serbe, notre allié, favorablement prévenu qu'il est par la presse française, portrait construit et complet rassemblant évidemment des éléments observés sur une période assez longue: "Dans la gare règne une animation extraordinaire: les quais sont trop étroits pour la circonstance: un régiment français débarque tandis que des serbes* les remplacent sur le train. Les journaux nous ont tant raconté l'héroïsme et le martyre de ces malheureux, que d'avance ils nous sont sympathiques, mais en les voyant nous avons d'eux un sentiment de pitié. La plupart doivent avoir plus de 40 ans, quelques-uns peut-être 60, beaux hommes, grands, bien batis*, bruns, le visage un peu bronzé et très grave, ne riant jamais. Mais quel équipement sordide: ils portent une culotte en grosse laine tissée par leurs femmes, d'une couleur indécise tenant du noir et du gris; comme forme elle ressemble assez $a^{*}$ une culotte de femme; étroite $a^{*}$ la cheville très large aux hanches et serrée a*la ceinture avec une corde. La très grande partie n'ont pas de souliers, ils sont pieds nus ou ils portent une sorte de savate en peau desséchée dans laquelle ils se plie ${ }^{55}$ le pied et qui s'y attache avec un lacet. Les chemises sont inconnues, ils ont une espèce de gilet en cotonnade et pour tout uniforme ils ont une capote en gros drap kaki et un calot. Leurs armes sont assez rudimentaires, dans une compagnie on rencontre au moins 5 ou 6 sortes de fusils qui ont été achetés aux grandes nations ou qui proviennent de ceux qu'ils avaient pris aux turcs* en 1913. Comme artillerie, ils ont quelques pièces modernes, mais la plupart sont d'ancien modèle et la très grande partie sont* traînées* par des bæufs. J'ai entendu dire qu'ils sont très mal nourris, les services de l'intendance prenant dans le pays où ils se trouvent les denrées nécessaires. Cette malheureuse nation a souffert un martyre qu'on ne peut se figurer, et comme ils sont loin et qu'on les considère comme des moitié sauvages et que nos écrivains ont peu pénétré dans leur malheureux pays pour nous peindre leur détresse, on les ignore. Le mot mourrir* de faim est employé chez nous toujours au figuré, car en France personne ne meurt de faim, mais chez eux, les malheureuses femmes, des pauvres enfants morts de faim pendant cette guerre se chiffreront par milliers."

Tout en continuant ce portrait compassionnel et élogieux, Camille en vient à des considérations stratégiques et politiques bien au-dessus du niveau d'information et de réflexion du soldat de base: "En attendant notre tour de débarquer, nous regardions avec une curiosité mêlée de tristesse ces malheureux dont les pantalons percés, les pans de capotes en dentelles couvraient mal leurs membres robustes. Nous les relevions ici qui était un point stratégique paraît-il* mais non encore menacé, et ils allaient dans la haute Serbie où les affaires tournaient mal.

\footnotetext{
${ }^{54}$ Allusion à son service militaire au Maroc, dans l'infanterie coloniale

${ }^{55}$ En français local de toute la région (Forez, Lyonnais et Velay dans le cas de Camille Richier) "plier" est utilisé au sens d'"envelopper"; on entend encore parfois dans un magasin: "Cette bouteille, pliez moi la donc dans un plastique!"
} 
Les communiqués ${ }^{56}$ étaient assez avares de nouvelles, mais l'on savait que l'armée autrichienne avait passé le Danube, Belgrade était pris. L'invasion commençait; on parlait d'une armée Bulgare* qui allait entrer en campagne par le sud est. A ce moment là, n'ayant pas de cartes, on ne se figurait pas bien la situation, cependant on avait le pressentiment que nous étions dans une impasse grâve*. On disait que le corps franco anglais* se composait de 125000 hommes, mais quelle résistance allions nous pouvoir opposer contre les bulgares* et les autrichiens* qui en plus du nombre avaient la commodité d'être sur place? Le gouvernement à cette occasion avait commis une grosse faute: d'abord nos diplomates n'avaient pas été $a^{*}$ la hauteur de leur tâche, parce que la Bulgarie eut* été pour nous; ensuite si les serbes* avaient été avant leur déclaration de guerre soutenus par un contingent français, les bulgares* auraient hésité davantage, à ce moment il fallait au moins 600000 hommes, ou il n'en fallait point; on ne fit ni l'une ni l'autre, ce fut la faute!"

Camille reprend ensuite sa narration, (ce qui montre l'habileté de ce récit construit, mêlant description et réflexions faites a posteriori) le trajet en train de son régiment s'achevant: "Enfin nous débarquons et nous campons $a^{*}$ quelques centaines de mètres de la gare. Pauvre pays, dans quel état il se trouve; de tous côtés, les traces de la guerre de $1913{ }^{57}$ sont encore visibles: dans la gare, on voit la tombe d'un général serbe qui fut tué là. Une route carossable* passe là mais le pont qui lui fait traverser le Vardar un peu en amont est coupé et n'a pas été réparé. Les villages des alentours sont $a^{*}$ moitié brûlés, de vastes étendues de champs sont incultes, les vignes ne sont pas taillées, les habitants ont disparu, morts de faim ou tués. Dans la suite nous devions voir encore bien d'autres ravages." L'œil exercé du paysan observe les anomalies dans l'agriculture, complétant l'acuité de jugement de l'observateur intelligent.

Installation de la batterie à Krivolak (Macédoine serbe) le 20 octobre, puis sur le Kara Odjalik le 30 et première bataille

Camille ramène la narration au sort de son régiment: "Le lendemain nous allons mettre en batterie dans une sorte de carrière située sur une petite crête d'où l'on domine la gare et les environs; notre but est de tenir sous notre feu les bords du Vardar en cas d'attaque". En l'absence d'attaque Camille et ses camarades font du tourisme, poussant jusqu'à la ville serbe voisine de Negotin, plus occidentalisée, mais portant les séquelles de la guerre de 1913. Camille va jusqu'à regretter les conditions de nourriture du soldat français, en oubliant presque la dureté de la guerre en France, dans un récit rétrospectif chargé de toute l'amertume à venir: "Nous étions à nos débuts dans cet Orient que nous devions tant maudire; il me semble que c'est le 20 octobre que nous étions arrivés à Krivolak; nous étions assez tranquilles, mais la terre était dure, la tente basse; on avait de l'argent mais on ne trouvait rien $a^{*}$ acheter; l'ordinaire était mauvais et absolument insuffisant; on ne touche que le strict réglementaire, et on ne trouve aucun remboursable $a^{*}$ acheter. En quelques jours, nous sommes dans la famine; on se partage avec parcimonie le maigre plat de riz que nous dédaignions dans les Vosges, nous n'avions eu encore aucun courrier de France, mais on écrit chez soi d'envoyer des colis."

Le 30 octobre, ayant traversé le fleuve Vardar, que Camille estime à 300 ou 400 mètres de large, dans des conditions assez périlleuses, sur des barques, la batterie va s'installer au sommet d'une montagne nommée Kara ${ }^{58}$ Odjalik, et y retrouve les deux compagnies du régiment qui l'ont précédée. Ce même jour, pas encore installée, la batterie va recevoir son baptême du feu en Orient:

"J'ai dit que nos étions sur la crête lorsqu' à l'avant, là où pouvaient être a* peu près nos petits postes ${ }^{59}$, retentissent quelques coups de feu, on n'y prête d'abord pas beaucoup d'attention, puis la fusillade augmente d'intensité et bientôt c'est un crépitement ininterrompu. Puis l'artillerie s'en mêle, les obus arrivent; nous marchons maintenant au pas de course, les mitrailleuses tirent, les balles sifflent nombreuses autour de nous. On arrive, en un tour de main, les pièces sont en batterie ${ }^{60}$ et tirent aussitôt. Notre infanterie est échelonnée sur une sorte de crête qui nous sépare de l'ennemi; le lieutenant qui ne connaît rien en artillerie fait mettre ses quatre pièces dans la même ligne, mais ou nous sommes gênés par la crête, ou les servants ${ }^{61}$ sont sous les balles. Les mulets sont abrités dans un petit ravin, les pièces tirent sans discontinuer, l'infanterie tire; par-dessus nos têtes les balles ennemies sifflent comme un essaim, les obus éclatent sur la crête, les soldats tombent autour de nous. Les Bulgares tentent un premier assaut, puis un deuxième et quoique contenus quelques-uns restent embusqués derrière des

\footnotetext{
${ }^{56}$ Les communiqués militaires officiels diffusés par la presse (mais reçoit-on la presse française? C'est peu probable) donnant le compte-rendu des récentes opérations militaires sur tous les fronts

${ }^{57}$ A l'issue de la deuxième guerre des Balkans, opposant à la Bulgarie l'alliance Serbie - Montenegro- Roumanie et Turquie, par le traité de Bucarest du 10 août 1913, la Serbie récupère le Kosovo ainsi que le nord et le centre de la Macédoine.

${ }^{58}$ Ce terme "Kara" est issu de la racine pré-indo-européenne "karr", pierre. Il a donné dans nos dialectes du Massif Central "cher" en franco-provençal (le "Cher du Fau" à Chazelles-sur-Lavieu dans les Monts du Forez = le rocher du hêtre), "chier, chière ou chirat" (voire "chirac") en nord-occitan désignant un amoncellement naturel de rochers ou de pierres, ou un sommet pierreux.

${ }_{59}^{59}$ Les petits postes, sont, comme sur le front français, les postes avancés des sentinelles

${ }^{60}$ La mise en batterie des canons suppose diverses opérations, comme parfois l'aplanissement du terrain, la mise à proximité du stock d'obus, le réglage du frein de recul du canon, le pointage, etc.

${ }^{61}$ Les soldats qui "servent" chaque canon en faisant le pointage, en le chargeant en obus, en retirant la gargousse (douille) vide
} 
rochers d'où ils fusillent les nôtres. Nos fantassins ont des morts, des blessés, ils tiennent bon, mais les cartouches commencent à diminuer, des cavaliers sont dépêchés (pour) demander des renforts et des munitions; à un troisième assaut, une mitrailleuse est détruite, et la fusillade bat son plein lorsqu'on commande: "Amenez les mulets". Sur notre tête, c'est un essaim de balles, les éclats d'obus frappent le sol autour de nous; nos bêtes ne veulent pas avancer, leur instinct les poussant certainement. On peut dire ce qu'on voudra des animaux, mais je certifie que nos mulets comprenaient fort bien que là-haut ça allait mal, car il fallut les frapper pour les faire avancer. Quand nous arrivons les pièces ne peuvent plus tirer l'ennemi, étant trop près; le lieutenant Lambert revient de l'observatoire, la joue traversée par un éclat de balle; le sous off de ma pièce qui voulait gagner de la gloire et faire le brâve* en observant l'ennemi reçoit une balle au ventre"

Suivent diverses observations sur les chefs de pièce, dont cette opposition classique dans les récits de nos témoins entre l'officier courageux (bien qu'ayant été déjà jugé incompétent en matière d'artillerie) et l'officier "froussard", bien que compétent: "Nous devons cette justice au lieutenant Lambert qui, quoique blessé, nous donne l'exemple du calme et du sang-froid, ce n'est pas sa faute s'il n'est pas stratégiste. Le lieutenant Arminot (nat?) qui se trouvait là en revanche ne fit pas honneur à son grade, et si ses qualités personnelles n'avaient racheté un peu sa "frousse", nous aurions eu sérieusement a* nous plaindre de lui ce jour-là.".

La bataille, très longuement racontée, continue avec l'arrivée du capitaine "âme de la batterie" et finit, au bout de deux jours et la survenue de renforts, par tourner à l'avantage des Français. Camille Richier livre au passage cette analyse très intéressante de la psychologie du soldat dans la bataille: "Nous nous sommes abandonnés, ce n'est pas que nous ne sentions pas le danger de la situation, mais nous sommes devenus des machines, on sent la mort qui nous frôle $a^{*}$ chaque instant, on n'y pense pas. Tout combattant a connu dans ces moments terribles cet anéantissement de la sensibilité qui n'est ni du désespoir, ni de l'esprit de sacrifice, mais comme une absence de pensée qui fait un corps un automate qui n'est plus guidé par une volonté endormie et qui suit le mouvement. C'est justement dans ces moments que les chefs sont l'âme de leurs hommes: qu'ils soient à la hauteur de leur tache*, tout va bien, que ce soient des "gourdes", rien ne va plus."

La hantise est d'être fait prisonnier: "Pour se rendre prisonnier, on hésiterait, car on croit que les bulgares* ne font pas quartier." Peu à peu la montagne du Kara Odjalik va prendre l'apparence connue du front français: "Nous on se fortifie; le kara* est un immense bastion creusé de mille tranchées, on y monte en masse du matériel: fils barbelés, piquets, grillages, poutres, étais, etc.; de bons sentiers muletiers y accèdent, il y a une forte garnison et nous ne sommes point inquiétés." Camille analyse l'intérêt stratégique éminent de cette position: "Cette montagne de Kara Odjalik mérite une mention spéciale, car elle est le tombeau de milliers de malheureux. Posée comme une tortue allongée, elle est la clef de la vallée du Vardar quelle* domine, et des nombreux petits passages qui aboutissent en Bulgarie. Si les bulgares* nous la prennent, ils vont jusqu'aux portes de fer ${ }^{62}$, ont la route qui par Negotin leur permettait de couper l'armée serbe par le derrière". Il s'y trouve les traces macabres de la deuxième guerre balkanique de 1913, qui viennent cruellement rappeler la fragilité de la condition humaine dès lors que la guerre intervient: "En 1913 les serbo-bulgares* y battirent les turcs*, puis les bulgares* la reprirent et enfin les serbo-grecs* en chassèrent les bulgares* C'est pour cela que sur cette montagne du malheur, en cheminant $a^{*}$ travers les broussailles ou les rochers qui la recouvrent on trouve par paquets des ossements humains, sur lesquels avait été jetée un peu de terre mais que les pluies ou le vent ont emportée et qui sont maintenant à nus*. On voit parfois de ces cadavres étendus, la tête contre une pierre derrière laquelle ils s'abritaient, et on voit encore des lambeaux d'étoffe de leurs habits et même leur équipement, quelque fois* leurs armes rongées par la rouille. Un jour que nous avions monté à la nuit notre tente, lorsqu'on fut couché un camarade avait une bosse sous les reins, il se lève et sous une mince couche de poussière arrache un crâne qu'il envoie rouler dehors, et l'on s'endort non en rêvant aux morts, mais peut-être à la faim qui nous tenaille. On dit qu'il y avait ainsi plus de 15000 cadavres, ce qui est fort possible."

\section{La retraite vers Salonique (décembre 1915)}

Finalement, face à la déconfiture de l'armée serbe, la position du Kara Odjalik est abandonnée à la fin novembre 1915, bien peu glorieusement, ce dont Camille Richier a visiblement honte, tout en se satisfaisant de la retraite: "Hier encore, Sarrail a dit: "Il ne faut pas leur laisser un manche de pelle". On réquisitionne aux habitants leur maïs, leur bétail afin, dit-on, que les bulgares* ne puissent se ravitailler sur le pays. Si les bulgares* ne peuvent se ravitailler, on condamne bien aussi les malheureux habitants $a^{*}$ mourir de faim, et leur détresse fait peine à voir. Vers la fin novembre, on déménage un soir $a^{*}$ la cloche de bois nos pièces du kara*, on couche à Pépélitch où nous étions installés assez confortablement dans les maisons et nous en partons un matin par une tourmente de neige très violente. Le grand mot de "retraite" est prononcé, nous nous en allons presque avec plaisir, car on a beau nous raconter des histoires, on combat a * regret loin de son pays!"

Harcelés par les Bulgares, les régiments entreprennent une retraite de Serbie par des marches forcées dans des chemins muletiers escarpés, puis dans la plaine insalubre jusqu'à Guevguelli (Gevgelija). Partagé entre le soulagement et la honte conjuguée à la pitié, Camille vit la déroute de la retraite, qui affecte les civils comme les

\footnotetext{
${ }^{62}$ Les "Portes de Fer" sont le nom d'un défilé du Danube, aux extrémités des Carpathes
} 
militaires: "De ce moment c'est le désordre d'une vraie retraite. Les nouvelles sont mauvaises: l'armée serbe n'existe plus. Monastir est pris, nous, nous sommes dans les machoires* d'une tenaille qui ne nous laisse de libre que la vallée (du Vardar); nos avant-postes luttent, mais les obus tombent sur nos routes de retraite. On voit de partout d'immenses incendies, dans les fossés des voitures, du matériel; la route est pleine d'un flot de bêtes, de monde, d'autos. Un grand nombre d'écloppés* suivent comme ils peuvent sans armes, sans sac. Enfin nous arrivons à Guevguelli et nous croyions être au terme de nos souffrances. On se montre la frontière grecque qui n'est qu'à trois kilomètres. Comme personne ne sait rien de certain, d'après les uns on va rentrer en France, d'autres disent que nous seront internés en Grèce jusqu'à la fin de la guerre. Cette dernière semaine a été si dure, et le moral est si bas, que cette dernière perspective nous sourit assez."

Cette retraite, très difficile, sera cependant, proportionnellement, assez peu meurtrière, s'il faut en croire Pierre Miquel qui écrit (nous l'avons vu au moment du décompte des pertes pour les Dardanelles): "Le corps expéditionnaire réussit pourtant sa retraite en file indienne sur les sentiers escarpés aux prix d'efforts démesurés qui exigent des hommes des marches épuisantes: elle ne laisse sur le terrain que 1800 hommes pour 50000 combattants. Sur les états du haut commandement, l'opération est jugée positive" ${ }^{63} \mathrm{Il}$ faut, pour faire le bilan de l'opération de Serbie de cette fin d'année 1915, y rajouter les tués de novembre-décembre avant la retraite, cette fois donnés à l'unité près par Pierre Miquel: "Il reste qu'en près de deux mois de guerre acharnée les "Jardiniers de Salonique ${ }^{\prime \prime 64}$ ont perdu 4822 des leurs, du 20 octobre au 12 décembre, pour les trois divisions engagées".

Finalement, le régiment, après une halte à Guevguelli, en part le 18 décembre et est ramené en train à Salonique où il va construire un camp retranché jusqu'en février 1916. Le mythe des "jardiniers de Salonique" va pouvoir se forger...

Et le mythe se fonde sur la réalité du terrain, comme en témoigne peu après Camille Richier, dans son récit: "chaque tente avait été aménagée où l'on croyait le plus convenable, ce qui faisait un peu de désordre, mais avec les sentiers assez bien entretenus, quelques jardinets autour, ce n'était pas d'un vilain coup d'œil: quelques unités d'infanterie avait* dessiné leurs camps d'une manière artistique avec des jardins, des pelouses, ce qui nous fit traiter en pleine séance à la chambre des députés de "jardiniers de Sarrail". Mais quelle vie monotone menait-on!"

De la mort sur la presqu'île de Gallipoli ou en Macédoine serbe aux jardinets des camps de Salonique ou de sa périphérie, l'année 1915 en Orient a été celle de tous les contrastes. Le mythe de l'Orient grandiose qui faisait rêver certains, comme Claudius Viricel, s'est effondré, et les maladies (dysenterie, paludisme, fièvres diverses) ont pernicieusement et grandement contribué à la mortalité. Mais on verra, surtout en 1917, après la boucherie du chemin des Dames et trois ans de guerre interminable, que les volontaires vont affluer pour combattre en Orient, où l'on meurt tout de même nettement moins qu'en France...

Nous n'irons cependant pas jusqu'à tenir pour totalement représentative de la réalité cette opinion extrême, à coup sûr excessive, de Léon Guichard (cl. 15), agriculteur à Igurerande (Saône-et-Loire) puis à Briennon (Loire) qui, soldat de l'infanterie coloniale, au front depuis le printemps 1915, dans l'Aisne puis dans la Somme en 1916, après avoir participé comme mitrailleur à la fameuse bataille du Chemin des Dames en avril-mai 1917 avec le $5^{\mathrm{e}} \mathrm{R}$. d'Infanterie Coloniale de Lyon, se porte volontaire pour l'Orient, et, versé au $44^{\mathrm{e}}$ R.I.C. , demeure en Macédoine serbe du 2 août 1917 à l'armistice demandé par la Bulgarie en septembre 1918, pour finir un mois et demi de marche forcée en direction de la Roumanie. Il répond à ma question portant sur sa guerre d'Orient, deux et trois ans après 1915:

E- "Mais autrement, à part les fièvres et les maladies, la guerre d'Orient, c'était plus tranquille qu'en France?

T- "Zéro! C'était zéro! C'était zéro! Zéro! [...] Oh ben, c'était de la promenade contre là (en France) [...] Je dis ben: on a eu ce Sénégalais tué à la compagnie, un jour... Mais non, c'était de la rigolade! Franchement, de la rigolade!"

Les combattants d'Orient n'auraient-ils pas été mortifiés d'entendre ces propos d'un des leurs, qui a pourtant connu les deux fronts?

\section{$* * *$}

\footnotetext{
${ }^{63}$ Pierre Miquel, op.cit. p. 181

${ }^{64}$ "Les jardiniers de Salonique" ou "les jardiniers de Sarrail" (du nom du général qui va les commander) sont les deux appellations ironiques et envieuses données en France par des Poilus et des chefs militaires aux combattants d'Orient, dont on a dit, surtout à partir de 1916, qu'ils avaient transformé leur camp retranché de Salonique en vaste jardin
} 


\section{Chapitre 11}

\section{La vie à l'arrière :}

Celle des femmes, des enfants, des très jeunes gens et des vieux après un an de guerre 


\section{Chap. 11 - 1915 - La vie à l'arrière des femmes, des enfants, des vieux et des très jeunes gens après un an de guerre}

"On arrachait les truffes comme des hommes, on était des gamines, on faisait la moitié, le quart du travail qu'il fallait, mais on le faisait quand même!... On a passé notre jeunesse dans un drôle de temps quand même! C'était une drôle d'existence! C'était triste! »- Mme Seychal, née en 1893, Saint- Jean-la Vêtre (hameau de Pragniot)

T- «Eh ben, ils (les gens) se débrouillaient... Les femmes! Et puis on leur aidait, nous! J'étais pas tout seul, quoi, à rester là, y en avait d'autres! Y avait les vieux aussi. Y avait pas d'hommes! On aidait les femmes à faire leur...(travail). Fallait ben qu'elles vivent, qu'est-ce que vous voulez!"

E- Ça devait être dur pour elles?

T- Bien sûr que c'était dur!» - Jean Brun (classe 1918), fils d'un tout petit agriculteur de Saint-Maurice-enGourgois, ayant 17 ans en 1915

$\mathrm{E}$-«Ils (les industriels stéphanois) embauchaient à ce moment-là? (après août 1914)

T- Ah ben bien sûr! Ils embauchaient à plein! N'importe qui, ils prenaient! Les femmes et tout, quoi! Fallait ben remplacer ceux qui étaient partis! Encore, ils en avaient gardé pas mal qui n'ont pas parti, des gens qui étaient en âge de partir! Mais qui vraiment faisaient faute! » - Maxime Jacquet (classe 1918), fils de serrurier de Sail-sous-Couzan, apprenti serrurier devenant ajusteur de précision à la Manufacture d'Armes de Saint-Etienne au tout début de la guerre, alors qu'il n'a que 16 ans

«Demain, comme je ne compte pas pouvoir aller à la messe, je ferai un bon matin dans mon lit. Je ne me lèverai qu'à 6 heures. Tu vas m'appeler paresseuse. Je le suis bien un peu par moments, mais plus tard je compte redevenir plus vaillante. »Antonia Reymondon, née en 1893, de Saint-Maurice-en-Gourgois (hameau de Sabonnaire), agricultrice dirigeant seule sa ferme, et écrivant le 13 novembre 1915 - alors qu'elle est enceinte de plus de cinq mois - à son mari Eugène, mobilisé.

"Aujourd'hui j'ai eu une personne qui est venue me demander si c'était bien vrai qu'il était tombé à tes côtés un jeune homme de Mardore, et on a insisté pour avoir des renseignements. Je vais t'expliquer: les parents du jeune homme dont tu m'as parlé et qui sont sans nouvelles de leur fils, ont appris que celui-ci avait été blessé sur le champ de bataille, mais ils ne savent pas ce que leur enfant est devenu. On leur a dit qu'il y a un gradé de Belmont au $158^{\text {ème }}$ qui est aspirant (rajouté au-dessus de la ligne: "et qui a dû le voir tomber") et alors ils ont voulu savoir ton adresse pour t'écrire. Tu recevras donc une lettre d'eux un de ces jours et il faudra que tu leur annonces la triste nouvelle [... IIls sont vraiment trop éprouvés, ils ont déjà perdu deux gendres à la guerre et un autre fils. Mon Dieu, que cette guerre est horrible! Que de deuils et de douleurs! »Lettre d'Eugénie Devaux, revenue pour la durée de la guerre à Belmont-de-la-Loire avec ses deux jeunes enfants, à son mari Joseph, cadre bancaire à Annonay (natif de Belmont), au front, alors aspirant au $158^{\text {ème }}$ R.I. de Lyon

\section{Le travail des femmes en usines d'armement : «les munitionnettes »}

C'est un fait bien connu: la guerre de 1914 a non pas créé, mais accéléré l'entrée des femmes dans divers métiers, avec des conséquences sociales et psychologiques très diverses, et l'économie de guerre, à l'arrière, a reposé majoritairement sur le travail des femmes complété par celui des hommes non incorporés, mais "mobilisés" en usine, et par celui des hommes pas encore mobilisables, car très jeunes, ou plus mobilisables, car trop "vieux", au-dessus de ces 47 ans qui marquaient la limite de la vie militaire possible, celle de l'incorporation dans l'armée territoriale

Maxime Jacquet (cl. 18) de Sail-sous-Couzan ${ }^{1}$ a fait un apprentissage de serrurier avec son père à Sail; en 1913, il se fait embaucher comme ajusteur de précision dans l'armurerie à Saint-Etienne, et en 1914 comme ajusteur à la célèbre Manufacture d'Armes de la capitale forézienne, où il demeurera jusqu'à son départ pour la guerre en avril 1917. Il témoigne de l'abondance de la main-d'oeuvre féminine (formant la corporation dite des "munitionnettes") à la Manufacture d'Armes dès l'entrée en guerre, s'accentuant avec les années:

E - "Ils embauchaient à ce moment-là? (après août 1914)

\footnotetext{
${ }^{1}$ Jacquet de Sail-sous-Couzan (Loire): comme son célèbre homonyme entraîneur national de football Aimé Jacquet auquel il était peut-être apparenté; mais la question n'a pas été posée, Aimé n'ayant pas atteint en 1987 (année de l'entretien) la notoriété nationale, et même internationale, que lui a valu le gain de la Coupe du Monde de football le 12 juillet 1998.
} 
T- Ah ben bien sûr! Ils embauchaient à plein! N'importe qui, ils prenaient! Les femmes et tout, quoi! Fallait ben remplacer ceux qui étaient partis! Encore, ils en avaient gardé pas mal qui n'ont pas parti, des gens qui étaient en âge de partir! Mais qui vraiment faisaient faute!"2

Sur ces fameux "mobilisés en usine", dont tous n'auraient pas vraiment "fait faute", et qui sont payés pour leur travail en usine, il y a beaucoup à dire, et nous verrons plus tard qu'ils excitaient la jalousie et la rancœur, voire la haine des vrais mobilisés qui risquaient leur vie sur le front, et qui les considéraient comme des "embusqués"...

Il explique très succinctement que les femmes "dégrossissaient aux machines" les pièces d'armurerie que les armuriers professionnels finissaient à la main: "A ce moment-là, les machines, elles fabriquaient des pièces, mais ces pièces n'étaient pas finies du tout! A ce moment-là, les pièces étaient brutes: elles venaient dans les mains de l'ajusteur: fallait tout ajuster au centième de millimètre bien souvent, surtout pour les mitrailleuses! J'étais à la fabrication des mitrailleuses, moi! ... Les ajusteurs faisaient la finition".

Une des deux mitrailleuses françaises portait d'ailleurs le nom de "Saint-Etienne"; un bijou, selon les utilisateurs, mais enrayable au premier grain de sable, au moindre fragment de terre ou de boue, d'où son remplacement par la mitrailleuse Hotchkiss, comme nous le verrons dans la partie technique consacrée à l'armement

Dans son numéro du 11 août 1915, la revue bien informée L'Illustration, consacre deux pages très denses à la technique du chargement des obus, mais le titre de l'article de $\mathbf{F}$. Honoré ("Les femmes dans l'artillerie") et l'introduction de ce long article constituent un hommage à la nouvelle main d'œuvre féminine des usines d'armement, représentée dans trois des cinq photos illustrant l'article très technique. On lit dans l'introduction: "Mais il est rassurant de constater que, dans la crise de main d'œuvre déterminée par la mobilisation générale, les femmes font vaillamment leur devoir. Si quelques-unes paraissent heureuses de vivre inoccupées en se contentant de leur indemnité de chômage ${ }^{3}$, un grand nombre semble mettre un certain point d'honneur à montrer que, dans beaucoup de métiers, elles sont capables de remplacer les ouvriers de l'autre sexe.

C'est peut-être dans la fabrication des obus que la coopération des femmes était le plus inattendue; c'est peut-être là aussi qu'elle apparaît de la façon la plus utile pour l'instant. Plusieurs milliers de femmes travaillent au Creusot et dans les autres Etablissements Schneider, où elles se sont vite adaptées à des manipulations ténues et délicates pour lesquelles elles paraissent spécialement douées. Beaucoup, même, acceptent des besognes plus ou moins dangereuses, maniant les amorces de fusée ${ }^{4}$ ou dosant les charges de mélinite ${ }^{5}$ : et la sécurité des ateliers de pyrotechnie improvisés ou agrandis n'en souffre point. Ce sont des femmes, presque exclusivement, que nous verrons aujourd'hui terminer les obus."

Concernant la répartition par sexe et par catégorie de cette nouvelle population ouvrière, Yves Pourcher, dans Les Jours de guerre - La vie des Français au jour le jour entre 1914 et $1918^{6}$ constate: "Parce que grande est l'urgence, le pays rassemble ses forces: pour l'industrie d'armement, plus de 500000 mobilisés et mobilisables sont renvoyés dans les usines grâce à la loi Dalbiez du 26 juin 1915, en plus des 425000 ouvriers civils, des 430000 femmes, des 133000 enfants de moins de dix-huit ans, des 13000 mutilés, des 108000 étrangers, des 61000 coloniaux et des 40000 prisonniers de guerre. Evoquant sans doute une année plus éloignée du début de la guerre que 1915, il précise: "Les femmes représentent $60 \%$ du personnel chez Citroën, $29 \%$ chez Renault, $20 \%$ chez Panhard, $10 \%$ chez Blériot", sachant qu'il faut voir autre chose que la simple production d'automobiles dans les trois premières marques citées. Et il poursuit: "Toutes ces munitionnettes s'activent pour fabriquer les obus, les fusées ${ }^{7}$, les grenades et les cartouches, pour enduire et vernir les ailes des aéroplanes ${ }^{\prime \prime}$. Dans la Loire, département qui comportait trois grands arsenaux (la Manufacture d'Armes de Saint-Etienne et les deux arsenaux importants de Roanne et de Saint-Chamond) sans compter de très

\footnotetext{
${ }^{2}$ L'expression "faire faute", encore très courante en français local forézien, signifie "manquer à" . Ce sont donc des spécialistes de l'armurerie, mobilisables, mais qui auraient beaucoup manqué à la Manufacture s'ils avaient été envoyés au front.

${ }^{3}$ Le journaliste stigmatise implicitement les femmes du peuple citadin lui paraissant choisir la voie de la facilité et de l'assistanat, et non les femmes de la bourgeoisie (son épouse peut-être!) "naturellement" vouées à la direction de la maisonnée...

${ }_{5}^{4}$ La fusée d'un obus est sa pointe en ogive contenant le mécanisme de percussion qui fait exploser l'obus.

${ }^{5}$ La mélinite est un explosif très puissant à base d'acide picrique; ce mot, apparu en 1885 , a une origine assez poétique contrastant avec son utilisation meurtrière: il provient, selon le Grand Larousse de la Langue Française, du latin "melinus" qualifiant le coing ou la fleur de coing, en raison de la couleur de cette poudre

${ }^{6}$ Yves Pourcher, op. cit. p.176

${ }^{7}$ Il s'agit évidemment des fusées tirées au pistolet spécial, munies d'un parachute pour permettre un éclairage nocturne plus long, employées pour éclairer le no man'land en cas de bruit suspect, pour pouvoir tirer sur la patrouille ennemie, ou des fusées colorées pour le réglage des tirs d'artillerie (voir chapitre sur l'armement).

${ }^{8}$ Ces ailes, au début de la guerre, étaient en toile épaisse soutenue par une forte armature de bois, d'où l'expression "casser du bois" employée pour qualifier un atterrissage brutal, après un tir ennemi endommageant le moteur de l'avion. C'est dans la toile de ses ailes, utilisée comme un linceul, que l'as de l'aviation Adolphe Pégoud, abattu en vol le 31 août 1915 , fut rapporté du lieu de l'écrasement du biplan par ses camarades de l'escadrille de Belfort.
} 
nombreuses petites entreprises françaises des zones occupées repliées sur Saint-Etienne, l'emploi féminin dans l'industrie d'armement a été particulièrement représenté.

Drame des épouses et des mères quand la lettre habituelle du front n'arrive plus ou quand la rumeur de blessure grave ou de mort n'est pas confirmée

Une lettre bien postérieure à 1915, puisqu'elle est datée du 28 juin 1918, nous renseigne sur ce qui a dû être l'angoisse permanente des familles, de 1914 à 1918. Eugénie Devaux, de Belmont-de-la-Loire, écrit à son mari Joseph , cadre au Crédit Lyonnais d'Annonay avant-guerre (classe 99, donc âgé de 39 ans en 1918), alors aspirant au $158^{\mathrm{e}}$ R.I. près de Souain en Champagne dite autrefois "pouilleuse", pour lui faire part d'une visite qu'elle vient de recevoir et qui lui a causé un vrai dilemme moral: "Aujourd'hui j'ai eu une personne qui est venue me demander si c'était bien vrai qu'il était tombé à tes côtés un jeune homme de Mardore, et on a insisté pour avoir des renseignements. Je vais t'expliquer: les parents du jeune homme dont tu m'as parlé et qui sont sans nouvelles de leur fils, ont appris que celui-ci avait été blessé sur le champ de bataille, mais ils ne savent pas ce que leur enfant est devenu. On leur a dit qu'il y a un gradé de Belmont au 158 ème qui est aspirant (rajouté au-dessus de la ligne: "et qui a dî le voir tomber") et alors ils ont voulu savoir ton adresse pour t'écrire. Tu recevras donc une lettre d'eux un de ces jours et il faudra que tu leur annonces la triste nouvelle. Je trouve qu'il est préférable qu'ils l'apprennent par toi que d'être dans l'incertitude pendant si longtemps, d'autant plus qu'ils m'ont fait demander si je savais quelque chose de leur fils. Je n'ai pas eu le courage de leur dire, je préfère que ce soit toi qui leur écrive*, tu sais si bien trouver les paroles qu'il faut en pareille circonstance ${ }^{I 0}$ si c'est cette famille qui est atteinte; ils sont vraiment trop éprouvés, ils ont déjà perdu deux gendres à la guerre et un autre fils. Mon Dieu, que cette guerre est horrible! Que de deuils et de douleurs!"

On pourrait penser qu'Eugénie aurait pu donner annoncer elle-même la terrible nouvelle et délivrer cette famille de sa cruelle incertitude; mais elle n'est pas tout à fait sûre de l'identité du mort, et il va sans dire que son mari, ayant été témoin de l'événement tragique, sera plus fiable, et que sa réponse écrite aura plus de poids et de compassion bien formulée, donc d'effet consolateur, qu'une nouvelle assénée brutalement dans une conversation, avec l'explosion de chagrin que cela suppose, si cette "personne" venue de Mardore est apparentée au mort, ce qui est plausible (car rien n'indique que ce soit un des deux parents).

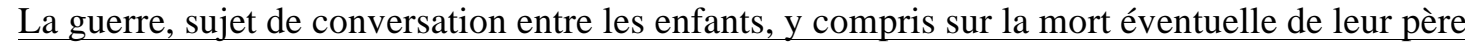

Le 9 décembre 1914, Eugénie Devaux, de Belmont-de-la Loire, écrit à son mari Joseph, alors âgé de 35 ans (né en 1879) et pour le moment bien loin du front, affecté à des tâches administratives au dépôt des blessés du $100^{\mathrm{e}}$ R.I à Tulle, et lui donne des nouvelles de leurs très jeunes enfants, Jeanne et Emile: "Les enfants vont bien, ils n'ont même pas été enrhumés encore. Jeanne commence à savoir lire. Hier, ils étaient quatre qui s'amusaient là, il y avait dans le nombre une petite voisine dont le papa n'a pas écrit depuis 3 mois. Le petit Sornin lui a dit "Ton papa est mort", la petite a répliqué "Et* non!". Comme le petit insistait, Jeanne a pris la parole et lui a dit: "Petit égoïste, est-ce qu'on dit ça? Ça l'ennuie, cette petite, et puis tu ne sais pas si ton papa ne mourra pas!"). Milou, qui est trop petit, criait: "Mon papa à moi il est pas mort!". Je te dis que ça me faisait de la peine de voir ces enfants discutant si le père était mort où* s'il ne l'était pas; sa femme le croit prisonnier, mais pour tout le monde, il est mort; on lui a envoyé son portemonnaie* qu'on a trouvé sur le champ de bataille."

Le petit Emile est sûr que son papa n'est pas mort; il ne sait pas que quatre ans plus tard, il apprendra sa mort, survenue cinq jours avant l'armistice, le 6 novembre 1918, à l'hôpital temporaire de Mont-Notre-Dame, dans l'Aisne, où il était hospitalisé après la grave blessure reçue au combat le 31 octobre, à la tête de sa section (il était alors sous-lieutenant) à Banogne, vers Rethel, dans les Ardennes ...

On ne peut s'empêcher de comparer le petit Emile Devaux (qui doit avoir deux ans) au petit Paul Amalric, très jeune écolier jouant à la guerre en cour de récréation ${ }^{11}$, au moment même où un voisin vient le chercher

\footnotetext{
${ }^{9}$ Mardore est un petit bourg du Rhône, au sud de Cours-la-Ville, donc en bordure de la Loire, et distant de Belmont, situé à l'extrémité nord-est de la Loire, d'une bonne quinzaine de kilomètres que cette personne a dû vraisemblablement parcourir à pied, pour s'adresser à l'épouse du gradé commandant la section où se trouvait le blessé présumé mort, afin de savoir son nom et son adresse militaire actuelle pour pouvoir lui écrire, et aussi de quêter des nouvelles auprès de l'épouse, et lever ainsi la cruelle incertitude

${ }^{10}$ Ce n'est pas une flatterie infondée de la part d'Eugénie: elle sait que son mari possède, comme je l'ai constaté en lisant leur abondante correspondance (692 lettres et cartes de lui, contre seulement 132 d'elle conservées) un style magnifique, une grande culture et une profondeur de pensée rare, formés par de solides études de théologie au petit séminaire de Saint-Jodard (Loire), puis au séminaire d'Alix (Rhône) et enfin au grand séminaire de Saint-Sulpice à Paris, car Joseph, fils d'agriculteurs, s'était d'abord orienté vers la prêtrise, avant de se marier en 1907, à 28 ans.

${ }^{11}$ Citation correspondante: "Le petit Paul portait son bouquet (de fleurs des champs) comme un cierge, et puis il faisait le tour de ceux qui étaient assis et il chantait:- La guerre! la guerre! la guerre!" in "Le Grand Troupeau" , édit. Folio, p. 78
} 
pour le ramener chez lui: sa mère Félicie vient d'apprendre la mort à la guerre de son époux Arthur, dit, du nom de sa ferme "L'Arthur des Buissonnades", père du petit Paul, dans le beau roman de Jean Giono (ancien Poilu que la guerre a rendu pacifiste à tout crin) Le Grand Troupeau paru en 1931.

$\underline{\text { La solidarité dans les campagnes et le travail des adolescents et des jeunes hommes de moins de } 19 \text { ans }}$

Louis Seux (cl .17) fils d'agriculteurs de Saint-Apollinard, dans le Pilat, issu d'une famille de sept enfants vivants, se retrouve en 1914-1915 soutien de famille après le décès de son père en 1910. Il se souvent du poids des nouvelles responsabilités qui lui incombait à la ferme, qu'il a assumées jusqu'à son départ à la guerre avec sa classe au début de janvier 1916:

E- Donc vous vous êtes retrouvés, vous les jeunes entre 17 et 19 ans...Vous étiez les hommes qui restaient?

$\mathrm{T}$ - Oui: les hommes valides!

E- Et vous vous êtes sentis des responsabilités?

T- Eh ben bien sûr oui! Moi, je peux vous le dire! Comme nous, à la campagne, je me rappelle, avec des copains, là, l'été après (donc l'été 1915), que nous étions pas partis, nous, eh bien on avait pris des prés à faucher pour des femmes que leurs maris étaient mobilisés, parce qu'il y avait personne pour le faire. Alors on y allait après la messe, le dimanche, après notre travail à nous, toute la matinée du dimanche $e^{I 2}$. On se faisait payer un petit peu, bien sûr! Et voilà! On était trois-quatre copains comme ça. C'était un petit exemple, mais enfin..."

Plus jeune que lui d'un an (classe 18), aussi fils de tout petit agriculteur possédant deux vaches et une activité annexe de maçon, au hameau de Sabonnaire, dans la commune de Saint-Maurice-en-Gourgois, Jean Brun a dix-sept ans en 1915, alors que la classe 16 a été incorporée en avril. Il évoque aussi cette solidarité des jeunes, dont il ne dit pas qu'elle pouvait être rémunérée.

E- "Vous m'avez dit que vous vous occupiez à la ferme. Mais avec tous ces hommes qui partaient, comment est-ce que les gens se débrouillaient?

T- Eh ben, ils se débrouillaient...les femmes! Et puis on leur* aidait, nous! J'étais pas tout seul, quoi, à rester là, y en avait d'autres! Y avait les vieux aussi. Y avait pas d'hommes ${ }^{13}$. On aidait les femmes à faire leur...(travail). Fallait ben qu'elles vivent, qu'est-ce que vous voulez!"

E- Ça devait être dur pour elles?

T- Bien sûr que c'était dur!"

\section{Les filles et les femmes de la campagne assumant des tâches masculines}

Madame Lucie Daval (nom de jeune fille inconnu) née en 1902 à Saint-Jean-la-Vêtre, au hameau de Pragniot $^{14}$, qui épousera en 1924 Antoine Daval (cl. 16) de six ans son aîné né aux Salles, et ses deux voisines de Pragniot, plus âgées qu'elle, Mme Seychal (née en 1893) et Mme Rouarey (née en 1898), toutes ex-agricultrices, se souviennent, en 1975, du travail des jeunes filles et des femmes pendant la Grande Guerre, en l'absence des hommes, avec parfois le concours d'hommes âgés. Nous traduisons du patois cette enquête de thèse:

E- «Qu'est-ce qu'elles faisaient, les femmes, quand il n'y avait pas d'hommes en 14?

Mme D.- Eh ben, écoutez, en 14, je m'en rappelle, mon vieux! Y avait une de mes sœurs, elle s'était mariée, elle habitait dans un petit village (= hameau) du haut de la commune ${ }^{15}$. Eh ben on était deux, moi fille et mon autre sœur qui était fillette, eh ben la première année (en 1914), on y est monté là-haut. J'avais mon frère et ma sœur qui avait quatorze ans: c'était elle qui aidait à ${ }^{16}$ mon frère (dans la ferme familiale habituellement, et

\footnotetext{
${ }^{12}$ On comprend à cette expression "toute la matinée du dimanche" que les jeunes devaient assister à la première messe du matin, souvent autour de 7 heures, voire avant, et non à la grand messe de 10 heures, qui aurait amputé sérieusement la matinée de fauchage! Dans beaucoup de localités même, trois messes se succédaient le dimanche matin: autres temps, autres moeurs!

${ }^{13}$ Cette phrase peut paraître cruelle, car les jeunes gens non encore incorporés et les hommes au-dessus de 47 ans ne sont pas considérés comme des hommes! Mais dans un métier peu mécanisé encore, où la force physique était essentielle, les vrais "hommes" étaient bien ceux qui étaient à la guerre...

${ }^{14}$ Mon épouse Françoise a fait ses débuts de jeune institutrice de 22 ans dans la petite école de ce même hameau de Pragniot, école à classe unique (neuf élèves de 5 à 14 ans) et a pris pension chez les Daval, qui possédaient un petit café en complément du revenu de leur ferme. Antoine Daval est un de mes premiers témoins $\left(\mathrm{n}^{\circ} 7\right)$ de mon enquête de thèse, interviewé en patois, lui parlant le sien, moi le mien, de Saint-Jean-Soleymieux, sans difficultés de compréhension compromettant le dialogue, très vivant.

${ }^{15}$ Pragniot étant déjà un hameau du haut de la commune de Saint-Jean-la-Vêtre, à près de 1000 m d'altitude à l'extrémité nord des Monts du Forez, cet autre hameau où demeurait la sœur aînée de Lucie devait être proche du sommet de la chaîne des Monts (la Côte, les Vernières ou Hauteville)

${ }^{16}$ En patois et en français local foréziens, le verbe "aider" se conjugue de manière transitive indirecte: "aider à quelqu'un"
} 
occasionnellement dans la ferme de la sœur aînée, privée de son mari par la guerre). Et après ils ont pris des vieux, du monde vieux ${ }^{17}$, qui avaient pas de ferme, et on les envoyait faire la ferme (de la sœur mariée) chacun leur tour, quinze jours ici (à Pragniot), quinze jours là (dans la ferme de la sœur mariée). Je m'en rappelle, on avait un vieux, nous, il était de Chambéon" ${ }^{18}$ et il a dit: (passage au français): "Je fais les foins chez les gens et ma femme se crève la peau du cul pour faire les siens"

Sa voisine, Madame Rouarey, née aussi à Pragniot, donne une précision intéressante à propos de cet homme, propos expliquant sa remarque amère: "Il était mobilisé, il était soldat, mais s'il avait été sur le front, il serait été..."(phrase inachevée, qu'on peut compléter: "bien plus mal!"). Rappelons qu'en 1914-1918, le terme "mobilisé" s'appliquait aussi à ceux qui étaient placés par les autorités militaires dans les usines, pour travailler, soit à l'armement, comme à Saint-Etienne, Saint-Chamond ou Roanne dans divers arsenaux, soit à la campagne comme ici, pour suppléer l'absence des hommes partis au front.

Mme D.- "Oh oui! Il savait qu'il était bien, qu'il était bien soigné! N'empêche qu'il a dit ça, il pensait à sa femme!

E- Il y avait des femmes qui charrolaient ${ }^{19}$ ? (labouraient à la charrue)

Mme D. - Ouh la! Y en avait qui fauchaient, qui charrolaient, j'en ai tant vu! Y a des femmes qui ont travaillé du temps de la guerre! ${ }^{20}$

Et Mme Rouarey de renchérir: "Toutes les femmes, elle s'y mettaient... Tout le monde se mettait au travail des hommes: elles arrachaient les truffes ${ }^{21}$, elles les piochaient..."

Mme Seychal, la doyenne des trois, précise: "On arrachait les truffes comme des hommes, on était des gamines, on faisait la moitié, le quart du travail qu'il fallait, mais on le faisait quand même! Nous étions obligées! C'était le reste! ${ }^{22}$ ! Nous étions bien obligées de planter tout ce qu'on pouvait, par qu'il en avait pas de reste! Ils nous modéraient: il y avait guère de pain et guère de rien: c'était pas la gloire!... On a passé notre jeunesse dans un drôle de temps quand même! C'était une drôle d'existence! C'était triste! Tandis que les jeunes, ils ont point de soucis, ces jeunes d'aujourd'hui! Prends les nôtres, prends les vôtres, de 13-14 ans, quand ils commencent à prendre du souci, tout ce qui arrive doit arriver". La phrase est un peu ambiguë, mais signifie à l'évidence que les adolescents ruraux de 1975 - date de l'enquête- alors que le chômage commençait juste à inquiéter après les effets du premier choc pétrolier, avaient en temps dû tout ce qu'ils pouvaient espérer.

\section{Les villages privés de boulanger}

Les commerces ruraux, souvent représentés à un seul exemplaire dans chaque commune, sauf si elle est importante, sont aussi affectés par le départ à la guerre du propriétaire artisan. Parmi eux, le plus indispensable est celui du boulanger, étant donné que beaucoup d'agriculteurs ont déjà renoncé, même avant la guerre de 14, à confectionner eux-mêmes leur pain. Les bouchers sont moins indispensables car la nourriture carnée essentielle des campagnes reste le porc, que l'on élève à la ferme, et que l'on tue pour en faire des salaisons. Beaucoup d'agriculteurs et plus largement, de ruraux, des Monts de la Madeleine, du Forez, du Beaujolais, du Lyonnais ou du Pilat, par exemple, ne mangeaient de viande de boucherie que deux à trois fois l'an, à Noël, à Pâques (le fameux bœuf de Pâques, qui venait rompre le jeune du Carême où lard, jambons et saucissons ne sortaient pas du saloir) et le jour de la fête patronale. ${ }^{23}$

Antoine Gayet (cl. 16)) de Mionnay, dans l'Ain, fils d'agriculteurs, travaille depuis $1913 \mathrm{chez}$ un coquetier ${ }^{24}$ de Parcieux (Ain) qui était aussi gros agriculteur, employant dix-huit personnes (dont dix servantes pour plumer les volailles) et possédant huit chevaux; la réquisition des chevaux et le départ des ouvriers agricoles à la guerre affectent gravement l'économie de la ferme; Antoine va suppléer l'unique boulanger de la commune, à la demande de son patron principal. Il sera mobilisé en mai 1915. Une blessure à la cuisse l'amènera après guerre à devenir métallurgiste aux usines Berliet de Vénissieux, puis dans les ateliers du P.L.M. à Oullins,

\footnotetext{
${ }^{17}$ En patois et en français local foréziens, "du monde" signifie "des gens"

${ }^{18}$ Près de Feurs, au coeur de la plaine du Forez, dont le patois franco-provençal était très différent du nord-occitan de Pragniot

${ }^{19}$ Dans mon patois, franco-provençal de Saint-Jean-Soleymieux, canton en bordure du nord-occitan du plateau de SaintBonnet-le-Château, «labourer» se dit «tsorula» (présence d'une affriquée pour rendre le son «che», comme dans «santa»= «chanter», ou «tsortsa»= «chercher »). Mais il est traduit, en français local, par «charroler» et non «charruler» : "J'ai charrolé toute la terre des Mazelles, ce matin, en m'y prenant (de) bonne heure »

${ }^{20}$ L'accentuation tonique de cette phrase montre qu'elle signifie que ces femmes ont beaucoup travaillé

${ }^{21}$ Les "truffes" sont les pommes de terre, en patois et en français local foréziens, mais aussi dans bien d'autres régions.

${ }^{22}$ Comme on le verra un peu après, ce "reste" désigne les restrictions alimentaires du rationnement imposé par l'Etat

${ }^{23}$ A ce sujet, voir le rapport de Mémoire Forézienne rédigé Daniel Palmier et moi-même pour l'Action Thématique Programmée du C.N.R.S. Rhône Alpes en décembre 1987, intitulé "L'Alimentation forézienne au XXe siècle": "L'autre viande dite "de boucherie" apparaissait peu sur les tables populaires foréziennes au début du siècle. Certains des témoins les plus âgés vont jusqu'à indiquer un achat de viande en boucherie deux fois par an: le jour de Pâques et le jour de la fête patronale." (page 8).

${ }^{24}$ Pour nos lecteurs non ruraux et jeunes: un coquetier est un négociant en œufs et volailles
} 
avant de prendre sa retraite à Feurs. De début août 1914 à mai 1915, il a vu les campagnes de l'Ain désertées par les hommes valides et l'effet de la réquisition des chevaux:

T- "Tout le monde était parti pour la guerre et c'est les femmes qui remplaçaient...

E- Vous, vous aviez dix-huit ans? (à la mobilisation)

$\mathrm{T}$, évoquant ses patrons, et les mélangeant dans une phrase complexe: "C'étaient des gens riches, alors ils m'avaient convoqué pour aller semer le blé (en automne 1914) parce que les femmes commençaient à labourer (leurs maris étaient partis et il n'y avait plus personne) avec des bœufs! Pas avec des chevaux: ils avaient été mobilisés, eux! Et alors après, le boulanger qui était tout à fait à côté... le mitron ${ }^{25}$ était parti, le patron était parti aussi, et il restait plus que la gosse qui avait quinze ans. Alors mon patron (on était déjà outillé avec le pétrin mécanique) qui s'appelait Antonin (le boulanger) mon patron (le gros coquetier), m'a dit: "Il faut que tu ailles donner la main ${ }^{26}$ à chez Antonin à faire du pain parce que dans la commune, y a plus de pain. Alors j'ai fait le boulanger pendant neuf mois avant de partir au régiment!"

E- Alors vous avez passé le conseil (de révision) quand?

T- J'ai passé le conseil le 9 avril 1915 et on est parti un mois après."

Le même déficit en boulangers va pousser un de ses conscrits de la classe 1916, mais de Haute-Loire, à faire le pain pour plusieurs communes. André Mathieu, de Landos, à $25 \mathrm{~km}$ au sud du Puy-en-Velay, fils d'agriculteurs, a fait son apprentissage de boulanger au Puy, et est revenu ensuite dans son Landos natal, comme garçon mitron d'un boulanger local. Quand la guerre survient, il va se retrouver, à dix-huit ans, responsable des pétrins et fournisseur de pain de trois communes voisines dont tous les boulangers, à l'instar de son patron, sont partis à la guerre: Landos, mais aussi La Sauvetat, sur la route du Puy à Mende, et Rauret au sud-est, non loin de Chapeauroux Il rendra ce service public pendant huit mois, jusqu'en avril 1915, où il est mobilisé. Il deviendra aussi boulanger dans la Loire, à Saint-Haon-le-Châtel en 1932, puis se reconvertira comme facteur à Saint-Germain-Laval à partir de 1936. Malheureusement, son témoignage oral est trop fragmenté pour être cité.

\section{L'opinion de deux jeunes gens de l'Allier (classe 1917) sur leur travail et celui des paysannes pendant la guerre}

Plus jeune d'un an qu'André Mathieu, car il est né le 27 février 1897 en Montaiguët-en-Forez (Allier), Ernest Pigeron, fils d'un hongreur ${ }^{27}$ qui mourra à 44 ans de pneumonie, laissant sa famille dans le besoin, a connu le travail agricole jusqu'au début de son apprentissage de boucher à Moulins. Il témoigne du malaise peu répertorié des jeunes gens devant le gros travail imposé, dans les fermes, aux femmes et aux enfants par le départ des hommes valides.

E- "Et vous, les jeunes de 16-17 ans, qu'est-ce que vous en pensiez?

T- Que voulez-vous qu'on en pense, nous? On travaillait, on ne se faisait pas d'idées, on disait: "Ben voilà, ils sont partis, c'est bien embêtant, tout ça!" On était un peu gêné de voir les femmes et les gosses travailler à la culture un peu partout, faire les foins, les moissons avec leurs propres moyens."

Il sera incorporé le 8 janvier 1916 au $2^{\mathrm{e}}$ Bataillon de Zouaves de Lyon.

Son compatriote et "classard" de l'Allier, Antoine Gacon, né à Lenax en 1897, fils d'agriculteurs métayers à Lenax, puis à La Pacaudière, a été loué deux ans (de douze à quatorze ans) comme "petit valet" à Urbize; puis il revient dans le domaine de la Pacaudière qu'exploitent ses parents comme métayers; Il y reste de 1911 à sa mobilisation le 3 janvier 1916. Il a connu ce surcroît de travail imposé aux jeunes comme lui, aux femmes et aux vieux par le départ des hommes de 20 ans (puis de 19 pour les classes 15 et 16) à 47 ans, qui laisse aux campagnes une allure désertée

E- Et vous, les jeunes, il fallait faire le travail? Pour ces hommes qui étaient partis?

T- Ah! On a resté! ... On faisait le boulot avec les femmes, tout! Dans les domaines, là, les fermes, c'étaient des femmes partout! Pfffttt! C'était pas pareil! ...Fallait ben faire quelque chose si on voulait manger!

E- Vous avez dû le sentir, le travail supplémentaire, vous les jeunes?

T- Ah ben, on était ben obligé de le sentir! On faisait le travail que les vieux faisaient... Qu'est-ce que vous voulez! Y avait plus personne! Tout le monde était parti! Y avait plus personne! Chez Godard, ils étaient tout seuls avec les... avec sa femme, quoi!

E- Mais quand il n'y avait pas de grand garçon dans une ferme, comment est-ce qu'ils s'arrangeaient?

T- Ah ben, c'était avec les femmes! On s'arrangeait avec les voisins"

\footnotetext{
${ }^{25}$ Le mitron est l'apprenti boulanger, mais ici plutôt l'assistant de son patron, puisqu'il est en âge d'avoir été mobilisé

${ }^{26}$ L'expression "donner la main", qui a presque disparu de l'usage, sauf chez les personnes âgées, signifie "aider quelqu'un", notamment dans une activité manuelle, mais pas exclusivement.

${ }^{27}$ Le hongreur était le technicien qui castrait les chevaux mâles dont on ne voulait pas faire des étalons mais des chevaux de trait, les veaux mâles qu'on voulait utiliser comme bœufs et non comme taureaux, et les cochonnets mâles pour les empêcher de devenir des verrats agressifs et pour accroître leur rapidité d'engraissement; cette activité castratrice est aussi exercée aujourd'hui par les vétérinaires.
} 
A ma demande, il évoque aussi les réquisitions de chevaux pour l'armée, douloureuses et parfois même refusées, comme dans l'exemple suivant.

$\mathrm{E}-\mathrm{Y}$ avait des réquisitions, aussi, je crois?

T- Oh ben, je pense bien! Oui... (rire) Y avaient même des réquisitions (phrase interrompue, mais dont le sens est implicite: "qui tournaient mal"). Ils avaient réquisitionné les bêtes... C'était Machin là...Contat, qui faisait ça, le père Contat. Et puis... Qu'est-ce que vous voulez! Ça, c'est comme les autres, ils (les paysans) gardaient ben ce qu'ils pouvaient, vous comprenez!

E- Bien sûr!

T- Même mon père, il voulait pas! Il avait encore un cheval ${ }^{28}$. Alors, ils voulaient prendre son cheval! Il a dit: "Nom de Dieu, j'ai trois garçons, j'en ai deux qui sont partis à la guerre! Eh ben, ils prendront pas mon cheval!". Et ils l'ont pas pris!"

Le fils d'Ernest, assistant à l'entretien, intervient alors pour renchérir: "Il a pas donné le cheval!"

T- Ah! Il a pas donné le cheval! Il l'a emmené... (phrase interrompue, qu'on peut comprendre: "il l'a emmené ailleurs, pour le dissimuler »). "Vous l'aurez pas du tout, voilà!"

Nouvelle intervention du fils, confirmant qu'il connaît l'histoire familiale, héroïsée, du coup de sang de son grand-père face aux personnes chargées de la réquisition: "Il a dit: "Vous l'aurez pas! Foutez-moi le camp! Vous aurez pas le cheval, voilà! Et j'emmène mon cheval!" Y avait besoin pour son boulot, quoi! ${ }^{29}$

On devine que c'en est trop, pour le père d'Antoine. Ses deux fils aînés, il n'a pas pu les refuser à la nation, car la loi militaire est inflexible. Mais son dernier cheval, il le refuse, encourant aussi, éventuellement, des poursuites...

Cette hostilité paysanne aux réquisitions, Yves Pourcher, dans son bel ouvrage Les Jours de Guerre l'a bien décrite. Après avoir longuement évoqué un fait divers dramatique, le meurtre à Verne, dans le Doubs, d'un officier d'intendance qui voulait réquisitionner l'unique bœuf d'un vieux paysan qui n'avait que trois bovins, et qui attelait ce bœuf avec son unique vache (le troisième étant un bouvillon), meurtre commis par ce propriétaire âgé à l'aide du couteau dont il était en train de se servir pour manger, l'auteur analyse le drame: "Parce que sans cesse elle enlève, parce qu'elle pénètre dans les fermes pour compter les sacs et les bêtes, la réquisition réveille l'antique et sensible soupçon paysan. Trop forte, trop pressante, elle exacerbe l'hostilité à l'égard des prélèvements des pouvoirs sur la récolte, hier ceux du seigneur et aujourd'hui ceux de l'Etat. Soumise à la ponction, la communauté se divise en autant d'intérêts particuliers que de domaines ou de familles. La guerre là-bas, les fils et les maris pris, puis tout le reste, le blé, les vaches et les porcs, jusqu'où faudra-t-il aller et jusqu'à quand? Ici, dans cette pauvre maison, on donne, mais ailleurs, chez le voisin ou dans le proche village? Alors, un matin de grande colère, d'aveuglement passionné, quand les mots et les cris ne suffisent plus à dire l'injustice, le sang coule. ${ }^{\prime \prime 30}$

Plus au sud, et même presque à l'extrémité sud du département de la Loire, Jean-Marie Chossy (cl. 18) de Saint-Maurice-en-Gourgois, (pays de petites propriétés pour la plupart, et non de métayage comme dans l'Allier, ou dans l'extrémité nord de la Loire, entre Roanne et La Pacaudière, ou dans la plaine du Forez avec ses grands domaines dépendant assez souvent d'un "château") sensiblement plus jeune que les précédents car il est de la classe 18, a connu tout le parcours du domestique de ferme du début du XXe siècle: dernier enfant d'une famille de huit, fils d'un petit agriculteur de Gourgois, loué à l'âge de neuf ans, en 1907, il a été successivement petit vacher, puis petit valet, puis valet et enfin grand valet dans diverses fermes de Çaloire, Saint-Rambert, Saint-Marcellin, puis Chambles. Alors que son frère vient de partir à la guerre, le dimanche $1^{\text {er }}$ août 1914, plein d'allant et qu'ils se sont séparés sur une gifle magistrale donnée par l'aîné à son cadet qui avait osé remettre en question l'optimisme de son frère en suggérant que lui aussi, qui n'a que 16 ans en août 1914,

\footnotetext{
${ }^{28}$ Ce qui signifie que les autres chevaux avaient été réquisitionnés, les vastes domaines de métayage du nord de la Loire et surtout de l'Allier nécessitant plusieurs chevaux et plusieurs paires de bœufs, pour des travaux agricoles différents.

${ }^{29}$ Cette résistance des paysans aux diverses réquisitions de bétail et des récoltes est bien évoquée par Jean Giono, de la classe 1915, incorporé au $140^{\mathrm{e}}$ R.I. de Grenoble où il fera toute la guerre, au chapitre IX intitulé "Et il n'y aura point de pitié" de son roman autobiographique paru en 1931 Le Grand Troupeau. Le "papé", père d'un des héros du livre, Olivier Chabrand, paysan provençal de ce plateau de Valensole (que Giono, né et vivant à Manosque, connaît bien) voit arriver un "réquisiteur", dans lequel il repérera assez vite un margoulin embusqué, accompagné de deux gendarmes dont il comprendra aussi qu'ils sont rémunérés par le "réquisiteur" véreux pour donner un air légal à son trafic. L'homme prétend réquisitionner ses six chèvres pour nourrir "les Indiens" (on devine que ce sont des soldats Hindous de l'armée anglaise qui refusent de manger des vaches, sacrées pour eux). Le "papé" explose, comme l'a fait le père d'Antoine Gacon: "Ça va, ne t'enrhume pas à crier. Je comprends, je comprends bien, je comprends trop: la guerre! Moi je te dis non, et c'est non! Alors les hommes; alors le blé; alors les moutons; alors les chevaux, les chèvres, tout alors, il lui faut tout! Et pourquoi allez-vous toujours chercher chez les mêmes? Pourquoi tu es là, toi? Tu es bien en chair, tu sais! Qu'est-ce que tu fais ici? Oh, gendarmes! Qu'est-ce qu'il fait ici, cet homme? Y a pas de place, là-haut (= au front) pour lui?" (p. 120 en édition Folio)..

${ }^{30}$ Yves Pourcher, op.cit. Plon 1994, pp. 128-129
} 
pourrait bien avoir à le rejoindre un jour (scène relatée au chapitre II) il va être chargé par son dernier patron, celui du hameau de Vassalieux à Chambles, de conduire à la réquisition un cheval dont lui, le grand valet, ne regrette pas le départ pour une raison personnelle.

T- "Et j'ai dit à mon frère; "Méfie-toi que je te remplace pas!" Il m'a foutu une gifle!

$\mathrm{E}-$ Ah bon? Mais la gifle, ça voulait dire quoi?

T- Ça voulait dire que j'étais qu'un imbécile de dire un* affaire comme ça! Je suis parti. Lui est parti du côté de Périgneux ${ }^{31}$, moi je suis parti du côté de Chambles, du côté du Teil (un hameau). Alors, en arrivant là-bas, à Vassalieux, vous savez pas ce que le patron m'a fait" ${ }^{32}$. Il m'a dit: "Faut mener le cheval à la réquisition!" Je l'ai mené à Andrézieux, le cheval, avec lui. Mais lui s'occupait de rien, il était à moitié saoul. J'ai pris le cheval à Vassalieux, je l'ai mené à Andrézieux. Mon bonhomme (le patron) il a été au bistrot et je l'ai plus revu. Alors la réquisition ${ }^{33}$ me dit... (les premières réquisitions qui ont passé) "Il est pas bien fameux, ce cheval. Allez, allez! Hop! A une* autre! Alors j'ai dit: "Ça va bien". A la fin, ils sont repassés, ils ont dit: "Ceux-là qui veulent vendre leurs chevaux, ils ont qu'à le dire!" J'ai dit: "Débarrassez cet âne, cette bourrique-là, je la veux pas!". Parce qu'il était méchant: il m'avait mordu plusieurs fois!

E- Ah bon? ... En 14, vous aviez seize ans... pas tout à fait, parce que vous êtes de la fin décembre (du 31!)

T- J'étais vers les paysans: y avait onze vaches et un cheval"

Cette dernière phrase montre qu'il s'agit d'une ferme relativement importante, selon les critères foréziens de l'époque, où beaucoup d'exploitations familiales ne possédaient pas plus de cinq ou six vaches, dont on attelait les deux plus fortes, pourvu qu'elles soient "dondées" (domestiquées pour l'attelage), et évidemment pas de cheval, signe en Forez d'une certaine aisance sociale. La scène racontée avec talent montre que le bétail réquisitionné est payé par les autorités qui réquisitionnent (mais à quel prix?), qu'il n'est pas ici saisi dans les fermes mêmes, mais amené après avis administratif sur le foirail d'Andrézieux. Quant à la passivité et à la relative indifférence du patron, on ne sait s'il faut l'attribuer à sa tendance à la saoûlerie (qui peut aussi révéler le contraire de l'indifférence) ou au fatalisme: ne pouvant rien contre les autorités militaires, il préfère confier à son valet le sort de son unique cheval et noyer son impuissance, et peut-être sa révolte, dans l'alcool des bistrots d'Andrézieux...

Henri Gerest, dans son ouvrage synthétisant sa thèse (qui fut, en juin 1975, la première soutenue à la jeune université de Saint-Etienne, au Centre d'Histoire Régionale) intitulé "Les populations rurales du Montbrisonnais et la Grande Guerre" précise dans une bonne quinzaine de pages quelles furent les conditions admnistratives de la réquisition et confirme la résistance des paysans à ces réquisitions, qu'elle concerne les chevaux ou les denrées alimentaires. Pour les étrangers au Forez, indiquons que Montbrison fut jusqu'au Second Empire le chef lieu de la Loire, alors que Saint-Etienne avait une population bien plus importante (mais sa composition sociale majoritairement ouvrière la rendait suspecte aux pouvoirs conservateurs), et représente depuis 1855 une des deux sous- préfectures de la Loire, au centre du département, avec Roanne au nord et Saint-Etienne au sud. C'était, au début du $\mathrm{XX}^{\mathrm{e}}$ siècle, un arrondissement essentiellement rural, avec beaucoup de petites propriétés sur les deux versants montagneux (les Monts de la Madeleine, le massif des Bois Noirs et les Monts du Forez à l'ouest et les Monts du Beaujolais et du Lyonnais à l'est) encadrant la plaine du Forez, dont Feurs est le centre, zone de grandes propriétés avec des fermiers (locataires de leurs fermes) ou des métayers (locataires payant en nature).

L'auteur donne d'abord le cadre juridique, administratif, des réquisitions: "Les campagnes ont fourni les hommes, il leur est encore demandé de livrer des chevaux, des voitures ${ }^{34}$, du bétail et des denrées agricoles [...]. Le préfet doit veiller à l'application d'un plan de réquisition départemental. Les réquisitions sont faites par l'intermédiaire de commissions civiles, dites commissions de ravitaillement; elles sont coiffées, dans chaque arrondissement, par une commission de réception, et doivent obtenir des communes qu'elles founissent les quantités de produits prévues pour chacune d'elles par le plan; les maires font connaître à leurs administrés ce qui est demandé par les commissions et les prix qu'elles proposent de payer, les achats sont faits à caisses ouvertes. Si les quantités spontanément apportées par les producteurs ne permettent pas de réaliser le contingent communal, le maire, jusque là simple intermédiaire, doit faire exécuter la réquisition des manquants. ${ }^{\prime 35}$

\footnotetext{
${ }^{31}$ Périgneux, où se trouve la gare la plus proche de Saint-Maurice-en-Gourgois

${ }^{32}$ L'emploi de "faire " au sens de "dire" était très courant en français populaire, mais a fortement décliné chez les jeunes.

${ }^{33}$ Cet emploi très particulier, par métonymie, de "réquisition" au sens de "ceux qui réquisitionnent" n'est apparu que cette fois-ci dans nos témoignages.

${ }^{34}$ Etant donné la rareté des automobiles en France, en 1914, a fortiori dans les campagnes, on ne peut interpréter ce terme "voitures" que comme "voitures hippomobiles" comme les chars à bancs (mais quel peut être leur usage à la guerre?) ou plus vraisemblablement, comme véhicules de transport de marchandises (chars à foin, tombereaux à pommes de terre, etc.) pouvant être tractés par les centaines de milliers de chevaux réquisitionnés, servant, entre autres, à tracter les canons et les caissons de munitions dans l'artillerie.

${ }^{35}$ Henri Gerest, Les Populations rurales du Montbrisonnais et la Grande Guerre publié en 1975 par le Centre d'Etudes Foréziennes de l'université de Saint-Etienne (qui ne s'appelle pas encore Jean Monnet), p. 115
} 
Henri Gerest signale dans une note que dans la Loire 17 commissions ont fonctionné, dont, en 1914, 5 dans l'arrondissement de Montbrison: Boën, Feurs, Montbrison, Saint-Galmier et Saint-Bonnet-le-Château. Trois autres seront créées plus tard dans la guerre: Noirétable, Saint-Rambert et Usson.

Dans le dossier sur la corrrespondance de ses parents que m'a aimablement prêté, en janvier 1990, Antoine Reymondon, agriculteur, né en mars 1916, au hameau de Sabonnaire, à Saint-Maurice-en-Gourgois, figurent deux de ces notifications de réquisition émanant de la commission de Saint-Bonnet-le-Château à l'adresse du grand-père maternel d'Antoine, "le sieur Fully Antoine": la première, datée du 13 septembre 1917 lui enjoint de fournir à l'administration militaire "cent quintaux métriques de foin", la seconde, datée du 8 décembre 1918 (mais l'arrêté municipal est du $1^{\mathrm{er}}$ décembre), requérant "12 quintaux métriques de pommes de terres de la récolte 1918"36, qui représente son quota sur le contingent global de "1 470 quintaux métriques" (donc 147 tonnes!) réclamé sans doute sur tout le territoire relevant de cette commission de Saint-Bonnet, bien que la formulation, mélangeant imprimé tamponné et manuscrit, laisse croire qu'il s'agit de la seule commune de Saint-Maurice, ce qui paraît invraisemblable. Pour la compréhension, nous adopterons trois polices, en conservant l'italique usuel gras pour le manuscrit, et en utilisant le caractère droit normal Arial Narrow pour l'imprimé et Arial Narrow gras pour le tampon:

"Avis Individuel - portant extrait de l'état de répartition établi, en exécution de l'article 20 de la loi du 3 juillet 1877 , pour la réquisition des pommes de terres de la récolte 1918 -

Le Maire de la commune de Saint-Maurice-en-Gourgois informe M. "Fully Antoine à Sabonneyre" qu'en exécution de l'ordre de réquisition notifié à la commune pour un contingent global de "1470 Quintaux métriques" le .......... .et de l'arrêté municipal en date du "1 $\mathbf{X b r e}^{37} \mathbf{1 9 1 8 ^ { \prime \prime }}$, il est tenu de fournir "Douze" quintaux métriques de pommes de terre de la récolte 1918, de qualité loyale et marchande."

Si les 1470 quintaux métriques concernaient la seule commune de Saint-Maurice-en-Gourgois, cela signifierait qu'il faudrait $1470: 12=123$ agriculteurs ayant des propriétés équivalentes (et produisant autant de pommes de terre!) à celle d'Antoine Fully, considéré, on le verra plus avant dans le chapitre, comme un "riche propriétaire" par la même commission, ce qui lui permet de refuser une allocation à sa fille Antonia qui, avec des domestiques, en l'absence de son mari Eugène incorporé, exploite la propriété, à 22 ans, son père étant âgé et mal voyant ...

Les denrées, qui sont de cinq types principaux selon Henri Gerest ("Le département a fourni aux armées essentiellement cinq produits agricoles: foin, paille, avoine, pommes de terre et viande" plus, en quantités très inférieures, orge, betteraves fouragères et vin: 13653 hectolitres, dont 20, $8 \%$ pour le Montbrisonnais) sont payées à un prix fixé par la commission départementale, parfois considéré comme raisonnable, mais parfois inférieur au prix du marché. Par ailleurs, les quantités réclamées ne tiennent pas compte des aléas climatiques: en 1916, l'intendance militaire a demande 388000 quintaux de foin pour la Loire, or le mauvais temps et le manque de main-d'oeuvre rendent impossible cette réquisition, et la commission départementale finit par la ramener à 200000 quintaux.

Les réactions des maires et des agriculteurs sont souvent hostiles, mais les premiers sont contraints administrativement d'obtempérer. Henri Gerest précise: "D'où protestations et mécontentement: des maires ont menacé de démissionner, des cultivateurs ont dî acheter des produits agricoles pour livrer la quantité demandée. Face à ces exigences, les producteurs résistent ou se dérobent d'autant plus que les prix de la réquisition finissent par être inférieurs à ceux du commerce, et que leurs besoins ont évolué". ${ }^{38}$

Parfois le préfet (ou, en l'occurrence, le sous-préfet de Montbrison) a recours à la force publique pour traquer les paysans et meuniers dissimulateurs: et frapper l'opinion publique: "Ce sont des commissaires de police et leurs agents qui procèdent aux perquisitions dont le sous-préfet surveille l'exécution. Ayant pris connaissance des déclaration faites en mairie et incité les cultivateurs à porter leur grain à un point fixé, ils visitent les fermes systématiquement et tout surplus constaté est frappé de réquisition. On découvre du grain camouflé dans des cuveaux de bois, dans des sacs enfouis sous la paille des granges ou placés dans des voitures; il est aussitôt chargé sur camions et dirigé vers les moulins de Montbrison. Le 6 juin, Feurs et sa région font l'objet d'une investigation systématique. Des minotiers ont fourni les noms des cultivateurs possédant des stocks; on a choisi un jour de foire pour mieux frapper les esprits. 30 tonnes de froment sont saisies à Chalain-le-Comtal, 27 à Saint-Laurent-le-Conche, 18 à Nervieux... Des meuniers, qui avaient fait d'importants approvisionnements dans l'attente d'une hausse, doivent abandonner les trois quarts de leurs réserves. ${ }^{139}$

\footnotetext{
${ }^{36}$ Donc pas de vieilles pommes de terre de la récolte de 1917, à supposer qu'elles aient pu se conserver...

${ }^{37}$ Cette façon d'écrire les mois se rencontre assez souvent à cette époque, et prête à confusion, le X ne devant pas être lu comme le chiffre 10 (ce qui renverrait à octobre) mais comme le latin $\mathrm{X}=$ « decem », donc décembre.

${ }^{38}$ Henri Gerest, op.cit., p. 120

${ }^{39}$ Henri Gerest, op.cit, p. 128-129
} 
On voit que, comme sous l'Occupation près de trente ans plus tard, la réquisition et la pénurie entrainent dissimulation, délation, et parfois spéculation (dans le cas des meuniers).

Il est dans la tradition rurale française, mais sans doute dans celle de tout pays, de chercher à dissimuler ses biens et récoltes quand l'Etat veut s'en approprier, ici pour une cause nationale juste qui dépasse évidemment les intérêts individuels, mais souvent par avidité des collecteurs d'impôts chargés de relayer, sous l'Ancien Régime, les exigences insatiables des Fermiers Généraux. On songe à ce court passage des Confessions, au livre IV, où le jeune Jean-Jacques Rousseau, se rendant à pied de Paris à Chambéry, en faisant étape à Lyon, en août 1731 (il a alors 19 ans) doit passer dans les environs de La Pacaudière, au nord du département de la Loire, et s'arrête dans la chaumière d'un paysan auquel il réclame à manger, moyennant paiement: "Il m'offrit du lait écrémé et de gros pain d'orge en me disant que c'était tout ce qu'il avait".. Mais le paysan, ayant vu au bout d'un moment que le marcheur était "un bon jeune honnête homme qui n'était pas là pour le vendre", change d'attitude: "Il ouvrit une petite trappe à côté de sa cuisine, descendit, et revint un moment après avec un bon pain bis de pur froment, un jambon très appétissant quoiqu'entamé, et une bouteille de vin", les offrit, et refusa le paiement de Jean-Jacques. Interloqué, celui-ci, citoyen suisse de Genève, lui demande la raison de la dissimulation, et le paysan, d'abord apeuré, finit par avouer qu'il fuit les collecteurs d'impôts: "Enfin il prononça en frémissant ces mots terribles de Commis et de Rats-de-Cave. Il me fit entendre qu'il cachait son vin à cause des aides ${ }^{40}$, qu'il cachait son pain à cause de la taille ${ }^{41}$ et qu'il serait un homme perdu si l'on pouvait se douter qu'il ne mourût pas de faim.". Et le Citoyen de Genève ${ }^{42}$, ami du peuple, de conclure l'anecdote en flétrissant la France et autres nations semblables qui pressurent d'impôts le Tiers Etat : " Je sortis de sa maison aussi indigné qu'attendri et déplorant le sort de ces belles contrées à qui la nature n'a déployé ses dons que pour en faire la proie des barbares publicains" 43

\section{Les diverses difficultés d'une très jeune femme pour gérer seule sa ferme}

Nous avons vu qu'il a plusieurs fois été question dans ce chapitre (c'est le hasard résultant de mes sources) de Saint-Maurice-en-Gourgois, gros bourg du plateau de Saint-Bonnet-le-Château, à l'extrémité sud-ouest du département de la Loire, et même, avec Jean Brun, du hameau de Sabonnaire. C'est dans ce même hameau que vivent les époux Reymondon, dont ce qui reste de leur correspondance m'a été prêté pour photocopie et étude par leur fils Antoine, né le 4 mars 1916.

Le mari, Eugène, né en févier 1878, a donc 36 ans et demi à la mobilisation, et il est de quinze ans plus âgé que sa très jeune épouse Antonia, née Fully, (née en 1893, donc n'ayant que 21 ans en 1914) originaire de Sabonnaire. Leur vie commune a été brève, car le mariage ne date que du 18 avril 1914, et il n'est pas question de concubinage précédant le mariage!

Fils d'agriculteurs du bourg de Saint-Maurice, Eugène est "venu gendre" à Sabonnaire, où il a pris en main la gestion du vaste domaine des parents d'Antonia, et associe à son activité paysanne un négoce déjà bien établi de machines agricoles. Mobilisé début août 1914 comme sergent au $3^{\mathrm{e}}$ Bataillon territorial de Barcelonnette, puis versé au $23^{\mathrm{e}}$ B.C.A. de Grasse en octobre 14, au moment de sa montée au front, Eugène a contracté la fièvre typhoïde en Belgique en décembre 14, et va d'hôpital en hôpital (Saint-Riquier, Abbeville, Bayeux), puis bénéficie en mai 1915 d'un congé de convalescence d'un mois chez lui, pour être enfin renvoyé au dépôt du régiment à Grasse. C'est au cours de cette permission que le petit Antoine, mon interlocuteur de janvier 1990, né le 4 mars 1916, sera «mis en route », comme on disait, au début du mois de juin 1915. Son père Eugène effectue ensuite un long stage de mitrailleur au $5^{\mathrm{e}}$ B.C.A. en subsistance à Antibes, et deviendra début 1916 sergent instructeur des jeunes de la classe 17 incorporés au $23^{\mathrm{e}}$ B.C.A..

Pendant ce temps, sa très jeune femme gère la ferme familiale, à l'aide de son père, déjà vieux et doté d'une très mauvaise vue, et d'un domestique, "le Vida" (il doit se prénommer Vital) qui lui donne du fil à retordre, et parfois de deux, avec "le Jean-Marie", qui partira de lui-même en octobre 1915. Dans ses lettres, elle a à cœur de prouver à son mari qu'elle fait face à la situation, mais certaines expriment son désarroi. Cependant, dans ce chapitre, nous n'évoquerons pas la partie psychologique (la relation de couple) qui trouvera sa place plus avant dans l'ouvrage, mais seulement les informations sur ses nouvelles responsabilités et celles qu'elle donne sur la vie à Saint-Maurice vidé de ses hommes jeunes ou dans la force de l'âge.

A propos des fenaisons, retardées par les pluies abondantes de cet été 1914, et le manque de main d'œuvre (et qui se faisaient beaucoup plus tard que l'ensilage actuel, surtout lorsque la commune était un peu en altitude), et des moissons qui suivent normalement, elle lui écrit le 5 septembre: "Nous aurions fini de faner

\footnotetext{
${ }^{40}$ Les aides, sous l'Ancien Régime, sont un impôt indirect sur la circulation des marchandises

${ }^{41}$ La taille, sous l'Ancien régime, est un impôt direct frappant tous les roturiers.

${ }^{42}$ Jean-Jacques Rousseau aimait faire suivre sa signature de cette fière mention "Citoyen de Genève", ce qui signifiait que, bien qu'écrivain francophone ayant longtemps vécu en France, il ne se considérait pas comme Français

${ }^{43}$ Ici "publicains" désigne des adjudicataires de l'Etat (comme les Fermiers Généraux) chargés de la collecte de l'impôt ou la réalisation de travaux.
} 
aujourd'hui s'il n'avait pas plu. Il ne nous reste que le foin du moulin ${ }^{44}$ à lever. Tout est coupé: froment ${ }^{45}$, orge et avoine, et, s'il fait beau la semaine prochaine, nous préparerons les gerbes pour battre à la machine". Elle n'indique pas dans cette lettre si cette batteuse (mue par une "loco" à l'époque, un tracteur à poulie plus tard, un peu avant ou un peu après la guerre de 1939-1945 avec une longue courroie de transmission en cuir) leur appartient, ce qui serait un indice certain d'aisance, ou, comme c'était plus courant, a été achetée par une collectivité de hameaux, à moins qu'elle n'appartienne à un entrepreneur privé, allant de village en village. La lettre du 5 septembre 1915 citée infra montre que c'est ce dernier cas, avec Pierre Bourgier comme entrepreneur de battage. Pour les battages, elle a eu du mal à rassembler des hommes, mais le chiffre qu'elle indique en septembre 1914 (26) montre clairement une exploitation riche, avec de grandes surfaces en céréales. L'année d'après, elle n'en trouvera plus que 10 , recrutés avec le plus grand mal le dimanche matin, sans doute à la sortie de la messe, ce qu'elle déplore dans sa lettre du 5 septembre 1915, un dimanche: "Il faut que je te parle des affaires de la maison. Ce matin, à St Maurice, j'ai demandé presque tous les hommes que j'ai rencontrés. Mais comme on battra le jeudi pour nous, à peu près tous m'ont refusét ${ }^{46}$. Il ne m'a été promis que quelques domestiques jeunes. Enfin, cette après-midi, je suis montée à Chaiseneuve. Pierre Bourgier y faisait travailler (à la batteuse) mais son monde travaillait mal. Quelques-uns avaient bu. Je l'ai grondé de m'avoir laissé* pour le jeudi et je l'ai mis en devoir de me procurer du monde s'il voulait faire le travail". Cette phrase signale l'existence d'une relation de dépendance entre le dénommé Pierre Bourgier et Antonia Reymondon: l'importance de la ferme Reymondon en fait un client à conserver, et Antonia le menace implicitement de recourir à un autre entrepreneur, et donc de la priver de sa clientèle pour les années à venir. Parmi le personnel participant au battage, un entrepreneur avait des employés qui faisaient toute la campagne, pour se procurer un revenu complémentaire ou pour une autre raison.. Antonia continue ainsi, montrant un succès partiel de son injonction: "L'homme pas sensible m'a tout de suite choisi 6 hommes parmi ceux qui battaient. Je l'ai remercié et suis revenue à Sabonnaire. Avec 14 que j'avais déjà trouvé*, ça me fait vingt. Je ne veux guère plus me déranger pour en chercher d'autres". Le fait que Bourgier puisse désigner six hommes sans qu'apparemment ceux-ci aient leur mot à dire indique une autre relation de dépendance: à la campagne, autrefois, tout était réglé par un troc de prêts de matériel, de services rendus, d'obligations ("tu me prêtes ton cheval pour piocher" - à la piocheuse tractée - "les betteraves ou les pommes de terre" - plantées en raies serrées, d'où le recours au cheval - et "je te le rends en journées"). Elle pense achever le recrutement sur place, auprès des quelques autres fermes du hameau de Sabonnaire, beaucoup moins importantes que la sienne, puisqu'elles n'occupent, à elles toutes, qu'une seule journée de battage: "Les deux jours qu'il y a à faire à Sabonnaire m'en feront peut-être trouver d'autres sur place"

Antonia passe ensuite à l'indispensable carburant de tous ces travailleurs: "Pour le vin, j'ai fait remplir le tonneau de 64 lit. ${ }^{47}$ à chez Badel » (sans doute un cafetier)

L'aisance financière de la famille Fully, selon les critères foréziens, est révélée par une fiche conservée dans le dossier, émanant de la commission cantonale de Saint-Bonnet-le-Château, relative à l'attribution éventuelle d'"Allocations aux familles des Mobilisés" (intitulé de la fiche, datée du 21 décembre 1915) indique que la demande de Mme Reymondon née Fully, a été rejetée aux motifs suivant, écrit à la main dans une fiche imprimée: "Pas d'enfant - Fille unique habitant avec son père riche propriétaire". "Pas d'enfant » en effet : Antonia est enceinte de cinq mois et demi au 21 décembre, mais ne sera pas mère avant le 4 mars 1916, ce qui modifiait alors son statut par rapport au premier critère de refus retenu. On ne barguignait pas avec la grossesse, dans les commissions cantonales, de la Loire et d'ailleurs !

\footnotetext{
${ }^{44}$ Le moulin (on attendrait Moulin) doit être le nom d'un pré, à proximité d'un moulin, en fonctionnement, en ruines, ou disparu.

${ }^{45}$ Le terme "froment" servait à désigner en Forez le blé proprement dit, le terme local "blé" ("blo/bla") en patois) qualifiant le seigle, qu'on pouvait aussi, dans certains lieux, appeler au féminin "la seigle"

${ }^{46} \mathrm{Ce}$ refus quasi collectif ne peut s'expliquer que par une activité mobilisant l'essentiel des hommes le jeudi. L'explication la plus vraisemblable paraît être le marché aux bestiaux de Firminy, qui avait lieu effectivement le jeudi, et où la présence des hommes était requise pour la vente des veaux et des porcs, éventuellement (mais bien plus rarement) l'achat de génisses et la vente de vieilles vaches, animaux qu'il fallait faire monter et transporter dans des tombereaux ou dans des carrioles adaptées, ce qu'une femme pouvait difficilement faire. Mme Jeannette Vincendon, membre de la Société de Généalogie de Firminy, propose une autre hypothèse: le jeudi de la semaine d'après aurait été celui de la plus grande foire annuelle aux bestiaux pour tous les agriculteurs des Monts du Forez, y compris ceux de Saint-Maurice-en-Gourgois, la fameuse Foire de la Croix de Saint-Anthème, en bordure sud-ouest du Puy-de-Dôme (foire dont j'ai entendu parler pendant toute mon enfance par les personnes âgées - «lo Fèir de lo Krouéi »- dans ma commune de la Loire, Chazellessur-Lavieu, limitrophe du Puy-de-Dôme), son nom renvoyant à la fête chrétienne de l'Exaltation de la Sainte Croix, célébrée en effet le 14 septembre. Mais un calendrier perpétuel nous révèle qu'en 1915, le 14 septembre tombait un mardi. Il faudrait donc supposer que cette grande Foire aux Bestiaux, notamment aux vaches Salers venue de l'Aubrac, pouvait être déplacée (en l'occurrence au jeudi 16 dans cette année 1915) si elle entrait en concurrence avec un marché important d'une ville voisine.

${ }^{47}$ Avec 64 litres pour une vingtaine d'hommes, Antonia a calculé un peu juste; mais la cave familiale fournira le complément...
} 
En 1915, Antonia ne peut que constater, après les battages, une baisse considérable de la production de céréales par rapport à 1914, car beaucoup moins de terres, sans doute, ont pu être emblavées, par manque de personnel masculin, et le temps n'a peut-être pas été aussi favorable aux cultures. Elle rend compte à son mari des quantités de céréales produites dans sa lettre du 9 septembre, en les évaluant, comme c'était la coutume, en doubles décalitres, cette mesure, récipient de bois ou en métal, figurant dans toutes les fermes pour manier aisément les grains, les ensacher notamment: "Nous en avons peu récolté: 185 de seigle, 41 d'orge, 52 de froment $^{\prime \prime 48}$, ce qui se monte à 278 doubles décalitres, soit guère plus de la moitié de la récolte de l'année précédente: 520 doubles décalitres (lettre du 17 septembre 1914).

Antonia fournit aussi à son mari des renseignements intéressants sur le menu des repas de batteuse, traditionnellement fournis, car le travail pénible exige qu'on restaure les forces des hommes et aussi parce qu'ils révèlent la générosité de la famille, qui sera commentée favorablement (la pingrerie - "se montrer rapia" - en ces occasions de travaux collectifs étant vite stigmatisée, et colportée, nuisant durablement à la réputation de la famille): "Quant à mes repas, j'ai mis le matin à 8 heures ${ }^{49}$ la soupe, saucisson, lard et fromage. A midi, viande en sauce, pommes de terre au four (le plat traditionnel), rôti, fromage et café. A souper: soupe, saucisson, salade de pois, riz au jus, rôt et fromage. Le tout était très bien apprêté. Je crois qu'il y en avait assez". On constatera que ce menu ne semble pas souffrir des restrictions alimentaires après plus d'un an de guerre, mais on est à la campagne, avec des provisions issues majoritairement de la ferme, et dans une ferme riche. Antonia est manifestement satisfaite d'avoir bien soutenu la réputation familiale, d'autant plus qu'elle est dans la ferme de ses parents, et elle avait même prévu plus large; elle parviendra à faire reprendre au boucher la viande de l'agneau tué qui n'avait pas été utilisée: juste équilibre entre prodigalité de bon aloi et économie... Elle a dû payer 2 francs pour la journée chaque homme, sauf l'un d'eux qui, on ne sait pourquoi, a exigé 3 francs; étant une femme, elle ne peut évidemment pas restituer en journées de travail chez les voisins la participation de ceux-ci à ses battages.

En dehors de ces gros travaux collectifs, comme ceux des battages, la jeune Antonia rend régulièrement compte à son mari du train-train de la ferme. Ainsi le septembre 1915, elle lui écrit: "Le taureau ${ }^{50}$ boite ces jours-ci. On ne voit rien à son pied. Il se serait peut-être rafoulế. ${ }^{51}$. Ce soir il parâ̂ssait* mieux marcher. Depuis plusieurs jours nous avons commencé de dompter une des braves ${ }^{52}$. On la fait herser tous les jours. Elle fait bien. Prochainement on pourra commencer à dresser l'autre. Le matin et l'après midi les hommes ${ }^{53}$ vont travailler aux grammes ${ }^{54}$, et à la matinée et le soir ils font de la feuille ${ }^{55}$. Le domestique laboure aux rivières. ${ }^{56}$ Le papa a dit qu'il le faisait bien.

Je voudrais bien acheter deux porcs pour engraisser. On m'a dit qu'ils avaient diminués*; mais je n'ai personne pour me les choisir. S'il ne pleut pas on ne pourra pas arracher les pommes de terre tant la terre est dure; mais ce temps est favorable au travail que nous faisons ${ }^{57}$. Je crois que tu n'auras pas à te plaindre. Je te fais des lettres assez longues malgré le peu de temps que j'ai".

\footnotetext{
${ }^{48}$ Le froment est le nom qu'on donnait en Forez au vrai blé, le terme "blo"/"bla" en patois ("blé" en français local étant faussement attribué au seigle, dont on voit que c'est de loin la céréale majoritaire à cette époque: plus de 3 fois plus que de seigle). A noter: l'absence surprenante d'avoine, pourtant nourriture préférée des chevaux; mais ceux-ci avaient été réquisitionnés.

${ }^{49}$ Une journée de battage commençait couramment à 6 heures, pour allonger la journée de travail et bénéficier de la fraîcheur du matin.

${ }^{50}$ La possession d'un taureau est un indice sûr de l'importance de la ferme, le reproducteur étant utilisé pour le cheptel important de la ferme et pour la saillie, payante, des vaches de fermes plus modestes ayant un troupeau plus réduit. Dans les petites communes, il n'y avait guère plus d'un ou de deux taureaux.

${ }^{51}$ Ce verbe de français local, qui n'est pas attesté dans l'ALLy (Atlas Linguistique du Lyonnais) et qui est inconnu de mon patois (celui du canton de Saint-Jean-Soleymieux), pourtant proche de Saint-Maurice-en-Gourgois, paraît signifier se donner une entorse, ici au genou.

${ }^{52}$ Cette expression signifie "domestiquer un génisse", pour l' accoutumer à porter le joug afin de servir d'attelage. Antonia francise en "dompter" le verbe patois "donda" signifiant "accoutumer au port du joug". Je l'ai vu faire assez faire assez souvent dans ma ferme familiale; il s'agissait soit d'atteler par le joug deux génisses entre elles, soit, bien plus couramment, d'atteler une vache plus âgée accoutumée au port du joug ("dondée" ou «donde ») à une génisse naturellement rétive au joug. On se contentait de les faire marcher ensemble plusieurs fois, sur une assez grande distance, puis de les atteler à un tombereau vide. Il fallait de nombreuses séances de ce genre pour qu'elles soient capables de tirer droit la charrue, ou de tracter un char de foin sans regimber ou s'arrêter net, tel un âne têtu.

${ }^{53}$ Les hommes, ce sont son père, âgé, et le domestique Vida (Vital) dont il sera question un peu plus loin.

${ }^{54}$ Le gramme, c'est le chiendent en patois et en français local forézien, mot directement dérivé du latin «gramen» signifiant «herbe » ou «plante». «Travailler au gramme», c'est l'extirper au croc (sorte de pioche à 4 dents fines) de la terre hersée pour éviter qu'il ne se multiplie l'année d'après, car c'est le cauchemar du paysan !

55 "Aller à la feuille" consiste à élaguer des arbres feuillus (en général des frênes bordant les chemins dans tous les monts du Forez) pour en faire des fagots qui serviront à nourrir les chèvres pendant l'hiver.

${ }^{56}$ Antonia doit oublier la majuscule: «les Rivières » sont sûrement le nom de terres situées à proximité d'une rivière.

${ }^{57}$ Le travail est principalement celui de labourer et "dégramiller" (extirper le chiendent), comme elle vient de l'expliquer, ce qui est plus facile quand la terre est sèche, car le chiendent sèche au lieu de s'enraciner à nouveau grâce à la pluie.
} 
Dans cet extrait, où patois et français local se mêlent au français correct, Antonia, qui n'a que 22 ans, montre à la fois qu'elle assure bien la direction de la ferme, qu'elle est capable d'initiative (elle veut acheter deux cochons - dont le prix aurait baissé, ce qui est surprenant en temps de guerre, mais tous les hommes au front sont autant de consommateurs en moins à la maison - afin d'avoir leur viande l'année d'après) mais qu'elle aurait besoin d'être guidée par un homme expérimenté pour effectuer un bon choix.

A cause de son jeune âge, malgré son statut de patronne (son père est âgé, et avait cédé la direction de la ferme à son gendre, âgé lui de 37 ans en 1915), elle souffre de son manque d'autorité face aux domestiques qui semblent réticents à être commandé par une femme, et une aussi jeune femme. Elle s'en plaint plusieurs fois à son mari, ainsi que du comportement d'un de ses oncles, sans doute un vieux célibataire vivant à la ferme, comme cela se pratiquait fréquemment autrefois, pour ne pas partager le domaine. Ainsi, dans sa lettre du 23 août 1915, elle lui écrit: "Quand je suis revenue à Sabonnaire (son hameau), il était près de 6 heures (18 heures). J'ai fait la soupe. Le Papa m'a dit que Jean-Marie et Vida n'étaient venus que tard pour sortir le bétail $^{58}$. Ils buvaient dans le village (au bourg de Saint-Maurice). Vida n'a pas voulu aller au champ ${ }^{59}$. J.M.a sorti les vaches, puis le papa qui ne voulait pas quitter la maison à* dit à mon oncle André qui se rendait de St Maurice un peu pompette de sortir les brebis. Il a grogné un peu puis finalement les a sorties. ${ }^{60} J e$ l'ai appelé pour souper à la maison. Comme il avait mis devant lui, pour se servir, l'assiette du fromage moitié sur la table, moitié en dehors, j'ai cru bon de lui dire gentiment: "Méfie-toi qu'elle tomberait"61 et en même temps je l'ai légèrement poussée sur la table. Figure-toi qu'il s'en est piqué (sans doute parce qu'il était bu*) et qu'il $m^{\prime}$ a incendié de sottises ${ }^{62}$ devant tous. Après avoir fini son verre il est parti. Oh! qu'il faut qu'il soit méchant quand même, car enfin je ne le méritais pas et ne lui avais pas mal parlé surtout. Ma pauvre Maman n'avait jamais pu le supporter, mais je ne m'en étonne guère. Le Papa ne lui a rien dit mais en a été fort attrappé* ${ }^{63}$. Vital, qui était un peu bu, en a profité pour nous critiquer à* Jean-Marie pendant qu'ils étaient à l'écurie. J'ai tout entendu. Et tout cela grâce à ${ }^{64}$ mon oncle. Je t'assure que j'en vois bien. ${ }^{65} \mathrm{Je}$ n'ai guère de contentements avec de tels personnages comme j'ai à la maison. Enfin j'offre bien tout à Dieu, les peines et le reste. Mais tout cela me fait beaucoup de peine. Ça se connaît que tu n'est* plus là pour m'appuier*. Oh! mon pauvre Eugène, qu'il faudrait bien que tu reviennes!"

On voit qu'Antonia reste bonne chrétienne malgré sa colère: elle pratique l'offrande à Dieu de ses peines (ses difficultés matérielles, les conflits qu'elle doit endurer, la douleur de la séparation d'avec son mari) pour que ses mérites et son absence de révolte devant l'affront, ou de représailles - comme le renvoi des domestiques; mais, même indisciplinés, ils sont trop précieux en ce temps de pénurie d'hommes - soient pris en compte dans la perspective du jugement divin décidant de l'envoi de l'âme au Paradis, au Purgatoire ou en Enfer...

Entre jeune patronne encore non aguerrie et domestiques en place, mais sans doute sollicités ailleurs, un subtil jeu de conflits et d'intérêts se déroule. Un mois et demi après la lettre précédente, le 2 octobre 1915, Antonia annonce à son mari Eugène le départ d'un des deux domestiques, Jean-Marie, et narre la petite comédie sociale qui a précédé ce départ, où une nouvelle intervenante prend sa part, la compagne dudit JeanMarie: "Ce soir J.M. est parti. Hier soir il a cherché tous les moyens de se faire renvoyer en nous disant certaines raisons ${ }^{66}$ auxquelles il n'a pas eu de réponse. En déchargeant un peu de pommes de terre qu'il avait

\footnotetext{
${ }^{58}$ Sortir le bétail au pâturage, dans l'après-midi, Antonia, dont c'est habituellement le travail, ayant rendu visite l'aprèsmidi, à leur demande, à deux tantes vivant dans un hameau éloigné, qui souhaitaient lui demander de pouvoir faire confectionner des fagots dans ses bois.

59 "Aller au champ" ou "en champ" signifie garder les vaches au pâturage, les prés n'étant pas encore clos de barbelés. Vital, éméché, doit refuser car il considère que ce travail ne fait pas partie des attributions normales d'un homme.

60 "Sortir" le bétail (les vaches, puis les brebis), ce n'est pas simplement le faire sortir de leur étable, mais le garder une heure ou deux au pâturage afin qu'il paisse; il n'y avait pas encore de prés "parqués" en ce temps-là, c'est-à-dire entourés de barbelés, qui économisaient le temps de la surveillance, sauf si l'on voulait "apartérer" l'herbe: la faire paître par petits secteurs, pour éviter qu'elle ne soit piétinée. Les clôtures électriques rendront ce service à partir des années 60 .

61 "Méfie-toi qu'elle tomberait": "Prends garde à ce qu'elle ne tombe pas" (par terre), le verbe "méfier", transitif et non pronominal, ayant le sens en patois et français local de "faire attention à" ou "remarquer": "Méfie-qu'elle en sait plus qu'elle en dit"!

62 "Qu'il m'a incendié de sottises": qu'il m'a lancé une bordée d'injures, ou de reproches

63 "Il en a été fort attrapé": fort surpris

64 "grâce à mon oncle": «à cause de mon oncle »; le contexte exclut le sens français, positif, de "grâce à", de même que tout usage ironique, par antiphrase, de l'expression.

65 "En voir", ou plus souvent "s'en voir", en français local, signifie "souffrir de quelque chose", "endurer des difficultés": Antonia "s'en voit" avec les domestiques et son oncle André, qui doit être un «vieux garçon », sans doute un frère de sa mère, ce qui expliquerait que son père n'ait pas réagi, ce qu'il n'aurait pas manqué de faire si André avait été son propre frère.

${ }^{66}$ Antonia rejoint ici un sens ancien du mot «raison» lorsqu'il est employé au pluriel. Ainsi le grand lexicographe contemporain Alain Rey, maître d'oeuvre de l'énorme «Dictionnaire Historique de la Langue française -Le Robert » (Paris, 1992), écrit : "chercher des raisons à quelqu'un », lui chercher querelle , "avoir des raisons avec quelqu'un », être en désaccord avec lui - $1835 »$ (p. 3074 de l'édition en taille réduite)
} 
arrachées, il nous traitait de mauvais riche ${ }^{* 67}$ et que de toute la maison il n'y en avait pas un qui puisse la gouverner. A tout cela je n'ai pas répondu un mot. Il n'a eu qu'à se taire. Mon oncle André a* qui j'ai répété ces paroles n'a guère été flatté. ${ }^{68} \mathrm{Je}$ crois bien que s'il s'y était trouvé sur le moment, ça n'aurait pas fait joli. Ce matin ce n'était plus son idée de vouloir s'en aller. Quand il buvait son café (donc le matin), il a dit au Papa: "Je vous avais bien dit que je partirais aujourd'hui; mais si vous voulez, je resterai bien encore. Le papa lui a dit de rester. Mais à midi sa belle est venue. Elle est allée le trouver à la terre. Lui est venu dîner ${ }^{69}$ avec nous, mais je n'ai pas vu elle jusqu'à 5 heures du soir que lui est arrivé pour s'habiller. Il est venu manger une portion au galop. Elle l'attendait au pré; mais je ne lui ai pas fait connaître que je l'avais vue. Il a bien fait le calin* avant de partir, disant qu'il était obligé de descendre ${ }^{70}$ pour arracher ses pommes de terre et qu'ensuite il remonterait. Ça c'est tout des contes auxquels nous n'avons pas répondu. C'est elle qui le mène. Elle est venue le chercher et il ne faut pas croire qu'elle le laisse revenir. Et puis, à ce que j'ai remarquer*, il consent bien à tout. Passe pour elle, mais c'est lui. J'aurais bien voulu qu'il reste encore au moins un mois. Mais il aurait fallu garder elle ${ }^{71}$ et encore pas sûr qu'ils soient restés. Ce n'était pas pour rien d'ailleurs. Lui pouvait faire sortir son mois; mais elle, pour ce qu'elle ne m'a que fait, et avec de telles dépenses pour sa nourriture, je pouvais être en retard joliment. ${ }^{72}$ C'est pour les pommes de terre que nous serons embarrassés. Il est vrai qu'il est de bonne heure et que les gens auront fini tôt. Probable qu'il se trouvera quelque ouvrier plus tard".

En effet, il n'y a pas que l'été où la présence d'hommes, en l'occurrence de domestiques, à la ferme soit indispensable; les campagnes foréziennes, dans la première moitié du $\mathrm{XX}^{\mathrm{e}}$ siècle, produisaient une abondante récolte de pommes de terre, arrachées évidemment à la main, à la pioche à quatre dents, et la campagne d'arrachage pouvait durer une, voire plusieurs semaines. Ici, Antonia espère, en raison de la précocité de la récolte, en cette année 1915, qu'une fois l'arrachage terminé dans les fermes des environs, il se trouvera des ouvriers agricoles occasionnels disponibles pour achever l'arrachage dans sa propre ferme.

Elle aura beaucoup de mal pourtant à trouver ces ouvriers agricoles. Trois semaines plus tard, dans sa lettre du 22 octobre, elle se plaint à Eugène: "J'ai demandé des hommes pour les pommes de terre. Il y en a 4 qui m'ont promis pour un jour, mercredi. J'en trouverais qui voudraient, mais il faut la compagnie et $^{73}$ tous ne s'accordent pas pour le même jour. Je te dis que c'est la galère pour faire faire son travail. Ceux du village qui n'ont rien à faire ne veulent pas aider. Il n'y a qu'à pâtir." Voilà qui met à mal les vertueuses évocations rétrospectives de la solidarité absolue dans les campagnes...

Après le départ du domestique Jean-Marie, voilà que l'autre domestique Vida (Vital en français) continue à faire des siennes de plus belle. Antonia fait part à son mari Eugène de nouveaux démêlés avec lui dans sa lettre du 12 décembre 1915: "Il est 9 h 1/2. Je viens de finir de traire avec Vida ${ }^{74}$ qui est saoul. Quand j'ai commencé ma lettre, il était $6 \mathrm{~h}{ }^{1 / 2}$ à peine. Lui était allé à la grange d'en bas pour faire des raves ${ }^{75}$. Il y est resté une

\footnotetext{
${ }^{67}$ On ne sait si Jean-Marie puise son expression dans l'Evangile, où le mauvais riche est souvent stigmatisé, ou dans le vocabulaire de la révolte sociale!

${ }^{68}$ On comprend que, dans ses reproches, le domestique Jean-Marie conteste la capacité de "gouverner la maison", donc de gérer la ferme, des trois membres de la famille: la jeune patronne Antonia, son père âgé, et aussi son oncle André qui doit être plus jeune que son beau-frère, le père d'Antonia. Il est clair qu'il conteste implicitement les ordres qu'on lui donne, et qu'il veut faire apparaître son départ comme une saine réaction à une aussi mauvaise gestion!

${ }^{69}$ En Forez rural, le dîner est encore le repas de midi, comme dans tous les romans de Balzac (première moitié du XIX e siècle). Pour ma part, bien que professeur de Lettres, je n'ai jamais pu me résoudre à appeler "déjeuner », le repas de midi et «dîner» le repas du soir) mais je ne l'appelle plus «dîner», comme ma mère et ses voisines et voisins le faisaient («dyina» en patois), et le font encore, en français, en 2012 : j'utilise les périphrases «repas de midi», et «repas du soir », comme beaucoup de gens connaissant l'usage du nord de la France, mais ne l'appliquant pas dans leur moitié sud de la France ! Tout en ayant constamment enseigné le bon usage contemporain à mes élèves, de 1973 à 2007 , mais en leur signalant la dérive sémantique des noms de repas depuis le XIXe siècle ...

${ }^{70}$ Jean-Marie doit résider dans un hameau ou un bourg situé plus bas que le hameau de Sabonnaire, donc vers Périgneux ou Chambles.

${ }^{71}$ On comprend ici que le fait que Jean-Marie ait une compagne ou une épouse (sans doute pas, car Antonia ne l'aurait pas appelée ironiquement "sa belle") implique qu'elle soit aussi nourrie, et peut-être logée, par l'employeur de son mari.

${ }^{72}$ Dans ce calcul, Antonia évalue l'intérêt de conserver Jean-Marie et sa compagne encore un mois: lui aurait pu, par son travail, compenser ce qu'il aurait coûté en gages et en nourriture, elle non!

${ }^{73}$ Ici, "il faut la compagnie" signifie que les ouvriers agricoles occasionnels contactés, se louant à la journée, ont, comme exigence implicite, d'être en groupe pour que le travail (fastidieux et très pénible pour le dos) d'arrachage des pommes de terre à la pioche à quatre dents soit plus intéressant, et ne dure pas des semaines, voire nettement plus d'un mois, si la surface est grande... Ce qui pourtant leur assurerait de l'emploi fixe pendant un bon laps de temps !

${ }^{74}$ La traite du soir (car à la fin de celle-ci Vital va se coucher) était normalement achevée vers 20 h; or elle s'est achevée à $21 \mathrm{~h} 30$, ce qui indique qu'Antonia est débordée de travail et que les horaires dérapent.

75 "Faire des raves" consiste à préparer des raves récemment récoltées en séparant les feuilles de la rave, en enlevant la terre sur la racine pivotante des raves, à tailler celles-ci en morceaux afin que les vaches ne risquent pas de s'étrangler en les avalant entières, à moins qu'il ne s'agisse de raves à cuire pour la pâtée des cochons.
} 
heure mais il a bien employé son temps! J'avais bien cloué une petite planche mince sur le bondon* ${ }^{76}$ de la pièce à cidre ${ }^{77}$, mais il l'a déclouée, arraché le bondon puis recloué la planche, et passé tranquillement un canon du foin (? peut-être à partir du fenil) entre la planche et le bois de la pièce. Profitant de ce qu'il n'avait pas fini quand moi $^{78}$ de traire sa vache, j'ai pu monter doucement à la grange et le hasard a fait que j'ai posé la main juste où il avait caché la bonde et son canon (= son verre) prêt à resservir. Le tout était derrière une poignée de foin, la place bien marquée. Il était gros, va, ce canon! Il pouvait en sucer! Je l'ai écrasé ${ }^{79}$ et j'ai conservé le bondon. Il vient de descendre se coucher et sera sûrement allé rendre visite à la pièce sans se douter que j'avais déniché sa cachette: mais il en trouvera bien d'autres: il n'en manque pas dans le foin! Je crois qu'en ce moment, s'il me tenait, je passerai un triste quart d'heure! Je ne lui en pas fait cas ${ }^{80}$ de tout le temps que nous avons fait le travail, ni même après, car j'aurais eu peur qu'il me donne quelque ${ }^{81}$ coup de fourche. Ah! Je t'assure qu'avec un pareil être, j'ai bien besoin de me soigner. Il aurait bien besoin d'aller un peu aux tranchées".

La jeune patronne enceinte terrorisée par le valet ivrogne et concluant sur le thème, bien ressassé depuis un siècle, et sans doute depuis bien plus longtemps du "il lui faudrait une bonne guerre", voilà qui est à la fois surprenant et conventionnel. On ne sait d'ailleurs pas pourquoi Vida n'y est pas, à la guerre, puisque la dernière phrase laisse entendre qu'il pourrait, qu'il devrait y être. Il n'a guère l'étoffe sociale d'un embusqué. Aurait-il quelque déficience?

Le penchant à la boisson de Vida revient occasionnellement comme thème des lettres, et va jusqu'à le faire partir en bordée lorsqu'il a de l'argent pour fréquenter les bistrots, de sorte qu'Antonia ne peut pas compter sur lui régulièrement; ainsi le 25 novembre, elle écrit: "Vida s'est montré hier après-midi. Il m'a aidé à traire le soir et ce matin. Mais il a encore de l'argent et quelque bouteille de goutte. Ce soir, après avoir passé la veillée je ne sais où, il s'est rendu ${ }^{82}$ assez ivre. J'ai pu l'avoir pour traire l'écurie d'en bas, mais à l'écurie d'en eau, il s'est tombé* dans le fumier avec sa seille (son seau) et le lait, c'est tout ce que j'en ai eu. S'il a un peu d'argent, je n'ai pas fini d'en voir et moi qui ne peux pas me tenir droite! "

Manifestement, si Antonia supporte toutes les incartades de son valet Vida, c'est qu'elle ne peut le renvoyer en cette période de pénurie de domestiques.

Antonia se préoccupe aussi de trouver une bonne pour la seconder, poursuivant ainsi, dans la lettre précédemment citée du 2 octobre 1915: "Quant à une bonne. Elles ne sont pas encore revenues de chez leurs maîtres et je ne pourrais sans doute qu'en trouver une plus tard. ${ }^{83}$. Je m'informe autant que je peux sur celles que je connais un peu, mais je n'ai pas l'occasion de bien voir de monde.". Or les servantes vont se raréfier, car comme elle l'indiquera plus tard à son mari Eugène, dans sa lettre du 13 décembre 1915, qui se trouve être un dimanche: "Eh bien, après la messe, le garde (champêtre) a demandé du foin à $7 f .25$ pour le ravitaillement, puis de l'avoine en quantité au prix de $25 \mathrm{f} 50$ les $100 \mathrm{~kg}$ et il a insisté pour que la commune fournisse cela. Puis il a dit qu'on faisait appel aux femmes et jeunes filles pour aller travailler dans les usines pour la guerre, et par ce moyen, pouvoir envoyer des hommes à l'armée. Il fallait pour cela se faire inscrire. Il y en a qui iront sûrement. Ce qui va finir de mettre rares les servantes. Hier j'en ai demandé une qu'on m'avait indiquée, mais sa mère m'a dit qu'elle tenait à la garder tout l'hiver. Je ne sais pas où j'en déchaverai* une ${ }^{84}$. On me conseillait celle du Tanfort qui était chez la Fanny Champagnat; après renseignements pris, elle n'est pas fidèle (honnête). Elle a été renvoyée pour avoir volé de l'argent que l'on a trouvé dans ses bas et son mouchoir de poche. Tout cela, je n'en avais rien su.". On aura compris que le garde-champêtre relaie auprès de la population une mesure gouvernementale: inciter la main d'œuvre féminine à s'embaucher dans les usines d'armements ou de fournitures pour l'armée pour libérer les hommes qui s'acquittaient jusqu'à maintenant de

\footnotetext{
${ }^{76}$ Le "bondon" est le nom en patois et en français local de la bonde du tonneau, le gros bouchon en liège fermant soit l'orifice de bas du tonneau, qui permet de tirer le liquide si on le remplace par un robinet, soit l'orifice du haut, qui permet de remplir le tonneau. La bonde est plutôt le bouchon du bas, mais on voit mal Vital ôtant la bonde: tout le cidre se répandrait dans la cave!

${ }^{77}$ Une "pièce" en Forez est un tonneau de 200-220 litres de contenance, soit le double d'une "cempote" (100 litres).

78 "Quand moi": cet usage, autrefois très fréquent en Forez de "quand" au sens de "en même temps ", s'est presque perdu, sauf chez les personnes âgées; on disait, à toutes les personnes, "il est venu quand moi/ quand toi / quand lui / quand nous..."

${ }^{79}$ Cette précision nous indique que le verre n'était pas en verre.

80 "Je ne lui en ai pas fait cas": je n'ai fait aucune remarque à ce propos.

${ }^{81}$ Il n'y a pas de faute d'orthographe ici, car ce «quelque » a une valeur indéterminée, et n'est pas un pluriel : Antonia ne craint pas de son valet plusieurs coups de fourche, mais un seul, qui pourrait lui être donné n'importe quand. Antonia rejoint ici un usage classique du XVII ${ }^{\mathrm{e}}$ siècle.

82 "Se rendre" employé intransitivement, en patois et en français local forézien, signifie revenir chez soi, en l'occurrence ici chez son employeur

${ }^{83}$ L'usage forézien pour les domestiques et les bonnes louées à l'année, était de commencer l'année de gages soit à la Saint-Martin (11 novembre), soit au Jour de l'An; les bonnes, au 2 octobre, n'ont donc pas achevé leur année de service.

${ }^{84} \mathrm{Ce}$ verbe patois de "déchaver" signifie découvrir en creusant; ici Antonia se demande où elle va bien pouvoir trouver une servante, le verbe expressif et concret insistant sur la difficulté de cette tâche.
} 
cette charge, et ce depuis plus d'un an déjà, en échappant au front, qu'ils vont devoir rejoindre, avec les périls que cela comporte... Quant au thème de la servante voleuse complétant celui du valet ivrogne, cela sentirait fort la comédie classique si ce n'était pas la triste réalité de la vie d'Antonia Reymondon. Et encore, son aisance financière lui permet-elle de pouvoir s'adjoindre les services d'auxiliaires masculins et féminins, ce qui est loin d'être le cas de toutes les épouses de cultivateurs...

Si l'on déborde un peu sur l'année 1916, on constate que dans sa lettre du 3 janvier, Antonia signale que la question de la bonne n'est pas résolue, et que les bonnes bonnes sont rares, donc fortement sollicitées: "La petite domestique qu'avait loué* la Claudia de chez Vida s'en est allée hier. Elle est bien planchée ${ }^{85}$, elle aussi! Tu vois ce que c'est que les bonnes. Je ne sais pas si je pourrais garder la Rigoune ${ }^{86}$. Il y en a plusieurs qui la demandent. Quant au couchage, je n'ai pas pensé de te dire qu'il m'était impossible de la faire coucher dans la maison du village ${ }^{87}$. Il y a trop de jeunesse. Je ne pourrais être tranquille. Je crois qu'il vaudrait bien mieux que j'achète un petit lit de fer pliant à une place" (pour la faire coucher dans la maison familiale). On voit que la jeune patronne s'inquiète aussi de la sauvegarde de la vertu de sa domestique: une jeune bonne isolée le soir et la nuit est une proie tentante et facile pour la "jeunesse" masculine du village, celle qui n'est pas encore incorporée, mais qui rêve de prouver sa virilité dans les combats de l'amour...

Antonia a d'autant plus besoin d'être secondée qu'elle dort très peu, se fatigue beaucoup, en étant enceinte, en octobre 1915, de quatre bons mois (son fils Antoine naîtra le 4 mars 1916). Ces journées de travail harassantes, dont elle parle peu par pudeur, fierté, dignité, il lui arrive pourtant de les évoquer, comme dans sa très brève lettre du 27 octobre, où revient l'obsession de l'arrachage des pommes de terre: "Mon chéri, Il est minuit. J'ai juste fini mes préparatifs pour demain. J'ai eu aujourd'hui 5 hommes pour les pommes de terre. Demain le papa en aura encore un. Je vais à Firminy ${ }^{88}$. Je vais bien. A demain une plus longue lettre car je n'ai que trois heures de repos. Toutes mes pensées. Antonia". Le lendemain, elle ne pourra pas faire la longue lettre annoncée: "Tout le jour j'ai été affreusement malade"...

La semaine d'après, elle n'est pas encore complètement remise. Elle écrit à Eugène le 5 novembre une lettre dont il convient de citer tout le début pour mesurer combien son travail d'agricultrice responsable de la ferme peut-être exténuant:, et combien l'effort d'écrire une longue lettre tous les deux ou trois jours peut être prenant, malgré le réconfort moral que cela apporte:

\section{Mon cher Eugène,}

"Sabonnaire le 5-11-15

Hier à la veillée j'étais tout à fait trop lasse pour t'écrire. je l'ai laissé pour ce matin. Oh si tu savais combien ces voyages à Firminy me sont pénibles. Je n'étais pas même remise de celui de jeudi dernier. Pour y aller il y a toute la facilité d'avoir le courier* et le tram ${ }^{89}$; mais pour venir du Pertuiset à Sabonnaire à pied, c'est trop long pour moi qui ne suis pas forte. Puis des personnes me disent aussi que ce n'est pas prudent pour mon état, que c'est trop fatiguant*. Je le sais bien et pourtant hier il a fallu que je fasse toute la route à pied. Tu ne peux pas croire comme j'étais lasse et, une fois arrivée, ne pas pouvoir me reposer une seconde. Tout était en désordre, tu le comprends bien. Le papa avait trois hommes ${ }^{90}$. Il avait de quoi se débrouiller, le pauvre, et il ne voit rien par moment. Ça fait certains jours. J'ai vite mis la soupe et fait la vaisselle de la journée. Quand les hommes ont eu soupé, je suis allée traire. Je t'assure que j'étais bien lasse. Tout le laitage d'hier est en retard. Il faudrait aller laver les torchons d'hier, mais je n'irai que l'après-midi, car je ne m'en sents* pas le courage. Je n'ai que le Duport aujourd'hui. Le Pierre Marie voulait aller à Saint-Bonnet ${ }^{91}$. Oh

\footnotetext{
${ }^{85}$ Cela signifie "elle (Claudia) est dans une situation difficile"

86 "la Rigoune": forme féminisée et patoisée du patronyme Rigaud, assez courant en Forez.

${ }^{87}$ Cette "maison du village" doit être une seconde maison que possède la famille Reymondon, au bourg de Saint-Maurice, ou, moins sûrement, au hameau de Sabonnaire.

${ }^{88}$ Il faut comprendre qu'Antonia se rendra le lendemain au marché hebdomadaire de Firminy, tenu le jeudi, pour vendre des produits de la ferme : beurre, œufs, peut-être volailles et lapins. Terminant sa journée du mercredi à minuit, elle devra se lever très tôt pour préparer les produits à vendre, aller à pied au bourg de Saint-Maurice pour prendre l'autocar, mais devra revenir du Pertuiset (localité située sur la rive droite de la Loire, au fond des gorges de ce fleuve) à pied, soit environ $12 \mathrm{~km}$ : $9 \mathrm{~km}$ du Pertuiset au bourg de Saint-Maurice (et $250 \mathrm{~m}$ de dénivelé, de $546 \mathrm{~m}$ d'altitude au Pertuiset à environ $800 \mathrm{~m}$ à Saint-Maurice, en bordure du plateau de Saint-Bonnet) et $3 \mathrm{~km}$ du bourg de Saint-Maurice au hameau de Sabonnaire)

${ }^{89}$ Le courrier est l'autocar qui assure le transport des voyageurs et du courrier de Saint-Bonnet-le-Château jusqu'aux abords d'Unieux-Fiminy, la ville de Firminy étant alors desservie par un tramway, qui permettait de gagner la place du marché

${ }^{90} \mathrm{Ce}$ sont trois ouvriers agricoles occasionnels venus pour l'arrachage des pommes de terre, dont le père d'Antonia a dû s'occuper, en l'absence de sa fille partie au marché de Firminy.

${ }^{91} \mathrm{Ce}$ sont deux des trois ouvriers agricoles dont il a été question. Il est à noter que le marché hebdomadaire de SaintBonnet-le-Château a lieu le vendredi.
} 
que je suis ennuyée! Le papa voudrait aller à Périgneux pour la foire. Pourtant il est impossible qu'il y mène des brebis ${ }^{92}$ et moi je ne peux pas y aller pour l'accompagner."

C'est très rarement que la vaillante jeune femme de 22 ans se laisse aller aux plaintes. Enceinte de cinq mois et demi, elle consent à s'octroyer, un matin d'un dimanche de novembre 1915, une grasse matinée...jusqu'à 6 heures du matin! Elle écrit à son Eugène un samedi soir, le 13 novembre: "Demain, comme je ne compte pas pouvoir aller à la messe, je ferai un bon matin dans mon lit. Je ne me lèverai qu'à 6 heures. Tu vas m'appeler paresseuse. Je le suis bien un peu par moments, mais plus tard je compte redevenir plus vaillante." Il y a toujours en elle, plus jeune de quinze ans que son mari (elle est née en 1893 et lui en 1878), le désir de bien faire de l'enfant travailleur par rapport à son père, ou de l'élève par rapport au maître d'école, et le souci constant de quêter son approbation.

Quand elle est exténuée, Antonia sent peser encore plus fort le fardeau moral de la séparation, et se laisse alors aller à évoquer l'évolution négative de sa grossesse. Ainsi dix jours plus tard, le 23 novembre, elle écrit à Eugène, qui après avoir été blessé, et avoir été hospitalisé, bénéficie d'une période de répit en effectuant un stage d'instructeur de mitrailleurs à Grasse, dont elle devine qu'il ne lui assurera pas d'éviter le retour au front: "Je me fais trop de mauvais sang, car il y a vraiment la place (vraiment de quoi). Te sentir loin de moi alors que j'aurais tant besoin que tu sois à la maison; et de plus toujours prêt à partir d'un jour à l'autre pour le front. C'est trop fort. Je ne sais si nos épreuves dureront longtemps, mais elles sont terribles en ce moment. Moi je souffre affreusement voilà déjà 15 jours. Ma jambe qui, comme je te l'ai dit, me fait de plus en plus souffrir, est bien l'effet de mon état ${ }^{93}$, et plusieurs femmes à qui j'en ai parlé m'ont dit que probablement cela durerait jusqu'à la fin. Hier et aujourd'hui je peux à peine me mouvoir; le bas des rheins* me fait mal aussi. Je ne puis absolument rien lever, même quand un seau ou une marmite est vide. Par moments j'en crierais. Tu vois que je suis dans un bel état et on me dit que si je me fatigue, je finirai par agraver* tout cela. Pourtant comment faire pour ne pas me fatiguer? C'est impossible. Il y a du travail aux écuries et à la maison aussi."

\section{Hausse des prix des denrées alimentaires, pénurie, mécontentement généralisé et agitation sociale}

Si nous avons évoqué si longtemps le cas d'Antonia Reymondon, c'est bien sûr que sa correspondance partiellement conservée, et complète sur cette période, nous permet de jeter un regard très précis, au jour le jour, sur ses épreuves personnelles. Mais celles-ci deviennent emblématiques et représentatives de toutes celles que subissent les épouses, les mères, voire les jeunes filles. Encore Antonia bénéficie-t-elle d'un avantage très appréciable: elle appartient à une famille aisée, de plus paysanne, pour laquelle ne se pose pas la question cruciale de la nourriture. Cela la met objectivement, malgré ses souffrances, en position de privilégiée. Car déjà, après plus d'un an de guerre, se pose le problème, pour l'Etat, de l'approvisionnement alimentaire de la population, donc pour beaucoup de citoyens, et surtout de citoyennes, l'angoissante question: qu'allons-nous manger?

Sa correspondance avec son mari Eugène, une fois de plus, nous permet d'éclairer cet aspect en cet automne 1915. Alors qu'elle fréquente régulièrement le marché de Firminy, ce qui lui permet de voir l'évolution des prix, elle n'a jamais signalé d'incident majeur jusque là. Or à partir de la mi-novembre 1915, les indications alarmistes commencent à parsemer ses lettres.

Le 13 novembre, elle écrit à Eugène: "A la messe, M. le Curé $\grave{a} *$ lu une lettre invitant les fidèles à prêter leur argent pour la guerre ${ }^{94}$. Je crois que de tous côtés ça tire $e^{95}$. On a taxé les farines et à partir du 25, on diminuera le prix du pain ${ }^{96}$. A Firminy c'est affreux. On* est pas maître de la marchandise ${ }^{97}$. Jeudi J.B. devait avoir une vingtaine de femmes qui lui enlevaient le beurre malgré lui. On l'insultait. Le beurre se vendait 42 sous $^{98}$ et il paraît qu'il a vendu ses æunfs 3 fa douzaine. Moi il y 7 semaines que je n'en lève pas un seul."

\footnotetext{
${ }^{92}$ Périgneux n'est distant que de $5 \mathrm{~km}$ de Sabonnaire, mais la très mauvaise vue du père d'Antonia lui interdit de pouvoir assumer ce trajet seul avec les brebis qu'il aurait l'intention de vendre à la foire.

${ }_{93}^{93}$ On aura remarqué avec quelle pudeur Antonia évoque son "état" de femme enceinte

${ }^{94}$ On voit que malgré les affrontements peu lointains de l'Eglise et de l'Etat (l'abolition des congrégations religieuses enseignantes, consécutive à la loi de séparation de l'Eglise et de l'Etat de 1905, a laissé des traces profondes dans les campagnes), l'Eglise apporte son soutien à l'Etat pour diffuser l'idée du devoir de souscrire à l'emprunt national.

95 "Ça tire" est une expression de patois et de français local signifiant "l'argent manque" ou "la nourriture manque"; on dit encore couramment, d'un ménage très pauvre: "Oh! ça tire chez eux!". Dans un autre contexte social, celle de gens relativement à leur aise, cette phrase, souvent entendue, peut aussi signifier "ils économisent à l'excès en se privant de nourriture... et en mesurant chichement la nourriture et la boisson à la servante et aux valets. »

${ }^{96}$ Il faut comprendre que l'Etat impose une baisse du prix réglementaire du pain, mais comme le prix de la farine a augmenté fortement, il faut modifier la composition du pain (plus que $74 \%$ de farine, comme l'indique la lettre du 17 novembre)

${ }_{97}^{97}$ Cela signifie que l'agriculteur, au marché, ne peut pas vendre sereinement ses denrées comme il le voudrait.

${ }^{98}$ Pour les jeunes lecteurs qui n'ont pas connu le sou: c'était la $20^{\mathrm{e}}$ partie du franc; une pièce d'un franc (ancien, d'avant la réforme monétaire de 1960), valait 20 sous, et les personnes âgées disaient couramment: "une pièce de vingt sous" pour un franc, et "une pièce de cent sous" pour cinq francs, et ce, encore dans la décennie 1970-1980. Tout comme elles
} 
Certes, pour les agriculteurs qui ont des denrées à vendre, au marché ou non, la hausse des prix est une aubaine. Mais l'effet d'enchaînement de la hausse se traduit aussi par une augmentation des fournitures de tous ordres. Le 17 décembre, Antonia revient sur le thème du pain réglementé et de la hausse des prix: "Il paraît qu'à partir de lundi on va manger le pain national à $74 \%$ de farine. Il ne sera pas fameux. Les génisses audessous de deux ans ne doivent pas être vendues et doivent être déclarées à la mairie. Donc hier, à Firminy, il paraît que les veaux valaient 40 sous (le $\mathrm{kg}$ ) et au-dessus. Cette fois on y est, à la famine. On a taxé le prix du froment à $30 \mathrm{f}$ (le quintal) je crois."

Une économie de guerre, de gestion de la pénurie alimentaire, se met donc en place, et les maires se voient contraints à relayer les contraintes étatiques auprès de leurs administrés, ce qui ne doit pas les réjouir, mais les affecte sûrement moins que le pénible devoir d'apprendre les décès des soldats aux familles.

Le 19 novembre, les thèmes de la pénurie et de l'inflation se mêlent dans sa lettre, associés à celui du départ de la classe 17 au service militaire (pas encore à la guerre, puisqu'il y a une période d'instruction faite au dépôt du régiment: dans sa ville de garnison): "Je crois que les jeunes gens de 17 ans ${ }^{99}$ vont partir au commencement de janvier ${ }^{100}$. On en envoye* aussi dans les usines. Bientôt il n'y aura plus de monde et plus d'argent. Tout est affreusement cher. Les porcs valaient jeudi jusqu'à 95 fle quintal, les veaux 40 à 42 sous (le $\mathrm{kg})$. Aussi tout ce qu'on achète est à des prix fou* et on ne trouve pas en quantité comme autrefois. J'ai suivi ce matin tous les épiciers ${ }^{101}$ pour trouver une vessie de porc pour faire le fromage. Il n'y en avait que chez Cusset et au prix de un franc pièce."

Le 26 novembre, sa lettre signale la montée de l'agitation sociale à partir de l'exemple du marché de Firminy: "Hier, à Firminy, on a fait bazard* ${ }^{102}$. On renversait les paniers, on prenait les livres de beurre sans payer. Ça ne faisait pas beau! La révolution n'est pas loin. On parle de faire le pain national, c'est-à-dire la farine toute pareille à $74 \%$, pain de luxe et autre. Je ne sais pas ce qu'on va voir."

Ainsi, au bout de quinze mois de guerre, les tensions s'exacerbent, les prix flambent. A $12 \mathrm{~km}$ de la ville la plus proche, Firminy, dans son hameau de Sabonnaire, Antonia en vit les retombées, mais la lucarne sur la vie citadine qu'ouvre la fréquentation régulière du marché du jeudi à Firminy, et les nouvelles que d'autres en rapportent si l'on a manqué une semaine, révèlent des convulsions sociales, sans doute amplifiées dans de plus grandes villes, comme Saint-Etienne (à $30 \mathrm{~km}$ ) ou Lyon (à $95 \mathrm{~km}$ ).

Ce mécontentement citadin, Yves Pourcher, dans Les jours de guerre, l'a repéré et lui a trouvé aussi d'autres causes que celles que nos témoins permettent de repérer:

"Parce que la guerre dure, le mécontentement gagne la ville. Il porte sur les prix, le ravitaillement et sur tout ce qui heurte les habitudes, le regard, la raison ou l'illusion. Quant vient l'été 1915, et durant l'automne qui suit, la question des loyers divisent les parties. Le moratoire ${ }^{103}$ que l'on prolonge pendant toute la durée de la guerre provoque la menace des uns et la colère des autres. Dans le $19^{e}$ arrondissement, les propriétaires crient bien fort qu'ils doivent être payés par les occupants ou par l'Etat. [...] L'inflation est générale touchant les denrées alimentaires, mais aussi le charbon, les tissus, le cuir et les objets manufacturés. Partout la population se plaint de l'inertie des autorités et surtout de l'absence de réelles mesures prises contre les intermédiaires et les spéculateurs. "104

Pourtant l'Etat a pris des mesures financières pour aider les familles des mobilisés. Yves Pourcher les précise: : "Solennellement, la loi du 5 août 1914 octroie à toute famille nécessiteuse dont le soutien est mobilisé une allocation journalière de 1,25 franc plus une majoration de 50 centimes par enfant à charge âgé de moins de seize ans ${ }^{105}$. Il se livre à une étude détaillée, en quatre pages, de la Corse, et n'hésite pas à parler de fraude, plus étendue dans "lîle de Beauté" qu'ailleurs en France: un des arrondissements corses atteindrait 83\% de nécessiteux! Pourcher n'hésite pas à écrire que cette allocation de guerre a créé une certaine prospérité inconnue avant la guerre, et a amplifié la circulation de l'argent dans des campagnes où dominait le troc:

disaient, dix ou vingt ans après : « un billet de mille », de cinq mille, de dix mille » (pour « de 10 francs, de 50 francs, de 100 francs. »)

${ }^{99}$ En fait ce sont les jeunes gens de 18 ans (nés en 1917) qui vont être incorporés, mais ceux nés en décembre 1897 n'ont pas encore leurs 18 ans, donc peuvent être considérés comme n'ayant que 17 ans; cette généralisation de l'âge de 17 ans à toute la classe 17, y compris à ceux nés en janvier-février 1917, proches de leurs 19 ans, souligne l'effarement d'Antonia de voir "partir" des hommes aussi jeunes, qu'à l'armée, on a appelés «les Bleuets ».

${ }^{100}$ La classe 17 partira effectivement en janvier 1916, alors que la classe 18 (qui a globalement 17 ans en 1915) partira en avril-mai 1917, à 19 ans (révolus pour ceux du début de l'année, à venir pour ceux du deuxième semestre).

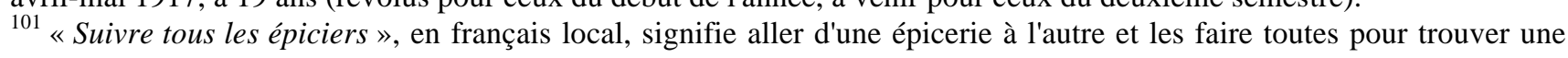
marchandise.

102 "Faire bazar" ou "faire chambard", c'est susciter ou manifester de l'agitation sociale, ou individuellement, faire un scandale

${ }^{103}$ Le moratoire est la suspension du paiement des loyers des familles de locataires dont le père de famille est au front, ce qui ne manque pas d'irriter tous les propriétaires!

${ }^{104}$ Yves Pourcher, op.cit, p. 166

${ }^{105}$ Yves Pourcher, op.cit, p. 100 
"L'argent de la guerre que l'Etat lance par larges poignées arrive de tous côtés: les allocations, les aides, les différents secours pour prix du départ des hommes, pour coût du travail acharné que ceux qui restent donnent. Ici il écarte seulement la misère parce que les besoins sont grands et la vie chère; ailleurs, dans les pauvres campagnes du pays, il compense largement le salaire du journalier. L'Etat achète le silence, la soumission quotidienne à cette guerre de fantassins qui a pris les hommes et donné l'allocation » ${ }^{106}$

On ne mentionne quasi jamais, dans les ouvrages consacrés à la Grande Guerre, ces diverses allocations, comme s'il était indécent d'évoquer des compensations financières pour prix de l'envoi des soldats au front, donc pour prix de leurs souffrances, de leurs blessures, peut-être de leur mutilation ou de leur mort. Pratiquement aucun de mes témoins n'évoque la question, comme si elle diminuait le mérite de leur famille. Il s'en est trouvé un seul pour aborder franchement et assez longuement la question, ce qui nous révèle aussi l'existence d'aides financières annexes: des municipalités et parfois des caisses de secours des entreprises importantes.

C'est Claudius Mestrallet, né en janvier 1896 à Roche-la-Molière, fils de mineur et de nourrice, orphelin de père à six ans, en 1906, devenu lui-même mineur à 13 ans à Roche, pour subvenir à ses besoins et à ceux de sa mère qui a été longuement hospitalisée, et incorporé à 19 ans, en avril 1915, au $1^{\text {er }}$ Régiment d'Artillerie de Montagne de Grenoble:

"Moi, j'avais ma mère, elle pouvait pas travailler, on avait rien, pas de pension, rien! Si: j'avais l'allocation de la Mine, de 53 sous par jour. Alors, ma mère, elle avait rien! Si: elle avait $10 \mathrm{~F}$ de caisse de secours par mois.

E- La Mine vous versait 53 sous?

T- Non, non! C'est le gouvernement, là! Mais la Mine, comme mon père avait été mineur, la Sécurité sociale de la Mine (dans ce temps-là, la mine avait une Sécurité sociale), on lui donnait $10 \mathrm{~F}$ par mois, ce qui payait notre loyer. Autrement, à part ça, elle avait rien. Alors quand je suis parti à la mine, j'avais 53 sous de la Mine qu'ils me donnaient; les veuves, comme ça, ou bien... Y a des endroits qu'ils touchaient tous! Ça dépendait tout de leur commune: y a des communes qui donnaient rien: à Saint-Genest (Lerpt)... y a des communes... comme Chambefort, y avait Perrin, les Sadeusse, qu'on appelait, ils touchaient rien! D'autres endroits qu'ils vous disaient: "Ils touchent tous chez nous!". Ça dépendait tout de la commune, des mairies!"

Pour clore ce chapitre, dressons un bilan: la guerre, en 1915, depuis le départ massif des hommes jeunes et dans la force de l'âge (de 20 à 47 ans, et bientôt de 19 à 47 ans), a, malgré l'aide financière de l'Etat, empiré le sort des femmes de l'immense majorité du peuple, a poussé parfois à leur exode vers la ville (en quittant la campagne pour aller travailler dans les usines d'armements ou de fournitures militaires), a empiré le sort des hommes plus mobilisables (car quinquagénaires et au-delà) en les obligeant à combler, surtout dans l'agriculture, le départ à la guerre des fils et des gendres, et a donné aux très jeunes gens, au-dessous de 18 ans, de lourdes responsabilités... Et la guerre durant, les prix montant, les hommes mourant ou revenant mutilés, le mécontentement s'est mis à enfler, surtout dans les villes...

Pourtant la guerre a aussi joué pour les femmes, obligées de suppléer à l'absence des époux, ou des hommes valides en général, mobilisés par le conflit, un rôle émancipateur, en leur permettant d'affirmer leurs compétences, qui n'étaient guère connues que pour les rurales, qui ont toujours tenu un rôle important dans le travail de la ferme. Ou pour les ouvrières quand elles travaillaient en usine et non chez elles, à la façon.

Sur cette question de l'émancipation féminine, nous déborderons le cadre de l'année 1915, car nous ne reviendrons plus sur ce thème. Cédons la place à une spécialiste pour une vision générale portant sur toute la guerre, et comparant la France aux autres pays belligérants, voire neutres parfois.

Dans sa contribution à "L'Encyclopédie de la Grande Guerre » réunissant, sous la direction de Stéphane Audouin-Rouzeau et de Jean-Jacques Becker 54 historiens de la Grande Guerre (42 Français et 12 autres, de 6 nationalités, dont les analyses s'étalent sur 1343 pages), contribution intitulée " Femmes et genre dans la guerre»(pp. 613-625), Françoise Thébaud, professeur d'histoire contemporaine à l'université d'Avignon, spécialiste de l'histoire des femmes au $X X^{\text {ème }}$ siècle, met quelque peu en doute l'unanimité qui semble établie dans le grand public quant à la valeur émancipatrice de la Grande Guerre pour les femmes en général : "La guerre a-t-elle émancipé les femmes? Malgré les analyses nuancées des historiens, l'opinion commune répond souvent positivement, particulièrement en France où s'est imposée l'image de la garçonne ${ }^{107}$ des années 1920.[...] Une première façon de répondre à la question est en effet de la contester et de souligner

\footnotetext{
${ }^{106}$ Yves Pourcher, op.cit p. 109

${ }^{107}$ Néologisme popularisé par le roman de Victor Margueritte, publié en 1922 et intitulé précisément «La Garçonne », qui fit scandale par ses audaces : une jeune femme, apprenant que son fiancé la trompe, décide de lui rendre la monnaie de sa pièce en menant une vie sexuelle très libre, en multipliant désormais les aventures. Ce roman, publié juste après la Grande Guerre, rappelait à la fois les infidélités de certaines épouses envers leurs époux cantonnés au front (thème du «Diable au corps » du très jeune Raymond Radiguet, paru en 1923), et paraissait encourager les jeunes femmes à réclamer et à pratiquer la même liberté de moeurs que leurs partenaires masculins (ce qui n'étonne plus guère aujourd'hui !). En guise de marque d'infamie, l'auteur se vit retirer sa Légion d'Honneur !
} 
que la guerre est avant tout une épreuve pour les femmes comme pour les hommes. Aux mères et aux épouses, aux jeunes filles condamnées au célibat, elle apporte d'abord la souffrance de la séparation et de la disparition d'être chers, même si le deuil est inégalement partagé entre nations (10 millions d'hommes sont morts au combat, dont 1,3 million de soldats français -soit 10\% de la population masculine-, 1,8 million de soldats allemands, 750000 Britanniques) et groupes sociaux: les longues listes des monuments aux morts des villages français disent le tribut payé par la France rurale et paysanne, sans compter les blessés et les mutilés. Pour beaucoup, la guerre impose aussi des pénuries qui pèsent particulièrement sur les femmes chargées de nourrir, de vêtir, de chauffer leurs familles, au prix de queues, de longs trajets et d'ingéniosité. »

Sa deuxième façon de répondre est d'observer, pays par pays, les preuves de l'émancipation à travers l'accès au droit élémentaire de la citoyenne, le vote. Dans trois pays du Nord de l'Europe (Finlande, Norvège, Danemark) l'obtention du droit de vote a précédé cette guerre. Au Royaume-Uni, la lutte des «suffragettes » n'aboutit à la vraie égalité devant le vote qu'en 1928, une forme inégalitaire (femmes au-dessus de 30 ans) ayant été obtenue en 1918. On sait qu'en France, il fallut attendre avril 1944 pour la loi, et 1945 pour le premier vote.

Du côté de l'entrée des femmes dans le travail salarié extérieur, le bilan est mitigé, alors qu'on le croit souvent exclusivement positif, et dépend des pays : "Demi échec en Allemagne, la mobilisation des femmes comme remplaçantes et ouvrières de guerre est particulièrement forte au Royaume-Uni, avec une croissance de 50\% de la main d'ceuvre féminine entre 1914 et 1918, ou 1 million de femmes travaillent dans les usines de guerre (en France, la croissance est de $20 \%$ et le chiffre de 400 000) [...] Après une démobilisation brutale fin 1918, le bilan est nuancé. La baisse globale de l'activité féminine recouvre bien des changements en France comme dans d'autres pays européens. Le recul des emplois domestiques, dénoncés comme asservissants, s'accélère. Malgré l'opposition des syndicats, l'expansion du travail féminin à l'usine se confirme, du moins dans la grande industrie moderne taylorisée (métallurgie légère et industrie électrique) qui confie aux femmes - leçon de la guerre - les travaux répétitifs non qualifiés. Les emplois tertiaires se féminisent »

L'auteur se concentre ensuite sur les violences faites aux femmes durant cette guerre, mutilant leur émancipation, violences quelque peu occultées par la mémoire collective, notamment pour les régions occupées pendant quatre ans par les Allemands au nord-est de la France : "Les rares témoignages recueillis par l'auteur de cet article dans les années 1980 souligne que l'occupation du nord de la France avait été plus durement ressentie en 1914-1918 qu'en 1939-1944, souffrances oubliées dans les mémoires collectives parce que, souligne aujourd'hui Annette Becker, les victimes en étaient essentiellement des femmes et qu'il ne fallait pas se distinguer de la France victorieuse. "

Nous verrons, dans un chapitre proche de la fin de l'ouvrage, qu'au moment de la libération de cette zone grise (couvrant en totalité ou en partie dix départements français), libération faite d'août à début novembre 1918 par les armées françaises et alliées, la découverte des conditions de vie réelles des femmes, des vieillards et des enfants, se fit, et bien des atrocités furent révélées, sans compter une oppression quotidienne étouffante, atrocités ou multiples vexations journalières que ne connaissaient pas toujours les époux, les fiancés ou les fils au front, en raison de l'absence de courrier et de l'impossibilité d'avoir une permission chez soi. Une vérité qu'il n'est guère séant de répéter aujourd'hui, alors que, fort heureusement, depuis 1950, l'ennemi de trois guerres est devenu l'ami, et le principal partenaire économique et politique, et que s'est édulcoré le vocabulaire des médias et des «décideurs»: les atrocités de la Seconde Guerre mondiale n'ont plus été commises que par les «troupes nazies », troupes toutes qualifiées de l'infamant sigle « $S S$ », alors que les Sections Spéciales étaient très minoritaires au sein de la Wehrmacht...

Revenons, paradoxalement, pour conclure, au tout début de l'article de Françoise Thébaud, qui souligne la place non marginale des femmes dans cette guerre d'hommes : "Les femmes sont donc au cœur de la guerre: figures essentielles de l' "autre front" (ouvrières, paysannes, infirmières), corps soumis aux barbarie de l'ennemi, victimes et icônes du deuil... ${ }^{108}$

\section{$* * *$}

${ }^{108}$ Françoise Thébaud, article «Femmes et genres dans la guerre », in » Encyclopédie de la Grande Guerre 1914-1918 », éditions Bayard, Paris 2004, pages 614, 615-616, 617-618, 622 et 613. 


\section{Chapitre 12}

1915 (janvier à septembre) : Un soldat d'allure nouvelle face à des armes nouvelles ou renouvelées 


\section{Chap. 12 - 1915 (janvier-septembre) : un soldat d'allure nouvelle face à des armes nouvelles ou renouvelées, à la veille de la grande offensive de Champagne}

"L'armée française a fait partir les Poilus en rouge: ils se voyaient de loin! Une chose qu'il fallait toute foutre... (en l'air), le rouge! Quand on a mis la couleur grise, les types se sont heurtés à des soldats! Parce que nous étions vraiment des bons soldats!". Louis Soulier, classe 1914, Saint-Etienne

"Nous avons touché des couvertures et des casques d'acier, destinés à nous protéger la tête, mais je les ai pas encore vus." Journal de Joseph Sorgues, classe 1915, Romanèche- Thorins (Saône et Loire), à la date du 7 septembre 1915.

"Il fallait aller ravitailler, aller chercher les torpilles pour les...les... Oh! la la! Comment qu'on les appelait? ...les crapouillots! Toute la nuit, allez, hop! Vous preniez la garde, facilement deux heures. On venait te relever, il te fallait aller aux crapouillots. Vous reveniez, vous vous couchiez une heure. Facilement, allez! Il fallait tourner prendre la garde! ...Ces canons, ces crapouillots, ils allaient pas extrêmement loin, mais ils étaient dangereux!" Claudius Recorbet, classe 1915, Saint-Romain-le-Puy.

"Même lorsque nous creusons des tranchées, il arrive que la pioche découvre ou les pieds ou la tête de quelques pauvres malheureux enfuient* ${ }^{*}$ ci de là par les torpilles, les obus ou les mines souterraines.

Ce n'est pas assez affreux. Ils paraît* qu'ils (les Français) cherchent a* se servir de gaz asphixiant*. Une lettre de Geneviève m'apprend que le frère d'une de ses amies a été envoyé à Paris pour l'essai de cette terrible chose: les gaz asphixiant.*" - Récit de guerre de Claude Coupade, classe 1915, La Ricamarie

\section{Le nouvel équipement du soldat français à la veille de la bataille de Champagne}

\section{L'équipement au début de la guerre décrit par un soldat qui a été fait prisonnier presque tout de suite, puis précisé par un manuel du fantassin}

Jean-Pierre Surieux, dit "le petit Jean-Pierre", mon grand-oncle du côté maternel, est mon premier témoin, interviewé le 11 novembre 1974 en patois de Saint-Jean Soleymieux (né à Chazelles-sur-Lavieu; ma commune d'origine, en 1891, agriculteur à Margerie-Chantagret, au hameau de Rossigneux; dès son mariage après la guerre de 14-18) et mort en 1981. Incorporé au $16^{\mathrm{e}}$ R.I. de Montbrison en 1912, il se trouve à Colmar lorsque la guerre éclate; il est fait prisonnier le 18 octobre 1914 sur la route de Lens et passera quatre ans en captivité en Poméranie, principalement dans une ferme à Rumpel, près de Bad Oldesloe. Il n'a connu que l'équipement du début de la guerre: "Nous autres, on n'avait que le fusil Lebel, et puis les cartouchières: deux devant, une derrière; et puis le sac, l'as de carreau ${ }^{\prime}$ qu'on appelait où y avait nos vêtements, nos chemises, le principal. Et puis une couverture de tente. Et puis on avait une bêche pour creuser dans la terre. Et puis on avait la gamelle pour manger la soupe.." On remarque que la couleur de l'uniforme n'est pas mentionnée, et qu'aucune critique des fameux pantalons rouge garance n'apparaît, même dans la suite de l'entretien.

Une description beaucoup plus complète et de fait, tout à fait exhaustive, de l'équipement du début de la guerre nous est fournie dans le "Petit manuel illustré du Soldat", surtitré "L'infanterie en cent pages" édité en 1914 par la librairie Chapelot, en possession de Jean Guillet, agriculteur à Chazelles-sur-Lavieu (Fortunières), né en 1892 à Chazelles, décédé en janvier 1975, avant que je ne forme le projet d'interviewer des derniers survivants de la Grande Guerre (le cas de mon grand-oncle étant une exception). Ses écrits et ses documents m'ont été aimablement communiqués par sa fille Marie-Thérèse, née en 1928, épouse de Roger Lyonnet, résidant à Margerie-Chantagret, qui a beaucoup écouté son père lui parler de sa guerre et de sa captivité. Ayant combattu d'août 1914 (au $23^{\mathrm{e}}$ R.I. de Bourg-en-Bresse, puis au $60^{\text {e }}$ R.I. de Besançon) à fin mars 1917, dans les Vosges, en Alsace, puis, dans la Somme en 1916, deux fois gravement blessé au bras, Jean a été fait prisonnier le 4 avril 1917, et a travaillé en Prusse Orientale dans une ferme jusqu'à l'armistice. Son petit manuel décrit en trois pages la tenue de campagne au début de la guerre, avec comme citation liminaire: "Une tenue complète et soignée dénote un bon soldat". Elle comporte un texte principal et des tableaux complémentaires insérés dans le texte ainsi que des notes explicatives. Le texte est le suivant, intégrant dans sa nomenclature aussi des accessoires indispensables pour chaque escouade (12 hommes en général), donc pas portés par chaque homme):

"L'homme revêt ses effets d'équipement dans l'ordre suivant:

$1^{e}$ Ensemble du ceinturon, des cartouchières et de bretelles de suspension, sans boucler le ceinturon

\footnotetext{
${ }^{1}$ Cette appellation était due à sa forme qui rappelait le losange que forme l'as de carreau; Jean-Pierre n'a pas connu l'appellation qui a suivi: "Azor" (sans doute parce que le sac vous accompagnait comme un chien de ce nom). Rappelons que la baïonnette était surnommée "Rosalie".
} 


\begin{tabular}{|c|c|c|c|c|}
\hline De l'homme & & & Paquetage extérieur & \\
\hline $\begin{array}{l}\text { Plaque d'identité } \\
\text { Chemise } \\
\text { Caleçon } \\
\text { Ceinture de flanelle (de laine pour les troupes } \\
\text { alpines) } \\
\text { Pantalon de drap } \\
\text { Bretelles de pantalon (paire) } \\
\text { Mouchoirs } \\
\text { Brodequins (paire) } \\
\text { Cravate } \\
\text { Capote (avec deux pattes d'épaules) } \\
\text { Paquet individuel de pansement } \\
\text { Képi } \\
\text { Ceinturon avec porte-épée } \\
\text { Epée-baïonnette }\end{array}$ & $\begin{array}{l}1 \\
1 \\
1 \\
1 \\
1 \\
1 \\
1 \\
1 \\
1 \\
1 \\
1 \\
1 \\
1 \\
1 \\
1 \\
1\end{array}$ & $\begin{array}{l}\text { Ustensiles de } \\
\text { campement } \\
\text { (par } \\
\text { escouade): }\end{array}$ & $\begin{array}{l}\text { Chaussures de repos - Dessous, } \\
\text { enveloppées dans des chiffons destinés } \\
\text { au nettoyage du fusil } \\
\text { Brosse d'armes } \\
\text { Brosse double à chaussures } \\
\text { Boîte à graisse garnie } \\
\text { Gamelle individuelle et nécessaire } \\
\text { individuel de campement } \\
\text { Gamelles de campement } \\
\text { Marmites de campement } \\
\text { Seaux en toile } \\
\text { Sacs à distribution }\end{array}$ & $\begin{array}{l}3 \\
4 \\
2 \\
2\end{array}$ \\
\hline
\end{tabular}

$3^{e}$ Le petit bidon, la courroie sur l'épaule gauche

$4^{e}$ Boucler le ceinturon en ne maintenant dessus que la partie antérieure de la courroie du petit bidon et la banderole d'étui-musette

$5^{e}$ Le havresac ${ }^{2}$ - Effets emportés en campagne:

\begin{tabular}{|c|c|c|}
\hline Paquetage intérieur & & Prescriptions diverses \\
\hline $\begin{array}{l}\text { Chemise } \\
\text { Vivres de réserve } \\
\text { (2 jours) } \\
\text { - Pain de guerre (2 jours) } \\
\text { - Boîtes individuelles de viande de conserve } \\
\text { - assaisonnée } \\
\text { - Boîtes de potage salé } \\
\quad \text { de café } \\
\text { Mouchoir } \\
\text { Calotte de coton (pour les réservistes et les } \\
\text { territoriaux) } \\
\text { Savon } \\
\text { Courroie de capote } \\
\text { Brosse à habit } \\
\text { Trois cartouchières modèle } 1898 \text { contenant: } \\
\text { - celles de devant chacune quatre paquets de } \\
\quad \text { cartouches } \\
\text { - celle de derrière trois paquets } \\
\text { (soit } 11 \text { paquets, } 88 \text { cartouches) } \\
\text { Bretelle de suspension } \\
\text { Etui-musette contenant: } \\
\text { - Quart } \\
\text { - Cuiller }\end{array}$ & $\begin{array}{c}12 \\
3\end{array}$ & 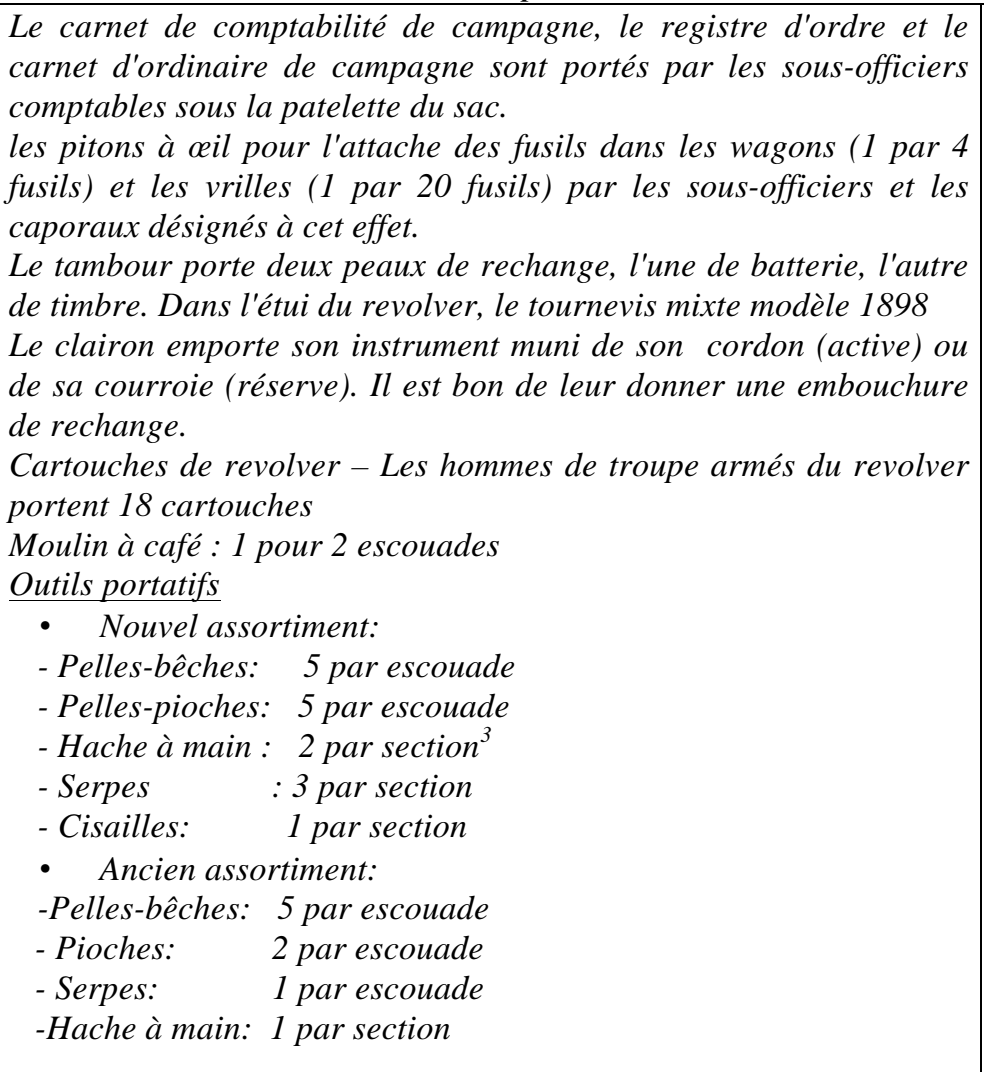 \\
\hline
\end{tabular}

\footnotetext{
${ }^{2}$ Aucun soldat, sauf exception rarissime, n'appelait le sac ainsi. Le mot "havresac", qui évoque l'armée napoléonienne, qualifie le sac du fantassin et a été introduit en français écrit en 1690, selon le Dictionnaire Historique de la Langue française dirigé par Alain Rey; il a été emprunté à l'allemand "Habersack", sac à avoine, rapporté par les soldats revenant d'Allemagne lors de la guerre de Trente Ans (1618-1648).

${ }^{3}$ Rappelons la hiérarchie des diverses unités militaires: : l'unité de base est l'escouade (12 hommes en général) commandée par un caporal; 2 escouades forment une demi-section (24 h.) commandée par un sergent; 4 escouades formant une section (48-50 h.) commandée par un lieutenant:, 4 ou 5 sections - avec la section de mitrailleurs - formant une compagnie (200 à 250 hommes) commandée par un capitaine, 4 compagnies formant un bataillon commandé par un commandant, et trois bataillons formant un régiment dirigé par un colonel. Il va sans dire que les pertes peuvent amoindrir considérablement ces unités (qui recevront alors des renforts).. Chez les Chasseurs (Alpins ou à pied) le terme de régiment n'est pas usité: on parle de bataillon.
} 
- Vivres de chemin de fer

Petit bidon avec courroie

Havresac

Fusil

Bretelle du fusil

Nécessaires d'armes: 4 par escouade plus 1

pour chaque sergent et fourrier

Trousse garnie renfermant:

- Ciseaux

- Bobine avec 6 aiguilles

- Fil noir, gris, garance

- Dé

- Peigne

- Lacets (paire)

- $\quad$ Ficelle de nettoyage de 2,50 à 3 mètres

Veste (ou tunique en jersey)

Couteau à conserve (1 pour 2 hommes)

Dans la poche de la patelette:

- Livret individuel

- Tiers de la baguette de fusil
- Hachettes: 3 par section

- Cisailles: 1 par section

Lanterne de cantonnement: 1 par escouade, portée par le caporal Bois pour faire le repas du matin

Une telle énumération, mettant sur le même plan le fusil et le dé à coudre, peut apparaitre dérisoire dans sa minutie, mais elle fixe les obligations du soldat, du sergent fourrier chargé de veiller à l'approvisionnement, délimite les exigences des officiers envers les hommes pour ce qui est du matériel à paqueter dans leur sac, et donne aux responsables de l'intendance les chiffres, astronomiques, des commandes à faire pour que les régiments soient équipés au complet, sachant qu'on passe de trois tranches d'âge incorporées ensemble après le vote de la loi de trois ans en 1913, formant l'armée active, à 29 tranches d'âge, ou classes (de 19 ans à 47 ans, pour les plus âgés des Territoriaux) après quelques mois de guerre.

On demeure effaré par l'abondance, donc le poids, des accessoires que doit porter le fantassin, qui constituent le fameux "barda". ${ }^{4}$ A combien évaluer ce poids? Un Normalien combattant, Jacques Meyer, dans son ouvrage remarquable "Les soldats de la Grande Guerre", évalue le poids du seul sac à $20 \mathrm{~kg}$ : "En plus des musettes et du précieux bidon, dont on ne se délectait qu'en dernier recours, le barda, c'était surtout le sac, pesant jusqu'à 20 kilos et souvent surnommé -pourquoi?- Azor ${ }^{\prime \prime}$. Si les musettes et le bidon sont pleins, avec le fusil Lebel, c'est le double de ce poids que doit porter le fantassin qui monte en ligne, dans des boyaux boueux! Jean-Jacques Becker, dans la petite rubrique "Les uniformes" de son ouvrage synthétique à présentation alphabétique des rubriques "La première guerre mondiale" donne une évaluation intermédiaire: "En outre, l'infanterie française était dotée d'un paquetage incroyablement lourd, environ trente kilogs. ${ }^{\prime 6}$

Jean-François Ollier, de Saint-Etienne, (cl. 13), fabricant de soieries, le plus gradé de mes témoins (il finira la guerre comme capitaine, et sera commandant de réserve en 1934) six fois blessé, sept fois cité, pense que le poids total porté par le soldat pouvait même atteindre, dans certains cas, $50 \mathrm{~kg}$, et pouvait avoir des conséquences dramatiques sur le sort du Poilu: :"Quand on entendait venir un obus (on l'entendait siffler comme devant arriver) on se foutait par terre; mais détail qu'il ne faut pas oublier: des hommes chargés de $50 \mathrm{~kg}$, ils hésitaient à se foutre par terre pour avoir le plaisir de se relever!"

E- $50 \mathrm{~kg}$ d'équipement?

T-Vous savez, le sac, ça avait vite fait de peser $30 \mathrm{~kg}$, avec tout le bastringue qu'on traînait. Alors, vous aviez en plus le fusil, les cartouches, le bidon, un peu de nourriture, etc. Voyez, le type chargé comme ça, c'est qu'après pour se relever, c'est pas rigolo. Alors quelquefois on faisait l'économie! Je vous donne la mentalité du type qui est là: "Oh! zut! Je me couche pas ce coup-là!". Il restait debout: ça pouvait être le coup qui le tuait... Mais quand vous faites ça toutes les dix secondes, et même toutes les trente secondes, avouez que...."

\footnotetext{
${ }^{4}$ Le "barda" est un terme d'argot militaire bien antérieur à la guerre de 14-18, puisque cet emprunt à l'arabe date de la conquête de l'Algérie (commencée en 1830) comme "gourbi", "toubib", "caoua", "kif kif" etc. Le Dictionnaire Historique de la Langue Française dirigé par Alain Rey en décrit l'étymologie et l'évolution sémantique: "Barda- nom masculin, d'abord noté "berdâa"(1848) puis adapté en "barda" (1863). est emprunté à l'arabe "barda'a", bât rembourré pour un âne ou une mule, et couverture de bât. L'usage du mot, qui fait partie d'une série d'emprunts à l'arabe d'Algérie ("toubib", etc.) s'est répandu par l'intermédiaire des soldats français ayant servi en Algérie. "Barda" désigne d'abord l'équipement du soldat (d'Afrique à l'origine) porté sur son dos. Par extension, il est passé dans l'argot des peintres (1881) (sans doute pour désigner leur chevalet et leur attirail portatif) et s'est répandu comme équivalent familier de "bagage" (1883).

${ }^{5}$ Jacques Meyer, op.cit. Hachette Paris 1966, p. 83

${ }^{6}$ Jean-Jacques Becker, op. cit., p. 205
} 


\section{L'évolution générale de l'équipement du soldat en 1915}

Dans son numéro du 22 octobre 1915, sous le titre "Le fantassin de 1915", la célèbre revue "L'Illustration" brosse le portrait du nouveau fantassin tel qu'il résulte des modifications apportées au cours de l'année, avec un style martial, optimistement patriotique, dégagé et presque désinvolte qui fait songer à un article de mode: "A part l'attitude, la figure ouverte, rayonnante d'intelligence et de résolution, et cet on ne sait quoi d'éveillé, de déluré, qui caractérise la race, nous aurions peine, si nous n'avions pas suivi une à une leurs transformations depuis un an, à reconnaître, dans ce fusilier et ce grenadier prêts au premier signal à s'élancer à l'assaut, deux troupiers français. Combien ils apparaissent différents de ce qu'ils furent avant la guerre! L'uniforme bleu horizon, qui a remplacé la sombre tenue rouge et gros bleu, en fait deux claires silhouettes. La bande molletière, dessinant jusqu'aux genoux des jarrets nerveux, accentue encore leur allure dégagée. Le casque du colonel Adrian qui, remplaçant le képi, a obtenu le succès que nous avons constaté déjà, les coiffe, de très élégante et martiale façon. On ne saurait vraiment être de meilleur air. Mais, alors que chez le fusilier, armé de son bon Lebel et de sa baïonnette, nous retrouvons l'équipement accoutumé, l'armement de son camarade, le nouvel armement imposé par la guerre de tranchées et la prudente tactique de l'ennemi pour déconcerter toutes nos habitudes d'oeil ${ }^{7}$. C'est, au côté gauche, une musette bourrée de projectiles à main, de grenades dont l'homme tient déjà quelques-unes en son poing fermé ; sur la poitrine, sur la bretelle de la musette, un pistolet à répétition, du genre du fameux browning; et enfin, plus étonnant, plus déconcertant au premier abord, à la ceinture, un long couteau dans sa gaine. Et nous voilà donc, par un miracle de kultur ${ }^{9}$, revenus, en l'an de grâce 1915, aux anciennes miséricordes ${ }^{10}$ du seizième siècle.

Ce soldat est un de ces "nettoyeurs" de tranchées dont nous parlions dans notre numéro du 9 octobre..."11

Un tel article, supposé insuffler la confiance dans les lecteurs, participe au fameux "bourrage de crâne" qui irritaient si fort les Poilus, indignés de voir leur pauvre condition enjolivée par des plumitifs de salon!

\section{Le remplacement des pantalons rouge garance et l'adoption de la tenue bleu horizon}

On sait qu'en dehors du rouge du képi, le rouge du pantalon dit "garance", du nom de la plante tinctoriale qui servait à les teindre, est emblématique de l'uniforme français du début de la guerre, et de l'irréflexion des chefs et des stratèges militaires quant aux impératifs d'une guerre moderne où l'on tue d'autant mieux, à très longue distance, avec des fusils ou des mitrailleuses, que l'on repère facilement l'ennemi; les camouflages modernes, avec leurs couleurs ternes et leur imitation de feuillage n'ont pas d'autre but que de dissimuler les soldats dans la végétation ou sur un sol sablonneux.

Mais s'il faut en croire l'une des notes très pertinentes que l'historien de la Grande Guerre Stéphane AudoinRouzeau ajoute en annexe du beau témoignage illustré de Gaston Lavy, édité en 2004, intitulé "Ma Grande Guerre $^{\prime 12}$, la note intitulée "Bleu horizon", la tenue voyante renvoyait à une "éthique du combat" qui plongeait ses racines dans l'histoire militaire française, et sans doute, dans son panache, fut-ce au détriment de l'efficacité, ce qui en l'occurrence, signifiait la survie des soldats, ou la minimisation des pertes: "Bleu horizon-L'uniforme bleu horizon remplace, au cours de l'année 1915, celui du début de la guerre, en grande partie inchangé depuis la guerre de 1870, et dont le pantalon rouge, en particulier, constituait une cible parfaite pour le tir allemand. Les différentes tentatives pour introduire un uniforme moins voyant dans l'armée française avant 1914 s'étaient traduites par un échec: à une éthique de la guerre correspondait une esthétique de la tenue au combat. On notera la joie que procure à Lavy et à ses camarades le port du nouvel uniforme, lié semble-t-il au sentiment d'être enfin de vrais soldats"

Cette idée se trouve déjà au début de la rubrique "Uniformes" précédemment citée du petit livre alphabétique de Jean-Jacques Becker, La première guerre mondiale, publié en 1985, "Les soldats sont partis pour la guerre avec un uniforme à peu près identique à celui de 1870, c'est-à-dire une tunique bleue et un pantalon garance et coiffés d'un képi également bleu et rouge, mais dont un manchon pouvait cacher la couleur trop voyante. Il avait été question, dans les années précédant la guerre, de remplacer le rouge par une autre couleur mieux adaptée à la guerre moderne; toutefois le projet avait été abandonné à la suite de l'intervention d'un parlementaire suivant lequel avec la disparition du pantalon rouge, c'était toute la tradition militaire française qui risquait de disparaître". Toutefois J.J. Becker a soin de rectifier une idée toute faite très souvent répétée dans les médias, partant dans le grand public, mais aussi notamment chez les élèves des lycées qui retiennent plus les simplifications

\footnotetext{
${ }^{7}$ Le verbe de la proposition principale manque.

${ }^{8}$ Manifestement, l'auteur de l'article n'a jamais vu lancer une grenade!

9 "Kultur": cette graphie allemande du mot "culture" est constante dans les journaux et revues de l'époque, pour stigmatiser la "barbarie allemande". Paradoxalement ici, c'est un retour bien français à une forme de barbarie d'antan, l'assassinat au poignard, qui est attribué à l'ennemi, qui nous aurait contraints à adopter une pareille arme et une pareille méthode, consistant à faire achever les blessés ennemis par les fameux "nettoyeurs de tranchées"

${ }^{10}$ Ce mot "miséricorde" désignait, au Moyen Age, selon le Dictionnaire Historique de la Langue Française dirigé par Alain Rey, "une dague utilisée pour menacer l'ennemi et le forcer à demander miséricorde". Mais le nettoyeur de tranchée n'est pas censé attendre que soit formulée cette demande par le soldat vaincu...

${ }^{11}$ L'Illustration, $^{\circ}{ }^{\circ}$ du 22 octobre 1915, pp. 423-424

12 Gaston Lavy, Ma Grande Guerre, Larousse 2004, comportant 318 pages de récit et dessins de grande qualité; postface et notes de Stéphane Audoouin-Rouzeau. La note citée "Bleu horizon" se trouve à la page 1 des Notes, après la page 318 du récit.
} 
caricaturales que la complexité de l'analyse de leurs professeurs d'histoire: "Il est juste de préciser que les énormes pertes des premiers temps de la guerre ne furent pas dues principalement à la couleur du pantalon des soldats, mais à la tactique utilisée, délibérément offensive, et au manque d'expérience en travaux de terrassement".

Il situe en avril 1915 le changement de tenue, ainsi que l'arrivée du casque dans les troupes, ce qui est, on le verra, pour ce dernier accessoire, une date prématurée de plusieurs mois: "Après divers tâtonnements en avril 1915 apparut l'uniforme "bleu horizon", et en même temps, le képi fut remplacé par le casque, appelé casque Adrian, du nom de l'intendant militaire qui l'avait conçu.".

La minutie des notes écrites au jour le jour d'un de mes témoins Joseph Sorgues (cl. 15) de RomanècheThorins (Saône-et-Loire) permet de faire remonter d'un mois l'apparition de l'uniforme bleu dans les premières unités, même si sa généralisation a dû se faire progressivement, étant donné le nombre considérable de régiments à équiper. Cet instituteur libre du pensionnat Bellegarde de Neuville-sur-Saône, incorporé depuis le 20 décembre 1914 au $23^{\mathrm{e}}$ R.I. de Bourg-en-Bresse, en instruction à Valdahon dans le Doubs, note dans son journal le samedi 13 mars 15: "Nous avons fait ce soir une marche de $24 \mathrm{~km}$ avec la grosse couverture roulée sur le sac. J'ai suivi l'itinéraire sur la carte: le Valdahon du milieu, le pont de l'Homme mort, Avoudrey, le chemin de terre qui passe au nord de la cote 746, le bois du Mont Vercel, Adam-lès-Vercel et retour au camp. Au Valdahon d'en bas, il y a le $170^{e}$, le $171^{e}$ et le 172 ; au Valdahon du haut, le $149^{e}$ et le $152^{e}$; à Etalans le $44^{e}$ et le $60^{e}$; à Fallerans, le $21^{e}$ et le

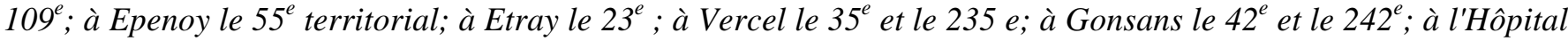
du Gros Bois le $60^{e}$ d'infanterie et le $54^{e}$ territorial. Ce sont des bataillons de marche destinés à former une nouvelle armée pour l'Alsace; tous sont vêtus en tenue bleu clair."

Cette énumération de régiments est fort instructive: elle signifie que 17 régiments (13 d'armée active, avec des numéros inférieur à 200,2 de réserve - avec 200 rajouté au $\mathrm{n}^{\circ}$ du régiment d'active - et 2 de l'armée territoriale), soit plus de 50000 hommes, en prenant une base de 3000 hommes par régiment (à moins que le régiment ne soit représenté que par un de ses trois bataillons) sont équipés de la nouvelle tenue le 13 mars 1915, et sans doute les jours précédents ${ }^{2}$. Il faut remarquer que ces régiments ont leur dépôt dans l'Est (Belfort pour le 35, le 42, le 171, le 172 et le 242, Epinal pour le 149 et le 170, Besançon pour le 60 et le 235), en Champagne ou à proximité (Chaumont pour le 109, Langres pour le 21 et le 152) et en région lyonnaise pour le $23^{\mathrm{e}}$ R.I. de Bourgen-Bresse auquel appartient Joseph Sorgues.

Trois semaines après, le 3 avril 1915, toujours au Valdahon, Joseph Sorgues assiste au départ du $407^{\mathrm{e}}$ R.I. de Besançon, qu'il n'avait pas mentionné dans la précédente énumération: "Lundi 3 avril - Aujourd'hui nous n'avons rien eu à faire. Je suis allé avec mes camarades voir embarquer le $407^{e}$ régiment de marche qui est dirigé sur Troyes pour se rendre probablement de cette ville au camp de Mailly. Tous les hommes sont revêtus de la nouvelle tenue: capote bleu clair avec écussons jaunes aux chiffres noirs, pantalons bleus, képis bleus, molletières bleues. J'aurai bien voulu partir, sauter dans ce train et m'enfuir de ce lieu sauvage où les jours sont des mois et les mois des siècles. Mais je pense que cela ne tardera pas..." . On remarquera, chez cet ardent patriote, que le temps de l'instruction (trois mois et demi depuis son incorporation) n'est pas un temps béni, et qu'il aspire à se trouver au front...

Quelques témoins présents au front ou déjà mobilisés, et en instruction, quand se produit le changement de tenue l'évoquent, mais ils sont très minoritaires. La précision est parfois neutre, comme chez Antoine Guillot (cl. 14), cordonnier à Perreux puis mécanicien à l'arsenal de Roanne, passant en février 1915 du $131^{\mathrm{e}}$ R.I. de Belley au $371^{\mathrm{e}}$ R.I. de Belfort, présent au front dans les Vosges au printemps 1915 (au Vieil Armand, où sa compagnie a 28 tués, puis au Ballon de Guebwiller):

E- «Vous êtes arrivé en février 15, à Belfort?

T- Oui! Ils nous ont donné des pantalons bleus, pour cacher le rouge, quoi! On avait des pantalons rouges à l'époque, l'infanterie. »

Mais en général, chez ces minoritaires, l'indication est critique et vise l'incompétence des chefs militaires qui avaient maintenu une tenue si voyante qui "constituait une cible parfaite pour le tir allemand", comme l'a indiqué S. Audouin-Rouzeau.

C'est le cas de Joseph Gilfaud (cl. 12) d'Ambierle, vigneron-épicier à Ambierle, qui a finit ses jours à l'hôpital de Bonvers, à Mably, où j'ai enregistré son témoignage en octobre 1988. Incorporé en octobre 1913 au $17^{\mathrm{e}}$ R.I. d'Epinal, il fut fait prisonnier le 24 août 1914 (en étant blessé aux deux mains et à la poitrine par la même balle) à Raon-l'Etape, dans les Vosges et subit quatre années de captivité en Bavière. Dès le début de l'entretien, il met en cause l'impréparation de l'armée française, symbolisée par le pantalon rouge, qu'il oppose à la préparation méthodique des Allemands: "Déjà tout jeune, moi, j'ai suivi un peu de la politique, même de ce qui se passait à l'étranger! Moi, j'ai vu les préparatifs de la guerre, la façon dont les Allemands s'armaient! Quand je pense que nous, fantassins... Je suis allé me battre, moi, au début de la guerre, en pantalons rouges! On n'avait rien préparé, nous! A peine! Si: on avait voté la loi de trois ans un an avant la guerre, en 13..."

C'est encore le cas de Louis Soulier (cl. 14), né à Tarentaize, fils de laitiers, qui sera après guerre mécanicien à Paris puis à Saint-Etienne avant de fonder son propre garage et sa concession Citroën dans la capitale forézienne. Il est un des trois marins parmi l'ensemble de mes témoins, mécanicien à bord du cuirassé Provence lors de l'expédition des Dardanelles sur printemps 1915.

T- «Nous étions des guerriers, hein! Les Français, on était des guerriers! On s'est défendu le mieux qu'on a pu, pour se défendre... 
E- Mais j'ai entendu dire...des gens de la 11, de la 12, m'ont dit: "On croyait au début qu'on allait gagner en quelques mois!"

T- Oh! (interjection tenue longtemps) La faute a été faite à l'armée française! L'armée française a fait partir les Poilus en rouge: ils se voyaient de loin! Une chose qu'il fallait toute foutre... (en l'air), le rouge! Quand on a mis la couleur grise, les types (= les Allemands) se sont heurtés à des soldats! Parce que nous étions vraiment des bons soldats!"

On a vu, dans cet extrait d'entretien, que c'est spontanément que Louis Soulier attribue au rouge des pantalons (et accessoirement des képis) les énormes pertes du début de la guerre, et à l'uniforme qui a suivi (qu'il voit gris et non bleu horizon) les victoires ultérieures. On retiendra aussi la glorification de la vertu guerrière des Français...

Même condamnation du rouge des pantalons et de l'impéritie de l'Etat-Major chez Antoine Frénéat (cl. 15), né à Sainte-Colombe-sur-Gand, fils d'agriculteurs devenu cheminot après guerre, s'étant établi à Montrond-les-Bains. Incorporé avec la classe 15 en décembre 1914 au $22^{\mathrm{e}}$ R.I. de Bourgoin, il monte au front en avril 15 en étant versé au $157^{\mathrm{e}}$ R.I. de Gap qu'il rejoint à Flirey, en Lorraine. La conversation porte sur un de ses cousins, incorporé dans les Chasseurs Alpins, tué dans les premiers jours de sa présence au front:

T- Oh! Vous vous rendez compte! Ils partaient comme des lapins, là! Les Allemands n'avaient qu'à tirer dessus!

E- Il a dû être tué en Alsace parce qu'ils ont presque tous été tués...

T- En Alsace, oui! Les Chasseurs Alpins étaient habillés un peu plus foncé, mais les fantassins avaient la culotte rouge! D'ailleurs, les Allemands les appelaient "Les culottes rouges"!

E- Est-ce qu'on s'est rendu compte tout de suite que c'était une erreur que d'avoir gardé les culottes rouges?

T- Oh! certainement! Mais ça s'est confondu avec autre chose! Ceux qui font des erreurs sont tellement haut placés qu'on en parle peu! Si c'est un lampiste, on en parle davantage!"

Par rapport à Louis Soulier, Antoine Frénéat rajoute le vieux grief, globalement fondé malgré l'exemple des limogeages de début de guerre, de l'aspect intouchable des haut gradés commettant des erreurs impunies dont le soldat de base est toujours la victime.

\section{La protection de la tête: la calotte métallique puis le casque Adrian}

C'est une erreur fréquente des scénaristes de cinéma, dont les scriptes n'ont guère de formation historique très précise, que de montrer des soldats au moment de la mobilisation, ou dans les premiers mois de guerre, munis du casque bien connu des Poilus. Or pendant un an, ils ont combattu sans casque! Celui-ci ne figure pas d'ailleurs dans la description minutieuse de l'équipement du fantassin de 1914 transcrite supra. Les Allemands ont, eux, en début de guerre, le casque à pointe ancien, en cuir bouilli, qu'ils remplaceront par un casque métallique.

Alerté sur l'abondance des blessures, souvent mortelles à la tête dans le tout début de la guerre, et sur l'opportunité de faire fabriquer des casques métalliques, le général Joffre aurait déclaré au colonel Pénelon (qui lui proposait un modèle de casque) d'après les Mémoires de Raymond Poincaré que cite Jacques Meyer: "Nous n'aurons pas le temps de les fabriquer, je tordrai les Boches avant deux mois"133. On reste stupéfait devant tant de présomption et d'aveuglement...

Un de mes témoins, caporal puis sergent fourrier au $298^{\mathrm{e}}$ R.I., Jean-Baptiste Grousson de Saint-Etienne (cl. 99) dont on a vu qu'il avait été témoin visuel de l'exécution de six Martyrs de Vingré, note dans son carnet à la date 15 novembre 1914: "On va se coucher à la petite grotte en haut de Vingré, on entend siffler les balles pour la $1^{\text {ère }}$ fois, on ne voit enterrer que des soldats frappés en pleine tête, dans nos tranchées".

C'est aussi la constatation qu'a fait bien tardivement, à la mi- février 1915 (il y a déjà six mois de guerre et des centaines de milliers de morts), le général Joffre, chef de l'Etat-Major, qui se ravise donc par rapport à l'optimisme présomptueux précédemment affiché, dont un rapport qu'il a commandé et cité par le $\mathrm{n}^{\circ}$ de L'Illustration du 3 juillet 1915: "La grande majorité des blessés actuels, écrivait-il, est constituée par des blessés à la tête qui, dans la plupart des cas, auraient été efficacement protégés par un casque métallique. Cette coiffure aurait arrêté non seulement les éclats d'obus et les balles de shrapnels qui n'ont pas une force de pénétration considérable, mais encore beaucoup de balles de fusils qui ne possèdent plus qu'une vitesse restreinte, ayant d'abord frappé le parapet de la tranchée.

Ces observations sont d'ailleurs confirmées par les statistiques. Les dragons ${ }^{14}$ ont perdu moins de monde dans les tranchées que les hussards".

Le même article énumère ensuite les diverses inventions qui ont cherché à protéger la tête du combattant, d'autant plus vulnérable en tranchée que c'est la seule partie du corps qui dépasse, quand la tranchée n'est pas assez profonde, ce qui est souvent le cas:

$1^{\mathrm{e}}$ - l'initiative de certains soldats = le couvercle de leur gamelle: "Nos soldats, d'abord, de leur propre initiative, se protégèrent comme ils purent contre ce risque, adoptant d'étranges coiffures de fortune, plaçant par exemple sur leurs képis les couvercles de leur gamelle"

$2^{\mathrm{e}}$ - des pare-balles dont la forme n'est pas précisée: "Des industriels saisirent l'occasion et lancèrent des pare-balles plus ou moins efficaces"

\footnotetext{
13 Jacques Meyer, op.cit. p. 80

${ }^{14}$ Leur uniforme comportait un casque métallique surmonté d'une crinière depuis fort longtemps (c'était déjà le cas en 1870)
} 
$3^{\mathrm{e}}$ - une calotte métallique sphérique placée sous le képi: "Dernièrement, enfin, on dota, à mesure de leur fabrication, certaines unités d'une calotte métallique sphérique dite "cervelière" ; qu'on inséra sous le képi, et que sa forme trop ronde empêcha d'ailleurs de s'adapter à la plupart des têtes, mais qui pourtant, assuraient à ceux qui la coiffaient une protection efficace". Cette protection a été évaluée à $60 \%$ pour ce qui est des balles de shrapnels d'après une étude faite dans un arsenal de Bourges. L'article précise que 700000 calottes ont été fabriquées et distribuées. Cette "cervelière", appelée plus couramment "couvre-nuque", Jean Fontaney (cl. 12), de Montrondles-Bains, instituteur devenu plus tard professeur puis directeur d'Ecole Normale (à Parthenay, puis à Poitiers), est un des rares à l'avoir mentionnée et en avoir évoqué deux utilisations très peu orthodoxes:: "Il faut dire qu'en ce temps-là (début 1915) on avait encore le képi rouge, mais avant de partir au front, on nous avait mis une calotte bleue sur notre képi ${ }^{15}$. Mais j'ai connu... on nous a donné d'abord...

E- Un couvre-nuque?

T- Un couvre-nuque, qu'on mettait à l'intérieur, et c'était de la tôle un peu résistante, mais qui faisait mal à la tête. On avait toujours un camarade pour se débrouiller à deux (l'homme est fait pour vivre à deux). Nous avions ça sous nos képis: l'un servait pour faire la salade, l'autre servait, quand on était au repos, de pot de chambre! (rire). On s'en est moqué, quoi! C'était pas pratique du tout, ça a été remplacé par le casque, heureusement!"

$4^{\mathrm{e}}$ - le casque dit Adrian, du nom de l'ingénieur colonel du Génie qui l'a conçu (comme les baraques du même nom). Elle est décrite ainsi dans l'article cité, d'abord en relation avec ses antécédents historiques, puis techniquement: "Nous reproduisons ici la photographie de la coiffure nouvelle. Elle ressemble assez, dans ses lignes, au casque des dragons privé de son cimier, et tel que nos cavaliers étaient autorisés à le porter depuis quelque temps dans les tranchées. Elle tient du "pot en tête" des sapeurs de Sébastopol ${ }^{16}$ et de la bourguignote ${ }^{17}$ des fantassins des Valois."

Etabli en acier suffisamment épais et très résistant embouti d'une seule pièce, ce casque constitue pour la tête et même le haut du visage, grâce à sa visière, une protection excellente, tout en ne pesant que 600 ou 700 grammes. Pourvu intérieurement d'une coiffe en cuir, avec un dispositif ingénieux d'aération, il s'adapte admirablement à la tête". De fait, ce doublage en cuir, un peu éloigné de l'intérieur métallique du casque, lui permet de se modeler à la plupart des formes de crânes, ce que ne permettait le couvre-nuque uniquement métallique.

Ce casque reçoit sur son devant des insignes qui permettent d'individualiser chaque arme: "Le nouveau casque est peint en gris, de la couleur du canon de 75, et porte sur le devant de la bombe un insigne distinctif suivant les armes et subdivisions d'armes: c'est pour l'infanterie de ligne la grenade, pour les chasseurs à pieds le cor de chasse, pour l'infanterie coloniale l'ancre, pour le génie la cuirasse et le pot en tête, pour l'artillerie les deux canons croisés; l'insigne est peint de la même façon que le casque."

A propos de la couleur, les deux exemplaires de casque que je possède ${ }^{18}$ (infanterie et artillerie) ne sont pas gris, mais plutôt gris bleuté foncé, sans doute pour s'harmoniser avec le bleu clair de la capote.

Pour prouver l'efficacité de ce nouveau casque, le $\mathrm{n}^{\circ}$ de L'Illustration du 30 octobre 1915 présente, dans un article intitulé "Le casque Adrian" (l'appellation s'est donc vite imposée) "aux batailles de Champagne et d'Artois" les photographie de six casques différents, fortement cabossés ou même perforés par des balles ou des shrapnells, avec la mention: "Six casques qui ont sauvé la vie de six soldats". L'article commence par une référence aux deux récentes grandes batailles et fait l'éloge de l'efficacité du casque: "On a déjà remarqué l'aspect nouveau que donne aux récentes photographies du front le casque dont sont maintenant munis nos combattants. L'emploi de cette coiffure a été, en effet, généralisé, et l'on a pu constater que l'efficacité de sa protection avait évité à nos troupes bien des pertes, en Champagne et en Artois, lors de notre dernière offensives. Les blessures à la tête, si fréquentes dans cette guerre, seront désormais bien souvent atténuées et, dans beaucoup de cas, évitées. "19

Quelle est la date d'introduction de ce nouveau casque? La question n'est pas insignifiante car son introduction trop tardive, même après l'adoption du couvre-nuque métallique, a entraîné sans doute des dizaines de milliers de

\footnotetext{
${ }^{15}$ Cette calotte bleue couvrant le képi servait à en dissimuler la couleur rouge, très voyante, qui facilitait les tirs ennemis à la tête

${ }^{16}$ Ceci est une allusion à la guerre de Crimée (1854-1855) sous le Second Empire; le 10 septembre 1855, Sébastopol a été prise par les troupes franco-anglaises après 350 jours de siège.

${ }^{17}$ La bourguignote: c'est ainsi que l'appelle le poète Guillaume Apollinaire, engagé volontaire, bien que polonais (avant d'être naturalisé français) dans les rangs français: "Le Decauville qui toussote // La tôle ondulée sous la pluie // Et sous la pluie ma bourguignotte", dans le poème Désir (écrit au moment de l'attaque de Champagne déclenchée le 24 septembre 1915 à laquelle il participe comme artilleur) envoyé à sa fiancée Madeleine Pagès, professeur de Lettres à Oran. Le terme "bourguignotte" renvoie à la Bourgogne par un biais que nous explique Alain Rey dans le Dictionnaire Historique de la Langue Française: "Bourguignote ou Bourguignotte: est la substantivation d'une variante ancienne (vers 1460) de "bourguignon", obtenue par substitution de suffixe; le mot est employé en terme d'habillement militaire à propos d'un casque léger à crête et couvre-nuque, utilisé pour la première fois au XVe siècle par les Ducs de Bourgogne et en usage jusqu'au XVIIe siècle. Par plaisanterie, il a été repris par les soldats de la guerre 1914-1918 au sens de "casque".

${ }^{18}$ L'un a été acheté en brocante, mais le second (qui possède encore sa coiffe en cuir) m'a été donné par mon voisin de Chatelville, mon hameau natal de Chazelles-sur-Lavieu, Jean Donnadieu: il appartenait à son père qui avait fait la guerre de 14. Qu'il en soit vivement remercié!

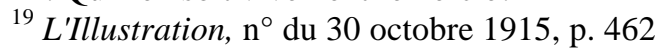


morts, et un nombre sans doute équivalent de trépanations imposées par de graves blessures au crâne ayant laissé des esquilles d'os dans le cerveau..

Si l'on parcourt toute la collection de L'Illustration depuis le début de la guerre, revue très informée toujours à l'affût des nouveautés et de photographies inédites, on constate que la première photographie où apparaît un casque sur la tête d'un soldat, en situation de guerre (et non comme modèle de démonstration pour illustrer la présentation de cette innovation) est celle qui figure en grand format à la page 341 du $n^{\circ}$ du 2 octobre 1915, où un soldat français casqué, armé de son Lebel, surveille une dizaine de prisonniers allemands capturés lors de l'offensive de Champagne.

Dans les témoignages écrits de nos témoins, donnant une datation fiable, les deux premières mentions sont de début septembre 1915:

* le 3 septembre, Claude Coupade (cl. 15), de La Ricamarie, ajusteur devenu mitrailleur à la guerre, puis mécanicien d'aviation, incorporé au $157^{\mathrm{e}}$ R.I. Alpine de Gap, est à Flirey, près de Pont-à-Mousson, en Meurthe-retMoselle, dans un secteur très exposé aux torpilles. Il note: "le 3 septembre 1915, c'est la distribution des premiers casques; cela paraît comique, et ce qui ne l'est pas moins, c'est quand* même temps ont* distribue des poignards pour se défendre dans les corps à corps".

* le 7 septembre, Joseph Sorgues (cl. 15 aussi) de Romanèche-Thorins (Saône-et-Loire), instituteur libre au pensionnat Bellegarde de Neuville-sur-Saône, alors au $160^{\mathrm{e}}$ R.I. (dépôt à Saint-Pierre-le-Moûtier dans la Nièvre), est en tranchées à Somme-Bionne, près de Sainte-Menehould en Lorraine. Il note dans son journal quotidien: "7 septembre - En allant à la corvée d'eau, j'ai pu savoir que nous sommes à Somme-Bionne, à 14 km de SainteMenehould, à $4 \mathrm{~km}$ de Valmy, la fameuse victoire de Kellermann. Nous avons touché des couvertures et des casques d'acier, destinés à nous protéger la tête, mais je ne les ai pas encore vus."

* un peu plus tard, mais toujours en septembre 15, le 24, jour du déclenchement de la grande attaque de Champagne, Amand Beyron (cl. 11), de Viricelle, fils d'un chapelier de Chazelles-sur-Lyon dont l'entreprise "Beyron Frères" a compté plus de 120 ouvriers, qui sera après guerre directeur de diverses usines de tissage (dont dix ans celle de Régny) et finira ses jours à Roanne, est musicien brancardier au $99^{\mathrm{e}}$ R.I. de Vienne, et se trouve à Somme-Suippes en Champagne. Il écrit dans son journal, toujours très précis: "Vendredi 24 septembre - Lever à 6 heures. Après la soupe on change nos képis contre des casques en acier, arrivés hier au train de combat... On nous distribue des vivres de réserve pour 6 jours. On change nos sabres (coupe-choux) contre des revolvers à 5 coups de répétition, avec étui (fabrication espagnole). On nous donne un bidon de 2 litres à la place de celui d'un litre et une musette supplémentaire avec des pansements et un flacon de teinture d'iode, plus une paire de ciseaux. De bonne heure un bombardement intensif de notre artillerie tire sur les tranchées ennemies".

A propos de la contenance du bidon (1 litre passant à 2 litres), certains Poilus malins parvenaient à l'augmenter en tirant une balle à blanc dans l'orifice: quand le bidon n'éclatait pas, il s'enflait sensiblement. Ils risquaient la punition pour l'amour du divin Pinard...

Un témoignage oral vient introduire une note un peu discordante en affirmant qu'au tout début, le casque n'a pas été distribué équitablement entre officiers et hommes de troupe: celui de Joseph Masclaux (né en 1885 à Solignac-sur-Loire, Haute-Loire, ce qui en fait le $3^{\mathrm{e}}$ par ordre d'âge des témoins interviewés), mineur à Roche-laMolière devenant sous-gouverneur à la mine jusqu'en 1931, puis chef de gare aux Houillères de la Loire jusqu'à sa retraite, en 1948. En septembre 1915, il est sergent au $201^{\mathrm{e}}$ R.I. à Cormicy, dans la Marne: "Au début...y en avait que pour les gradés, et puis après, quand je suis été blessé, tout le monde avait le casque. Mais quand je suis sorti du poste de secours, qu'on venait de me faire le pansement, on m'a pris mon casque et on m'a dit: "Prends ton calot de campagne et puis laisse ton casque pour le front". Voyez!"

Aucun autre témoignage ne vient attester cette inégalité de traitement. Quant à demander au Poilu blessé, qui va être évacué dans une ambulance provisoire, puis dans un hôpital, de laisser son casque à la disposition d'autres soldats restant au front, cela n'a rien de scandaleux, surtout à une période où il n'y a sûrement pas assez de casques fabriqués... Ce n'est qu'à la fin de la guerre que les soldats se verront octroyer le droit de rapporter leur casque chez eux, comme un bien personnel, et que leur sera distribuée la visière en cuivre doré, ornée de feuilles d'olivier, épousant la forme de la visière normale, avec cette inscription honorifique dans le cartouche central: "Soldat de la Grande Guerre 1914-1918" ${ }^{20} \ldots$

\section{Les innovations en matière d'armement liées à la guerre de tranchées}

\section{De nouveaux modes de lancement de la grenade}

La grenade n'est pas une invention de la guerre de 14-18, il s'en faut de beaucoup. Son apparition en français, au sens militaire dérivé de la comparaison avec le fruit, date du milieu du XVIe siècle, selon le Dictionnaire Historique de la Langue Française dirigé par Alain Rey: "Grenade, nom de fruit, est entré par analogie de forme

\footnotetext{
${ }^{20}$ Cette visière ornée, en forme de croissant de lune, avec cette inscription, tous ne l'avaient pas mise sur leur casque. Mon grand-père maternel et parrain, Jean Surieux, l'avait clouée sur l'extérieur de la porte d'entrée de sa maison, à Chatelville, hameau de Chazelles-sur-Lavieu. Les multiples enquêtes faites pour ma thèse de linguistique, puis pour Mémoire Forézienne de 1976 à 1996, m'ont permis de la voir en d'autres points de la façade des maisons du Forez et de l'Auvergne, mais toujours fièrement exhibées.
} 
dans le vocabulaire militaire pour désigner (1558) un projectile explosif lancé à la main, puis avec une arme (fusil lance-grenades)".

Par manque de grenades usinées, certaines unités ont employé, au début de l'année 1915, des pétards sur raquette, que présente la revue L'Illustration, dans son numéro du 22 mai 1915 (page 530) en même temps que la version initiale de la grenade, la grenade à bracelet, dans un article de deux pages signé T.C., intitulé "L'offensive de percée" illustré de cinq photos d'engins et d'une photo d'un soldat lançant une grenade à bracelet. Le pétard sur raquette est une charge explosive dans une petite boîte métallique carrée (l'une d'elle est même une boîte de "singe", nom familier du corned beef) ficelée sur une planchette en bois ressemblant à une petite planche à découper; la mise à feu se fait par mèche à amadou d'une dizaine de centimètres, le pétard étant lancé avec sa raquette dès l'allumage de la mèche.

La grenade à bracelet et son mode de mise à feu et de lancement sont décrits ainsi: "La grenade à main employée par nous est la grenade à bracelet, à mise à feu automatique, composée d'une boule de fonte ${ }^{21}$ remplie d'explosif, et d'un bracelet de cuir que l'on fixe au poignet. Le bracelet est prolongé par un morceau de filin de 30 centimètres de longueur environ terminé par un crochet en fer. Au moment du jet de la grenade, le crochet est passé dans l'anneau du rugueux, placé à l'intérieur du bouchon de mise à feu qui ferme la boule de fonte. Au départ de la grenade, par un mouvement brusque de retrait du poignet, l'anneau, avec le rugueux d'amorçage, retenu par le crochet du bracelet, s'arrache et la mise à feu est faite. L'explosion a lieu 4 à 5 secondes après. Cette grenade est fournie dans la zone de combat toute prête. Elle est assez compliquée. Elle peut être lancée à 25 mètres environ."

Mais en dehors de ces formes primitives (bien que la grenade à bracelet soit "assez compliquée" et donc fabriquée en arsenal), à la guerre de 14-18, dès l'année 1915, dans l'armée française, les grenades ont été principalement de deux types: la grenade à cuillère, et la grenade quadrillée dite citron, car elle en avait la forme et le volume. Jacques Meyer, combattant de 14, nous les présente (ainsi que leur utilité) dans son ouvrage Les Soldats de la Grande Guerre: "Pour l'attaque ou la défense rapprochée, pour les patrouilles, la grenade s'imposa très vite. Elle seule permettait d'atteindre, en trajectoire courbe, les occupants des tranchées non exposés au tir tendu des fusils. On confectionna d'abord des pétards sommaires avec des boîtes de conserve ou des bouteilles munies de détonateurs. On retira des arsenaux jusqu'aux modèles sphériques des guerres de l'Empire. On créa assez vite des types nouveaux de grenades, offensives et défensives: celles à cuillère, dont la fabrication, souvent défectueuse, et le maniement délicat, coûtèrent la vie à de nombreux soldats, et à bien des officiers instructeurs; la grenade dite citron, à cause de sa forme, entourée d'une enveloppe de fonte à quadrillage en relief, était d'un emploi plus sûr, et rien ne nettoyait mieux un abri conquis qu'un citron jeté du haut de l'escalier. ${ }^{\prime 22}$

A différence de l'armée allemande, l'armée française n'avait pas de grenade cylindrique à manche de bois, cet accessoire faisant propulseur permettant de la projeter fort loin.

Un très bon lanceur pouvait projeter la grenade, avec un tour de bras énergique, guère au-delà de 30 mètres. Mais dès le début de la guerre de 14, on s'est ingénié à tenter d'accroître cette distance, d'abord artisanalement en adaptant à la grenade la technique du lance-pierre ou de la fronde, familière à tous les garçons, surtout les ruraux, en utilisant des fourches d'arbres munis de gros élastiques (lance pierre) ou une courroie de cuir (fronde). Puis le Génie militaire a produit des engins moins rustiques.

Une invention peu connue actuellement est l'arbalète lance-grenades, que la revue hebdomadaire L'Illustration, dans son numéro du 24 juillet 1915 (page 86), avec une photo en pleine page de deux soldats utilisant l'arme, avec la légende: "L'arbalète lance- grenade - A l'aide de cet engin, dit "sauterelle", on lance une grenade à parois segmentées à une distance de 20 à 80 mètres". Le texte de bas de la page, après avoir donné une citation de Lazare Carnot dans son traité sur la Défense des Places-fortes (1812) faisant l'éloge de l'arbalète, présente l'appareil: "En attendant que nos poilus des tranchées se soient décidés à remplacer leurs bruyants $86^{23}$ par les silencieuses arbalètes dont Carnot préconisait l'usage, il y a un peu plus d'un siècle, les sapeurs ont déjà commencé à employer une arbalète spéciale et fort ingénieuse pour projeter d'excellentes grenades, chargées d'explosifs puissants, qui vont débusquer dans leurs boyaux les fantassins ennemis et ouvrir la voie à nos colonnes d'assaut"

Mais l'arme de propulsion la plus efficace fut une adaptation du fusil Lebel, dit Viven-Bessières ou V.B. du nom de son concepteur. Jacques Meyer, dans la suite de sa présentation des grenades, le décrit: "Le fusil français Viven-Bessières (V.B.) était un Lebel pourvu d'un tromblon percé d'un trou; par celui-ci passait la balle qui projetait une grenade, placée dans le tromblon, à une distance que n'aurait pu atteindre le bras d'aucun lanceur; c'était une arme simple, inspirée d'une invention de la guerre russo-japonaise" ${ }^{\prime 24}$. Jean-Jacques Becker donne une

\footnotetext{
${ }^{21}$ Sa dimension, à en juger par les photos, est celle d'une boule de pétanque

22 Jacques Meyer, op.cit; pp. 87-88

${ }^{23} \mathrm{Ce}$ sont des obusiers à tir court, de calibre $86 \mathrm{~mm}$ (donc avec un obus légèrement supérieur en diamètre au fameux 75 de l'artillerie de campagne)

${ }^{24}$ Cette guerre qui opposa la Russie tsariste et le Japon impérial en 1904-1905, notamment à propos de leurs projets respectifs d'annexer la Mandchourie (pour avoir un port non pris par les glaces l'hiver comme Vladivostok, plus au nord que Port-Arthur en Mandchourie) et la Corée vit la victoire du Japon: le Russie dut céder Port-Arthur - qu'elle avait pris- et une partie de la
} 
idée de cette distance considérable et date l'apparition de cette invention: "Il existait dans les arsenaux français une antique grenade en fonte, dite de Sébastopol, mais qui était d'utilisation difficile et de médiocre efficacité. Après différents tâtonnements, à la fin de 1915, apparurent différents types de grenades "modernes", grenade défensive, grenade offensive qui n'était dangereuse que dans un rayon de quatre mètres, grenade incendiaire et aussi la grenade V.B. (du nom de son inventeur le capitaine Viven-Bessières) qui pouvait être tirée par un fusil muni d'un tromblon à une distance de 200 mètres" ${ }^{\prime 25}$.

La consultation de tous les numéros de l'année 1915 de L'Illustration ne m'a pas permis de découvrir la présentation de ce tromblon, dans une revue pourtant à l'affût de toutes les nouveautés de guerre, et dont les articles techniques sont extrêmement denses et précis. Constatons simplement que s'il est introduit "à la fin de 1915", comme l'écrit J.J. Becker, les Allemands ont au moins six mois d'avance dans cette technique, puisque l'article cité sur les pétards à raquette et les grenades à bracelets, contenu dans L'Illustration du 22 mai 1915 (page 530), présente aussi la grenade à fusil allemande ainsi qu'une photographie de l'engin; il s'agit d'une grenade cylindrique, de la taille d'une canette moderne, prolongée par un tige métallique, en cuivre, qui fait 4 fois la longueur de la grenade environ. Elle est propulsée par le procédé ainsi expliqué: "Pour lancer la grenade, une cartouche sans balle est introduite dans la chambre (le canon) du fusil; la quantité de poudre laissée dans la cartouche est réglée suivant la distance à laquelle on veut envoyer l'engin. Au moment du départ du coup, les gaz d'explosion s'introduisent entre le manchon et la tige, et coincent le manchon contre les rayures du canon. Le manchon et la tige, qui est solidaire, prennent un mouvement de rotation dans le parcours des rayures du canon, ce qui assure la direction de l'engin.". La portée maximale annoncée est, six mois avant l'arrivée du tromblon français V.B., le double des 200 m indiqués par J.J. Becker: "Employée avec le fusil, cette grenade va au maximum à 400 mètres", note T.C., l'auteur de l'article.

Ce tromblon V.B., Séraphin Rejony (cl. 18) de Roanne, qui fut toute sa vie employé aux papeteries Navarre de Roanne, l'a utilisé dans ses deux régiments successifs: le $22^{\mathrm{e}}$ B.C.A. d'Albertville et le $3^{\mathrm{e}}$ B.C.P. de ClermontFerrand. Dans l'épisode raconté, il évoque la mort d'un camarade tué par une grenade à ailettes allemande: "Le capitaine nous a dit comme ça: "Allez les gars! Restez pas là! Les Boches sont de l'autre côté de la route!" Eh bien, ils nous envoyaient des grenades à ailettes. Alors y a un petit copain... Parce qu'on faisait notre trou avec une petite pelle-bêche... Alors, il l'a reçue sur lui, mais il a pas fait attention. Alors la grenade a éclaté! On recevait des bouts de viande comme ça, là!

E- Comme le poing?

T- Oh oui! Il était dépecé! Dépecé complètement! Je m'en rappelle: un petit Savoyard, Vincent, il s'appelait! Un petit Savoyard! De son nom de famille! Et il a été complètement en morceaux! Des grenades à ailettes! Ils lançaient ça comme... Nous, on avait des tromblons: c'était un tromblon qu'on mettait au bout du fusil: on mettait une petite machine qui restait dans le tromblon, et puis ça tirait, comme de là à l'autre côté de la rue. Et chez eux, c'était les mêmes, c'était pareil que chez nous, exactement pareil!"

Un de ses camarades, plus âgé de trois ans (cl.15), René Villemagne, né à Chazelles-sur-Lyon, chapelier devenu prothésiste-dentaire à Saint-Etienne par suite de l'amputation de sa jambe gauche, affecté au $38^{\mathrm{e}}$ R.I. de Saint-Etienne, puis au $294^{\mathrm{e}}$ R.I. de Bar-le-Duc, se souvient même du nom précis du tromblon: "On avait des grenades qui se jetaient avec le fusil, les Viven-Bessières: on mettait le tromblon au bout du fusil, on enfilait une grenade et on mettait une cartouche. Le gaz dégagé par la cartouche faisait partir la grenade: mais ils allaient à 80-100 mètres! Et les Allemands les craignaient!". Cette explication laisse supposer que c'était une cartouche spéciale qui était utilisée pour propulser la grenade.

On a vu, dans l'analyse de Jacques Meyer, le danger que pouvait représenter la grenade à cuillère ("celles $\underline{a}$ cuillère, dont la fabrication, souvent défectueuse, et le maniement délicat, coûtèrent la vie à de nombreux soldats, et à bien des officiers instructeurs"). Plusieurs témoignages recueillis corroborent ce danger.

Jean-Marie Quet (cl. 17) d'Essertines-en-Chatelneuf, carrier avant guerre à Essertines, puis scieur de long à Montbrison (à la scierie Hilaire, sur la "route nouvelle"), et enfin ouvrier agricole après 50 ans, décrit la grenade à cuillère et le temps, assez bref mais suffisant selon lui, qu'on avait pour la lancer avant qu'elle n'explose, sauf si, malencontreusement, on la gardait dans la main: "Les grenades à manche, on n'en avait pas, nous! C'est les Boches qui les avaient! Nous, on avait des grenades à la cuillère. Y avait une cuillère. On prenait la grenade, on mettait la cuillère dans la main, puis on la tenait comme ça, fermée: y avait un percuteur dessous. Et puis, hop! On balançait la grenade!"

$\mathrm{E}-$ On avait combien de secondes?

T- Oh! On avait bien le temps de se coucher, de se garantir de ses éclats, oui, oui! Oh! c'était pas franc ${ }^{26}$ tout de suite! Fallait la lancer! Ah! Fallait pas la garder dans la main, par hasard! ${ }^{27}$..

presqu'île de Sakhaline. Elle fut par bien des points (les tranchées, l'emploi des barbelés, des mitrailleuses, des grenades...) une préfiguration de la guerre de 14-18

${ }^{25}$ Jean-Jacques Becker, La Première Guerre mondiale, article "La grenade", p. 83

26 "Pas franc" au sens de "pas tout à fait" est encore courant dans le français local forézien. Il s'emploie aussi sans négation: "il est franc fou, cet homme!" (complètement fou)

27 "Par hasard": locution adverbiale qui, en français local, signifie "par contre, en revanche"; encore très usitée et non perçue comme locale par la plupart des Foréziens. 
E- Quand on lançait la grenade, on la lançait dans la première ligne des Boches, en face? Il fallait que les deux premières lignes soient près l'une de l'autre?

T- Ah ben! A 20 mètres, à peu près."

René Villemagne, précédemment cité, un peu après dans l'entretien, signale le danger des grenades non percutées traînant sur le sol -dans le système de percutage précédant la cuillère- et les accidents qui en résultaient (il est alors dans un coin des Vosges, à Lesseux, à l'est de Saint-Dié, avec le 294' R.I. de Bar-le-Duc, où il est brancardier) et il évoque un bel exemple d'humanité en temps de guerre: "Dans le secteur dont je vous parle, on était dans les bois. Alors par terre, devant les tranchées, y avait toujours une couche de feuilles mortes. Et on allait faire des patrouilles des fois entre les lignes. Et souvent, dans ce tapis de feuilles mortes, on trouvait des grenades qui étaient pas amorcées. Parce qu'à ce moment-là, les grenades, il fallait les percuter; après, y avait une cuillère, c'était automatique. Il fallait les percuter, et vous savez, y en avait toujours qui les percutaient plus ou moins, qui les jetaient. Alors elles n'explosaient pas parce qu'elles n'étaient pas amorcées. Alors il est arrivé que les Poilus, pendant la patrouille, avec un coup de godillot, ils amorçaient la grenade: "Paouff!" Ça petait! Et il fallait aller les chercher entre les lignes! Monsieur, une fois, ça m'est arrivé d'aller chercher un petit gars (il était blessé au ventre, il avait plusieurs éclats dans le ventre) en plein jour! Les Allemands ont pas tiré! Et ils nous voyaient bien: on avait un brassard blanc avec la croix rouge. On a ramassé notre blessé qui criait. Ils l'entendaient! Les Allemands n'ont pas tiré! Pas un coup de fusil! " René fait aussitôt le geste de soulever sa casquette.

E- Là, vous faites signe: "Chapeau!"

T- Ah oui! On savait pas comment leur dire merci...".

Des accidents, parfois mortels, pouvaient aussi résulter de la chute malencontreuse, ou par lassitude, de la musette de grenades.

Pierre Sabatier $(\mathrm{cl.13})^{28}$ de Firminy, petit goujat en maçonnerie, puis métallurgiste, puis mineur avant guerre, après guerre tourneur à l'usine Holtzer d'Unieux où il finira contremaître, est grenadier au $35^{\mathrm{e}}$ R.I. de Belfort quand survient l'accident qu'il évoque:

$\mathrm{E}$ - "Vous aviez combien de grenades dans votre musette?

T- Oh! 25... Je sais pas combien...

E- On m'a dit que parfois certains faisaient une fausse manœuvre et qu'une grenade leur pétait dans la musette! Est-ce que vous avez déjà vu ça?

T- J'ai vu un type quand on montait à.. à... On montait dans les tranchées. Et tout par un coup ${ }^{29}$. J'ai qu'entendu le type: "Tac!" Parce qu'il a jeté son sac comme ça, là! Il était fatigué: il jette sa musette! J'ai entendu: "Tac!" Hop! Je me suis foutu à plat ventre , j'ai compris! "Baoum!" La grenade éclate, puis fait éclater les autres: "Baoum! Baoum! Baoum!" Le type, les jambes coupées! Le type qui portait le machin! Par sa bêtise! Une autre fois, on faisait l'exercice... Y en a un qui faisait l'exercice, il jette la grenade de l'autre côté! Elle lui échappe des mains, elle tombe sur des types, des Français! En faisant de l'exercice! Mais ça a pas...

$\mathrm{E}-$ Et elle éclate?

T- Eh oui! Il avait blessé un type, là!

E- Il fallait faire très attention, avec les grenades!

T- Ah! Ça rigolait pas, bien sûr!"

Un accident de même type, mais plus grave encore, m'a été raconté par Antoine Gacon (cl. 17), né dans l'Allier à Lenax, fils de métayers venus ensuite à La Pacaudière (Loire); après guerre, il fut successivement, à La Pacaudière, épicier puis charpentier, puis maçon (une chute d'un toit l'ayant fait renoncer à la charpenterie) puis épicier à nouveau, avant de prendre sa retraite. L'accident relaté se passe alors qu'il est pourvoyeur de fusilmitrailleur dans son quatrième régiment, le $119^{\mathrm{e}}$ R.I.: "Basmaison, il était de ma classe aussi, et il a été tué làbas. Il a été tué bêtement: on montait en ligne, moi j'étais...Vous savez, le boyau, ça faisait comme ça, et puis un machin comme ça (fait des gestes de la main montrant des sinuosités), et moi j'étais là...

E- $Y$ avait des pare-éclats, oui! ? $^{30}$

T- Voilà: des pare-éclats! C'est-à-dire des tournants. Et il arrivait de permission, et nous on remontait des fils de fer. ...Et lui il en avait marre (il arrivait de permission), il montait un sac de grenades. Tout par un coup, il dit: "Oh! J'en ai marre! Font chier! Je vais leur casser la gueule, Bon Dieu!" Il balance le sac de grenades sur le parapet, là! "Crac! Broum!" Mis en bouillie!

E- Ah bon, Les grenades se sont amorcées toutes seules?

T- Oui!

E- Du choc?

\footnotetext{
${ }^{28}$ Son arrière-petit-fils Philippe Sabatier, résidant aussi à Firminy, excellent dessinateur, a fait une superbe exposition de dessins sur la Grande Guerre en 2007, intitulée "Ceux de 14-18" - par allusion à l'ouvrage autobiographique de Maurice Genevoix - à la M.J.C. de Firminy en mars, et dans divers lieux ensuite. Comme il ignorait presque tout de la guerre de son aïeul, j'ai eu le plaisir de lui photocopier l'entretien que j'avais réalisé avec lui en 1989 (témoin alors âgé de 96 ans, décédé en 1994, à 101 ans).

29 "Tout par un coup" : expression adverbiale encore très usitée en Forez pour dire "tout à coup"

${ }^{30}$ Le pare-éclat est un coude ou une avancée de terre dans un boyau ou une tranchée pour en interrompre l'aspect rectiligne, afin qu'un éclat d'obus, ou une balle de fusil ou de mitrailleuse prenant le boyau ou la tranchée en enfilade rencontre un obstacle qui l'arrête.
} 
Fils de T: Du choc, oui! Y en a une qui a dû se dégoupiller!

T- En bouillie!

[...] E- C'était vraiment une mort idiote, là!

$\mathrm{T}$ - Ah ben ça, c'était couillon! Après le cabot (le caporal) a dit: "Bon Dieu! Comment qu'il a fait son compte?" Aller lâcher un sac de grenades comme ça! Et que ça s'amorce! Et puis, ça y est! Patatrac! On pouvait y passer tous les trois!"

Un des 27 témoignages écrits évoque les mêmes circonstances. C'est celui de Jean Farigoules (cl. 16) né à Cheyssac, hameau de Saint-Pierre-du-Champ, vers Retournac, en Haute-Loire, fils d'agriculteurs, devenu boulanger-pâtissier, profession qu'il exercera après guerre essentiellement à Brives-Charensac (Haute-Loire) jusqu'à sa mort en 1947. Versé au $67^{\mathrm{e}}$ R.I. de Soissons, il se trouve vers Soupir, dans l'Aisne lorsque survient l'épisode dramatique qu'il relate: "Les obus tombent, mais ne peuvent pas trop nous prendre, nous restons dans nos trous le jour et la nuit, on fait des corvées en ligne, on monte des grenades. C'est là que Grosperrin trouve la mort, il tombe son sac de grenades ${ }^{31}$ et le ramasse en retour, mais dans le choc, une grenade se percute et les 15 grenades éclatent sur son dos. Il eut la tête emportée, heureusement que les autres poilus avaient compris le danger et avaient eu le temps de fuir."

Tous ces témoignages d'accident ne concernent pas exclusivement l'année 1915, mais sont symptomatiques du danger de la manipulation des grenades.

\section{Les mortiers de tranchée ou "crapouillots"}

Le rapprochement progressif, au fil des mois de guerre de position, des premières lignes ennemies, d'une centaine de mètres à quelques dizaines de mètres (voir le chapitre VIII) voire exceptionnellement à 15-20 mètres, a rendu l'artillerie de campagne moins opérante pour le travail de "grignotage" de terrain préconisé par l'Etat-Major, et dangereux pour ses propres soldats, car comment, avec des batteries à 3,4 ou $5 \mathrm{~km}$, voire nettement plus, ajuster à coup sûr, le tir du canon de 75 - ou du 77 allemand, dans le camp adverse - sur la première ligne ennemie quand la sienne en est si proche? De nombreuses "bavures", on le verra, furent commises. Il s'avérait donc intéressant, en dehors des grenades, de posséder des canons de tranchées à tir très court et courbe, en cloche, pour atteindre la tranchée ennemie proche à partir de sa propre tranchée de première ligne. On voit donc se créer une artillerie très spéciale, qui retrouve le contact avec l'infanterie, une artillerie dite "de tranchée".

Celle-ci est d'origine allemande. Jacques Meyer, combattant et écrivain, l'indique dans Les soldats de la Grande Guerre: "Pour remplacer l'artillerie lourde, largement et judicieusement utilisée par eux dès le début, mais qu'ils ne pouvaient employer dans la guerre de retranchements vu la proximité des lignes adverses, les Allemands avaient, avant 1914, inventé des pièces lançant en tir courbe des grenades et des mines (granatenwerfer et minenwerfer). Ces armes, dont la portée et la rapidité furent constamment augmentées, se révélèrent économiques et efficaces. Leurs projectiles étaient très démoralisants; leur souffle, surtout celui des "seaux à charbon"132, chargés de $50 \mathrm{~kg}$ de cheddite ${ }^{33}$,ébranlait et leur explosion détruisait d'énormes morceaux de tranchées ou défonçait les abris même bien protégés ${ }^{\prime 34}$. Mais J. Meyer tempère cette description effrayante par un brin d'optimisme: "Heureusement, vu la lenteur relative des minen, nos hommes avaient parfois le temps de les éviter".

L'antériorité allemande sur l'armée française en ce domaine est corroborée par un petit article de L'Illustration du 23 janvier 1915 (page 73), intitulé "Minenwerfer", qui pose à l'auteur de l'article un problème linguistique de traduction, et dont l'étrangeté à la fois pour l'armée française et pour les deux journalistes intervenant (l'auteur de cet article et l'auteur de l'article du Figaro cité) atteste la nouveauté, comme le fait de l'exposer au Havre, et de se rendre de Paris au Havre pour le décrire. Il mérite d'être cité en entier, car il donne, sous la plume du journaliste du Figaro, un superbe exemple de subjectivité patriotique dans la dévalorisation par l'animalisation du canon"boche": "Minenwerfer" - Ce mot baroque est apparu depuis moins d'un mois dans les communiqués et les compte-rendus du front. On a compris, par le contexte, qu'il désignait un engin spécial, destiné de lancer d'assez près de gros projectiles sur nos tranchées. On ne l'a pas trouvé joli, ni clair. On a songé à le traduire, et deux mots français ont été proposés pour le remplacer: d'abord "lance-mines" qui en est la traduction littérale - mais le mot "mine" n'a jamais désigné en français la bombe, l'obus ou la grenade, ni aucun projectile; puis "crapouillot", qui est le nom que donnaient les soldats de la Grande Armée ${ }^{35}$ à un engin semblable, et qui est un vocable imagé, amusant, et sentant son terroir. La langue officielle a préféré lance-mines. Acceptons lance-mines!

\footnotetext{
${ }^{31}$ Le verbe "tomber" au sens de "laisser échapper" s'emploie transitivement en Velay, en Forez, en Lyonnais, dans le français local, ainsi que dans une bonne partie du sud de la France

${ }^{32}$ Surnom familier donné à ces obus lents en raison de leur forme évoquant le seau à charbon d'antan (mais objet ménager très familier au début du $\mathrm{XX}^{\mathrm{e}}$ siècle)

${ }^{33}$ La cheddite est un explosif dont le nom apparaît en 1908; elle tire son nom de Chedde, la localité de Haute-Savoie où elle fut d'abord fabriquée; selon le Grand Larousse de la Langue Française, c'est un explosif à base de chlorate de potassium.

${ }^{34}$ Jacques Meyer, op.cit., pp. 37-38

35 "Crapouillot": ce mot d'argot militaire apparu, selon Le Dictionnaire Historique de la Langue Française dirigé par Alain Rey, avant 1794, donc avant les guerres napoléoniennes, a été popularisé par celles-ci, pour désigner un petit mortier de tranchée. Il dérive du mot "crapaud" désignant déjà, vers 1400, un petit mortier. par analogie de forme avec le batracien. Rappelons qu'il a fourni le titre a une célèbre revue satirique dont le premier numéro a paru en août 1915.
} 
Quant à l'engin lui-même, qu'est-ce au juste? Quelle en est la forme? Comment fonctionne-t-il? On a fait làdessus mainte et mainte supposition, tant qu'on n'en avait pas vu, qu'on n'en avait pas capturé. Or, en voici la photographie, et notre confrère Louis Latzarus qui est allé, au Havre, contempler le monstre lui-même, en a donné au Figaro cette description pittoresque: "C'est tout simplement un affreux petit canon, qui a l'air le plus sournois du monde. Sa longueur est de 90 ou 95 centimètres. Son calibre: $170^{36}$. II peut se mouvoir verticalement et horizontalement, pour le pointage. Une bêche à l'arrière. Deux bêches ${ }^{37}$ à l'avant, une à droite, une à gauche. II doit s'agripper fortement au sol, comme un roquet rageur, avant d'aboyer. Il est monté sur un affût d'acier boulonné. II a des roues. Voilà. C'est un petit canon bas et lourd: 500 kilos sans les roues. Le projectile y entre par la bouche. On y met le feu par la culasse au moyen d'une étoupille quelconque. Retirez les appareils de visée et vous n'aurez pas un engin très supérieur aux vieux mortiers de bronze exposés aux Invalides. II n'est pas probable qu'il puisse lancer une bombe à plus de 500 mètres. Plus exactement, il ne la lance pas: il la crache."

Comme pour les grenades, avec le pétard sur raquette, et le lancer de la grenade à la fronde géante, le bricolage commença à pallier le retard d'armement spécifique français. Dans son numéro du 21 août 1915, pages 192-193, sous le titre "Crapouillots, lance-bombes et lance-grenades", un court article de L'Illustration commentant une double page de six photos, présente, entre autres, un canon bricolé de très petit modèle qui n'a pas laissé de traces dans les ouvrages des historiens: le taupia. Il est décrit ainsi: "Le taupia fut une improvisation de nos officiers et soldats du génie: c'est un simple obus de 77 allemand, non éclaté, dont on dévisse l'ogive ${ }^{38}$ et à la base duquel on perce une lumière: la mise à feu se fait par mèche, et ce petit tube peut lancer une bombe allongée pesant environ un kilo. " La photo illustrant l'article présente deux soldats chargeant chacun un taupia, qui a la longueur de leur avant-bras environ, sur le rebord intérieur d'une tranchée.

On peut considérer aussi comme une forme de bricolage l'adaptation de mines au bout du fût de petits canons de montagne, de calibre 58 ou 80, faits pour tirer des obus courts, de manière classique. La photo illustrant cet article montre trois artilleurs dans un abri derrière un petit canon monté reposant sur des blocs de bois; au bout du fût une mine cylindrique de diamètre triple par rapport au fût du canon, ressemblant à une bouteille courante de gaz butane. Le texte explique: "Mais le plus impressionnant de nos lance-mines n'est autre que le canon de 80 de montagne dont les roues ont été supprimées. Le tube et l'affût sont placés sur une plate-forme en chêne et des contrepoids convenablement disposés diminuent l'effet du recul. Ce canon peut lancer de petites mines de 58 kilos, des moyennes de 78 kilos et des grosses de 105 kilos. Notre cliché montre seulement une petite mine. La plus employée est la moyenne, qui fait un entonnoir de 8 mètres de diamètre sur 2 mètres 50 de profondeur. Le tir se règle à un mètre près."

Une idée de la diversité de ces engins-canons de tranchées, parfois éphémères, nous est fournie par le poète Guillaume Apollinaire, qui, venant de passer de l'artillerie où il était brigadier dans une batterie du $38^{\mathrm{e}} \mathrm{R}$. d'Artillerie de Nîmes, à l'infanterie, où il vient d'être promu sous-lieutenant au $96^{\mathrm{e}} \mathrm{R}$. d'Infanterie de Béziers $\left(6^{\mathrm{e}}\right.$ compagnie), écrit du front à sa fiancée Madeleine Pagès, professeur de lettres au lycée de jeunes filles d'Oran (rencontrée dans un train allant de Nice à Nîmes début janvier 15). Pour elle, dans sa lettre du 30 novembre 1915, il passe en revue les divers obus de tranchées - dans l'appellation familière donnée par les Poilus français qui les reçoivent - et les innovations pour les rendre plus meurtriers: "A certaines heures à peu près fixes on nous bombarde des obus de 105 et quelques 77 fusants ${ }^{39}$, une pièce qui doit être tout près. Mais enfin pr* le moment pas de ces horribles engins de tranchée qui sont plus terribles que tout et dont on parle si peu:

Youyous ainsi nommés du bruit plaintif qu'ils faisaient entendre en venant et que les Boches sont arrivés à supprimer. Si bien qu'on ne les entend plus venir et comme ils les peignent maintenant en bleu ciel on ne les voit plus non plus.

Bô̂tes à merde, sortes de lits ou de grandes malles qui arrivent à une $60^{\text {aine }}$ de mètres de hauteur et piquent brusquement et détruisent $200 \mathrm{~m}$. de tranchée avec tout ce qui s'y trouve.

Seaux à charbon, espèce de bombes ainsi nommées de leur forme et pleines de toutes sortes de ferraille. Engin horrible.

Marie-Louise, le plus grand de tous ces engins, bombe très haute et d'effets épouvantables.

Nous, nous n'avons que nos petits paniers avec les grenades à mains.

\footnotetext{
${ }^{36}$ Le calibre 170 signifie un obus de calibre relativement gros $(17 \mathrm{~cm}$ de diamètre, au lieu de $7,5 \mathrm{~cm}$ pour le fameux obus de 75 , dont tout le monde, ou presque, a vu un exemplaire de douille en cuivre jaune transformé en pot de fleur...)

${ }^{37}$ Ces "bêches" sont des systèmes d'ancrage au sol, en forme de bêche, pour encaisser à chaque coup tiré l'effet de recul du canon, et le remettre en position de tir (les bêches avant servant à neutraliser l'effet propulseur de la bêche arrière)

${ }^{38}$ L'ogive est la pointe de l'obus, de forme ogivale, vissée quand l'obus a reçu son chargement de poudre et de shrapnells (billes de plomb ou éclats métalliques destinées à se disperser en gerbe pour accroître l'effet meurtrier).

${ }^{39}$ Un obus fusant éclate en l'air, un peu au-dessus du sol, de manière à ce que sa gerbe d'éclats soit la plus meurtrière possible, même avec de petits obus comme ceux du 77 (77 mm de diamètre) allemand, alors que l'obus percutant éclate en touchant le sol et en s'y enfonçant: les éclats se dispersent moins, mais l'effet de souffle est considérable (mort immédiate par explosion des poumons des soldats à proximité) ainsi que le volume de terre remuée et projetée en l'air (ensevelissement des soldats) surtout si l'obus est gros.
} 
La section de réserve tandis que nous veillons fabrique les sphères, les chevaux de frise, les trébuchets pour augmenter nos défenses accessoires. " ${ }^{40}$

Ainsi, dans cette année 1915, la mine, comme la bombe de diverses formes, est une arme redoutable, avec des charges moyennes lancées dans l'air, et plus terrible encore, avec des charges énormes de poudre explosant au fond de la galerie de sape patiemment creusée par les mineurs-sapeurs pendant des semaines, pour rejoindre la tranchée ennemie, comme nous l'avons vu dans le chapitre sur la guerre des mines. De la terre et du ciel, la mort vient...

Mais en dehors de ces formes bricolées, le "crapouillot" est un mortier classique tirant des torpilles à ailettes, qui se répandit dans les tranchées au fur et à mesure où la production industrielle s'intensifiait. Le Normalien souslieutenant Jacques Meyer, qui les a côtoyés, les décrit ainsi: "Puis l'on inventa une série d'engins de types très divers. Le nom de l'un des plus puissants, "le crapouillot" fut donné plus particulièrement à un mortier de 58 qui lançait à une centaine de mètres une puissante torpille à ailettes. Malgré son réglage assez peu précis et les risques d'éclatement prématuré, cette arme put rivaliser avec les minenwerfer allemands. Souvent le tir du crapouillot constituait une sorte de rite quotidien, à heure presque fixe, destiné à animer le secteur, sur ordre du commandement. Après une salve d'un certain nombre de coups, l'équipe d'artilleurs quittait en hâte le petit boyau creusé pour loger la pièce $e^{41}$, en avant d'une tranchée de deuxième position, pour aller se mettre à l'abri plus à l'arrière. Car, d'une part, ces sapes étaient facilement repérables et, d'autre part, de larges représailles s'abattaient généralement sur les tranchées et les abris."

Les relations entre les fantassins et ces artilleurs de tranchées ne sont pas idylliques, comme l'explique J. Meyer: "Déprimés par l'ébranlement et le bruit de l'explosion des minen, quand les parois de l'abri ne cédaient pas en écrasant ses habitants, les fantassins maudissaient souvent ces "sacrés crapouilloteurs", dont les expériences de tir entraînaient au minimum le "chamboulement" du secteur: "Comme toujours, c'est les biffins ${ }^{42}$ qui paient les pots cassés". Mais il arrivait que la réserve de nos torpilles fût atteinte par les projectiles ennemis, et les servants des crapouillots sautaient avec elle. Les "crapouilloteurs" restaient presque à demeure dans le même secteur. ${ }^{433}$

Certains de mes témoins fantassins évoquent spontanément les "crapouillots". Dans l'enquête de thèse de dialectologie, un de mes premiers témoins, Claudius Recorbet (cl. 15), né à Fos-sur-Mer (Bouches-du-Rhône), mais venu dans sa petite enfance dans la Loire avec son père garde-chasse, principalement à Sury-le-Comtal, ouvrier à Sury, a été interviewé en patois le 29 août 1975, en compagnie de son ami plus jeune de neuf ans, Benoît Baudet. Il a "servi aux crapouillots" dès l'année 15, dans les rangs du $16^{\mathrm{e}}$ R.I. de Montbrison, et en dénonce le danger en cas de tir mal ajusté: "C'était en 15, au mois d'octobre. C'est là qu'on est resté longtemps. Oh! On en a bavé! Il fallait aller au ravitaillement, il fallait aller ravitailler, aller chercher les torpilles pour les...les... Oh! la la! Comment qu'on les appelait? ... les crapouillots! Toute la nuit, allez, hop! Vous preniez la garde, facilement ${ }^{44}$ deux heures. On venait te relever: il te fallait aller aux crapouillots. Vous reveniez, vous vous couchiez une heure. Facilement, allez! Il fallait tourner prendre la garde! ...Ces canons, ces crapouillots, ils allaient pas extrêmement loin, mais ils étaient dangereux parce que ces machins étaient derrière la première ligne; et si les artilleurs qui tiraient ajustaient mal leur tir, tu le recevais facilement sur le... Les Français, facilement, le recevaient sur la tête!".

Un de ses "classards" de la 15, mais plus jeune de neuf mois, Pierre Rivollier, né au hameau d'Etrat, à SaintJust-sur-Loire, dont les parents agriculteurs s'installeront en 1906 à Chénieux, autre hameau de la même commune (ferme qu'il exploitera toute sa vie), incorporé dans le même régiment, le $16^{\mathrm{e}}$ R.I. de Montbrison, se trouve vers la Butte de Tahure, en Argonne, au moment de la grande offensive de Champagne lancée le 24 septembre 1915. Il évoque brièvement le tir des crapouillots allemands, les fameux "Minenverfer": "Paraît qu'il en est resté quatre cents, dans cette bataille-là! Pour traverser la plaine! Eh pensez-vous: les Allemands étaient de l'autre côté, sur la côte: ils les empêchaient de venir!

E- Est-ce qu'ils étaient mieux armés, les Allemands?

\footnotetext{
${ }^{40}$ Guillaume Apollinaire, Lettres à Madeleine - Tendre comme le souvenir, $1^{\text {ère }}$ édition en 1952, réédité en 2005, Gallimard NRF, p. 354

41 "La pièce" est le terme toujours usité par les artilleurs pour désigner un canon

42 "Biffin" est le nom du fantassin (le soldat de l'infanterie") en argot militaire, car il appartient à "la biffe" (l'infanterie). L'étymologie du terme est intéressante, éclairée par le Dictionnaire de la Langue française dirigé par Alain Rey: "De "biffe", tissu, conservé dans les dialectes, provient "biffin" qui signifie d'abord "chiffonnier" (1838) et qui ne prend que plus tard (1878) son sens moderne de "fantassin" par comparaison du havresac du soldat avec la hotte de chiffonnier - "Biffin" a produit "biffe" (1878) au sens de "corporation de chiffonniers" (la biffe) et passé dans l'argot militaire pour "infanterie" (1898)". Comme souvent, ces termes d'argot militaire sont antérieurs à la guerre de 14-18, mais c'est elle qui les a popularisés par l'énorme brassage de plus de 8 millions de soldats français mobilisés (pas en même temps) et aussi, diffusé dans le grand public, à cause de la lecture assidue de la presse pendant quatre ans, les journalistes ayant le souci de pimenter leurs récits avec des termes familiers ou argotiques. Un des ouvrages de témoignage de Jacques Meyer est intitulé "La Biffe".

${ }^{43}$ Jacques Meyer, Les soldats de la Grande Guerre, pp. 38-39

44 "Facilement" en patois et en français local foréziens, encore actuellement, peut signifier, comme ici "au moins", et dans la phrase suivante "parfois" (notion de probabilité); mais il a aussi le sens normal du français.
} 
T- Peut-être pas... A peu près... Ils étaient ben rupins. $!^{45}$ Ils étaient ben malins! Quand ils envoyaient des bombes à ailettes, dans les tranchées, ça en blessait, là! Ils avaient des crapouillots, on les voyait venir! Ça allait pas loin, ça allait à peu près à 300 mètres. C'est là que Rival s'est fait blesser par un éclat, Rival de Montbrison..."

Un autre témoignage sur les crapouillots allemands fourni par l'un de mes témoins principaux (par la longueur de l'entretien ${ }^{46}$ et la qualité de l'analyse) provient de Jean-Louis Monier (cl. 13), fils d'agriculteurs de Marols (hameau de Chabanne), qui a exploité lui-même toute sa vie cette ferme qu'il a léguée à son fils Joseph, et maire de Marols de 1952 à 1959. Au régiment depuis l'automne 1913, Jean-Louis a connu successivement l'artillerie (le $53^{\mathrm{e}}$ R.A. de Clermond-Ferrand, puis trois autres régiments d'artillerie en 1918) et l'infanterie (le $363^{\mathrm{e}}$ R.I. de Nice) d'où sa vision d'ensemble. Il évoque la redoutable efficacité des "marmites" ou "seaux à charbon" que projetaient les Minenwerfer, alors qu'il se trouve un peu en retrait de la première ligne, en forêt d'Argonne: "La guerre de tranchées, c'était organisé, si vous voulez. Alors, ils nous envoyaient des espèces d'affaires (on appelait ça des "seaux à charbon", je sais pas ce que c'était...), c'était des grosses "marmites" ${ }^{\prime \prime 7}$, si vous voulez, qui arrivaient et qui tombaient en arrière des lignes et qui, paraît-il, vous tuaient un homme à 10 mètres sans le blesser: rien que l'explosion! Et ça ne m'étonne pas, parce que dans ce ravin (il s'interrompt quelques instants pour dessiner les positions des deux régimes ennemis), je regardais... C'était assez loin: 150 mètres peut-être de moi - les chênes montaient en l'air et tombaient de l'autre côté: ça coupait le chêne ras le sol, l'explosion! Je me demande comment ils avaient... Je regardais ça, je me disais: "Mon vieux, ceux qui sont là-bas!". Je les plaignais."

Parmi les 32 artilleurs représentés dans mes témoins (ayant servi partiellement ou totalement dans l'artillerie), il s'en trouve un seul à avoir fait partie de l'artillerie de tranchée, celle des crapouillots. Il se singularise aussi par un autre aspect, dramatique: c'est la seule "gueule cassée" parmi les 160 témoins enregistrés ${ }^{48}$. Il s'agit de Baptiste Bussy (cl. 13), né à Régny, fils d'agriculteurs devenant mécanicien sur cycles au Coteau et à Roanne, ayant passé la fin de sa vie à l'hôpital de Bonvers, à Mably, où je l'ai interviewé en 1987. Il était incorporé au $53^{\mathrm{e}} \mathrm{R}$. d'artillerie, avec le grade de brigadier, et témoigne de sa voix cassée: "Les crapouillots, vous savez ce que c'était? C'étaient des bombes à ailettes. C'était pas très gros, ça pesait à peine 20 kilos. Et alors, on les mettait dans les tranchées, on faisait une position dans les tranchées parce qu'ils étaient pas volumineux. Puis alors, ça partait comme ça (geste de la main vers le haut)

E- Ça partait en hauteur? Vertical?

T- Oui! Là, on a changé. Ils ont mis des batteries de crapouillots à partir de 100: c'était la $101^{\text {ème }}$ batterie du $59^{e}$ régiment d'artillerie. Alors, c'étaient les bombardiers: c'était nous, ça!

$\mathrm{E}-$ Et vous étiez en première ligne?

$\mathrm{T}-$ Oui... J'étais passé brigadier

E- Ah bon? Eh bien, pour quelqu'un qui était contre l'armée ${ }^{49}$, vous aviez pris du galon!

T- J'étais bien classé! Parce que j'étais hardi! J'avais pas peur! J'étais brigadier à une pièce.. Chaque pièce, y avait un brigadier. Y avait le pointeur, le brigadier, et puis un sergent pour les deux pièces."

E- Toujours servant?

T- Non! Je m'occupais de la pièce. C'était moi le directeur de la pièce.

E- Vous saviez viser, alors?

T- Non! Y'avait le pointeur. C'est moi qui mettais le feu, qui faisais partir. Mais il fallait préparer la pièce; un mettait la bombe dedans; y'avait un tube qui était grand comme ça, qu'on rentrait dans le canon. Et on mettait le feu! Et "Boooum!". Ça partait!

E- Et ça partait pas très loin?

T- Non! Notre travail, c'était surtout de nettoyer pour les attaques. On était tout le temps dans les offensives, parce que c'était pour nettoyer les... Entre les tranchées, y avait des réseaux de fils de fer. Quand on faisait une attaque,

\footnotetext{
45 "Rupins" signifie évidemment "riches", mais ici en armement, ce qui est un usage inusité du mot, signifiant habituellement riche en argent, en biens, avec la connotation péjorative d'affichage de cette richesse. par ses habits, son train de vie, ses manières...

${ }^{46} \mathrm{La}$ transcription de cet entretien qui a duré plus de 4 heures, à Marols, dans la ferme du témoin, le 11 novembre 1980, comporte 84 pages quadrillées en lignes très serrées: Jean-Louis Monier, mon $17^{\text {ème }}$ témoin (mais le $6^{\mathrm{e}}$ après les enquêtes de thèse de dialectologie, -soutenue en déc. 1978- où le thème de 14-18 n'était qu'accessoire) a joué un rôle essentiel dans ma décision d'interviewer les derniers survivants de la Grande Guerre de la Loire et de sa périphérie. J'ai eu avec lui des entretiens ultérieurs portant sur d'autres thèmes, soit à Marols, soit à la maison de retraite de Saint-Jean Soleymieux.

${ }^{47}$ Selon le Dictionnaire Historique de la Langue Française dirigé par Alain Rey, le terme "marmite" a pris, par analogie de forme, le sens de "bombe" (1847) puis de "gros obus" dans la guerre de 1914-1918; en parallèle, le verbe "marmiter", transitif, est apparu en 1894, et s'est répandu parmi les Poilus au sens de "bombarder". En revanche, ce dictionnaire ne mentionne pas ce sens métaphorique de "seau à charbon", pas plus que le GLLF (Grand Larousse de la Langue Française) alors qu'on le rencontre dans les revues paraissant pendant la Grande Guerre, L'Illustration et Le Miroir, dont je possède les collections, et dans la citation de Jacques Meyer au début de cette rubrique..

${ }^{48}$ En fait, deux témoins sur les 187 (témoignages oraux + écrits) sont des "gueules cassées", le dossier d'un autre blessé du visage, Claude Martinon (cl. 14) de Chateauneuf, près de Rive-de-Gier, m'ayant été communiqué par sa famille, car il était décédé depuis longtemps. Nous verrons plus loin dans l'ouvrage le cas particulier de ces blessés défigurés.

${ }^{49}$ Allusion à sa désertion du régiment, en avril 1914, à cause d'un conflit permanent avec un gradé. Baptiste passe en Suisse (il se trouvait à Besançon, au $4^{\mathrm{e}}$ Régiment d'Artillerie), puis en Italie, et ne reviendra en France...qu'en mai 1915, après l'entrée en guerre de l'Italie! Nous reviendrons sur ce cas singulier.
} 
il fallait faire des passages dans les réseaux, parce qu'alors, y avait les mitrailleuses en face, vous comprenez! Il fallait détruire les fils de fer pour qu'on puisse passer quand on attaquait."

E- Mais ce n'étaient pas vos crapouillots qui détruisaient les fils de fer? Y avaient des hommes qui allaient les couper? $?^{50}$

T- Oh non! Non! Les crapouillots! ...C'étaient les bombes: dès qu'elles touchaient le fer, elles éclataient! Alors, on voyait les piquets, les réseaux de fils de fer, ça sautait en l'air, mon vieux!

E- Donc ça rasait tout? Ça préparait le terrain?

T- Ça préparait le terrain, ça faisait des passages sur le terrain, pour que l'infanterie puisse passer."

Ainsi, les crapouillot vont jouer un rôle spécifique, lié à la guerre de position, au creusement des tranchées et à leur rapprochement progressif. Nous verrons plus loin le cas de l'artillerie classique, préexistante à la guerre de 1914-1918.

\section{Les gaz toxiques}

Il est très rare de connaître le jour précis de la première utilisation d'une nouvelle arme, sauf si celle-ci, terrifiante, a frappé durablement les esprits. C'est le cas de la première utilisation militaire de la bombe atomique, par les Américains, à Hiroshima, le 6 août $1945^{51}$. C'est aussi le cas pour les gaz asphyxiants dits aussi "gaz de combat". Pourtant interdits par la Convention de la Haye du 29 juillet 1899, dont la France et l'Allemagne étaient signataires, ils ont été utilisés pour la première fois, selon tous les historiens, par l'Allemagne le 22 avril 1915, à Langemarck, au nord d'Ypres (Yper en flamand), en Belgique, d'où le nom d'ypérite qui fut donné plus tard, en 1917, à ce gaz, qui était du sulfure d'éthyle dichloré. Cette violation de la convention de la Haye inaugura, de la part des belligérants des deux camps, l'utilisation de gaz variés avec des effets de plus en plus meurtriers.

Cet emploi marque une escalade dans ce que l'historien Pierre Miquel appelle "la guerre terroriste". Dans son gros ouvrage La Grande Guerre ${ }^{52}$, il commence par analyser cette étape décisive dans l'immoralité de la guerre, immorale par nature: "L'emploi par les Allemands des gaz asphyxiants, au printemps de 1915, fut l'acte le plus spectaculaire de la guerre terroriste. L'idée de gazer comme des renards ou des rats les hommes dans leurs tranchées était fascinante: les vainqueurs dotés de masques n'avaient plus qu'à s'avancer en terrain conquis, l'arme à la bretelle. Même les chevaux seraient cloués au sol."

Puis il décrit précisément l'événement: "Le 22 avril, au nord d'Ypres, sur le front de Steenstraat, de Langemarck, et plus à l'est, les Allemands ont disposé des tubes à gaz à raison d'une batterie tous les quarante mètres. Ils ont attendu un vent favorable pour que le gaz lourd, de couleur jaunâtre ou verdâtre, soit poussé vers les lignes alliés. Les territoriaux de la $87^{e}$ division française sont totalement surpris. Ils tombent comme des mouches. Depuis le 16 avril, l'état-major belge avait averti les Français que les Allemands avaient fait confectionner à Gand 20000 couvre-bouches en tulle "imbibé d'un liquide approprié " et recouverts d'une enveloppe imperméable; les effets du gaz portaient à un kilomètre".

Ce premier lancer de gaz toxique est relaté au style indirect par la légende d'un dessin pleine page fait d'après les descriptions des gazés, intitulé "Le rideau de lourdes vapeurs asphyxiantes" dans le n du 8 mai 1915 de L'Illustration: "Un officier a déposé qu'on vit d'abord une vapeur blanche monter des tranchées allemandes jusqu'à une hauteur d'un mètre environ; puis, au devant de cette vapeur, parut un nuage verdâtre, qui s'élevait à près de trois mètres de haut et qui roula le long du sol, comme un mur mouvant, poussé par un vent régulier, jusqu'aux tranchées françaises et anglaises; toux ceux qui, croyant à une attaque simplement protégée par un rideau de fumée ordinaire, s'étaient élancés en avant pour la repousser, tombaient asphyxiés ou devaient reculer: il fallut céder le terrain qu'envahissait rapidement le flot des gaz empoisonnés."

Pierre Miquel résume ensuite un rapport très rapidement transmis au président du Conseil ${ }^{53}$ : "Nos hommes ressentirent immédiatement, lui explique-t-on, des picotements et une irritation intolérable dans la gorge, le nez et les yeux, ainsi que des suffocations violentes et de fortes douleurs dans la poitrine, accompagnés d'une toux incoercible. Beaucoup tombèrent pour ne plus se relever. D'autres, essayant vainement de courir, durent, sous les

\footnotetext{
${ }^{50}$ On voit ici comment l'idée fausse de l'enquêteur (moi: Baptiste Bussy n'est que mon $28^{\mathrm{e}}$ témoin; j'avais encore beaucoup à apprendre d'eux!) peut amener celui-ci à préciser un point. Certes, on coupait bien les fils de fer à la cisaille, mais c'était beaucoup plus pour se frayer un chemin, la nuit, par des brèches ponctuelles, pour effectuer une patrouille (avec quelques hommes) entre les deux premières lignes ennemies que lors d'une attaque d'envergure.

${ }^{51}$ A ce propos, ayant accompagné cinq fois de suite (à la demande de l'organisatrice, Louise Berlier, professeur d'anglais, ma collègue et amie) le voyage aux Etats-Unis - deux fois au Kansas, trois fois au New Hampshire - de nos élèves du lycée François Mauriac-Forez d'Andrézieux-Bouthéon, j'ai été choqué, lors des deux visites faites au Mémorial Truman d'Independence, dans le Missouri (état voisin du Kansas), par la pierre de granite installée à côté de la tombe du président Harry Truman et de son épouse; dans la petite pelouse se trouvant au centre du Mémorial. On y lit, en inscription principale: "In gratitude to President Harry S. Truman for saving many lives by using atomic weapons to end World War II" ("En reconnaissance envers le Président Harry S. Truman pour avoir sauvé de nombreuses vies en utilisant les armes atomiques afin de mettre fin à la Deuxième Guerre Mondiale"). Certes, des vies de soldats américains ont été indéniablement sauvées en poussant le Japon à la capitulation presque immédiate, mais que dire des vies japonaises civiles prises à Hiroshima et à Nagasaki (plus de 300 000)? Et cette inscription ne date pas des années 50, mais du 5 août 1995, où la pierre a été placée au cours d'une cérémonie solennelle qui commémorait le 40 eme "anniversaire" de la bombe d'Hiroshima...

${ }^{52}$ Pierre Miquel, op.cit., pp. 327-328

${ }^{53}$ Il s'agit, pour les jeunes lecteurs, de l'ancien nom donné au Premier Ministre, et ceci jusqu'à la fin de la IVème République
} 
balles et les obus, se replier en titubant, en proie à des souffrances cruelles et pris par des vomissements dans lesquels apparaissaient des filets de sang. Un certain nombre d'entre eux, malgré les soins qu'on leur prodigua, ne tardèrent pas à succomber à l'asphyxie provoquée par les lésions pulmonaires."

L'effet est d'autant plus dévastateur que l'armée française ne dispose pas de masques à gaz! On eut recours à des moyens de fortune, qu'évoque P. Miquel: "Les premiers moyens distribués aux hommes par le service de santé sont de simples "baillons-tampons", des compresses imbibées d'hyposulfite de soude ou d'un mélange d'huile de ricin et de ricinate de soude. Pour protéger les yeux, des lunettes en fil de fer modelable.".

Pris de court, n'ayant pas envisagé la production de gaz asphyxiant, l'Etat-Major français (et aussi l'Etat-Major anglais, s'il faut en croire P. Miquel "En France et en Angleterre, il n'existe en 1915 aucune fabrique de chlore ou d'autres substances toxiques"), et le Ministre de la Guerre Albert Thomas vont lancer un arsenal de chimistes à la fois dans la recherche d'une parade à ces gaz, sous forme de masques, et dans la recherche de gaz toxiques offensifs, ce qui prit pratiquement une année pour avoir une production industrielle à grande échelle: "C'est seulement à partir d'avril 1916 que les hommes disposent au front de protections plus efficaces: 1 million de masques T, près de 7 millions de masques T.N."

Cette absence de masques à gaz va inciter l'industrie privée à s'attaquer à ce marché "juteux" pendant l'année 15 , en spéculant sur l'angoisse des familles. On en trouve une trace dans une publicité que l'on peut lire, entre autres, dans le numéro de L'Illustration du 19 juin 1915, deux mois après l'attaque d'Ypres, dans les réclames de la page 2, entre les lotions L.T. Piver et le chronographe Just recommandé aux officiers et sous-officiers: la réclame s'intitule "Contre les gaz asphyxiants".et occupe un quart de page. Sous la photo d'un soldat entouré de nuées sombres, portant le masque vanté, le texte est le suivant:

"Le laboratoire Robert et Carrière, à qui l'on doit tant d'innovations si utiles à nos soldats (iode en ampoules pinceaux, pharmacies du soldat, aliments en tubes, etc.), vient de créer contre les gaz asphyxiants un masque, dont nous avons pu constater la parfaite efficacité, et qui remplacera avantageusement les modèles improvisés, un peu sommaires, employés jusqu'à présent.

Ce masque protège non seulement les organes respiratoires, nez et bouche, mais il garantit également la vue contre ces gaz qui sont si irritants pour les yeux. Ce masque est inattaquable par les acides; il sera aussi, par conséquent, d'une efficacité absolue contre les jets de vitriol.

Le même Laboratoire, continuant sa magnifique série de perfectionnements, vient de créer une ligature individuelle, d'un maniement idéalement simple, pour arrêter instantanément les hémorragies les plus graves.

On trouvera ces précieux objets à la Pharmacie Robert, 37, rue de Bourgogne, Paris. (Le masque antiasphyxiant, avec deux tubes de solution antiasphyxiante et différents accessoires (breveté S.G.D.G.) 9 fr. $50^{54}$; franco, 10 fr.; le tube de solution seul, 0 fr. 60 ; franco, 0 fr 70; la ligature hémostatique (déposée) 2 fr. 50, franco 2 fr. 60.

Dernières nouveautés - Ouate camphrée contre l'odeur cadavérique ${ }^{55}$, 0 fr. 70 franco; Tube de mixture contre les piqûres de moustiques, 1 fr. franco.

Cette première historique de l'utilisation des gaz toxiques par les Allemands, le 22 avril 1915, vers Ypres, un de nos témoins, grand lecteur de la presse, la commente dès le surlendemain, ce qui indique au moins que la nouvelle avait transpiré dans les journaux. Il s'agit de Joseph Sorgues (cl. 15) de Romanèche-Thorins (Saône-etLoire), enseignant au pensionnat de Bellegarde à Neuville-sur-Saône, incorporé le 20 décembre 1915 au $23^{\mathrm{e}}$ R.I. de Bourg-en-Bresse, qui vient d'achever sa période d'instruction militaire au Valdahon, dans le Doubs. Il note dans son journal tenu, pour le moment, au jour le jour: Samedi 24 avril - Sur le front belge, du côté de l'Yser, violentes attaques allemandes, toutes repoussées. Vers Ypres, les Allemands, décidés à tout prix à venger leurs échecs répétés, ont lancé sur les troupes alliées des bombes asphyxiantes au mépris de toutes les conventions de la Haye qui en interdisent l'emploi. Nous avons dû reculer de dix kilomètres, mais l'offensive allemande a été enrayée et une contre-attaque vigoureusement menée nous a permis de regagner une partie du terrain perdu.". Joseph n'a pas encore appris à décrypter la rhétorique des communiqués militaires et son optimisme forcené, relayé par la presse, compensant toute annonce de recul par une "vigoureuse contre-attaque"... Les "échecs répétés" des Allemands ne les empêchent pas d'avoir conquis la plus grande partie du territoire belge!

Que les Allemands se flétrissent en étant les premiers à utiliser l'arme déloyale des gaz, d'autres Poilus le signalent. Jean-François Ollier (né en 1894, mais ayant devancé l'appel pour partir au régiment avec la classe 13) de Saint-Etienne, fabricant de soieries dans cette ville, n'est encore, au printemps 1915 , que sergent au $38^{\mathrm{e}}$ R.I. de Saint-Etienne (il terminera la guerre comme capitaine, et sera commandant de réserve en 1934); deux fois blessé aux combats d'Alsace en août 14, il subit une longue hospitalisation fin 14-début 15, et ayant ensuite suivi la formation d'élève-officier, sera nommé sous-lieutenant en décembre au $14^{\mathrm{e}}$ B.C.A.. A une question portant su l'achèvement des blessés (pratique que nous évoquerons plus tard), il a répondu par ce jugement "Il y a quand même une manière on pourrait dire presque honnête de faire la guerre", d'où ma question:

\footnotetext{
${ }^{54}$ A titre indicatif, la revue de qualité L'Illustration, épaisse, dense en textes et très illustrée, parfois de portraits en couleur de chefs militaires ou d'aquarelles de guerre, vaut 1 franc le numéro au début de l'année 1915 (la revue plus populaire, grand public, Le Miroir, mince avec peu de texte, valant 0,25 franc)

${ }^{55}$ Comme on le verra, plus loin, l'odeur des cadavres non enterrés, putréfiés, pouvait être, l'été, absolument insupportable, et taons, mouches et moustiques proliféraient sur ces cadavres, s'attaquant aussi aux vivants...
} 
E- Donc il y avait des pourparlers sur la façon correcte de faire la guerre? Mais dans ce cas-là, que peut-on penser des gaz? Est-ce que les gaz faisait partie de la façon correcte de faire la guerre?

T- Ah non! Sûrement pas! D'ailleurs...correcte... on pourrait dire: à la guerre, à l'exception de l'achèvement des blessés, on pourrait dire que tout est permis. Mais il paraît qu'il y avait eu, avant guerre des ententes qui n'ont pas été respectées, qu'on ne se servirait pas de ces machins-là!

E - Qui a pris l'initiative...A Ypres?

$\mathrm{T}$ - Sûrement les Allemands! Remarquez, j'ignore ce qu'ont fait les Français dans ce sens...autrement dit, s'ils se sont servis des gaz. Je ne le sais pas. Les Allemands, alors, oui!"

On peut s'étonner qu'un officier français ignore l'emploi des gaz dans l'armée française. Mais peut-être JeanFrançois Ollier n'en a-t-il pas été témoin lui-même?

Plus jeune de trois ans, Etienne Poyet (cl. 17), né à Sail-sous-Couzan de parents agriculteurs venus s'installer à Pommiers dans son enfance, a été officier de police, principalement à Saint-Etienne (police des mœurs) puis dans l'arrondissement de Montbrison (renseignements généraux) avant de prendre sa retraite à Saint-Bonnet-le-Château. Il sera gazé le 9 mai 1918, mais évoque ici 1917, alors qu'il est conducteur de chevaux au $36^{\mathrm{e}} \mathrm{R}$. d'artillerie de Moulins. Il indique sans complexe l'utilisation d'obus par les Français, mais toujours comme réplique aux Allemands!

T- "On a eu passé 800 obus de gaz par jour, pour une réplique, par exemple ${ }^{56}$ ! Quand notre secteur avait été gazé, qu'on avait supporté l'artillerie allemande avec des obus à gaz, que tant bien que mal, on avait pu s'en tirer. Quelquefois, y avait pas de dégâts parce que le vent nous avait été favorable. Le lendemain ou le surlendemain, on préparait un stock, nous, pour la réplique: à peu près 8 ou 900 obus par pièce! Et on attendait que le vent nous soit favorable pour leur rendre la monnaie de la pièce! Alors, vous voyez le travail!

E- Donc les Français n'utilisaient les obus à gaz qu'en réplique?

T- Oui!

E- Pas comme première attaque?

T- Ah! Non! Non! Non! Qu'en réplique!"

On remarquera qu'Etienne change totalement d'échelle dans le nombre d'obus entre le début et le milieu de son témoignage: le nombre 800 (ou 900) est d'abord donné sans précision, de sorte qu'on pense qu'il caractérise toute la batterie (4 canons), ou plutôt l'ensemble des batteries réunies dans une position commune, ce qui est déjà considérable; quand il passe à 800-900 "par pièce" (par canon), on ne peut s'empêcher d'être dubitatif. Notons le rôle essentiel du vent: il est un allié s'il entraîne le gaz chez l'ennemi, mais un adversaire s'il le ramène sur les canons qui l'ont lancé, ou sur l'infanterie française en première ligne!

Même comme réplique, les gaz ne sont pas admis par tous les Poilus. Ainsi Claude Coupade (cl. 15) de La Ricamarie, ajusteur à Saint-Etienne avant guerre, puis mécanicien au P.L.M au dépôt de la gare de Chateaucreux (Saint-Etienne) après guerre, en condamne spontanément l'usage et même la recherche quand il se trouve, avec le $157^{\mathrm{e}}$ R.I. Alpine de gap, à Flirey, à $15 \mathrm{~km}$ à l'ouest de Pont-à-Mousson, du 10 juillet au 30 septembre 1915, dans un secteur très exposé aux torpilles des Minenwerfer allemands: "Ce secteur a toujours été terrible: entre les lignes, il y a toujours des quantités de cadavres qui sont la depuis la dernière attaque; même lorsque nous creusons des tranchées, il arrive que la pioche découvre ou les pieds ou la tête de quelques pauvres malheureux enfuient* ${ }^{*} i$ de là par les torpilles, les obus ou les mines souterraines.

Ce n'est pas assez affreux. Ils paraît* qu'ils (les Français) cherchent a* se servir de gaz asphixiant*. Une lettre de Geneviève m'apprend que le frère d'une de ses amies a été envoyé à Paris pour l'essai de cette terrible chose: les gaz asphixiant. *"

Mais aucun de mes témoins ne fera l'expérience des gaz en 1915 où leur usage demeure limité par rapport aux deux dernières années de guerre, et surtout 1918. Une bonne vingtaine sera gazée plus ou moins gravement.

Les Allemands seront continuellement accusés, dans la presse française, d'avoir ouvert la boîte de Pandore des armes interdites, déloyales (dont fera partie aussi le lance-flammes). On trouve un écho de cette condamnation sous la plume du romancier Pierre Loti, chroniqueur épisodique pour L'Illustration, dans le $\mathrm{n}^{\circ}$ du 4 décembre 1915, où la conclusion-péroraison du grand texte d'une page serrée, à la fois narratif - il raconte sa visite à un hôpital provisoire du front- et polémique, intitulé "Les gaz de mort", est la suivante: "Nos pauvres asphyxiés, haletants sur leurs petits lits, combien j'aurais voulu les montrer à tous, à leurs pères, à leurs fils, à leurs frères, pour porter au paroxysme les indignations sacrées et les soifs de vengeance; oui, les montrer partout et faire entendre leurs râles, même aux si impassibles Neutres ${ }^{57}$, pour convaincre d'inintelligence ou de crime tant d'obstinés Pacifistes, pour semer partout l'alarme contre la Grande Barbarie, en éruption sur l'Europe!..."

Concernant l'arrivée des premiers masques à gaz, Claude Coupade (cl.15) de La Ricamarie, qui vient d'être cité, donne dans son récit de guerre -rédigé d'après ses carnets tenus régulièrement- une date sensiblement plus précoce que Pierre Miquel (qui, il est vrai, en parlant d'avril 1916, évoque l'arrivée massive des masques perfectionnés dans les régiments français), celle du 5 août 1915: "Le 5 août nous venons de terminer nos deux

\footnotetext{
56 "Par exemple" a ici le sens de "par contre, en revanche", et renforce l'opposition entre l'initiative allemande et la réplique française

${ }^{57}$ Les Neutres qu'il flétrit ici pour leur indifférence sont les Etats qui ne se sont engagés dans aucun camp; non seulement la Suisse, pays neutre par tradition, mais l'Espagne, les pays nordiques, et au-delà des mers, les Etats-Unis, qui ne s'engageront qu'en avril 1917. Mais l'Italie a franchi le pas en s'engageant aux côtés de la France et de l'Angleterre en mai 1915.
} 
journées assez calmes, parce qu'il n'a cessé de pleuvoir, et nous rentrons mouillés jusqu'à* la peau, nos effets sont surchargés de boue. Nous n'étions pas cette fois avec le $157^{\circledR}$ mais avec le $339^{e}$ qui est un régiment de réservistes, et qui fait brigade avec le 157. Ce jour là nous recevons tous des masques contre les gazs*".

Ainsi, après un an de guerre, c'est un soldat à l'allure renouvelée, moins voyant dans son uniforme bleu horizon, mieux protégé par son casque, mais affrontant des armes encore plus redoutables, dont la panoplie s'est élargie, qui va combattre dans l'enfer des tranchées...

\section{$* * *$}




\section{Chapitre 13}

\section{5 (septembre - octobre) :}

La grande offensive de Champagne 


\section{Chap. 13 - 1915 (septembre-octobre) : La grande offensive de Champagne}

"Nous avons touché deux grenades par homme, et les grenadiers en ont six dans leurs* musette, ils ont reçu aussi des revolvers brownings ${ }^{1}$ et des couteaux, de vrais couteaux d'apaches ou de bouchers à lame triangulaire plate. Où sont-ils, les temps chevaleresques, où l'on faisait la guerre en dentelles, avec des armes courtoises et loyales, où l'on se saluait avant de se tirer dessus? Le soldat français a été réduit à se battre comme ces assassins d'Allemands qui ont déshonoré la guerre." - Journal de Joseph Sorgues, classe 1915, Romanèche-Thorins (Saône et Loire) à la date du 24 septembre 1915, veille de l'attaque.

"Je regarde une dernière fois mes photographies et mes souvenirs de famille avec émotion. C'est pour des êtres chéris que je suis ici, que je vais tout à l'heure m'élancer hors de mon abri vers la victoire ou vers la mort. Un signe de croix, une brève recommandation à Dieu, et en Avant! Si je viens à être tué, ne me pleurez pas, chers Parents, j'aurais eu la plus belle mort que puisse souhaiter un soldat, combattant pour son Dieu et la Patrie." - Journal de Joseph Sorgues à la date du 25 septembre 1915, quelques minutes avant l'attaque.

"On a fait un grand nombre de prisonniers et surtout le $99^{e}$ qui s'est distingué au "Bois Sabot" et au "Trou Bricot"... Sans arrêt, toute la nuit, nous parcourons le champ de bataille, allant où l'on entend crier "au secours", dans la nuit obscure et sous la pluie..... Triste corvée, à en pleurer." --- "A 10 heures, je vais avec 3 musiciens tâcher de sortir d'un éboulement de tranchée un pauvre type qu'on entend crier au secours une partie de la nuit. Il mourut en arrivant au poste de secours, en demandant sa "maman". Nous l'avons enterré aussitôt dans un trou d'obus".

Journal d'Amand Beyron, classe 1911, Chazelles-sur-Lyon, musicien-brancardier au $99^{\mathrm{e}}$ R.I. de Vienne, aux dates des 25 et 26 septembre 1915

" Mais les renforts attendus, indispensables, ne viennent pas, on ne ravitaille même pas les troupes qui ont avancé, les boches reviennent, nous refoulent en nous infligeant de rudes pertes. De partout on crie: "Nous sommes trahis, nous sommes vendus!" Est-ce qu'un jour l'histoire ne mettra pas un peu de lumière sur ces fait* ténébreux qu'on nous a si obstinément cachés pendant toute la guerre?!!"

Récit de sa guerre par Camille Richier, classe 1910, Saint-Julien-Chapteuil (Haute-Loire).

Le hasard et la chance m'ont fait bénéficier de deux documents d'époque, deux journaux intimes, d'une très grande qualité humaine et intellectuelle, sur cette offensive de Champagne; celui d'un fantassin de la classe 15, et celui d'un brancardier de la classe 11. Les deux sont des intellectuels, d'où la qualité de la langue. Disposant de documents d'une telle qualité, nous les laisserons qu'un seul tenant sans les entrelacer, même si la chronologie des faits et la logique des événements poussaient à cette seconde option.

\section{L'offensive de Champagne à travers le point de vue d'un fantassin: Joseph Sorgues}

Un témoignage écrit très circonstancié sur l'offensive de Champagne et sa préparation méthodique est fourni par le journal de Joseph Sorgues (cl. 15) de Romanèche-Thorins (Saône-et-Loire), enseignant au pensionnat catholique de Bellegarde, à Neuville-sur-Saône, qui sera blessé le premier jour de cette attaque. Son régiment, le troisième depuis son incorporation en décembre 1914, le $160^{\mathrm{e}}$ R.I. (dépôts à Neufchâteau et à Saint-Pierre-le. Moutier), se trouve au tout début de septembre 15 en Champagne à Somme-Bionne, à $15 \mathrm{~km}$ à l'ouest de SainteMenehould, puis va être transféré vers la ferme de Beauséjour, près du massif de la Main de Massiges, en bordure d'Argonne.

Il évoque longuement la préparation de l'offensive et les travaux de terrassement qu'elle implique:

8 septembre - "Nous voilà aux tranchées en seconde ligne, à gauche de la ferme Beauséjour. Nous passons en première ce soir. Puisque c'est le jour de la Nativité ${ }^{2}$ que nous prenons les tranchées, je pense que la Sainte Vierge me consolera et me gardera sain et sauf; je finis justement ce matin une neuvaine en son honneur.

9 septembre - Première ligne; de garde au poste d'écoute, sorte d'étroit boyau à fleur de terre à dix mètres du poste boche, où l'on ne va qu'à plat ventre. Nous restons là trois heures, sans bouger, sous les obus et les fusées qui

\footnotetext{
${ }^{1}$ Le browning (mot apparu en 1906) du nom de son inventeur américain, est un pistolet automatique à chargeur; en 1925 Browning inventera le fusil à canons superposés.

${ }^{2}$ La Nativité (le 8 septembre) est une des quatre grandes fêtes mariales catholiques (avec la Purification de la Vierge Marie ou Présentation du Seigneur du 2 février, l'Assomption du 15 août et l'Immaculée Conception du 8 décembre); elle célèbre la naissance de la Vierge Marie.

${ }^{3}$ Une neuvaine est, pendant neuf jours consécutifs, un exercice de piété, généralement la récitation du chapelet, visant à prier Dieu, Jésus ou la Vierge, voire un saint intercesseur, souvent pour obtenir une grâce particulière.
} 
tombent si près de nous que nous sentons leur chaleur. Puis c'est la garde aux crénaux* d'où l'on aperçoit les lignes ennemies dans la plaine, à trois cents mètres de nous.

11 septembre - Même vie qu'hier et avant-hier jusqu'à midi, où nous avons été relevés par le $2^{\text {ème }}$ bataillon. Un camarade de l'escouade, Gardès, a été évacué, blessé hier matin d'un éclat d'obus à la cuisse. Il avait déjà été évacué pour dysenterie et il était revenu à la compagnie depuis huit jours. Nous revenons sur la route où nous étions arrêtés avant de monter en seconde ligne, la fameuse route qui court derrière tout le front de Champagne.

12 septembre - Nous travaillons, section par section, deux heures la nuit et quatre le jour : il faut élargir tous les boyaux pour le transport des blessés dont je serai peut-être, et le passage des troupes. En outre, nous creusons des boyaux longs de 50 mètres, et terminés en cul-de-sac, pour masser les compagnies de réservet. Le travail est dur, mes mains ne sont guère habituées au labeur du terrassier et s'écorchent avec une facilité déplorable. Mais puisque c'est nécessaire pour la réussite de la France et le salut ${ }^{5}$ de la France, tant mieux!

14 septembre - Même travail. Le $3^{e}$ bataillon prend les premières lignes à la place du $2^{e}$ qui a été très éprouvé, comparativement au nôtre. Nous allons, nous, travailler entre les lignes, à la construction d'une parallèle de départ qui nous épargnera 50 mètres de terrain découvert lors de l'attaque. Ce travail est très dangereux, car il faut creuser à cent cinquante mètres de la ligne boche avec un parapet ${ }^{6}$ insuffisant. Fritz ${ }^{7}-c^{\prime}$ est ainsi que nous appelons le soldat d'en face - soit qu'il ait le trac ou qu'il veuille nous le donner, tiraille toute la nuit à travers ses créneaux. Une balle perdue est bien vite attrapée; à la grâce de Dieu! [...]

15 septembre - Encore rien de nouveau. On glane les nouvelles de part et d'autres*. C'est ainsi que j'ai appris de la bouche d'un caporal que chacune de nos batteries de 75 aurait 10000 obus à tirer, qu'un $270,{ }^{8}$ silencieux jusque là devait être chargé de démolir à lui seul une gare régulatrice très importante pour nos adversaires ${ }^{9}$; que les artilleurs du bas de la route seraient logés sous la crête percée en tunnel et seraient ainsi impossibles à repérer; que nos crapouillots auraient 375 torpilles à lancer; enfin que le bombardement aurait lieu sur un front de $25 \mathrm{~km}$ de largeur et de 12 de profondeur. L'attaque de notre secteur cö̈nciderait avec une attaque anglaise sur Lille, et une autre, française, entre Soissons et Reims. Si tout cela est vrai, il est impossible que notre attaque échoue: c'est la conviction de tous. Et vraiment, à voir le soin avec lequel elle est préparée, on est presque certain de la victoire. La route où nous cantonnons et la crête qui la dérobe aux yeux des Boches ${ }^{10}$ présente l'aspect d'un chantier au travail intense, où se meuvent des milliers d'hommes. Le spectacle est vraiment intéressant: je ne veux décrire que ce que j'ai vu, sur un espace de 4 à 500 mètres, mais il est certain que tout le long de la route, pendant des kilomètres et des kilomètres, c'est la même chose."

Suit une méditation sur la mort à partir de la vision du petit cimetière militaire, que nous verrons dans le thème de la religion, puis la longue description de la "petite ville" coquette où se trouvent le P.C. des colonels des quatre régiments rassemblés $\left(146^{\mathrm{e}}\right.$ R.I., $153^{\mathrm{e}}$ R.I., $156^{\mathrm{e}}$ R.I. et $160^{\mathrm{e}}$ R.I.) et tous les services administratifs.

16-17 - Travail la nuit entre les deux lignes: aucune perte malgré les coups de fusils et la pétarade des mitrailleuses. On sent que les Allemands nous sont matériellement et moralement inférieurs: dès que leur artillerie veut envoyer quelques obus, les claquements secs de nos 75 , leurs petits "tsiou!" rageurs les font taire.

On mesure à quel point les préparatifs considérables de cette offensive de Champagne ont fait naitre un immense espoir dans l'armée française; Joseph Sorgues n'étant jamais d'un optimisme béat :

18 septembre - Notre dernière nuit de travail aux tranchées a été tragique. Alors que nous n'avions eu jusqu'ici aucune perte, ma section a maintenant à déplorer deux morts et deux blessés, dont l'un grièvement. C'était sur le coup de minuit, nous travaillons* comme d'habitude depuis huit heures du soir à la parallèle et les Boches nous avaient laissés assez tranquilles, lorsque pour répondre à quelques furieuses salves des 75 , deux bombes arrivèrent dans la tranchée. La première tua Honoré d'un éclat à la tête, traversa le bras droit et le côté de Kerjouan et le

\footnotetext{
${ }^{4}$ Ces boyaux de stationnement provisoire des troupes de réserve sont les parallèles de départ.

${ }^{5}$ Chez Joseph Sorgues, profondément chrétien, ce mot "salut" est constamment, implicitement, lié au Salut, celui de l'âme dans l'au-delà, l'accès au Paradis.

${ }^{6}$ Le parapet est la butte de terre rejetée en avant de la tranchée, lors de son creusement, pour en accroître la profondeur, donc l'effet protecteur.

${ }^{7}$ Fritz, selon le Dictionnaire Historique de la Langue française dirigé par Alain Rey, est une dénomination péjorative apparue en 1914 pour "Allemand", car c'est un prénom allemand courant, diminutif de Friedrich. Il a été altéré en "frisé" (1914) et plus tard (1940) en "frisou" pour désigner les Allemands de façon péjorative. On trouve aussi "fridolin"dès 1880, du prénom allemand Fridolin, diminutif de Friedo, venant aussi de Fritz. Pourquoi ce prénom et non un autre? A. Rey ne le dit pas, mais on peut penser que le nom du grand roi de Pusse, Frédéric II, n'y est pas étranger, ou plus proche, le succès d'un roman comme celui d'Emile Erckmann et Alexandre Chatrian, L'Ami Fritz, paru en 1864 (où Fritz Kobus est un Alsacien ), roman qui a fourni de nombreuse dictées d'école primaire sous la IIIe République, en un temps où l'Alsace-Lorraine perdue était vénérée.

${ }^{8}$ Un 270 est un canon lourd, lançant des obus de $27 \mathrm{~cm}$ de diamètre. Dans l'artillerie lourde française, il est seulement surpassé en calibre par le 380 (38 cm de diamètre d'embouchure) et le 420 (42 cm de diamètre d'embouchure) qui, lui, projetait des obus de $923 \mathrm{~kg}$ à $14 \mathrm{~km}$.

${ }_{9}^{9}$ Cette gare régulatrice très importante pour les Allemands, il la nommera plus loin: c'est celle de Vouziers.

${ }^{10}$ On aura remarqué, en comparant avec l'expression "la ligne boche" du 14 septembre, que Joseph pratique strictement la règle orthographique : une minuscule à l'adjectif de nationalité, mais une majuscule au nom, faisant ainsi prévaloir l'orthographe sur le mépris de l'ennemi, règle que la plupart ne respectent pas, à supposer qu'ils la connaissent...
} 
poignet de Lecomte. Un des éclats de la seconde, tombée plus en arrière, atteignit le pauvre sergent Finck à la tête, le blessant mortellement: il est mort pendant qu'on l'emmenait. Par un hasard extraordinaire, je n'ai eu aucun mal: ma capote est tachée du sang de Kerjouan, j'ai été aveuglé et étourdi par la seconde bombe, mais c'est tout. Dieu m'a protégé!"

On verra, dans le chapitre relatif à la blessure, que, pour les esprits religieux, le camarade tué à côté de soi est le plus sûr indice de la protection divine. Dans l'ouvrage collectif de Mémoire Forézienne, Et délivrez-nous du Mal ... - Signes et rites de protection en Forez rural, après avoir cité le témoignage recueilli par mes soins en 1987 de Jean Salanon (cl. 14) agriculteur à Saint-Georges-Hauteville, dont le copain vient d'être tué à ses côtés par un éclat d'obus ("Eh ben c'est ce jour-là que celui de Boën a été tué à côté de moi"), le soldat épargné se sentant miraculé et attribuant aussitôt sa sauvegarde à la Vierge Marie, par l'entremise de la médaille de la Vierge de la rue du Bac cousue dans son béret de chasseur alpin (sous l'insigne du cor de chasse), l'auteur du chapitre concerné, Bernard Blethon, conclut: "Lorsque le malheur épargne celui qui est porteur du signe tandis qu'il frappe tout à côté, quelle preuve peut être plus pertinente de son efficacité?"Il

19 septembre - Nous sommes au repos dans des baraquements près de Somme-Bionne, le long de la route de Châlons à Ste Menehould. Nous avons travaillé jusqu'à une heure du matin à la parallèle déjà ensanglantée, et nous avons fait nos dix-huit kilomètres pour revenir en arrière. Aussitôt après notre arrivée, des corvées sont allées au village pour apporter des vivres et de la boisson. C'est alors que j'ai pu constater la bizarrerie et le peu de raison du caractère humain en général, du soldat en particulier. Ces hommes, il y a une heure à peine, étaient déprimés et n'aspiraient qu'au repos. Ils se sont réveillés de leur torpeur. Des bouteilles de champagne, de vin vieux, de Fleurie, de Saint-Emilion, de Banyuls, de Graves, ont été apportées et ont circulé dans les groupes. Tout le monde, joyeux, excité, a trinqué à la réussite de l'attaque, à la victoire prochaine, à la libération de la France. Jusque là, tout était bien, mais ce qui m'a semblé drôle, c'est d'entendre ces mêmes soldats se dire: "Si je ne reviens pas de l'attaque, mon argent sera perdu, aussi vais-je tout le dépenser dans ces quelques jours de repos." Alors les achats de provisions et de vin ont fait fureur, et c'est à qui dépenserait le plus. J'avoue que je me suis laissé aller moi-même à l'entraînement général, et j'ai fait des emplettes comme les autres, pour les tranchées."

Il est certain, pour le moraliste chrétien qu'est Joseph Sorgues, que la guerre éclaire d'un jour cru les contradictions de la nature humaine, et lui révèle des faces cachées de son propre caractère.

Et Joseph de continuer en revenant avec des informations plus précises, plus fiables, sur l'offensive imminente, ce qui montre, par parenthèse, que le secret n'a pas pu être gardé par l'Etat-major. Mais chacun ayant vu les énormes préparatifs, le secret n'en est plus un, et les Allemands ont, évidemment, été informés, par leurs ballons et avions d'observation, mais aussi par leurs patrouilleurs, et sans doute aussi, leurs espions.

"Nous avons maintenant des renseignements officiels sur l'attaque. Elle sera générale, mais se produira de la façon suivante. Attaque anglo-belge en Belgique et vers Arras, attaques françaises entre Soissons et Reims, en Champagne et en Alsace, préparées par un bombardement infernal de 3 jours. Si nous avançons sur ces points, tous les autres points seront également attaqués, la cavalerie fonçant dans les intervalles, les avions ayant pour mission de bombarder ${ }^{12}$ les gares régulatrices et les convois de ravitaillement. De nombreuses divisions de réserve suivront les troupes de première ligne pour les remplacer et pousser la poursuite le plus loin possible.

Dans notre secteur, le $1^{\text {er }}$ bataillon sera en $1^{\text {ère }}$ ligne, $1^{\text {ère }}$ et $2^{\text {ème }}$ compagnies dans les parallèles de départ, $2^{e ̀ m e}$ et $3^{\text {ème }}$ bataillons en réserve. Nous aurons à enlever trois lignes de tranchées formant un ouvrage connu par sa

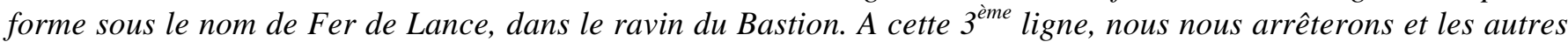
passeront devant nous. C'est une tâche glorieuse qu'on nous confie et je serai fier de faire tout mon devoir, ce jourlà!"

Joseph se trouve appartenir au premier bataillon, celui qui va attaquer, et dans une des deux compagnies qui lanceront l'assaut. Il ne frémit pas à cinq jours du déclenchement de l'attaque qui peut lui être fatale... Mais un accident va obscurcir l'horizon de sa compagnie.

21 septembre - Un nouveau malheur vient d'arriver à la compagnie, le capitaine Cambis vient d'être blessé très gravement au cours d'un exercice de lancement de grenades. L'éclat l'a atteint à la poitrine alors qu'il était à genoux, a pénétré dans le côté droit sans ressortir, brisant probablement une ou deux côtes, car le blessé se plaint beaucoup des reins. C'est un véritable malheur pour nous car nous perdons un chef aimé et énergique. Par sa bonté grave, par son affection pour ses soldats, sa science militaire, notre capitaine était universellement vénéré dans la compagnie et nous l'aurions suivi jusqu'à la mort avec une entière confiance aux jours de la prochaine bataille. Son patriotisme était ardent, et je me rappelle encore sa causerie et ses recommandations dans les rues

\footnotetext{
${ }^{11}$ Lucien Barou, Bernard Blethon, Tony Kocher et Daniel Palmier, "Et délivrez-nous du Mal"- Signes et rites de protection en Forez rural, Publications de l'Université de Saint-Etienne, 1998, chap III "Essai de compréhension du système de protection", p. 206

${ }^{12}$ On est passé à un second stade de l'aviation: essentiellement d'observation au tout début de la guerre, en dehors des duels aériens où il s'agissait d'éliminer un avion ennemi, elle assume maintenant aussi des missions de bombardement d'objectifs stratégiques, souvent trop éloignés du front pour être accessibles aux obus des canons à longue portée (12-15 km) de l'artillerie lourde.
} 
dévastées de Gerbéviller, où il nous exhortait à lutter sans pitié jusqu'au dernier contre les incendiaires et les voleurs. Que Dieu lui accorde une prompte guérison et le ramène bien vite au milieu de nous!"

Quand on a lu tout le journal de Joseph Sorgues (1456 pages!), on sait qu'il n'est pas du genre à encenser systématiquement les officiers qui le commandent. On mesure ici, et dans bien d'autres témoignages que nous évoquerons plus tard, combien la perte, ou l'éloignement durable, d'un chef aimé et respecté peut affecter le moral, donc l'efficacité militaire, de sa section, de sa compagnie, de son bataillon, de son régiment.

Le 23 septembre, le bataillon de Joseph remonte en première ligne. Joseph constate l'énormité des bombardements de la préparation d'artillerie: "Depuis le matin comme les jours précédents, notre artillerie légère et lourde bombarde avec une extrême violence les tranchées boches. On ne voit en face qu'un nuage de fumée blanc et noir produit par l'éclatement d'obus de tous calibres. Aussi on peut regarder sans crainte par-dessus le parapet, sans qu'une balle mal intentionnée vienne siffler aux oreilles. Qu'est-ce qu'ils prennent dans les premières lignes! Et pourtant il y a des hommes dans ces trous, car nous en voyons se sauver le long d'un parapet éboulé. Comme ils sont obligés de passer à découvert, s'ils ne veulent pas être ensevelis sous nos torpilles, ils se résignent et nous leur tirons dessus comme des lapins! C'est tout à fait amusant! Nous attaquons samedi, c'est officiel!"

Il est surprenant, pour qui connaît Joseph Sorgues, de voir un tel homme, ardent patriote mais chrétien profondément moral, respectueux de la vie humaine, éprouver de la jubilation lorsqu'il tire sur les ennemis qui tentent de s'enfuir, ressentir le plaisir du chasseur tirant sur "des lapins". Mais il est vrai qu'ici la distance déréalise l'acte de tuer.

\section{4 septembre - "Nous passons la journée en seconde ligne pour nous reposer avant le dernier coup de collier.}

A onze heures du matin, le bombardement reprend, effroyable, infernal, un véritable supplice pour les oreilles. Ce ne sont que sifflements et miaulements ininterrompus, accompagnés du fracas des gros obus comparable au roulement peu éloigné d'une voiture sur une route. Les explosions se suivent comme les cahots d'un chemin de fer. Il en passe, des kilos de ferraille à l'adresse des Allemands; si les gaillards peuvent tenir ça, ils seront solides. Tant mieux car chaque obus tiré épargne peut-être la vie d'un fantassin. Quant on songe que 48 mitrailleuses ont été repérées, rien que dans notre secteur d'attaque, sans compter celles qui n'ont pu l'être! Les canons boches ne répondent pas, deux ou trois obus seulement dont l'un est venu tomber dans la tranchée, à l'endroit même où je venais de passer pour porter le jus à la $3^{\text {ème }}$ escouade."

Voilà donc Joseph encore une fois divinement protégé, mais il ne l'exprime pas cette fois-ci... La suite de la séquence du 24 septembre détaille l'armement distribué à la veille de cette attaque décisive: "Nous avons touché deux grenades par homme, et les grenadiers en ont six dans leurs* musette, ils ont reçu aussi des revolvers brownings et des couteaux, de vrais couteaux d'apaches ${ }^{13}$, ou de bouchers à lame triangulaire plate. Où sont-ils, les temps chevaleresques, où l'on faisait la guerre en dentelles, avec des armes courtoises et loyales, où l'on se saluait avant de se tirer dessus? Le soldat français a été réduit à se battre comme ces assassins d'Allemands qui ont déshonoré la guerre."

$\mathrm{Si}$ Joseph Sorgues se révolte contre l'usage des couteaux par les soldats français, il exonère en partie ses compatriotes en attribuant l'initiative de la "sale guerre" aux Allemands, qui, il est vrai, ont durablement marqué les esprits avec l'emploi des gaz asphyxiants à Ypres, le 22 avril de cette même année. Mais il est très clair qu'il idéalise la guerre d'antan, la guerre médiévale, mais aussi la guerre sous l'Ancien Régime, d'avant la Révolution honnie... Il poursuit son énumération des armes distribuées par les munitions: "Nous avons reçu 250 cartouches ${ }^{14}$ et un dispositif très ingénieux se fixant à la poignée de la baïonnette pour couper les fils de fer au moyen d'une balle. J'ai astiqué ma Rosalie ${ }^{15}$, et j'espère bien que nous ferons tous deux du bon travail demain. Ce soir, nous allons à huit heures dans la parallèle d'où nous sortirons demain, à 10 h du matin."

Cette journée du 24 septembre, le poète Guillaume Apollinaire la vit aussi en Champagne, entre LeMesnil-lès-Hurlus et la ferme de Beauséjour, dans l'artillerie lourde, celle du $38^{\mathrm{e}}$ R.A.L. de Nîmes, où il s'est

\footnotetext{
${ }^{13}$ Le nom "apache" désignait les voyous qui se battaient et assassinaient volontiers au couteau, les "surineurs". Le nom dérive de celui de la tribu indienne des Apaches, par un fait médiatique très précis repéré par Alain Rey, principal rédacteur du Dictionnaire historique de la Langue française; il s'agit d'un article du journaliste Victor Moris, paru en 1902, où l'auteur comparaît les agissements des malfaiteurs parisiens à la ruse et à la férocité attribuées aux Indiens Apaches des Etats-Unis.

${ }^{14}$ Rappelons, comme on l'a vu dans la revue de l'équipement complet du soldat, au début du chapitre précédent, que chaque soldat reçoit normalement 8 paquets de 11 cartouches, soit 88; c'est donc trois fois ce nombre qui est remis à ceux qui participent à l'offensive de Champagne, accroissant d'autant le poids du fameux "barda"

${ }^{15}$ Rosalie est le prénom donné à la baïonnette (comme Azor au havresac). Ce sobriquet affectueux viendrait de la chanson à boire de Théodore Botrel (1868 - 1925) intitulée "Rosalie", qui est un hommage à la baïonnette comparée à une femme, une cantinière (comme la Madelon) qui abreuverait les Poilus du sang "boche". Début: "Rosalie est si jolie // Que les galants de Rosalie // Verse à boire! // Sont au moins deux, trois millions// Buvons donc! // Rosalie est élégante // Sa robe fourreau collante // Verse à boire! La revêt jusqu'au quillon // Mais Rosalie est irrésistible // Quand elle surgit, terrible // Verse à boire! // Toute nue...//. Le quillon est la petite tige fixée à l'extrémité du fusil de guerre Lebel pour permettre la formation de faisceaux de fusils, au bivouac. Cette chanson a connu un succès proche de celui de "La Madelon".
} 
engagé en novembre 14 à 34 ans, bien que n'étant pas encore naturalisé français; en effet, il est polonais, bien que né à Rome en 1880. Il s'appelle en réalité Wilhelm Appollinaris de Kostrowitzky -particule apparue sur son livret de naissance- comme sa mère, Angelica Kostrowicka, née en Finlande en 1858, dont les parents se sont réfugiés à Rome quand elle avait six ans; son père, beaucoup plus âgé (né en 1835), le comte Francesco Fuigi d'Aspermont, lui-même fils d'un général aide de camp du roi Ferdinand II, roi des Deux-Siciles, ne l'a pas reconnu, pas plus que son frère cadet.. Le 24 au matin, il a écrit à Madeleine Pagès, la jeune professeur de Lettres au lycée d'Oran rencontrée en janvier dans le train de Nice à Nîmes, qu'il a demandée en mariage en août: "Ma chérie, Quand tu liras cette lettre souhaite que nous soyons loin dans les terres françaises. Nous partons demain en territoires occupés. On nous a monté les selles hier soir. Les paquetages sont prêts et les avant-trains sont munis de fascines ${ }^{16}$ pour le passage des tranchées [...] En ce moment tout marche, c'est fantastique comme orchestre. Des fantassins passant disent que chez les Boches, aussi loin qu'on peut voir, la terre est comme la mer soulevée par des vagues.".

Le lendemain 25, sa nouvelle lettre commence par: "Mon amour, On a canonné toute la journée. C'est le soir, je me repose jusqu'à minuit trente où je reprends le feu avec ma pièce. Nous partons demain - pour où?"'17. Peu de temps après, le 6 octobre, il lui enverra le beau poème Désir, en vers libres, dont les deux dernières strophes évoquent l'intense canonnade à laquelle il a participé:

Je désire // Te serrer dans ma main, Main de Massiges "18// Si décharnée sur la carte // Le boyau Goethe où j'ai tiré // J'ai tiré même sur le boyau Nietzsche // Décidément je ne respecte aucune gloire // Nuit violente et violette et sombre et pleine d'or par moments // Nuit des hommes seulement"

Nuit du 24 septembre // Demain l'assaut // Nuit violente ô nuit dont l'épouvantable cri profond devenait plus intense de minute en minute // Nuit qui criait comme une femme qu'on accouche // Nuit des hommes seulement ".

Mais revenons, non loin de la position de l'auteur d'Alcools et de Calligrammes, à Joseph Sorgues, dans la journée décisive de l'assaut, le 25 septembre, où il écrit jusqu'au dernier moment, sans que sa plume tremble:

Samedi 25 septembre - 8 heures - Nous voilà au grand jour. Dans la parallèle, je mets mon Journal au point pendant que mes camarades constatent les effets du bombardement qui continue depuis hier avec une intensité toujours croissante.

Je mets le nez à un créneau, en m'élevant par les petits escaliers que chacun a façonnés devant lui pour bondir plus vite quand le signal sera donné. Les ouvrages ennemis sont informes, tout a été bouleversé, les dépôts de munitions soigneusement repérés, mais bombardés au dernier moment, ont fait explosion toute la nuit, projetant des gerbes de flammes de 25 à 30 mètres de hauteur et éclairant le ciel d'une sinistre lueur rouge. Et toujours ce vacarme incessant, déchirant, stupéfiant: il doit y avoir quelque cercle de l'enfer ${ }^{19}$ où l'on entend ce bruit là! A cette heure la gare de Vouziers ${ }^{20}$ doit être détruite par nos 380, et dans quelques minutes, le fortin de Beauséjour, patiemment miné, sautera dans un fracas épouvantable, donnant le signal de l'attaque.

Je regarde mes camarades: les figures, un peu pâlies par l'angoisse inévitable dont on ne peut se défendre, car c'est notre première attaque ${ }^{21}$, sont toujours vaillantes et résolues à faire leur devoir; il y a même de la gaieté sur certains visages, on se serre la main, on se serre la main en se souhaitant bonne chance.

Je regarde une dernière fois mes photographies et mes souvenirs de famille avec émotion. C'est pour des êtres chéris que je suis ici, que je vais tout à l'heure m'élancer hors de mon abri vers la victoire ou vers la mort. Un signe de croix, une brève recommandation à Dieu, et en Avant! Si je viens à être tué, ne me pleurez pas, chers Parents, j'aurais eu la plus belle mort que puisse souhaiter un soldat, combattant pour son Dieu et la Patrie......"

La moitié basse de la page reste blanche, avec seulement, en travers, cette mention en petites lettres : "Attaque à 9 h 15' - arrêt jusqu'au $1^{\text {er }}$ novembre". Et de fait, la page suivante porte la date du $1^{\text {er }}$ novembre. Joseph Sorgues a été gravement blessé dans l'attaque et n'a pu écrire. Retenons avec quelle foi et quel patriotisme il a

\footnotetext{
${ }^{16}$ Les avants-trains sont ceux des caissons d'artillerie charriant les obus, tirés par plusieurs chevaux. Les fascines sont normalement des assemblages de branchages fortement serrés pour soutenir une terre remblayée qui s'éboule, ou pour combler un fossé afin de pouvoir le franchir. Etant donné le poids considérable des caissons d'artillerie, il faut supposer que ce ne sont pas de simples branchages, mais de fortes branches, voire des madriers, pour pouvoir franchir l'obstacle des tranchées une fois le terrain conquis.

${ }^{17}$ Guillaume Apollinaire, Lettres à Madeleine - Tendre comme le souvenir, 1ere édition en 1952, réédition en 2005, Gallimard N.R.F., pp. 203- 204.. Le poème Désir se trouve aux pages 226-228.

${ }^{18}$ C'est le nom d'un massif montagneux en bordure d'Argonne, dont la forme évoque une main, les diverses collines la composant portant le nom des doigts de la main.

${ }^{19}$ Ici Joseph Sorgues fait allusion à L'Enfer, une du trois parties, (avec Le Purgatoire_et Le Paradis) de l'œuvre majeure et monumentale du poète italien Dante Alighieri (1265-1321) : LA Divine Comédie, écrite entre 1307 et 1321.

${ }^{20}$ La gare régulatrice de Vouziers, en zone occupée par les Allemands (qui l'utilisent pour acheminer hommes et armement) se trouve à environ $40 \mathrm{~km}$ au nord du secteur où se trouve Joseph Sorgues, en bordure de l'Aisne, située sur la route de plaine qui longe le massif de la forêt d'Argonne, à gauche, conduisant de Sainte-Menehould à Rethel.

${ }^{21}$ C'est la première attaque pour les bleus, les jeunes, ceux de la classe 15 à laquelle il appartient, incorporés fin décembre 14, en instruction jusqu'à fin mai (lui, le 31) ou début juin, et versés ensuite au $160^{\mathrm{e}}$ R.I., où les plus anciens ont attaqué plus d'une fois.
} 
attendu l'instant de l'assaut et peut-être l'imminence de la mort. Il emploie à peu près les mêmes mots que les hommes politiques du temps, mais eux sont à la tribune de l'Assemblée Nationale, et non dans la tranchée, à l'heure critique du grand bond "en Avant"...

Comment Joseph va-t-il reprendre son journal après plus d'un mois d'interruption, lui qui saute rarement un jour? Va-t-il décrire les conditions de sa blessure? Pour le savoir, passons à la page suivante, bien qu'un chapitre spécifique soit prévu pour les blessures et l'hospitalisation, et bien que cela déborde le cadre strict de ce chapitre, l'offensive de Champagne de fin septembre-début octobre 1915. La qualité de cet homme mérite qu'on le suive dans son épreuve. Dès les premières lignes, on constate que, contrairement à toute attente, sa petite écriture droite, élégante, aux lignes fermes, n'a pas changé, alors qu'elle deviendra de plus en plus penchée dans les carnets suivants.

\section{" $1^{\text {er }}$ Novembre -}

Comment vais-je pouvoir continuer mon Journal, étendu sur le dos dans un lit, sans pouvoir seulement m'asseoir, ne me tournant sur le côté droit qu'au prix de mille difficultés, et la main fatiguée au bout de cinq minutes de travail? Comment vais-je pouvoir noter les événements survenus depuis ce fatal 25 septembre, alors qu'ils se brouillent dans ma pauvre tête en une formidable vision de gloire et de sang? ? Comment vais-je traduire mes impressions, alors qu'elles se résument dans les pensées monotones d'un malade simplement désireux de retrouver la santé et qui trouve d'une longueur désespérante les journées d'hôpital, pendant que les camarades se battent toujours et moissonnent la gloire à pleines mains."

A travers cette dernière expression, stylistiquement belle dans sa métaphore des moissons, Joseph, qui est, rappelons-le, enseignant, - et enseignant profondément chrétien -, et non militaire de carrière, s'éloigne très sensiblement du point de vue de mes autres témoins (sauf exception), et même de ceux dont les écrits permettent de percevoir la mentalité qu'ils avaient à l'époque, et non autour de leurs 90 ans, comme la majorité de ceux que j'ai interviewés dans la décennie 80-90, où la gloire militaire leur importait fort peu.

"Je vais essayer tout de même de mettre en ordre mes idées sans trop de travail, pour obéir au médecin, et de les jeter sur le papier, selon l'inévitable manie des jeunes filles, des poètes et des amoureux" On voit que Joseph n'a pas perdu le sens de l'autodérision. Il continue: Si parfois la lassitude écourte mes développements, si elle raréfie mes pensées, si la souffrance un peu plus forte imprime son empreinte sur mes appréciations ou dérange la suite de mes raisonnements, je me reconnaîtrais bien toujours dans ce petit confident que je destine à être lu de personne." Et là, je m'arrête: ne trahit-on pas le vœu de Joseph Sorgues en incluant son témoignage dans un livre et en le lisant? On pourrait répondre que sa famille, dans une belle relation de confiance dont je la remercie ${ }^{22}$ en a décidé autrement. Mais à le voir si bien écrire, on se demande si ce n'est pas là une coquetterie, et si son vœu secret n'était pas justement, pour lui, le familier de la littérature, d'être lu? Joseph continue:

"Je saurais bien rétablir la vérité, redresser tel ou tel jugement, adapter ma compréhension aux circonstances et au milieu."

Ces souvenirs d'hôpital vont être parmi les plus ingrats de mon Journal de guerre" Ecrit-on cela pour soi? N'est-ce pas plutôt pour prévenir un éventuel lecteur de s'attendre à moins de rebondissements, ou simplement de variété, dans les événements racontés?

"Mais ils sont nécessaires cependant, pour fixer plus complètement mon existence pendant la guerre. Après mon passage de l'élément civil au dépôt, ${ }^{23}$ puis mon passage du dépôt au front, ils me feront connaître la vie dans les hôpitaux et les ambulances ${ }^{24}$. Après le milieu qui travaille et espère, le milieu qui se prépare et s'entraîne, le milieu qui lutte et qui combat, voilà le milieu qui souffre et qui meurt." Indiscutablement, Joseph manie la rhétorique ${ }^{25}$ comme il respire...

Nous garderons cependant pour un chapitre consacré à la religion la belle et longue méditation consacrée, le lendemain 2 novembre, Jour des Morts, aux morts parmi lesquels il ne figure pas, convaincu qu'il est d'avoir bénéficié une nouvelle fois de la protection divine.

On en arrive à la reconstitution des circonstances de sa blessure du 25 novembre, jour du déclenchement de l'assaut, ce qui nous pénétrer de belle manière dans la psychologie du soldat lors de cet assaut: "Je revois encore, à

\footnotetext{
${ }^{22}$ Cette relation de confiance est double: le journal de Joseph Sorgues m'a été confié (pour photocopie) en 2001 par une famille amie et voisine de La Fouillouse, Paulette et François Merle, qui au courant depuis de nombreuses années de la gestation de ce travail, en avait parlé à leurs amis, Josette Montoy, nièce et filleule de Joseph Sorgues, et son époux Bernard, habitant dans le Rhône.

${ }^{23}$ Le dépôt est la caserne, et par extension la ville, où se trouve le régiment en temps de paix, et où s'effectue le plus souvent l'instruction des jeunes recrues.

${ }^{24}$ Une ambulance est un hôpital provisoire, au front, soit dans des baraques Adrian, soit dans une maison ou une école réquisitionnée.

${ }^{25}$ A titre indicatif, cette dernière phrase cumule une gradation ascendante, quatre périphrases, un parallélisme à quatre éléments, un rythme binaire dans les propositions et un rythme quaternaire dans la phrase entière... Sans compter sans doute une allusion historique à la division en trois groupes de la société médiévale: "bellatores" (ceux qui combattent: les chevaliers, la noblesse d'épée), "oratores" (ceux qui prient: les membres du clergé), "laboratores" (ceux qui travaillent : les autres,, constituant le Tiers Etat).
} 
travers les blanches murailles de la salle d'hôpital, ce matin brumeux du 25 septembre, où la nature fut tristement épouvantée du massacre qui se préparait. Je ne puis suivre la minute d'émotion indescriptible où l'on lança ces commandements:" Sac au dos! Baïonnette au canon!" , puis, vers neuf heures un quart, cet "En Avant!" si attendu. Mais je vois encore très bien mon bond par-dessus le parapet à l'air libre, ma course acharnée vers les tranchées boches, mes camarades et moi hurlant cette clameur formidable de l'assaut qui glace le sang de nos ennemis. Je me souviens m'être couché une fois à côté du lieutenant commandant la compagnie, sous une grêle de balles de mitrailleuses qui fauchaient l'herbe sous nos pieds, puis être reparti, toujours, en courant, aux cris de "En avant! ${ }^{26 "}$ à travers le fracas des gros obus commençant à tomber et que je n'entendais pas. Ma main tremble en écrivant cela, tellement je sens encore l'enthousiasme fou et sacré qui nous animait tous et nous faisait lutter de vitesse dans cette course à la gloire et à la mort. Je vivrai cent ans que je n'oublierai jamais ces instants, cet enivrement de triomphe et de sacrifice qui soulevait nos âmes jusqu'au ciel et jetait nos corps dans la fournaise."

Cette dernière phrase permet de rectifier l'interprétation de la première référence de Joseph à la gloire, qu'on aurait pu croire simplement militaire et profane, liée à l'honneur et aux honneurs que vaut une conduite héroïque. Ce mot a ici, chez lui le mystique chrétien, un sens sacrificiel, représentant une sublimation de soi dans le don de sa vie, qui l'apparente, me semble-t-il, à la "gloire" de Jésus mourant sur la croix pour sauver les péchés des hommes. Mais laissons-le poursuivre: "Je venais de tirer un coup de fusil dans un abri de la première tranchée ennemie et je franchissais les réseaux de fils de fer étendus en désordre à terre par nos canons, lorsqu'une balle m'atteignit par derrière, dans les reins. Un choc épouvantable qui me fit pirouetter et tomber sur le dos, me coupant instantanément les jambes et toute la partie inférieure du corps. J'agitais les jambes inconsciemment et je me dis: "Tu vas mourir!", car je ne me sentais plus; ô moment terrible et suprême où j'allais me trouver face à face avec mon Créateur! Ce moment ne vint pas. Un camarade grenadier de la $3^{e}$ escouade, Mangin, passait: "Défais-moi mon sac!" lui criais-je, dans un suppliant appel. Il ne s'arrêta pas, me dit non, et passa outre, et je l'en remercie, car il n'a fait que son devoir. ${ }^{27}$ Je pus me débarasser* de mon sac fort lourd, de ma musette à vivres, et de celle à grenades et de mon bidon; puis, l'instinct de conservation aidant, je me glissais à plat ventre dans un large trou d'obus. Je restai là une demi-heure, priant de tout mon cour pour obtenir le pardon de mes fautes, et m'interrompant pour appeler au secours; j'étais brûlé de fièvre, sans une goutte d'eau, et je me rappelais avec amertume que mon bidon, abandonné à l'endroit où j'étais tombé, contenait deux litres de vin. Mais impossible d'aller le chercher; j'étais prostré et anéanti, et tout autour de moi les obus éclataient avec un bruit de tonnerre se mêlant au sifflement rageur de milliers de balles; ce n'était pas le moment de montrer sa tête. Près de moi, dans un petit boyau, passaient les camarades $d u 2^{e}$, puis $d u 3^{e}$ bataillon, puis les mitrailleurs, me regardant d'un air de pitié. Je restai ainsi longtemps sans perdre connaissance, presque sans souffrir, mais broyé et incapable de me soulever. Soudain les mitrailleurs que je venais de voir passer, puis une chaîne de tirailleurs se mirent à reculer. Je crus que les Allemands avaient l'avantage et la frayeur d'être fait prisonnier me galvanisa: je sautai d'un bond hors de mon trou où s'était formé une petite flaque de sang vermeil et je roulai tête la première dans le boyau. Ce fossé, d'environ soixante centimètres de profondeur, conduisait à nos lignes; j'y rencontrai Valat, un camarade de la $4^{e}$, blessé à la cuisse, qui m'encouragea et m'attendit pour se sauver avec moi. Quel calvaire furent pour moi ces trois cents mètres qui me séparaient du salut! Marchant sur les genoux et sur les mains, courbant la tête sous les rafales de mitraille des tirs de barrage, m'arrêtant exténué à tous les cinquante pas, enjambant les morts et les blessés avec terreur, comment ai-je pu arriver jusqu'à notre tranchée sans avoir été atteint et sans être mort d'épuisement en route? Plus j'y réfléchis, plus je n'y vois qu'une explication: la protection de la sainte Vierge, car en ce moment un cierge brûlait pour moi, devant son autel, dans la petite église de mon village, et ma pieuse mère unissait sa prière à celle de la flamme montant droit dans le ciel."

Une nouvelle fois, Joseph a la profonde conviction d'une protection divine, en l'occurrence mariale cette fois, sauvegardant sa vie alors que les circonstances naturelles devraient le condamner. La coïncidence entre l'instant de sa blessure et le moment de la présence de sa mère dans l'église de Romanèche-Thorins peut paraître, à juste titre, miraculeuse, mais nous n'avons aucun élément, évidemment, pour en infirmer ou confirmer la véracité...

Nous reviendrons, dans un chapitre spécifique, sur le trajet de Joseph de poste de secours en ambulance, puis en hôpital après son évacuation du front. Sa guerre est terminée. La balle qui s'est fichée tout contre sa colonne vertébrale ne pourra être extraite lors qu'une première opération le 8 octobre; elle ne le sera qu'à Paris, dans une annexe du Val-de-Grâce, le 12 avril 1916. Réformé provisoire en janvier 1917, puis versé dans le service auxiliaire

\footnotetext{
${ }^{26}$ On aura peut-être remarqué que le "En Avant" décisif, le premier, celui qui lance l'assaut, a été en quelque sorte solennisé, sacralisé, par la majuscule, alors que ces "en avant" multiples, au cours de l'assaut, ne reçoivent qu'une minuscule.

${ }^{27}$ On peut légitimement être surpris à la fois du refus de Mangin et de l'approbation de cette conduite par Joseph Sorgues.. C'est oublier que dans l'assaut, tout secours à un camarade était strictement interdit, car cela aurait pu servir de prétexte à trop de soldats pour s'arrêter, et casser la vague d'assaut. Mais, humainement, c'est pousser bien loin, de la part de Joseph, le sacrifice de soi, l'abnégation! On peut rapprocher cela du témoignage de Marius Guinand, de Sorbiers, blessé au col de la Chipottte dan les Vosges, le $1^{\mathrm{er}}$ sept. 1914, qui demande à son camarade de l'emmener, et ce dernier répond: "Non, je peux pas t'emmener, tu sais bien ce qu'on a dit!" et Marius d'expliquer: "C'est vrai, la veille, ils avaient dit: "Défendu de s'occuper d'un blessé" parce qu'il y en avait trop..." (chap. III)
} 
en avril, il sera affecté dans l'armée de réserve en décembre 17, et passera l'année 18 comme secrétaire du commandant dans l'un des deux dépôts du $153^{\mathrm{e}}$ R.I, à Saint-Pierre-le-Moutier, dans la Nièvre.

\section{L'offensive de Champagne à travers le point de vue d'un brancardier: Amand Beyron}

Un brancardier ne participe pas à l'attaque, mais il la voit, et en voit surtout les conséquences quand il lui faut, avec ses camarades, ramasser les blessés sur le champ de bataille pour les rapporter au poste de secours, et parfois, quand il le peut, quand il dispose d'un peu de temps, consoler les mourants, les assister dans leurs derniers moments, leur promettre de transmettre leur portefeuille et leur montre à leur famille. De plus, ne vivant pas en tranchées, mais un peu en retrait, et proche des officiers commandant le régiment, discutant avec les agents de liaison, il bénéficie de plus d'informations que le fantassin dans sa tranchée. Rappelons qu'on est musicienbrancardier: musicien quand la fonction de brancardier ne l'emporte pas, dans les périodes calmes, pour préparer les morceaux de musique qui seront joués dans les parades, les défilés.

Le journal d'Amand Beyron (cl. 11) de Chazelles-sur-Lyon, fils de patron chapelier, bachelier, puis élève pendant trois ans de l'Ecole Supérieure de Tissage de Lyon (il sera dans sa vie directeur de plusieurs usines de tissage) m'a été confié le 31 décembre 1987 par lui-même, dans sa maison de Roanne où il avait pris sa retraite; je l'ai aussi interviewé, de sorte qu'il est à la fois témoin oral et témoin écrit. Son journal, il l'a rédigé juste après guerre en recopiant fidèlement sur plusieurs cahiers les carnets de guerre qu'il avait tenus au jour le jour, et en les complétant, de temps à autre, par des extraits de l'Historique de son régiment, le $99^{\mathrm{e}}$ R.I. de Vienne. Il est aussi d'une grande qualité stylistique et humaine, comme celui de Joseph Sorgues

Son récit de l'offensive de Champagne, il le commence justement par un long extrait de l'Historique du $99^{\mathrm{e}}$ R.I. dont voici une petite partie (page 142 du Journal):

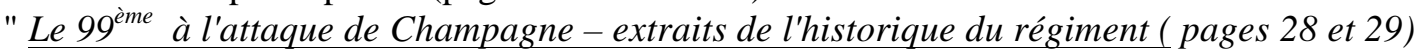

"La grande période de stabilisation du front dans la Somme avait assez duré. Une grande offensive se préparait en Champagne. Le $99^{e}$ devait y participer et jouer un grand rôle. Durant la période d'Août à Octobre, le $99^{e}$ va fournir une somme de travail extraordinaire. Dès son arrivée un secteur lui est confié. Il faut le défendre tout en l'organisant pour la grande attaque qui est proche et sur laquelle l'espoir est fondé. Jour et nuit, pendant 2 mois, tout le monde travaille à la construction de boyaux larges et profonds, de parallèles de départ ${ }^{28}$, d'abris, etc. Quelques jours avant l'attaque le commandant Rousselon du $1^{\text {er }}$ bataillon, promu lieutenant-colonel, succède au Colonel Marty, nommé général de brigade, et va dans un état-major. Le jour de l'attaque arrive enfin. Offensive longuement préparée. Un bombardement de 72 heures l'avait préparée".

Voici maintenant in extenso le récit d'Amand Beyron; l'usage des points de suspension est, chez lui, très fréquent: ce ne sont donc pas des coupures que j'aurais pratiquées dans son texte.

p. 150 - Vendredi 24 septembre - Lever à 6 heures. Après la soupe on change nos képis contre des casques en acier, arrivés hier au train de combat. On nous distribue des vivres de réserve pour 6 jours. On change nos sabres (coupe-choux) contre des révolvers ${ }^{* 29}$ à 5 coups de répétition, avec étui (fabrication espagnole). On nous donne un bidon de 2 litres à la place de celui d'un litre et une musette supplémentaire avec des pansements et un flacon de teinture d'iode, plus une paire de ciseaux. De bonne heure un bombardement intensif de notre artillerie tire sur les tranchées ennemies. En fin de soirée, nous mettons sacs et instruments de musique à la voiture au train de combat, et partirons demain matin aux tranchées avec une couverture roulée en bandouillère* et nos brancards. On nous laisse nos bidons de 1 litre, rempli* de "gnole"avec défense de s'en servir. Cet alcool est réservé aux mourants et aux blessés, et on compte sur nous pour être raisonnables et ne pas se "saouler" avec......Toute la soirée a été mouvementée dans le camp. Un bombardement intense des tranchées boches a duré toute la nuit sans faiblir.... Mon frère Jean et son camarade Michalon du $416^{e}$ sont venus me voir, avec l'espoir de se retrouver après la bataille, et bu une bonne bouteille de vin cachete ${ }^{31}$

Samedi 25 septembre - Jour "J"- Nous quittons notre camp (cote 152) à 3 heures du matin et par les "boyaux" sur 6 kilomètres. Nous allons dans notre poste de secours à 500 mètres de la tranchée de repli de la $1^{\text {ère }}$ ligne en avant...L'artillerie de campagne de 75 tire sans arrêt... Bruit infernal de sifflements d'obus sur nos têtes... L'ennemi répond faiblement, mais il envoie beaucoup de "scrapnels" ${ }^{32}$ sur les boyaux de l'arrière... A 9 heures les

\footnotetext{
${ }^{28}$ Un parallèle de départ est boyau assez large, parallèle à la tranchée de première ligne, creusé en vue d'une attaque pour faire stationner les troupes de réserve dont l'assaut suivra celui des premières vagues.

${ }^{29}$ Pour ne pas être encombré dans le transport des blessés, les brancardiers n'avaient pas de fusil, mais des sabres, puis ici des revolvers, comme les officiers.

${ }^{30}$ On verra qu'il est de tradition d'effectuer une distribution d'alcool avant l'attaque, mais, pour les fantassins qui attaquent (pas le cas des brancardiers) c'est pour soutenir le moral, donner un "coup de fouet", dissiper la peur...

${ }^{31}$ Cachetée de cire, une bouteille était censée contenir du bon vin, et non la piquette des cantines du soldat, ou des cafetiers.

${ }^{32}$ Amand orthographie mal ce mot qui possède deux graphies autorisées ("shrapnel" ou "shrapnell") apparu en français en 1860, désignant un obus rempli de billes de plombs ou d'éclats métalliques qui se dispersent quand il explose. C'est le général
} 
régiments s'apprêtent à sortir des tranchées et nous entendons du côté boche une vive fusillade, sans arrêt... Les renforts montent en ligne dans les boyaux en file indienne... Le bruit des départs ${ }^{33}$ devient si intense qu'on ne s'entend même plus parler..... A 9 h 15 (heure $J^{34}$ ), le $99^{e}$ avec ses 3 bataillons ${ }^{35}$ sort de ses tranchées en "hurlant" et en courant, baïonnette en avant sur les lignes allemandes, sous la fusillade intense des mitrailleuses et des éclatements d'obus, mais sans la protection de nos 75 qui peu à peu allongent leur tir ${ }^{36}$ L'ennemi est rapidement culbuté malgré son tir de barrage, et c'est le corps à corps dans ses tranchées, les "abris" attaqués à la grenade et au couteau des sections de nettoyage ${ }^{37}$......Peu de temps après arrivent de nombreux prisonniers déséquipés ${ }^{38}$, hagards, les mains en l'air, courant à l'arrière par les boyaux encombrés et éboulés à certains endroits, sous une pluie de "scrapnels"*... Les blessés légers aussi arrivent assez vite et nombreux pour se faire panser, et font queue indienne dans le boyau d'accès du poste de secours.... A 9 h 40 nous sortons à notre tour avec nos brancards, et à découvert, au-dessus des boyaux. Nous filons droit devant nous au-delà de la $1^{\text {ère }}$ ligne allemande, et ramassons les premiers blessés couchés que nous amenons à découvert ${ }^{39}$, pour aller plus vite à notre poste de secours.... Sans arrêt, nous repartons et ramassons, sans nous soucier de notre fatigue.... A $10 \mathrm{~h} 1 / 2 \mathrm{il}$ faut dégager le poste de secours trop petit et encombré par de trop nombreux blessés couchés, amenés par les brancardiers des compagnies. Tout le long du boyau d'accès au poste de secours les pauvres blessés attendent, et je suis chargé de faire aider le transport de blessés par les prisonniers qui ne cessent d'arriver et d'obstruer les boyaux.... On demande d'urgence les brancardiers divisionnaires et ceux du Corps d'armée ${ }^{40}$ et bientôt ils sont surchargés.... A 12 heures la $2^{\text {ème }}$ section de musique est désignée pour faire le transport du poste de secours central au poste de secours de la division, à $1 \mathrm{~km} 500$ en arrière de nous, et à découvert, par dessus les boyaux encombrés et éboulés par endroits, malgré le tir infernal des "scrapnels"* qui sifflent aux oreilles, cet qui rend difficile et périlleux le transport des blessés sur brancards. Nous apprenons par la liaison du P.C ${ }^{41}$. du colonel que le fort du Trou Bricot est encerclé et qu'il ne résistera pas longtemps. Peu de temps après on nous dit qu'il avait été pris malgré une défense acharnée de l'ennemi, avec beaucoup de pertes des deux côtés... On se battait à la grenade et au corps à corps avec couteaux et bä̈onnettes ${ }^{42}$... Vers 13 heures nos troupes continuent d'avancer... Notre artillerie cesse son tir pour aller se mettre en batterie de notre $1^{\text {ère }}$ ligne de départ ${ }^{43}$, et dès installée elle se met à tirer sans arrêt jusqu'à épuisement des obus. C'est impressionnant à regarder, à travers les obus qui éclatent à travers ${ }^{44}$.... Jusqu'à la nuit on ramasse les blessés allongés par terre et éparpillés sur le terrain, jonché de morts et de mourants criant "au secours"..... A 17 heures , on nous donne l'ordre au poste de secours par le major ${ }^{45}$, d'aller ramasser les blessés en $2^{\text {ème }}$ ligne allemande, enlevée paraît-il à la bä̈onnette par les troupes de renfort. D'abord les blessés français, les allemands* ensuite ${ }^{46}$.... Leurs tranchées sont complètement

anglais Schrapnell (1761 - 1842) qui l'a inventé. Ce type d'obus, selon Emile Littré, aurait été employé pour la première fois par l'armée anglaise en 1795, au siège de Dunkerque.

${ }^{33}$ Ces "départs" sont les départs des obus sortant des gueules des canons.

${ }^{34}$ On s'attendrait à ce que ce soit heure $\mathrm{H}$ (comme jour J), mais le "J", fautif mais plus fréquemment employé, a dû primer pour Amand

${ }^{35}$ Dans le chap. V, nous avons vu qu'Amand Beyron notait qu'au départ de Lyon, le $99^{\mathrm{e}}$ R.I. de Vienne, avec ses trois bataillons, comportait 3860 hommes. Ayant perdu 3700 hommes (tués, blessés, disparus, prisonniers) après les combats d'août et la bataille de la Marne, il avait été entièrement reconstitué par l'envoi de renforts; mais il avait dû essuyer de nouvelles pertes à la fin de 1914 et durant les neuf premiers mois de 1915 .

${ }^{36}$ Cet allongement du tir est indispensable pour ne tirer sur les plus avancés des soldats français participant à l'attaque, et pour poursuivre et si possible anéantir les ennemies qui fuiraient.

${ }^{37}$ Les grenades jetées dans les abris servaient à en tuer les occupants (à supposer qu'il y en ait encore), et le couteau des "nettoyeurs de tranchées" à achever les blessés, quoi qu'on en ait dit...

${ }^{38} \mathrm{Ils}$ sont déséquipés soit parce qu'ils ont été surpris par l'attaque et n'ont pas eu le temps de prendre leur équipement, mais c'est hautement improbable, étant donné qu'il y a eu 72 heures continues de bombardement avant l'attaque (la préparation d'artillerie), soit, et c'est de loin le plus plausible, parce que les Français les ont désarmés et ne leur ont pas permis de prendre leur paquetage avant de les emmener comme prisonniers

${ }^{39}$ Cette précision est importante et indique les risques que prennent les brancardiers: au lieu d'acheminer les blessés en passant dans les tranchées et les boyaux, où l'on est relativement protégé des balles et des éclats d'obus, mais où la progression d'un brancard est assez lente, surtout si la tranchée est encombrée ou boueuse, ils les acheminent sur le terrain naturel, donc en pleine vue de l'ennemi, avec le risque d'être pris comme cible et tués.

${ }^{40}$ Les brancardiers attachés aux régiments étant débordés par l'afflux de blessés, il est fait appel aux brancardiers des deux groupements supérieurs (la Division et le Corps d'armée), normalement en réserve, pour faire face à la situation.

${ }^{41}$ P.C. = Poste de Commandement

${ }^{42}$ Même si l'on attaque toujours "baïonnette au canon", le recours effectif à cette arme blanche est en réalité assez rare, comme on le verra. En précisant cela, Amand veut signifier que les corps à corps sont nombreux et acharnés.

${ }^{43}$ Cette avancée signale une progression de l'infanterie française de plusieurs kilomètres.

44 Cette seconde locution "à travers" signifie "çà et là", donc un peu partout; en français local forézien quand on dit, par exemple: "les moutons sont à travers", cela indique qu'ils sont dispersés n'importe où dans les prés, et non rassemblés dans un pré et gardés par une bergère.

45 Le "major" est le médecin major, commandant donc les brancardiers, ayant grade de capitaine.

${ }^{46}$ Le fait, pour les brancardiers, de s'occuper aussi des blessés ennemis n'est pas rare, mais il n'est pas systématique, loin de là. 
bouleversées et remplies de cadavres. L'évacuation par les boyaux est impossible, trop encombrés et défoncés par un bombardement intense, et les transports de blessés se font à découvert, par dessus... Vers 20 heures nous savons que pour ce premier jour d'attaque, ça a bien marché devant nous, et par côtés aussi, mais hélas! avec beaucoup de pertes en hommes. On nous apprend aussi que le général Barret, commandant du XIVe corps d'armée est satisfait... On a fait un grand nombre de prisonniers et surtout le $99^{e}$ qui s'est distingué au "Bois Sabot" et au "Trou Bricot".... Sans arrêt, toute la nuit, nous parcourons le champ de bataille, allant où l'on entend crier "au secours", dans la nuit obscure et sous la pluie..... "Triste corvée, à en pleurer".

Dimanche 26 septembre - "Au petit jour, je tombe de lassitude et de sommeil. Je n'ai même pas le courage de manger, même un biscuit. On a soif, et plus d'eau dans nos bidons de 2 litres. Dans mon bidon de 1 litre, il ne me reste que 1/3 d'eau-de-vie que je garde pour les pauvres mourants et les grands blessés.... Je suis si fatigué que je bois q.q. (quelques) gorgées qui me donnent l'illusion d'aller mieux, avec plus de courage.... Le major nous fait dire que le colonel réclame les brancardiers au "Trou Bricot" où il y a beaucoup de grands blessés français et allemands à évacuer rapidement, étant non pansés, ou très sommairement...... Cette nuit le $99^{e}$ a fait, en plus, 800 prisonniers dont 2 généraux, 1 colonel et son état-major...A 10 heures je vais avec 3 musiciens tâcher de sortir d'un éboulement de tranchée un pauvre type qu'on entend crier au secours une partie de la nuit. Il mourut en arrivant au poste de secours, en demandant sa "maman". Nous l'avons enterré aussitôt dans un trou d'obus, avec des pelles-bêches trouvées à proximité et pris sa médaille de recrutement et sa montre, portefeuille et objets que je ferai envoyer à la famille. C'est un soldat du $22^{e}$ Rég ${ }^{t,}{ }^{47}$ Pierre Boyer, de Bourgoin (Isère) ${ }^{48}$. A la nuit nous remontons au "Bois Sabot" qui a été pris et repris 2 fois, après une lutte acharnée et rempli de cadavres français et allemands.... Nous passons toute la nuit dans la tranchée allemande "Veser" ${ }^{49}$, au-delà de leur $2^{e}$ ligne. Notre artillerie qui s'est de nouveau déplacée en avant vient se mettre en batterie à côté de nous et tiraille sans arrêt jusqu'au petit jour et s'arrête par manque de munitions, qui arrivent peu de temps après..... Dans cette tranchée "Veser" nous avons trouvé un abri, et après avoir dégagé l'entrée, nous descendons les escaliers et nous trouvons une salle bien étampée ${ }^{50}$ où nous nous sommes écroulés de fatigue et où nous avons pu dormir q.q. heures sans nous soucier des obus qui éclataient autour de nous.... Nous avons su qu'à 23 heures l'ennemi avait contr'attaqué à "Beauséjour" ${ }^{51}$ et avait été repoussé... A 3 heures du matin je suis réveillé en sursaut par un obus éclaté tout près de l'entrée de notre abri sans l'obstruer....Je monte sur la tranchée... Le ciel était illuminé par les fusées éclairantes de toutes couleurs: blanches - vertes -rouges ${ }^{52}$, un vrai feu d'artifice, et je vois arriver sous la pluie qui commence à tomber des dragons $d u 17^{e}$ Régt avec leurs chevaux, et se mettre en batterie à 200 mètres de notre abri... Quelques moments après, étant rentré dans la sappe*, des hommes descendent l'escalier; parmi eux, un qui paraissait plus âgé, pour se mettre à l'abri de la pluie. Nous causons q.q. instants... Kakoi, qui ne perd pas le nord, avait trouvé dans une cagna boche un petit réchaud à alcool et des tablettes ${ }^{53}$, se préparait à faire dans un bouteillon ${ }^{54}$ boche en aluminium un peu de café...... On ne voyait pas bien clair dans le "gourbi" faiblement éclairé par un bout de bougie qui menaçait de s'éteindre à chaque éclatement d'obus dans la tranchée... Il a demandé à un des hommes s'ils avaient un peu d'eau pour allonger le café... On a partagé le jus entre nous, et le brave Kakoi qui n'en rate point, dit au plus vieux des dragons: "Vous n'êtent* pas cinglés de venir avec vos bourrins vous faire esquinter si vous chargez les boches à la "Reischoffen" ${ }^{55}$ dans les barbelés".... A ce moment, un homme dégringole dans les escaliers et se mettant au garde à vous devant le vieux dragon, lui remet un pli en lui disant:

\footnotetext{
${ }^{47}$ Le $22^{\mathrm{e}}$ R.I. (et son régiment de réserve, le $222^{\mathrm{e}}$ R.I. ) a son dépôt à Bourgoin; le mort était donc incorporé dans le régiment de sa petite ville.

${ }^{48}$ Après avoir écrit ces lignes, j'ai pris contact avec le bureau du journal "Le Dauphiné Libéré" à Bourgoin-Jallieu, dans l'Isère, pour que soit tentée une recherche afin d'informer les descendants de la famille Boyer des conditions de mort de Pierre Boyer. Une journaliste, Myriam Karsentty, a bien voulu s'en charger, nantie de cet extrait du journal d'Amand Beyron. Malheureusement, sa recherche a dû être infructueuse.

${ }^{49}$ La graphie correcte est évidemment " Weser," nom d'un fleuve allemand prenant sa source en Thuringe et se jetant dans la Mer du Nord au-delà de Brême

50 "Une salle bien étampée" : cet abri souterrain est bien étayé, avec des madriers soutenant le toit en rondins, recouvert sûrement d'une couche épaisse de terre, pour éviter qu'un obus ne fasse s'effondrer l'abri

${ }^{51} \mathrm{La}$ ferme de Beauséjour est un des hauts lieux des diverses batailles de Champagne, à proximité de la fameuse Main de Massiges

${ }^{52}$ Comme on le verra, chaque couleur correspond à un code pour, à partir des tranchées, déclencher le tir de l'artillerie, lui faire allonger ou raccourcir le tir. Les fusées blanches servent à éclairer le terrain la nuit.

${ }_{53}$ Ces tablettes sont des pastilles d'alcool solidifié

54 "Bouteillon" était la déformation très courante de "bouthéon", désignant, du nom de son inventeur, l'ingénieur militaire Bouthéon, une marmite métallique aplatie dont le couvert pouvait servir d'assiette. On trouve ce terme notamment dans $\underline{L e ~ F e u}$ d'Henri Barbusse.

${ }^{55}$ Reichshoffen est la localité du Bas-Rhin, proche de la frontière allemande (Palatinat) où eut lieu, le 6 août 1870 , l'héroïque mais vaine charge des cuirassiers français commandés par le général Michel contre les Prussiens, qui les exterminèrent. Une comptine enfantine chantée a été tirée de ce fait d'armes: "C'était un soir à la bataille de Reichshoffen (prononcé souvent "Réchauffée") // Il fallait voir les cavaliers charger..."
} 
"Urgent, mon général!" qui fait signe, après avoir lu, de partir avec lui aux 3 dragons... Kakoi était décontenancé et balbutia: "Mon général, excusez-moi de ce que je vous ai dit, je ne savai* pas, je croyais parler à des camarades" ....Le général lui mit la main sur l'épaule et lui dit gentiment: " Mon ami, merci pour ton bon café, moi aussi j'étais fatigué, ça m'a fait du bien... Bon courage, mes enfants, et bonne chance"...... Kakoi ne répondit rien, s'assied par terre... Quand ils furent remontés, au bout d'un petit moment, dit simplement: "Ah! ....merde alors !!!" Après un moment de silence, il se mit à gueuler: "Beyron, as-tu encore de la "gnole" dans ton bidon?"...Le peu qui restait fut partagé et le bidon vidé fut quand même gardé pour y mettre un rabiot de flotte quand on en trouverait."

Cette scène à rebondissements (le vieux dragon inconnu se révélant être le général du $17^{\mathrm{e}}$ régiment de Dragons - basé à Auxonne et Dijon - , et ce dernier ne s'offusquant pas des propos démobilisateurs de l'ami Kakoi, et mieux le remerciant pour son café) paraîtrait peu crédible, voire invraisemblable, si on la trouvait dans un roman de guerre. J'ai pourtant eu plusieurs témoignages de Poilus corroborant ce genre de visites incognito de hauts gradés (le colonel du régiment, ou le général de brigade ou de division) pour prendre le moral des troupes de base, au lieu de recevoir les informations filtrées d'officiers de carrière subordonnés, attachés à lui plaire pour se concilier ses bonnes grâces et soigner leur avancement.

Mais laissons Amand Beyron poursuivre son récit qui est d'un grand intérêt documentaire et humain:

Lundi 27 septembre - Nous partons de bonne heure pour le "Trou Bricot", en fouillant les cagnas boches vides de leurs occupants "résédas" et ramassons des souvenirs: casques à pointe, écusson, pain K.K. ${ }^{56}-1$ pot de 3 kgs* de confiture, tout ce qu'on a pu trouver à emporter dans nos musettes et celles des boches, récupérées en supplément.... Avant d'arriver au "Trou Bricot" nous avons fait une courte halte pour manger un peu. On en avait bien besoin avec toutes ces émotions de la nuit... Nous retrouvons notre bon "major Mayaux" installé dans un luxueux poste de secours allemand, avec des salles souterraines bien équipées, infirmerie, salles de repos avec des lits à étages, éclairage électrique, etc., de quoi faire rêver... Nous étions "pantois" en pensant à nos propres postes de secours pitoyables! Nous ne comprenons pas que les boches, si bien retranchés dans leurs fortifications, leurs abris, leurs tranchées bien aménagées, n'aient pas pu résister plus longtemps... Il est à croire que nos soldats avaient le diable au corps des volontaires de "Valmy" en les chargeant, "baïonnettes en avant"....... Nous passons la journée et une partie de la nuit suivante à transporter les grands blessés à l'ambulance divisionnaire, autant français qu'allemands. Dans la journée notre artillerie tire sans arrêt. Les régiments de la $20^{e}$ division $\left(99^{e}-22^{e}-\right.$ $\left.30^{e}-416^{e}\right)^{57}$ sont fortement engagés pour essayer d'enfoncer les boches de leur grande ligne de résistance, avec une épaisse défense de fils de fer barbelés intacts, à 6 kilomètres derrière leur ancienne $1^{\text {ère }}$ ligne... C'est en vain...

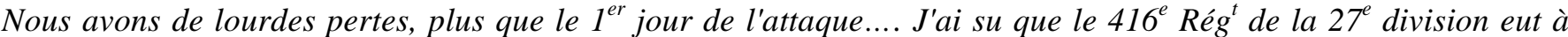
souffrir d'un bombardement trop court de notre artillerie $e^{58}$, s'étant trop avancé, et eu* de grosses pertes en se repliant.....A côté du luxueux palace poste de secours boche, nous nous installons dans une cagna à côté, mais où nous sommes entassés comme des sardines en boîte... Etant las, nous avons peu mangé dans la journée, ne pensant qu'à nous coucher pour dormir un peu. Pour ma part je souffre de violentes coliques qui m'ont empêché de me reposer dans la nuit."

La surprise d'Amand et de ses camarades devant le confortable et même luxueux aménagement des abris et postes de secours allemands sera celle de tous les Poilus, nombreux, qui vivront cette situation, comme on le verra dans un chapitre ultérieur.

On voit que l'euphorie du premier jour d'une victoire facile ne s'est pas prolongée. Amand vit précisément la retombée des illusions qu'aura l'armée française: la victoire obtenue va s'avérer, au fil des jours, une semi-défaite...

Le lendemain, la mort d'un officier au destin original, qu'Amand connaissait dans le civil, occupe une place de choix dans la séquence écrite pendant la journée:

"Mardi 28 septembre - Au petit matin, je vois, amené par un brancard, tué, le capitaine Berger, par les brancardiers de la compagnie. Je le connaissais bien; quand je le rencontrai, nous causions amicalement de Lyon, de nos bonnes relations, de nos amis communs. ${ }^{59}$. Il était né aux Brotteaux, d'une excellente famille bourgeoise lyonnaise, et établi à Toronto, au Canada, où son beau-père avait monté un commerce très important de soieries et de fourrures. Plusieurs fois par an, il venait à Lyon faire des achats de tissus de soie pour doubler les fourrures

\footnotetext{
${ }^{56}$ Le pain K.K. , pour lequel on trouve deux étymologies allemandes différentes (soit "Kleie und Kartoffeln" = son et pommes de terre, soit "KriegesKartofelbrot" = pain de guerre aux pommes de terre) est un pain de rationnement adopté en Allemagne pendant la Grande Guerre, et comportant très peu ou pas du tout de farine. Il a fait en français l'objet de nombreuses plaisanteries scatologiques germanophobes en raison de l'homophonie avec le "caca"...

${ }^{57}$ Ces régiments combattant ensemble sont respectivement de Vienne (99 ${ }^{\mathrm{e}}$ R.I.), de Bourgoin (22 ${ }^{\mathrm{e}}$ R.I.), d'Annecy (30 ${ }^{\mathrm{e}}$ R.I.) et de Narbonne ( $416^{\mathrm{e}}$ R.I.).

${ }^{58}$ Ce genre de "bavure", que les Anglo-Saxons appellent "friendly fire" (feu amical!), a été courant à la guerre de 14-18, comme s'en sont plaints nombre de mes témoins. On abordera ce point plus tard.

${ }^{59}$ Bien qu'originaire de Chazelles-sur-Lyon, dans la Loire, Amand connaît bien Lyon pour y avoir effectué la fin de ses études: après une scolarité dans l'enseignement privé en Forez (chez les Frères Maristes de Chazelles-sur-Lyon puis au lycée de Valbenoite à Saint-Etienne), il a fait, après le baccalauréat, trois ans de spécialisation professionnelle à l'Ecole Supérieure de Tissage de Lyon. Il y a commencé sa carrière ensuite, comme il l'explique.
} 
(chez les Petits-fils de C.J. Bonnet, rue du Griffon) où j'étais au rayon doublures. Il m'avait proposé une belle situation chez lui, à Toronto, à la fin de mon service militaire!!! Hélas, la vie est cruelle..." Cruelle pour le capitaine Berger, ou cruelle pour la carrière d'Amand Beyron? On ne lui fera pas l'affront de choisir cette seconde version...

Puis Amand reprend le récit de la journée qui est la routine d'un brancardier au lendemain d'une grande bataille: "Dans la matinée nous allons plus en avant aux postes de secours des bataillons et recherchons les grands blessés encore éparpillés sur le champ de bataille et restés sans soins, dans un état lamentable... Nous rencontrons à travers les trous d'obus une cuisine roulante ${ }^{60}$ et ses courageux cuistots qui ont eu le mérite de venir dans ce coin de "l'enfer"."

L'attaque reprend le 28 septembre mais le $99^{\mathrm{e}}$ R.I. est mis tout entier (avec ses trois bataillons) en réserve; cependant les brancardiers ne vont pas manquer de travail. Ainsi, quatre jours plus tard, Amand écrit:

"Samedi 2 octobre - Toute la nuit duel d'artillerie... Dans la journée, les boches bombardent les camps et l'arrière... Une rafale d'obus tombe sur une batterie pas loin de l'endroit où nous sommes, au moment d'un ravitaillement d'obus, et font éclater plusieurs caissons ${ }^{61}$, tuant 5 à 6 chevaux, 5 artilleurs et des blessés... Nous nous portons à leur secours et les évacuons sur leur poste de secours... Dans l'infanterie on dit; "Oh! les artilleurs sont plus à l'abri"'62, mais en rase campagne, ce n'est pas toujour* vrai, on ne peut pas faire passer les bourrins (les chevaux) dans les boyaux avec leurs caissons... N'ayant pas beaucoup de blessés à transporter, on relève les morts que l'on achemine au poste de secours de l'armée à l'arrière où les brancardiers du C.A. (Corps d'Armée) les enterrent dans de grandes fosses."

Le lendemain, Amand, toujours avide d'informations, pourra faire le bilan pour son régiment, le $99^{\mathrm{e}}$ R.I. de Vienne, et pour la division entière, de l'offensive du 25 septembre:

Dimanche 3 octobre - Enfin, dans la matinée, nous touchons un peu de ravitaillement en vivres et de la paille que nous arrangeons au mieux dans notre abri précaire ${ }^{63}$..... Arrivent du dépôt de Vienne 2 convoyeurs apportant au P.C. du colonel des paquets et colis et nous disent bonjour en passant. Par eux nous apprenons les résultats de notre offensive du 25/9: nombreux prisonniers, on dit plus de 25 000, de nombreux canons, du matériel, mais nous ignorons les pertes en hommes... Je sais seulement: ont été tués au $99^{e}$ les capitaines Dreyfuss, Berger, Raymond, Fontan, les lieutenants Marmoz et Bard, les s/lieutenants Millet, Carrère, Mestral, Mas, Fauchier, Drevon et Payan. J'ai eu des nouvelles de mon frère. Le $416^{e}$ est à la maison forestière au repos."

Il est regrettable qu'on ne connaisse pas le nom et le nombre des gradés tués (en dessous de sous-lieutenant) et les pertes du côté des soldats de base. Mais Amand a soin de noter: "Le beau fait d'armes du 99e lui vaut une citation à l'ordre de l'armée et son drapeau reçoit la Croix de guerre avec palme". Il est mis au repos ensuite, en Haute-Saône pendant un mois et demi, où il va se reformer pour combler, avec des nominations d'officiers et des renforts de troupe, les grands vides laissés par sa participation à la grande offensive de Champagne.

\section{L'offensive de Champagne à travers le point de vue d'un artilleur éloigné de la Champagne: Camille Richier}

Camille Richier (cl. 10) de Saint-Julien-Chapteuil (Haute-Loire), fils d'agriculteurs, qui exploitera toute sa vie la ferme de son oncle et parrain au hameau de La Chapuze jusqu'à sa mort d'un cancer en 1954, a été affecté au $19^{\mathrm{e}}$ R. d'Artillerie de Montagne de Grenoble, qui fait corps avec le $20^{\mathrm{ème}}$ Bataillon de Chasseurs. Fin août 1915, son régiment est transféré dans les Vosges, à Germaingoutte, vers Saint-Dié, sur les contreforts du col du Violu et y reste jusqu'à fin septembre; Camille vient d'être nommé téléphoniste de la batterie après avoir été servant d'un canon et conducteur de mulet dans les déplacements de la batterie. Son récit est écrit juste en 1919, d'après les notes qu'il a prises sur des carnets et les lettres, numérotées, qu'il a envoyées à ses parents. Il n'est donc pas participant à la bataille de Champagne, mais synthétise ce qu'il en a appris de son poste de téléphoniste, et sans doute de témoignages de camarades et de lectures ultérieures. Il montre tout l'espoir qu'a suscité cette offensive avec son succès initial, et la désillusion qui a suivi:

\footnotetext{
60 La cuisine roulante, ou plus communément "la roulante", fait partie des innovations de l'année 1915; elle centralise la cuisine que chaque escouade faisait auparavant séparément, mais suppose, comme on le verra, des déplacements souvent longs et périlleux de la part des hommes de corvée pour aller chercher, la nuit, les vivres de la journée pour l'escouade entière.

61 Un caisson d'artillerie est une sorte de tombereau très solide, tiré par des chevaux, qui sert à transporter des obus du dépôt le plus proche (en général éloigné de plusieurs kilomètres: parfois plus de dix) aux batteries en position qui utilisent ces obus. En prévision d'une attaque, on constitue, à proximité des batteries, un stock d'obus, qui peut exploser si un obus ennemi y tombe dessus.

${ }^{62}$ C'est effectivement, comme j'ai pu le constater, un refrain de fantassins, enviant le sort privilégié, par rapport à eux, des artilleurs. Et de fait, c'est objectivement vrai: les pertes sont bien moindres dans l'artillerie que dans l'infanterie. Ceci se sachant, beaucoup, à partir de 1916 surtout, devanceront l'appel pour pouvoir avoir le privilège de choisir leur arme, presque toujours l'artillerie...

${ }^{63}$ Cette paille sert évidemment ici à constituer une sorte de matelas de fortune, le sort habituel du soldat étant de coucher sur la terre...
} 
"Je devais passer quatre jours en bas; le second l'adjudant m'envoie au central où il fallait un téléphoniste de la batterie; j'acceptais d'y rester en permanence, bien qu'il me fit* beaucoup de peine de quitter les camarades de la pièce (du canon) et principalement Bonnaud et Vidal. Mais j'étais si bien là que j'acceptai. C'est à ce moment que s'était déclanchée* l'offensive de Champagne; c'était vers la mi-septembre; deux fois par jour nous recevions des communiqués enflammés: nos troupes ont brisé le front, la cavalerie charge, nos avant-gardes sont aux portes de Laon ${ }^{64}$. On se reprend à espérer, on lit avec anxiété ces communiqués, on se communique les tuyaux: qu'attendon pour attaquer partout à la fois? Le sang français se réveille. Ah! On voudrait bien en finir avant l'hiver! Au bout de trois au quatre jours, le communiqué ne vient plus, on ne sait rien de se* qui se passe, on est tous dans l'angoisse; puis on sait, c'est l'échec! Nous avons emporté brillamment les premières lignes: il n'y avait plus de boches, le front est bien ouvert, les troupes qui ont donné l'assaut se précipitent dans la brèche, mais les renforts attendus, indispensables, ne viennent pas, on ne ravitaille même pas les troupes qui ont avancé, les boches reviennent, nous refoulent en nous infligeant de rudes pertes. De partout on crie; "Nous sommes trahis, nous sommes vendus!" Est-ce qu'un jour l'histoire ne mettra pas un peu de lumière sur ces fait* ténébreux qu'on nous a si obstinément cachés pendant toute la guerre?!!"

La rumeur de trahison ressurgit chaque fois qu'un succès escompté, amorcé, se transforme en semi-défaite ou en défaite. Les soldats de base sont prompts à voir dans certains de leurs grands chefs, et dans les politiques de haut rang, des traîtres cachant leur jeu, des valets de l'industriel français de l'armement Schneider (et de ses épigones) ${ }^{2}$ qu'on considère comme allié objectif, voire subjectif, du géant allemand Krupp pour faire durer la guerre et s'enrichir.

\section{La vision de deux historiens français contemporains et d'un général, aussi contemporain...}

On pourrait multiplier les points de vue d'historiens sur cette seconde offensive de Champagne de fin septembre 1915, la première, de bien moins grande ampleur, ayant eu lieu à la fin de l'hiver (seconde quinzaine de février et première de mars). Nous retiendrons ceux de Jean-Baptiste Duroselle, professeur notamment à la Sorbonne, membre de l'Institut, qui est mort le 12 septembre 1994, juste avant la publication de son ouvrage $\mathrm{La}$ Grande Guerre des Français 1914-1918, et le classique de Pierre Miquel, professeur à la Sorbonne, historien très prolifique sur 14-18, avec La Grande Guerre publié en 1983. Ces deux livres sont de forts volumes, respectivement de 515 et 663 pages, très denses.

Le tableau que donne J.B. Duroselle, à la page 102 de son étude, donne une idée très claire de l'importance de l'offensive de Champagne par rapport aux trois autres grandes offensives de 1915: la première en Champagne, et les deux offensives d'Artois, dont la seconde est simultanée de la grande attaque de Champagne. Nous reproduisons tel quel ce tableau comparatif, qui aurait été conçu initialement par le général Gambiez et le colonel Suire en 1967 65

Offensives de 1915

\begin{tabular}{|c|c|c|c|c|c|}
\hline Lieu et date & $\begin{array}{c}\text { Moyens } \\
\text { C.A. }=\text { corps d'armée }\end{array}$ & $\begin{array}{c}\text { Préparation } \\
\text { d'artillerie (durée) }\end{array}$ & $\begin{array}{l}\text { Durée de } \\
\text { l'offensive }\end{array}$ & $\begin{array}{l}\text { Largeur du } \\
\text { front initial }\end{array}$ & Résultats \\
\hline$\frac{\text { Champagne I }}{15 \text { fév. -18 mars }}$ & $\begin{array}{c}3 \text { CA dont } 1 \text { en } \\
\text { réserve } \\
100 \text { pièces lourdes }\end{array}$ & $\begin{array}{l}\text { Quelques } \\
\text { heures }\end{array}$ & 31 jours & $8 \mathrm{~km}$ & $\begin{array}{c}2000 \text { prisonniers } \\
\text { progression: } 2 \text { à } 3 \mathrm{~km}\end{array}$ \\
\hline $\begin{array}{c}\text { Artois I } \\
9 \text { mai-18 juin } \\
\text { avec les Anglais }\end{array}$ & $\begin{array}{c}6 \mathrm{CA} \\
\text { et } 400 \text { pièces } \\
\text { lourdes }\end{array}$ & 4 heures & 40 jours & $15 \mathrm{~km}$ & $\begin{array}{l}7500 \text { prisonniers } \\
\text { progression: } 4 \mathrm{~km}\end{array}$ \\
\hline$\frac{\text { Champagne II }}{25 \text { sept. }-6 \text { oct. }}$ & $\begin{array}{c}10 \mathrm{CA} \\
1100 \text { pièces lourdes } \\
1450 \text { de campagne } \\
4 \text { CA et } 400 \text { pièces } \\
\text { lourdes pour } \\
\text { opérations } \\
\text { secondaires }\end{array}$ & 4 jours & 12 jours & $35 \mathrm{~km}$ & $\begin{array}{l}25000 \text { prisonniers } \\
\text { progression: } 4 \mathrm{~km}\end{array}$ \\
\hline $\begin{array}{l}\text { Artois II } \\
25 \text { sept. }-11 \text { oct. } \\
\text { avec les Anglais }\end{array}$ & $\begin{array}{c}\text { 6 CA français } \\
4 \text { CA anglais } \\
660 \text { pièces lourdes } \\
1300 \text { de campagne }\end{array}$ & 4 à 6 jours & 17 jours & $40 \mathrm{~km}$ & $\begin{array}{l}\text { Progression: } 2 \text { à } 3 \mathrm{~km} \\
\text { (nombre de prisonniers: pas } \\
\text { indiqué) }\end{array}$ \\
\hline
\end{tabular}

\footnotetext{
${ }^{64}$ Laon renvoie à l'offensive d'Artois qui se déroule simultanément avec celle de Champagne.

${ }^{65}$ Général Fernand Gambiez, L'Epée de Damoclès, Paris 1967
} 
Ainsi tant par l'ampleur des moyens mis en œuvre, en hommes : 14 corps d'armée $(10+4)$, et en matériel: $1500(1100+400)$ canons lourds, du 105 au 420, 1450 canons de campagne (essentiellement le 75), que par les résultats obtenus en nombre de prisonniers: 25 000, soit plus de 12 fois plus que la première attaque du printemps en Champagne (ce qui confirme, par ailleurs, le chiffre obtenu par Amand Beyron le dimanche 3 octobre) parmi lesquels des officiers supérieurs, sans compter un nombre impressionnant de canons et de mitrailleuses récupérés, cette offensive est bien la plus importante et la plus efficace de 1915. En revanche la progression en terrain reconquis $(4 \mathrm{~km}$, soit l'équivalent de la première offensive d'Artois, qui avait mobilisé plus de deux fois moins d'hommes et d'armement) est très décevante, et loin des espérances que nourrissait l'Etat-Major et qu'expriment à la fois l'instituteur - plus tard professeur - Joseph Sorgues et le poète Guillaume Apollinaire. Le front allemand n'a pas été brisé, ni en Champagne, ni en Artois, et à l'immense espérance d'en finir une bonne fois pour toutes a succédé la déception.

J.B. Duroselle conclut, en annonçant son tableau: "Les grandes offensives préparées par Joffre en 1915 n'ont pas percé, comme il l'annonçait, les lignes ennemies. Elles ont donc échoué." ${ }^{66}$. Le grignotage de Joffre (on se souvient de sa fameuse phrase, devenue quasi proverbiale: "Je les grignote", phrase qui a servi de refrain à une chanson à succès de cette guerre) n'a avalé qu'une infime partie du gâteau-territoire occupé par les Allemands...

Il explique ensuite cet échec, relatif tout de même, par une insuffisance de l'artillerie française, insuffisance qui était encore plus criante en août 1914, et par des défaillances surprenantes des obus: "Joffre, d'accord avec Foch, estime qu'il s'agit là d'une "guerre de siège". Il faut donc briser la fortification ennemie par de puissants tirs d'artillerie et posséder et multiplier les engins à tirs courbes, mortiers, canons de tranchées. Cela exige beaucoup d'obus. En janvier 1915, on estime qu'il faut disposer de 80000 coups par jour pour les 75, en septembre 1915, l'évaluation atteint 150 000. Or la production ne suit pas encore la courbe des besoins. Elle est improvisée. Au printemps 1915, 236 obus éclatèrent prématurément, détruisant les canons. Les offensives de 1915 seront engagées avec des moyens insuffisants."

Si des obus éclatent, détruisant le canon et tuant les servants qui sont tout autour, souvent il leur arrive de ne pas éclater en arrivant sur les tranchées ennemies. Mais les Français, qui par définition, ne se trouvent pas à l'endroit où leurs obus éclatent, ou n'éclatent pas (sauf quand ils sont victimes d'un tir trop court de leur artillerie, ce qui paraît assez fréquent d'après les témoignages recueillis) peuvent constater que nombre d'obus allemands n'éclatent pas non plus, pour leur plus grand bonheur! On verra des témoignages spectaculaires sur ce thème. A ce moment, en 1915, on parle encore de malfaçons accidentelles dans les arsenaux; plus tard, en 1917, surtout après les deux révolutions russes (celle de février et celle d'octobre), et la lassitude engendrée par trois ans de guerre prévalant, on parlera de sabotage, et cela ne sera pas que de la paranoïa de généraux cherchant des boucs émissaires; il s'est trouvé plus d'un ouvrier d'arsenal pour s'en vanter...

Une autre explication de ces échecs est l'indéniable supériorité allemande en matière de logistique, de stratégie, et de technique de construction de tranchées. Ainsi J.B. Duroselle explique: "Les Allemands, meilleurs constructeurs de tranchées qu'ils soutenaient par du béton, alors que les Français se contentaient de rondins, avaient de plus en plus tendance à organiser leur défense en profondeur: première position de 2 à 3 lignes de tranchées espacées de 200 à 300 mètres, deuxième position de 3 à 5 kilomètres en arrière, si possible à contrepente. C'est de là que partaient les réserves fraîches pour la contre-offensive. ${ }^{167}$

Le général Patrick Sans, bâtissant une réflexion générale et stratégique autour du commentaire éclairé du carnet de guerre de son grand-père par alliance, Edouard Duchamp (1893 -1931), huissier de justice, incorporé au $98^{\mathrm{e}}$ R.I. de Roanne où il sera sergent fourrier, blessé en septembre 14, gazé en août 18 (document ${ }^{68}$ qui m'avait été transmis auparavant par le propre fils d'Edouard, Henri, beau-père du général Sans, par ailleurs un ami) constate et déplore la minceur des acquis par rapport aux pertes dans son ouvrage-hommage intitulé "Le 98 ème Régiment d'Infanterie dans la Grande Guerre" ${ }^{69}$ : "Au début de l'automne, Joffre lançait une nouvelle offensive, à la fois en Artois et en Champagne. Il rassembla 18 divisions, appuyées par 700 canons lourds sur $30 \mathrm{~km}$ de front, alors que les Britanniques engageaient 5 divisions soutenues par 420 pièces lourdes. Partout, la première ligne de tranchées allemande fut enlevée, mais les Alliés échouaient devant la seconde, avec des pertes effroyables contre 85000 seulement du côté allemand. Ces offensives réussirent certes à bousculer quelque peu les dispositifs de Falkenhayn, mais les combats de Souain, de Tahure, des Eparges ou encore de Vimy n'aboutirent qu'à de minces succès tactiques et se soldèrent surtout par des pertes effroyables. "Je les grignote" disait Joffre; pourtant les pertes de l'armée française en 1915 seront les plus lourdes de la guerre: 375000 tués ou disparus (31 000 par mois en moyenne), 960000 blessés graves. La seule bataille de Champagne du 25 septembre 1915 et des jours suivants

\footnotetext{
${ }^{66}$ Jean-Baptiste Duroselle, op. cit., p. 101

${ }^{67}$ Jean-Baptiste Duroselle, op. cit. p. 103

${ }^{68}$ Document cité déjà deux fois dans le chap. III, "Le premier mois de combat: de l'illusion à la retraite", notamment à propos de" l'horrible carnage" de Doncières, au nord de Rambervillers, dans les Vosges, perpétré au début de septembre 1914.

${ }^{69}$ Ouvrage que je possède en version "tapuscrite" fort bien illustrée, grâce à Henri Duchamp, fils d'Edouard, administrateur de biens à Saint-Etienne, vivant à Saint-Galmier, par ailleurs président de la LIGER (organisme fédérant 70 sociétés dites "savantes" de la Loire) pendant de longues années.
} 
coûta 135000 tués et 290000 blessés et montra finalement que la percée est impossible avec les moyens notoirement insuffisants du moment, et que, dans cette guerre, la défensive était supérieure à l'offensive. "70

Pierre Miquel, dans le chapitre 8 "La guerre terroriste" de son ouvrage La Grande Guerre, fait alterner jugements positifs et négatifs (dont des éléments impondérables, comme un temps défavorable) sur la préparation et le déroulement de cette offensive de Champagne, donnant au passage quelques raisons, non vues encore, de son échec relatif. Ayant énuméré les moyens considérables mis en œuvre: 39 divisions contre 17 allemandes, 1100 pièces lourdes, 1400 canons de campagne, il en déduit: "Jamais l'armée française ne devait par la suite se trouver en condition plus favorable, avec une telle supériorité d'effectifs". Mais il constate ensuite: "Mais les hommes étaient trop nombreux, sur les 40 kilomètres de front. La préparation d'artillerie avait été efficace, les lignes allemandes semblaient broyées sous les obus des 155 longs et des 355 montés sur voie ferrée de la $4^{e}$ armée. Les pièces lourdes avaient assez d'obus pour tirer sans arrêt pendant cinq jours. Mais à l'aube du 25 septembre 1915, la pluie tombait régulièrement sur les unités d'assaut qui s'étaient élancées au signal du clairon. Le redoutable massif de la Main de Massiges avait été investi par les troupes de Pétain au prix de pertes très lourdes. le "bois allongé", le "ravin des cuisiniers", le système défensif de la "brosse à dents", le "trou Bricot" et le village de Tahure étaient remplis de cadavres français et allemands au bout de quelques heures d'engagement. Des deux côtés, la rage de vaincre était incroyable. A la tête du $2^{e}$ colonial, le célèbre commandant Marchand, devenu général, emportait la ferme de Navarin avant de tomber, blessé au ventre par une rafale de mitrailleuse.

Après la prise de la deuxième ligne, l'afflux de troupes de renfort, violemment bombardées par l'artillerie, s'effectuait dans le plus grand désordre: on avait même demandé à des cavaliers de charger; le $11^{e}$ chasseurs et le $5^{e}$ hussards devaient attaquer au galop les secondes positions et se faire inutilement massacrer. On commençait à douter du succès de l'offensive quand, soudain, le bruit courut dans les rangs que la "tranchée des Tantes", sur la $2^{e}$ position allemande, venait d'être prise. L'enthousiasme était tel autour de Castelnau ${ }^{71} q u e$ personne ne songea à vérifier: 40000 hommes furent aussitôt envoyés en renfort sur ce point précis, attaquant dans le désordre sous le feu des canons qui devaient tuer $40 \%$ des assaillants. L'arrivée de renforts venus de Russie avait permis aux Allemands d'encercler les troupes aventurées dans la brèche trop étroite: de nouveau c'était l'échec. Le 6 octobre, le général Curières de Castelnau, qui venait de perdre à l'ennemi son troisième fils, donnait le signal de la fin des combats. les deux "offensives" de l'Artois et de Champagne avaient coûté 250000 hommes (tués, blessés, disparus), les Allemands n'en avaient perdu que 140 000, dont 24000 prisonniers."

Concernant les chiffres des pertes, toujours un peu variables d'un auteur à l'autre, on peut admettre aussi ceux relevés (où?) par un modeste menuisier, mais qui a la noblesse d'un Poilu de la Grande Guerre. Dans un bloc-notes consignant des notes éparses, ayant servi de premier jet au brouillon pour la rédaction d'un discours prononcé lors des cérémonies d'un 11 novembre, Benoît Desseigné (né en 1896, mort en 1981), ayant fait la guerre au $5^{\mathrm{e}}$ R.I. Coloniale de Lyon, régiment d'attaque, artisan menuisier à Villers, près de Roanne, inscrit le bilan de l'offensive de Champagne de septembre 1915: "La seule offensive de Champagne en sept 1915 nous coûte 135 o00 tués et 290000 blessés."

Ainsi cette seconde offensive de Champagne, la plus grande opération militaire concertée en 1915, entreprise avec des moyens humains et matériels considérables, commencée dans l'enthousiasme et l'espoir de donner l'assaut décisif, espoir confirmé par les deux premiers jours de combat, s'acheva dans la désillusion, mais ni les Poilus ni l'arrière ne furent pas informés par la presse de l'ampleur de nos pertes, et la certitude de "la victoire de Champagne" perdura longtemps...

\section{$* * *$}

\footnotetext{
${ }^{70}$ Général Patrick Sans, op.cit, p.109 dans ma version « tapuscrite »

${ }^{71}$ Edouard de Curières de Castelnau est le général commandant la II $^{\mathrm{e}}$ armée; il perdit trois de ses fils durant la Grande Guerre.
} 


\section{Chapitre 14}

\section{Trois grands évènements internationaux de 1915, \\ liés à la guerre, ayant trouvé un écho chez les Poilus :}

Torpillage du paquebot Lusitania le 7 mai 1915, entrée en guerre de l'Italie le 13 mai 1915, exécution de Miss Edith Cavell à Bruxelles le 12 octobre 1915 


\section{Chap. 14 - Trois grands événements internationaux de 1915, liés à la guerre, ayant trouvé un écho chez les Poilus}

"Un nouvel attentat qui excite l'indignation générale a été commis sur mer par les Boches. Un de leurs sousmarins a coulé le grand paquebot anglais Lusitania qui faisait le service de New York et transportait 1978 passagers, presque tous américains. Le navire coula en 20 minutes." - Journal de Joseph Sorgues (classe 1915) à la date du 9 mai 1915, Romanèche-Thorins (Saône-et-Loire)

\section{E- "Ah bon! Racontez-moi ça! Qui est-ce qui vous a fait crier "Viva l'Italia!"?}

T- Eh ben, c'était un règlement quoi! Il fallait crier ça, parce qu'elle se mettait avec nous! Alors de la Suisse en Belgique, il fallait crier au même moment: "Viva l'Italia!". C'est là qu'on a eu vingt tués à la compagnie!"

- Antoine Guillot, classe 1914, Perreux.

"Pendant ce temps, un officier allemand assassinait froidement, après un honteux jugement, une jeune infirmière anglaise de Bruxelles, miss Edith Cavell dont le seul crime avait été de procurer la liberté à des soldats anglais et belges. Ce crime odieux, cet assassinat d'une pauvre jeune fille évanouie, dont le cour battait encore, souleva dans l'univers entier une profonde horreur et une indignation plus violente que pour le torpillage du "Lusitania". - Journal de Joseph Sorgues à la date du 28 novembre 1915.

\section{Le torpillage du paquebot anglais Lusitania le 7 mai 1915}

Le torpillage d'un navire qui sombre en quelques minutes ou dizaines de minutes, emportant au fond des mers tout son équipage et ses passagers est chose malheureusement assez banale en temps de guerre. On l'a vu lors de l'expédition de Dardanelles avec le torpillage du "Bouvet" français, de l'Ocean et de l' Irresistible anglais, envoyés par le fond par une torpille ou des mines flottantes, et faisant périr l'essentiel de l'équipage et des passagers. Mais c'étaient des navires de guerre, des cuirassés, qui subissaient le sort tragique, mais normal, des bateaux vaincus. C'est tout autre chose quand c'est un navire civil qui est coulé, avec des passagers civils, étrangers à la guerre. Le retentissement est alors considérable, et bien peu de navires, à part le Titanic en 1912, eurent une "couverture médiatique" et un écho compassionnel dans l'opinion publique semblable à ceux de l'infortuné Lusitania.

Le numéro de L'Illustration du 15 mai 1915 y consacre une large place. Sa première page informative, après les trois pages de "réclames" est un très grand dessin légendé "La guerre navale allemande" montrant un enfant noyé flottant sur l'eau, ce qui est expliqué par le commentaire: "Plus de quarante enfants ont péri dans le torpillage du Lusitania...L'un d'eux, un petit bonhomme de trois ans, reposait dans les bras de sa mère: quand on les recueillit, flottant sur l'eau, la mort même n'avait pas pu faire se desserre l'étreinte", explication suivie d'imprécations vengeresses: "Ce crime viole le droit des gens et les conventions de tous les civilisés. Nous portons donc contre les officiers du sous-marin allemand, contre l'empereur et le gouvernement de l'Allemagne, qui leur en ont donné l'ordre, l'accusation d'assassinat en bloc.". Trois pages plus loin, quatre dessins répartis sur une double page illustrent techniquement, d'après le récit d'un des rares survivants, ce que déclare la légende qui les rassemble: "L'assassinat de douze cents passagers en pleine mer: le torpillage du "Lusitania". A la fin du numéro, après cette mise en condition psychologique des lecteurs par les dessins et les formules choc, arrive enfin l'article explicatif de fond, écrit par Raymond Lestonnat, sous le titre "Le paquebot Lusitania torpillé", dont voici des extraits:

"Le vendredi 7 mai, à 2 heures de l'après-midi, un sous-marin allemand, qu'il a été impossible d'identifier, a torpillé et coulé, sans avertissement, le paquebot-poste anglais Lusitania, de la Cunard Line, à huit milles dans le sud-ouest de Kinsale, sur la côte sud d'Irlande. Ce paquebot, venant de New York, faisait route pour Liverpool, avec environ dix-neuf cents passagers et hommes d'équipage, sur lesquels sept cent soixante seulement ont pu être sauvés.

D'après la déposition faite par le capitaine Turner, commandant du paquebot, au coroner de Queenstown, il est établi que deux torpilles ont atteint le navire qui a sombré en vingt minutes. Certaines personnes assurent avoir vu le périscope du sous-marin apparaître au moment où le navire s'enfonçait".

Le journaliste explique ensuite que la forte inclinaison immédiate du bateau sur tribord a empêché la mise a l'eau des embarcations de sauvetage de ce côté et rendu très difficile la même opération pour l'autre côté, puis donne quelques indications techniques sur le paquebot qui avait effectué son premier voyage transatlantique le 7 septembre 1907: 245 mètres de long, 45000 tonnes de déplacement d'eau en pleine charge, propulsion assurée par quatre turbines dont la puissance totale avoisinait 70000 chevaux et consommant 1350 tonnes de charbon pour 24 heures soit "presque une tonne par minute", une vitesse moyenne de croisière de 25 nœuds, une capacité de 3250 personnes équipage compris. Il analyse ensuite, avec un recul d'une semaine, l'impact du drame sur l'opinion publique mondiale: 
"Ce crime abominable, perpétré avec une froide cruauté contre d'inoffensifs voyageurs et l'équipage civil d'un navire marchand sans défense, a causé dans le monde entier une explosion de colère. Il atteint aussi bien les sujets des nations belligérantes que ceux des neutres. Ainsi, sur 188 passagers américains qui s'étaient embarqués à bord, 150 se sont noyés. Parmi ces victimes de la barbarie allemande, se trouvent plusieurs personnages de la haute société américaine, parmi lesquels il faut citer, pour son geste chevaleresque, M. Alfred G. Vanderbilt ${ }^{l}$ qui périt pour avoir offert à une femme sa ceinture de sauvetage." Et R. Lestonnat de conclure:

"Les Allemands manifestent une très grande joie, tout comme s'il s'agissait d'une victoire navale hérö̈quement remportée. Ils déclarent que leur ambassadeur à Washington avait prévenu les passagers du sort qui était réservé au paquebot sur lequel ils s'embarquaient et que, par conséquent, ceux-ci ne devaient pas partir. Cette explication établit la préméditation du crime au lieu de l'atténuer."

On rapporte que le capitaine du sous-marin allemand, de type U 20, le capitaine Schwieger aurait déclaré après le drame: "Kein Bedauern" ( "Pas de regrets"). Le jour même du torpillage, le président américain Woodrow Wilson convoqua l'ambassadeur d'Allemagne à la Maison Blanche, en exigeant des excuses de son gouvernement, un désaveu officiel de l'acte, et des dédommagements pour les familles des victimes américaines (de 124 à 150: les chiffres varient). L'Allemagne de Guillaume II refusa de désavouer la décision du capitaine Schwieger, mais consentit au dédommagement, apparemment des seules victimes américaines.

Ce torpillage du Lusitania, dans les années 80, était bien loin et aucun témoin oral ne l'a évoqué, et je n'ai pas songé à les interroger là-dessus, même ceux, comme Jean-Louis Monier, de Marols, ou Jean-François Ollier, de Saint-Etienne, à la mémoire exceptionnelle, très informés de tout, avec qui l'entretien a duré autour de quatre heures. Mais il se trouve un journal de guerre à y faire référence; c'est celui de Joseph Sorgues, enseignant au collège catholique de Bellegarde, à Neuville-sur-Saône, qui, avec la classe 15, a été incorporé fin décembre 1914. Il écrit dans son troisième carnet, à la date du dimanche 9 mai 1915, surlendemain du drame: "Un nouvel attentat qui excite l'indignation générale a été commis sur mer par les Boches. Un de leurs sous-marins a coulé le grand paquebot anglais Lusitania qui faisait le service de New York et transportait 1978 passagers, presque tous américains. Le navire coula en 20 minutes. Cet abominable crime a été commis sans avertissement préalable et la préméditation est nettement établie par l'annonce publiée par l'ambassade allemande de Wasington* dans la presse américaine. Personne n'y avait ajouté foi, car personne ne croyait les Allemands capables d'un pareil acte de barbarie envers de paisibles passagers.

Le chiffre des morts s'élève à un millier, dont plusieurs notabilités américaines, notamment M. Vanderbilt, le célèbre millionnaire. Et maintenant que vont faire les Etats-Unis? La nation qui fit la guerre à l'Espagne pour l'explosion mystérieuse du Maine en rade de La Havane saura-t-elle donner la réponse nécessaire à cet acte de banditisme en déclarant la guerre à l'Allemagne au cri de "Souvenez-vous du Lusitania!"? C'est ce que pense la colonie américaine de Londres.

Le torpillage du Lusitania forme un tryptique monstrueux avec le bombardement de Reims et le sac de Louvain. Il salira à jamais le nom de l'Allemagne et c'est un acte de piraterie de plus que les Boches auront à expier.

Je ne suis pas allé en permission aujourd'hui et cependant j'en avais grande envie, parce que c'est le jour de la première communion de Lili..." (sa jeune sœur).

Les deux premiers tableaux du "triptyque monstrueux" sont des saccages de monuments historiques et religieux du début de la guerre qui ont révolté l'opinion publique mondiale: l'incendie de la ville belge de Louvain (Leuven en flamand) dans la Belgique pourtant neutre à ce moment, avec la destruction de ses bâtiments universitaires vieux de six siècles le 25 août 1914, et le bombardement suivi d'incendie de la cathédrale de Reims le 19 septembre 1914. La cathédrale, touchée par cinq obus le 18, à nouveau bombardée le 19, s'est enflammée dans sa charpente de chêne, mais aussi à partir de sa nef qui, dans le bref intervalle où ils avaient occupé Reims, avait été transformée en hôpital provisoire par les Allemands, qui, faute de matelas, y avaient apporté environ 15 000 gerbes de paille pour servir de litière à leurs blessés.. Mais c'étaient des blessés français qui l'occupaient le 25 août, puisque Reims avait été repris. En France, le cri d'indignation avait été unanime. En témoignent ces lignes incendiaires, si l'on ose écrire, d'Anatole France, le sceptique rationaliste et agnostique (qui a alors 60 ans) dans La Guerre Sociale du 22 septembre 1914: "Les barbares ont incendié, en invoquant le dieu des chrétiens, un des plus magnifiques monuments de la chrétienté. Ils se sont ainsi couverts d'une infamie immortelle, et le nom "Allemand" est désormais exécrable à tout l'univers pensant. Qui donc, dans le ciel, peut douter maintenant qu'ils sont les barbares et que nous combattons pour l'humanité?". Cinq mois plus tard, comme on va le voir, Joseph Sorgues pouvait rajouter un quatrième volet au triptyque illustrant la "barbarie allemande": l'exécution à Bruxelles de l'infirmière anglaise Edith Cavell.

Quant au rapprochement du torpillage du Lusitania avec à "l'explosion mystérieuse du Maine en rade de la

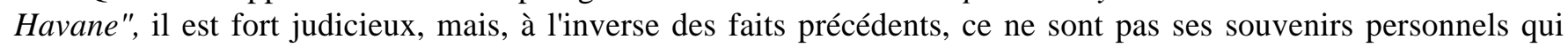
inspirent la comparaison que fait Joseph Sorgues, car l'événement remonte à 1898, alors qu'il n'avait que trois ans!

${ }^{1}$ Alfred Gwynne Vanderbilt était l'héritier, à la quatrième génération, de la colossale fortune de Cornelius Vanderbilt (17941877), magnat autodidacte, qui se bâtit un empire maritime et ferroviaire dans la première moitié du XIXe siècle 
Le cuirassé USS Maine avait été envoyé par les Etats-Unis à la Havane pour y protéger les intérêts financiers américains, alors que Cuba était encore une colonie espagnole. Une explosion dont l'origine ne fut pas identifiée à l'époque, et qui le fut à peu près lors du renflouage du navire en 1911 (il s'agissait vraisemblablement de l'explosion accidentelle d'un moteur dans la salle des machines; mais certains experts n'ont pas exclu une torpille) envoya le navire de guerre par le fond, le 15 février 1898, et fit 266 morts par l'équipage militaire. Une campagne de presse virulente s'engagea contre l'Espagne dans les journaux américains, menée par le magnat de la presse William Randolph Hearst, dont le journal principal, l'influent New York Journal, répétait inlassablement ce leitmotiv rimé: "Remember the Maine! In hell with Spain!" ( "Souvenez-vous du Maine! L'Espagne en enfer!" ou plus vulgairement: "Que l'Espagne aille se faire foutre!"). La phrase de Sorgues, sans doute empruntée à la presse, "Souvenez-vous du Lusitania", est donc une allusion directe à ce slogan de la presse Hearst, aussitôt popularisé aux Etats-Unis. Cette campagne de presse, soutenue par les bellicistes nombreux dans le pays, fut si efficace que le président Mac Kinley, après un vote favorable du Congrès, déclara la guerre à l'Espagne le 25 avril 1898. A l'issue de cette guerre, les Etats-Unis prirent à l'Espagne non seulement Cuba, mais Porto Rico dans le golfe du Mexique, et les îles d'Hawaï et de Guam dans le Pacifique, et occupèrent les Philippines... C'est donc une entrée en guerre immédiate des Etats-Unis contre l'Allemagne, par représailles, qu'attend Joseph Sorgues, et de nombreux Français et Anglais.

Elle se produisit deux ans plus tard. Le drame du Lusitania avait marqué profondément les esprits aux EtatsUnis, restés neutres, et dans les pays opposés ou hostiles à l'Allemagne. Quand celle-ci, en mars 1917, déclara la guerre marine et sous-marine totale, y compris à l'encontre des navires commerciaux, le président Woodrov Wilson, réélu en novembre 1915 sur une position pourtant non-interventionniste dans la guerre d'Europe, ne tarda guère à en tirer la conséquence, et demanda au Congrès le 2 avril de déclarer l'entrée en guerre des Etats-Unis contre l'Allemagne et ses alliés, ce qui fut ratifié le 6.

\section{L'entrée en guerre de l'Italie le 23 mai 1915}

Dans son journal tenu quotidiennement, le 23 mai 1915, l'instituteur libre à Neuville-sur-Saône Joseph Sorgues (cl 15) incorporé depuis fin décembre 1914 s'enthousiasme, allant même jusqu'à écrire en italien, langue qu'il ne pratique pas: "Dimanche 23, Lundi 24 ami - "Eviva l'Italia! Elle a déclaré la guerre à l'Autriche! J'ai appris cela en permission, dans ma famille. Vivre le nouvel allié contre la barbarie germaine! Saluons maintenant la Quadruple Entente opposée à la Double Alliance. ${ }^{\prime 2}$. Il n'indique pas que pour pousser l'Italie à faire ce choix, les Alliés de la Triple Entente lui ont promis, en cas de victoire, les possessions autrichiennes du Trentin, du haut Adige, une partie des côtes est de l'Adriatique et un quart de l'Anatolie turque...

Son collègue de l'école laïque de Chamboeuf Antonin Granet, (cl. 03), sergent au $38^{\mathrm{e}}$ R.I. de Saint-Etienne, n'est pas en reste,; il écrit dans son récit tenu en captivité à partir de mars 1916, recul temporel qui explique une plus grande modération qui n'exclut pas l'optimisme: "Enfin une espérance nouvelle avec un nouvel allié. Après de nombreuses tergiversations, des pressions diplomatiques de part et d'autre, l'Italie s'est mise à nos côtés. Son entrée en lice sera-t-elle décisive? Aux bravos ironiques éclatant un soir dans les tranchées ennemies à l'annonce d'un nouvel adversaire, nos voix ont répondu par des vivats à nos frères latins. un nouveau front à garder par l'Autriche, une activité d'armement chez nos alliés les Anglais, le blocus maritime qui sévit sur les puissances centrales semblent pour nous de bons présages pour l'avenir."

A ces "vivats" aux "frères latins" poussés par les Poilus français, le cordonnier Antoine Guillot (cl . 14) de Perreux, qui était alors au Vieil Armand (Hartmanwillerkopf) dans les Vosges du Haut-Rhin avec le $371^{\mathrm{e}}$ R.I. de Belfort, a ajouté sa voix, dans une immense clameur, planifiée par les Etats-Majors, qui a couru tout le long du front occidental et qui aurait enclenché un bombardement de riposte de la part des Allemands:

T- "Oh! C'était peut-être le 15 mai. Et si on a eu nos tués, c'est parce qu'ils nous ont fait crier: "Viva l'Italia"!. On devait crier!

E- Ah bon! Racontez-moi ça! Qui est-ce qui vous a fait crier "Viva l'Italia!"?

T- Eh ben, c'était un règlement quoi! Il fallait crier ça, parce qu'elle se mettait avec nous! Alors de la Suisse en Belgique, il fallait crier au même moment: "Viva l'Italia!". C'est là qu'on a eu vingt tués à la compagnie!

E- $A$ cause de ce cri?

T- A mon avis! A mon avis! On aurait peut-être pas dû... Je sais pas... C'était le règlement à l'époque: fallait crier!

E- Donc toute l'armée française a crié: "Viva l'Italia!" au même moment?

T- Tous ceux qui étaient au front, oui!

E- Parce que l'Italie venait de se mettre en guerre?

T- De se mettre avec nous! A nos côtés!

\footnotetext{
${ }^{2}$ En prenant position aux côtés des Alliés, l'Italie complète la Triple Entente (France, Grande-Bretagne et Russie) combattant contre la Double Alliance (Empire allemand et Empire austro-hongrois) devenue la Triple Alliance après l'entrée en guerre de la Turquie le 30 octobre 1914.
} 
E- Et chez vous, ça a déclenché le bombardement?

$\mathrm{T}-$ Ah ben oui! Vous pensez, quand ils ont entendu ça, de l'autre côté là-bas, les Allemands! Alors bien sûr, ils ont fait un bombardement terrible! Bien sûr!

E- Au Vieil Armand!

T- Oui, mais nous, on était à 5 mètres, on craignait rien, on avait que les torpilles et les grenades! On a peu combattu en somme, quoi!"

Il n'y a pas là de contradiction; la section d'Antoine est extrêmement proche de la première ligne allemande, et cette proximité incroyable la protège des obus; mais les trois autres sections de la compagnie doivent être plus éloignées et subir, elles, le bombardement ennemi. Quant au nombre de tués, qui est annoncé de 20 ici, Antoine l'a chiffré précédemment à 28: "Ah ben, au Vieil Armand, alors là, on a eu 28 tués dans la compagnie, sans combattre! Sans combattre! On a pas attaqué, on a rien fait; mais alors, on recevait quelque chose!"

Ce vivat général et cette réplique allemande, le poète Guillaume Apollinaire (cl. 10) alors encore dans l'artillerie, brigadier au $30^{\mathrm{e}}$ R.A.de Campagne de Nîmes, en batterie vers Perthes-les-Hurlus, en Champagne, les atteste dans sa lettre du 24 mai 1915, écrite dans la "nuit de la Pentecôte", à sa maîtresse la comtesse Louise de Coligny-Châtillon (de son nom complet Geneviève-Marguerite-Marie-Louise de Pillot de Coligny-Châtillon, née à Vesoul le 30 juillet 1881: 34 ans en 1915, soit un an de moins que le poète) dite "Lou"3 ${ }^{3}$. Cette lettre débute par: "Après quelques jours de calme qu'est-ce qu'on nous envoie aujourd'hui nuit de la Pentecôte. C'est une heure du matin. Hier matin, j'ai été voir nos bombardiers détachés dans les tranchées. ${ }^{\prime \prime}$. Une page après, on peut lire: "Puis on a téléphoné la décision de l'Italie et me suis trotté pour rentrer chez nous. A une heure donnée, tout le front a tiré une salve d'honneur, en l'honneur de la nouvelle alliée, c'était magnifique, la nuit était tombée, les tranchées ont poussé un vivat unanime. Puis maintenant les Boches répondent - Il me tarde de lire les journaux pour savoir ce qui se passe sur le nouveau front italien après la déclaration de guerre. Evidemment, ça va occuper pas mal de soldats boches. Enfin tant mieux, plus il y aura de gens dans la danse, moins, j'espère, la guerre durera et plus tôt nous serons rendus à nos occupations civiles. ${ }^{.5}$.

Dans la longue lettre à Madeleine Pagès, sa "chère petite fée si lointaine" (elle réside et enseigne le français à Oran) écrite le lendemain 25 mai, jour de Pentecôte, lettre brûlante de passion amoureuse, la seule allusion à l'entrée en guerre de l'Italie est contenue dans la phrase suivante, qui fait suite à l'évocation de sa visite rendue aux tranchées à ses "crapouilloteurs", sous les obus: "Voilà donc un récit dont les détails sont plus pathétiques que la réalité qui ne l'est point car l'après-midi a été charmant et nous avons de façon congruente sablé du champagne en l'honneur de l'Italie et encore une fois je ne voudrais nullement que vous preniez ce récit pour les déclarations de quelqu'un qui veut se faire plaindre..."

Comme presque toujours, son expérience guerrière inspirera sa poésie. Ainsi en août 15 , il compose un très long poème en vers libres intitulé "A l'Italie" (cette Italie où il est né, à Rome, le 26 août 1880, fils naturel d'un officier noble italien qui ne l'a pas reconnu, le comte Francesco Flugi d'Aspermont, déjà âgé de 45 ans - sa mère polonaise Angelica Kostrowicka de 22 seulement - fils lui-même, et reconnu, du général maréchal de camp de Ferdinand II, roi des Deux-Siciles). On y lit dans un style qui n'a rien de solennel: "Italie // Toi notre mère et notre fille quelque chose comme une soeur // J'ai comme toi pour me réconforter // Le quart de pinard // Qui met tant de différence entre nous et les Boches // J'ai aussi comme toi l'envol des compagnies de perdreaux de 75 // Comme toi je n'ai pas cet orgueil sans joie des Boches et je sais rigoler...". Plus loin, il se fait moins familier envers la soeur latine de la France: "Je pense à toi pays des 2 volcans // Je salue le souvenir des sirènes et des scylles mortes au moment de Messine // Je salue le Colleoni équestre de Venise // Je salue la chemise rouge ${ }^{7} / / \mathrm{Je}$ t'envoie mes amitiés Italie et m'apprête à applaudir aux hauts faits de ta bleusaille.." ${ }^{\prime 8}$

Nous reviendrons plus loin sur cet éloge du divin "pinard", compagnon de misère du Poilu... Quant aux "hauts faits de la bleusaille" italienne, ils laisseront bien sceptiques les soldats français qui devront se rendre en Italie après le désastre de Caporetto de fin octobre 1917...

\footnotetext{
${ }^{3}$ En ce moment, le poète est en pleine duplicité amoureuse, avec deux fers aux feu, et des lettres adressées quotidiennement à deux femmes! Il continue de correspondre avec sa maîtresse Lou avec qui la liaison a débuté fin novembre 1914, mais celle-ci lui préférant ouvertement un artilleur surnommé "Toutou", qui est au front, Apollinaire a commencé de correspondre début avril avec la très jeune (22 ans) Madeleine Pagès, professeur de lettres au lycée de jeunes filles d'Oran, qu'il a rencontrée le 2 janvier 1915, dans le train de Nice -où il venait de passer le Jour de l'An avec Lou - à Nîmes, où il faisait ses écoles à feu au $30^{\mathrm{e}}$ R.A.de Campagne. Il demandera Madeleine en mariage en août 1915, et elle acceptera.

${ }^{4}$ Ces "bombardiers" sont détachés en première ligne pour servir l'artillerie de tranchée, les crapouillots au tir court et en cloche, dont les torpilles peuvent atteindre les tranchées ennemies très proches

${ }^{5}$ Guillaume Apollinaire, Lettres à Lou, pp. 401-402, éditées en 1969 par Gallimard, réédition de 1990.

${ }^{6}$ Guillaume Apollinaire, Lettres à Madeleine, Tendre comme le souvenir, pp. 48-49, réédition en 2005

${ }^{7}$ Cette "chemise rouge" est une allusion à une autre alliance de l'Italie, pas encore unifiée, avec la France, en 1859, avec l'expédition dite des "Mille" ou des "Chemises rouges" de Garibaldi pour la conquête de la Lombardie et de la Sicile, aux côtés des troupes de l'armée de Napoléon III. Zola a fait participer à ce corps expéditionnaire Jean Lantier, son héros malheureux de La Terre et de La Débâcle

${ }^{8}$ Guillaume Apollinaire, Calligramme, poème "A l'Italie" pp. 141-146 dans l'édition Poésies Gallimard de 1966 (1ere édition 1925)
} 
Des désillusions, il y en aura avant, si comme Joseph Sorgues, comme Antonin Granet, comme Guillaume Apollinaire, les soldats au front attendent de cette entrée en guerre une accélération des événements pour une victoire finale plus prompte. Cet optimisme, Gaston Lavy l'exprime aussi dans son beau témoignage illustré $M a$ Grande Guerre, annoté et préfacé par un historien de cette Grande Guerre Stéphane Audouin-Rouzeau. Gaston Lavy interrompt le récit de ses faits et gestes, en mai 1915, par "Hier grande nouvelle........L'ITALIE SE DECLANCHE*" et poursuit: "Rompant sa neutralité l'Italie se joint à nous. "Mon vieux Sicot (le vaguemestre) cette fois ça y est les boches sont bien foutus." Cette phrase nous jaillit de la glotte en voyant venir notre bon camarade qui nous apporte le courrier. Pour nous le concours de l'Italie c'est la fin de la guerre, encore quelques mois de patience pensons-nous, et notre cauchemard* prendra fin et cette idée nous remonte le moral malgré le sourire sceptique de notre ami Kneicht. Cependant que nous échangeons nos réflexions, une très forte canonnade se fait entendre au loin, qui dure plusieurs heures. Que se passe-t-il la*-bas?"

Kneicht le sceptique avait raison... Et S. Audouin-Rouzeau de commenter et d'éclairer cette courte séquence "L'Italie se déclanche*" : "L'Italie, liée aux puissances centrales avant la guerre, a maintenu sa neutralité en 1914. Les deux camps entreprennent ensuite une négociation complexe qui fait basculer l'Italie dans le camp allié. Au cours du mois d'avril 1915, le gouvernement italien prépare l'opinion à l"intervention" voulue par une minorité composite mais bruyante (nationaliste, républicains garibaldistes, une fraction des syndicalistes révolutionnaires et des socialistes proches des positions de ces derniers). Pour autant l'intervention est refusée par une majorité de l'opinion. L'entrée en guerre de l'Italie contre l'Autriche-Hongrie intervient le 24 mai. Bien qu'écrits après coup, les propos de Lavy témoignent des espoirs soulevés dans le camp allié par cette entrée en guerre qui, pourtant, n'a pas modifié l'équilibre des forces. "I"

Pour en revenir aux faits, et à l'accueil de cette entrée en guerre par les Poilus, il semble que ce mot d'ordre consistant à crier à l'unisson, sur toute la longueur du front, de la Suisse aux plages belges de la Mer du Nord, "Viva l'Italia" n'ait concerné que les soldats en ligne. Car un musicien-brancardier au $99^{\mathrm{e}}$ R.I. de Vienne, Amand Beyron n'en fait pas état dans son journal aussi tenu quotidiennement. En revanche, les officiers s'octroient un extra, les hommes sont dispensés d'exercices et de corvées, et la musique du régiment va être requise pour fêter l'événement, à Bray-sur-Somme: "Lundi 24 mai - Au rapport de 10 heures, on nous annonce officielement* l'entrée en guerre de l'Italie à nos côtés. De ce fait, repos l'après-midi. On en profitera pour aller à la pêche aux étangs. A 11 h le chef (de la musique) part en auto avec le lieutenant Marc de la C.H.R (Compagnie Hors Rang) et le Colonel. Ils vont déjeuner à Amiens, et de là à l'hôpital du C.A. (Corps d'Armée) pour décorer mon vieil ami stéphanois de la $11^{e}$ Cie, le sergent Pierre Faure, de la médaille militaire. On pensait aller à la pêche, mais à 15 h. on est venu me dire qu'il y aurait à 17 heures un grand concert devant l'Hôtel de Ville de Bray par les deux musiques réunies des $99^{e}$ et $22^{e}$, en l'honneur de l'intervention italienne en guerre. On ne joue que des pas redoublés et des défilés avec la clique et les Hymnes nationaux des Alliés, plus celui de l'Italie pour la $1^{\text {ere }}$ fois qui fut "furieusement" applaudit*, avec la Marseillaise chantée par la foule. Au départ du concert, le colonel revient nous voir pour nous complimenter et nous dire qu'à l'occasion de l'aubade que nous lui avons faite samedi (veille de Pentecôte), il nous offre, pour la musique et la clique, 100 litres de bonne bière ${ }^{10}$. Soit 1 litre pour chacun. Il nous dit qu'il est content de nous: bonne tenue, bonne exécution de musique aux concerts..."

Pour une fois, Amand Beyron ne livre pas son analyse de l'événement, et s'en tiendra à boire son litre de bière, et à savourer les compliments du colonel...

\section{L'exécution de Miss Edith Cavell à Bruxelles le 12 octobre 1915}

Une autre preuve de la "barbarie boche" fut, en 1915, l'assassinat d'Edith Cavell.

Dans son journal, à la date du 28 novembre 1915, Joseph Sorgues écrit, après une récapitulation de divers faits de guerre des mois passés qu'il a lus dans la presse: "Les Italiens pour soulager la Serbie prenaient l'offensive autour de Gorizia et s'emparaient, après de violents combats, de plusieurs tranchées autrichiennes. Pendant ce temps, un officier allemand assassinait froidement, après un honteux jugement, une jeune infirmière anglaise de Bruxelles, miss Edith Cavell dont le seul crime avait été de procurer la liberté à des soldats anglais et belges. Ce crime odieux, cet assassinat d'une pauvre jeune fille évanouie, dont le cœur battait encore, souleva dans l'univers entier une profonde horreur et une indignation plus violente que pour le torpillage du "Lusitania". Des services solennels eurent lieu en Angleterre et en France, et un monument va être élevé à cette martyre du dévouement et du patriotisme au cœur de Paris. Ce meurtre infâme, après tant d'autres, sera éternellement commémoré, et plus que jamais nous sommes décidés à écraser le monstre "Germania"."

Dans son émotion et son indignation, Joseph Sorgues rajeunit beaucoup Edith Cavell, qui n'est pas "une jeune infirmière" ou "une pauvre jeune fille", mais une infirmière juste quinquagénaire puisque née à Norwich, dans le

\footnotetext{
${ }^{9}$ Gaston Lavy, Ma Grande Guerre, éd. Larousse 2004, page 65 pour l'extrait de Lavy et page III des Annexes (après p. 318) pour la note explicative de S. Audouin-Rouzeau

${ }^{10}$ Il était déjà plus facile de se procurer de la bière dans le Nord que du "pinard", et les musiciens, issus d'un milieu social sensiblement plus élevé que les hommes de troupe, peuvent être plus enclins à aimer cette boisson.
} 
Norfolk, le 4 décembre 1865, fille de pasteur.. Mais peut-être certains journaux ont-ils procédé à ce rajeunissement pour rendre son cas encore plus émouvant?

Qui était Edith Cavell et quelles furent les circonstances de sa mort? Un site officiel de Chemins de Mémoire (www.cheminsdememoire.gouv.fr/page/affichegh.php") la présente en deux pages. Mais je citerai plus volontiers un travail d'ECJS (Education Civique Juridique et Sociale) du lycée Perrier de Tulle (appella.ac.limoges.fr/lycperrier-tulle/ecjs/guerre/femmes.htm) montrant que le nom de l'hérö̈que infirmière anglaise est connu de certains lycéens français de 2007:

"Edith CAVELL, 50 ans, infirmière britannique fusillée par les Allemands. En 1907, elle avait été invitée à Bruxelles, pour fonder la première école d'infirmières selon les méthodes de Florence Nightingale. En 1914, lors de l'invasion allemande, l'école devint un hôpital de la Croix-Rouge où furent soignés des blessés de toutes nationalités. Quand les autorités allemandes exigèrent que les Belges en âge d'être soldats soient signalés à la police, Edith Cavell, considérant que c'était son devoir de chrétienne, aida, avec le soutien de ses infirmières, des réfractaires à passer clandestinement aux Pays-bas (restés neutres), ainsi que des soldats britanniques et français, soit environ 200 personnes au total. Arrêtée en août 1915, elle fut condamnée à mort et exécutée le 12 octobre. Sa mort suscita une intense émotion en Europe et jusqu'aux Etats-Unis. La propagande alliée l'utilisa comme symbole des crimes de guerre allemands en Belgique. Miss Cavell fut enterrée non loin de son village natal, dans la cathédrale de Norwich, et une statue lui fut élevée à Londres, sur la place Saint Martins. Quelques jours après sa mort, naissait une petite Française à laquelle son père donna le prénom de l'hérö̈ne: c'était la future Edith Piaf."

Les divers biographes d'Edith Piaf, née Edith Gassion le 19 décembre 1915, soit un peu plus de deux mois (et non "quelques jours") après la mort de l'infirmière anglaise - et juste 50 ans après sa naissance- indiquent en effet qu'elle doit son prénom à la vague de compassion et d'indignation que suscita l'exécution d'Edith Cavell.

Imaginer quelle fut l'émotion internationale suscitée par l'exécution d'Edith Cavell est difficilement concevable de nos jours. Pour les Alliés, et pour les neutres, et pour la conscience mondiale, s'il en est une, elle devenait l'incarnation de la "barbarie allemande". La lecture des journaux du temps est éloquente ${ }^{11}$, tout comme la revue, par un moteur de recherche comme Google, de tout ce qui a pris son nom dans le monde: des milliers de rues, des écoles de tous niveaux, des hôpitaux, des bateaux, un mont et un glacier au Canada, en Colombie britannique. Et des centaines de monuments partout. Celui de Paris qu'évoque Joseph Sorgues fut détruit lors de l'arrivée des troupes allemandes à Paris, en juin 1940 (tout comme le bas-relief à son nom au Musée du Jeu de Paume); les co-auteurs d'une étude sur les statues urbaines en France, Patrice Cornu et Frédéric Sorbier, éditée par le C.N.D.P en 2001, bien renseignés sur leur sujet, mais très mal sur la personnalité d'Edith Cavell, écrivent à son propos: "En 1940, dès l'occupation de Paris, le monument dédié à Edith Cavell (espionne anglaise fusillée par les Allemands en 1915, et "héroïsée" (les guillemets sont indécents!) par les Français, est détruit par les nazis". Le monument près de la cathédrale de Norwich, sa ville natale, dans le Norfolk en Angleterre, porte l'inscription "Nurse, Patriot and Martyr" ("Infirmière, Patriote et Martyre"). Celui de Londres, impressionnant par ses dimensions, et sa situation a proximité de Trafalgar Square, entre la National Gallery et l'église Saint-Martin-inthe-Fields porte, sous la statue quasi hiératique de l'infirmière exécutée, l'inscription "Edith Cavell Brussels Dawn October $12 \mathrm{~h} 1915 \quad$ Patriotism is not enough. I must have no hatred or bitterness for anyone" ("Edith Cavell Bruxelles Aube du 12 octobre 1915 "Le patriotisme ne suffit pas ; Je ne dois ressentir ni haine ni rancoeur envers quiconque"), ce qui reprend ce qui aurait été ses dernières paroles: "Standing as I do in view of God and eternity, I realize that patriotism is not enough; I must have not hatred or bitterness for anyone" ( "Me tenant en vue de Dieu et de l'éternité, je prends conscience que le patriotisme ne suffit pas. Je ne dois éprouver aucune haine ni rancœur envers quiconque").

En France, on composa une chanson qui eut un grand succès et qui fit aussi beaucoup pour étendre sa popularité. Quand j'ai interrogé, en patois (enquête de thèse), en août 1975, le Poilu Claudius Recorbet (cl. 15) à Sury-le-Comtal, son ami maçon Benoît Baudet, né en 1904, et bon chanteur, a entonné spontanément, à la fin de l'entretien, juste après "A la gloire de Pégoud" (hommage au célèbre aviateur tué en combat aérien), la chanson "Sur l'assassinat de miss Edith Cavell"...

Parmi ces trois événements, il va sans dire que c'est l'entrée en guerre de l'Italie, le 23 mai qui trouva le plus un écho chez la grande majorité des Poilus, surtout avec l'initiative de leur faire crier, en italien, d'un bout à l'autre

\footnotetext{
${ }^{11}$ A titre indicatif, le numéro du 30 octobre 1915 de la revue bien informée L'illustration y consacre un peu plus d'une grande page (pp 448-449) avec deux photos, une de Miss Cavell quadragénaire avec deux de ses chiens, assise dans un jardin, et une autre d'une rue anglaise, où un officier sur une tribune, au côté d'un panneau portant une très grande photo qui est la même que la précédente, harangue la foule; la légende est: "Un appel pour venger Miss Cavell: le capitaine Rees, du 2eme régiment de Londres, montre un portrait agrandi de l'infirmière assassinée et demande des recrues pour le régiment". La conclusion de ce très long article cite un journal américain, le "New York World" (qui appartenait depuis 1883 à Joseph Pulitzer, et qui disparaîtra en 1931): "Mieux eût valu" a écrit un journal américain, le New York World, commentant ce lugubre assassinat, "mieux eût valu pour l'Allemagne perdre un corps d'armée que d'avoir fait ainsi exécuter Miss Cavell". Et ce mot résume lapidairement l'opinion du monde civilisé". Et en effet, l'émotion suscitée aux Etats-Unis par cette exécution, après le torpillage en mai 1915 du Lusitania par un sous-marin allemand, fera beaucoup pour préparer l'opinion publique américaine, jusque là réticente, à intervenir dans cette guerre, mesure d'intervention qui sera votée en avril 1917.
} 
du front, à la même minute, leur admiration pour l'initiative de la soeur latine, dont on ne pas exactement si cela a été fait avec le cri "Viva l'Italia" ou, comme l'écrit le cultivé Joseph Sorgues, "Eviva l'Italia". Mais les deux autres événements, par le nombre (près de 1200) de victimes innocentes, étrangères au conflit, dans le torpillage du Lusitania, ou par la personnalité morale exceptionnelle d'une seule victime ${ }^{12}$, l'infirmière anglaise Edith Cavell, et l'indignation qu'inspira son exécution, touchèrent aussi tous ceux qui avaient accès à la presse, presse nationale, régionale ou de tranchées, par le biais des petites brochures produites dans les régiments. Les trois se conjuguèrent, après la rumeur des mains coupées aux garçons alsaciens reprise de la guerre de 1870 pour les empêcher de tenir le fusil, après la destruction des merveilles architecturales et culturelles de Louvain et de Reims en août et septembre 1914, pour illustrer la "barbarie allemande", la sauvagerie de la "Kultur" teutonne...

\section{****}

\footnotetext{
${ }^{12}$ A vrai dire Edith Cavell ne fut pas la seule condamnée, même si elle fut finalement la seule exécutée: avec elle, inculpées aussi d'avoir facilité le passage de soldats blessés (anglais, français, belges) vers les Pays-Bas en leur fournissant de faux papiers, donc inculpées d'intelligence avec l'ennemi, se trouvent les belles figures féminines de la comtesse Jeanne de Belleville et de l'institutrice Louise Thuliez. La condamnation à mort de ces deux femmes fut commuée par le tribunal allemand en travaux forcés à vie, sous la pression des interventions du pape Léon XV, du roi d'Espagne Alphonse XIII et de l'ambassadeur de France. Par ailleurs, Louise de Bettignies, leur amie, transmettait, sous le pseudonyme d'Alice Dubois, aidée de son "lieutenant" Marie-Léonie Vanhoutte, alias Charlotte, des informations aux services secrets anglais: les deux femmes furent arrêtées une semaine après l'exécution d'Edith Cavell, furent aussi condamnées à mort et eurent la même commutation de peine. Elles furent enfermées, avec les autres, à la prison de Siegburg, à $20 \mathrm{~km}$ au sud-est de Cologne, tout comme leur "complice" de la haute aristocratie, la princesse Marie de Crö̈ (condamnée à dix ans de travaux forcés), qui hébergeait les blessés alliés dans son château de Bellignies Une dernière femme résistante, membre de ce réseau d'aide à l'évasion, et parfois de transmission de renseignements aux armées alliées, surtout anglaise, Henriette Moriamé, entra en religion chez les Rédemptoristines et y mourut le 24 août 1918. Toutes les prisonnières furent délivrées en octobre 1918, sauf Louise de Bettignies qui, après trois ans de détention à Siegburg, avait été délivrée par la mort -de la tuberculose- dans un hôpital de Cologne, le 27 septembre 1918, à l'âge de 38 ans (elle était née le 15 juillet 1880 à Saint-Amand-les-Eaux, dans le Nord).
} 


\section{Chapitre 15}

\section{Décembre 1915 :}

Bilans après 17 mois de guerre 


\section{Chap. 15- Décembre 1915: bilan de l'affectation des jeunes classes, de l'inégalité face au danger, de la loi Dalbiez et des permissions, de l'espoir vain en une fin rapide de la guerre}

\section{E -" C'était par patriotisme que vous êtes parti?}

$\mathrm{T}$ - Ah oui! Pour défendre la France! Pas les laisser rentrer! Ils auraient pris toute la France, les Allemands! Vous savez, ils nous auraient fait marcher comme des nègres! Vous les connaissez pas, les Allemands! Moi, je les connais! Ça aurait été un malheur, un grand malheur! Parce que les Allemands, ils voulaient dominer toute la France, ils nous auraient pris comme colonie, ils nous auraient même chassés de chez nous pour mettre les leurs! Oh, vous savez, ils étaient cruels! Quand ils ont avancé, en 14, ils tenaient presque quatre départements, ils saccageaient tout! Ils tuaient les femmes, les hommes et les enfants!"- Etienne Carton, classe 1918, engagé volontaire, artilleur, Feurs

"Alors là, j'ai d'abord passé une visite. J'en avais passé d'autres. C'est là que le fameux médecin a dit: "Y a que les fantassins qui fassent la guerre!". C'est celui-là, tenez. Alors, après m'avoir bien palpé, m'avoir regardé, il a dit à l'autre: "Je ne crois pas que cet homme-là soit capable de franchir une tranchée!"- Jean-Louis Monier, classe 1913, Marols, relatant son conseil de réforme qui le fait passer de l'infanterie dans l'artillerie.

"On a vu l'infanterie l'hiver, quand ils changeaient de position: c'étaient pas des hommes, c'étaient des bouts de boue! C'étaient des boues qui marchaient!"- Antoine Mounioloux, classe 1908, Saint-Romain-les-Atheux, artilleur.

"Sois bien persuadée que cette triste guerre durera moins que l'on ne croit car les armées sont bien épuisées. Les Alliés n'ont pas trop de courage déjà et quand*à l'Allemagne ce doit être autre chose. Je suis bien certain qu'il y a longtemps que la moitié de la durée de la guerre est passée." - Lettre du 14 février 1915 d'Eugène Reymondon, classe 1898, à sa jeune femme Antonia, vivant dans leur ferme de Saint-Maurice-en-Gourgois (hameau de Sabonnaire)

Il convient, en cette fin de l'année 1915, de revenir sur le thème des affectations, puisque de gros contingents ont été affectés depuis la mobilisation d'août 1914: les classes 15 et 16, la 17 allant l'être les 7 et 8 janvier 1916. Par commodité, pour ne pas revenir sur cet aspect, nous inclurons aussi la classe 18, mobilisée en avril-mai 1916.

\section{Père et fils mobilisés}

Il arrive que le père, s'il est encore relativement jeune et s'il s'est marié tôt (ce qui n'était pas fréquent autrefois pour les hommes, surtout à la campagne - mes témoins sont majoritairement des agriculteurs fils d'agriculteurs - où le fils aîné servait souvent de domestique à ses parents jusqu'à 28-30 ans en échange de la reprise promise de la ferme, associée en général au quart préciputaire - un quart de l'héritage dévolu à ce fils, comme paiement différé de son travail, étant donné qu'il avait aussi droit à une part égale à ses frères et sœurs dans les trois quarts restants - se retrouve à la guerre en même temps que son fils aîné, voire que plusieurs de ses fils. On a le cas célèbre du général de Castelnau, commandant de la II $^{\mathrm{e}}$ Armée, avec six fils à la guerre dont trois ont été tués, mais lui, étant général, dépassait de beaucoup l'âge maximal (48 ans) de l'incorporation pour les hommes, dans l'armée territoriale; né à Saint-Affrique, en Aveyron, en 1851, il avait donc 63 ans en 1914. Parmi mes témoins oraux, il s'en est trouvé quatre, un de la classe 16, deux de la 17 et un de la 18 pour me signaler que leur père était mobilisé alors qu'eux aussi l'étaient, mais la question n'ayant pas été posée systématiquement - rarement même- on ne peut en tirer aucune observation statistique.

C'est le cas d'Antoine Monthelymard (cl. 17) né à Terrenoire, enfant de métallurgiste qui a repris le métier paternel (il a été tourneur-usineur dans diverses usines stéphanoises, dont la Manufacture d'Armes et de Cycles) avant de prendre sa retraite, veuf, chez ses enfants à La Talaudière. Son père était mobilisé dès 1914 comme tourneur aux ateliers de la Marine à Saint-Chamond, et lui incorporé le 8 janvier 1916 au $152^{\mathrm{e}}$ R.I. de Montélimar, avant de monter au front à la fin de 1916 au $358^{\mathrm{e}}$ R.I. de Lyon, comme pourvoyeur de fusil-mitrailleur. Malheureusement son témoignage, arraché par bribes, est trop fragmenté pour être cité.

C'est aussi le cas de Claude Pin (cl 18) né à Poncins, fils d'agriculteurs s'installant en 1912 à Cleppé, reprenant la ferme familiale après la guerre. Son père (cl. 92) ayant 42 ans en 1914 a été mobilisé dans la réserve de l'armée territoriale, et Claude incorporé en mai 1917 au $113^{\mathrm{e}}$ R.A.Lourde d'Issoire. Il se trouve à la guerre en même temps que son père, comme le confirme son épouse, présente à l'entretien: "J'étais bonne, là, moi à ce moment. T'as ben resté deux ans, avec ton père, à la guerre?"

$\mathrm{T}$ - "A peu près deux ans"

Le père et le fils s'écrivaient: "On se racontait nos petites misères... On s'apprenait pas grand chose parce qu'on était bien au courant tous les deux" 
Selon lui, il fallait avoir six enfants pour ne plus être mobilisé.

C'est encore le cas d'André Mathieu (cl. 16) né à Landos (Haute-Loire), fils de petits paysans, qui a fait un apprentissage de boulanger et a exercé ce métier après guerre jusqu'en 1932 (à Saint-Haon-le-Châtel), puis est rentré dans les Postes comme facteur, principalement à Saint-Germain-Laval, jusqu'en 1958. Incorporé en avril 1915 au $2^{\mathrm{e}}$ B.C.A d'Embrun, il est trouvé à la guerre alors que son père était mobilisé dans l'armée territoriale. Il cite le cas analogue, mais tragique, d'un cousin du côté maternel (ne s'appelant donc pas Mathieu) du hameau d'Escubac, sur la commune de Landos: "Y a un de mes cousins et son père, ils sont été tués tous les deux, à la même guerre! D'Escubac!"

Quant à un de mes témoins extérieurs à la région (mais interviewé à Feurs, chez sa fille, épouse du docteur Porte), Léopold Bayle (cl. 17) de Tresques, dans le Gard, il a vécu une rencontre rare. Ayant travaillé à la ferme familiale jusqu'à son départ à la guerre en 1916, il a bénéficié de la présence de son père (cl. 92) à la guerre, dans les territoriaux: cela lui a d'abord valu, au conseil de révision, un ajournement de quelques mois, avant d'être incorporé au milieu de l'année 16 (et non le 7-8 janvier, comme les autres), au $61^{\mathrm{e}}$ R.I. de Privas:

E- Combien vous étiez de la classe 17, à Tresques?

T- On était bien 6 ou 7. Mais moi, j'ai été ajourné six mois, je pesais que $56 \mathrm{~kg}$. . On a passé le conseil de révision en plein été (1915).. A la campagne, à ce moment-là, on n'est pas gros! Le major a hésité, il s'est tourné vers le maire, qui a dit: "Son père est déjà à la guerre". Alors le major a dit: "Ajourné!" Et je suis parti quelques mois plus tard."

E- Qu'est-ce que vous avez pensé, quand vous avez été ajourné?

T- Moi, j'ai été content pour ma mère, et pour mon père aussi. Mais moi, j'étais vexé d'être ajourné! Seulement, pour ma mère, c'était bien. Mon frère était jeune, il avait douze ans. Alors je suis resté six mois de plus avec eux.. Comme on le donnait, il fallait le prendre..."

Son père avait été incorporé, à 42 ans (cl. 92) en 1914, dans l'armée territoriale, dès la mobilisation:

$\mathrm{E}-$ Vous aviez dix-sept ans. Je suppose que les premiers morts du village, ça a dû créer la consternation?

T- Oui, la première annonce a été brutale. C'étaient surtout des réservistes qui sont partis. Ils allaient à Briançon, le train a déraillé et il y a eu pas mal de morts. Dans le village, il y a avait plusieurs morts avant d'arriver à la caserne! Alors, ça a été la première émotion. Ils allaient revêtir l'uniforme, ils étaient appelés, c'étaient des territoriaux. ${ }^{1}$.

E- Est-ce que votre père a été mobilisé avec eux?

T- Il a été mobilisé avant eux. C'est les plus vieux qui ont été mobilisés les premiers jours, parce qu'il fallait garder les voies ferrées pour permettre aux autres mobilisés d'être acheminés. Il fallait surtout protéger les voies ferrées."

Et chose extraordinaire, unique parmi nos témoins, le père et le fils se sont rencontrés, alors qu'ils étaient tous deux mobilisés. Bien que cette rencontre ait eu lieu en 17 , et non en 15 , nous faisons cette entorse à la chronologie pour un thème sur lequel nous ne reviendrons pas. Le long récit très circonstancié qu'y consacre Léopold indique à quel point cette rencontre, qu'il raconte 72 ans après les faits, en février 1989, s'est gravée dans sa mémoire; il révèle aussi combien il était hasardeux et difficile de programmer une rencontre, alors que l'on dépendait, de part et d'autre, de l'itinéraire de deux régiments différents, ne faisant pas division ensemble et que l'on ne pouvait pas clairement désigner le lieu où l'on se trouvait, ceci étant interdit par le règlement militaire:

T- "Il n'est pas allé loin, je me rappelle pas où. Il n'est pas monté dans la direction du front, à ce moment-là, mais après il y est monté, il est même allé au front.

E- Pendant que vous, vous étiez mobilisé?

T- Eh oui! Je vais vous dire dans quelles conditions je l'ai vu. On revenait d'Alsace et on remontait vers le Nord. On passe à Beauvais, c'était en 17, on fait la pause à Beauvais sur un champ d'aviation immense. Je vois des soldats évidemment, de vieux, des jeunes. Et après, on repart loin, on fait une marche et on arrive dans un patelin à la limite de l'Oise. On avait quitté l'Alsace, et là, on nous distribue le courrier qui nous avait suivis, huit jours après. On me donne une lettre de mon père qui me fait comprendre qu'il était à Beauvais. Il pouvait pas le dire en toutes lettres, mais il me le fait comprendre... Il a parlé de Jeanne d'Arc, je suppose ${ }^{2}$. Il était à ce moment-là dans

\footnotetext{
${ }^{1}$ Léopold ne distingue pas clairement les soldats proprement territoriaux, et ceux qui sont réservistes de l'armée territoriale. Rappelons les répartitions en fonction de l'âge précisées par le général André Bach dans son ouvrage "Fusillés pour l'exemple" 1914-1915, op.cit., p. 36: "A partir de 1913, une recrue sortait du service actif à 23 ans, passait dans la réserve de l'armée jusqu'à 34 ans, ce qui voulait dire que, en cas de mobilisation, les recrues les moins âgées venaient compléter les régiments d'active et constituer les divisions de réserve, censées compléter l'action des divisions d'active. A partir de 34 ans, les hommes étaient considérés comme faisant partie d'une deuxième armée, l'armée territoriale, destinée officiellement à être utilisée de manière plus statique. Pour la maintenir en état et la compléter, on pouvait avoir recours à la réserve de cette armée en appelant les hommes instruits âgés de 41 à 48 ans"; instruits signifiant ici formés à la discipline militaire, et non dotés de diplômes.

${ }^{2}$ Cela suppose que Léopold et son père connaissent assez bien l'un et l'autre la biographie de Jeanne d'Arc, capturée à Compiègne en mai 1430 (du diocèse de Beauvais) à l'âge de 18 ans, vendue aux Anglais (10 000 livres) en décembre, et jugée à Rouen en mai 1431, le tribunal étant présidé par Pierre Cauchon, évêque de Beauvais, les principaux chefs d'inculpation retenus contre elle étant religieux.
} 
l'aviation, comme rampant. Il avait 45 ans. Il n'était plus à un poste de combattant comme il a été à un moment: il a été dans les tranchées, lui, plus que moi! J'ai donc compris qu'il était par là, grâce à un code, un peu enfantin. Il ne l'a pas écrit clairement, parce que c'était interdit. Il était à Beauvais dans le camp d'aviation où nous avions séjourné quelques heures! J'avais sûrement vu ses camarades. Ça m'énervait! Alors, je vais trouver le capitaine, et je lui dis: "Voilà, mon père, il est là où nous étions tout à l'heure.". Il me dit: "Mais, mon ami, vous savez bien que nous ne venons pas là pour cueillir des violettes!" Je le savais, mais... Que faire? Partir? Laisser mes affaires, mes armes? Je vais vers la porte, et le capitaine me dit: "Ecoutez, nous avons une réunion d'état-major dans un quart d'heure, j'en parlerai en haut lieu". Je pensais qu'il me disait ça pour me faire comprendre... Il était gentil. Il y en avait qui m'auraient traité de crétin! Un moment après, les camarades me disant: "Ecoute, le planton ${ }^{3}$ du commandant te cherche. Voilà son vélo, là-bas!". Il me demandait dans le village; il s'amène et il me dit: "Le commandant veut te parler, il est au premier étage, va le voir tout de suite!". J'y vais. Un monsieur très chic! Il me dit: "Vous savez dans quelle situation nous sommes. Vous voyez les camions dans la rue?" La rue était pleine de camions militaires. "Le conducteur est à son volant et il doit pas le quitter. Et ils sont pour nous, ces camions! J'attends un ordre qui peut venir d'une minute à l'autre, pour aller...je ne sais pas où!". J'ai dit: "Je comprends, mon commandant!". Je voulais pas discuter. Je le savais. J'étais au courant des consignes. Mais je faisais quelque chose! J'aurais eu une bêche, j'aurais bêché la terre, pour faire quelque chose! Je remercie le commandant.. J'étais à la porte, et il me dit: "Si nous sommes obligés de partir, et si vous n'êtes pas là, je saurai pourquoi vous n'êtes pas là...". Alors je suis parti. J'ai dit au commandant de garder mon sac, mes armes, je ne sais plus... On était à 25 km de Beauvais, je suis parti à pied..."

E- Vous aviez vraiment envie de le voir!

T- Envie de le voir, non, mais c'était le fait de... S'il avait pas été au même endroit, j'y aurais pas pensé. Mais là, au même endroit! "

On peut s'étonner d'une telle compréhension de la part du capitaine, et tacitement, de la part du commandant, qui, sans le dire, donne à Léopold la permission de partir, en lui assurant que, connaissant le motif de son départ, il n'y aura pas de sanction, ou au moins pas de sanction grave, s'il est absent au moment du départ inopiné du régiment. C'est oublier que l'image de l'officier est globalement bonne durant la Grande Guerre, à l'exception de l'officier peureux, et de celui qui est jugé "vache", car réglant des inimitiés personnelles en désignant ceux qu'il n'aime pas pour des patrouilles très dangereuses. C'est un certain antimilitarisme de la seconde moitié du XXe siècle et la focalisation de la littérature, du cinéma, et des médias sur les "bavures" de la discipline et de la justice militaires qui ont forgé l'image de l'officier inhumain (qui existait, certes) et des mauvais rapports entre soldats de base et leurs chefs.

Mais comment Léopold a-t-il pu retrouver son père, au milieu de la foule des soldats de divers régiments stationnés sur le terrain d'aviation et aux alentours? Il l'explique: "Je pars, mais à l'arrière du front, y avait pas mal de voitures militaires qui circulaient, et j'en ai trouvé une qui allait dans le sens de Beauvais. Alors j'arrive, je cherche ses camarades, je les trouve, et ils me disent: "Il est parti: il est allé faire des livraisons dans le camp d'aviation.". Bon! Alors, je fais un mot et je leur dis: "Voilà: vous lui donnerez ça quand il reviendra." Et je retourne immédiatement là où j'étais. J'étais à-bas quand il s'amène deux ou trois heures après. Il était un peu plus libre que nous! Nous, les camions pouvaient nous emmener pour 100 ou 200 kilomètres: après on est allé en Belgique, et on venait d'Alsace!"

E- Alors, comment s'est passée cette entrevue entre le fils et le père?

T- Oh, lui, il est très émotif... Ça s'est passé très rapidement. On n'a pas fait de discours... Pour moi, ça a été une satisfaction de le voir... On n'est pas resté ensemble longtemps... Mais du moment que j'avais la possibilité... S'il avait fallu 100 ou $200 \mathrm{~km}$, j'aurais pas essayé, mais de savoir que j'étais resté 4 ou 5 heures là où il était... Je trouvais ça un peu fort de café! "

Léopold n'en dira pas plus sur cette entrevue avec son père qu'il a si sobrement, si pudiquement, évoquée... Si son père a été "très émotif", selon son tempérament (remarquons le présent "est très émotif" qui fait ressusciter ce père aimé, dans l'évocation retenue de cette brève rencontre) c'est bien qu'il y a dû avoir des larmes...

\section{Les conseils de révision pendant la guerre}

Le conseil de révision s'applique aux soldats incorporés pour la première fois. Avant la guerre, jusqu'en 1912, l'incorporation se faisait à 21 ans, et le conseil de révision se passait l'année précédente, ou six mois avant. Le vote de la loi de trois ans, en 1913, amène à incorporer la classe 13 à 20 ans, en décembre 1913, soit deux mois seulement après la classe 12, qui avait été incorporée normalement, à l'âge de 21 ans, étant donné - c'est une

\footnotetext{
${ }^{3}$ Le "planton" est, en argot militaire, le nom donné par les soldats au camarade occupant la fonction d'ordonnance d'officier. Ce mot est apparu dans ce sens en 1790 et il dérive de la position de ce soldat, censé être "planté" à la porte de l'officier qu'il sert, dans l'attente d'un ordre.
} 
évidence bonne à rappeler - que les natifs de la fin de l'année sont toujours plus jeunes que ceux nés dans l'hiver ou au début du printemps de cette même année! La saignée effroyable incroyable du début de la guerre va amener les autorités militaires à incorporer des garçons de plus en plus jeunes, jusqu'à la classe 17, donc à avancer le conseil de révision; ainsi la classe 15 est incorporée en fin décembre 1914, soit avant l'année de ses 20 ans, la classe 16 en avril 15, donc à 19 ans (voire moins pour les natifs de fin d'année), et la classe 17 début janvier 1916 (les 7 et 8), soit à moins de 19 ans pour tous, sauf pour ceux du début janvier (et même pratiquement à 18 pour les natifs de novembre- décembre 1897). La classe 18 sera, elle, incorporée à 19 ans (un peu moins pour ceux de fin d'année) en avril 1917, ou au début mai pour les agriculteurs, et la classe 19, qui a peu combattu en raison d'un allongement du temps de l'instruction en caserne (porté à 4, voire 6 mois), au même âge, car incorporée à la mi-avril 1918.

\section{L'écart entre la date du conseil de révision et celle de l'incorporation}

Avec l'arrivée de la guerre, l'écart de temps s'est réduit entre la date du conseil de révision et celle de l'incorporation, sans être fixe, car le passage de la commission d'affectation de canton en canton s'étalait sur plusieurs mois. Quelques-uns de nos témoins ayant gardé en mémoire les deux dates nous permettent de mesurer cet écart.

Ainsi pour la classe 1914, incorporée à 20 ans début septembre 1914, et généralement envoyée au front fin novembre 1914 après deux mois d'instruction, Mathieu Grand de La Tuilière a passé son conseil le 17 mars 1914 à Saint-Just-en-Chevalet et est parti le le 3 septembre. Quant à Jean Salanon de Boisset-Saint-Priest, son conseil a eu lieu le 5 juillet 1914 à Saint-Jean-Soleymieux, pour un départ deux mois après, le 4 septembre

Pour la classe 1915 incorporée à 19 ans (ou 19 ans 1/2 pour les natifs du début de l'année) en décembre 1914 et généralement envoyée au front au printemps 1915 pour l'infanterie, plus tard pour l'artillerie dont la formation (les écoles à feu") nécessite plus de temps, on ne dispose d'aucune indication concernant un conseil de révision. Mais le témoignage écrit de Claude Coupade de La Ricamarie, nous permet de mesurer, pour un artilleur devenant mitrailleur dans l'infanterie alpine, en 1915, l'écart entre incorporation, fin de classes et arrivée au front: incorporé le 14 décembre 1914, au 5 $5^{\mathrm{e}}$ R.A. Lourde de Valence, il est versé le 10 avril 1915 au $157^{\mathrm{e}}$ R.I. Alpine de Gap et part au front le 12 juin 1915

Pour la classe 1916, incorporée à 19 ans (ou 18 ans 1/2 pour les natifs de la fin de l'année) début avril 1915 et généralement envoyée au front à l'automne 1915 après six mois d'instruction, on sait qu' Eugène Troncy de Belmont-de-la-Loire a passé son conseil le 18 janvier 1915 à Belmont, mais il n'a pas donné la date précise de son incorporation, ce qu'ont fait, en revanche Francis Ferret de Coise (Rhône), venu à Châtelus (Loire) et plus tard agriculteur à Saint-Christo-en-Jarez, dans la Loire : conseil le 15 janvier 1915 à Saint-Galmier et départ le 10 avril, et Antoine Gayet de Mionnay (Ain), plus tard fraiseur-tourneur à Vénissieux, puis à Oullins, retraité à Feurs: conseil début février 1915 à Trévoux (Ain) et départ le 9 avril.

$\mathrm{Au}$ front, la jeunesse de cette classe 1916 a frappé les soldats plus âgés, comme le poète Guillaume Apollinaire, alors âgé de 35 ans, devenu sous-lieutenant dans l'infanterie, qui écrit le 27 octobre 1915 le très long poème "Chant de l'horizon en Champagne", dédié au substitut Granié, dont il envoie une copie à sa fiancée Madeleine Pagès, à Oran; on y lit ces deux vers libres: "Creusez des trous enfants de 20 ans creusez des trous // Sculptez les profondeurs...".

Pour la classe 1917, incorporée à nettement moins de 19 ans (sauf pour les natifs de janvier; guère plus de 18 pour ceux nés en fin d'année) le 7 janvier 1916 et envoyée au front à l'automne 1916 ou dans l'hiver 1916-1917, on dispose de deux témoignages:. Celui, un peu imprécis, d'Antonin Compigne: conseil en mai 1915 à Néronde et départ en janvier 1916, et celui très précis d' Ernest Pigeron de Montaiguët-en-Forez (Allier), plus tard boucher au Coteau et à Roanne dans la Loire, et retraité à Renaison: conseil le 22 juin 1915 et départ le 8 janvier 1916, mais avec une longue formation militaire aboutissant à l'envoi sur le front en fin d'année 1916 seulement:

Ce dernier précise: "Y avait pas de contingent à ce moment-là! Ça partait tout! Y avait les gars de la fin de l'année qui avaient juste 18 ans! Moi, j'étais près de mes 19 puisque je suis du mois de février". Il revient plus tard sur cette jeunesse exceptionnelle de sa classe pour l'incorporation:

E - Finalement, vous êtes monté sur le front à quel moment? Dans l'année 16?

T- En fin d'année 16. Nous sommes montés dans un bataillon de marche qui a été constitué pour la classe 16, parce qu'il paraît... On était jeune, trop jeune, et il paraît qu'il en est tombé en 16... C'est nous la classe la plus jeune qui est partie, notre classe! Bon: ils avaient constitué un bataillon et puis alors ils nous envoyaient faire des travaux! On a vu le baptême du feu, nous, sans autorisation de tirer! On nous envoyait derrière les lignes décharger les camions d'obus, ou faire des terrassements: c'était une réserve qui était là! La réserve, on puisait dedans quand on avait besoin de renfort..."

Bien que nous en soyons à décembre 15- janvier 1916 dans l'ouvrage, évoquons rapidement les deux dernières classes concernées, incoporées plus tard, car nous ne reviendrons pas sur ce thème. Cinq témoignages précis quant aux dates, pour la classe 1918, montrent le décalage de trois semaines entre agriculteurs et autres professions. Un gareur en tissage comme Christophe Dumas de Bourg-Argental passe son conseil à Bourg en février 1917 et part le 17 avril, le même jour qu'Antoine Colombier de Montbrison, fils de maçon et ouvrier maçon et parfois ouvrier 
agricole, qui avait passé son conseil en décembre 1916 à Montbrison. En revanche, trois fils d'agriculteurs, restés avant leur départ à la guerre dans la profession (mais plus après), comme Antoine Colombier, Pierre-Faure et Claude-Marie Ginet partent début mai: le 2 précisément pour Claude-Marie Ginet de Saint-Nizier-sous-Charlieu et Pierre Faure de Monistrol-sur-Loire (La Chapelle d'Aurec), qui travaillera et résidera après guerre à La Ricamarie; début mai sans plus de précision pour Antoine Damas de Montverdun, qui avait passé le conseil le 31 janvier 1917 à Boën-sur-Lignon.

Quant la dernière classe, celle de 1919, incorporée à 19 ans (ou 18 ans 1/2 pour les natifs de la fin de l'année) à la mi-avril 1915, elle a été généralement envoyée au front en octobre ou novembre 1918, ou après l'armistice pour l'occupation en Allemagne, ou affectée en France à des missions de maintien de l'ordre, notamment pour s'opposer à quelques grandes grèves locales. En matière de dates, nous ne pouvons nous fier qu'au témoignage oral et écrit de Lucien Faugère, fils d'épiciers de Balbigny, devenu instituteur puis après guerre, professeur de mathématiques au lycée de Montbrison, et capitaine en septembre 1939, au 53 Régiment d'Artillerie mobile, fait prisonnier le 22 juin 1940 (libéré le 9 août 1941). Ayant passé son conseil de révision en février 1918 à Balbigny, il est incorporé le 17 avril au $16^{\mathrm{e}}$ R. d'Artillerie de Campagne, suit le peloton des élèves sous-officiers au G.I.A.C. (Groupement d'Intruction d'Artillerie de Campagne) à Saint-Julien-du-Sault dans l'Yonne, du 20 juin au 25 septembre, nommé brigadier à la $8^{\mathrm{e}}$ batterie du $16^{\mathrm{e}}$ R.A.Lourde, après avoir bénéficié d'une permission de vingt jours pour vendanges, il arrive fin octobre 18 dans le secteur de Verdun et y participe aux derniers bombardements précédant l'armistice.

\section{Les décisions de la commission médicale dans quelques communes foréziennes}

La commission médicale, sous les ordres du médecin-major, au conseil de révision, prononçait trois avis: "Bon pour le service", "Ajourné" ou "Réformé" (définitif ou parfois temporaire, si la maladie était susceptible de guérir); la décision étant très rapide, au vu du conscrit. On peut penser qu'en raison des énormes pertes des premiers mois de guerre en 1914 et de toute l'année 15, les commissions ont eu pour consigne d'être de plus en plus strictes afin d'accorder de moins en moins d'ajournements et de réformes ou exemptions. Malheureusement, il ne se trouve qu'une douzaine de témoins pour se souvenir de la décision de la commission médicale pout tous les conscrits de leur commune. Nous les livrons à partir de la classe 14. Ce sont essentiellement des ruraux, car à la campagne, on connaît tous les jeunes, garçons et filles, nés la même année que vous; la stabilité plus grande de la population fait qu'on se retrouve ensemble à l'école primaire et au catéchisme, ce qui scelle des liens durables.

Pour la classe 14, Mathieu Grand, agriculteur à La Tuilière avant guerre, futur facteur, principalement à Panissières et futur centenaire, passant son conseil avant la déclaration de guerre à Saint-Just-en-Chevalet, se souvient que sur les 11 conscrits de la Tuilière, 8 ont été pris, 2 réformés (dont un pour une tache à l'oeil), 1 ajourné ; mais les 3 derniers seront pris plus tard. Quant à Antoine Guillot de Perreux, cordonnier, puis employé à l'arsenal de Roanne, incorporé le 3 septembre 1914 au 133 R.I. de Belley, il indique que 15 de ses conscrits (sur combien?) de la classe de 14 de Perreux ont été pris au conseil de révision, parmi lesquels 7 sont morts; les deux ajournés étaient l'un blessé à une main, le second tuberculeux; tous deux ont été récupérés plus tard et l'extuberculeux, guéri ou non, a été tué...

Pour la classe 15, on dispose de trois témoignages. Dans les Monts du Lyonnais, celui d' Antoine Frénéat (cl 15), fils d'agriculteurs de Sainte-Colombe-sur-Gand, futur cheminot domicilié à Montrond: les 12 conscrits de Sainte-Colombe ont été pris; et celui d' Eugène Troncy, de Belmont-de-la Loire, qui a passé le conseil le 18 janvier 1915 à Belmont: sur les 27 conscrits de Belmont, 18 ont été pris, 8 ajournés, et 1 réformé définitif. Les 8 ajournés ont finalement tous été pris et ont eu proportionnellement plus de morts que les 18 pris aussitôt. De l'autre côté de la Loire, dans les Monts de la Madeleine, Antonin Cote, fils de cultivateurs de Laprugne (Allier), venu après guerre dans la ferme familiale de son épouse à Saint-Priest-La-Prugne (Loire), a passé son conseil de révision au Mayet-de-Montagne (Allier). Ils étaient 9 de Laprugne, 7 de la classe 15 et 2 ajournés de la classe 14; les 7 de la classe 15 ont été pris, les deux ajournés l'ont été à nouveau, l'un pour être trop maigre, l'autre pour être borgne.

Pour la classe 16, aucun des témoins ne s'est souvenu précisément, ou la question n'a pas été abordée dans l'entretien.

Pour la classe 17, deux témoins se souviennent. Selon Antonin Compigne (cl. 17) agriculteur à Balbigny, les 11 conscrits de Balbigny ont été pris, sachant que 2 de la classe 17 s'étaient engagés auparavant. Quant à Marius Verdier (cl. 17), agriculteur à Rozier-en-Donzy, il affirme que sur les 17 conscrits de Ronzier, 14 ont été pris, 2 ajournés, et 1 réformé provisoirement qui, blessé au genou par un coup de hache, sera pris plus tard.

La classe 18 est celle qui représente, sur ce point, le plus de souvenirs précis: on dispose de cinq témoignages. Trois témoins sont fils d'agriculteurs, les deux autres fils de maçons ruraux.

Au nord du département de la Loire, Edmond Buisson, agriculteur à Mars, qui sera amputé du bras droit, il se souvient que sur les 11 conscrits de Mars, 10 ont été pris, et 1 ajourné a été pris plus tard.

$\mathrm{Au}$ centre ouest, à Montbrison, Antoine Colombier (le fils d'un maçon qui s'est tué en tombant d'un échafaudage en 1908) se rappelle qu'au conseil de révision passé à Montbrison en novembre ou décembre 1916, il n'y aurait pas eu plus de deux ajournés sur au moins 80 conscrits (taux exceptionnellement bas): "Oh! Ils raclaient tout! Tous bons pour le service!". Lui a bénéficié d'une affectation de faveur en raison de sa situation de famille: "Y 
avait l'adjudant, comme j'étais le fils aîné d'une veuve de six (enfants), il a dit: "Je vais te mettre dans l'artillerie". Il partira en effet, le 17 avril 1917, au $11^{\mathrm{e}}$ R.d'Artillerie de Grenoble. Non loin de Montbrison, à Verrières-enForez, Pierre Néel, qui sera plus tard cantonnier, puis chef cantonnier, sait que sur les 18 conscrits de Verrières, 10 ont été pris et 8 ajournés, ce qui est une proportion très inhabituelle d'ajournements, dans le même conseil de révision que celui d'Antoine Colombier, qui aurait été si drastique pour les conscrits de la commune de Montbrison: E- "Votre conseil de révision, vous l'avez passé quand?

T- En 16, à Montbrison. On était 18 à le passer, de Verrières. La moitié a été prise, l'autre moitié a été ajournée. Il y avait des infirmes; $y$ en a qui tombaient du mal caduc ${ }^{4}$ Y Y avait beaucoup de ces cas, et puis y en avait que c'était de la faiblesse: ils étaient pas assez costauds pour faire des soldats. Guère plus de la moitié. Et puis ils ont repassé des conseils. Y en a qui, au bout d'un an, ils sont* été mobilisés, ils sont*été dans l'auxiliaire, d'un côté d'autre."

Au sud du département, Jean-Marie Ollier, de Périgneux, futur marchand de fromages sur les marchés, basé à Saint-Marcellin-en-Forez, a passé le conseil de révision à Saint-Rambert-sur-Loire: sur 12 conscrits de Périgneux, 11 ont été pris, et 1 exempté définitivement, car il avait deux doigts manquants à la main droite, par infirmité de naissance (il sera plus tard garde-champêtre à Périgneux.). Quant à Jean Brun de Saint-Maurice-en-Gourgois, fils de maçon-paysan, plus tard employé de bureau aux usines Verdier de Firminy, puis Holtzer d'Unieux, il a passé le conseil de révision à Saint-Bonnet-le-Château: sur les 14 conscrits de Saint-Maurice, 11 ont été pris, 1 a été versé dans le service auxiliaire (lui-même, à cause d'une forte déficience de vision à l'œil droit), et 2 ajournés pour poids trop faible ont été pris six mois après.

Qu'en conclure? Que rien ne permet de dire, contrairement à ce qu'affirme Antoine Colombier ("Oh! Ils raclaient tout! Tous bons pour le service!") et à ce qu'on lit parfois dans des romans de guerre, que les commissions du conseil de révision, dans la Loire, entre 1914 et 1917, aient été impitoyables, insensibles à des motifs médicaux d'exemption, même si, on le verra, du côté du poids minimal, il semble que le critère se soit durci. On voit aussi que parfois, la situation de famille (cas d'Antoine Colombier, aîné de six enfants orphelins de père depuis 1908, donc soutien de famille) peut incliner à l'indulgence dans l'affectation dans une arme, l'artillerie, beaucoup moins meurtrière.

\section{Critères d'ajournement ou d'exemption}

\section{1- Le handicap, la blessure ou la maladie grave:}

On l'a vu dans les témoignages précédents, le handicap (deux doigts manquants, un œil droit déficient, une tache à l'œil, le fait d'être borgne, la faiblesse de constitution), la maladie chronique grave (l'épilepsie, la tuberculose) ou la blessure (coup de hache au genou, main blessée) sont pris en compte pour la réforme définitive, ou l'ajournement si le mal est guérissable.

Un cas de maladie peu courante, une maladie de peau, nous a été donné comme cause d'ajournement. Eugéne Troncy (cl. 16) de Belmont-de-la Loire rapporte: "J'avais un costaud qui était quasi le plus fort de la classe (16) qui avait pas été pris parce qu'il avait des dartres: dans une ferme, il avait attrapé des dartres!"

\section{2- L'insuffisance pondérale:}

Les conscrits de 18 ou 19 ans, en Forez, ruraux et citadins, étaient rarement grands et rarement lourds: le travail précoce très pénible, la malnutrition consécutive à une pauvreté relative, freinaient la croissance. Dans les années 1950-1960, alors qu'ils étaient encore assez nombreux dans les communes, et participaient encore aux cérémonies du 11 novembre, j'avais été frappé de leur petite taille (autour d'1,60 m) quasi générale.

Le poids souvent faible des conscrits est attesté par quelques témoignages, dont un précis pour le versant auvergnat des Monts de la Madeleine, ainsi, dans l'enquête de thèse en patois, Adolphe Courpière (cl. 18) de Vollore-Montagne (Allier) signale que sur les 13 conscrits de la classe 1918 à Vollore, 4 seulement dépassaient 50 $\mathrm{kg}$ ! Il n'indique pas combien ont été pris. Dans la Loire, à Saint-Germain-Laval, les conscrits sonts un peu plus lourds, mais les poids plumes existent et sont incorporés: Etienne Poyet (cl. 17) de Pommiers-en-Forez, futur inspecteur de police à Saint-Etienne puis à Montbrison et retraité à Saint-Bonnet-le-Château, constate que les conscrits de sa classe, au conseil de Saint-Germain-Laval, au printemps 1915, étaient des poids légers, qui étaient pris alors qu'ils auraient été réformés auparavant, avant la guerre:

$\mathrm{E}$ - "Comment se passait ce conseil de révision en temps de guerre?

T- Le conseil de révision, ça n'avait pas changé, les formalités étaient les mêmes. Seulement on recrutait...évidemment, y avait des besoins: y avait déjà eu des pertes pas mal; alors y avait des jeunes gens qui en temps normal auraient été ajournés ou réformés, et ils étaient pris pour le service armé!

E- On n'était pas trop regardant sur les déficiences?

T- Ah! Pas du tout! Pas du tout! On était 3-4, des conscrits, on pesait $53 \mathrm{~kg}, 54 \mathrm{~kg} . .$. Ils en ont pris un, pour les Chasseurs Alpins, il faisait $54 \mathrm{~kg}$ : il est parti quand même! Y avait un besoin urgent de combler les pertes."

Plusieurs évoquent le poids de $50 \mathrm{~kg}$ comme un seuil d'ajournement, et non de réforme, car avec un an de plus, au conseil de révision suivant, on pouvait avoir pris quelques kilos. Ainsi Antoine Gacon (cl. 17), né à Lenax (Allier), vacher puis valet de ferme à Urbize, dans la Loire, puis aidant ses parents dans leur nouvelle ferme

\footnotetext{
4 "Le mal caduc": l'épilepsie, en français régional
} 
de La Pacaudière, a passé le conseil de révision à La Pacaudière au milieu de l'année 1915, à moins de 18 ans (né le 2 septembre 1917); il a été pris, à la limite de poids: "Moi, je faisais combien? $50 \mathrm{~kg}$ et 1,60 m, c'est tout ce que je faisais! Mais ils m'ont pris quand même; ils m'ont dit:"Il est bon!" Eh ben, il est bon, ça ira! Il était bien bon, la preuve!" (grand rire: non seulement il a survécu à cette guerre, mais il a encore bon pied bon œil à 91 ans, en ce 22 décembre 1988, après avoir été successivement épicier, charpentier et maçon!)). Deux de ses conscrits, Thély et Meunier, n'ont pas été pris "parce qu'ils étaient pas assez costauds; ils ont été ajournés; ils sont partis qu'après, avec les récupérés."

Plus au sud, Félix Barrier, né le 16 mai 1894 à Saint-Bonnet-le-Courreau, au hameau de Pramol, enfant d'agriculteurs qui a repris la ferme familiale, a été ajourné en 1914 à cause de son faible poids: $48 \mathrm{~kg}$; il est parti avec la classe 15, sans avoir beaucoup grossi. De même, Marc Delime (cl. 15) de Boën-sur-Lignon, cordonnier avant guerre, affûteur-outilleur après, n'a pas pu partir avec ses conscrits de la classe 15 à cause de son poids inférieur à $50 \mathrm{~kg}$ : "Je voyais tous les copains qui partaient, de la classe 15. Et moi j'ai été ajourné la première fois: je faisais $49 \mathrm{~kg}$ ! J'étais pas assez lourd! Mais la deuxième fois, ils m'ont raflé, avec $50 \mathrm{~kg}$ ! C'était du monde qu'il fallait!"

Certains, pesant juste $50 \mathrm{~kg}$, sont à la limite de l'ajournement, et consultés sur cette opportunité par le major, prennent, comme dans l'exemple suivant, l'incroyable décision de choisir l'incorporation. Louis Guillaume (cl. 18) de Mizérieux, agriculteur, a passé son conseil de révision à Boën-sur-Lignon, dont dépendaient les communes de Nervieux et Mizérieux avant la guerre de 14-18; sur les quelque 20 conscrits de ces deux communes, deux ont été ajournés pour poids trop faible, inférieur à $50 \mathrm{~kg}$. Quant à lui, il aurait pu échapper à la conscription cette année là, mais ne l'a pas voulu: "Moi, j'ai passé près d'être ajourné: je pesais juste $50 \mathrm{~kg}$ ! Faible! On m'a demandé si je voulais partir. Alors j'ai dit oui. Je serais été ajourné d'un an, à la classe d'après.

E- Pourquoi est-ce que vous avez dit oui?

T- Je ne sais pas. Ça me retardait dans mon...C'était ma place, quoi! Il me semblait qu'il fallait que je parte!". Il a foi en la victoire proche en cette fin d'année 1916: "Je croyais au miracle: je croyais qu'on allait bouffer les Allemands! Et puis ça a été le contraire!".

Même réaction patriotique de la part d'un autre petit gabarit, de deux ans plus âgé, André Deloy (cl. 16), de Fraisses, métallurgiste à l'usine Jacob Holtzer de Firminy, qui exprimer sa peur d'être réformé pour insuffisance pondérale lors de son conseil de révision, au début de 1915: "Y avait le patriotisme en 14: Houla! J'avais peur qu'on me réforme, moi, j'étais gros comme un lapin... qu'on me fasse comme exempt! On m'a pas exempté, heureusement! Ah non! On était content!"

Toutefois, quelques témoignages montrent que la commission d'affectation a pu descendre un peu en-dessous de ce seuil des $50 \mathrm{~kg}$ pour incorporer les conscrits: ainsi Alphonse Berne (cl. 18) de Poncins pesait lui $54 \mathrm{~kg}$, mais il a eu un des ses conscrits, Jean Tarasse, pris alors qu'il ne pesait que $49 \mathrm{~kg}$.. Quant à son "classard" de la 18, agriculteur aussi, Edmond Buisson, il se souvient qu'à Mars, sur les 10 concrits pris sur les 11 présentés au conseil de révision, un était de fort petit gabarit: $1,53 \mathrm{~m}, 48 \mathrm{~kg}$, fait qu' il commente sobrement, avec un humour noir: "On n'était pas à un kilo près pour se faire tuer!"

Le faible poids peut valoir aussi une affectation spéciale, à défaut d'ajournement: Ainsi Léon Girard (cl. 13) d'Olloix (Puy-de-Dôme), comptable de profession à Paris jusqu'en 1939, puis à l'arsenal de Toulon jusqu'en 1959, retraité à Andrézieux, avait été, avant guerre, versé dans le service auxiliaire car il pesait moins de $50 \mathrm{~kg}$ : il a été nommé commis aux écritures du $152^{\mathrm{e}}$ R.I. de Clermont-Ferrand, et sans avoir pris de poids, pendant la guerre, a été maintenu dans cet emploi de bureau, dans divers régiments, jusqu'en 1919.

3- l'intervention d'une personnalité influente:

Un de mes témoins - que je ne nommerai pas - du centre du Forez, de la classe 16, typographe, m' a confié qu'il avait été ajourné à deux conseils de révision successifs en raison de l'intervention de son patron, homme politique local et proprétaire de journal.

4- un critère surprenant et rare: la fin de l'ordre alphabétique!

Apparemment, dans certains conseils de révision, il valait mieux s'appeler Vial ou Zimmermann (la Loire en comporte, du fait de la venue d'Alsaciens-Lorrains fuyant l'occupation, puis l'annexion prussienne en 1870-71) qu'Achard ou Barou! Deux témoignages concordant, un pour la classe 1915, un pour la classe 1916, tous deux des monts du Lyonnais, montrent que l'ajournement, donc en fait la chance de faire un an de moins de guerre, avec tous les risques de blessures et de mort que cela comporte, pouvait tenir à l'initale de votre patronyme!

René Villemagne (cl. 15) né à Chazelles-sur-Lyon, chapelier avant guerre, prothésiste dentaire à SaintEtienne après à cause de son amputation de la jambe gauche, a passé le conseil de révision à Chazelles-sur-Lyon, sans doute à l'automne 1914; tous les conscrits dont le nom avait une initiale après la lettre $\mathrm{S}$ ont été ajournés:

$\mathrm{E}$ - "Au conseil de révision, vous avez été ajourné: est-ce que je peux vous demander pour quelle raison? Vous étiez trop léger? 
T- J'ai été ajourné! Eh bien, nous avons eu de la chance, les dernières lettres de l'alphabet: ça a commencé à T: T..U..V: ajournés! Ils nous ont bazardés! Mais après, ils nous ont fait passer les premiers ${ }^{5}$, alors on a ben été pris! $Y$ a des costauds qui ont été ajournés! Ça faisait même blaguer les gens. Un tel qui faisait 80 kilos: ajourné!

C'est la même raison alphabétique qui a amené deux autres soldats de la classe 16, deux cousins au patronyme identique, Véricel, tous deux de Grammond, a être ajournés au conseil de révision du début de l'année 1915, passé sans doute à Saint-Héand. Victor Véricel, agriculteur et tisseur à Grammond, témoigne: "Ma classe, elle a passé la révision en 1915, je me rappelle bien, janvier - février, quelque chose comme ça. On était 9 de Grammond, 7 avaient été pris, les 2 derniers, un Véricel comme moi, un cousin d'ailleurs (ils devaient avoir pris leur contingent imposé) on a été ajournés! Une chance d'être ajourné! On a été ajournés tous les deux! On a dit: «Oh! » Pas plus contents que ça; "Oh! Dans deux ou trois mois, on repassera. Et puis la guerre sera finie". On a repassé en 1916; on a resté deux ans sans être rappelés, pas exactement deux ans: vingt mois. On a fait passer ceux qu'on appelait les récupérés: y avait des ajournés des classes 13,14, 15, 16, 17. J'ai été appelé en août 16.".

La chance de posséder un patronyme terminant l'alphabet a donc valu à ces deux cousins Véricel de Grammont, de la classe 16, d'être incorporés après même la date d'incorporation de la classe 17, en janvier 1916, donc de gagner seize mois par rapport à leurs conscrits de la classe 16, partis à l'armée en avril 15 et envoyés au front en général à l'automne 1915, et sans doute "vingt mois", comme il l'indique, par rapport à la montée au front. Ce sursis inespéré n'empêchera pas Victor de perdre un œil à cause de petits éclats d'obus reçus au visage le $1^{\mathrm{er}}$ juin 1918, à Château-Thierry...

On comprend que la commission d'affection devait avoir rempli son contigent d'incorporation; mas on demeure pantois devant une telle inégalité qui, ici, est matière de vie ou de mort...

5- le souci de préserver, en 1918, une corporation ayant eu de nombreux morts, les instituteurs

Lucien Faugère né en 1899 à Balbigny, après guerre instituteur à Moingt et Montbrison, puis professeur à Montbrison, sera incorporé au $16^{\mathrm{e}}$ R.A. Lourde d'Issoire à partir du 17 avril 1918, et atteindra la grade de capitaine à la seconde guerre mondiale. Il a passé son conseil de révision à Néronde en février 1918 et rapporte dans son récit écrit de guerre la petite conspiration féminine qui lui a valu son affectation dans l'artillerie alors que son métier d'instituteur se conjuguant à sa morphologie et à son poids auraient pu, d'après lui, le faire ajourner: "1918 Conseil de révision passé à Néronde - en février- 1 jour de congé! "Indice" trop grand, poids insuffisant - proposé pour l'ajournement car trop d'instituteurs sont restés à la guerre "qui va bientôt finir" affirme le sous-Préfet Protestation indignée de ma part, car j'ai tous les diplômes de préparation militaire: C.P.S.M. 6 spécialités, le brevet de moniteur qui donne droit à la $1^{\text {ère }}$ classe au bout de 3 mois de classe - Tout cela pour l'infanterie.

La commission du conseil de révision déjeune à l'Hôtel de l'Europe (Magat) en face de notre épicerie rue de la Gare à Balbigny. Catherine, après entente avec ma mère, "fait de l'œil" et soigne bien le sergent de Recrutement qui fait les affectations des jeunes recrues, et me fait affecter dans l'artillerie (où l'on risque moins que dans les autres armes) en prétextant que je suis son fiancé ...

Heureusement que je ne l'ai su qu'un an après..."

Tirons-en deux enseignements: l'affectation pouvait n'être pas neutre et subir l'influence d'un rapport personnel qui ne passait même pas ici par le médecin-major, mais par son subordonné, le sergent, sensible aux œillades et aux bons plats de Catherine Magat, la fille de l'Hôtel de l'Europe, et il était de notoriété publique, après plus de trois ans de guerre, que l'artillerie était moins exposée que l'infanterie. Retenons aussi qu'un instituteur patriote, et féru de l'art militaire, s'indignait de ce qu'on puisse le proposer à l'ajournement en février $1918 \ldots$

\section{Un critère de démobilisation: le fait d'avoir six enfants}

Sans aucun rapport avec le conseil de révision, puisqu'on n'a pas une famille nombreuse à dix-huit ans, mais à relier avec la notion d'exemption, pour un soldat relevant, vers 40 ans et plus (jusqu'à 48) de l'armée territoriale ou de sa réserve, ou avec celle de démobilisation, si la sixième naissance survient alors que l'on est à la guerre, il semble que le seuil d'exemption du devoir militaire ait été de six enfants (c'est ce qu'a indiqué Claude Pin, dr Cleppé), ce qui n'était pas rare à l'époque, et ce qui a pu déclencher, lors de permissions du père de famille, la décision de concevoir un ou deux enfants supplémentaires, afin de revenir du front.

Ainsi Maxime Jacquet (cl. 18) de Sail-sous-Couzan, serrurier puis ajusteur de précision (et après guerre commerçant itinérant en bonneterie) sera incorporé dans l'aviation comme mécanicien. Il a eu son beau-père envoyé au front puis retiré pour charge de famille, précisément pour ce nombre de six enfants, un enfant étant né après son incorporation. Sa femme témoigne: "Mon père est parti et il en est mort. Alors! Seulement il a jamais rien touché! Il est parti, on l'a renvoyé comme père de six enfants. Il a resté six mois chez ma mère, il est mort, on n'a jamais touché un sou, jamais!... Il a été fatigué, pas gazé... Il était malade, il a eu le cour, il a eu tout ce qui s'ensuit! Non! Parlez-moi pas de cette guerre!". Maxime lui-même a été incorporé malgré son format réduit:

E- "Vous me disiez que vous n'étiez pas un gros lapin?

T- Je vous dis bien: 1,50 m, $50 \mathrm{~kg}$ ! Oh! mais ils les ramassaient tous!"

${ }^{5}$ Après, c'est-à-dire au conseil de révision suivant, avec la classe 16. 
En fait, il semble bien que cette démobilisation des pères de six enfants, soit une des conséquences de la loi Dalbiez (sur laquelle nous reviendrons en fin de ce chapitre) votée par les députés le 26 juin 1915, promulguée par le président de la République le 17 août 1915 (au J.O. le 19), stipulant dans son article 5 + alinéa b que "Les gradés et les hommes de troupes placés:

$1^{\circ}$ - Dans des emplois sédentaires, soit dans la zone de l'intérieur, soit dans la zone des armées;

$2^{\circ}$ - Dans les servbices automobiles de l'intérieur

seront remplacés [...] b- Par les hommes sur service auxiliaire et, à défaut, par des réservistes territoriaux ou des territoriaux, en commençant par les pères des familles les plus nombreuses et des classes les plus anciennes." . De l'affectation militaire de ces pères de familles nombreuses - sans doute en partant du nombre d'enfants le plus élevé, qui pouvait excéder de loin six- - en service auxiliaire, en remplaçant d'hommes valides et mobilisables (les fameux "embusqués") qu'on renvoie au front, on passe alors à une forme de démobilisation...

\section{Critères d'affectation à un régiment particulier}

1 - dans les cuirassiers: la taille et la prestance:

Louis Seux (cl. 17) de Saint-Apollinard, puis de Saint-Chamond, que nous avons évoqué précédemment, incorporé au $23^{\mathrm{e}}$ R.I. de Bourg-en-Bresse, évoque le prestige des cuirassiers: "Et puis les beaux garçons, les bien charpentés, allaient aux cuirassiers à Lyon parce que c'étaient tous des gens qui avaient 1,80 - 1,85 m."

Son aîné d'un an Georges Montagne (cl. 16) de Bussières, patron tisseur, incorporé au $28^{\mathrm{e}}$ Bataillon de Chasseurs Alpins de Grenoble, confirme ce prestige des cuirassiers: "J'ai connu des camarades qui ont fait leur service... C'étaient des beaux gaillards, des campagnards qui avaient 1,90 m et des épaules comme ça, des gens très droits et très costauds, généralement des cultivateurs...

E- C'était l'élite, les cuirassiers?

T- Ah oui! C'était l'élite!"

Ce régiment d'élite en l'occurrence, pour la région, le $10^{\text {ème }}$ Régiment de Cuirassiers de Lyon, Jean Pouzerat, d'Arfeuilles (Allier) de la classe 13, y a été incorporé en décembre 13, deux mois après la classe 12, par l'effet de la loi de trois ans, avec la taille et la carrure pour y figurer dignement, mais il lui manquait une aptitude essentielle:

$\mathrm{E}$ - "Est-ce que vous saviez monter à cheval?

$\mathrm{T}-\mathrm{Du}$ tout! Mais je vous garantis que les deux fesses en prenaient parce qu'il fallait marcher trois mois sans les étriers, hein! Alors, toujours au tape-cul, assis sur le cheval comme ça, hein! On avait juste la selle, mais pas d'étriers! Après il fallait faire de la voltige et tout un tas de bazars formidables!"

Finalement, à la mobilisation, il sera versé au $17^{\mathrm{e}}$ R.I. de Lyon, puis montera au front au $158^{\mathrm{e}}$ R.I. de Lyon, qu'il rejoindra fin 1914 vers Saint-Quentin.

2- dans l'artillerie alpine et de montagne: la force physique

Louis Seux (cl. 17) de Saint-Apollinard, précise, après avoir évoqué les cuirassiers:

"Et puis alors, l'artillerie de montagne, on prenait aussi les plus costauds, pour l'artillerie alpine, parce qu'il fallait manoeuvrer les pièces à bras ${ }^{\prime \prime}$. Non seulement les manœuvrer à bras, sur la position de batterie, mais les démonter et en charger les éléments sur des mulets pour les transporter sur terrain montagneux, comme les Vosges, alors que les pièces de l'artillerie de campagne (les 75) et de l'artillerie lourde étaient tractées par trois-quatre paires de chevaux, voire cinq paires pour les 155 longs, très lourds, qui pouvaient tirer à $18 \mathrm{~km}$, comme l'indique Antoine Colombier, de Montbrison, incorporé au $304^{\mathrm{e}}$ puis au $104^{\mathrm{e}}$ Régiment d'Artillerie Lourde. Auguste Rousset (cl. 18), vitrier-miroitier au Coteau, qui a servi au $1^{\text {er }}$ Régiment d'Artillerie de Montagne de Grenoble, détaille la façon dont les canons de montagne de 65 étaient démontés pour être chargés à bras sur les mulets: "Je vous explique qu'il y avait le tube (le canon proprement dit) sur un mulet, le frein sur l'autre (l'amortisseur du recul), la flèche (partie arrière de l'affût du canon, servant à l'attelage) sur l'autre qui portait les appareils de pointage, et puis les roues sur l'autre: fallait quatre mulets pour mener la pièce! Puis derrière, y avait les mulets avec les obus, quoi, les caisses d'obus..."

3- dans les Chasseurs Alpins: la résistance et l'aptitude à la marche

Mais tout en étant conscient du prestige des cuirassiers, Georges Montagne (cl 16) de Bussières, est fier d'avoir été incorporé dans les Chasseurs alpins du $28^{\mathrm{e}}$ B.C.A. de Grenoble: "On nous passait une visite sérieuse, comme bon marcheur, les pieds surtout. Et puis la tête, et puis proportionnellement nerveux, au point de vue physique... Mais surtout les pieds... Il vous regardait les pieds, les mollets surtout... et puis la poitrine...

E- Donc c'étaient les plus résistants, les Chasseurs? C'était une sorte d'élite de l'infanterie?

T- Oui! D'ailleurs, on était division volante, on n'avait pas de corps d'armée: quand y avait un coup dur, on nous appelait. On était fier d'être dans les Chasseurs parce que c'était la marque. Vous savez qu'on avait une discipline très sévère! Et on marchait à 120 pas à la minute, les autres fantassins à 80 au maximum!"

\footnotetext{
${ }^{6}$ Dans l'artillerie de montagne, les petits canons de 67 ou de 37,5 sont mis en batterie à la main, et sont démontés pour être transportés, sur des terrains accidentés, sur les bâts des mulets.
} 
Un autre chasseur alpin, au $22^{\mathrm{e}}$ B.C.A. d'Albertville, Mathieu Grand (cl. 14) de La Tuilière, agriculteur avant guerre, aura l'occasion d'exercer son aptitude à la marche à pied en devenant facteur après guerre, principalement à Panissières; il se souvient de la palpation très spéciale du médecin major au conseil de révision: "Le major m'avait repéré en me touchant les nerfs, de la colonne vertébrale jusqu'au jarret."

\section{Les fortes têtes dans un régiment maudit: le $17^{\mathrm{e}}$ de Ligne!}

S'il est un régiment où l'on affecte prioritairement ceux qui sont précédés de la réputation de "fortes têtes" (ce qui suppose que des renseignements ont été transmis auparavant à la commission médicale d'affectation: par les renseignements généraux, ou les confidences de maires?) ou qui se révèlent l'être en se présentant en retard, ou pas du tout au conseil de révision, c'est bien le $17^{\mathrm{e}}$ dit "de Ligne" par tradition, avant d'être nommé $17^{\mathrm{e}}$ Régiment d'infanterie, ayant son dépôt à Béziers avant de l'avoir à Lyon, tout comme son régiment de réserve, le $217^{\mathrm{e}}$.

Quiconque a été quelque peu informé de la grande révolte des vignerons du Languedoc et du Roussillon en 1907, avec son chef charismatique Marcellin Albert, le cafetier-vigneron d'Argeliers, dans l'Aude (mais très proche de Béziers, dans l'Hérault) d'où est parti le mouvement le 11 mars, sait à peu près le rôle - mais avec une confusion très fréquente- qu'y a tenu le $17^{\mathrm{e}}$ de Ligne de Béziers, qui, après la fusillade qui fit six morts à Narbonne, tués par l'armée les 19 et 20 juin 1907, se mutina ce même 20 juin.

Cette connaissance, mais aussi cette confusion, nous la trouvons dans le témoignage du capitaine d'artillerie Etienne Becouse (cl.13) de Saint-Nizier-sous-Charlieu, qui évolua du grade de sergent (maréchal des logis) à celui de lieutenant dans la guerre de 1914-1918 dans divers régiments d'artillerie, puis fut capitaine au $36^{\mathrm{e}} \mathrm{R}$. d'Artillerie Lourde d'Issoire de septembre 1939 à juin 1940, où il fut fait prisonnier (le 20 juin) avec son régiment, et encoyé en captivité en Allemagne, d'où il fut libéré, en tant qu'ancien Poilu, en juin 1941 :

$\mathrm{T}$ - "Il y a eu une régiment qui a été en quelque sorte sanctionné : le $17^{e}$ d'Infanterie, en 1906, quand il y avait eu les troubles des viticulteurs du Midi. Ce régiment était cantonné à Narbonne à ce moment-là. Alors les autorités politiques ont envoyé un régiment.

$\mathrm{E}$ - C'était un régiment originaire de Béziers, je crois...qui avait refusé de tirer contre les viticulteurs...

$\mathrm{T}$ - Contre les viticulteurs... Alors, comme ils étaient tous de la région, vous comprenez, ils ont refusé, ils on levé la crosse en l'air. Ensuite, ce régiment a été envoyé à Sidi-Bel-Abbès en punition, puis ensuite il est revenu à Belfort quelque tempsavant 1914. Et comme c'était un régiment disciplinaire, toutes les fois qu'il y avait des attaques extrêmement dangereuses, c'était lui qu'on faisait attaquer en première ligne!

$\mathrm{E}$ - Pourtant, les gens qui y étaient à ce moment-là n'avaient rien à voir...

T - C'était complètement idiot, attendu que les gens qui y étaient en 1914, c'était pas les mêmes que ceux qui y étaient en 1906 !"

Composé principalement (à $80 \%$ ) de soldats du Biterrois, le $17^{\mathrm{e}}$ R.I. avait deux de ses bataillons casernés à Béziers et le troisième à Agde, mais le régiment entier avait été transféré depuis peu pour manœuvres et exercices de tir à Agde. Rémy Pech et Jules Maurin, dans leur ouvrage commun "1907 - Les Mutins de la République - La révolte du Midi viticole" paru en 2007 (éd. Privat) racontent que les mutins du 17e, qui ne représentaient qu'une partie de l'effectif total (les estimations varient de 350 à 800 , avec une moyenne assez consensuelle de $560=40 \%$ environ du régiment ${ }^{7}$ ), armés de 12000 cartouches prises dans la poudrière de la caserne Mirabel d'Agde, semblant reconnaître l'autorité d'un leader, le caporal Joseph Fondecave (de Béziers ${ }^{8}$ ) marchèrent sur Béziers, en ne tenant aucun compte des admonestations du général Lacroisade, qui avec son $81^{\mathrm{e}}$ R.I (dépôt à Rodez) tenta de les arrêter. Le rapport du préfet, cité par les auteurs, indique que les mutins "se dirigèrent dans la nuit vers Béziers où ils entrèrent, crosse en l'air", le 21 à 5 heures du matin, après avoir méconnu les ordres et repoussé les prières du général de brigade qui s'était porté à leur rencontre. ${ }^{10 " . ~ I l s ~ s ' i n s t a l l e ̀ r e n t ~ e n ~ h a u t ~ d e s ~ l o n g u e s ~ a l l e ́ e s ~ P a u l ~ R i q u e t, ~ q u i ~}$ s'achèvent vers le théâtre, lieu emblématique pour tout Biterrois, en un jour de marché au vin. Après de multiples tractations dans la journée, un début d'alerte (les mutins, en position de combat, tirèrent en l'air car ils crurent à une attaque des gendarmes), une rencontre avec le général de corps d'armée Bailloud venu exprès de Montpellier, les mutins consentirent à rendre leurs armes le soir du 21 juin, et rentrèrent à Agde par le train le lendemain matin. Dûment encadrés, ils furent envoyés en train à Gap le 24 juin, et embarqués à Villefranche-sur-Mer, avec comme objectif assigné Gafsa, dans le Sud tunisien, où on les soumit à la discipline de fer des Bat' d'Af.

\footnotetext{
${ }^{7}$ En 1907, les régiments, avec leurs trois bataillons, avaient un effectif inférieur de moitié environ à ce qu'il sera pendant la Grande Guerre. Ainsi Rémy Pech et Léon Maurin indiquent que Béziers, en 1907, avec les 2 bataillons du $17^{\mathfrak{e}}$ R.I. et 3 escadrons du $13^{\mathrm{e}}$ R. de Chasseurs, hébergeait 1500 soldats environ, et Agde 400, avec le $3^{\mathrm{e}}$ bataillon du $17^{\mathrm{e}}$.

${ }^{8}$ Il gérait, avec sa famille, la centrale électrique privée de Capestang, en un temps où la production et la distribution électriques n'étaient pas nationalisées.

${ }^{9}$ Cette expression, devenue célèbre, signale et stigmatise la mutinerie, par le refus de porter réglementairement le fusil, et symboliquement, par le refus de s'en servir comme une arme. Les mutins de 1917 "ont mis la crosse en l'air", même si beaucoup d'entre eux n'ont jamais, littéralement, fait ce geste.

${ }^{10}$ Rémy Pech et Jules Maurin, op.cit. p. 56
} 
Contrairement à la légende, il n'y eut donc jamais refus de tirer sur le peuple en révolte. Mais les mutins du $17^{\mathrm{e}}$ furent promus héros révolutionnaires dans le contexte pré-révolutionnaire de la révolte des vignerons du Midi, relayés par les municipalités qui avaient démissionné pour suivre le mot d'ordre lancé le 10 juin par la comité d'Argeliers, mot d'ordre suivi par 76\% des municipalités de l'Hérault, 53\% de l'Aude, 44\% des Pyrénées Orientales et $8 \%$ : du Gard ${ }^{11}$, mot d'ordre qui prônait aussi la grève de l'impôt. Mais ce fut surtout, en un temps où la France chantait beaucoup, la célèbre chanson de Montéhus ${ }^{12}$ "Gloire au $17^{\text {ème }}$ composée en 1907 qui popularisa sa révolte en France et accrédita le refus de tirer et celui d'embrocher. Le premier couplet approuve leur refus supposé, en se terminant par "Soldats, votre conscience est nette // On ne se tue pas entre Français; // Refusant de rougir vos baïonnettes, // Petits soldats, oui, vous avez bien fait!". Et qui ne connaît le célèbre refrain qui revient quatre fois: "Salut, salut à vous, // Braves soldats du $17^{\text {eme }}$; // Salut, braves pioupious ${ }^{13} / /$ Chacun vous admire et vous aime; // Salut, salut à vous, // A votre geste magnifique; // Vous auriez, en tirant sur nous, // Assassiné la République. //?

Pour avoir vu début avril 2007, à Capestang, où mon beau-père Léon Guilhaumon est né en 1908 et repose depuis 1983, à $15 \mathrm{~km}$ à l'ouest de Béziers, la ferveur entourant le commémoration du centenaire de la révolte des vignerons, et admiré la spectaculaire exposition de faisceaux de douelles de tonneau peintes en bleu-blanc-rouge envahissant toute la grande place Jean Jaurès, à côté de la collégiale, douelles symbolisant les faisceaux pacifistes de fusils du $17^{\mathrm{e}}$ de Ligne ${ }^{14}$, je puis dire que la révolte du $17^{\mathrm{e}}$ parle encore aux coeurs des Languedociens.

Certains conscrits de la Loire, étiquetés "fortes têtes" se retrouvent au $17^{\mathrm{e}}$ R.I. ayant désormais son dépôt à Lyon.

C'est le cas de Marius Redon (cl. 14) de Grand-Croix, fils d'un briquetier, travaillant aux ateliers de la Marine de Saint-Chamond avant d'aller à la guerre, qui y retourna pendant 14 ans après guerre, avant d'exercer pendant 24 ans la profession de facteur à Rive-de-Gier puis à Saint-Chamond.

Il vient de signaler que le $17^{\mathrm{e}}$ R.I auquel il a été incorporé, en même temps que ceux de sa classe, en septembre 1914, et où il restera jusqu'à sa grave blessure à l'oeil reçue le 9 juin 1915, vers Abbeville, qui le fera longuement hospitaliser puis verser finalement dans le service auxiliaire (il perdra totalement la vision de cet œil) avait plus souvent qu'à son tour droit aux attaques, et aux attaques les plus difficiles:

T- "Chaque fois qu'on attaquait, qu'on redescendait, fallait boucher les trous, remplir les vides! Alors, on allait au repos pendant un mois, deux mois...

E- Vous aviez beaucoup de pertes?

T- Beaucoup de pertes! C'était obligé: chaque fois qu'on montait en ligne, c'était pour attaquer! C'était pas pour tenir les tranchées! Alors, on se faisait nettoyer chaque fois! "Eh, oui, le régiment est toujours au repos! ${ }^{15 "}$. Ils se doutaient pas que chaque fois qu'on montait, ben on redescendait, il en manquait la moitié!

E- Donc vous avez l'impression que vous attaquiez plus que les autres régiments?

T- Oh oui! Je sais pas d'où ça vient... Pourtant, mon régiment, c'était un régiment comme les autres!

E- Non, justement! C'était pas un régiment comme les autres!

$\mathrm{T}$ - Eh, le $17^{\text {ème }}$, il a payé la faute de ceux qui y étaient avant la guerre!

E- Est-ce que vous le saviez, que vous alliez dans un régiment spécial?

T- Oh! pas du tout! Non, non, non! Ça risque pas!

E- Et on vous l'a appris après? Qu'est-ce qu'il avait fait, le $17^{\text {ème }}$ ?

\footnotetext{
${ }^{11}$ Pourcentages cités dans le site Internet "1907 - 2007 Centenaire de la révolte viticole - Salut, salut à vous..." de La Commune, Section française de l'Union Internationale des Travailleurs.

${ }^{12}$ Montéhus (1872-1952), de son vrai nom Gaston Mordachée Brunschwig, d'abord socialiste modéré, évolua vers un antimilitarisme virulent avant de se rallier en 1914 à L'Union Sacrée. Ses chansons les plus célèbres, en dehors de "Gloire au $17^{e " ~}$ sont "Lettre d'un Socialo", et surtout "La jeune Garde" et "La Butte Rouge" qui célèbre le martyre des Communards. Comme juif, malgré son âge et sa réputation, il fut contraint au port de l'étoile jaune sous le gouvernement de Vichy. Il reçut la Légion d'Honneur en 1947.

${ }^{13}$ Le terme "pioupiou" pour désigner familièrement un jeune fantassin, est selon Alain Rey, dans le "Dictionnaire Historique de la Langue française" apparu en 1838, et dérive de l'onomatopée enfantine imitant le cri des poussins.. Il a engendré l'adjectif rare "pioupiesque" employé par Baudelaire et Rimbaud

${ }^{14}$ C'est l'interprétation symbolique qui m'a été donnée par son concepteur le jour même de cette inauguration à Capestang, le 7 avril 2007, contrairement à la lecture symbolique qu'en donne Jean Clavel, à propos de Montpellier (où cette exposition a fini son parcours, conformément à la succession des meetings de 1907), dans son site Internet, par ailleurs de grande qualité, présentant en 20 pages l'histoire de la révolte viticole de 1907 et le calendrier des manifestations de commémoration: "Il y a sur l'Esplanade de Montpellier une création-composition-exposition étonnante qui occupe beaucoup de place. Elle est composée principalement de rangées de trépieds fabriqués à partir de douelles de tonneaux de 220 litres de vin, les uns colorés aux 3 couleurs françaises symbolisant l'armée d'occupation du Languedoc et de rangées couleurs bois, symbolisant les manifestants." Pour le concepteur, les faisceaux de douelles en bois naturel, non peint, représentaient les civils, vignerons manifestants, et pour certains, victimes de la répression.

${ }^{15}$ Marius ici insère, sans prévenir, une phrase qu'il a souvent entendue dire à propos du $17^{\mathrm{e}}$ R.I. par des camarades, envieux de ces fréquents repos entre deux attaques, camarades appartenant à d'autres régiments d'infanterie.
} 
T- Eh! Il avait refusé de tirer pour les grèves... On le savait ${ }^{16}$, on n'avait pas besoin de nous le dire. Quand on avait recruté au $17^{e ̀ m e: ~ " A h, ~ b e n, ~ u n ~ b o n ~ r e ́ g i m e n t, ~ l a ̀, ~ t i e n s ! " ~(i r o n i q u e) . ~ E h ~ b e n, ~ c ̧ a ~ y ~ e s t ! ~}$

E- Et vous, c'est le hasard qui vous a fait recruter au $17^{\text {ème ? }}$

T- C'est-à-dire que moi, je me suis pas présenté à Saint-Etienne, là... J'habitais à Saint-Chamond, et mon père habitait Saint-Etienne. Et quand j'ai reçu la convocation pour la guerre, ben mon vieux, ça fait que je me suis pas présenté du tout! J'ai dit: "Ils feront ben ce qu'ils voudront!" Puis alors, bien sûr, faut pas demander: j'ai passé

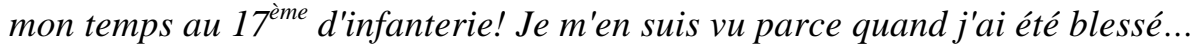

E- Ils vous ont retrouvé au bout de combien de temps?... Vous êtes pas allé à Saint-Etienne au moment de la mobilisation...

T-Oui!

E- Et on vous a retrouvé au bout de combien de temps?

T- Avec le départ de la classe: ça a pas tardé! A la fin de l'année, quoi! $!^{17}$

E- Vous aviez conscience que vous preniez des risques?

T- Non, non! C'était pareil! Y en a bien qui ont fait comme moi! "Ils viendront bien nous chercher s'ils nous veulent!" (rire). On était pour partir, alors, de toute façon, y avait pas à chercher de conseil de réforme, là, hein!"

On croit d'abord que c'est par simple négligence que Marius ne s'est pas présenté à le "convocation pour la guerre", qui a dû arriver à l'adresse parentale à Saint-Etienne au lieu d'être adressée à Saint-Chamond, où travaillait et résidait Marius. Mais sa réflexion: "Ils feront ben ce qu'ils voudront!" et la généralisation de son cas à d'autres réfractaires ("Y en a bien qui ont fait comme moi!") montre qu'il joue avec le feu et espère sans doute n'être pas retrouvé par l'administration militaire.

Marc Delime (cl. 15), cordonnier à Boën-sur-Lignon avant guerre, affûteur-outilleur à l'usine Gauchon de Boën pendant 47 ans après guerre, a, lui, été affecté au $17^{\mathrm{e}}$ R.I. sans raison disciplinaire à l'été 1915 , après trois mois passés au $2^{\mathrm{e}}$ R.I. de Granville, son incorporation s'étant faite avec la classe 16, après un ajournement pour insuffisance pondérale ( $49 \mathrm{~kg}$ ). Avec le $17^{\mathrm{e}}$ R.I. , il est allé trois fois à Verdun en 1916, alors que la grande majorité des régiments d'infanterie n'y faisait qu'un seul séjour, de deux ou trois semaines, le général Pétain ayant organisé la rotation des régiments pour leur permettre de tenir. Il est resté deux ans au $17^{\mathrm{e}}$ R.I., et y a gagné la croix de guerre pour avoir capturé des Allemands lors d'une patrouille nocturne, ainsi qu'une blessure à l'épaule, puis a été versé au $158^{\mathrm{e}}$ R.I. de Lyon. Il a bien conscience de la mauvaise réputation qui pesait sur le $17^{\mathrm{e}}$ R.I. , apparemment répétée par les officiers:

E-" Vous dites que le plus terrible, c'étaient les bombardements?

T- Moi, j'ai souffert beaucoup des bombardements, je vous dirai pourquoi/ Parce que j'étais dans un régiment, "le Puni", qu'on appelait! Vous comprenez, il avait été puni quand ils faisaient les grèves des vignerons, je sais pas quoi! Alors, moi j'étais là-dedans! J'en attrapais comme les autres!

E- Mais alors ce régiment de "punis"...

T- Faut pas marquer "puni", hein! (l'assistance familiale éclate de rire, mais pas lui!)

E- Vous êtes le troisième que je vois qui a fait partie de ce régiment, vous comprenez, notamment le facteur de Saint-Chamond ${ }^{18}$. Comment est-ce qu'on vous faisait payer d'être dans un régiment de "punis"? ... On vous maintenait plus longtemps en première ligne?

T- Eh ben, pas du tout! On était relevés tous les quinze jours! A la fin, c'était tous les huit jours!

E- Mais alors, comment est-ce qu'on vous faisait sentir que vous étiez punis?

T- Eh ben, on nous disait que c'était un régiment de punis! Mais on nous donnait à manger!"

Si Marc Delime indique qu'ils étaient relevés souvent et ne restaient pas longtemps en première ligne, c'est que, considéré comme un régiment d'attaque, le $17^{\mathrm{e}}$ R.I. était relevé dès que l'attaque avait été faite, pour être transféré sur un secteur voisin, en perspective d'une nouvelle attaque. Par ailleurs on constate avec plaisir qu'on n'affamait pas ces "punis", ce qui aurait affaibli leur efficacité combattante!

Interwievé entre Marius Redon (le 18 janvier 88) et Marc Delime (le 6 avril 88), Jean Pouzerat (vu le 5 février à son domicile d'Arfeuilles) de la classe 13, né à Arfeuilles (Allier) dans une famille de métayers, ayant après guerre cultivé comme métayer aussi la ferme d'Arfeuilles, puis comme agriculteur propriétaire, exploité une ferme au Breuil (Allier) de 1931 à 1958, avant de revenir pour sa retraite à Arfeuilles, est passé du 10 R. de Cuirassiers de Lyon où il était depuis décembre 1913 au $17^{\mathrm{e}}$ R.I. à la mobilisation d'août 14, mais est monté au

\footnotetext{
${ }^{16}$ La contradiction n'est qu'apparente: Marius n'était pas informé avant guerre de la mauvaise réputation du $17^{\text {ème }}$, aux yeux de la hiérarchie militaire (il n'avait que 13 ans en 1907), mais il l'a apprise dès son incorporation., et l'a vécue douloureusement dans le traitement de choc qu'on lui imposait à la guerre...

${ }^{17}$ La réponse est ambiguë: on ne sait pas si Marius a été retrouvé juste avant le départ de la classe 14, donc début septembre 1914, soit seulement au moment de la montée de la classe 14 au front (vers fin novembre), ce qui correspondrait effectivement à "la fin de l'année". On conçoit alors qu'un retard de trois mois à la conscription soit une très grave faute au regard de la justice militaire, d'où l'envoi au $17^{\mathrm{e}}$ pour mater celui qu'on devait considérer comme un déserteur!

${ }^{18}$ Ce facteur de Saint-Chamond est évidemment Marius Redon, qui vient d'être cité, que j'avais interviewé le 18 janvier 1988 , trois mois avant cet entretien qui date du 6 avril 1988
} 
front, fin décembre 1914 , dans l'Aisne, avec le $158^{\mathrm{e}}$ R.I. de Lyon et y est resté toute la guerre. Son séjour au $17^{\text {ème }}$ a donc peu duré, mais il en connaît la réputation sulfureuse sans toutefois bien en identifier l'origine:

E- "C'était un régiment connu, le $17^{\text {ème }}$, non?

T- "Parce que je sais pas... Y avait eu des bêtises, je me rappelle pas bien... Alors, ils étaient vissés un petit peu! S'il y avait un coup dur, ils étaient toujours les premiers à y partir, quoi!"

Mais il ne sait pas précisément pourquoi il était connu, même quand je lui suggère, en me trompant à l'époque: "Il avait pas levé la crosse devant les vignerons du Midi?".

Un autre Poilu de Saint-Chamond, vu un moins d'un mois (le 12 février 1988) après le précédent Marius Redon qui m'en avait indiqué l'existence, Louis Seux (cl. 17) fils de paysans de Saint-Apollinard, vers Pélussin, resté à la ferme jusqu'à son incorporation, devenu après guerre comptable puis chef de fabrication aux Manufactures Réunies de Tresses et Lacets de Saint-Chamond (700 ouvriers) n'a jamais été au $17^{\mathrm{e}}$ R.I. (il a été successivement au $23^{\mathrm{e}}$ R.I. de Bourg-en-Bresse, au $35^{\mathrm{e}}$ R.I. de Belfort, puis au 360 ème R.I. de Toul), mais il l'a côtoyé dans la même division:

E- "Y avait monsieur Redon qui était dans votre cas, mais on se posait le problème... Il était au $17^{e}$ et on se demandait si on faisait pas payer au $17^{e}$ ses ennuis...

T- D'avant guerre! Parce qu'ils en ont subi, au 17è à cause de ça! On les ménageait pas! On les ménageait pas! Mais d'un autre côté, ça a été en leur faveur quelquefois, parce que quand on était dans un endroit délicat, on les envoyait pas bien! Parce qu'on était pas sûr d'eux!

E- Et pourtant...

T- Et pourtant,ils se sont bien conduits!

E- Ceux qui y étaient à ce moment-là n'avaient rien à voir avec...

T- Non, non! Mais les officiers, vous comprenez.

E- C'étaient les mêmes, vous croyez?

T- Ah! Il se pouvait qu'il y en ait des mêmes... Ils avaient la renommée, voilà! C'était une renommée qui les avait suivis!

E- Parce que c'est l'épisode de Marcellin Albert...

T- Oui, de 1905, par là! ${ }^{19}$

E- $5-7 \ldots$

T- Et de Clémenceau qui était, lui, pour la répression!

E- $Y$ avait donc des régiments maudits, où il valait mieux pas tomber?

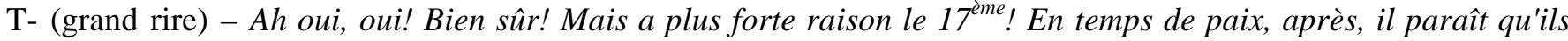
étaient considérés comme un régiment de bagnards, pour ainsi dire..."

Ainsi donc, la belle conduite du $17^{\mathrm{e}}$ R.I. à la guerre n'aurait pas suffi à effacer, aux yeux de l'armée, la tache originelle de la mutinerie de 1907. Dans ce témoignage, on constate que pour Louis Seux, la mauvaise réputation devient un avantage: se méfiant du régiment, l'Etat-major aurait parfois renoncé à l'engager dans des assauts, de crainte sans doute de mauvaise volonté, voire de révolte.. Cependant, le témoignage des soldats incorporés au $17^{\mathrm{e}}$ ne vient pas corroborer cette affirmation.

Mais le $17^{\mathrm{e}}$ n'est pas le seul à souffrir de cet ostracisme, même s'il est le seul à être connu de tous pour ses antécédents de 1907, glorieux pour les pacifistes, mais plus que fâcheux pour l'Etat-major. Ainsi Pierre Néel, né le $1^{\text {er }}$ juin 1918, fils de cantonnier de Verrières-en-Forez, devenu cantonnier puis chef contonnier lui-même à Saint-Georges-en-Couzan, puis à Moingt, où il a pris sa retraite avant de revenir chez son fils, garagiste à MargerieChantagret, raconte comment il a été muté, sans raison apparente indiquée, dans un bataillon disciplinaire, après une première incorporation au $38^{\mathrm{e}}$ R.I. de Saint-Etienne, puis au $321^{\mathrm{e}}$ de Montluçon (Riom) en mai 17:

T- "J'ai été affecté au 38 de Saint-Etienne, et du 38 je suis monté au 321 et au front au 3eme bataillon du 321, au bataillon disciplinaire. Il a été disciplinaire en 14. Alors ce bataillon...ceux qui ont tombé dedans, ma foi, ça pas été le rêve!

E- Oui mais ce n'était pas de leur faute! Les jeunes comme vous...ça n'était pas de votre faute!

T- Eh oui! C'était pas de notre faute, mais a fallu payer! Le $3^{\text {ème }}$ bataillon du 321 !

E- [...] Pourquoi est-ce qu'on vous avait mis dans ce bataillon? Vous ne l'aviez pas demandé!

T- Jamais j'ai rien fait de grave dans ma vie. Eh ben, c'est un hasard!"

Un hasard qu'il lui faut payer cher. D'abord par une instruction réduite en un envoi très rapide au front:

T- "Je suis monté au front le $1^{\text {er }}$ juin 17! Juste à mon âge! Le $1^{\text {er }}$ juin 17!

E- Vous aviez 19 ans, le $1^{\text {er }}$ juin 17 !

T- Je suis monté à 19 ans!

E- Ouh! Mais alors, vous êtes arrivé au front bien avant ceux de votre âge, parce que ceux de votre âge (la classe 1918) y sont arrivés soit à la fin de l'année 17, soit au début de 18!

T- Ça a été rappelé deux-trois fois. Mais moi je suis parti du premier contingent!"

19 "Par là", encore très usité en Forez, signifie "environ" en français local 
Hasard qu'il faut ensuite payer par des attaques très fréquentes, avec une telle fréquence qu'elle paraît pire que celle qui a été imposée au $17^{\mathrm{e}}$ R.I.:

T- "Après l'Alsace, on a fait des contre-attaques en partie tout le long du front. Des contre-attaques parce que le $3^{e}$ bataillon était disciplinaire et devait faire les contre-attaques. Alors on faisait les contre-attaques tout le long du front, quoi, partout où il y avait des contre-attaques. Et on avait fini là, on recommençait plus loin, et tout de suite, et ça a duré longtemps! Des fois deux fois par semaine, des fois trois! Ah! oui!

$\mathrm{E}-$ Mais il devait y avoir beaucoup de morts?

T- Ah! Y avait beaucoup de morts! Dans les contre-attaques, pensez-vous qu'il y a toujours des morts! Y a pas de doute!

E- Mais alors on vous renouvelait sans arrêt?

T- Ah oui! Tous les jours, on recevait du renfort! Tous les jours qui arrivaient: renfort!

E- Ça doit être exceptionnel comme vous, de s'en être tiré?

T- Ça a été la chance, au petit bonheur... Parce que j'en ai passé bien près, plusieurs fois! Je suis été transpercé comme ça à l'épaule, ça a raclé la peau. Ah! ce jour on était du côté de Verdun, en arrière de Verdun. C'est nous qui l'avons pris, Verdun! C'est nous qu'on a gagné la fourragère à la couleur de la Légion d'Honneur, le $3^{e}$ bataillon!"

Il décrit plus loin dans l'entretien l'organisation logistique de ces contre-attaques: "On était emmené par des camions autour d'une quarantaine de kilomètres à l'arrière, $50 \mathrm{~km}$, pour nous déplacer d'un côté à l'autre, mais autrement tout à pied.

E- On vous faisait longer le front?

T- On longeait le front!

E- Et vous étiez dans tous les coups durs?

T- Nous autres, je vous dis bien: le $3^{e}$ bataillon du 321 était spécialisé aux contre-attaques. Alors partout où y avait des attaques, allez: contre-attaque! Alors, fini celle-ci, c'était signalé qu'il y en avait une autre $2 \mathrm{~km}$ plus loin, $1 \mathrm{~km}$ plus loin, 500 mètres: allez, contre-attaque! C'était pas le meilleur moyen... (pour rester en vie?)

E- Vous dites le $3^{e}$ bataillon: les autres bataillons du 321, ils le faisaient pas?

T- Non! Ils se battaient bien, mais ils n'étaient pas pour aller faire la contre-attaque! Le $3^{e}$ bataillon, c'était LE bataillon disciplinaire!"

On voit donc qu'on peut appartenir sans raison apparente à un bataillon ou un régiment disciplinaire, ne concevoir aucune amertume de cette injustice du sort, et même s'enorgueillir de ses faits d'armes et de ses récompenses militaires... Le mitrailleur Pierre Néel gagnera plus tard, pour lui et non pour le drapeau du régiment, la fourragère de la Légion d'Honneur à la prise de Saint-Quentin, en juin 1918, et une citation à l'ordre du régiment.

\section{Les engagés volontaires et leurs motivations}

Nous n'envisagerons pas le cas, rare au demeurant, des engagés volontaires avant que la guerre ne se déclare, généralement pour se débarrasser au plus vite du service militaire, afin de pouvoir se lancer dans la vie, notamment en cessant d'être un valet non rémunéré à la ferme familiale. Après le service militaire, on peut travailler pour son compte si l'on n'a pas pu le faire avant, les gages perçus servant souvent de complément de revenus aux familles, surtout si elles sont nombreuses. Et au bout de quelques années d'économies, épouser la jeune fille qu'on fréquente.

Mais une fois la guerre déclarée, s'engager, c'est devancer l'appel, donc hâter la confrontation avec le feu, avec la mort toujours possible. A-t-on cessé alors de s'engager? Certes, non, mais le phénomène reste marginal parmi nos témoins (quatre sur 104 incorporés relevant des classes 15 à 19, plus un cas particulier de la classe 12). Quelles en sont les motivations, probables ou déclarées?

Comme ces cas sont rares, nous ne reviendrons pas sur ce thème, ce qui nous amène a dépasser le strict cadre chronologique de l'année 1915.

Un cas intéressant est représenté par Jean Fontaney né en 1892, de Montrond-les-Bains (Meylieu), instituteur, puis professeur et futur directeur d'Ecole Normale, ajourné au service militaire en 13, définitivement exempté au printemps 14 pour faiblesse de constitution, qui s'est pourtant engagé pour la durée de la guerre le 20 septembre 14 "non pas parce que j'étais cocardier, non plus parce que je croyais que la guerre était une marche joyeuse vers Berlin (on était déjà fixé un peu) mais simplement vis-à-vis de moi. Comme pour avoir bonne conscience et parce que dans ma famille je comprenais mal que mes deux aînés soient partis et risquent de mourir pendant que moi je restais célibataire et en somme...embusqué, comme on disait... ». Il a été incorporé au $60^{\mathrm{e}}$ R.I. de Nantes.

En dehors de ce cas exceptionnel, ce n'est pas faire injure à nos autres engagés du temps de guerre de dire qu'ils l'ont vraisemblablement fait d'abord pour être incorporés dans l'artillerie (c'est le cas de trois sur quatre, le dernier allant dans la marine) arme s'étant vite avérée beaucoup moins meurtrière que l'infanterie -même si elle a eu aussi beaucoup de pertes- comme on a déjà pu le constater dans le témoignage de Lucien Faugère que la conspiration féminine de sa mère et de la fille de l'auberge où mangeaient les membres de la commission d'affectation a réussi à faire affecter dans l'artillerie. Cependant, ils peuvent invoquer d'autres motifs. 
Engagements dans l'artillerie

Etienne Carton (cl. 18), né à Poncins dans la ferme que louaient ses parents, s'installant ensuite comme propriétaires à Saint-Etienne-le-Mollard, qui sera après guerre 36 ans cantonnier à Feurs, a ses deux frères aînés revenus du front blessés en 1914 (l'aîné à l'épaule gauche, en août, dans le combat de Baccarat avec son $2^{\mathrm{e}}$ Dragons de Lyon, le second, Antoine, $216^{\mathrm{e}}$ R.I. de Montbrison, en septembre, à la Marne, blessé au nez et à un œil , qui a perdu la vision) et réformés au moment où il s'engage, en 1916. Il demande à être incorporé au $113^{\mathrm{e}} \mathrm{R}$. d'Artillerie Lourde où se trouve un autre de ses frères, Etienne, et invoque avant tout la défense de la France comme motif de son engagement, mais aussi le désir de rejoindre Etienne pour lui porter secours au besoin:

T- "Alors mes deux frères étaient revenus, la guerre dure. En 1916, je décide de m'engager, d'aller avec mon autre frère qui était au front, il était au 113 justement. Alors je m'engage...

$\mathrm{E}-$ Vous avez décidé de vous engager pourquoi exactement?

$\mathrm{T}-$ Ah ben, pour défendre la France!

E- Vous auriez pu ne pas vous engager!

T- J'aurais pu attendre ma classe, elle est partie en 17 !

E- Est-ce que vos frères, ceux qui étaient revenus du front, vous en avaient parlé, de la guerre?

T- Ah la la! Il m'avaient dit...Oh! ben, j'ai dit, je vais partir avec Etienne, mon frère, s'il y a un qui tombe, l'autre le relèvera!

E - Pourtant vous saviez ce que vous risquiez!

T- Ah ben sûrement! Je risquais la mort tous les jours!

$\mathrm{E}-$ C'était par patriotisme que vous êtes parti?

$\mathrm{T}$ - Ah oui! Pour défendre la France! Pas les laisser rentrer! Ils auraient pris toute la France, les Allemands! Vous savez, ils nous auraient fait marcher comme des nègres! Vous les connaissez pas, les Allemands! Moi, je les connais! Ça aurait été un malheur, un grand malheur! Parce que les Allemands, ils voulaient dominer toute la France, ils nous auraient pris comme colonie, ils nous auraient même chassés de chez nous pour mettre les leurs! Oh, vous savez, ils étaient cruels! Quand ils ont avancé, en 14, ils tenaient presque quatre départements, ils saccageaient tout! Ils tuaient les femmes, les hommes et les enfants!

E- Est-ce que vous pensez que si vos deux frères étaient restés sur le front, vous vous seriez engagé aussi?

T- La même! $!^{20}$ Je pensais à défendre la France! Oui, c'était mon cœur!"

Un autre Poilu de Feurs, d'un an plus jeune, Pierre Mollon (cl. 19), en 1917 ouvrier à la Manufacture d'Armes et de Cycles de Saint-Etienne, qui deviendra transporteur et marchand de matériaux de construction à Feurs, s'est engagé avec son copain Marius Berticat, en 1917, à 18 ans, aussi dans l'artillerie lourde, sur un coup de tête selon lui, et lui accueille avec scepticisme l'explication suggérée du patriotisme:

"J'ai été immobilisé* à Lodève: je m'étais engagé dans l'artillerie lourde, hein! Je me méfiais pourtant de l'incorporation, parce que j'étais dans les plus loin ${ }^{21}$. Mais je t'en fous! Quinze jours, je suis resté. Et puis un jour, j'entends crier dans la rue...je vois un peloton qui se forme dans la cour de la caserne. Et puis j'entends crier: "Mollon! Mollon! Mollon!" J'y suis descendu. Alors on m'a dit: "Eh ben allez! Va chercher ton fourbi! Et puis tu pars avec le peloton". Il se souvient que c'est en 1917, mais pas exactement de la date. Puis la conversation continue:

E- "Est-ce que vous vous souvenez pourquoi vous vous êtes engagé?

T- Ben, j'en sais rien du tout! C'est une idée qui nous a pris: on était gamins, quoi! A ce moment-là, on a pris idée de s'engager, puis c'est tout! La guerre finissait pas! Lui, il avait été embusqué à Paris, il avait mieux réussi, il est resté à Paris; après je l'ai perdu de vue. Et moi, ce qui m'a fait embarquer là-dedans, c'est ma spécialité de mécanicien-chauffeur. Et comme il fallait des chauffeurs pour les mener, ces machins, pffuitt! J'ai été embarqué!

E- Donc, ça n'est pas... c'est quand même par patriotisme que vous êtes parti?

$\mathrm{T}-O h$ ! Si on veut, hein! (ton dubitatif suivi d'un rire)

E- Moyennement?

T- Parce que... si c'était maintenant, je le referai pas! "Parce que pour voir ce qu'ils ont fait de la France, eh ben!

E- Mais c'était peut-être aussi pour connaître l'aventure?

T- Oh! Même pas! Est-ce qu'à cet âge-là on peut bien réfléchir?"

Et c'est ainsi que de l'artillerie lourde, Pierre Mollon passa presque aussitôt à la conduite d'un char Renault, au $504^{\text {ème }}$ Régiment de chars d'Orléans, et y fit la fin de la guerre, de l'automne 1917 à l'armistice.

En revanche, l'engagement patriotique est clairement revendiqué par le troisième engagé dans l'artillerie, au moins au départ, Jean-Baptiste Biosset, de Renaison, né le 9 octobre 1898 à Saint-Haon-le-Chatel, engagé en décembre 1916, alors qu'il était chauffeur d'un député du Roannais dont il aurait pu sans doute attendre un appui

\footnotetext{
20 "La même" : expression locale signifiant la même chose, pareillement, ou parfois volontiers (quand on répond à une proposition, par exemple de prendre un verre: "- Tu prendras bien un pastis? - La même!"

21 "J'étais dans les plus loin": Pierre doit vouloir dire qu'étant de la classe 19, et qui plus est de la fin de l'année (né le 7 novembre 1899), il était dans les plus éloignés risquant de partir au front. A moins que le fait d'être artillerie lourde le place dans les combattants les plus éloignés du front, mais le "parce que" succédant à la notion d'incorporation ne se comprendrait pas, dans ce cas.
} 
pour un ajournement, ajournement que son poids réduit pouvait lui valoir directement. Son acharnement à vouloir combattre atteste l'authenticité de la motivation. Son témoignage est d'abord lu (car le rendez-vous avait été pris la semaine précédente et quelques témoins ont réagi ainsi, en écrivant dans l'intervalle certains faits de leur guerre jugés importants), puis devient un dialogue avec l'enquêteur:

T- "A l'approche de mes 18 ans, j'ai voulu m'engager. J'avais peur d'être ajourné au conseil de révision car je ne pesais que $49 \mathrm{~kg}$ pour 1,59 m, et une santé précaire. Mais je voulais être soldat! Me sentant pas assez solide pour servir dans les troupes à pied, j'avais choisi l'aviation en disant: "La machine t'emportera!" . Mais je n'ai pas réussi mon engagement dans l'aviation, car j'avais une tare au cour. Il me restait l'artillerie motorisée. Un seul régiment acceptait des engagés ${ }^{22}$ : c'était le $81^{e}$ Régiment d'Artillerie Lourde au camp de Satory à Versailles. Cette artillerie lourde se révéla au-dessus de mes moyens physiques. Les classes terminées, je fus classé "Inapte au front" et fus versé au service automobile à Boulogne-sur-Seine pour former des chauffeurs, étant moi-même chauffeur mécanicien. Un jour on a demandé des chauffeurs qualifiés pour une formation d'auto-canons de 75 du $62^{e}$ d'Artillerie de Saint-Cloud. Je me suis fait inscrire. Quelques jours après, je partais en formation à Arnouvilleles-Gonesse, au nord de Paris. Après quelques jours d'entraînement intensif, j'ai dû être hospitalisé le 27 juillet 1917 à l'hôpital militaire Villemain à Paris, pour crise cardiaque aggravée en service commandé. A ma sortie de l'hôpital le 13 août 1917, il fallut faire de la place aux blessés venant du front. Je devais rejoindre mon dépôt à Arnouville comme me l'indique ma feuille d'hôpital. Là, j'aurais pu obtenir une convalescence ou être classé "Service auxiliaire". Ce n'était pas mon but. Lorsque je me suis retrouvé seul dans la rue, je me suis posé la question suivante: "Tu t'es pas engagé pour traîner dans les dépôts jusqu'à la fin de la guerre. Tes camarades sont au front! Allez! En route pour le front!" qui m'avait toujours tenté. Alors, au lieu de me diriger sur la gare du Nord pour Arnouville, je me suis dirigé sur la gare de l'Est où, clandestinement, j'ai pris un train de permissionnaires en partance pour le front, et cela, à un moment critique de la guerre où des régiments refusaient le combat. ${ }^{23}$ Après trois jours et deux nuits et divers renseignements dans les gares régulatrices, j'ai pu rejoindre mon unité qui tenait position au Chemin des Dames, secteur 102, le 15 août 1917. A la suite de cela, j'ai été porté déserteur par mon dépôt d'Arnouville que je n'avais pas rejoint à la sortie de l'hôpital. Une enquête de gendarmerie auprès de mes parents leur appris que j'étais au front, lettres et adresse à l'appui. L'enquête vint me rejoindre au front. Mon capitaine, très surpris, me rassura (émotion). Je ne lui avais pas dit que je venais directement de l'hôpital sans être passé par le dépôt. Voilà. Voilà...

E- Donc vous avez devancé l'appel à la fois pour être dans l'arme qui vous convenait et par patriotisme?

T-Eh bien, oui, parce que je vous dis: j'avais peur d'abord d'être ajourné, ce que je ne voulais pas!

E- C'est ça. Pourtant bien d'autres se seraient contentés de cet ajournement!

T- Eh bien oui! Et puis j'aurais pu même, par la suite, je vous dis, être classé dans l'auxiliaire puisqu'on ne voulait pas de moi au front."

Au camp de Satory, près de Versailles, où se seraient retrouvés 2000 engagés volontaires de la France entière. Parmi eux, un engagé exceptionnel: "Y en avait de tous les coins de la France! Et y avait même un général, n'est-ce pas, qui avait été ... comment dirais-je? atteint par la limite d'âge, et qui avait rendu ses galons, et qui s'était réengagé comme simple soldat!

E- Comment s'appelait-il?

T- Ah, son nom! ... Je l'ai perdu! Y a longtemps! Alors évidemment, on l'aurait chahuté! On l'avait pas mis avec nous, on lui avait donné une chambre de sous-officier, mais il venait répondre à l'appel! Il venait pas en exercice avec nous, mais il venait tous les jours matin et soir répondre à l'appel, sur les rangs, avec nous, comme un simple soldat! C'était un peu pour montrer l'exemple, sans doute..."

Une recherche sur toute l'année 1917 dans la revue L'lilustration, pourtant prompte à exalter les héros, ne m'a pas permis de découvrir le nom de ce général rentré dans le rang pour servir sa patrie à l'âge de la retraite, à moins qu'il ne se soit engagé dans les années antérieures à 1917.

Amand Beyron (cl. 11) a vu un de ces engagés héroïques que célébraient à l'envi les journaux et les revues patriotiques. Ce musicien-brancardier au $99^{\mathrm{e}}$ R.I. de Vienne, originaire de Chazelles-sur-Lyon, mais ayant ensuite, après la guerre, dirigé diverses usines de tissages dans des localités différentes, dans le Rhône, l'Isère puis la Loire, notamment l'usine Boussac de Régny, note dans son récit à la date du 11 janvier 1915:

Lundi 11 janvier - Toute la nuit la canonade* a fait rage sur la droite. Dans la matinée duel d'artillerie. Après la répétition, on nous annonce une prise d'armes à Chuignolles ${ }^{24}$, pour la décoration de la médaille militaire du vieux "Papa Fabre", engagé volontaire à 58 ans, vieux vétéran de 1870. Départ à 13 heures. Le Bataillon au repos rend les honneurs. Le drapeau est déployé, encadré par les sapeurs. Le colonel descend de cheval et décore le vieux bonhomme très ému, surtout quand il fut embrassé par le colonel, comme on le fait

\footnotetext{
${ }^{22}$ On voit par les autres cas que d'autres régiments les acceptent, et on comprend mal quelle serait la raison de cet ostracisme.

${ }^{23}$ Jean-Baptiste Biosset oppose son obstination à combattre au refus de combattre de certaines unités: si l'on consulte la chronologie des faits, à la mi-août 1917, les mutineries consécutives à l'échec du Chemin des Dames sont achevées et la répression a commencé.

${ }^{24}$ Chuignolles se trouve dans la Somme, à une quinzaine de $\mathrm{km}$ au sud-est d'Albert
} 
seulement pour la Légion d'honneur. Le vieux retourne à sa compagnie et défile en tête. Il se redresse comme un jeune homme."

Par ailleurs, deux mois après, à la date du 12 mars, il signale une mesure particulière prise en faveur d'une catégorie particulière d'engagés, les Alsaciens-Lorrains des territoires annexés depuis 1870, qui se sont engagés dans l'armée française en fuyant la conscription allemande, donc en étant considérés comme des traîtres à leur nouvelle patrie: "Dorénavant les engagés alsaciens-lorrains seront relevés du régiment et partiront au Maroc, car il paraît que ceux qui étaient faits prisonniers étaient fusillés sur le champ par les boches*."

Engagement dans la marine

Un dernier cas d'engagement dans une arme originale, ou pour le moins inhabituelle chez des habitants du centre de la France, est celui d'un autre soldat de la classe 19, Noël Botton, de Charlieu, âné de six enfants, tisseur à façon comme son père. Malheureusement sa mémoire défaillante a abouti un entretien très fragmenté, avec des confusions et une recomposition mémorielle du passé. C'est ainsi qu'il est persuadé que son engagement, sans doute en 1917, a entraîné le retour chez lui de son père, territorial de la classe 90, qui aurait été dans la Somme:

E- "Donc l'initiative de s'engager, c'est votre mère qui vous l'avait suggérée?

T- Eh oui!

$\mathrm{E}-$ Qu'est-ce qu'elle vous a dit, votre mère?

T- Elle m'a dit: "Tu vois dans l'état où nous sommes! Nous avons pas d'argent! Ton père est parti et tu peux le remplacer! Alors, je l'ai pris au mot, je me suis engagé tout de suite et j'ai été pris, pris pour le service, et mon père est revenu presque aussitôt après.

E- C'était une sorte d'échange, alors?

T- Ah! c'était un échange! J'ai été échangé avec mon père!"

Et c'est ainsi que le tisseur de Charlieu se retrouva matelot soutier sur le cuirassier Bretagne. Quant à l'échange avec son père, il parait être une recomposition du passé, attendu qu'en tant que père de six enfants, son père devait de toute façon être démobilisé (quand est né le sixième enfant, donnant cet avantage? La question n'a malheureusement pas été posée), et il n'est pas avéré que son retour ait succédé à l'engagement du fils aîné.

Deux engagés volontaires exceptionnels: 15 ans 3 mois et 76 ans!

Pour ce qui est des engagements spectaculaires d'hommes ne relevant pas de la conscription, parce qu'ils sont trop jeunes (moins de 19 ans, puis moins de 18 ans pour les classes 17-18-19) ou n'en relevant plus, parce qu'ils sont au-delà des 48 ans fixés pour la limite de la réserve de l'armée territoriale, nous n'en avons aucun parmi nos témoins.

En France, à la différence de l'Angleterre où l'on enrôlait des volontaires et où, apparemment, il était plus facile de tricher sur son âge ${ }^{25}$, on a peu incorporé en-dessous de la limite d'âge. Stéphane Audouin-Rouzeau, dans un article de la revue L'Histoire de septembre 1993 intitulé "1914-1918 - Quand les enfants font la guerre", cite quelques cas avérés dont le plus jeune est le Breton Jean-Corentin Carré: "Mais le destin le plus exemplaire reste celui de Jean-Corentin Carré, jeune Breton du Faouët, auquel un "monument au mort" fut dédié dans sa commune d'origine. A quinze ans, il parvint, grâce à un faux état-civil, à s'engager dans un régiment d'infanterie. Deux ans plus tard, après avoir mené une campagne hérö̈que comme fantassin et ayant atteint l'âge légal, il demanda à s'engager sous son vrai nom quitte à perdre ses grades de sous-officier acquis entre-temps; Il rejoignit ensuite l'aviation où il trouva la mort dans un combat aérien, en 1918. On a conservé son journal de marche et ses lettres, cités pendant et après la guerre dans nombre d'articles de presse. Une grande affiche destinée aux écoles fut imprimée et une brochure "Le plus jeune héros de la guerre: Jean-Corentin Carré, 1900-1915-1918" fut rédigée par un inspecteur d'académie." Cette affiche, reproduite en bordure de ce texte, nous apprend que le jeune héros s'engagea à 15 ans et trois mois, et mourut à 18 ans et deux mois, et elle comporte aussi un texte patriotique édifiant extrait d'une lettre que Jean-Corentin avait (aurait? La falsification est si courante dans ces extraits, qui font parler ou écrire le mort, notamment sur les images religieuses avec portrait du héros...) adressée à son instituteur. Voici in extenso le texte figurant sur l'affiche:

\section{"A la Gloire de Jean-Corentin Carré"}

né au Faouët le 9 janvier 1900

Engagé au 41e Regt d'Infanterie ${ }^{26}$ le 27 avril 1915

mort en combat aérien le 15 mars 1918 .

\footnotetext{
${ }^{25}$ Dans le beau livre de Max Arthur Last Post (publié en 2005 par l'éditeur Weidenfeld et Nicholson) recueillant les témoignages des 21 derniers Poilus britanniques, on a un exemple, celui d'Albert "Smiley" Marshall, né le 21 mars 1897, qui s'engage à 17 ans et demi dans le régiment Essex Yeomanry en prétendant être né en 1896 (p. 31).

${ }^{26} \mathrm{Le} 41^{\mathrm{e}}$ R.I. avait son dépôt à Rennes, qui se trouve à près de $150 \mathrm{~km}$ du Faouët (Morbihan). Si le jeune J.C. Carré avait voulu s'engager dans un régiment plus proche, à supposer qu'il ait eu le choix, il aurait pu aller à Lorient à Vannes, à Quimper, à Brest, à Saint-Brieuc, villes où casernait à demeure un régiment d'infanterie.
} 
"Je ne pourrais pas vivre sous le joug de l'ennemi, c'est pourquoi je suis soldat. Eh! bien, ce sentiment de l'honneur, c'est à l'école que je l'ai appris, et c'est vous mon cher maître un de ceux qui me l'ont enseigné! Je souhaite que tous les petits écoliers comprennent les leçons qui leur sont données de la même manière que je les ai comprises. La vie en elle même n'est rien si elle n'est bien remplie."

Lettre de Jean-Corentin Carré à l'instituteur du Faouët."

Un site Internet "Pages 14-18. Mes discussions.net" précise que Jean Corentin Carré a pu s'engager si jeune grâce à une supercherie: il a emprunté l'identité d'un réfugié des Ardennes, et l'a conservée pendant près de trois ans. Sur le point d'atteindre l'âge légal, il demande au général de division de reprendre son identité: "J'aurai 19 ans le 9 janvier prochain. C'est pourquoi je vous écris pour savoir s'il ne serait pas possible de reprendre mon véritable nom. J'ose m'adresser à vous; sans passer par la voie hiérarchique, parce que s'il ne m'était pas possible de changer d'identité sans quitter le front, je préférerai* rester Ardennais jusqu'à la fin de la guerre et sans que mes chefs directs ne sachent la vérité."

Le sergent ardennais redeviendra simple soldat breton de $2^{\mathrm{e}}$ classe, et il mourra sous son vrai nom... La fin du texte contient les propos que le jeune héros aurait tenu au général lors d'un repas auquel celui-ci l'aurait convié, qui reproduisent, mais avec de très importantes variantes (même si l'esprit est conservé), la citation que l'affiche attribuait faussement à la lettre à son instituteur: "La France a besoin de tous ses enfants. Tous doivent être prêts à se sacrifier pour elle. Je ne pourrai pas vivre sous le joug d'ennemis qui, à chaque instant, me feraient sentir leur supériorité. C'est pourquoi je suis soldat. La vie en elle-même n'est rien si elle n'est bien remplie." Aucun hommage à son "cher maître" et aucune leçon de patriotisme aux "petits écoliers" de France...

A l'autre extrémité des engagements volontaires hors d'âge, le plus âgé semble bien être ce vétéran que présente le numéro de L'Illustration du 25 décembre 1915 (avec une photo occupant toute la page 701) atteignant l'âge canonique de ...76 ans! Ce qui dépasse de presque vingt ans l'âge du vétéran de 58 ans dont parlait Joseph Sorgues, le vieux "papa Fabre" ! La très grande photo représente un vieillard à barbe blanche, mais aux traits énergiques, en capote et képi devant la sortie d'un abri, et elle est légendée ainsi: "Le caporal Surrugue - Ancien combattant de 1870, chevalier de la Légion d'honneur, engagé volontaire pour la durée de la guerre à l'âge de 76 ans;"!

Le texte de l'article figurant en face de la photo permet de mieux connaître ce soldat exceptionnel. Le caporal Charles Surrugue, qui avait exercé la profession d'ingénieur civil chargé plus particulièrement de la construction de voies ferrées, chef de service des voiries de la Dordogne puis de l'Yonne, puis vers la fin de sa carrière, appelé à l'inspection générale de la vicinalité au ministère de l'Intérieur, fut maire d'Auxerre "pendant les douze années qui précédèrent le conflit", donc à partir de 1902. Il répond très modestement au journaliste venu le trouver en tranchée, qui le questionne d'abord à propos de sa Légion d'honneur qui "a dû mettre en éveil ses camarades": "Oh! non, parce que ma foi, mon ruban rouge, je ne l'ai porté que lorsque j'ai eu la croix de guerre à mettre à côté. Ils ne savent pas grand chose de moi et ce n'est pas moi qui leur raconterai quoi que ce soit. Je suis Surrugue qui fait son bout de tranchée dans le même temps que les autres et voilà tout." Il indique qu'il s'est engagé en mars 1915, justifiant son acte ainsi: "Quand les hommes ont une vigueur physique qu'on peut utiliser, pas d'hésitation: au front.". Il a été nommé caporal le $1^{\text {er }}$ octobre 1915 (alors que son grade en 1871, comme chef de section principal au génie civil dans l'armée de Faidherbe correspondait au rang de capitaine). Il affiche l'attitude d'un sage, mais capable d'enthousiasme: "Le seul bénéfice de l'âge, voyez-vous, c'est d'avoir tout de même un peu d'action morale sur les plus jeunes. Quand ils s'impatientent, je peux leur parler de 70, leur dit ce que j'ai senti et souffert alors et ce que je sens aujourd'hui. Nous qui n'étions pas prêts, nous avons arrêté sur la Marne et sur l'Yser un ennemi supérieur et formidablement organisé! Mais c'est magnifique!"

Comme on le voit, les motivations des engagés volontaires sont complexes, allant du plus pur patriotisme à la gestion réfléchie et prudente du risque de mort: si l'on doit de toute façon partir puisque la guerre s'éternise, n'est-il pas préférable de le faire un an avant en ayant le privilège de choisir une arme beaucoup moins meurtrière que l'infanterie, où l'on risque fort d'être incorporé autrement?

Parmi les motivations diverses de l'engagement, il y en a sûrement une autre, non formulée par un de nos engagés, mais par un soldat qui n'a pas devancé l'appel sous les drapeaux. Il s'agit de Robert Estienne (cl. 17), fils de cafetiers-limonadiers de Sées (Orne), bachelier en 1915, ayant réussi en 1920 le concours spécial organisé par H.E.C. pour les démobilisés bacheliers, cadre administratif à Paris, devenu entre 1940 et 1963 chef du service commercial de l'entreprise Jacob Holtzer d'Unieux (Creusot-Loire après son rachat). Il a été incorporé, avec la classe 1917, le 9 janvier 1916, précisément au 51 ${ }^{\mathrm{e}}$ R.I. de Beauvais, replié à Lambézellec, dans la banlieue de Brest, et répond à une question posée dès le début de l'entretien:

E- "Vous qui aviez 17 ans, est-ce que vous pensiez, en août 14, qu'un jour vous partiriez à la guerre?

T- "Eh bien, j'espérais! ...J'espérais que j'aurais l'occasion de vivre ces moments historiques! (rire). Et le temps avançant, non seulement j'espérais, mais je souhaitais vivement de participer à la guerre, étant donné qu'entre temps j'avais eu deux de mes cousins germains qui avaient été tués en même temps. Et je voulais servir dans l'infanterie et les venger! Voilà un peu quel était mon état d'esprit à l'époque!" 
S'engager pour venger la mort d'un proche, un père, un frère, un cousin, un ami, tuer quelques-uns de ces Boches qui avaient tué cet être cher, a dû aussi être la motivation de certains engagés volontaires, et a animé la volonté de nombre de soldats ayant attendu la date d'incorporation normale de leur classe.

Toutefois relativisons encore. Un bref témoignage écrit nous aide à le faire. Il s'agit de celui de Gabriel Peyrard, un peu après la fin de 1915. Ce soldat de la classe 17, de Villars, dont on ignore la profession, est incorporé au $98^{\mathrm{e}}$ R.I. de Roanne début janvier 1916, et écrit des cartes - à l'orthographe plus qu'incertaine ${ }^{27}$ - à sa sœur Claudine et à leur mère demeurant à Villars, près de Saint-Etienne. Le 3 mars, il fait référence au début de la bataille de Verdun: "Tu me di que le 38 et partit a Verdun mes sa me fèr rint si sété moi paseque les sodal snont apeure de rien" ("Tu me dis que le 38 - le 38e R.I. de Saint-Etienne- est parti à Verdun. Ça me fait rien si c'était moi parce que les soldats ça a / $n$ ' ont peur de rien"). Après avoir signalé, dans des cartes postérieures, que des renforts sont partis de Roanne pour Verdun, il écrit le dimanche 23 avril 1916: "je vous diré que le caporale a vai filè a permision pour 8 jours met il en à que pasèt deux chet lui il a reçus une dépèche q'ille foulet partire sur le front alors il a gouté du ronme juqua nous il demandet des volonter pour filet sur le front il y a nat que sise qui on de mandé a filet" ("Je vous dirai que le caporal avait filé (était parti) en permission pour 8 jours, mais il en a que passé deux chez lui: il a reçu une dépêche qu'il fallait partir sur le front. Alors il a goûté du rhum, jusqu'à nous demander des volontaires pour filer / partir) sur le front. Il y en a eu que 6 qui ont demandé à filer" ). On voit donc, alors que la bataille de Verdun fait rage depuis deux mois, que ni le caporal -qui se réfugie dans l'alcool- ni les camarades de la compagnie de Gabriel (sauf six), appartenant à la jeune classe 17, ni lui-même ne sont volontaires pour aller sur le front, à Verdun!

Le soldat Gabriel Peyrard, du $13^{\mathrm{e}}$ Bataillon de Chasseurs Alpins, fut tué près de Rikkebus (Belgique) le 28 mai $1918 \ldots$

\section{La grande diversité des affectations et les conditions de guerre très différentes}

\section{Tableau récapitulatif des affectations}

Si l'on fait un tableau des incorporations des 185 témoins dont l'affectation est connue (ce qui en exclut deux dont l'itinéraire, inconnu, est représenté par trop peu d'éléments), en dépassant donc ce tournant fin 1915-début 1916, où les deux plus jeunes classes, la 18 et la 19, ne sont pas encore incorporées (mais la 18 l'est au printemps 17), on a une idée de la diversité des affectations, même si l'infanterie est largement dominante. Nous compterons séparément ceux qui passent de l'infanterie à l'artillerie ou l'inverse:

Infanterie classique: 93

Infanterie coloniale : 14 ventilée comme suit: Infanterie coloniale classique: 8 Zouaves: $\quad 5$

$\begin{array}{llll}\text { Chasseurs: } & 17 \text { ventilés ainsi: } & \text { Thasseurs à pied: } & 2 \\ & \text { Chailleurs } & \\ \end{array}$ Chasseurs Alpins: $\quad 15$

Territoriaux restés dans l'armée territoriale pendant toute leur guerre: 2

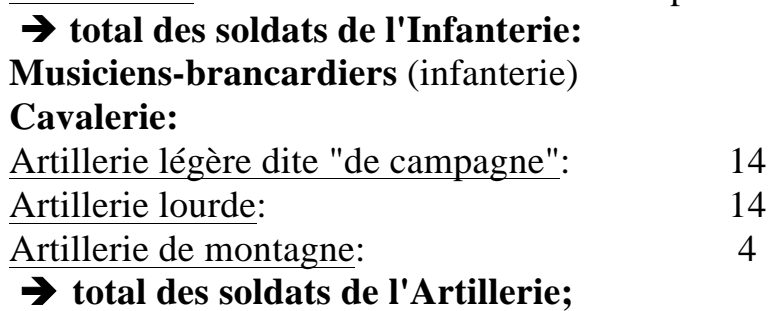

Soldats de l'infanterie passés dans l'artillerie: 5

Soldats de l'artillerie passés dans l'infanterie: 3 d'aviation)

$\rightarrow$ total des soldats ayant connu les deux:

Chars d'assaut:

Génie:

Train des équipages:

Marine ( 2 mécaniciens, 1 boulanger)

124

4

2 (1 Dragon, 1 Chasseur à cheval)
14

32
$8(+1)$

1

4

1

3
1 (un Français blanc)

2
2

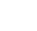

Aviation (1 magasinier +1 mécanicien venu de

l'artillerie puis infanterie)

Cordonniers aux armées

Commis aux écritures aux armées

(+1 passant l'essentiel de sa guerre comme mécanicien

2

1

Secrétaire d'un capitaine à Paris (service auxiliaire) $\mathbf{1}$

(Service auxiliaire après infanterie ou artillerie

185 (chiffres entre parenthèses pas comptés)

\footnotetext{
${ }^{27}$ Nous renonçons temporairement à la convention personnelle de l'astérisque signalant chaque faute d'orthographe pour ne pas étoiler le texte, chaque mot, ou presque, étant mal orthographié, la syntaxe et la conjugaison étant plus que malmenées...
} 
On voit donc que 127 des témoins (et partiellement les 8 qui ont sont passés par l'infanterie, avant ou après avoir été incorporés dans l'artillerie; quand c'est avant, c'est en général en raison d'une blessure ou d'une incapacité aux effets persistants qui les rend inaptes à l'infanterie) donc 135 sur 185 , soit $73 \%$, ont connu plus ou moins longtemps (de quelques mois à quatre ans et trois mois) la vie de fantassin, et de fantassin en tranchées pour la période allant de la fin de l'automne 1914 - avec le creusement des tranchées- au printemps de 1918 - avec la reprise de la guerre de mouvement- (encore que la guerre en Orient, que 15 ont vécue, plus ou moins longtemps, soit assez éloignée par ses conditions de celle du front français) Les autres non, et leur guerre peut être très différente, tout comme le rapport au risque de blessure et de mort. C'est cette diversité que nous allons essayer de décrire.

\section{Une réalité avérée et reconnue: l'infanterie plus exposée au risque que l'artillerie}

Reprenons brièvement la fin du témoignage du futur capitaine (à la guerre de 1939-1945) Lucien Faugère, de Balbigny, fils d'épiciers, appartenant à la très jeune classe 19, racontant par écrit la petite conspiration féminine qui avait conduit, à son insu, à son affectation dans l'infanterie, au moment du conseil de révision: "La commission du conseil de révision déjeune à l'Hôtel de l'Europe (Magat) en face de notre épicerie rue de la Gare à Balbigny. Catherine, après entente avec ma mère, "fait de l'oil" et soigne bien le sergent de Recrutement qui fait les affectations des jeunes recrues, et me fait affecter dans l'artillerie (où l'on risque moins que dans les autres armes) en prétextant que je suis son fiancé ...

Heureusement que je ne l'ai su qu'un an après..."

Et de fait, Lucien Faugère sera artilleur au $16^{\mathrm{e}}$ R.A. de Campagne d'Issoire à partir du 17 avril 1918, mais n'aura connu de la guerre que les derniers bombardements de fin octobre 18 et de début novembre, avant de partir en occupation en Allemagne. Il est donc de notoriété publique, en février 1918, que l'artillerie est nettement moins dangereuse que l'infanterie.

Il en est de même un an plus tôt, si l'on se réfère au témoignage de Claude Pin, (cl. 18), agriculteur à Cleppé, pas très loin de Balbigny, qui a passé son conseil de révision au début de l'année 1917, avec, comme on l'a vu , son père, né en 1872, donc ayant 45 ans en 1917, mobilisé depuis 1914 dans la réserve de l'armée territoriale:

E- "A votre avis, les plus exposés, c'était qui?

T- Les fantassins! Oh oui! Oh, nous les artilleurs, on était favorisé." . Sachant cela, son père a fait une démarche pour que son fils soit affecté dans l'artillerie: "Ceux qui avaient des enfants, qui étaient mobilisés, ils faisaient des demandes pour que leurs enfants choisissent le régiment. On accordait pas toujours, mais enfin...à peu de chose près, quoi! ${ }^{28}$

E- Donc vous, vous avez choisi l'artillerie?

$\mathrm{T}$ - Oui, oui.. D'après mon père, qui était bien au courant, c'était moins exposé. Parce que les fantassins, je vous assure, ils l'avaient pas belle, hein! Autrement, on allait tous dans l'infanterie, nous les paysans!"

C'est ainsi que Claude a été affecté au $113^{\mathrm{e}}$ R.A. Lourde d'Issoire, qu'il a rejoint en mai 1917.

Il en est encore de même apparemment deux ans plus tôt, en 1915, s'il faut en croire le récit de guerre de Claude Coupade (cl. 15), né à la Ricamarie, ajusteur à Saint-Etienne avant son départ à la guerre le 14 décembre 1914, pour rejoindre le $5^{\mathrm{e}}$ R.A. Lourde de Valence, mécanicien au P.L..M, , intégré plus tard dans la S.N.C.F., en gare de Chateaucreux après guerre. Et voici que le 9 avril 1915, alors qu'il est encore en instruction à Valence, arrive une demande: "Le 9 avril on demande des volontaires pour l'infanterie, il en faut 45, mais personne ne lève la main. Il est décidé de tirer au sort, et là, dans un manège, je suis plein d'émotion en attendant le sort qui me sera désigné, hélas, le sort veut que je parte, et sans attendre le lendemain, je quitte le $5^{e}$ d'artillerie pour partir dans un endroit encore inconnu. Adieux* Valence! La ville qui m'avait bien plue*, adieux aussi les petites permissions qui me rendaient heureux! Pourrais-je encore revoir mes parents et ma fiancée? C'est avec un chagrin terrible que je quitte Valence le 10 avril 1915 à $2 \mathrm{~h} 40$ du soir pour être dirigé au $157^{e}$ d'infanterie alpine à Gap (Hautes-Alpes); arriver* dans cette ville le 11 avril à 6 h 30 du matin. Gap nous paraît bien triste, je me serais jamais douté quand* faisant mes classes dans l'artillerie, je vienne échouer dans l'infanterie. On ne peut mieux se rapprocher du carnage."

Si aucun des artilleurs en instruction n'est volontaire pour partir dans l'infanterie, c'est bien que chacun préfère rester dans l'artillerie, et la dernière réflexion de Claude, touché par le sort néfaste qui le rapproche "du carnage", est éloquente!

Cette constatation, un écrivain combattant fantassin, élève de Normale Sup. et historien de la Grande Guerre à travers son expérience, Jacques Meyer, l'a faite aussi, ainsi que ses camarades de combat. Il écrit dans "Les soldats de la Grande Guerre": "Les énormes différences du péril suivant les armes, les biffins (fantassins) les ont toujours amèrement ressenties. ${ }^{\prime 29}$. Et de citer aussitôt, à l'appui de son affirmation, le témoignage du capitaine

\footnotetext{
${ }^{28}$ Ce poids de $56 \mathrm{~kg}$, excédant nettement les $50 \mathrm{~kg}$, qui, d'après de nombreux témoins, constituaient la limite de l'ajournement, ne suffisait donc pas à lui obtenir ce délai d'incorporation.

${ }^{29}$ Jacques Meyer, op.cit. p. 41
} 
Delvert, qui, décrivant sa montée à Verdun à la tête de sa compagnie de fantassins, et croisant deux batteries d'artilleurs de canons de 100 (pièces de marine), écrit: "Pas un homme à pied. Tout le monde en auto. Je demande à un sous-officier s'il y a beaucoup de pertes à la batterie. "Non, très peu.". Et son air surpris me laisse entendre que c'est peut-être "pas du tout". Je voyais mes pauvres troupiers traîner lamentablement sur la route, et cela pour aller se faire écrabouiller dans les tranchées boueuses. Non, décidément, il n'y a pas eu de parité entre les souffrances endurées par les différents combattants du front".

L'oeuvre du capitaine Delvert Histoire d'une compagnie, parue en 1918, a été étudiée par Jean-Norton Cru, combattant au $250^{\mathrm{e}}$ R.I. (dépôt à Commentry) dans Témoins, analyse monumentale de 304 récits de guerre parus en librairie entre 1915 et 1928, avec comme critère principal la véracité du témoignage, d'où certains éreintements de témoignages pourtant célèbres sur le plan littéraire, comme "Les Croix de Bois" de Roland Dorgelès ${ }^{30}$ Il présente l'auteur: "Charles L. Delvert est né à Paris le 27 avril 1879. Elève à l'Ecole Normale Supérieure, il faut le contemporain de Pierre-Maurice Masson et d'Emile Clermont ${ }^{31}$. Agrégé d'histoire, il devint professeur dans un lycée quand la guerre survint". Après avoir décrit son itinéraire de guerre, qui se termine par un détachement à l'Etat-Major en août 1916, il indique sa carrière civile de 1919 à 1928: "Depuis la guerre, Delvert occupe une chaire d'histoire au lycée Jeanson-de-Sailly". Puis il analyse longuement son récit de guerre; l'admiration, chez ce critique à la dent dure, est sensible dès les premières lignes: "Nous parlerons surtout ici de l'excellent journal des tranchées, cette histoire d'une compagnie -la huitième du $101^{e}$ R.I. (dépôt à Dreux) que Delvert commanda du 11 novembre 1915 au 26 juin 1916, et qui fut alors dissoute. Ernest Lavisse ${ }^{32}$ en a écrit la préface, lui qui n'était pas prêt à présenter n'importe quel livre, et qui n'a présenté en effet que deux livres de guerre, le "Sous Verdun",33 de Maurice Genevoix et celui-ci, deux oeuvres admirables. ${ }^{\prime 34}$

Si Charles Delvert, le capitaine d'infanterie, à l'opinion si fiable, affirme, à travers cet exemple de rencontre avec un de ses collègues officiers de l'autre arme, la disparité de danger entre l'infanterie et l'artillerie, on doit aussi pouvoir le croire. Mais examinons plus avant les réponses de nos témoins, par catégories, à cette question, pas systématiquement, mais souvent posée: on pourra découvrir toutes les nuances de leur argumentation, quand la réponse est argumentée, et faire la somme des raisons qui permettent d'affirmer que l'infanterie est à la fois plus misérable, dans les conditions de vie qu'elle offre, et plus exposée au risque, ce qui signifie blessures et mort...

\section{1- Opinions de soldats n'étant ni fantassins ni artilleurs: un sapeur, un brancardier}

Au front, il n'y a pas que des fantassins et des artilleurs. Il y a aussi les soldats du Génie, peu représentés dans nos 187 témoins dont l'affectation est connue: 4 seulement, soit 2,1\%, ce qui doit être sensiblement inférieur à la réalité nationale. L'un d'eux s'est prononcé sur la question abordée. Il s'agit d'Antoine Morin (cl. 16). Fils d'agriculteurs de Pralong, par suite du divorce de ses parents, Marius a suivi un d'entre eux (sans doute sa mère) et s'est installé à 17 ans au Chambon-Feugerolles, et il est rentré aussitôt à la mine. En avril 1915 il est incorporé au $86^{\mathrm{e}}$ R.I. du Puy, mais quelques mois après, il répond à une demande de mineurs volontaires faite par l'armée et rejoint le $4^{\mathrm{e}}$ Régiment du Génie de Grenoble. Parti au front en décembre 15, il va, dans ce régiment, puis au $10^{\mathrm{e}}$ Régiment du Génie de Toul, creuser des galeries de sape pour la guerre des mines, creuser des tranchées, des abris ${ }^{30}$ Petit échantillon de cet éreintement, qui court sur 6 pages (p. 586-593), tiré de la page 592: "Je n'ai pas énuméré toutes les
sottises que j'ai relevées dans "Les croix de bois", mais j'en ai cité assez pour faire voir que l'auteur, qui se pose en interprète
de la tranchée devant la France entière, est un des écrivains les plus ignorants de la vie des combats et des souffrances du
poilu."
${ }^{31}$ On le sait trop peu maintenant, mais Emile Clermont est lié à notre région. Auteur d'un récit de guerre très apprécié de Jean-Norton Cru, intitulé Le Passage de l'Aisne, paru de façon posthume en 1921, d'une œuvre historique et de romans, il est présenté ainsi par J.N. Cru: "Emile Clermont - 63 Division, $125^{e}$ brigade; $238^{e}$ R.I. (régiment de réserve du $38^{\mathrm{e}}$ R.I. de SaintEtienne) - Né au hameau de La Combelle, commune d'Auzat-sur-Allier, Puy-de-Dôme, le 5 août 1880. Il passa son enfance à Saint-Etienne, Loire. Il était licencié en philosophie avant d'entrer à l'Ecole Normale Supérieure, le premier de sa promotion. Il y passa trois ans (1902-1905), mais échoua à l'agrégation. Il abandonna la carrière de l'enseignement et se consacra à la littérature." . Son itinéraire de guerre est résumé ainsi par Cru: "Mobilisé le 4 août (1914) comme sergent au $238^{e}$ de SaintEtienne, il ne rejoignit le front que le 12 septembre comme son régiment, après la bataille de l'Ourcq, allait aborder l'Aisne. A une date inconnue il faut promu sous-lieutenant au $67^{e}$ R.I. (dépôt à Ancenis) de la $12^{e}$ Division. Il fut tué dans la tranchée le 5 mars 1916 à Maisons de Champagne (ferme à 2 km au sud-est de Ripont, canton de Ville-sur-Tourbe, Marne)."

${ }^{32}$ Ernest Lavisse est un célèbre historien (1842-1922) auteur d'œuvres historiques dont une monumentale "Histoire de

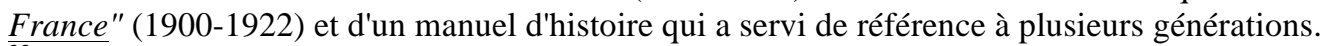

33 "Sous Verdun" est une des parties, avec "Nuits de guerre", "Au seuil des guitounes", "La boue", "Les Eparges" (parties éditées séparément de 1914 à 1923) de l'admirable témoignage de sa guerre de Maurice Genevoix, (autre élève de l'Ecole Normale Supérieure de la rue d'Ulm), grièvement blessé à la tranchée de Calonne le 25 avril 1915, qui les réunit sous le titre "Ceux de 14". Jean Norton Cru, jugeant toujours selon la véracité, tient son récit en très haute estime: "Parmi tous les auteurs de la guerre, Genevoix occupe le premier rang, sans conteste. Ce n'est point là une opinion dogmatique, ce n'est pas l'expression d'un goût individuel. Cela n'a rien de commun avec le jugement d'un lecteur qui préfère un roman à un autre, lequel sera préféré par d'autres lecteurs [...] Dans son oeuvre de guerre, Genevoix a révélé une conscience, une aptitude, un talent, je voudrais ajouter un génie, mais le mot ferait sourire, qui constituent un cas unique, non seulement dans notre guerre, mais dans toute notre histoire." (p. 144 de "Témoins")

${ }^{34}$ Jean Norton Cru, op.cit., édité à Paris en 1929, réédité en 1993 par les Presses Universitaire de Nancy, pp. 122 et 123. 
souterrains et les étayer, dans divers secteurs, jusqu'au début octobre 18 où il est blessé au visage par une série de petits éclats d'obus. Il a donc côtoyé longtemps infanterie et artillerie (infanterie surtout), et témoigne:

T- "On était en première ligne comme eux (les fantassins)! C'est nous qu'on faisait les tranchées!

E- Parce que je crois que les gens de première ligne (l'infanterie, les biffins) ils aimaient pas trop les gens de l'artillerie, ceux qui étaient en arrière...

T- Ah! l'artillerie, y en a qui étaient loin! y en a qui étaient à 2-3 km! Alors ceux-là, ils craignaient moins! Ils craignaient l'artillerie, mais c'était tout! Tandis que nous, on craignait comme l'infanterie!"

De fait, ce sapeur du Génie se sent solidaire des fantassins dont il a partagé les dangers. On remarquera qu'il est bien sobre dans son argumentation, en indiquant une distance modeste de 2-3 kilomètres de retrait de l'artillerie par rapport aux premières lignes, alors que cela pouvait dépasser $10 \mathrm{~km}$ (jusqu'à 15) pour l'artillerie lourde...

Même avis de la part d'un musicien-brancardier Louis Plagnial (cl. 11) né en Ardèche (à Devesset, du canton de Saint-Agrève) dans une famille paysanne pauvre, avant guerre valet de ferme, puis, après la mort de son père, s'embauchant comme mineur à Saint-Etienne, ville où il entra après guerre, comme gérant de succursale, à la firme alimentaire Casino qui finira par le nommer inspecteur, puis inspecteur régional jusqu'à sa retraite, prise à Roanne. Il a passé, depuis son service militaire commencé en octobre 1912 , sept ans dans le même régiment, le $52^{\mathrm{e}}$ R.I. de Montélimar, caporal musicien-brancardier pendant la guerre; il a été le président fondateur de l'amicale "Ceux de Verdun" dans le Roannais. Comme brancardier, il a été le témoin des misères du "pauvre fantassin".

E- "A votre avis, justement, puisqu'on aborde la question: qui étaient les plus exposés, entre les fantassins et les artilleurs?

T- Ah! toujours le pauvre fantassin! C'était toujours lui, la victime! Les artilleurs, avec leur matériel, n'est-ce pas... évidemment, c'était pas le rêve, mais ils avaient tout de même quelques moments de répit. Tandis que le fantassin était toujours dans son terrain, dans sa boue! Oui.. les artilleurs se déplaçaient un peu... Y avait évidemment l'artillerie, les forts, le Morthomme et tout ça. Je n'ai pas eu à défendre, mais j'ai pu voir les souterrains quand même des forts. Y avait eu du travail de fait, là, vous savez! Les forts étaient bien organisés, ils avaient tout prévu.. Oh, ils étaient bien, les gars qui étaient dans les forts, ils s'en faisaient pas, eux! Par rapport à nous, fantassins, ils s'en faisaient pas!" "

On voit que le brancardier Plagnial s'assimile au fantassin de base, tout comme le sapeur Morin, même si l'un et l'autre ne participent pas aux attaques, et si le poste de secours, lieu habituel de séjour des brancardiers, en dehors des interventions sur le champ de bataille pour ramasser les blessés, n'a pas l'inconfort de la tranchée. En attirant l'attention sur une artillerie méconnue, celle des forts, notamment des grands forts entourant Verdun, Louis Plagnial souligne le confort relatif et la sécurité qu'ils offrent à leurs occupants... sans préciser qu'ils sont la cible privilégiée de l'artillerie ennemie!

2 - Opinions de soldats ayant connu les deux armes (les plus informés et les plus objectifs)

Louis Laroux (cl. 10), né à La Tour-en-Jarez, fils d'un agriculteur-carrier mort à 53 ans, est entré à 16 ans à la mine de la Chazotte à Saint-Jean-Bonnefonds, puis à son retour du régiment (fait au début dans l'artillerie, le $11^{\mathrm{e}}$ R.A de Briançon, puis, victime du mal de l'altitude, versé au 54 ${ }^{\mathrm{e}}$ R.I. de Lyon) en 1913, a repris la ferme familiale. Il a été mobilisé au $75^{\mathrm{e}}$ R.I. de Romans, a combattu en Champagne et dans la Somme en 15, dans divers secteurs de Verdun en 16, entre mars et août, puis a été grièvement blessé par une bombe lancée d'avion devant Saint-Quentin, le 25 mars 1917, ce qui lui a valu l'amputation du bras droit et de deux doigts. Ayant conservé des relations dans l'artillerie où il avait fait son régiment, il répond à ma question:

E- "Vous qui avez vécu les deux, qu'est-ce que vous voyez comme différence de danger entre l'infanterie et l'artillerie?

T- Ah ben! Je crois qu'il y en avait un grand! Parce que les artilleurs étaient à l'arrière. Et nous, on était face à face, à quelques mètres!

E- Alors, il aurait mieux valu que vous restiez dans l'artillerie?

T- Oui! Seulement, à ce moment-là, y avait moins besoin d'artilleurs que de fantassins. Alors plusieurs jeunes comme moi ont été versés dans l'infanterie."

Pour Louis, c'est la très grande proximité avec l'ennemi qui crée le danger, et ce n'est que logique. Réformé au début de 1918, Louis devra renoncer à sa ferme, retournera à la mine de la Chazotte où il sera contremaître chargé du boisage jusqu'à sa retraite. Il deviendra centenaire. ${ }^{35}$

Jean-Louis Monier (cl. 13) agriculteur à Marols, après un début de guerre au train des équipages $\left(13^{\mathrm{e}}\right.$ escadron) a connu l'artillerie au $53^{\mathrm{e}}$ R. d'Artillerie de Clermont-Ferrand en 1916, puis l'infanterie au 306 ${ }^{\mathrm{e}}$ R.I. de Nice d'août 1916 à avril 1917, dans l'Argonne et la plaine de Reims. Après des blessures aux jambes par de multiples petits éclats d'obus, une période d'hospitalisation suivie d'un conseil de réforme, il a été reversé dans l'artillerie au $38^{\mathrm{e}}$ R.A. de Campagne de Nîmes en décembre 1917; en 1918 sa batterie est allée ensuite en renfort de trois régiments d'artillerie successifs en 1918 (le $30^{\mathrm{e}}$, puis le 26 , puis le $245^{\mathrm{e}}$ ) de sorte qu'il possède une expérience variée des deux armes.

\footnotetext{
${ }^{35}$ Je l'ai interviewé le 4 novembre 1987, au domicile de ses enfants à Sorbiers. A leur demande, en janvier 1990, à l'occasion de son centenaire, je suis venu évoquer sa guerre devant l'assistance.
} 
Il explique son séjour assez long (qui lui permettra de lire les pièces de Corneille!) au dépôt de Nîmes pendant l'hiver 1917-1918 et au début du printemps: "Il faut vous dire que si je suis resté si longtemps à Nîmes...J'y serais pas resté si longtemps si ç'avait été un régiment d'infanterie... parce que justement y avait très peu de tués (dans son régiment d'artillerie). Alors, il en manquait guère, sur le front. Il fallait attendre qu'il en manque. C'étaient les gens les plus malades qu'on évacuait.".

Il avait auparavant rapporté les propos du médecin qui l'avait examiné au conseil de réforme du 26 novembre 1917: "Alors là, j'ai d'abord passé une visite. J'en avais passé d'autres. C'est là que le fameux médecin a dit: "Y a que les fantassins qui fassent la guerre!" C'est celui-là, tenez. Alors, après m'avoir bien palpé, m'avoir regardé, il a dit à l'autre: "Je ne crois pas que cet homme-là soit capable de franchir une tranchée!"

Le poète Guillaume Apollinaire (classe 1900), que je me plais à associer à mes témoins foréziens anonymes, artilleur de novembre 1914 à novembre 1915 au $38^{\mathrm{e}}$ R.A. de Campagne de Nîmes (où se trouvera J.L. Monier en 17) de Nîmes, au front depuis avril 15, avec participation à la grande offensive de Champagne fin septembre; comme brigadier, passe vers le 20 novembre 1915 sous-lieutenant au $96^{\mathrm{e}}$ R.I..de Béziers, et exprime très fortement la différence qu'il perçoit entre les deux armes.. Il écrit à sa fiancée Madeleine Pagès, professeur de lettres au lycée de jeunes filles d'Oran le 29 novembre 1915: "Pas de fils de fer barbelés. Je vais les faire placer la nuit et agrandir les boyaux et creuser des cagnats pour les hommes qui n'en ont pas. Maintenant c'est la guerre pour de bon, j'écris accroupi, sur mon genou.".Et le surlendemain $1^{\text {er }}$ décembre : "Mon amour je t'adore. J'ai dormi une heure cet après-midi tandis que je n'étais pas de quart. Ah! quelle autre vie celle des fantassins que celle des artilleurs. Ceux-ci font à peine la guerre. Une vraie idylle à côté du drame nu et profondément fatal de la guerre de première ligne. ${ }^{136}$,

La force du style, pourtant sobre dans sa prose par rapport à des poèmes en vers libres qu'il insère dans ses lettres à Madeleine ou à Lou, poèmes annonçant le surréalisme avec une décennie d'avance, ajoute ici à la vigueur du jugement.

\section{3 - Opinions des fantassins:}

Logiquement, on ne peut guère s'attendre à trouver des fantassins jugeant leur situation plus confortable et moins risquée que celle des artilleurs. Et la réalité des enquêtes confirme la vraisemblance: pas un seul parmi plusieurs dizaines à s'être exprimés sur ce point n'est venu démentir l'avis général. Pour les représenter, nous ne retiendrons que le plus circonstancié des témoignages.

Jean Fontaney (cl. 12) de Montrond-les- Bains, est cet instituteur, exempté de service militaire pour faiblesse de constitution, s'engageant par mauvaise conscience (vis-à-vis de ses deux frères incorporés) et par patriotisme le 20 septembre 1914. Il a été affecté au $65^{\mathrm{e}}$ R.I. de Nantes où il combat jusqu'à ce qu'il soit fait prisonnier le 9 juin 1915. Il différencie clairement les risques courus par les diverses armes, et selon le niveau dans la hiérarchie militaire: "On a exigé trop d'efforts des fantassins. La vie d'un fantassin n'était pas du tout amusante! Il y a des gens qui ont fait toute la guerre mais sans être obligés de tuer ou... Mais ils étaient embusqués à un moment donné, ne serait-ce que comme magasinier ou comme cuisinier, ou je ne sais quoi, ou bien dans l'artillerie... Faut pas comparer, entre un fantassin (mais un fantassin jusqu'au grade de sous-officier) et... y'avait pas...C'est pas possible qu'il fasse toute la guerre sans être blessé! C'est pas possible! [...]

E- Et pensez-vous qu'il y ait eu - parce que je l'ai constaté assez souvent - une sorte de jalousie justement des fantassins vis-à-vis des artilleurs?

T- Ah! Certaine! On les considérait comme privilégiés! Ils étaient... Y avait point de comparaison entre la vie d'un fantassin (la seule que j'ai connue, moi) et puis celle d'un artilleur. Les 75 étaient assez près du front...

E- A $3 \mathrm{~km}$ environ...

T- Oh! Oui, tout près... Mais les grosses pièces d'artillerie, ça n'a rien de commun! Ils pouvaient recevoir un gros obus évidemment, mais ça n'était pas de la mitraille jour et nuit! Evidemment, j'ai pas connu des moments durs, moi...Verdun, c'était quelque chose! C'est vraiment la guerre! Vraiment quelque chose d'horrible"

Et d'ajouter modestement, alors qu'il a combattu dans la Somme, vers Albert, en décembre 1914 et qu'il a été gravement atteint au bras par un éclat d'obus dans ce même secteur de la Somme, ce 9 juin 15 où il a été fait prisonnier: "Mais moi, je suis un combattant en dentelles! De courte durée! Et favorisé sur toute la ligne." On verra en effet qu'il est le seul des 17 prisonniers figurant parmi mes témoins à avoir été libéré après un an et demi de captivité, à cause de sa blessure au bras mal guérie, à la suite de la visite d'une commission suisse inspectant les camps de prisonniers.

Retenons que Jean, dans l'artillerie, fait, dans le danger encouru, une distinction logique entre l'artillerie légère, dite"de campagne" (les 75) assez proche des lignes, et l'artillerie lourde (les 155 et au-delà) beaucoup plus éloignée, donc moins soumise au pilonnage des obus, et subissant des tirs moins précis du fait de la distance.

4 - Opinions d'artilleurs: une très majoritaire, une très minoritaire

Il va sans dire que si les artilleurs reconnaissent leur moindre exposition au risque, leur avis a plus de poids encore que celui des fantassins.

\footnotetext{
${ }^{36}$ Guillaume Apollinaire, Lettres à Madeleine, op.cit, p. 353 et 357
} 
A- L'avis très majoritaire parmi les trois catégories d'artilleurs (légère ou de campagne, lourde et de montagne)

Pour un jeune artilleur (de la classe 18) comme Barthélemy Bonnet, boucher au Chambon-Feugerolles avant guerre, devenu employé municipal à la Ricamarie après guerre du fait de l'amputation de son bras gauche (touché par un obus allemand le 19 mars 1918, vers Reims, alors qu'il était tireur au canon de 75 au $16^{\mathrm{e}}$ R.A. de Campagne d'Issoire), son cas personnel ne doit pas cacher la réalité générale:

E- "Je vais vous poser une question que je pose à tous ceux qui ont fait l'artillerie: à votre avis, entre l'artillerie et l'infanterie, qu'est-ce qui était le plus exposé?

T- L'infanterie, bien sûr! Nous, on n'avait pas de balles! Nous on risquait pas de recevoir des balles! Mais on avait des éclats d'obus, hein!"

Cette menace des balles, à laquelle on songe peu quand on n'a pas fait la guerre, obnubilé qu'on est par l'horreur spectaculaire des bombardements, le pouvoir dévastateur des obus qui déchiquettent les corps, ou les ensevelissent, un conscrit du précédent, Pierre Dubanchet, de Saint-Genest-Lerpt, passementier, artificier au 113 e R.A.Lourde d'Issoire en 1917 et 1918, l'indique immédiatement aussi comme principale différence entre les deux armes, quand il répond à ma question modalisée par diplomatie ("parfois" pour "toujours"):

E- "J'entends parfois des gens de l'infanterie dire: "Dans l'artillerie, ils avaient plus de chance que nous!". Qu'estce que vous en pensez?

T- "Oh! Ça se compare pas! On avait pas... On était à l'abri des balles! On avait les obus comme tout le monde, mais les balles! On était loin de l'infanterie!

E- Donc, vous vous considériez un peu comme privilégiés? Par rapport à l'infanterie?

T- Oh! Bien sûr! On était des privilégiés, l'artillerie! Hou la la! L'infanterie, malheur!..." (long silence)

Même avis encore chez cet artilleur plus âgé de quatre ans (cl. 14) Jean Martel, agriculteur comme ses parents à Bourg-Argental (hameau de la Siauve), qui a fait les quatre ans de guerre dans quatre régiments d'artillerie lourde ( $11^{\mathrm{e}} \mathrm{RAL}$ de Grenoble, $101^{\mathrm{e}} \mathrm{RAL}, 320^{\mathrm{e}}$ RAL le plus longtemps et $54^{\mathrm{e}} \mathrm{RAL}$ de Lyon):

E- "Les gens de l'infanterie, ils me disent parfois qu'ils étaient pas dans les mêmes conditions que vous! Est-ce que vous avez l'impression que vous étiez quand même privilégiés par rapport à l'infanterie?

T- Ah oui! Ah oui! Ah oui! Ah oui! Ah oui! Oui! L'artillerie quand même était mieux privilégiée que les fantassins, quoi!

E- Ça tenait à quoi, ça?

T- Ah mais! ...Les fantassins, les chasseurs, ils étaient peut-être à trois ou quatre mètres des lignes boches! Faulait* pas qu'ils sortaient la tête! Tandis que nous, on pouvait quand même..."

Cet argument, évident, du danger accru par la grande proximité de l'ennemi (que Jean exagère, en donnant pour habituelle une distance infime qui a été rarissime) a pourtant été assez peu avancé.

Pour un autre artilleur, encore plus âgé (classe 1908, donc ayant 34 ans à la mobilisation) Jean-Claude Lafay, agriculteur à La Tuilière, conducteur de chevaux au $36^{\mathrm{e}} \mathrm{R}$. d'artillerie de campagne de Clermont-Ferrand de 1914 à 1918, la comparaison n'est pas possible entre les deux armes: "En 17, on courait de droite à gauche, on suivait les lignes, le front, on se déplaçait souvent. Comme j'ai dit: "Où le régiment était, j'étais.". J'ai jamais sorti de lui! J'ai tout le temps été avec lui! Il naviguait ${ }^{37}$ : aussitôt qu'il y avait une attaque, il se déplaçait. On gardait un petit front, si c'était pas trop dur, pendant quelque temps. Ou si c'était dur, on restait là, ça dépend...

E- Et là, vous aviez moins de blessés que l'infanterie?

T- Ah! Bien moins! On avait pas l'occasion! Moins! L'infanterie, elle avait bien 50 à comparer de nous! C'était obligé! L'infanterie avait toutes les balles, les obus qui tombaient sur lui *, et nous on avait quelques éclats qui tombaient!"

Il revient spontanément sur ce thème plus loin dans l'entretien: "Nous, on avait plus de chance, l'artillerie! Mais l'infanterie! Je la pardonnai, moi ${ }^{38}$ : l'infanterie a eu trop de malheurs! Elle pouvait pas se protéger, elle! C'est nous qu'on l'a aidée tout ce qu'on a pu! C'est nous qu'on l'a protégée. Elle pouvait pas, pouvait pas! Pas toute seule!"

La solidarité avec l'infanterie, la grande compassion pour les fantassins qu'il a plusieurs fois manifestée, de façon très émouvante, dans les trois entretiens que nous avons eus, le 29 juin 1987, le 7 juillet 1988 et le 15 octobre $1989^{39}$, alors qu'il était âgé de 99 à 101 ans, le fait même être injuste avec son arme, l'artillerie, qui, selon lui, serait cinquante fois moins dangereuse que l'infanterie!

Certains artilleurs, quand ils occupent la fonction d'observateur chargé d'aider le réglage des tirs des canons, vont parfois en tranchées, et se trouvent donc au contact des fantassins; c'était le cas de Jean Fournel (cl. 15) né à

\footnotetext{
37 "Naviguer" signifie souvent, en français local forézien, changer de lieu, aller ça et là.

${ }^{38}$ Il faut comprendre "je la prenais en pitié", comme le prêtre qui, prenant en pitié les pêcheurs qu'il confesse, leur pardonne au nom de Dieu

${ }^{39}$ Ces trois entretiens, en trois années de suite, s'expliquent par le fait qu'une relation d'amitié s'est créée entre la famille Barlerin de La Tuilière (Mme Barlerin est la fille de M. Lafay) et ma femme et moi, se traduisant par des visites annuelles jusqu'au décès de M. Barlerin, en 2004. On m'a fait l'honneur de me demander de prononcer l'éloge funèbre de Jean-Claude Lafay, à l'église de La Tuilière, lors de ses funérailles fin mars 1991, à l'âge de 103 ans.
} 
L'Etrat, ayant reçu une formation de mécanicien-ajusteur, qui va créer après guerre un atelier de fabrique de joints industriels qui occupera une dizaine d'ouvriers, dans le quartier de la Rivière à Saint-Etienne. Il présente le cas classique du métallurgiste affecté à l'artillerie, en l'occurrence au $114^{\mathrm{e}}$ R.A.Lourde de Valence, où il a été aussi pointeur de canons de 105. C'est spontanément qu'il aborde la question de la différence de conditions de vie entre artilleurs et fantassins: "On mangeait je sais pas comment. Et encore, on avait pas à se plaindre parce qu'on était encore dans l'artillerie, nous. Les fantassins, c'était ben pire!

E- Donc vous étiez favorisés, dans l'artillerie?

T- Oh oui, quand même! Vous comprenez, ceux qui étaient dans les tranchées, hein, qu'est-ce que vous voulez, ils étaient ben obligés de rester là et puis de pas bouger! Tandis que nous, c'était pas pareil! Nous, on pouvait nous envoyer faire les courses, par là, à tort (sic) et à travers, s'ils avaient besoin...

E- Donc vous vous sentiez un peu favorisés?

T- Oh oui! Oh oui, quand même! Comparativement à l'infanterie! Parce que moi, j'ai été régler des tirs dans l'infanterie, j'ai ben vu comment ça faisait! Et quand ça bombardait évidemment... Quand ça prenait à bombarder! Ils nous bombardaient bien, nous! Mais dans l'infanterie, c'était plus souvent qu'ils étaient bombardés encore que nous! Parce que nous, il fallait qu'ils nous repèrent pour nous tirer dessus!

E- Bien sûr! Tandis qu'eux, ils étaient juste au contact...

T- Tandis qu'eux, on savait bien les tranchées où elles étaient! Et alors, ça tombait dessus!

E- [...] Vous n'auriez pas voulu y rester!

T- Oh, je m'en serais bien passé! (rire) . Je les plaignais bien, moi!"

On voit comment de l'avantage des artilleurs en matière de nourriture, puis de liberté de mouvement, on glisse vers le danger moindre pour l'artillerie: moindre fréquence dans les bombardements, et difficulté de repérage de la position de la batterie (installée sous des abris camouflés, ou à contre-pente d'une colline douce, à bonne distance de l'ennemi).

L'artilleur le plus connu parmi mes témoins n'est autre qu' Antoine Pinay (cl. 11), maire de Saint-Chamond pendant 48 ans (1929-1977), député de la Loire pendant 14 ans, sénateur, plusieurs fois ministre (des Travaux Publics de 1950 à 52, des Affaires Etrangères en 1955, des Finances de 1958 à 1960), et Président du Conseil (Premier ministre) du 6 mars au 2 décembre 1952. On a vu dans le chapitre sur la bataille de la Marne que, maréchal des logis commandant la $4^{\mathrm{e}}$ batterie au $5^{\mathrm{e}} \mathrm{R}$. d'Artillerie de Campagne de Besançon, il avait été grièvement blessé au bras le 9 septembre 1914 par des éclats d'obus et avait échappé de justesse à l'amputation. Sa guerre s'arrêta là, et il fut réformé définitif en 1917, après plus de deux ans d'hospitalisation. Il n'esquive pas la question, pourtant modalisée, posée sur la dangerosité moindre de l'artillerie, mais la ramène à son cas personnel, éloquent, ce qui plaide pour l'exposition des artilleurs:

E- "Vous avez dî souvent entendre certaines récriminations des fantassins parce que...cela frappe; beaucoup disent "Les artilleurs étaient protégés!". Est-ce que vous avez cette impression, ou...

T- Sûrement l'impression que les artilleurs couraient moins de risque que les fantassins! Ils ne couraient des risques que par les bombardements! Moi, j'ai été très très bombardé! L'obus qui m'a blessé est tombé sur le...entre le caisson et le canon, et a fait exploser les obus qui étaient dans le caisson, et a tué trois hommes et blessé les autres...".

Il reviendra en fin d'entretien sur l'exposition considérable au risque des fantassins, à partir d'une réflexion générale sur le moral de la population française: "Vous savez, moi, je suis très admiratif de la mentalité de la population pendant les premières années de guerre..."

E- La population qui a tenu?

T- La population de l'arrière qui a tenu. Les paysans ont été les grandes victimes de la guerre. Ils étaient tous fantassins, presque tous fantassins. ils ont subi des pertes effroyables

E- C'est vrai! Comment se fait-il qu'ils étaient plus fantassins qu'artilleurs? Parce qu'ils n'avaient pas de compétences particulières?

$\mathrm{T}$ - Ils ne demandaient rien du tout! Et comme il y a avait...quand on recrutait des gens, sur dix hommes il y avait neuf fantassins! Moi, je me demande comment j'ai été choisi...envoyé dans l'artillerie. Je crois que j'ai été envoyé dans l'artillerie parce que j'avais un permis de conduire automobile."

A ce stade de l'enquête (Antoine Pinay est seulement mon $54^{\mathrm{e}}$ témoin, vu à son domicile le 19 septembre 1987, sept ans avant sa mort à 103 ans, le 12 décembre 1994), je croyais en effet, comme lui - il a cependant corrigé son affirmation par "presque tous fantassins"- et comme la plupart des historiens l'affirment, que tous les paysans étaient systématiquement incorporés dans l'infanterie, et le fils de paysan que j'étais se satisfaisait de cette idée qui inscrivait la profession au sommet du martyrologe de la nation, débitrice envers elle d'une dette de sang.. Rétrospectivement, ayant beaucoup plus de témoins, j'ai été amené à corriger un peu cette croyance. Si l'on fait une statistique sur tous mes témoins, oraux ou par écrit, qui étaient agriculteurs au moment de leur incorporation (un nombre non négligeable changera de profession après), en ne considérant que l'affectation du départ (et en excluant de la profession ceux qui n'étaient plus agriculteurs au moment du conseil de révision décidant de l'affectation, donc dans la dernière année précédant l'incorporation, et ceux qui ne le redeviendront que plus tard, 
après guerre), on constate que les trois quarts sont affectés dans l'infanterie, ce qui fait qu'un quart ne l'est pas. Voici la répartition plus précise:

Infanterie: 52 sur 69, se ventilant comme suit:

$\begin{array}{lr}\text { infanterie classique } & \mathbf{3 8} \\ \text { infanterie coloniale et zouaves } & \mathbf{6} \\ \text { chasseurs alpins ou à pied } & \mathbf{7} \\ \text { infanterie territoriale (de 14 à 18) } & \mathbf{1}\end{array}$

Artillerie: 15 sur 69 dont 6 comme conducteurs de chevaux,

les autres étant servants des canons

(canonnier tireur, pointeur, signaleur)

\section{Génie: 1 sur 69}

Train des équipages: 1 sur 69

La familiarité des agriculteurs avec les chevaux, même s'ils n'en possédaient pas un eux-mêmes (car c'était un indice de relative aisance dans les petites fermes foréziennes du début du XXe siècle) les prédisposait évidemment, s'ils étaient affectés dans l'artillerie, à devenir conducteurs de chevaux tractant les caissons d'artillerie et déplaçant les batteries d'un secteur à l'autre, en cas de proximité (sinon les canons étaient chargés sur des trains).. Mais on constate que 6 seulement sur 15 le sont, et un de ces 6 ne l'a été qu'un temps: Joseph Virieux (cl.18), agriculteurarboriculteur à La Cula (ancien nom de Génilac), incorporé au $113^{\mathrm{e}}$ R.A. Lourde d'Issoire, puis au $107^{\mathrm{e}}$ R.A.L., a aussi été servant du canon lourd de 155. De sorte qu'on constate que 9 d'entre eux ont occupé des fonctions plus techniques auprès des canons, qu'on dit souvent réservées aux métallurgistes.

Par ailleurs, les paysans - toujours définis selon les critères qui viennent d'être exposés avant le tableau précédent - sont loin de représenter toute l'infanterie dans notre panel de témoins, et ils représentent presque la moitié des artilleurs. Voici les pourcentages précis, en éliminant ceux qui ont connu les deux armes:
* Infanterie: 52 agriculteurs sur un total de 127 fantassins "purs"
- infanterie classique:
38
- infanterie coloniale + zouaves:
- chasseurs alpins et à pied
96
17

$$
\begin{gathered}
=\mathbf{4 0 , 5} \% \\
39,5 \% \\
43 \% \\
41 \% \\
=\mathbf{4 7 \%}
\end{gathered}
$$
* Artillerie: 15 agriculteurs sur un total de 32 artilleurs "purs"

Mais cet échantillon massivement forézien est-il représentatif de la masse des paysans français? Il est impossible de le dire. Ajoutons simplement que le département de la Loire ne disposait pas d'aucun régiment d'artillerie, en dépit de ses activités industrielles importantes et de ses trois arsenaux (Manufacture d'Armes de Saint-Etienne, arsenaux de Saint-Chamond -Aciéries de la Marine- et de Roanne) ce qui impliquait une affectation au plus près dans le Rhône (à Lyon), dans le Puy-de-Dôme (à Clermont-Ferrand ou Issoire) ou dans l'Allier (à Montluçon). Mais revenons à nos témoins artilleurs.

Antoine Mounioloux (cl. 08) fils d'agriculteurs de Saint-Romain-les-Atheux, ayant repris après guerre la ferme familiale jusqu'en 1963, a fait son régiment dans l'artillerie, de 1909 à 1911 au $4^{\mathrm{e}}$ R.A. de Campagne de Besançon. A la déclaration de guerre, il a été affecté au $5^{\mathrm{e}}$ R.A.Lourde de Valence, qui deviendra le $114^{\mathrm{e}}$ R.A.L., où il fera toute la guerre. L'ajourné d'un an au service militaire, pour "faiblesse de constitution" qu'était Antoine, est devenu centenaire, allant en pèlerinage à Lourdes peu avant... Il agrée à ma question pourtant dérangeante, malgré sa modalisation ("un peu plus"):

E- "Les gars de l'infanterie disaient que vous, les artilleurs, vous étiez un peu plus protégés qu' eux: c'est vrai?

T-Oh! c'était pas le même travail! On était des embusqués devant (par rapport à) l'infanterie!

E- Par rapport à eux?

T- On a vu l'infanterie l'hiver, quand ils changeaient de position: c'étaient pas des hommes, c'étaient des bouts de boue! C'étaient des boues qui marchaient!"

En ayant le courage d'appliquer aux artilleurs, dont il fait partie, le mot honni par excellence d'embusqués ${ }^{40}$, qui s'emploie normalement pour ceux qui échappent totalement au danger, en restant "dans les bureaux", Antoine introduit un autre critère de différenciation: le mode de vie qui expose bien davantage les fantassins aux désagréments et aux rigueurs du climat, car eux vivent en permanence dans la tranchée, ou, souvent, ils ne disposent même pas d'abris (les "cagnas" ou "gourbis"). Bien plus loin dans l'entretien, invité à faire un bilan, il revient sur cette différence: "Ceux qui étaient dans l'infanterie, c'était bien pire! Passer des années dans les tranchées! Nous, on a bien souffert, mais eux, c'était pas le même moral!

E- C'était plus dur l'infanterie?

T- Oh! Comme le jour et la nuit! C'étaient des vrais martyrs! Mais martyrs! "

Il arrive même à quelques rares artilleurs, parmi nos témoins, non seulement de s'estimer favorisés par rapport aux fantassins (donc par rapport au pire), mais relativement satisfaits de leurs conditions de guerre, étant donné qu'ils ont intériorisé l'obligation de la guerre. C'est le cas de Louis Deloire (cl 14), fils d'agriculteurs-vignerons de

${ }^{40}$ Cette détestation unanime des embusqués (on dirait des "planqués" de nos jours) fera l'objet d'un chapitre ultérieur. 
Cordelle, qui a exploité une ferme de jusqu'en 1937 à Lay, puis de 1937 à 1960 à Cordelle (Le Perron). Il a passé toute la guerre au $4^{\mathrm{e}}$ R.A. de Campagne de Besançon, où il était conducteur de chevaux, et a été gazé en 1918 dans la Somme, à Suzanne, vers Bray-sur-Somme: La question de la comparaison entre les deux armes a été posée au bout d'une bonne heure d'entretien:

E- "Par rapport à l'infanterie, comment c'était l'artillerie?

$\mathrm{T}$ - (long silence) "L'infanterie...(silence)

E- C'était moins exposé?

T- Oh! Beaucoup moins! Nous autres, on était très peu exposés! Je dis ben, moi, l'obus qui a tombé le plus près de moi, peut-être de la traversée de la cour (environ $10 \mathrm{~m}$ ), un obus à gaz...

E- Donc, finalement, ça a été une chance pour vous que d'être dans l'artillerie?

T- Oh oui! Oh ben, je pense!"

Il faut une belle dose d'honnêteté pour déclarer "On était très peu exposés" quand on est interrogé sur sa guerre! J'ai souvent pensé, devant des confidences de ce genre, où le témoin faisait des déclarations qui ne faisaient pas de lui un héros, que seul le grand âge, la sagesse qu'il confère à certains, permettent de se détacher d'une forme de pose inhérente à la jeunesse, et même à l'âge mûr, tant que l'on se préoccupe de donner de soi aux autres une image valorisante, quitte à travestir peu ou prou la réalité.

B- L'avis très minoritaire:de trois artilleurs:

Si elle est très largement majoritaire parmi les artilleurs, cette opinion reconnaissant la supériorité du risque et l'infériorité des conditions de vie chez les fantassins, n'est toutefois pas unanime. Trois témoins pensent le contraire, le premier distinguant nettement entre deux types d'artillerie.

Claude Richard, né en 1891 à Cuzieu (Les Guichards), fils d'agriculteurs aisés devenu agriculteur lui-même, maire de Cuzieu de 1953 à 1965, a effectué son service militaire à partir d'octobre 1912 au $1^{\mathrm{e}}$ R.A. de Montagne de Grenoble, où il se trouve encore lorsqu' éclate la guerre. Il fera toute la guerre dans ce régiment, dont Verdun en juin 1916 et l'Alsace ensuite. Dès le début de l'entretien portant sur sa guerre (après l'évocation de l'itinéraire de sa vie civile), il tient à préciser les choses: "J'ai fait toute la guerre en première ligne, avec un canon de 65. J'étais maître pointeur, vous comprenez. J'étais pas embusqué! Nous étions les plus...les plus...

E- Exposés?

T- Les plus exposés, oui, certainement!"

Plus loin dans l'entretien, il tient à faire sentir la différence entre l'artillerie de montagne, proche des premières lignes, donc exposée, et l'artillerie lourde, éloignée, donc plus protégée, notamment à partir de la situation de son régiment à Verdun, à proximité du fort de Tavanne, à $800 \mathrm{~m}$ selon lui des Allemands::

E- Donc Verdun, c'est le pire que vous ayez connu.?

T- Oh oui! Y a eu d'autres moments où ça a été mauvais aussi, mais c'était pas comparable! Que Verdun! Quante* nous étions repérés, vous comprenez, les Allemands nous sortaient! Oh! Ils étaient pas des mous!

$\mathrm{E}-$ Donc vous étiez vers le fort et vous aviez les fantassins juste à côté de vous?

T- Oui, oui...des fantassins...Et puis ils avaient ben une tranchée au-dessus de nous, encore

E- Les artilleurs qui étaient aux très grosses pièces, eux ils étaient plus loin à l'arrière?

T- Oh! Ils étaient plus loin, bien sûr! Ils étaient jamais inquiétés! Les Allemands tiraient pas si loin! S'ils en tiraient, c'était pas précis, vous comprenez!"

Pierre Favier, né aussi en 1891, mais à à Bordeaux, ajusteur aux chantiers navals de la Gironde, a été mobilisé, après deux ans de guerre comme téléphoniste au $58^{\mathrm{e}}$ R.A. de Campagne de Bordeaux, puis surtout au 10e R.A de Vannes, a été retiré du front en août 1916 et mobilisé comme ajusteur aux Aciéries de la Marine à SaintChamond, où il a fini par se marier et s'établir, en devenant contremaître aux aciéries, jusqu'à sa retraite en 1960. Selon lui, le danger était semblable entre les deux armes, sauf en cas d'attaques (ce qui est tout de même une grosse exception!), mais sa position est argumentée:

E- "Quand j'interroge les gens de l'artillerie, je leur pose toujours la question: qui était le plus exposé à la guerre?

T- Vous savez, devant ou derrière... Ils étaient les plus exposés, quand ça bardait devant, qu'il y avait des attaques... Mais autrement après, derrière, c'était pareil, hein! Derrière, c'était pareil! Parce que l'artillerie (allemande) elle tapait derrière plutôt que devant! Parce que, des moments, les lignes étaient très rapprochées: on était pas loin les uns des autres, dans les premières lignes.."

Pierre Favier, que j'avais interrogé à l'âge de 96 ans, le 24 février 1988, atteindra (au moins) l'âge canonique de 108 ans, devenant le doyen des Poilus de la Loire. ${ }^{41}$

Quant au troisième témoin en divergence avec la majorité de ses camarades artilleurs, le risque est même plus élevé pour ceux-ci que pour les fantassins. Etienne Carton (cl. 18) est un fils d'agriculteurs, fermiers à Poncins, puis à Saint-Etienne-le-Mollard, ayant repris cette activité après guerre, puis bifurqué vers le métier de cantonnier, exercé 36 ans, à Feurs. Il s'est engagé en décembre 1916, cinq mois avant la date d'incorporation des agriculteurs (début mai 17) dans l'arme qu'il a pu choisir: l'artillerie, au $113^{\mathrm{e}}$ R.A. Lourde d'Issoire. D'abord conducteur de chevaux, il a été ensuite agent de liaison du commandant Guillemet jusqu'à l'armistice:

${ }^{41}$ Cf article de la Tribune -Le Progrès du 11 novembre 1999. 
T- "Nous sommes arrivés à Verdun, y avait plus rien! Y avait plus que les lieutenants qui faisaient fonction de capitaines! On a relevé des fantassins, qui gardaient les pièces (les canons), et puis on a tenu assez longtemps. Dans l'hiver, on a mis une batterie de 75 à notre place. La batterie de 75, elle faisait pas comme nous, elle avait pas fait des cagnas, elle venait foutre une rafale au Carrefour de la Santé, et puis ils se taillaient derrière! Parce que nous étions repérés, hein! Vous savez, l'artillerie, on recevait mieux des obus que l'infanterie, hein!

E- Ah bon?

T- Oh la la! Dix fois plus! Nous étions repérés! C'était un duel d'artillerie, pour ainsi dire! Les fantassins intervenaient qu'après!

E- Certains m'ont dit: "L'artillerie, ils risquaient moins que nous! " Ce n'est pas votre avis! Certains de l'infanterie disaient que dans l'artillerie...

T "Ils étaient camouflés!" (a continué ma phrase). Les fantassins le disaient, mais pas du tout! C'est nous qu'on était visés! D'abord, premièrement, les gaz, ils (les Allemands) pouvaient pas les jeter en première ligne! Ils les jetaient où? Sur l'artillerie, en arrière, les gaz! L'ypérite! J'en avais pris, moi! Alors on a été gazés! (obus)...percutants, fouilleurs! C'étaient des duels d'artillerie!

E- Donc, à votre avis, vous étiez plus exposés que l'infanterie?

T- Oh la! C'est l'artillerie qui a gagné la guerre!"

Etienne Carton a une opinion très minoritaire, et il doit le savoir, d'où le recours, qu'il a sans doute souvent utilisé dans les discussions d'après-guerre, à l'argument massue des gaz, que les Allemands ne pourraient jeter en première ligne sous peine de les voir revenir sur leur propre première ligne, ce qui s'est parfois passé, ou d'avoir leur avancée gênée par ces mêmes gaz. C'est oublier qu'en utilisant un vent favorable, on pouvait pallier cet inconvénient, et que l'infanterie a été massivement attaquée avec les gaz asphyxiants, et ceci dès leur première expérimentation, vers Ypres, le 22 avril 1915. Si l'on rapprochait les approximations numériques de dangerosité entre Jean-Claude Lafay (infanterie 50 fois plus exposée que l'artillerie) et lui (infanterie 10 fois moins exposée) on obtiendrait une divergence de 500 fois! Et pourtant tous deux étaient dans l'artillerie tout le temps de leur guerre!

5- Une disparité dans le risque encouru qui aurait engendré des dissensions après guerre, entre Poilus:

Cette différence quant au danger, donc face à la blessure grave et face à la mort, aurait perturbé les discussions d'après guerre entre anciens fantassins et anciens artilleurs, selon Marius Rochette (cl. 17) agriculteur à Gumières (hameau de Prolange), incorporé dans deux régiments d'infanterie $\left(98^{\mathrm{e}}\right.$ R.I. de Roanne, puis $22^{\mathrm{e}}$ R.I. de Bourgoin), ayant eu les pieds gelés pendant l'hiver 17, et le bras traversé par une balle le 22 avril 18 au Mont Kemmel, en Belgique):

E- "Et après, entre anciens de la guerre, vous vous réunissiez? Vous en parliez?

T- Oui, un peu, oui. On se réunissait oui, un peu... (silence) Mais, dans le fond, on aimait pas tellement s'en parler! Oh non! Parce que nous... Les artilleurs, d'accord, c'était moins dangereux, bien sûr, et ils souffraient moins que nous, parce que c'était toujours mieux en arrière. Mais l'infanterie, eh ben, on n'en parlait pas beaucoup parce qu'on avait trop souffert, moi, je crois.

E- Les artilleurs, c'était moins exposé que vous?

T- Oh! beaucoup moins! Beaucoup moins! Les 75, eux, ils étaient plus près des lignes, mais les 210, ils étaient déjà en arrière! "

On a vu que l'idée a surgi spontanément, dans un contexte qui ne l'impliquait pas du tout. La hiérarchie du danger encouru a créé des clivages, des rancoeurs peut-être, qui nuisaient à la discussion d'après guerre. On remarque aussi que Marius introduit une distinction déjà signalée dans le danger, entre l'artillerie de campagne (les 75) plus proche du front car la portée des canons est plus réduite et l'artillerie lourde (ici les canons de 210), nettement plus éloignée: $12-15 \mathrm{~km}$, voire 18 à la portée maximale des 155 longs au lieu de 5 à 8 (parfois moins si l'ennemi s'est éloigné, lors d'une attaque).

On a vu comment, exprimée par des sensibilités variées, des mots divers, des arguments différents, s'éclaire cette question très méconnue de la disparité des guerres vécues, très méconnue et aussi presque tabou surtout parmi les articles qui fleurissent dans les journaux aux abords de chaque 11 novembre, où toute réserve sur l'adoration ambiante des derniers Poilus serait perçue comme sacrilège...

Trouve-t-on des statistiques officielles pour corroborer cette opinion générale de la moindre dangerosité de l'affectation dans l'artillerie? Malgré une recherche importante (en librairie et sur Internet), je n'ai rien trouvé de chiffré sur les pertes de l'artillerie. Mais les historiens s'accordent pour dire que l'infanterie était la plus touchée. En les citant, nous conserverons aussi les indications sur d'autres disparités, que notre enquête, portant sur une cohorte trop réduite de cas, bien qu'elle avoisine 200 témoins, et évidemment ne concernant, pour l'oral, que des vivants interviewés, et pour l'écrit, pas plus de 4 morts sur 31 cas (un disparu sous un bombardement, deux tués au combat, un mort en captivité), ne permet pas d'évaluer: la disparité selon l'âge, et la disparité selon le grade militaire, en considérant les officiers jusqu'au grade de capitaine, c'est-à-dire ceux qui mènent leur compagnie ou leur section dans les assauts, et non les officiers supérieurs plus éloignés des troupes. 
Olivier Faron, dans l'article "Une catastrophe démographique majeure" inséré dans le numéro spécial de la revue mensuelle L'Histoire intitulé "1914-1918 La Grande Guerre", paru au 4 e trimestre 2003 (p. 86-88), précise l'inégalité professionnelle liée à l'inégalité de la mortalité selon l'arme d'affectation:

"Socialement, les paysans, qui fournirent l'essentiel des troupes de fantassins, ont été proportionnellement plus touchés que les autres catégories sociales: ils représentaient $30 \%$ de la population active à la veille du conflit, mais $41,5 \%$ des pertes après". Il indique aussi l'inégalité selon l'âge, donc la classe, au sens militaire du mot:

"Toutefois, un chiffre caractérise mieux que tout autre le conflit: celui des pertes totales. Pour la France, à la date du $1^{\text {er }}$ juin 1919, elles s'élevaient à 1394388 victimes. Près de 28\% des combattants et 16,8\% des mobilisés ont ainsi perdu la vie. Avec plus de 20\% de pertes, ce sont nettement les générations nées entre 1897 et 1895 (âgées de 19 à 27 ans en 1914) qui ont été les plus touchées. On atteint presque 30\% de disparitions pour les hommes de 1894 (20 ans en 1914)".

Dans son petit ouvrage synthétique à classement alphabétique "La première guerre mondiale" paru en 1985, Jean-Jacques Becker, voit deux classes plus affectées que la classe 14, dans sa rubrique sur "Les pertes de la guerre" (pp. 157-159): "La classe d'âge la plus éprouvée fut la classe 1915 avec 77700 morts sur 279000 appelés (27,8\%) suivie par la classe 1912, 77200 pour 279 000, soit 27,6\%, la classe 14 venant ensuite avec 652000 Morts sur 292 000, soit 22,32\%.

Il atteste aussi, que contrairement à une opinion largement répandue dans le public: "La mort a frappé plus durement les officiers: $18,5 \%$ que les soldats (16\%), et parmi les catégories sociales, les agriculteurs suivies par les classes moyennes, puis les ouvriers.".

Dans l'ouvrage collectif rassemblant des historiens de diverses nationalités Guerre et Cultures 1914-1918 dirigé par J.J. Becker, J. M. Winter, G. Krumeich, A. Becker et S. Audouin-Rouzeau (édité par Armand Colin, en 1994), Françoise Thébaut, de l'Université de Lyon II (Lumière) écrit dans la même optique (p. 104): "L'inégalité résulte à la fois de l'âge et du groupe social lié à l'arme. C'est l'infanterie qui a subi les plus grosses pertes (22,5\% des fantassins sont morts) bien loin devant la cavalerie, l'artillerie, le génie ou le train des équipages. D'autre part, les officiers ont été proportionnellement plus touchés que les hommes de troupe. Aussi deux catégories ont-elles subi beaucoup de pertes : la jeunesse des écoles, les professions libérales, et les paysans qui peuplent l'infanterie et qui forment plus du tiers des victimes de guerre. »

Ce chapitre a été écrit trois mois avant la sortie du numéro de novembre 2007 de la revue L'Histoire comportant un fort intéressant dossier sur "Déserteurs, mutinés et embusqués" au cours de la guerre 1914-1918. Dans le bel article de Charles Ridel, auteur d'une thèse sur les embusqués, article intitulé "La chasse aux embusqués", j'ai enfin trouvé, dans une note, la réponse statistique à mon interrogation sur la disparité dans les pertes selon les armes; faisant référence à l'introuvable rapport de Louis Marin intitulé "Rapport sur le bilan des Pertes en morts et en blessés des nations belligérantes", paru dans le Journal Officiel en 1920, l'auteur écrit: "Dans la troupe, les taux de pertes (morts et disparus) par arme sont les suivants: 22,9\% dans l'infanterie, 7,6\% dans la cavalerie, 6,4\% dans le génie, 4\% dans l'artillerie, etc.". Ainsi l'infanterie s'est révélée presque six fois plus meurtrière que l'artillerie! Et sans doute aurait-il fallu distinguer entre artillerie de campagne, relativement proche des premières lignes, et artillerie lourde, beaucoup plus éloignée, en raison de la longue portée des canons, donc nettement moins exposée.. Et Charles Ridel de citer des notes de juin 1915 du jeune lieutenant d'infanterie Charles de Gaulle (classe 10), dont l'ironie caustique et l'exagération sont révélatrices: "L'existence de l'artilleur est confortable. Il a des cagnas magnifiques, à l'épreuve de tous les obus[...] Il envoie quelques rafales sur les fantassins ennemis, rend compte qu'il a bombardé des tranchées et détruit un blockhaus. Puis il va faire un bridge."

\section{Deux mesures essentielles de 1915 affectant la vie des soldats: la loi Dalbiez et le décret instituant les permissions}

\section{La loi Dalbiez (juin-août 1915) et ses effets}

Votée en le 26 juin 1915, et promulguée par le président de la République le 17 août (Journal Officiel du 19), la loi Dalbiez, du nom de son instigateur, le député radical- socialiste des Pyrénées Orientales Victor Dalbiez ${ }^{42}$, organise à la fois le retour au front des "mobilisés" en usine, dans les mines, ou dans d'autres secteurs vitaux - ou tout début de la guerre, pour motif de défense nationale, ou de soldats mis trop complaisamment dans le service auxiliaire, et le retour dans les usines affectées à la défense nationale de soldats du front ayant un métier les rendant utiles pour cette même défense nationale.

Les articles 1 et 2 de la loi précisent la nécessité d'incorporation rapide des hommes jusque là "mis à la disposition des ministres de la guerre ou de la marine" ou "placés en sursis d'appel pour le service des

\footnotetext{
${ }^{42}$ Victor Dalbiez (1876- 1954) est passé à la postérité grâce à cette loi. Il aurait pu y passer par son activité parlementaire très riche, car il a déposé de nombreux projets de loi durant sa vie de député. Caporal au 126 R.I.Territoriale en août 1914, promu sous-lieutenant en février 15, il était député radical-socialiste des Pyrénées Orientales depuis octobre 1909; battu aux élections de 1919, il fut à nouveau député de 1924 à 1927, puis sénateur de 1927 jusqu'en 1935. Il faut aussi maire de Perpignan, président du Conseil général des P.O. et ministre des Régions Libérées de juin 1924 à avril 1925 (chute du cabinet Herriot).
} 
administrations publiques" et leur remplacement par "des fonctionnaires, agents ou sous-agents retraités", "des militaires mutilés ou réformés" ou par "leurs femme, mère, filles ou sœurs ou, à défaut, des femmes, mères, filles ou sœurs des militaires tués ou blessés pendant la guerre."

Le mouvement inverse est lui organisé par l'article 6, fort long, dont voici le début: "Le ministre de la guerre est autorisé à affecter aux établissements, usines et exploitations travaillant pour la défense nationale les hommes appartenant à l'une des classes mobilisées ou mobilisables, chefs d'industrie, ingénieurs, chefs de fabrications, contremaîtres, ouvriers, et qui justifieront avoir, pendant un an au moins, exercé leur profession, soit dans lesdits établissements, usines et exploitations, soit dans des établissements, usines et exploitations similaires, Pour les exploitations houillères, le délai d'un an est réduit à six mois". Le législateur n'étant pas naïf, il envisage la possibilité de fraude, et annonce pour les fraudeurs qu'ils "seront poursuivis devant le conseil de guerre et punis d'un emprisonnement de deux à cinq ans et d'une amende de 500 à 5000 francs", la dernière somme étant considérable à l'époque. ${ }^{43}$ Même peine de prison et même amendes pour "tout chef de service" civil ou militaire, "tout directeur d'usine" et "toute autre personne qui aura facilité sciemment le délit" du fraudeur.

Selon les historiens, ce dernier article aurait contribué à retirer du front environ 500000 soldats, ce qui est énorme, et ce qui a créé bien des jalousies, voire des haines, de la part des soldats restant en tranchées envers ces hommes qualifiés d'"embusqués", selon le terme méprisant très répandu à l'époque. On en a un exemple dans le témoignage récemment édité d' Etienne Tanty, intellectuel versaillais sorti de la khâgne du lycée Henri IV et de la Sorbonne, futur professeur, caporal au 129e R.I du Havre, puis au $24^{\mathrm{e}}$ R.I. de Bernay, plusieurs fois blessé, sous le titre: "Les Violettes des tranchées - Lettres d'un Poilu qui n'aimait pas la guerre ${ }^{\prime \prime 44}$. Il écrit dans la lettre du 6 juillet 1915 adressée à ses parents et à ses sœurs: «J'ai lu hier soir la loi Dalbiez, dans l'Officiel. Ça m'a fait l'effet d'une belle fumisterie. C'est de la haute comédie comme le reste, et toujours la même histoire. Il y a des gens qui sont sous les crapouillots et d'autres qui n'y sont pas. Ceux qui n'y sont pas ne veulent pas y aller et ceux qui y sont voudraient bien s'en aller. Tout est là". Et, un peu plus loin dans la même lettre, il s'indigne du comportement de ceux qui, mobilisés en usine dès le début du conflit, se permettent de faire grève début juillet 1915: «Il y en a d'autres qui réclament parce que leur salaire ne leur plaît pas! Morbleu! qu'on les envoie au front, ces messieurs syndiqués; les Boches leur en foutront des heures à 0,90 F ou 0,80 f. Mobilisés dans leur emploi, pas de crapouillos*, ayant leur vie normale, et ça grogne encore, c'est pas assez heureux, ça réclame! Vous avez une chance, un privilège inouï, et vous n'êtes pas content! Je ne suis pas suspect d'aimer le capitalisme, mais il y a des réclamations de syndicat encore plus scandaleuses! Tout ça n'est que gargotage et pitrerie. »(p. 478). Et Annette Becker, aussi préfacière de l'ouvrage, d'expliquer en note " En 1914, dans l'espoir d'une guerre courte, de nombreux ouvriers des industries d'armement avaient été mobilisés. Le conflit s'enlisant, le stock d'obus baissa dangereusement. C'est la raison pour laquelle fut votée, le 26 juin 1915, la loi Dalbiez prévoyant le retour de 500 000 mobilisés dans les usines - ce qui ne fut pas sans provoquer un certain malaise parmi ceux qui restaient dans les tranchées. Par la suite, d'autres combattants du front, y compris des gradés, cherchèrent à bénéficier, avec plus ou mois de bien-fondé, de cette mesure". (p. 478)

Selon Françoise Thébaut de l'Université de Lyon II (Lumière) intervenant dans l'ouvrage collectif déjà cité Guerre et Cultures 1914-1918, cette loi a non pas créé (elle existait depuis la mobilisation d'août 1914) mais amplifié une autre forme d'inégalité entre ouvriers citadins pouvant relever de la loi Dalbiez et ruraux n'y pouvant prétendre, et donc entre leurs familles respectives:: "L'inégalité devant la mort transcende l'inégalité sociale et les femmes de mineurs, de cheminots ou d'ouvriers qualifiés (500 000 rappelés dans le cadre de la loi Dalbiez) ont le privilège inoü̈ d'avoir un mari loin des combats et même souvent à leur côté. L'opposition monde rural métropoles et villes industrielles est sur ce point particulièrement forte. ${ }^{\prime 45}$

Cependant il convient de noter que certains métallurgistes sont retirés du front pour être "mobilisés en usine" avant même l'adoption de la loi Dalbiez. On en trouve une petite illustration dans le journal d'Amand Beyron (cl; 11), musicien-brancardier au $9^{e}$ R.I. de Vienne, qui note à la date du mercredi 23 juin 1915: "Nos copains Brunon et Gauthier, brancardiers à la $10^{e} \mathrm{C}$ ie, partent à Saint-Etienne pour travailler comme "tourneurs" à la Manufacture d'Armes de l'Etat. Ils viennent nous dire au revoir avec le sourire. Ils sont heureux de partir après ces bombardements. Ils reverront au moins leurs familles en gardant un mavvais souvenir de ces 3 derniers jours." Nulle amertume de la part d'Amand envers ces camarades plus chanceux, retirés du front grâce à leur métier. Il n'en sera pas de même de la part de la grande majorité des Poilus qui nourriront à l'égard de ces chanceux (et parfois de ces tricheurs, car il y aura, malgré les peines menaçant les fraudeurs, de fausses déclarations) une aversion tenace.

Nous reviendrons longuement, plus avant dans l'ouvrage, sur la haine des "embusqués" qui constitue un trait essentiel de la psychologie des soldats du front. Ne retenons pour le moment que trois témoignages renvoyant clairement à la loi Dalbiez (parfois confondue avec la loi Mourier qui, à partir d'une proposition de loi émise en mars 1917, tentera à la fois de la compléter et de l'amender).

\footnotetext{
${ }^{43}$ Selon des prix recueillis auprès d'agriculteurs foréziens ayant vécu cette période, la somme de $5000 \mathrm{~F}$ représenterait le prix d'achat de 12 ou 13 belles génisses en 1914 (autour de $400 \mathrm{~F}$ ).

${ }^{44}$ Etienne Tanty : "Les Violettes des tranchées - Lettres d'un Poilu qui n'aimait pas la guerre" avec une préface d'Annette Becker - édité en 2002 par France Bleu et Editions italiques

${ }^{45}$ Françoise Thébaut, op. cit., p. 104
} 
Jean-Louis Monier (cl. 13), agriculteur à Marols, est un des rares agriculteurs à n'avoir pas été envoyés au front immédiatement à la mobilisation (il était au service militaire depuis décembre 1913, en application de la loi de trois ans qui avait fait incorporer la classe 1913 à 20 ans au lieu de 21, comme les classes précédentes). Déjà présent au $13^{\mathrm{e}}$ escadron du Train des équipages à Clermont-Ferrand à la mobilisation, il participe à l'intendance des régiments d'infanterie dans les Vosges, puis dans l'Oise, vers Beauvais, puis dans la Somme, vers Fontaine-sousMontdidier, l'essentiel de l'année 1915: "Fontaine, c'est un petit bourque ${ }^{46}$ pas grand et c'est à 4 km de Montdidier. Alors la compagnie où j'étais, nous partions tous les jours prendre du ravitaillement en gare de Montdidier et la mener au train régimentaire qui se trouvait dans la plaine bien plus en avant, je sais pas à combien de kilomètres (je me rappelle plus du nom de l'endroit). Alors on allait faire le ravitaillement tous les deux jours. On y allait, je crois, tous les jours, mais c'était intercale $e^{47}$. C'est là, entre autres, que j'avais vu pas mal de gens du pays. Enfin, bref. Et nous sommes restés un an dans ce pays! Trop longtemps!

E- A combien du front à peu près?

T- Oh...4-5 km du front!

E- C'est à dire que vous entendiez bien...

T- Ah ben bien sûr!

E- Mais vous n'étiez pas bombardés!

T- On risquait rien! On risquait rien! On risquait que des accidents, mais on risquait rien de la mitraille! A cette époque, d'ailleurs, y avait très peu d'artillerie lourde. Nous étions en arrière de tout cela.

E- [...] Et là, à $5 \mathrm{~km}$ du front, comment ça se passait, la vie?

T- Ah mais c'était pas évacué! Les paysans y étaient! Les gens y étaient! C'était une petite commune: y avait rien, quoi ${ }^{48}$ ! Y avait deux ou trois paysans, puis d'autres..."

E- Mais y en avait pas qui étaient partis, qui avaient quitté la ferme?

T- Ah non, non, non! Mais les Allemands y étaient pas arrivés: on les avait arrêtés avant!"

Ce régiment du train se trouve donc dans une sécurité relative, bien qu'il soit assez proche des premières lignes. Bien plus loin dans l'entretien, qui a été très long (plus de quatre heures!), Jean-Louis revient sur cette relative sécurité qu'il a eu le courage d'avouer: "Les régiments d'infanterie allaient au front, l'artillerie un peu en arrière, et puis alors nous, qui étions pour le ravitaillement, nous étions tout à fait en arrière. Nous, on risquait à peu près rien!";

Puis ce régiment réputé tranquille participe au début de la bataille de Verdun où il essuie tout de même des pertes conséquentes, au point d'être reformé. Touché par la loi Dalbiez (mais après les autres, puisqu'il était tout de même au front, et non dans les villes de l'arrière) Jean-Louis, de retour au dépôt de Clermont, va être affecté à l'artillerie: "Là, il y a eu les fameuses lois Dalbiez et Mourier où il a fallu sortir les jeunes de l'arrière, si vous voulez, et les mettre à l'avant. Donc j'étais au Train et je passai dans l'artillerie à Clermont. Alors, là, j'ai eu

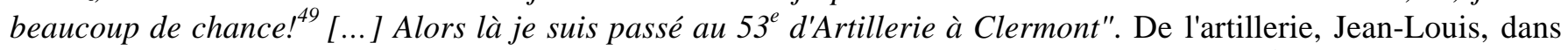
un trajet qui le rapproche du danger, passera ensuite dans l'infanterie, en août 1916, au $363^{\mathrm{e}}$ R.I. de Nice, et sera blessé par de multiples éclats d'obus le 2 avril 1917, à Villers-Franqueux, au nord-ouest de Reims.

Un cas sensiblement différent, mais relevant aussi de la loi Dalbiez est représenté par un autre soldat de la classe 13, Pierre Sabatier de Firminy, qui, avant guerre, avait successivement été, à dix ans, petit valet dans une ferme de Saint-Ferréol d'Auroure, puis à treize ans, goujat en maçonnerie au chantier de construction de l'église du Mas, à Firminy, puis à quinze ans, ouvrier aux laminoirs à l'usine Limouzin de Firminy, où il est gravement brûlé. Après un bref passage à la mine, il redevient métallurgiste à l'usine Verdier, puis chez Holtzer d'Unieux, comme tourneur à l'atelier de fraises et forets. Marié en 1912, il a un enfant la même année, et un autre en 1915. Ajourné au conseil de révision de la classe 1913, pour faiblesse de constitution, il part au régiment (le $38^{\mathrm{e}}$ R.I. de SaintEtienne) au printemps 1914. Versé à l'automne 1914 au 86 ${ }^{\mathrm{e}}$ R.I. du Puy, il est rappelé en 1915 à l'usine Holtzer en application de la loi Dalbiez: "Le début, je suis pas parti. J'ai couru de régiment en régiment. On est parti et puis au bout de 7-8 mois qu'il y avait la guerre $e^{50}$, chez Holtzer, ils m'ont fait rappeler pour travailler. J'ai été démo... J'y suis resté jusqu'en $17 \ldots$

E- Ah bon?

T- Oui... Alors j'ai que fait la guerre en 17 et 18! [...] On faisait des forets de 2,5 $\mathrm{mm}$ à $100 \mathrm{~mm}$.

E- Ceux qui étaient avec vous, c'étaient des gens qui étaient chez Holtzer avant?

\footnotetext{
46 "Bourque" est la prononciation forézienne courante de "bourg", parmi les gens nés avant 1940, n'ayant eu qu'une scolarité primaire ou du début du secondaire. On dit "Bourque" pour Bourg-Argental (Loire) ou Bourg-en-Bresse (Ain).

${ }^{47}$ Il semble, d'après cette explication, que deux sections devaient aller le ravitaillement un jour, et les deux autres sections de la compagnie le lendemain.

${ }^{48}$ Cette expression sous-entend qu'il n'y avait pas de commerces dans ce très petit bourg

${ }^{49}$ La chance d'être affecté dans l'artillerie, plutôt que dans l'infanterie, beaucoup plus meurtrière.

${ }^{50}$ Si Pierre Sabatier a effectivement été rappelé 7 ou 8 mois après le début de la guerre, il l'est avant le vote de la loi Dalbiez, en juin 1915. . Mais il se pourrait bien que ce soit 7-8 mois après son incorporation qui n'a pas été immédiate à la mobilisation.
} 
T- C'étaient des types qu'ils embauchaient parce qu'il y en a qu'ils sont été tués à la guerre, même pas mal qui sont pas revenus: ils ont été tués au début. c'est ça... Et j'ai beaucoup de camarades, moi, je les ai pas revus, ils sont été tués à la guerre, ils sont pas revenus!

E- Donc vous, avez eu de la chance...

T- Oui, j'ai eu cette chance, moi! Mais quand je suis revenu, je suis retourné partir à la guerre, en 17...et j'y ai passé près plusieurs fois!"

E- On va en parler... Donc vous êtes resté en 15, en 16...et toujours pour faire des forets?

T- Oui, oui! On a acheté des machines, on les montait... des femmes qui... On embauchait des femmes pendant la guerre!

E- Ben oui: y a eu beaucoup de femmes qui ont travaillé...

T- Ben, y avait des types qui les réglaient (les machines!). Puis alors moi, comme je connaissais un peu le métier, j'étais chef d'équipe; j'étais régleur au départ, puis je suis passé chef d'équipe presque tout de suite.

E- Chez Holtzer, ils avaient bien embauché des Chinois aussi?

T- Oui: y a eu une histoire de Chinois aussi!

E- Qu'est-ce c'est que cette histoire de Chinois? On m'en a parlé; y a eu des bagarres, non?

T- C'est-à-dire... y avait un soldat qui était venu en permission, et les Chinois l'ont couru ${ }^{51}$ sur le remblai, là, et plus loin le Pont d'Issol, ils ont tué le soldat! C'était un Alsacien! Et les Alsaciens, ils étaient à part: les prisonniers qu'on avait pris, ils logeaient rue Bodécoule, à Fraisses. Y a l'usine maintenant. Ils se sont révoltés,:les cafés qu'il y avait vers le Pont du Sauze, ils ont tout saccagé, ils se sont battus, je sais pas!

E- Mais alors, qui est-ce qui s'est révolté? Les Chinois?

T- Les Chinois... C'était In-do-chi-nois! Vous savez, les...

E- Les Annamites!

T- Oui, qu'ils étaient avec nous! Y a eu la guerre après (guerre d'Indochine), ils ont fait la guerre...

E- Mais pourquoi ils ont tué cet Alsacien?

T- Ah...je...."

E- Ils le prenaient pour un Allemand ou pas?

T- Ah! J'en sais rien! C'était dans le café, y avait une histoire, ils ont foutu le café en l'air, cassé les carreaux, tout cassé!"

J'ai laissé se développer le témoignage au delà du cas particulier de Pierre Sabatier, ramené par la loi Dalbiez à l'usine Holtzer pour y fabriquer des forets, car la fin de cet extrait révèle à la fois le recours à la main d'œuvre de nos colonies pour pallier l'absence des ouvriers partis sur le front (employés à des travaux de manœuvre le plus souvent, dans les usines et fonderies) et les tensions raciales qui pouvaient exister, allant jusqu'au meurtre par les Indochinois d'un Alsacien enrôlé dans l'armée allemande et fait prisonnier. Les bagarres m'avaient été indiquées par un Poilu de Fraisses vu avant.

Je suis revenu un peu après sur ce cas personnel de Pierre Sabatier et de ceux qui avaient bénéficié du même retrait du front, en essayant de lui faire prononcer le mot de l'époque, employé par les Poilus restés au front pour stigmatiser leurs camarades chanceux: "embusqués". Mais il l'évite:

E- Mais alors ceux de votre classe, et qui étaient à la guerre, ils devaient vous considérer comme des ... ... favorisés?

T- Ah ben, je sais (embarras)

E- Vous n'en parliez pas?

T- On n'en parlait pas!"

En février 1917, sous l'effet de l'autre volet de la loi Dalbiez (car la loi Mourier, qui en reprend l'esprit, ne sera proposée au parlement qu'en mars 1917 et promulguée sensiblement après), Pierre Sabatier est rappelé au front, au $35^{\mathrm{e}}$ R.I. de Belfort. Envoyé en Belgique à la fin du printemps 17, il découvre la vie de tranchées et les bombardements, et les combats, comme grenadier voltigeur. Il combattra dans divers secteurs en 17 et 18 , et parviendra à l'armistice en ayant eu la chance de ne pas être blessé...

Pour illustrer les effets de la loi Dalbiez de 1915 nous allons voir un troisième et dernier cas, différent aussi des deux précédents, bien que ce témoin ait un métier dans la métallurgie, comme Pierre Sabatier. Il s'agit de Pierre Favier, de deux ans plus âgé que les précédents, car né en 1911, à Bordeaux. Fils de cordonnier, il devient ajusteur avant guerre aux chantiers navals de la Gironde, jusqu'à son départ pour le service militaire en octobre 1912, effectué dans l'artillerie ( $24^{\mathrm{e}}$ R.A. Légère de Tarbes, puis $58^{\mathrm{e}}$ RA. de Campagne de Bordeaux). A la mobilisation, il est envoyé en renfort du $10^{\mathrm{e}}$ R.A. de Vannes, comme téléphoniste, essentiellement en Champagne pendant l'année 1915, installant et réparant sur le terrain les lignes coupées par les obus. Au printemps 1916, son régiment prend part à la bataille de Verdun, vers Fleury-devant-Douaumont. En août 1916, en application de la loi Dalbiez, Pierre est retiré du front et mobilisé comme ajusteur:

E- "Donc vous en êtes parti au mois d'août?

51 "Courir quelqu'un" en français régional forézien, c'est le poursuivre 
T- Oui: je suis venu mobilisé ${ }^{52}$; alors la guerre a été finie pour moi!

E- Ça c'est aussi intéressant. Donc c'est votre spécialité de tourneur...

T- D'ajusteur!

E- D'ajusteur, pardon, qui vous a fait mobiliser ...

T- Aux aciéries de la Marine

E- De Saint-Chamond?

T- Oui, j'ai rejoint Paris, au dépôt des métallurgistes, à Paris.

E- Vous étiez plusieurs dans votre cas?

T- Ouh là, y en avait!

E- Mais dans votre compagnie?

T- Ah non! J'étais tout seul moi!

E- Est-ce qu'il vous avait fallu faire une demande?

T- Oh non, non, non! On nous avait demandé au début de la guerre, tous ceux qui étaient métallurgistes et tout ça, où c'est qu'ils avaient travaillé."

J'interroge ensuite Pierre Favier sur les modalités de son travail à Saint-Chamond:

E- Donc vous étiez pas en caserne?

T- Ah non, non! On était mobilisé: nous étions soldats, mais libres!

E- [...] D'accord. Donc là, vous aviez tous une spécialité de métallurgistes?

T- On travaillait dans son métier, quoi! Y avait les tourneurs, y avait des fraiseurs, y avait des forgerons, y avait de tout, quoi!

E- Vous y êtes restés combien de temps, à Saint-Chamond? Jusqu'à la fin de la guerre?

T- J'y suis resté tout le temps, jusqu'à que j'ai fini de travailler!" [...] On faisait 10-12 heures, on a eu même fait 14 heures... Le dimanche matin, ça arrivait souvent! Fallait pas chômer, fallait pas que ça s'arrête de tourner!

E- Est-ce que c'était une discipline militaire, ou est-ce que c'était comme à l'usine?

T- Nous étions civils...mais on était militaires!"

C'est là toute l'ambiguïté de ce statut hybride de "mobilisés en usines", dépendant de la hiérarchie militaire, ne pouvant quitter leur emploi, mais bénéficiant de tous les avantages de la vie civile, côtoyant au travail des civils, recevant la même paie, et rentrant chez eux le soir, donc pouvant mener une vie de famille!

T- "Nous étions sous l'autorité militaire: on était militaire sans l'être.

E- Et vous étiez payés comme eux? (les civils)

$\mathrm{T}$ - Ah! Comme les ouvriers!

E- Et ça correspondait à quoi, comme salaire?

T- (cherche) ...5-6 francs par jour

E- On ne faisait pas de différence entre vous et les ouvriers?

T- Oh non non non! C'était tout les mêmes salaires suivant votre ... (qualification)...Y avait les manøuvres et les professionnels, quoi!

E- Et on pouvait monter en grade, même si on était militaire?

T- Ah! oui, oui, oui!

E - Vous aviez de bons rapports entre civils et...

T- Mais nous étions civils! On n'était plus militaires, hein! On était civil, d'ailleurs on était habillé en civil, pas en militaire!"

On le voit à cette contradiction: il est bien difficile de maintenir la quasi fiction du statut militaire, puisque la vie quotidienne ressemble par presque tous ses aspects à la vie civile des ouvriers qu'on côtoie, et qui sont sans doute au-delà des 48 ans, limite de l'incorporation dans la réserve de l'armée territoriale, ou réformés pour raison médicale, ou très jeunes attendant leur incorporation à 18 ans. Un seul détail vestimentaire signale les "mobilisés en usine" des ouvriers civils: un brassard, comme s'en souvient son épouse: "Vous aviez un brassard rouge!"

T- Oui, on portait le brassard... Mais le dimanche, on le portait même pas, des moments!"

Pierre Favier le Girondin se sent tellement civil qu'il va se marier, en cette année 1917, avec une jeune fille forézienne de Saint-Chamond, d'où ma question:

E- "Est-ce qu'il y en a d'autres qui se sont fixés dans la région, qui venaient d'ailleurs?

T- Y en a bien qui se sont fixés! Surtout des gens du Nord...Y avait même des Belges qui étaient là, qui se sont fixés jusqu'à la mort, quoi! Qui sont pas repartis! Oh! Y en a beaucoup!"

"Fixé jusqu'à la mort" à Saint-Chamond, où l'on a été affecté par le ministère de la guerre, ce sera le cas de Pierre Favier, qui fera toute sa carrière aux Aciéries de la Marine jusqu'à sa retraite prise en 1960, que j'ai interviewé le 24 février 1988 dans sa maison de Saint-Chamond, et qui est devenu le doyen des Poilus de la Loire, à 108 ans, comme l'atteste un article de La Tribune-Le Progrès du 11 novembre 1999...

\footnotetext{
${ }^{52}$ Pierre Favier, dans l'entretien, emploie constamment ce terme de "mobilisé" pour qualifier son emploi d'ajusteur aux Aciéries de la Marine de Saint-Chamond, terme militairement approprié, mais entretenant la confusion pour le profane qui l'assimile à "mobilisé sur le front"!
} 
Pour ces mobilisés en usine, la guerre apparaît lointaine:

E- "Est-ce que vous continuiez à avoir des nouvelles de la guerre?

T- Oh non! On en avait par les journaux, c'est tout!"

Reste à poser la question cruciale, que je n'ai pas pu, décemment, (car on ne brutalise pas un témoin, surtout un témoin qui a 55 ans de plus que vous et qui a fait deux ans de Grande Guerre) formuler avec la franchise totale, qui aurait consisté à dire: "Vous ne vous sentiez pas un embusqué?".

E- Est-ce que vous aviez... (là, c'est une question un peu délicate)...est-ce que vous aviez le sentiment d'être quand même un peu privilégié par rapport à ceux qui étaient au front?

T- Ah ben...dans un sens... ça ...(gêne)...dans un sens..."

Son épouse, qui est sa seconde épouse, née en 1901 (épousée pendant l'Occupation alors qu'ils étaient tous les deux veufs, et qu'elle avait deux enfants à élever, ce qu'elle faisait en travaillant aussi aux Aciéries de la Marine) est plus franche, avec cette réaction immédiate: "Ah oui! Ça oui! Ils étaient à l'abri!"

T- On était à l'abri."

Pour finir sur ce témoignage très intéressant, sans doute représentatif de l'ambiguité de la situation de tous les mobilisés en usine, dépassons la fin de l'année 1915 pour nous projeter en 1917. Après la fin de l'entretien, magnétophone éteint, Pierre a rajouté une information sur la "relève des métallurgistes" en 1917, ce qui a entraîné, avec son accord, la reprise de l'entretien enregistré:

T- "En 17, il y a eu le départ...

$\mathrm{E}-\mathrm{La}$ "relève des métallurgistes"?

T- La relève des métallurgistes: il a fallu avoir deux ans de front pour ne pas repartir, parce qu'il y en avait qui avaient été mobilisés (en usine: toujours la même ambiguïté du terme!) et qui n'avaient pas deux ans de front, et d'autres qui n'étaient pas partis du tout! Qui avaient été mobilisés au départ! Alors tous ces gens qui n'avaient pas deux ans de front, qui étaient mobilisables, ils sont partis en 17!

E- Ah voilà! Et vous, vous les aviez!

T- Eh oui!

E- Donc des gens qui s'étaient cru à l'abri tout le temps qui sont partis!

T- Qui sont partis! Y en a qui s'étaient fait mobiliser (en usine) en 14, pour pas partir à la guerre! Ils avaient dit:

"On va se faire mobiliser, on partira pas!". Ils ont été obligés de partir en 17!"

Il est clair (et c'est logique) qu'aux yeux de Pierre Favier, qui a commencé par faire deux ans de guerre, d'août 1914 à août 1916, que les "embusqués" (il ne prononce toutefois pas ce terme, sans doute douloureux, car des camarades ayant fait toute la guerre le lui ont peut-être appliqué) que la nouvelle loi Mourier de 1917 envoie au front, ce sont eux, et pas lui! Et son épouse, qui avait alors 16 ans, et qui résidait aussi à Saint-Chamond, de donner une précision bien intéressante sur les réactions des épouses: "A la gare de Saint-Chamond, je me rappelle bien, quand on les a relevés, qu'il fallait qu'ils partent, eh bien y avait des femmes qui s'étaient couchées sur la voie pour pas que le train parte! Oh! Je me rappelle bien ça, moi! Puis alors, bien entendu, le train est parti quand même! Oh mais! ça a fait un bruit à ce moment! Y en a qui sont jamais partis, vous comprenez!

T- Ils étaient jamais partis, ils étaient pas contents de partir! Et ceux qui étaient partis au début, ils y étaient! Y en a qui y sont restés les quatre ans de guerre, hein! Alors!

E- Bien sûr! C'était une mesure de justice!

T- Ben oui, c'était juste, dans un sens..."

L'entretien s'est achevé définitivement sur ces mots..."Dans un sens" est une locution bien commode pour ne pas se prononcer clairement, pour ménager la chèvre et le chou, quand on est assis entre deux chaises, avec deux statuts successifs: combattant au front (dans l'emploi très périlleux de téléphoniste) dans les deux premières années de guerre, "mobilisé en usine" menant une vie civile dans les deux dernières...

\section{La création des permissions en juillet 1915}

Si les permissions existaient pendant "les classes", la période d'instruction de quelques mois où l'on restait, en général, à la caserne du dépôt de la ville où se trouvait le régiment en temps de paix, permission de quelques jours permettant de rentrer chez soi en train, il n'en était pas de même quand on était envoyé au front dans toute la première année de guerre. Les permissions n'ont été créées pour les soldats du front qu'en juillet 1915, et certains, à Noël 15, n'avaient pas encore eu leur première permission depuis août 1914! En revanche, les soldats blessés avaient eu droit, à la fin de leur hospitalisation, à une permission de convalescence chez eux, d'une durée variable fixée par un médecin-major, mais fréquemment d'un mois, voire plus. A la suite de quoi ils remontaient au front, sauf si leur état grave relevait du conseil de réforme.

Une fois de plus, le minutieux Joseph Sorgues (cl. 15), de Romanèche-Thorins (Saône-et-Loire), instituteur libre au pensionnat de Bellegarde à Neuville-sur-Saône, incorporé depuis décembre 1914, qui note tout ce qu'il lit dans son journal de guerre, s'avère précieux pour la datation et les modalités précises d'une mesure militaire, et pour la qualité de l'analyse, superbement écrite de surcroît, qu'il en donne. Le 6 juillet 1915, alors qu'il est au front 
depuis le 31 mai, dans le Pas-de-Calais, il écrit: "6 Juillet - Il va y avoir des permissions pour les combattants du front; partiront d'abord les anciens qui n'ont jamais été évacués (pour blessure) depuis le début de la guerre. La proportion des permissionnaires ne pourra pas excéder $5 \%$ des unités au front et $10 \%$ des unités au repos.

Quelle joie pour nous, car je compte bien en profiter aussi quand j'aurai six mois de front. Ces permissions, dont l'accord peut paraître surprenant parce qu'il ne s'est jamais produit dans aucune autre campagne, sont pleinement justifiées par la longueur et le genre de méthodes de cette guerre. Six jours de permission ${ }^{53}$, c'est d'abord beaucoup de bonheur en perspective pour le poilu et sa famille, c'est une retrempe physique et morale d'où le sortira plus fort et plus patient, c'est une occasion de constater si les civils tiennent et si les soldats n'ont pas perdu confiance, c'est l'intérieur communiquant plus intimement avec l'atmosphère d'élite de la zone des armées, c'est le mélange de l'avant et de l'arrière, de la France qui lutte et souffre avec la France qui espère et travaille. Cette mesure est très juste et très opportune; elle sera accueillie avec enthousiasme par l'armée tout entière, à en juger le bruit qu'elle soulève dans notre cantonnement. Les permissionnaires de ma compagnie sont $16,{ }^{54}$ dont le sous-lieutenant Poussin, l'adjudant Joyeuse, Verchère l'ordonnance du capitaine, etc. Bon voyage, chers camarades et revenez-nous pleins d'espoirs, confiant plus que jamais en la victoire finale!"

On verra plus tard que, malheureusement, les permissions permettront aussi de voir une certaine indifférence de l'arrière quand aucun membre de la famille n'est au front, et de constater, en passant dans les grandes villes, que certains se divertissent au bal, dans les théâtres, comme en temps de paix! Et que les embusqués engalonnés plastronnent aux bras des jolies femmes, sur les boulevards!

Un autre instituteur, mais farouchement laïc, Antonin Granet, plus âgé de douze ans, car né à Savigneux en 1883, fils d'un agriculteur exerçant aussi la fonction de garde-champêtre, en poste à Chamboeuf depuis 1912, où il passera après guerre le reste de sa carrière jusqu'à sa retraite prise en 1940, rédige le récit de sa guerre, à partir de carnets antérieurs, alors qu'il est en captivité en Allemagne depuis le 13 mars 1916. Ce sergent au $38^{\mathrm{e}}$ R.I. de Saint-Etienne écrit à propos des permissions: "Depuis juillet les permissions du front fonctionnent. Démarre le traîneur de cafard, le broyeur de noir est des premiers favorisés. Il nous revient encore plus sombre et plus écoeuré. Avec ces premiers permissionnaires nous percevons plus nettement l'opinion de l'arrière, du cour de la France, opinion sur laquelle la grande presse bluffe constamment. Une vie de circonstance a repris dans le pays. Tant bien que mal les travaux s'exécutent grâce à la bonne volonté de toutes les forces encore valides. Avec fièvre on forge munitions et armements. Les familles qui souffrent de l'absence des leurs qui sont au danger sont lasses, et la vue de ceux qui rapportent un air du front les émeut. Mais ceux qui profitent de la guerre, ceux qui ne courent aucun risque pour leur personne ou leur famille, ceux-là ont des réparties avec des sourires ironiques: "Mais que faites-vous là-bas? Vous ne bougez pas de place!" Le pauvre permissionnaire aux habits boueux au visage de terre, ne sait que répondre à de pareilles questions. Que dire, en effet, à des gens qui, férus de stratégie, gagnent des victoires en chambre, qui, bourrés par la grande menteuse, la presse, s'écrient: "On les aura quand on voudra!" Quel tableau faire à des gens qui, convaincus par la vue de belles gravures, jugent la vie de tranchée d'après les belles photographies prises bien à l'arrière du danger et animées d'acteurs dont les rôles sont joués par les embusqués du front? Car il y a des embusqués au front! Si dans les dépôts militaires se prélassent des jeunes gens valides, mais pistonnés, si les usines métallurgiques servent de refuge à ceux dont la profession est d'être fils à papa, il y a plus près de nous, assez loin du danger cependant, une foule de favoris qui deviennent chaque jour plus nombreux. Au sein même des unités, que de tirage au flanc! 50 hommes d'effectif, 30 hommes pour prendre le service! Le reste échappe à la dure corvée et le camarade paye cette fuite autorisée en heures de veille supplémentaires.

Ah! oui! On les aura! Ce ne sera toujours pas vous, MM. les embusqués avec vos belles paroles! Cette tâche est trop noble pour vous! Elle incombe à ceux que vous appelez les vulgaires, les humbles fils de France! "Nous ferons ceci, nous attaquerons par là" dites-vous devant un bon feu, le ventre à table! Tandis qu'à tous les dangers exposés, les poilus grelottent de froid ou de crainte, serrant la ceinture pour calmer l'attente d'un repas additionné de terre." tard.

Nous avons vu surgir le grand thème des embusqués détestés, sur lequel nous reviendrons longuement plus

La juxtaposition, à propos d'un même fait, la création des permissions pour les hommes du front à partir de juillet 1915, de ces deux témoignages de grande qualité, mais si différents, ne traduit pas seulement une opposition de caractère, donc de vision, entre le jeune idéaliste chrétien de 21 ans et le sceptique rationaliste de 33 ans. Elle traduit aussi un décalage d'une année entre celui qui tient son journal au jour le jour, Joseph Sorgues, qui ne sait donc rien des effets pernicieux des permissions se mettant juste en place, et celui qui, une année plus tard, reprend au propre la rédaction de ses carnets de guerre en les modifiant quelque peu, riche de l'expérience et des désillusions accumulées par les permissionnaires, dont lui.

\footnotetext{
${ }^{53}$ Six jours pleins chez soi, plus la durée du voyage aller et retour en train, variable selon l'emplacement du front où l'on se trouve, souvent de deux jours pour chaque trajet, car il faut du temps pour gagner la gare la plus proche.

${ }^{54} 16$ permissionnaires sur une compagnie, dont l'effectif tourne habituellement, quand elle est au complet (sans morts ni blessés non remplacés), autour de 250 hommes, cela représente $6,4 \%$ soit un peu plus que les $5 \%$ alloués. Si 16 représentaient juste les 5\%, la compagnie serait de 320 hommes, encadrement compris, ce qui serait inhabituel.
} 
L'organisation des tours de rôles pour les bénéficiaires des permissions va s'avérer difficile, d'autant plus qu'elles sont supprimées en perspective d'une attaque locale, ou générale, comme dans le cas de la grande offensive de Champagne de fin septembre 1915. Antonin Granet espère la sienne pour septembre 1915 mais ne l'aura pas:, bien qu'il soit sergent: "J'ai tenté un subterfuge pour devancer mon départ en permission, mais en vain! En Champagne, en Artois se préparent les formidables attaques du 257 bre, les permissions sont suspendues". Quel subterfuge? Il ne l'indique pas. C'est en général un télégramme à faux contenu (demandé par le soldat) émanant de la famille annonçant le décès d'un proche. Et Antoine ne va pas s'appesantir sur cet échec, il continue en évoquant l'autre échec, relatif, des attaques tentées fin septembre 1915, dont il connaît le bilan puisqu'il écrit en 1916: "Chamapagne, Tahure, Sommepy, Artois, Souchez, le Labyrinthe, noms célèbres dans ces essais de percée; résultats: des milliers de prisonniers, quelques kilomètres d'avance et comme toujours des sacrifices énormes.". Il aura sa première permission fin novembre 1915, soit 15 mois après son départ du 7 septembre 1914 (il avait été retenu un mois au dépôt de Saint-Etienne pour encadrer les manœuvres des soldats de réserve), permission qu'il attend avec fébrilité: "Enfin je vais pouvoir jouir de cette permission si longtemps attendue! Du fait que je n'avais pas été favorisé par le système de départ différent (différé?) à deux reprises. J'avais d'abord dû laisser partir les plus chargés que moi en famille et ensuite les plus anciens en séjour sur le front! Maintenant je compte les jours, les départs nombreux et réguliers en raison de notre situation au repos me permettent de prévoir une date de départ prochain.

23 novembre! Avec Souchon Pierre, Vaury, Blin, nous nous mettons en route. Ah! le beau jour! Comme allègrement nous nous rendons à Tricaud où nous prenons le train!"

Nous verrons dans le chapitre consacré spécifiquement aux permissions dans quel état d'esprit Antonin a vécu la sienne, en retrouvant à Chamboeuf sa chère épouse Rosalie, son petit garçon de quatre ans "Féfé" (Ferdinand), ses parents et beaux-parents.

Quant à son collègue et cadet de douze ans Joseph Sorgues, gravement blessé le premier jour de l'offensive de Champagne, le 25 septembre au matin, il n'aura pas à attendre sa permission pour voir sa famille: son père lui rendra une longue visite, le 22 novembre, à l'annexe de l'hôpital du Val-de-Grâce, à Paris, où il attend l'extraction de la balle qui s'est logée tout contre la colonne vertébrale. Il évoque avec tendresse cette visite paternelle:

"22 Novembre - Mon père est arrivé, il sort de là, et je savoure encore délicieusement le bonheur qu'il m'a apporté, le bonheur de le savoir près de moi pour cinq jours encore. Il m'a embrassé, puis contemplé avec inquiétude, comme s'il essayait de deviner mon état physique, de sonder la gravité de ma blessure. Il est parti rassuré tout à l'heure, en voyant que j'étais bien soigné et que mon moral était bon. Nous avons parlé longuement, toute la soirée, de la petite famille....".

Cinq jours après, son père, resté à Paris, lui rend sa dernière visite, et Joseph note dans son carnet: "27 Novembre - Mon père vient de partir, tout à fait rassuré sur mon état et certain que je suis entre bonnes mains. Il emporte de bonnes nouvelles à ma mère et l'espérance de me voir bientôt guéri d'une façon définitive; je l'ai chargé d'une foule de baisers pour distribuer à tous dans la petite maison du bourg. ${ }^{55}$ De mon côté, je vais prendre patience plus aisément, et j'espère bien qu'au mois de mars j'irai moi-même faire la distribution avec les premiers jours du printemps."

En mars 16, Joseph ne pourra pas se rendre dans sa famille, il devra rester au Val-de-Grâce, sa balle n'étant finalement extraite que le 12 avril $1916 \ldots$

\section{Ententes tacites et fraternisation autour de Noël 1915}

Après avoir longtemps occulté les fraternisations, les historiens les soulignent depuis quelques décennies, parfois même en réunissant des chercheurs des principaux pays belligérants, comme le récent ouvrage collectif Frères de tranchées de Marc Ferro, Malcom Brown, Rémy Cazals et Olaf Mueller, qui reconnaissent volontiers ce silence chez leurs prédécesseurs, en fin d'introduction: "Et comme ces fraternisations-là n'ont pas changé le cours de la guerre, bien des historiens ont pu, à tort, les ignorer. Au mieux, ils les ont considérés comme une sorte de fait divers, symptôme certes des malheurs de la guerre, de son absurdité, mais rien de plus, et ils n'ont pas cru devoir en garder le souvenir. Les textes qui suivent permettent de combler cette lacune. ${ }^{156}$.

Il s'est cependant établi l'idée, surtout auprès du grand public avec le grand succès du film "Joyeux Noël" de Christophe Trossignon, présenté au festival de Cannes 2005, qu'elles concernent essentiellement, voire exclusivement le premier Noël de guerre. Nous verrons qu'elles courront tout au long de la guerre, et débordent la stricte période de Noël.

C'est une forme d'entente tacite, non de fraternisation, que décrit dans son récit de guerre Claude Coupade (cl. 15), de La Ricamarie, ajusteur à Saint-Etienne avant guerre, versé en avril 15 au $157^{\text {ème }}$ T.I. Alpine de Gap, ayant passé l'été en tranchées à Flirey (à $15 \mathrm{~km}$ à l'ouest de Pont-à-Mousson), dans un secteur très exposé aux torpilles, avant de rejoindre la forêt d'Apremont, à $20 \mathrm{~km}$ plus à l'ouest environ, en bordure du département de la Meuse:

\footnotetext{
${ }^{55}$ Il s'agit de son bourg natal, Romanèche-Thorins, en Saône-et-Loire.

${ }^{56}$ Frères de tranchées, ouvrage collectif, éditions Perrin collection Tempus (de poche), p. 12-13, édité en 2005 et 2006
} 
"Le 8 octobre 1915 nous prenons positions* dans notre nouveau secteur, il nous fallu* faire une bonne marche pour y arriver. Ce ne sera plus Flyret*, tout est calme, nous sommes en plaine* forêt d'Apremont, le séjour sera de huit journées; face à nous ce* trouve le village d'Apremont dans lequel sont les Allemands. Une grande prairie nous séparent* d'environs* 1500 mètres. Des petits postes sont placés dans cet intervalle, aucun coup de fusil ne doit être tiré à moins d'une alerte, c'est bien le secteur de repos. Le moral y est bon; rarement nous trouvons des poux...". Si la consigne française est de ne pas tirer, c'est pour ne pas attirer de riposte allemande, et préserver la période de semi- repos du bataillon; mais, implicitement, elle suppose que l'ennemi en ait fait de même et continue à observer cette restriction. Les $1500 \mathrm{~m}$ sont bien inférieurs à la portée du fusil Lebel, qui tire très précisément jusqu'à $800 \mathrm{~m}$, mais dont la portée maximale peut atteindre $3200 \mathrm{~m}$. Quant à l'existence des "petits postes" français (les Allemands ayant les mêmes) ou postes pour deux sentinelles, creusés çà et là dans le no man's land, (sans être trop éloignés des lignes françaises), elle signale aussi implicitement qu'aucune patrouille nocturne - ni française, ni allemande - ne cherche à s'emparer des soldats en sentinelle pour leur extorquer des renseignements, et les garder prisonniers, ce qui romprait la fragile trêve. Nous avons employé le terme de "semi-repos", car en fait le vrai repos se passe beaucoup plus à l'arrière, et pas en tranchées, comme on le verra, et il dure plus longtemps: trois semaines, voire un mois.

Précédant un peu Noël 1915, une fraternisation méritant ce nom nous est décrite par Joseph Devaux (cl. 99, donc ayant déjà 36 ans) qui est passé de l'armée territoriale à l'armée active fin août 1915, au $158^{\mathrm{e}}$ R.I. d'Infanterie de Lyon, où il est alors caporal. Il se trouve en tranchées en décembre 1915 en Artois, au bois en Hache, à l'ouest de Lens, entre Aix-Noulette et Souchez. Le 14 décembre 1915, il écrire à sa "chère Ninette", son épouse, à Belmont-de-la Loire: "Ne t'étonnes* pas que je ne puisse pas t'écrire des tranchées, je vois bien que tu ne rends pas compte de notre situation, nous sommes littéralement couverts de boue, on ne peut mettre ses mains à ses poches parce que celles-ci seraient aussitôt pleine* de terre [...] Mais sois bien tranquille à mon sujet, on ne court pas grand risque du côté des Boches. Je n'ai pas encore tiré un coup de fusil, nous sommes de plus en plus camarades, nous causons d'une tranchée à l'autre, on échange du pain et des cigares; comme nous, ils sont fatigués de la guerre. Nous avons encore une période de quatre jours à faire là-bas, après quoi nous serons vingt jours de repos."

Dix jours avant Noël 1915, donc, ce Noël qu'il passera au repos (ce qui nous empêche de savoir si l'état d'esprit qu'il décrit a perduré) on a donc les caractéristiques de la fraternisation: le dialogue d'une tranchée à l'autre et l'échange de cadeaux (pain de la part de Français, cigares de la part des Allemands, comme dans le témoignage qui suivra de Jean Rivet, et comme dans ceux - déjà cités au chapitre des fraternisations de la fin 1914- d'Antonin Granet de fin novembre 1914 et d'Armand Primpier pour Noël 14, le tout dans une psychologie de lassitude de la guerre. Le fait d'échanger des cadeaux suppose le déplacement vers la tranchée de l'ennemi, donc la confiance en ce dernier, dont on dénonce pourtant la traîtrise en temps ordinaire, ce qui est une conversion mentale considérable! Cela implique aussi un minimum de connaissance de la langue de l'autre, ou le recours à ces bilingues que sont les Alsaciens enrôlés dans l'armée allemande. On peut supposer que les Français ont un approvisionnement national en farine plus abondant, puisqu'ils y ont pris plus tard, et de façon moins drastique, la mesure du pain réglementaire à moindre teneur en farine (pain K.K. pour les Allemands), alors que les Allemands, qui n'ont pourtant pas de colonies produisant du tabac, doivent le tirer d'une culture nationale des plants de tabac pas trop affectée par la guerre.

Pour ce qui est de l'échange linguistique, on a vu en Noël 1914, qu'au sentiment de plusieurs Poilus, les Allemands connaissaient en plus grand nombre le français que l'inverse. C'est aussi ce que l'on lit dans l'ouvrage collectif Frères de tranchées de Marc Ferro, Malcom Brown, Rémy Cazals et Olaf Mueller, au chapitre "Les Français et les Boches parlent ensemble": "Des Allemands et quelques Français connaissant la langue de l'ennemi, sans oublier les Alsaciens présents dans les deux armées. Cependant la différence des langues parlées fut parfois un obstacle à l'entrée en relations amicales: "Si je savais parler le boche", s'exclame un poilu du 201 e R.I. en octobre 1916, alors que sa tranchée est à quelques mètres de l'autre. Mais cette barrière n'est pas insurmontable. Différentes formes de communication furent utilisées, successivement ou simultanément ${ }^{\prime 57}$. Et les auteurs de citer, à partir d'exemples précis de correspondances ou de carnets de guerre, des rires, des gestes, des chants, des airs de musique, des pantomimes, ou des pancartes élevées au-dessus de la tranchée...

Un témoignage indirect sur une période de fraternisation, non circonstancié, mais intéressant en raison du lieu emblématique qu'il concerne, Verdun, nous est fourni spontanément (sans être sollicité sur ce thème) par un autre soldat de la classe 1915, Antonin Cote, agriculteur, avant son incorporation, à Laprugne (Allier) avant de venir exploiter, après guerre, la ferme familiale de son épouse à Saint-Priest-la-Prugne, en limite ouest de la Loire, entre Bois Noirs et Monts de la Madeleine. Son régiment, le $121^{\mathrm{e}}$ R.I. de Montluçon va être transféré de la Somme à Verdun au début du printemps 1916, mais il a appris que dans la période précédant le début de la grande bataille, le 21 février 1916, depuis quelques mois, il y avait eu fraternisation entre les ennemis:

E- "Je crois que ça a beaucoup bombardé à Verdun?

${ }^{57}$ Frères de tranchées, éditions Perrin, 2005 et 2006, p. 154 
T- Ah! Ça a bombardé, Verdun! Ça a été...ça a passé un moment que c'était pas bien joyeux, non! En commençant, c'était bien, la ville de Verdun; soi-disant qu'ils naviguaient ensemble! ${ }^{58}$

E- Qui est-ce qui naviguaient ensemble?

T- Les Boches et les Français, soi-disant... Avant que ça soit si méchant, ils fraternisaient ensemble!

E- Ah bon?

T- J'ai entendu dire qu'ils fraternisaient!

E- $A$ Verdun?

T- A Verdun!

E- Mais c'était déjà la guerre?

T- Oh! C'était la guerre, oui, oui! Ils étaient aux tranchées. Mais ils naviguaient ensemble! Et ça s'est su, ça! C'est à cause de ça que ça a été si méchant après! Oh! Verdun, ça en a tombé des soldats là-bas!"

Le lien de causalité qu'introduit Antonin Cote entre les fraternisations qu'on lui a rapportées (de la fin de l'année 1915? de janvier 1916?) et la violence de la bataille de Verdun est intéressant, bien que des motifs stratégiques évidents, liées à la position de Verdun, entouré de forts, soient une cause militaire bien plus avérée. Pour lui, et les soldats qui ont pensé comme lui, la violence des bombardements et des combats qui se sont déroulés à Verdun serait une punition, qui n'avait pu être décidée que par les Etats-majors qui l'ont su (au moins, dans sa position, par l'Etat-major allemand, qu'il est plus facile de charger de toutes les arrière-pensées retorses) des fraternisations qui avaient précédé... Donc ce serait une façon de châtier ses propres soldats de s'être laissés aller à perdre l'esprit offensif, belliqueux!

La même idée, sans sollicitation, de fraternisation avant la bataille de Verdun mais sur les jours précédant le déclenchement de cette bataille, nous a été rapportée par un soldat de l'autre côté de la Loire, dans le coin nord est du département, à Belmont-de-la Loire, limitrophe de la Saône-et-Loire, Eugène Troncy (cl. 16), soldat d'abord au même régiment, le $121^{\mathrm{e}}$ R.I. de Montluçon, avant de passer au $105^{\mathrm{e}}$ R.I. de Riom à la fin de 1915:

E- Est-ce qu'on avait conscience qu'à Verdun, c'était une énorme bataille qui se livrait?

T- Oh oui! Y a bien passé un moment, hein, ça allait pas bien! Et quand ça s'est déclenché, des anciens m'avaient fait voir... La veille que ça s'est déclenché (les Boches étaient malins, hein! ...oh! je devrais pas parler comme ça! (dire "Boche"!)...Ils se fréquentaient, les lignes étaient pas loin, ils se donnaient une poignée de main... Mais les Allemands, dans la nuit, avaient envoyé des troupes, toutes d'autres troupes, et le matin, ils ont attaqué! Oh! Y a été violent!

E- Donc ils étaient venus repérer les lieux, vous voulez dire?

T- Oui!..Oh non! On doit pas répéter... Vous comprenez, y a eu des survivants qui étaient avec nous, qui avaient fait (remarqué) cet* détail! Ils nous y racontaient, les survivants qui étaient au $105 \ldots$

E- Ce que je voulais dire, c'était: les Allemands avaient profité que les Français n'étaient pas trop méfiants pour venir repérer les endroits?

T- Oui, mais ils avaient changé leurs régiments, eux!"

On trouve ici aussi l'idée développée par François Potin, pour Noël 1914, reflet de ce que doivent penser la plupart des officiers supérieurs; la fraternisation n'est qu'un subterfuge des Allemands, ces traîtres, pour repérer les lieux et préparer une offensive plus meurtrière, avec de nouveaux régiments, donc pas impliqués dans la fraternisation antérieure. Cette hantise de l'Etat-Major de voir les soldats français pactiser avec l'ennemi, les soldats la ressentent à travers ceux de leurs officiers proches (lieutenants plus accessibles souvent que capitaines) qui partagent cette vision. Dans l'ouvrage collectif cité plus haut, Frères de tranchées, on a cette confirmation: "Le commandement tente de culpabiliser les poilus en affirmant que les fraternisations sont voulues par les Allemands pour affaiblir la France." (p. 182).

Jean Rivet (cl. 16) de Pouilly-sous-Charlieu, agriculteur devenu coquetier en gros, a écrit un texte de 14 pages sur sa guerre, après la fin de celle-ci, à partir de carnets, ce qui a servi de support chronologique précis à notre entretien du 6 février 1988 à son domicile. Incorporé le 9 avril 1915 au $121^{\mathrm{e}}$ R.I. de Montluçon, il monte au front en décembre 15 au $105^{\mathrm{e}}$ R.I. de Riom se trouvant à Thieux, dans l'Oise. Il y a été témoin d'une brève scène de fraternisation quelques jours après Noël 1915:

T- "Oh! A Thieux, y avait des vieux territoriaux qui étaient sur la place, ils nous ont dit: "Les Boches sont tranquilles! (suite, brève, inaudible). On a monté trois ou quatre jours après, ils (les Allemands) étaient sur un talus, sur le terrain... Y a en a un qui dit: "Broute! Broute!"- "Mais qu'est-ce qu'il veut? - "Il veut du pain! ${ }^{59}$ " "Ah! Il veut du pain!" On va chercher dans le ...(incident technique: le magnétophone change de vitesse! Arrêt puis reprise) "Ils sont venus chercher la boule de pain: ils étaient très contents! Ils nous ont envoyé des cigares!

E- Ah bon? A quel endroit?

T- $A$ Thieux!

E- A Thieux! Donc le premier contact que vous avez eu, il était bon!

\footnotetext{
${ }^{58}$ Le verbe "naviguer", en français local forézien, signifie "se déplacer ça et là"; mais ici, il paraît presque un équivalent de "frayer ensemble", donc de fraterniser

${ }^{59}$ On ne fera pas l'injure au lecteur de lui rappeler qu'en allemand "pain" se dit "Brot" (même origine que l' anglais "bread")
} 


\section{T- Il était bon!}

E- Mais c'était en période de Noël?

T- Non! On a fait Noël à Saint-Just-en-Chaussée! ${ }^{60}$

E- Ça n'était donc pas Noël, donc [récapitulation]. Et alors, ils sont venus jusque vers vous?

T-Non! On leur a lancé la boule de pain à 10-15 mètres... à peu près...

E- Ils vous ont lancé les cigares? T- Oui! - E- Vous étiez à 10-15 mètres?

T-Oh! On était à 20 mètres les uns des autres...̀̀ peu près...

E- Ah oui...Mais vous aviez pas envie de vous tirer dessus?

T- Oh mais les territoriaux qui avaient pris les tranchées avant nous, ils nous avaient dit: "Ils sont gentils, ces gens-là! Ils vous diront rien! "Ils sont venus chercher la boule de pain, et d'une main: "Kamarade!"

E- D'une main, ils vous ont fait signe: "Kamarade"? T - Oui! - E- Ils vous l'ont dit, "Kamarade"?

T-Oui! ...Et après nous sommes allés dans la Somme."

On a ici les ingrédients d'une fraternisation classique, mais très mesurée, donc crédible, avec une variante: ceux qui arrivent en ligne ont été informés par les soldats territoriaux, qui pouvaient suppléer les soldats de l'active ou de la réserve dans l'occupation des tranchées, des intentions pacifiques des vis-à-vis allemands, ce qui suppose une cohabitation assez longue.. Les distances 10-15 mètres et 20 mètres ne sont pas contradictoires: les tranchées de première ligne, la française et l'allemande, sont à une vingtaine de mètres l'une de l'autre, mais la boule est lancée sur le no man's land, entre les deux, à 5 mètres ou un peu plus de la tranchée allemande. Des ennemis (un seul aurait suffi!) doivent donc s'aventurer à découvert, donc prennent le risque d'être tués, pour aller chercher cette boule, d'où le geste de la main - sans doute une main levée- signifiant l'intention pacifique, et le mot "Kamerad", que les Français entendent comme "Camarade", l'expression "faire Kamarade" voulant dire "se rendre" en 14-18, ce qu'auraient signifié les deux mains levées. On remarque que les Français, prudents, n'ont pas pris le risque de porter le pain dans la tranchée des Allemands, et que ces derniers n'ont pas pris le risque non plus d'apporter leurs cigares...

\section{Bilan de fin décembre 1915 dressé par un grand blessé qui, par ailleurs, fête Noël}

Le 31 décembre 1916, l'instituteur libre au pensionnat de Bellegarde à Neuville-sur-Saône, Joseph Sorgues (classe 15, alors au dépôt du $160^{\mathrm{e}}$ R.I. de Pierre-le-Moutier dans la Nièvre, après plus d'un an d'hospitalisation consécutif à la balle fichée juste contre sa colonne vertébrale, reçue le jour même du déclenchement de la grande offensive de Champagne, le 25 septembre 1915) coupe son long bilan, jugé positif, de l'année 1916 par un bref bilan plutôt négatif de l'année 1915, en sortant du cadre du seul front français. Retenons -le, tout en sachant qu'il écrit avec un recul d'un an par rapport à la fin de l'année 15, de près de deux ans par rapport à son début, et qu'il est nourri par une lecture assidue de la presse, divertissement principal du blessé: "En 1915, nous avions obtenu deux succès, un en mai dans l'Artois, l'autre en septembre en Champagne; nous avions été obligés de nous arrêter, faute de matériel suffisant. Les Allemands avaient fait reculer les Russes de plusieurs centaines de kilomètres, conquis Varsovie, toute la Pologne, la Courlande et la Lithuanie*. La Bulgarie passait dans leur camp; en deux mois, ils envahissaient la Serbie, le Monténégro; et inauguraient bruyamment le train Berlin - Constantinople. Notre expédition des Dardanelles échouait, les Russes étaient refoulés au Caucase, et notre corps de Salonique se ramassait en boule au bord de la mer, derrière des défenses hâtivement construites, au milieu de forces grecques quasi menaçantes. Bref, à la fin de 1915, les pangermanistes se croyaient bien tranquilles du côté de l'Orient, et ils ont voulu en finir avec la France." D'où le déclenchement de l'immense offensive de Verdun le 21 février 1916. Il va sans dire que le bilan de 1916, après la fin de la grande bataille de Verdun en décembre, qui a consacré l'échec de la stratégie de percée allemande, sera plus positif, malgré l'immense saignée humaine de Verdun, de la Somme et des batailles moins spectaculaires...

Un an plus tôt, le 26 décembre 1915, Joseph Sorgues était plus préoccupé de sa survie, ne sachant pas que sa balle ne pourrait être extraite qu'en avril 1916, mais s'estimait content de la fête de Noël réservée aux grands blessés de l'annexe de l'hôpital du Val de Grâce à Paris:

"Dimanche 26 décembre - Nous avons eu hier une petite fête charmante, le dépouillement du traditionnel "Christmas-tree" ${ }^{\prime 61}$ ! Le préau de l'hôpital était rempli de monde: les blessés, étendus sur des chaises longues contre le dortoir des infirmiers, les infirmières à droite et à gauche du grand sapin, et les invités à la suite. Nous avons tous eu nos étrennes, comme de grands enfants, : on appelait nos numéros de lit et nous recevions notre cadeau J'ai reçu, pour ma part, un portefeuille vert et un porte-monnaie avec une pipe aux couleurs des alliés et une superbe épingle de cravate (?). Après la distribution des dons, on a dépouillé l'arbre de Noël à la plus grande joie

\footnotetext{
${ }^{60}$ Saint-Just-en-Chaussée est environ à $10 \mathrm{~km}$ au sud-est de Thieux, et à peu près équidistant (30-35 km) de Beauvais et de Compiègne, mais plus au nord que la ligne qui relierait ces deux villes.

${ }^{61}$ Bien que l'on trouve la coutume du sapin de Noël attestée par des textes dès le XVIe siècle, et pratiquée dans la bourgeoisie française au XIXe siècle, le sapin de Noël est loin d'être perçu comme "traditionnel" en France, dans tous les milieux, comme le prétend Joseph Sorgues. Une preuve est qu'il l'affuble de son nom anglais, comme s'il percevait la coutume comme purement anglo-saxonne.
} 
des enfants que leurs parents avaient amenés et à la nôtre aussi, car les infirmières, tourbillonnant autour de l'arbre et s'amusant de tout leur cour, nous lançaient un tas de jouets à treize sous et des serpentins multicolores qui se croisaient en tout sens. On n'aurait pas dit un hôpital de grands blessés, à voir la lueur de joyeuse folie qui passait dans nos yeux et à entendre tous ces rires et ces exclamations. Nous avons oublié nos souffrances pendant trois bonnes heures. Je suis remonté dans la chambre avec Laplace qui était venu me voir avant de partir en permission; il portait tout mon butin; outre les objets mentionnés plus haut, deux ou trois petits sacs de bonbons, un mirliton, une coiffure de papier en forme de tête de coq et un petit piano mécanique. Déjà le matin Mlle Marguerite nous avait donné de gentilles petites blagues à tabac remplies de bonbons, Mme Gonderax une trousse complète pour entretenir le linge, et Mlle Suzanne, un superbe porte-cigarette en métal. De son côté, Mme Larivière a fait don à tous les amputés d'une superbe montre en argent gravée à leur nom avec la date et le lieu de leur blessure. Nous sommes vraiment trop gâtés par ces bonnes dames."

Qu'on ne s'y méprenne pas. Ces "bonnes dames" ne sont pas des infirmières salariées qui se ruineraient en cadeaux coûteux (surtout pour les montres en argent) pour les blessés, l'archétype du blessé héroïque étant l'amputé. Ce sont, on le verra dans un chapitre spécifique, des infirmières bénévoles issus de familles bourgeoises, voire nobles, jeunes filles ou femmes mariées, qui puisent dans leur cassette pour faire ces cadeaux à leurs protégés. N'en concluons pas non plus que tel est le sort de tous les blessés en France: on est ici à Paris, dans une annexe du Val-de-Grâce, et l'aisance financière de la bonne société parisienne explique l'abondance et la valeur de ces présents de Noël. Mais cela est révélateur du statut éminemment glorieux du blessé de guerre et de l'admiration qu'il inspire pendant la guerre, plus guère après, hélas!

\section{L'espoir d'une fin rapide de la guerre mais le sentiment douloureux de l'écoulement du temps}

Nous savons que la grande Guerre s'est achevée le 11 novembre 1918. Mais les combattants en 1915, en 1916, en 1917 ne le savaient pas, et le temps leur a souvent paru interminable, même si des bouffées d'espoir, liées à des victoires militaires, amplifiées par la presse, pouvaient leur laisser espérer une victoire définitive prochaine, donc la fin de la guerre.

Ainsi le caporal au $23^{\mathrm{e}}$ B.C.A. de Grasse Edmond Deloule (cl. 13) de Saint-Martin d'Ardèche (Ardèche), maçon avant guerre, employé à l'octroi de Paris après guerre, car bénéficiant d'un emploi réservé à la suite de sa grave blessure au visage (trépanation et perte de l'œil gauche) par des éclats d'obus reçus le 15 août 1915, vers le Linge, en Alsace, écrivait à ses parents le 7 janvier 1915 cette lettre récapitulative de son itinéraire: "Ah! je commence. Nous avons passé un bon mois de repos à Ménil-la Tour ${ }^{62}$, où là nous étions très bien, bien nourris, pas trop de travail, le dimanche de libre. Nous y avons passé les fêtes de la Toussaint, et on comptait y rester le restant de la guerre car on ne croyait pas qu'elle soit si longue; et ma foi, malgré toutes ces bonnes pensées, on attaquait le $119^{\text {bre (novembre) à Toul distant de } 10 \mathrm{~km} . . . "}$

Croire, à la Toussaint 1914, voire début janvier 1915, que le repos accordé au régiment va pouvoir durer jusqu'à la fin de la guerre (ce qui la porte à la fin de l'année 1914 ou au début de l'année 1915!), c'est ne pas avoir renoncé à l'illusion de la victoire rapide du début de la mobilisation...

Cela rejoint le témoignage écrit d' Etienne Tanty, dans "Les violettes des tranchées - Lettres d'un Poilu qui n'aimait pas la guerre ${ }^{\prime \prime 63}$ qui, déjà, dans sa lettre du 21 novembre 1914 adressée à ses parents et à ses sœurs, signalait l'idée obsessionnelle de la paix dès fin novembre 14: "On n'a plus qu'une idée, je dirais presque une monomanie, une obsession: la fin, la paix. Et le désir en est tel que les pires énormités, si elles le flattent, se propagent aussitôt avec une créance invraisemblable; chacun attend l'armistice du jour au lendemain, d'une heure à l'autre presque. " ${ }^{64}$

Ainsi encore, un bon mois après Edmond Deloule, le 14 février 1915, un autre caporal - qui deviendra sergentau même régiment, Eugène Reymondon (classe 98, donc âgé alors de 37 ans) écrivait à sa jeune épouse de 22 ans Antonia, qui exploitait, avec son père et deux domestiques rétifs, la ferme familiale au hameau de Sabonnaire, à Saint-Maurice-en-Gourgois, alors que lui-même était hospitalisé à Saint-Riquier, près d'Abbeville; pour soigner la fièvre typhoïde contractée en Belgique à la mi-décembre 14: "Sois bien persuadée que cette triste guerre durera moins que l'on ne croit car les armées sont bien épuisées. Les Alliés n'ont pas trop de courage déjà et quand*à l'Allemagne ce doit être autre chose. Je suis bien certain qu'il y a longtemps que la moitié de la durée de la guerre est passée."

Pronostiquer, à la mi-février 1915, alors que la guerre dure depuis six mois, que plus de la moitié de la guerre s'est écoulée, et cela depuis longtemps, c'est estimer qu'au pire, la guerre sera achevée fin septembre 1915. On sait ce qu'il en est! Achevée par une victoire ou une défaite, ou un "match nul" résultant de l'épuisement des deux camps? Eugène ne s'aventure pas à le prédire...

\footnotetext{
${ }^{62}$ Cette localité se situe au nord de Toul; le régiment, envoyé au repos pour un mois en octobre et début novembre 1914, y a été reformé après les lourdes pertes essuyées aux combats de Lorraine, en août et septembre.

${ }^{63}$ Etienne Tanty : "Les violettes des tranchées - Lettres d'un Poilu qui n'aimait pas la guerre" avec une préface d'Annette Becker - édité en 2002 par France Bleu et Editions italiques

${ }^{64}$ Etienne Tanty, op. cit., p. 175
} 
Nous allons avoir recours à un document extérieur à notre "corpus" de témoins, mais relié à l'un d'eux, JeanBaptiste Grousson (classe 95, donc ayant 40 ans en 1915), avant guerre gareur dans une usine de tissage de Bourg-Argental, puis entrepreneur de tissage après guerre, toujours à Bourg, et enfin, après 1942, négociant en rubans et soieries à Saint-Etienne. Il est passé du $102^{\mathrm{e}}$ R.I. Territorial de Saint-Etienne au $298^{\mathrm{e}}$ R.I. de Roanne caporal fourrier puis sergent) où il a été témoin, on l'a vu, de l'exécution des six Martyrs de Vingré, le 4 décembre 1914. Fin mars 1915, sa femme reçoit cette lettre (datée du 26 mars) de son capitaine à la C.H.R. - Compagnie Hors Rang- du $298^{\mathrm{e}}$ R.I., qui a été aussi compagnon de son mari au $38^{\mathrm{e}}$ R.I. de Saint-Etienne, pour leur service militaire commun, avant 1900. La signature n'est pas totalement lisible: A. Célade ou A. Pélade, ou A. C/Péladée si l'accent du deuxième "e" a été omis, ou A. C/Péladre". La lettre finit ainsi: " La guerre, je l'espère, ne durera pas aussi longtemps qu'on pouvait tout d'abord le croire; les allemands* ne luttent plus maintenant que pour obtenir une paix qui ne leur coûte pas trop cher; nous les mènerons cependant assez loin pour qu'ils n'aient plus ni le désir ni la force de recommencer. Nous ne reverrons plus, je crois, les terribles batailles des débuts et votre mari vous reviendra, j'en suis certain, sain et sauf avec l'auréole de la victoire.

Veuillez, Madame, embrasser pour moi vos enfants qui veulent bien penser au Capitaine dans leur prière et agréer l'assurance de mes sentiments très respectueux."

Ce "Capitaine au 298" , comme il indique après sa signature, ne pronostique pas de date ni de délai pour la fin de la guerre, mais son ton montre qu'il la sent proche et victorieuse. Quant à la fin des "terribles batailles" comme celles d'août-septembre 1914, on demeure songeur en pensant que cela a été écrit un an avant le début de la bataille de Verdun...

De deux ans plus jeune que Jean-Baptiste Grousson, et d' un an plus âgé qu'Eugène Reymondon, car né en 1877 (cl. 97, donc âgé de 38 ans en 15), François Baizet, agriculteur à Chassigny-sous-Dun (Saône-et-Loire), passé en octobre 1914 de l'armée territoriale à l'armée de réserve de l'active, au $153^{\mathrm{e}}$ R.I. de Béziers, où il est sergent, a été blessé au genou dans les tranchées de Zonnebecke en Belgique le 8 avril 1915; après un mois d'hospitalisation à Malo-les-Bains, puis à Paris, il écrit dans son journal à la date du mardi 4 mai 1915, d'abord à propos d'un camarade d'hôpital, puis de lui-même: "Le temps dure à sa femme, et elle voudrait bien que ça finisse bientôt. Pour ma part, je ne compte pas que cela finisse de sitôt. Je compte au moins le restant de l'année. Que de souffrance à endurer encore pour tout le monde! Enfin Dieu nous fera peut-être miséricorde. Nous allons chez Gabrielle. Pauvre fille, son tribut à la guerre est très fort. Son pauvre Jules est resté là-bas en Belgique tué par un obus. Nous allons voir ensuite Claudia qui a été si gentille pour moi en venant me voir toutes les fois qu'il y avait visite à l'hôpital. Nous rentrons à 7 heures à l'hôpital."

François croit se montrer plus raisonnable que la femme de son camarade, en repoussant son "bientôt" pour l'achèvement de la guerre à la fin de l'année 1915 ("le restant de l'année"). Et lui, encore célibataire à 38 ans, comprend les drames des couples, et en compagnie de camarades pouvant marcher, va faire des visites de condoléances aux veuves de camarades de son régiment tués à la guerre, et demeurant à Paris.

Le célibataire qu'il est a le sentiment que sa vie s'écoule sans qu'il ait construit une famille, et cela transparaît, par bribes, dans son journal, surtout en 1916 et 1917, comme on le verra. Il verra la fin de la guerre pourtant, se mariera, aura un fils, Robert ${ }^{65}$ mais il ne le verra pas grandir puisqu'il décédera le 30 mars 1928, à l'âge de 51 ans...

Un autre célibataire, mais qui vient d'entrer, à 35 ans, dans un projet de mariage avec la jeune Madeleine Pagès, professeur de Lettres à Oran, le poète Guillaume Apollinaire, écrit du front, en octobre 1915, un très grand poème en vers libres intitulé "Champ de l'horizon en Champagne". On y lit cette strophe à la nostalgie poignante, qui a dû refléter l'état d'esprit de beaucoup de combattants non mariés: "Tandis que nous n'y sommes pas // Que de filles deviennent belles // Voici l'hiver et pas à pas // Leur beauté s'éloignera d'elles "

En dehors d'Edmond Deloule (cl. 13, donc ayant 22 ans en 1915), les autres soldats cités ont plus de 35 ans, et sont naturellement plus sensibles à l'écoulement du temps, à la maturité venue alors qu'ils sont loin des leurs, au gâchis de leur jeunesse...

\section{****}

\footnotetext{
${ }^{65}$ Robert Baizet, fondateur des Ets Baizet SA (fabrique de vêtements à façon employant plus de 300 personnes et commercialisant la marque Baitex,) à Vendrennes, en Vendée, est venu m'apporter à domicile les photocopies des carnets de guerre de son père à la suite d'un grand article de Françoise Bouligaud paru le 22 janvier 1988 dans le Pays Roannais, portant sur ma recherche de témoignages de Poilus.
} 
"Même lorsque nous creusons des tranchées, il arrive que la pioche découvre ou les pieds ou la tête de quelques pauvres malheureux enfouis de ci de là par les torpilles, les obus ou les mines souterraines. Cen'est pas assez affreux. Il paraît qu'ils cherchent à se servir de gaz asphyxiant. Une lettre de Geneviève m'apprend que le frère d'une de ses amies a été envoyé à Paris pour l'essai de cette terrible chose : les gaz asphyxiants."

Claude Coupade, classe 1915, La Ricamarie 